\title{
TEMPERATURE AND SHRINKAGE CRACKING IN REINFORCED CONCRETE WALLS
}

\author{
by \\ Dylan James Matin \\ MASc., Islamic Azad University, Najafabad, Iran, 2011
}

A dissertation presented to Ryerson University in partial fulfillment of the requirements for the degree of Doctor of Philosophy in the Program of Civil Engineering

Toronto, Ontario, Canada, 2015

(C) Dylan James Matin 2015 


\section{AUTHOR'S DECLARATION}

I hereby declare that I am the sole author of this dissertation. This is a true copy of the dissertation, including any required final revisions, as accepted by my examiners. I authorize Ryerson University to lend this dissertation to other institutions or individuals for the purpose of scholarly research I further authorize Ryerson University to reproduce this dissertation by photocopying or by other means, in total or in part, at the request of other institutions or individuals for the purpose of scholarly research. I understand that my dissertation may be made electronically available to the public. 


\section{Abstract}

Concrete cracking due to restrained thermal and shrinkage strain is a widespread problem that could happen to any structural element including base restrained walls. This type of crack usually occurs in structures with rigidly interconnected parts cast after their adjacent parts are hardened. As concrete undergoes volumetric deformations right after casting, the developing strains due to temperature drop and moisture loss get restrained by neighboring parts which causes stress development and could lead to formation of cracks. Cracking could reduce the structure's integrity and serviceability, cause deterioration which could also lead to esthetical concerns. Therefore, structures should be designed to limit cracks to an acceptable level depending on the functionality requirements of the structure and its exposure conditions. Although it has been proven that it is almost impossible to completely eliminate cracking, providing an adequate amount of appropriately positioned reinforcement can reduce the width of cracks significantly. This study aims to investigate the behavior of base restrained reinforced concrete (RC) walls under volumetric changes due to thermal and shrinkage strains and providing a procedure to determine the amount of reinforcement needed to control the width of cracks. The ABAQUS finite element (FE) program is used to simulate the structures used in this study. The models are verified by comparing the results with previous experimental studies. Based on the performed parametric study, a procedure is suggested to determine the amount of steel reinforcement required to satisfy the cracking limitations based on major parameters that affect the crack width.

Key words: Reinforced concrete wall, finite element, shrinkage, temperature, cracking. 


\section{ACKNOWLEDGEMENTS}

I wish to express the deepest appreciation to my supervisor Professor M. R. Kianoush, who continually supported me through every step of this journey. Without his guidance, encouragement, advice and persistent help, this dissertation would not have been possible.

I would also like to thank Dr. H. Abrishami and Professor H. Marzouk for their contributions and support during this period. 


\section{DEDICATION}

I would like to dedicate this dissertation to my mother and father, to whom I owe all I have and to my brother who has been my best friend since he was born. 


\section{Table of Contents}

AUTHOR'S DECLARATION ....................................................................................................

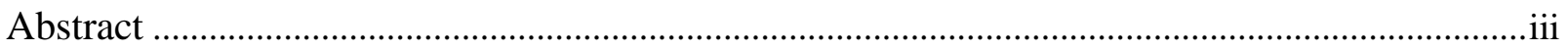

ACKNOWLEDGEMENTS ........................................................................................................ iv

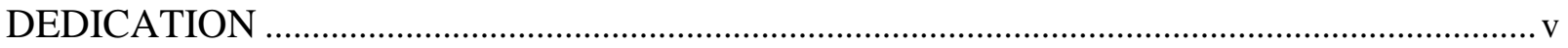

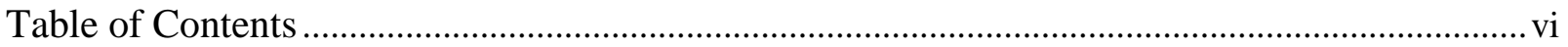

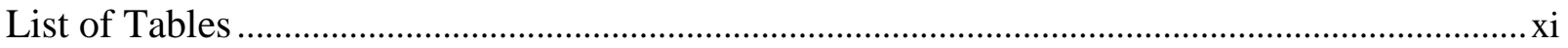

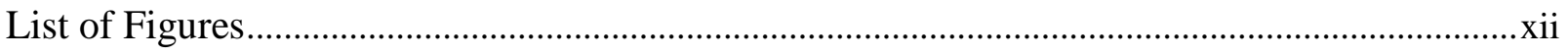

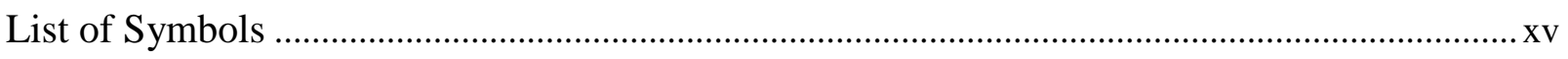

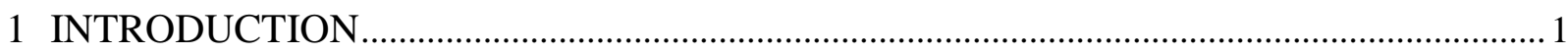

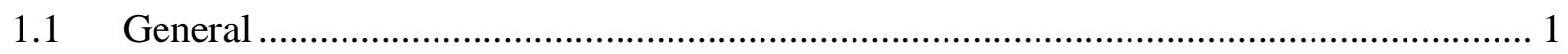

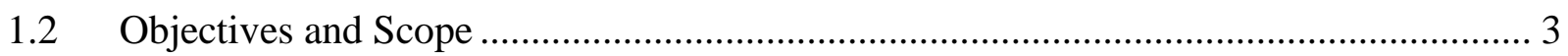

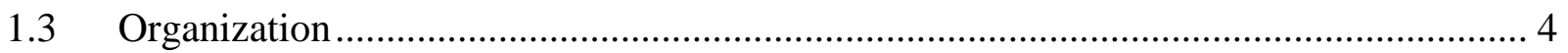

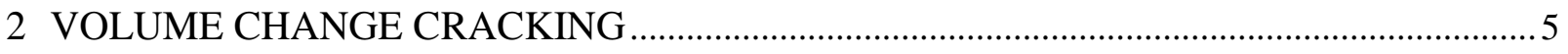

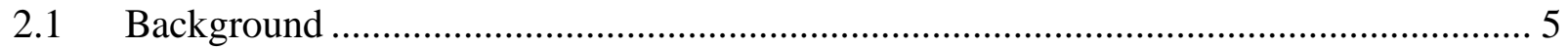

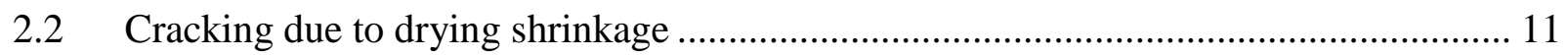

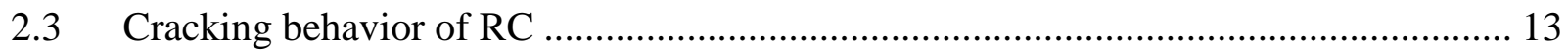

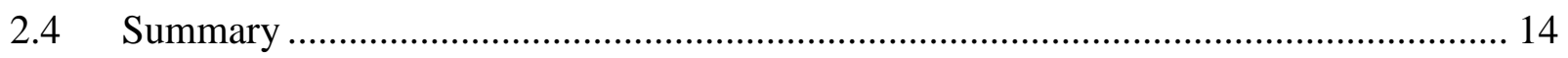

3 CRACK PREDICTION MODELS AND ANALYSES …………………………………......15

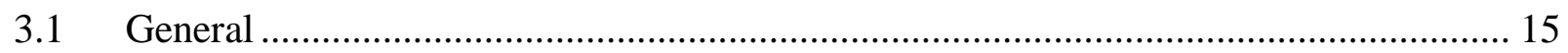

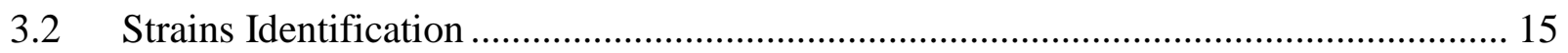

3.3 ACI 209R-92 model for shrinkage and creep ……………………………............. 16

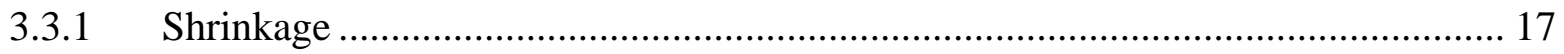

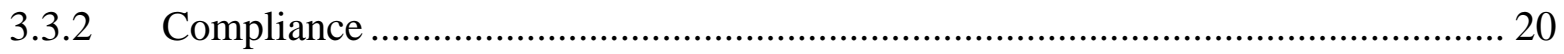

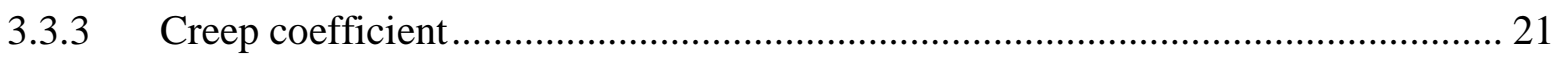




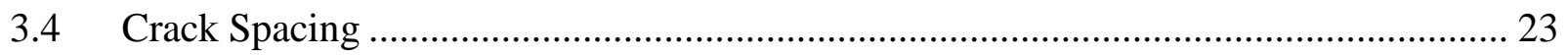

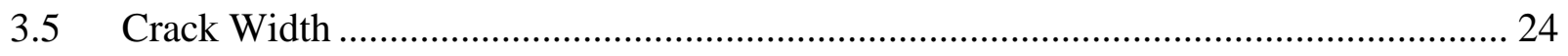

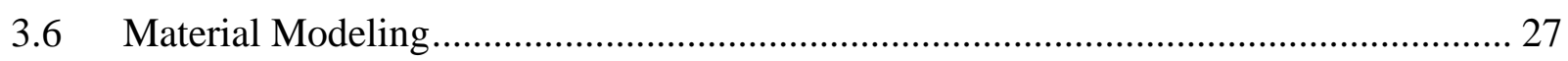

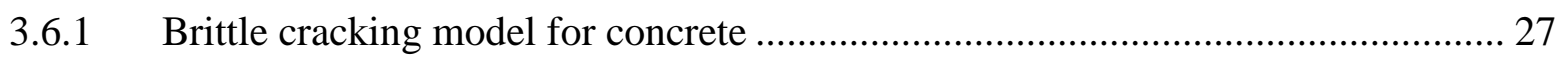

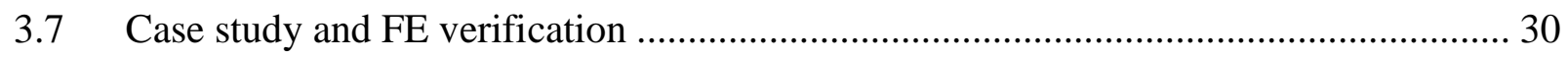

3.7.1 Base restrained wall (creep effect not included) ………..................................... 30

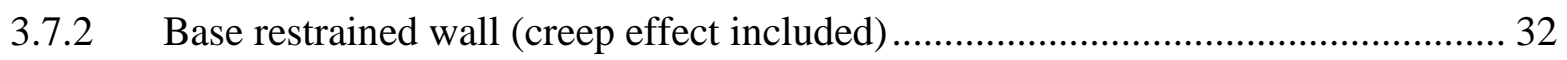

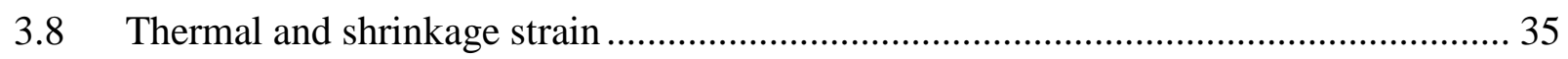

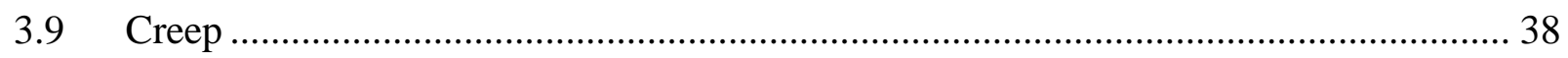

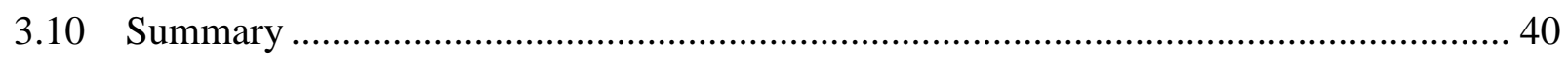

4 RESPONSE OF BASE RESTRAINED WALLS ……………………....................................

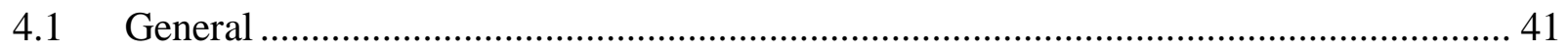

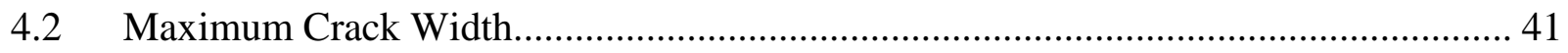

4.2.1 Effect of wall geometry .................................................................................... 41

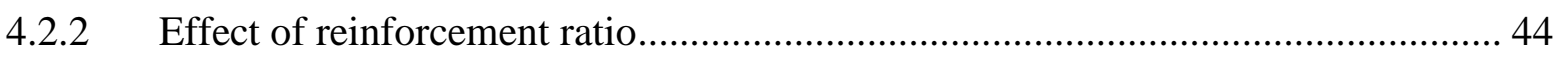

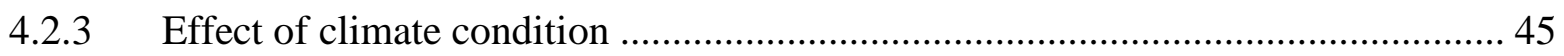

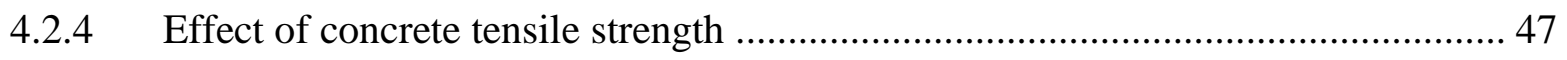

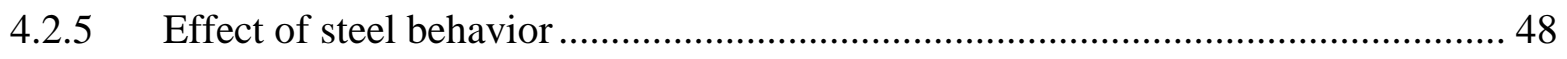

4.2.6 Effect of steel yield strength on crack width .................................................. 51

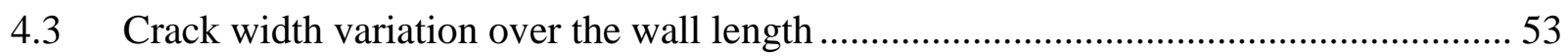

4.3.1 Effect of wall dimensions ……………………….............................................. 53

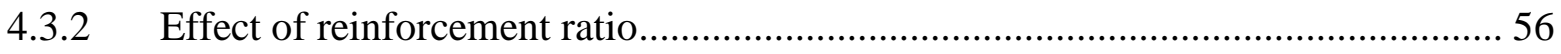

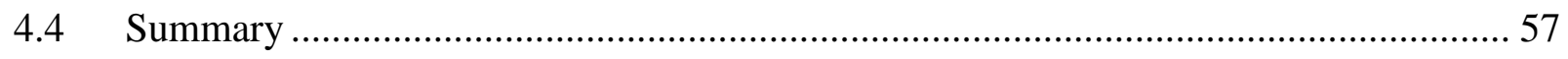

5 RESPONSE OF BASE RESTRAINED WALLS WITH PARTIAL SIDE RESTRAINT ....58

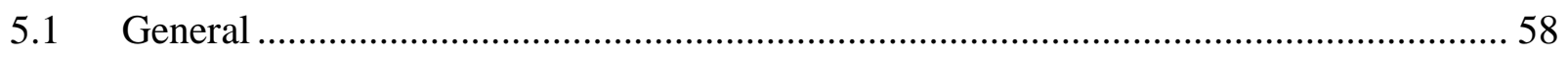




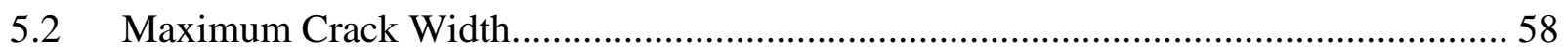

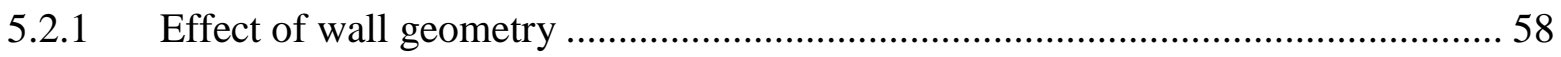

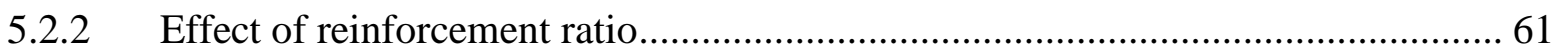

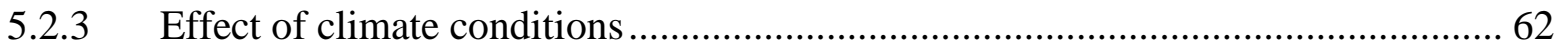

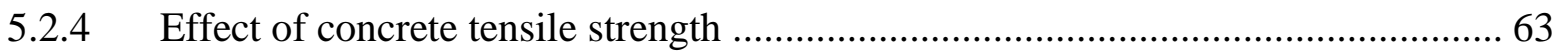

5.2.5 Effect of steel nonlinearity on the crack width ..................................................... 64

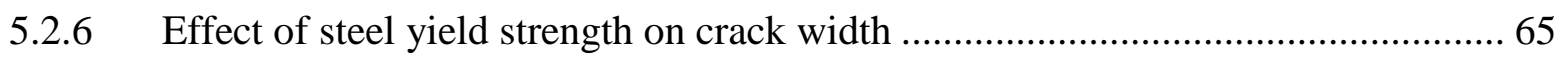

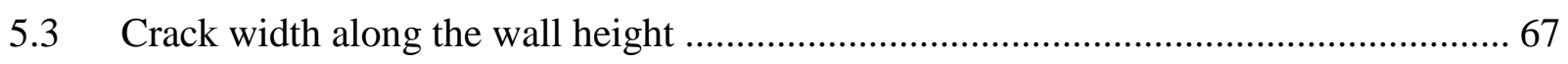

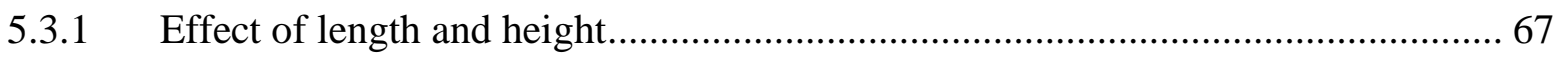

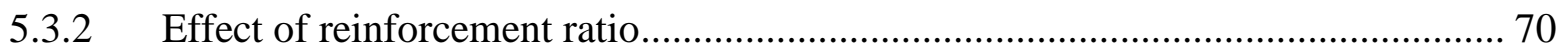

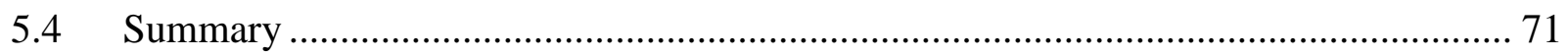

6 RESPONSE OF BASE RESTRAINED WALLS CONSIDERING THE EFFECT OF

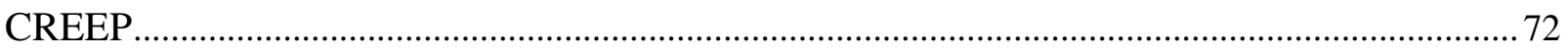

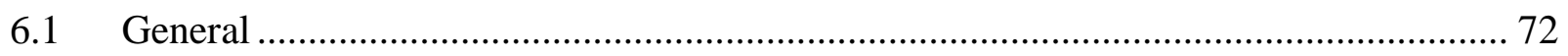

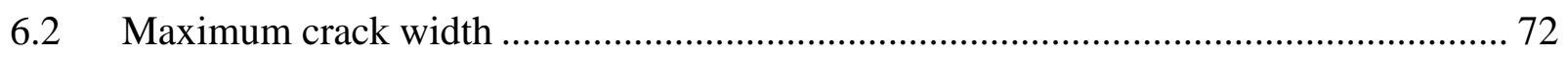

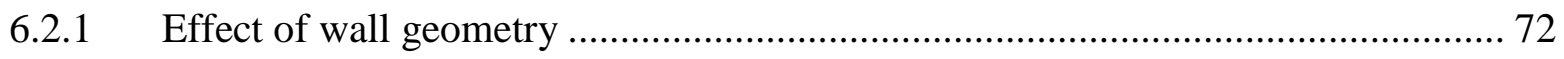

6.2.2 Effect of reinforcement ratio............................................................................ 74

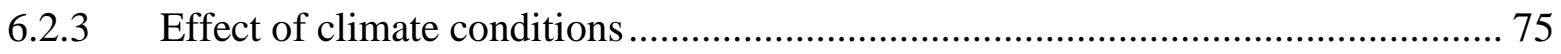

6.2.4 Effect of concrete tensile strength ...................................................................... 76

6.2.5 Effect of steel nonlinearity on crack width ....................................................... 77

6.2.6 Effect of steel yield strength on crack width ...................................................... 79

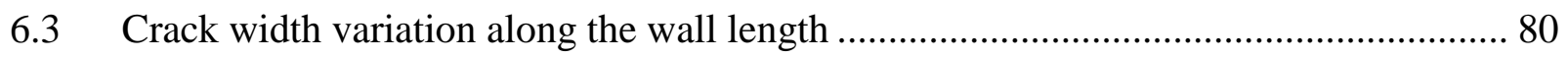

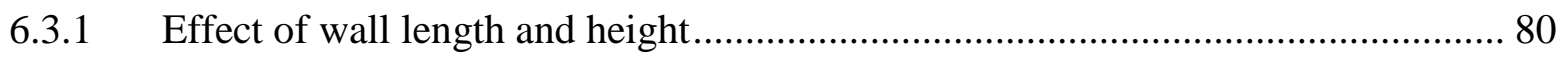

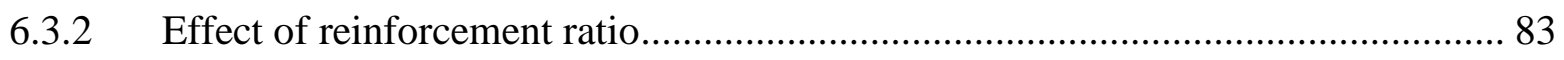

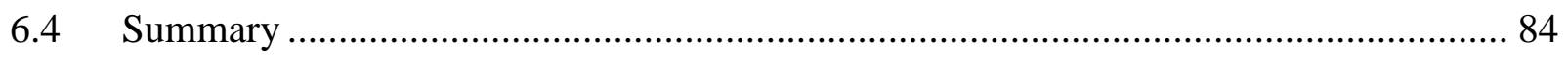




\section{COMPARISON OF CRACK WIDTH IN DIFFERENT FE MODELS AND DESIGN}

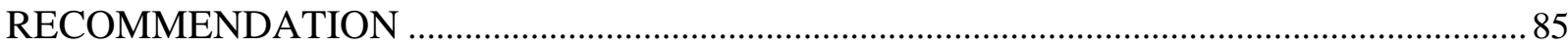

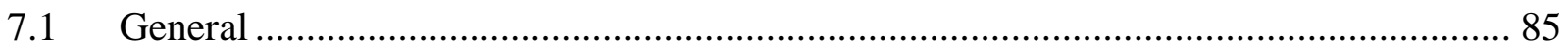

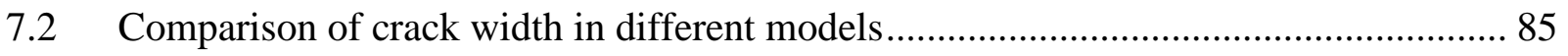

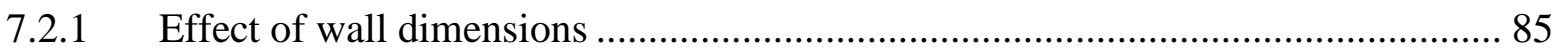

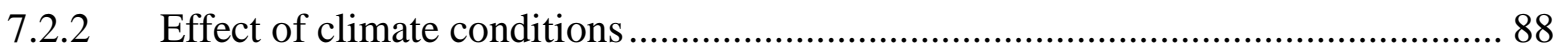

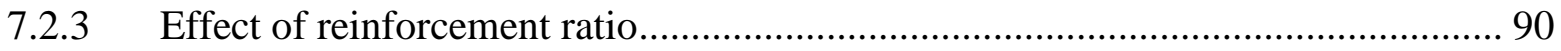

7.2.4 Effect of concrete tensile strength ....................................................................... 91

7.3 Minimum reinforcement ratios in different codes ...................................................... 93

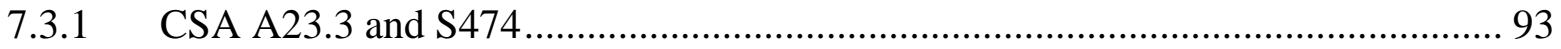

7.3.2 ACI 318

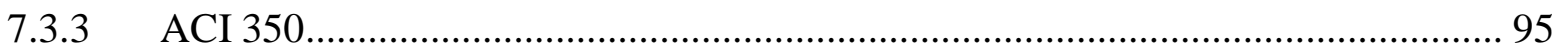

7.3.4 Alternative ACI 350 Committee recommendations ……….................................. 97

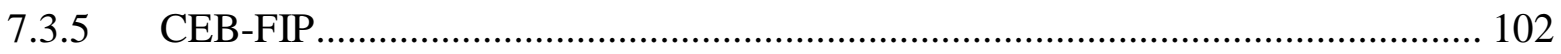

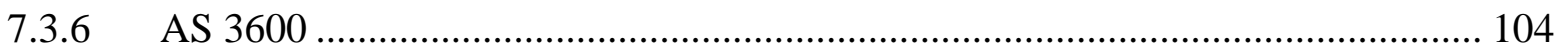

7.3.7 Other codes …………………....................................................................... 104

7.4 Minimum reinforcement ratio ............................................................................... 104

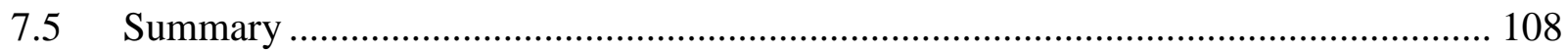

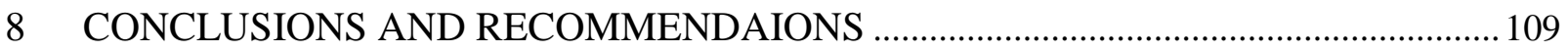

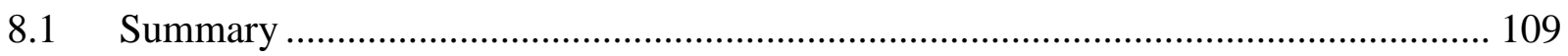

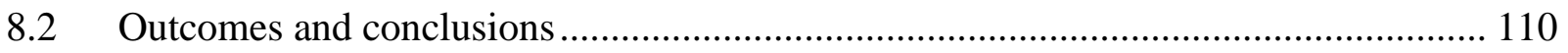

$8.3 \quad$ Recommendations for future research …………................................................. 111

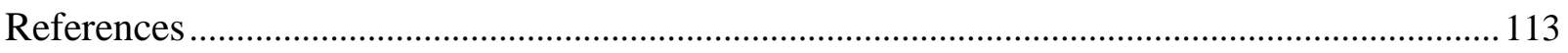

APPENDIX A - RESULTS OF BASE RESTARAINED WALLS ..............................................118

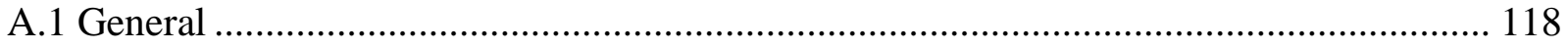


A.2 Results of the parametric study

APPENDIX B - RESULTS OF BASE RESTRAINED WALLS WITH PARTIAL

RESTRAINT AT THE SIDES 136

B.1 General 136

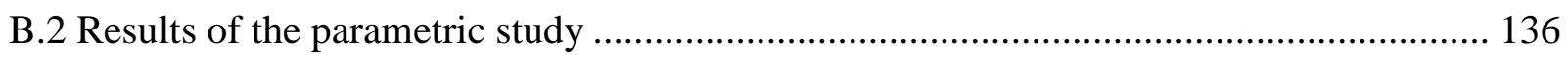

APPENDIX C - RESULTS OF BASE RESTRAINED WALLS CONSIDERING THE EFFECT OF CREEP 155

C.1 General 155

C.2 Results of the parametric study 155

APPENDIX D - RESULTS OF WALLS REINFORCED BASED ON MINIMUM STEEL RATIO RECOMMENDAITONS

D.1 General 173

D.2 Results of the FE study. 173

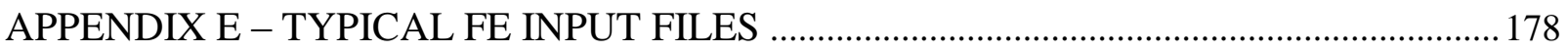

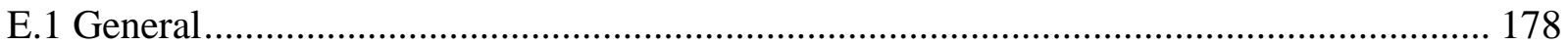

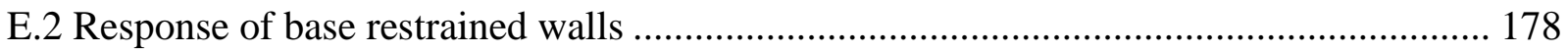

E.3 Response of base restrained walls with partial restraint at the sides ............................ 183

E.4 Response of base restrained walls considering the effect of creep............................. 193 


\section{List of Tables}

Table 3-1 Shrinkage correction coefficient for initial moist curing (ACI 209R) ..................... 18

Table 3-2 Shrinkage correction coefficient for average thickness method............................... 19

Table 3-3 Values for the constant a and be to be used in Equation 3-17 ............................... 21

Table 3-4 Creep correction factors for average thickness of members (d) ............................... 22

Table 3-5 Material properties of concrete and steel............................................................ 31

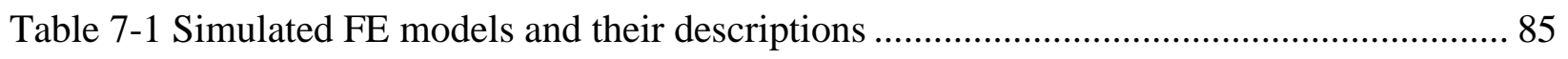

Table 7-2 ACI 224R allowable crack width based on exposure conditions ............................ 93

Table 7-3 ACI 350-06 proposed minimum reinforcement ratio ........................................... 96

Table 7-4 ACI 350 recommended reinforcement ratio (Rec. I) .......................................... 98

Table 7-5 ACI 350 recommended reinforcement ratio (Rec. II) .......................................... 98

Table 7-6 Modification factors for the proposed minimum reinforcement ............................ 105 


\section{List of Figures}

Figure 2-1 Cracking in fully restrained members (ACI 224R-01) ....................................... 12

Figure 2-2 Effect of creep on tensile stress with time (ACI 224R-01) ..................................... 12

Figure 3-1 Post failure behavior of RC concrete in tension............................................... 28

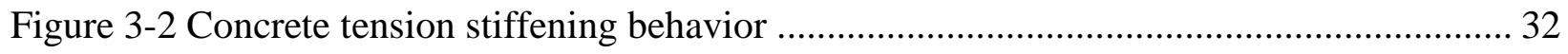

Figure 3-3 Comparison of crack pattern and width in experimental study with FE model......... 32

Figure 3-4 Shrinkage strain in 2 months period after concrete casting ................................. 33

Figure 3-5 Equivalent temperature drop in the 2 months period ........................................ 33

Figure 3-6 Creep coefficient variation with time over 2 the months exposure ......................... 34

Figure 3-7 Compliance variation with time in the 2 months exposure.................................. 34

Figure 3-8 Comparing the crack pattern and width in experimental study with FE model......... 35

Figure 3-9 Shrinkage and thermal strain versus time in the 6 months period of exposure.......... 38

Figure 3-10 Creep coefficient versus time in a period of 6 months after casting ..................... 39

Figure 3-11 Compliance versus time in a period of 6 months after casting ............................. 40

Figure 4-1 Effect of wall length, L/H, height, and thickness on the crack width ..................... 44

Figure 4-2 Effect of reinforcement ratio on the crack width .......................................... 45

Figure 4-3 Effect of volumetric strain on crack width............................................... 47

Figure 4-4 Effect of concrete tensile strength on crack width .......................................... 48

Figure 4-5 The influence of steel behavior on the crack width ........................................ 50

Figure 4-6 The effect of steel yield strength on the crack width ....................................... 53

Figure 4-7 Effect of wall length on the crack width along the wall height ............................. 54

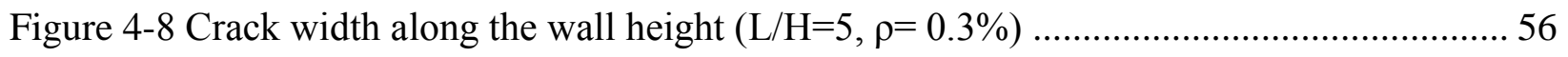

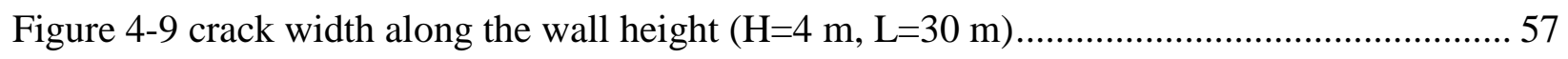


Figure 5-1 Effect of wall length, L/H ratio, height and thickness on crack width..... 60

Figure 5-2 Effect of reinforcement ratio on the crack width of $4 \mathrm{~m}$ tall walls 61

Figure 5-3 Effect of volumetric strain on the crack width of $4 \mathrm{~m}$ tall walls............................ 62

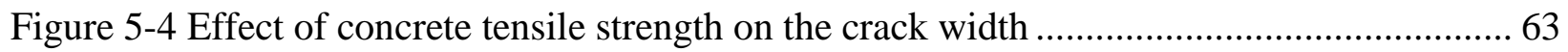

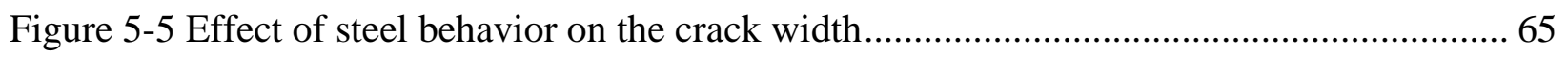

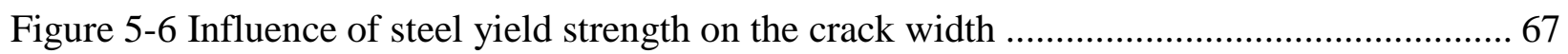

Figure 5-7 Effect of wall length on the crack width over the wall height ............................. 68

Figure 5-8 Effect of wall height on the crack width along the wall height ............................. 70

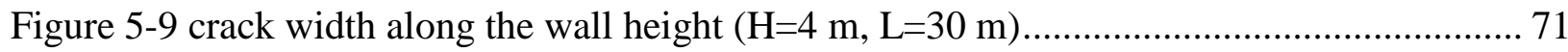

Figure 6-1 Effect of wall length, L/H, height and thickness on the crack width ...................... 74

Figure 6-2 Effect of reinforcement ratio on the crack width .............................................. 75

Figure 6-3 Effect of climate condition on the crack width ............................................. 76

Figure 6-4 Effect of concrete tensile strength on the crack width ..................................... 77

Figure 6-5 Effect of steel nonlinearity on the crack width ............................................... 78

Figure 6-6 Effect of steel yield strength on the crack width........................................... 80

Figure 6-7 Effect of wall length on the crack width along the wall height ............................ 81

Figure 6-8 Effect of wall height on the crack width over the wall height ............................. 83

Figure 6-9 Effect of reinforcement ratio on the crack width along the wall height................... 84

Figure 7-1 Comparing the effect of wall length on the crack width ................................... 87

Figure 7-2 Comparing the effect of $\mathrm{L} / \mathrm{H}$ on the crack width ........................................... 88

Figure 7-3 Comparing the effect of climate condition..................................................... 89

Figure 7-4 Comparing the effect of reinforcement ratio on the crack width .......................... 91

Figure 7-5 Comparing the effect of reinforcement ratio on the crack width ........................... 92 
Figure 7-6 Crack width of walls reinforced based on CSA 23.3 minimum reinforcement ratio.. 94

Figure 7-7 Crack widths of walls reinforced based on ACI 350-06 $(\mathrm{H}=4 \mathrm{~m}, \mathrm{e}=900 \mu \epsilon) \ldots \ldots \ldots \ldots . . . .97$

Figure 7-8 Crack width of 6 m high RC walls reinforced based on ACI 350 Rec I................ 100

Figure 7-9 Crack width of $4 \mathrm{~m}$ high RC walls reinforced based on ACI 350 Rec II ............... 101

Figure 7-10 Crack widths in RC walls reinforced based on CEB-FIP ( $\mathrm{H}=4 \mathrm{~m}, \mathrm{ft}=3.5 \mathrm{MPa}) \ldots . .103$

Figure 7-11 Crack widths of walls reinforced based on the proposed steel ratio ..................... 108 


\section{List of Symbols}

A concrete area

A area of concrete symmetric with reinforcing steel divided by number of bars, $\mathrm{mm}^{2}$

$\mathrm{A}_{\mathrm{ct}} \quad$ area of concrete tension zone before cracking, $\mathrm{mm}^{2}$

$\mathrm{A}_{\mathrm{e}} \quad$ effective cross-sectional area of concrete, $\mathrm{mm}^{2}$

$\mathrm{A}_{\mathrm{g}} \quad$ gross area of section, $\mathrm{mm}^{2}$

As area of non-prestressed tension reinforcement, $\mathrm{mm}^{2}$

$\mathrm{A}_{\mathrm{s}, \min }$ minimum steel reinforcement area, $\mathrm{mm}^{2}$

a constant describing the concrete strength gain development

b constant describing the concrete strength gain development

a aggregate content of concrete, $\mathrm{kg} / \mathrm{m}^{3}$

c cement content of concrete, $\mathrm{kg} / \mathrm{m}^{3}$

d average thickness of a member $(=4 \mathrm{~V} / \mathrm{S}), \mathrm{mm}$

$\mathrm{d}_{\mathrm{c}} \quad$ distance from center of bar to extreme tension fiber, $\mathrm{mm}$

E elastic modulus

$\mathrm{E}_{\mathrm{C}} \quad$ elastic modulus of concrete, $\mathrm{MPa}$

$\mathrm{E}_{\mathrm{s}} \quad$ elastic modulus of reinforcement, $\mathrm{MPa}$

$\mathrm{E}_{\mathrm{sm}} \quad$ effective elastic modulus of steel to that of concrete

$\mathrm{E}_{\mathrm{cm}} \quad$ mean elastic modulus of concrete, $\mathrm{MPa}$

$\mathrm{E}_{\mathrm{cm} 28}$ mean elastic modulus of concrete at 28 days, $\mathrm{MPa}$

$\mathrm{E}_{\mathrm{cmt}} \quad$ mean elastic modulus of concrete at age $\mathrm{t}, \mathrm{MPa}$

$\mathrm{E}_{\mathrm{cm} \text { to }}$ mean elastic modulus of concrete when loading starts at age $\mathrm{t}_{0}, \mathrm{MPa}$

$\mathrm{f}_{\mathrm{cm}} \quad$ mean compressive cylinder strength of concrete, MPa 
$\mathrm{f}_{\mathrm{cm} 28}$ mean compressive cylinder strength of concrete at 28 days, $\mathrm{MPa}$

$\mathrm{f}_{\mathrm{cmt}} \quad$ mean compressive cylinder strength of concrete at age $\mathrm{t}, \mathrm{MPa}$

$\mathrm{f}_{\mathrm{cmtc}} \quad$ mean compressive cylinder strength of concrete when drying starts at age $\mathrm{t}_{\mathrm{c}}, \mathrm{MPa}$

$\mathrm{f}_{\mathrm{cmto}} \quad$ mean compressive cylinder strength of concrete when loading starts at age $\mathrm{t}_{0}, \mathrm{MPa}$

$\mathrm{f}_{\mathrm{ct}, \max }$ concrete tensile strength

$\mathrm{f}_{\mathrm{r}} \quad$ modulus of rupture of concrete, $\mathrm{MPa}$

$\mathrm{f}_{\mathrm{s}} \quad$ stress in reinforcement, $\mathrm{MPa}$

$\mathrm{f}_{\mathrm{scr}} \quad$ steel stress after crack occurs, $\mathrm{MPa}$

$\mathrm{f}_{\mathrm{c}}^{\prime} \quad$ concrete specified cylinder strength at 28 days, $\mathrm{MPa}$

$\mathrm{f}^{\prime}{ }_{\mathrm{c}} \quad$ compressive strength of concrete

$\mathrm{f}_{t}^{\prime} \quad$ tensile strength of concrete, psi

$\mathrm{h} \quad$ relative humidity expressed as a decimal

$\mathrm{J}\left(\mathrm{t}, \mathrm{t}_{\mathrm{o}}\right)$ concrete compliance at age $\mathrm{t}$ when loading starts at age $\mathrm{t}_{0}, 1 / \mathrm{MPa}$

$\mathrm{K}$ factor correcting the area of $\mathrm{A}_{\mathrm{s}}$ depending on the type of imposed deformation

$\mathrm{K}_{\mathrm{c}} \quad$ factor accounting the scheme of tensile stress distribution

n the ratio of modulus of elasticity of steel to that of concrete

$\mathrm{S} \quad$ bar spacing, $\mathrm{mm}$

s slump, mm

$\mathrm{T}$ temperature, ${ }^{\circ} \mathrm{C}$

t age of concrete, days

$\mathrm{t}-\mathrm{t}_{\mathrm{c}} \quad$ duration of drying, days

$t_{c} \quad$ age of concrete when drying starts at end of moist curing, days

$\mathrm{t}_{\mathrm{e}} \quad$ effective concrete cover, $\mathrm{mm}$ 
$t_{0} \quad$ age of concrete at loading, days

V/S volume-surface ratio, $\mathrm{mm}$

$\mathrm{W}_{\mathrm{c}} \quad$ unit weight of concrete, $\mathrm{kg} / \mathrm{m}^{3}$

$\mathrm{W}_{\max }$ most probable maximum crack width, $\mathrm{mm}$

W water content of concrete, $\mathrm{kg} / \mathrm{m}^{3}$

z factor limiting distribution of reinforcement

$\alpha^{\prime} \quad$ air content expressed as percentage

$\alpha \quad$ coefficient of thermal expansion of concrete

$\beta \quad$ ratio of distance between neutral axis and tension face to distance between neutral axis and centroid of reinforcing steel

$\gamma_{\mathrm{c}} \quad$ unit weight of concrete, $\mathrm{kg} / \mathrm{m}^{3}$

$\gamma_{\mathrm{sh}} \quad$ shrinkage correction factor also used as product of all applicable correction factors

$\gamma_{c} \quad$ creep correction factor also used as product of all applicable correction factors

$\gamma_{\mathrm{cl}} \quad$ climate modification factor

$\gamma_{\mathrm{H}} \quad$ Height modification factor

$\gamma_{\mathrm{L} / \mathrm{H}} \quad \mathrm{L} / \mathrm{H}$ modification factor

$\gamma_{\mathrm{ft}} \quad$ concrete tensile strength modification factor

$\Delta \mathrm{T} \quad$ temperature variation, ${ }^{\circ} \mathrm{C}$

$\varepsilon \quad$ total volumetric strain (summation of thermal and shrinkage strain), $\mathrm{mm} / \mathrm{mm}$

$\varepsilon_{\mathrm{s}} \quad$ tensile strain in reinforcing bar, $\mathrm{mm} / \mathrm{mm}$

$\varepsilon_{\mathrm{sh}}\left(t, t_{c}\right)$ shrinkage strain of concrete at age $t$ since the start of drying at age $t_{c}, \mathrm{~mm} / \mathrm{mm}$

$\varepsilon_{\text {shu }} \quad$ notional ultimate shrinkage strain, $\mathrm{mm} / \mathrm{mm}$

$\rho \quad$ reinforcing ratio $=\mathrm{As} / \mathrm{Ag}$ 
$\rho_{\mathrm{e}} \quad$ reinforcement ratio based on the exposure condition

$\rho_{\text {min }} \quad$ minimum shrinkage and temperature reinforcement

$\varphi\left(t, t_{0}\right)$ creep coefficient

$\varphi_{\mathrm{u}} \quad$ ultimate creep coefficient

$\sigma_{\mathrm{s} 2} \quad$ steel stress

$\psi \quad$ ratio of fine aggregate to total aggregate by weight expressed as percentage 


\section{INTRODUCTION}

\subsection{General}

Concrete is one of the most popular structural materials because of its cost effectiveness and ease of fabrication. However, its weakness in tension could lead to formation of cracks in members under tensile stresses. Cracks could affect the functionality and performance of the structure, reduce the strength, increase the porosity, damage aesthetic appearance and reduce the lifespan of the structure. Therefore, crack control measures must be considered when designing the RC members.

Restrained volumetric change is one of the reasons that could initiate cracking in concrete. These volumetric deformations start right after casting and continue throughout the life span of the structure given the seasonal changes in ambient temperature and humidity. Cement hydration generates heat inside the recently cast concrete causing the concrete to expand immediately after it is cast. Thereafter, the temperature gradually decreases until it reaches the ambient level causing the concrete to contract. If the member is not restrained, expansion and contraction does not cause any stress in the member. However, since most structural members are restrained to some extent in reality, there is always some level of stress in the member exposed to volumetric deformations. After the temperature drops to the ambient level, the fluctuation in seasonal temperature causes contraction and expansion over a longer term. Volumetric deformation due to moisture content variations is more complex compared to temperature changes. The most influential type of shrinkage is drying shrinkage which occurs when the concrete loses water. The rate of drying shrinkage is highest right after the curing period is finished as a result of concrete being exposed to the outside environment. Needless to say, this type of shrinkage is highly affected by the ambient relative humidity and is more significant in dryer climates. 
In general, restraint induced stresses are considerably lower than stresses caused by applied loads but they might exceed the tensile strength of concrete and that is when the cracks start to develop. There are two types of restraint conditions depending on the structure's geometry, namely, internal and external restraint. Internal restraint happens when the restraint condition comes from the element itself which is a common problem in thick sections. This is due to out-of-phase deformation of inner and outer parts caused by non-uniform temperature or moisture distribution in the section. The exterior which is exposed to the outside environment cools down or dry faster than the inner section which is shielded. This gradient disappears quite quickly in thin sections and does not cause any major issues. In mass concrete, however, the warmer or moister inner part expands while the outer portion restrains this expansion causing compressive stresses in the inner part and tensile stresses in the outer concrete leading to cracking in the outer surface which is under tension.

External restraint condition is independent of the concrete thickness and could cause permanent and full-depth cracks. It usually occurs when there is differential deflection between previously cast and recently poured concrete elements in a structure. A typical example of external restraint could be a new wall cast on an existing foundation or base slab. When the newly poured concrete expands because of the hydration temperature rise, compressive and tensile stresses develop in the wall and foundation respectively due to the external restraint. When the temperature starts to decrease and the wall begins to contract, tensile stresses develop in the wall causing the foundation to go under compression which could lead to cracking in the wall under tension. This temperature variation is accompanied by drying shrinkage especially after the curing period when concrete is exposed which also contributes to increasing the tensile stresses and cracking. 
In the past, due to practical restrictions in performing experimental studies in this field, design engineers used to consider the temperature as the sole parameter in estimating the risk of cracking. However, recent developments in computer technology and laboratory testing methods have helped to expand the knowledge of crack estimation in RC.

\subsection{Objectives and scope}

This study aims to investigate the cracking behavior of base restrained $\mathrm{RC}$ walls due to restrained temperature and shrinkage strains. The primary objective is to determine the minimum reinforcement ratio considering the major parameters that influence thermal and shrinkage cracks focusing on the long term behavior as opposed to the early age cracking. The FE program ABAQUS (Hibbit et al. 2004) has been used to simulate the behavior of the walls. The FE model was first verified by comparing the crack width and pattern with the results of an existing experimental study. The parametric study is first performed on single base restrained walls (with no side restraint) under ultimate volumetric strains. Then, in addition to the fully fixed base, the sides are partially restrained to take into account the effect of perimeter walls in structures such as rectangular tanks in liquid containing structures. In addition, the influence of creep is considered in some models in which the thermal and shrinkage strains are applied in a timely manner over a period of six months. The effect of wall length, height, thickness, reinforcement ratio, climate condition, concrete tensile strength and steel yield strength on the maximum crack width and its variation along the wall height is investigated and discussed. The results of different models are compared to determine the effect of creep and side restraint on the maximum crack width. The minimum reinforcement ratios proposed by different codes are discussed and examined. Finally, a procedure is proposed to determine the minimum required reinforcement ratio which considers the major parameters that influence the crack width. 


\subsection{Organization}

This dissertation is categorized into eight chapters and five appendices excluding the abstract and references. Chapter 1 includes the introduction, objectives and scope. The second chapter reviews the related previous research studies in addition to basics of volume change cracking including cracking mechanism. Chapter 3 presents different methods to predict shrinkage and creep. It also contains the details of the FE modeling and verification used in this study. Chapter 4, 5, and 6 present the results of the parametric study. Chapter 4 is dedicated to the results of single base restrained RC walls under ultimate volumetric strains. Chapter 5 presents the results of the RC walls fully restrained at the base and partially restrained at the sides under volume change cracking. Chapter 6 introduces the factor of time into the equation and discusses the results of RC walls subjected to thermal and shrinkage strain over a 6 months period considering the effect of creep. The comparison between the three models as presented in chapters 4, 5, and 6 is discussed in chapter 7. It continues with a short review of the minimum reinforcement ratios recommended by different guidelines and ends with proposing a new procedure to determine the shrinkage and temperature reinforcement in RC walls. Afterwards, the summery of this study and conclusions are presented in Chapter 9 followed by references. Appendices A, B, C, and D demonstrate the remaining results (graphs) of chapters 4, 5, 6, and 7 respectively and Appendix E presents the typical FE input files. 


\section{VOLUME CHANGE CRACKING}

\subsection{Background}

Thermal and shrinkage cracking in RC members has been studied by several researchers in the last few decades. Carlson and Reading (1988) investigated the stress conditions in base restrained walls having different shapes, with and without openings considering various degrees of restraint by performing experiments on models made of rubber. They verified their results by comparing them with crack pattern of samples made of mortar. They concluded that the degree of restraint and conditions of the foundation have the most substantial influence on the developed stresses and cracks. They observed that using steel reinforcement among other remedial measures could significantly reduce cracking in these structures.

ACI 224.2R-92 (1992) discusses crack control and prediction focusing on members under direct tension. It contains a review on primary causes of direct tension cracking followed by the formulas proposed to estimate the width of cracks and the spacing between them. ACI 207.2R-07 (2007) discusses the cracking behavior of massive concrete elements under temperature and shrinkage strains. Thermal behavior, heat transfer, internal and external restraint and crack widths are among the topics covered by this report. ACI 209R-92 (2008) provides a review on the existing methods to estimate creep, shrinkage and temperature effect in concrete structures. It overviews the concrete material response, creep and shrinkage theories and equations.

Al Rawi and Kheder (1990) conducted an experimental study on thin base restrained mortar walls. They poured reduced-scale mortar wall models and exposed them to natural drying condition so as to investigate the influence of reinforcement ratio and wall dimensions on the width and spacing of cracks. They observed that base restrained walls experience narrower cracks with smaller spacing compared to end restrained members. Their experiments showed that the crack spacing is 
mainly influenced by the horizontal reinforcement and height of the walls. They also concluded that the variation of the crack width over the wall height is primarily related to the restraint in the wall and influenced by the $\mathrm{L} / \mathrm{H}$ ratio. Using the change of restraint principle, they suggested a formula to predict the maximum crack width along the height of the wall.

Kheder et al. (1994) studied the shrinkage and temperature cracking in base restrained RC walls. They measured the width of primary and secondary cracks of 61 full-size and 14 experimental walls. They demonstrated that the crack spacing and width is larger in taller walls and therefore a larger reinforcement ratio is required for them. They also concluded that since the crack width changes along the wall height based on the degree of restraint, the amount of reinforcement could also be specified accordingly for an efficient and economical design.

Kheder (1997) showed that the degree of restraint which is not uniform throughout a base restrained wall depends not only on the $\mathrm{L} / \mathrm{H}$ ratio but also the position of the point on the wall. $\mathrm{He}$ used 2D finite element analysis to determine the restraint factor throughout the wall considering different $\mathrm{L} / \mathrm{H}$ ratios. He demonstrated that the crack width is proportional to the change of restraint before and after cracking. He developed idealized diagrams of change of restraint in walls and used them to determine the required amount of steel to control cracking in such walls.

Harrison (1981) studied early age cracking and thermal contraction of concrete because of heat dissipation after hydration and developed a theory to estimate the crack width based on the bond force between steel and concrete. Pettersson and Thelandersson (2001, a \& b) used the FE method to study the behavior of base restrained walls under self-imposed deformations. They used two dimensional four node elements for concrete and spring elements to simulate the closing forces in cracks. The stiffness of simulated spring was estimated based on bond stress-slip relations and concrete tension stiffening. Steel yield was also defined as part of the steel behavior. They 
investigated the effect of reinforcement and concrete properties as well as the geometry of the walls on the crack width and spacing. They showed that the existing restraint along the wall base facilitates distribution of cracks and reduces the crack width to almost half the width of fully restrained members. They also observed that even low values of reinforcement ratio decreases the width of cracks. In addition, the crack width increases in walls made of concrete with higher tensile strength. They also argued that the effect of bar diameter and bond stiffness on the crack width is not substantial.

Thelandersson et al. (1998) studied the behavior of end restrained walls due to sudden and slow changes in temperature using a computer program. They simulated temperature in concrete and concluded that rapid temperature changes is less critical in terms of cracking in comparison with slow temperature variations. Therefore, a lower reinforcement ratio is required to control cracking in walls under rapid temperature drops mainly because of the formation of internal restraint.

Elbadry and Ghali (1995) investigated thermal cracking in pre-stressed concrete and concluded that partial pre-stressing could be more effective than full pre-stressing since it allows the concrete tensile stresses to be relieved by crack formation. They also calculated the amount of reinforcement necessary to minimize crack width based on the change of stresses in the reinforcement at cracking. A case study was performed by Liou (1999) on a cylindrical cast-in-place diaphragm wall which served as a cofferdam during construction of the permanent structure. He monitored the behavior of the wall and discussed the correlation between the stress data recorded by the instrumentation system and the changes of thermal conducting environment around the wall. It was shown that under certain conditions, thermal stresses alone could be much larger than those caused by actual structural loads. 
The report published by CIRIA (Bamforth, 2007) is a thorough discussion on early-age thermal crack control in concrete. It presents the design procedure and factors that influence early age cracking, methods of crack control and testing and monitoring this phenomenon. Saetta et al (1995) presented a numerical procedure for stress-strain analysis of RC structures subjected to thermal loads based on the FE method. They simulated different environmental conditions using suitable boundary conditions imposed on the differential equations governing the phenomenon. Ayotte et al (1997) performed a detailed numerical and experimental study of thermal strains and induced stresses in large-scale mass concrete. They monitored the thermal behavior of mass concrete subjected to heat of hydration and subsequent freeze and thaw cycles. Bosnjak and Kanstand (2001) simulated a structure to compare the FE simulation outcome with their experiments. They measured temperature and strain development in different parts of a structure during its construction. Anderson (1998) presented a complete review of the methods that can be used to prevent early-age cracking. Chantelois et al (1999) performed an experimental study to investigate thermal fracture in notched concrete wall samples exposed to severe cooling thermal gradients. Three-point bending test (standard cylinders) was performed on notched beams to study the variations of compressive and tensile strengths, elastic modulus, fracture energy and coefficient of thermal expansion of concrete over a temperature range varying from 20 to $-40^{\circ} \mathrm{C}$.

Gilbert (1992) investigated shrinkage cracking due to direct tension in fully restrained RC members. Mechanism of direct tension and behavior of restrained members were discussed. He presented an approach to determine the number, spacing and width of cracks caused by axial restraining force due to shrinkage in fully restrained member. His method is based on principles of mechanics and proved to be in good agreement with experimental results. The proposed 
procedure could be used to determine the amount of required steel reinforcement to control cracking in practical situations.

Nejadi and Gilbert (2004) extended and modified Gilbert's previous work analytically and also performed experiments to investigate the shrinkage cracking behavior of fully restrained members. They cast and monitored eight longitudinally restrained slab samples with different reinforcement layouts for up to 150 days to measure the influence of shrinkage on development of tension cracks. They monitored strains in both concrete and steel during the tests. In addition, the age of concrete when each crack started to develop, the crack locations and the change in crack width with time was measured. Influence of different parameters including reinforcement ratio, bar diameter and spacing was studied and discussed. They showed that the proposed method to determine the crack spacing, width and number of cracks in fully restrained slab is in good agreement with the experiments.

Huang (1999) presented a numerical model for the simulation of material properties, the temperature and the stress fields as well as development of cracks. He investigated a freshly concreted wall on top of an old foundation as an example and considered both surface and inner cracks by employing the smeared approach of crack distribution in three dimensional hardening concrete.

Vitharana et al. (1998) performed experiments on a series of half-scale RC wall units. The wall units were subjected to applied and thermally induced flexural moments with or without a simultaneous in-plane tensile force. The moment-curvature response under both uni-directional and bi-directional flexural moments were investigated. They observed that the concrete tensile strength corresponding to cracking in the wall units is much lower than those recommended in 
codes of practice or those given by standard concrete specimen testing under laboratory conditions, resulting in a significant relaxation of thermal stresses.

Acarcan and Kianoush (2004) performed a FE study to investigate the crack width and required reinforcement ratio for crack control within the design specifications. They simulated a culvert wall that was previously built and compared the results of the FE model with the results collected from the monitoring devices. It included thermal analyses due to the heat of hydration and stress analysis in early age. They used incremental numerical technique to provide realistic simulation of stress-strain history. They also conducted a parametric study to estimate the reinforcement ratio required for fixed base walls. Kianoush et al. (2008) studied the cracking behavior of RC walls under restrained volumetric deformations using the computer program ABAQUS/6.4. They simulated RC walls with the ACI 350-06 (2010) recommended minimum steel and concluded that the suggested steel percentage may not be sufficient for many cases.

Ouzaa and Benmansour (2010) developed a FE method and used it to find the degree of restraint, sequence, and distribution of cracks and the effect of the horizontal reinforcement of the wall using a rectangular 4-node element. Their suggested model included material nonlinearity, smeared crack representation, tension stiffening, stress degradation of concrete in the parallel crack direction, and shear retention of concrete on the cracked surface.

Ziaolhagh et al. (2008) performed a nonlinear FE study to investigate the response of reinforced concrete walls to shrinkage strains. They modeled walls with different boundary conditions and discussed their crack width in each case considering different parameters including wall dimensions and reinforcement ratio. 


\subsection{Cracking due to drying shrinkage}

Drying shrinkage is the volume reduction due to loss of water which could be defined as the timedependent linear strain measured on an unloaded sample while drying at a constant temperature. A typical value of $600 \times 10^{-6} \mathrm{~mm} / \mathrm{mm}$ could be considered as the final shrinkage strain in concrete. Therefore, cracks could easily develop as a result of restraining a concrete member since the tensile-strain capacity of concrete is usually somewhere in the area of $150 \times 10^{-6} \mathrm{~mm} / \mathrm{mm}$ or less. Since a wide number of parameters influence the shrinkage in concrete, there is a high degree of uncertainty in prediction of shrinkage. Composition of concrete, source of aggregate, geometry of specimen, ambient relative humidity, and the ratio of the exposed surface to the volume of the member are some of the most important factors that influence the concrete shrinkage strain.

Internal shrinkage restraint occurs due to moisture gradients before a concrete member reaches moisture equilibrium. This moisture gradient can cause tensile and compressive stresses on the surface and in the interior of the member respectively. If not relieved or reduced by creep, this stress could cause cracking in the concrete.

The concrete member experiencing a contraction due to drying shrinkage could always be subjected to some degree of external restraint. This restraint could be from the foundation, another part of the structure, or even the reinforcement inside the member. When the shrinkage is restrained, tensile stresses start to develop within the concrete which could cause cracking if they exceed the tensile strength of concrete (Figure 2-1).

Stress relaxation or creep reduces the tensile stress caused by restrained drying shrinkage with time as shown in Figure 2-2. Cracks occur as soon as the net tensile stress reaches the tensile strength of concrete. Relative humidity, aggregate type and content (or paste content), water content, and w/c are the most important parameters that influence the ultimate drying shrinkage. Drying time, 
distance from the exposed surface, relative humidity and size of the member are among the parameters that affect the shrinkage and rate of moisture loss in concrete.

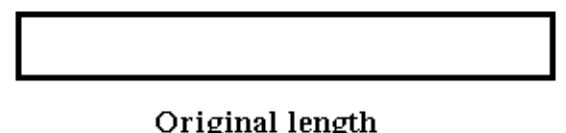

Original length

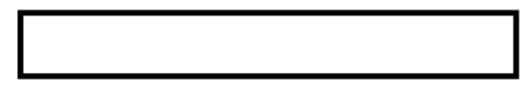

Volume change (shrinkage) in unrestrained member

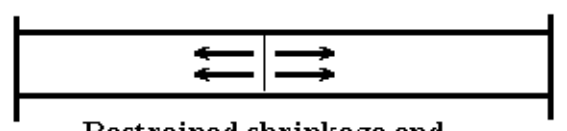

Restrained shrinkage and

development of tensile stresses

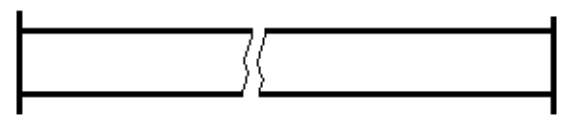

Concrete cracking when tensile stress exceed the tensile strength of concrete

Figure 2-1 Cracking in fully restrained members (ACI 224R-01)

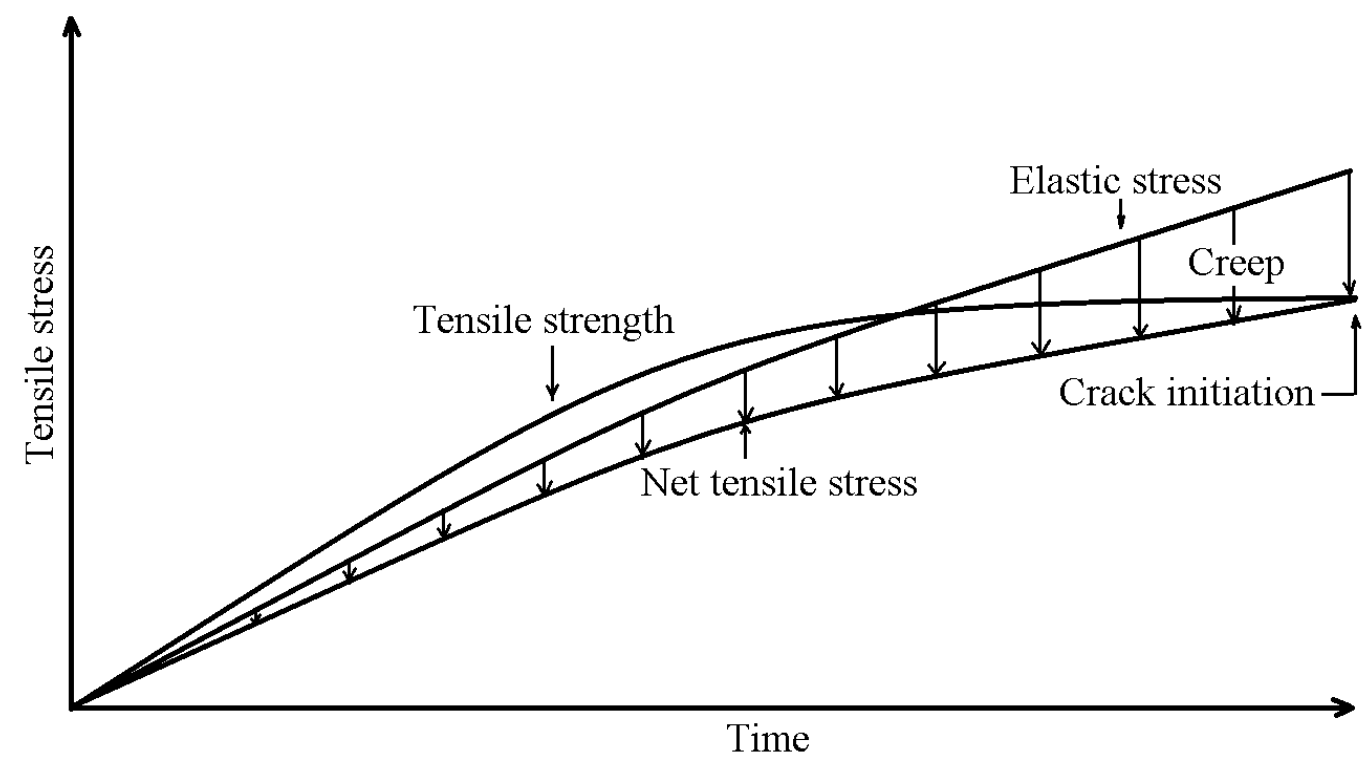

Figure 2-2 Effect of creep on tensile stress with time (ACI 224R-01) 


\subsection{Cracking behavior of $\mathrm{RC}$}

Shrinkage and temperature drop lead to development of tensile strains and stresses in the restrained member. Cracks occur when the tensile stresses reach the tensile strength of concrete. Thermal and shrinkage induced tensile strains can reach $1000 \mu \varepsilon$, while the concrete may be able to withstand not more than $100 \mu \varepsilon$ at which the cracking process commences (Kianoush et al 2008).

A tensile restraining force develops in an RC member as it starts to shrink when it is prevented from shortening by adjacent parts or existing supports. In a fully restrained beam, the stress in concrete could gradually reach the tensile strength as it shrinks or contracts, causing a full-depth direct tension crack. If the member is unreinforced, the restraining force drops to zero after a wide crack occurs leading to the failure of the member. If an inadequate amount of reinforcement is provided, as the concrete cracks and the tensile stress is transferred to the steel at the cracked location, steel yields since it is unable to withstand the applied stress. Therefore, the crack widens and the restraining force drops to less than its original value prior to cracking. In case the member is provided with a relatively large reinforcement ratio, the crack width remains small as the steel does not yield and the restraining force remains high with an insignificant stiffness loss in the member. Thus, highly reinforced members will experience several cracks, but these cracks will be narrow and well controlled. In an intermediately reinforced members, crack development causes a drop in the stiffness of the member and the reduction of the axial force and a crack width that may or may not be tolerable. The steel ratio is one of the major influential parameters that affect the crack width of a fully restrained member under tension along with the bond quality between the steel and concrete, size and distribution of the rebars and the concrete quality. Cracks caused by direct tension are proven to be less dependent on the concrete cover compared to flexural cracks since they are more parallel sided. 


\subsection{Summary}

In this chapter, a brief review of the previous studies on thermal and shrinkage cracking in RC members was presented. Related experimental, numerical, and analytical studies performed by different researchers were discussed. Then, the cracking mechanism due to drying shrinkage in restrained concrete members along with the effect of creep was explained followed by a brief review of the cracking behavior of RC due to thermal and shrinkage strains. 


\section{CRACK PREDICTION MODELS AND ANALYSES}

\subsection{General}

A proper portrayal of the mechanical properties of the material including the time-dependent strains in hardened concrete is necessary to predict the strength and serviceability of RC structures. Shrinkage and creep need to be estimated in order to determine the risk of cracking. This chapter presents the prediction models used to determine the concrete shrinkage and creep, the constitutive model used to simulate the concrete non-linear behavior and the details of the FE model and its verification.

\subsection{Strains identification}

The total strain in the member considering the shrinkage and creep as additives is presented in Equation 3-1 as follows:

Total strain $=$ shrinkage strain + compliance $\times$ stress

Where Compliance could be defined using Equation 3-2 as follows:

Compliance $=($ elastic strain + basic creep + drying creep $) /$ stress

The compliance could be determined in a shrinkage and creep test program by measuring the total strain and shrinkage strain. Two identical samples subjected to the same curing condition and environmental situation could be used for this purpose. One sample is not loaded and only used to determine shrinkage strain while the other specimen is subjected to a load that is 20 to $40 \%$ of the concrete compressive strength. The strain in the sample that is not loaded would be equal to the shrinkage strain. The total strain of the second specimen that is loaded is the summation of shrinkage and load-induced strains. Therefore, the load induced strains could be calculated by deducting the shrinkage strain measured on the unloaded sample from the total strain of the loaded 
sample which is equal to the elastic strain plus the basic and drying creep. Although the elastic strain could be measured in the early age of concrete, it could be difficult to differentiate between the early age creep and the elastic strain.

Basic and drying creep could be calculated by deducting the elastic strain from the compliance. However, implicit errors may raise from the measurement of elastic strains, total strains, and shrinkage which could reflect the computation of creep strain and compliance. If there is no moisture movements in the specimen (sealed condition), the compliance and total strain equations could be simplified as below since the drying creep and shrinkage strain are out of the equation.

Total strain $=$ compliance $\times$ stress

Compliance $=($ elastic strain + basic creep $) /$ stress

\subsection{ACI 209R-92 model for shrinkage and creep}

Branson and Christason (1971) first developed an empirical model which was modified and introduced in the ACI Committee 209 report in 1982 (ACI 209R-82). In 1992, ACI 209R-92 published a further developed and modified model to predict the shrinkage and creep in concrete members. Al-Manaseer and Prado (2015) performed a statistical study on six different shrinkage and creep compliance models and concluded that the ACI 209R-92 performs best in the prediction of both shrinkage and creep of concrete. The ACI 209R-92 model is chosen here in this study mainly because of its simplicity and given the fact that there was no specific data on the simulated concrete that would require a complicated model to determine a precise number for shrinkage or creep. A hyperbolic curve which tends to an asymptotic value also known as ultimate value is the basis of all the models that predict creep and shrinkage strains as a function of time. These equations have been formed to be as convenient as possible to be used by designers. Curing conditions, the age at which the load is applied to the member, concrete mixture and proportioning, 
and ambient temperature and humidity are the major parameters that determine the ultimate value and the shape of this curve.

The design approach proposed to predict shrinkage and creep is meant to be used for standard conditions and therefore, some correction factors have been introduced to be applied to ultimate values in order to include other-than-standard situations. The correction factors suggested in the procedure are also applicable to short-term creep and shrinkage since the creep and shrinkage equations are linear functions of the ultimate values for any period of time.

\subsubsection{Shrinkage}

The shrinkage strain at the age of t days, measured from when the curing period ends and drying starts ( $\mathrm{t}_{\mathrm{c}}$ days) can be calculated using Equation 3-5 as follows:

$\varepsilon_{s h}\left(t, t_{c}\right)=\frac{\left(t-t_{c}\right)^{\alpha}}{f+\left(t-t_{c}\right)^{\alpha}} \times \varepsilon_{s h u}$

Where,

$f=35$ for 7 days moist cured and 55 for 1 to 3 days steam cured concrete;

$\alpha=1$ considering flatter hyperbolic form;

$\varepsilon_{\text {shu }}=780 \times 10^{-6} \mathrm{~mm} / \mathrm{mm}$, in the absence of detailed shrinkage data, for the standard conditions considering a relative humidity of $40 \%$.

Coefficients $f$ and $\alpha$ are constants that are meant to define time-ratio $(f=35$ and $\alpha=1)$, for a given shape and size and $\varepsilon_{\text {shu }}$ is the ultimate shrinkage strain.

The ultimate shrinkage strain value could be determined introducing correction factors as presented in Equation 3-6 as follows:

$\varepsilon_{\text {shu }}=780 \gamma_{\mathrm{sh}} \times 10^{-6} \mathrm{~mm} / \mathrm{mm}$

In which,

$\gamma_{s h}=\gamma_{s h, t c} \gamma_{s h, R H} \gamma_{s h, v s} \gamma_{s h, s} \gamma_{s h, \psi} \gamma_{s h, c} \gamma_{s h, \alpha}$ 
Where, $\gamma_{s h}$ is the cumulative product of the correction factors.

$\gamma_{s h, t c}$, has been defined as initial moist curing coefficient which would be equal to 1 given the assumption that the concrete is wet cured for 7 days based on Table 3-1.

Table 3-1 Shrinkage correction coefficient for initial moist curing (ACI 209R-92)

\begin{tabular}{|c|c|}
\hline Moist curing duration $\mathrm{t}_{\mathrm{c}}$ (days) & $\gamma_{s h, t c}$ \\
\hline 1 & 1.2 \\
\hline 3 & 1.1 \\
\hline 7 & 1.0 \\
\hline 14 & 0.93 \\
\hline 28 & 0.86 \\
\hline 90 & 0.75 \\
\hline
\end{tabular}

The coefficient of ambient relative humidity can be determined using the following equations depending on the range of relative humidity:

$\gamma_{s h, R H}=1.40-1.02 h \quad(0.4 \leq h \leq 0.8)$

$\gamma_{s h, R H}=3.00-3.00 h \quad(0.8 \leq h \leq 1)$

$\gamma_{s h, v s}$ is the size and shape correction factor which depends on the volume to surface ratio and could be determined using Equation 3-9 as follows:

$\gamma_{s h, v s}=1.2 e^{-0.00472\left(\frac{V}{S}\right)}$

Where,

$V$ : The volume of the member $\left(\mathrm{mm}^{3}\right)$;

$S:$ The surface area of the concrete member $\left(\mathrm{mm}^{2}\right)$;

This model defines a parameter known as the average thickness (d), which is four times the volume to surface ratio and presents an alternative method to consider the influence of the member shape and size on the ultimate shrinkage. Table 3-2 presents shrinkage factors that could be used in the average thickness method when the member thickness is $150 \mathrm{~mm}$ or less. 
Table 3-2 Shrinkage correction coefficient for average thickness method

\begin{tabular}{|c|c|c|}
\hline $\begin{array}{c}\text { Average member } \\
\text { thickness }(\mathrm{mm})\end{array}$ & $\begin{array}{c}\text { Volume/Surface } \\
\text { ratio }(\mathrm{mm})\end{array}$ & Shrinkage factor $\gamma_{s h, d}$ \\
\hline 51 & 12.5 & 1.35 \\
\hline 76 & 19 & 1.25 \\
\hline 102 & 25 & 1.17 \\
\hline 127 & 31 & 1.08 \\
\hline 152 & 37.5 & 1.00 \\
\hline
\end{tabular}

Equations 3-10 should be used when the average member thickness is between 150 and $380 \mathrm{~mm}$.

$\gamma_{s h, d}=1.23-0.006\left(\frac{V}{S}\right) \quad$ for less than a year drying $\left(t-t_{c}\right) \leq 1$ year

$\gamma_{s h, d}=1.23-0.006\left(\frac{V}{s}\right) \quad$ for ultimate values $\left(t-t_{c}\right) \geq 1$ year

It should be noted that this coefficient should be more than 0.2 for either method. In addition, if the concrete is exposed to seasonal wetting and drying cycles $\gamma_{s h, d}$ should be more than $100 \times 100^{-}$ ${ }^{6}$ and for sustained drying conditions it should be at least $150 \times 10^{-6}$.

Slump factor is one of the correction factors that is meant to take into account the composition of the concrete and could be found using the following equation having " $\mathrm{s}$ " as the fresh concrete slump:

$\gamma_{s h, s}=0.89+0.00161 s$

Fine aggregate coefficient is another composition related correction factor that could be computed using Equation 3-12 as follows:

$\gamma_{s h, \psi}=0.3+0.014 \psi$ when $\psi \leq 50 \%$

$\gamma_{s h, \psi}=0.9+0.002 \psi$ when $\psi>50 \%$

Where,

$\psi$ : Ratio of weight of fine aggregate to total aggregate 
Cement content factor $\left(\gamma_{s h, c}\right)$ and air content factor $\left(\gamma_{s h, \alpha}\right)$ are also defined to describe the composition of concrete and could be computed using Equations 3-13 and 3-14 respectively.

$\gamma_{s h, c}=0.75+0.00061 c$

$\gamma_{s h, \alpha}=0.95+0.008 \alpha \geq 1$

\subsubsection{Compliance}

ACI 209R defines compliance as the function of elastic modulus and creep coefficient to represent the total stress-dependent strain by unit stress as presented in Equation 3-15:

$J\left(t, t_{0}\right)=\frac{1+\phi\left(t, t_{0}\right)}{E_{c m t o}}$

In which,

$E_{c m t o}$ : The concrete elastic modulus when load is applied at $t_{0}$ in $\mathrm{MPa}$;

$\phi\left(t, t_{0}\right)$ : The creep coefficient which is defined as the ratio of creep strain to elastic strain when the loading starts at $t_{0}$ days.

The secant elastic modulus of concrete $E_{c m t o}$ at the age of $t_{0}$ could be calculated using the following equation:

$E_{c m t o}=0.043 \gamma_{c}^{105} \sqrt{f_{c m t o}}(\mathrm{MPa})$

Where,

$\gamma_{c}$ : The concrete unit weight $\left(\mathrm{kg} / \mathrm{m}^{3}\right)$;

$f_{c m t o}$ : The mean compressive strength of concrete when loading is being applied.

Equation 3-17 is the general relationship that could be used for the compressive strength of concrete at any given time $(\mathrm{t})$ :

$f_{c m t}=\left[\frac{t}{a+b t}\right] f_{c m 28}$

In which, 
$f_{c m 28}$ : The mean compressive strength of concrete after 28 days in MPa;

t: The age of concrete (days);

Coefficients "a" and "b" are constants that vary based on curing conditions and cement type as provided in Table 3-3. The "a/b" ratio is the age when concrete reaches half of its ultimate compressive strength.

Table 3-3 Values for the constant "a" and "b" to be used in Equation 3-17

\begin{tabular}{|c|c|c|c|c|}
\hline \multirow{2}{*}{$\begin{array}{c}\text { Type of } \\
\text { cement }\end{array}$} & \multicolumn{2}{|c|}{ Moist-cured concrete } & \multicolumn{2}{c|}{ Steam-cured concrete } \\
\cline { 2 - 5 } & $\mathrm{a}$ & $\mathrm{b}$ & $\mathrm{a}$ & $\mathrm{b}$ \\
\hline I & 4.0 & 0.85 & 1.0 & 0.95 \\
\hline II & 2.3 & 0.92 & 0.7 & 0.98 \\
\hline
\end{tabular}

\subsubsection{Creep coefficient}

The creep value and its development with time are the two major components of the creep model presented by ACI 209R-92. The creep coefficient is the ratio of creep strain to the initial strain and is independent of the applied load as presented in Equation 3-18 as follows:

$\phi\left(t, t_{0}\right)=\frac{\left(t-t_{0}\right)^{\psi}}{d+\left(t-t_{0}\right)^{\psi}} \phi_{u}$

Where,

$\phi\left(t, t_{0}\right)$ : The creep coefficient in $t$ days after the load is applied at the age of $t_{0}$ days;

$\phi_{u}$ : The ultimate coefficient of creep that could be taken as 2.35 assuming standard conditions when there is a lack of specific data.

The coefficients $\mathrm{d}$ and $\psi$ consider the time ratio for a given shape and size and could be taken as 10 and 0.6 respectively as recommended by ACI 209R-92.

The ultimate creep coefficient could be determined more precisely using Equation 3-19 for nonstandard conditions introducing 6 correction factors as given in Equations 3-19 and 3-20:

$\phi_{u}=2.35 \gamma_{c}$

$\gamma_{c}=\gamma_{c, t 0} \gamma_{c, R H} \gamma_{c, v s} \gamma_{c, \psi} \gamma_{s h, \alpha}$ 
In which,

$\gamma_{c}$ : The cumulative product of the creep correction factors.

The age of loading factor $\left(\gamma_{c, t 0}\right)$ is given in Equation 3-21 which is applicable when the age at which the loading is applied is more than 7 days and 3 days for moist cured and steam cured concrete respectively.

$\gamma_{c, t 0}=1.25 t_{0}^{-0.118}$ for moist cured concrete

$\gamma_{c, t 0}=1.13 t_{0}^{-0.094}$ for steam cured concrete

The relative humidity factor $\left(\gamma_{c, R H}\right)$ is given in Equation 3-22 as follows:

$\gamma_{C, R H}=1.27-0.67 h$ for $h \geq 0.4$

In dry climates where the relative humidity is less than $40 \%(\mathrm{~h}<0.4)$, a value larger than 1.0 is suggested to be used.

$\gamma_{c, v s}$ is the member size and shape (volume to surface ratio) factor and could be determined using Equation 3-23 as follows:

$\gamma_{c, v s}=\frac{2}{3}\left(1+1.13 e^{\{-0.0213(V / S)\}}\right)$

Alternatively, the average thickness method could be used to consider the influence of member size which commonly gives higher correction factor values compared to volume-surface ratio method. Table 3-4 could be used for average thicknesses lower than $150 \mathrm{~mm}$ corresponding to the volume ratios below $37.5 \mathrm{~mm}$.

Table 3-4 Creep correction factors for average thickness of members (d)

\begin{tabular}{|c|c|c|}
\hline $\begin{array}{c}\text { Average member } \\
\text { thickness, } \mathrm{d}(\mathrm{mm})\end{array}$ & $\begin{array}{c}\text { Volume/Surface } \\
\text { ratio }(\mathrm{mm})\end{array}$ & $\begin{array}{c}\text { Shrinkage factor } \\
\gamma_{s h, d}\end{array}$ \\
\hline 51 & 12.5 & 1.3 \\
\hline 76 & 19 & 1.17 \\
\hline 102 & 25 & 1.11 \\
\hline 127 & 31 & 1.04 \\
\hline 152 & 37.5 & 1.00 \\
\hline
\end{tabular}


When the average thickness is not in the range given by table 3-4 (150 $\leq d \leq 380)$, Equation 3-24 can be used to compute this coefficient as follows:

$\gamma_{c, d}=1.14-0.00092 d$ when $\left(t-t_{0}\right) \leq 1$ year

$\gamma_{c, v s}=1.10-0.00067 d$ when $\left(t-t_{0}\right)>1$ year

Where,

$d: 4\left(\frac{V}{S}\right)$, known as the average thickness of the part of the member under construction.

The correction factors that are meant to take into account the composition of concrete are slump, fine aggregate and air content factors that are given in equations 3-25 to 3-27 as follows:

$\gamma_{c, s}=0.82+0.00264 s$

Where, $\gamma_{c, s}$ is the slump factor and $\mathrm{s}$ is the fresh concrete slump in $\mathrm{mm}$.

$\gamma_{c, \psi}=0.88+0.0024 \psi$

Where, $\gamma_{c, \psi}$ is the fine aggregate factor and $\psi$ is the weight percentage of fine aggregate to total aggregate.

$\gamma_{c, \alpha}=0.46+0.09 \alpha \geq 1$

Where, $\gamma_{c, \alpha}$ is the air content factor and $\alpha$ is the air content percent.

\subsection{Crack spacing}

As cracks develop in a member under tension, the stress pattern changes between the cracks. By increasing the applied stress on the member, further cracks occur until the crack spacing becomes almost twice the concrete cover measured to the centre of the bar. The spacing between the external cracks could vary significantly throughout the member due to any of the following reasons:

a- Variability of concrete tensile strength;

b- Inconsistency of bond integrity of the bar;

c- Proximity of previous primary cracks which reduces the local tensile stress. 
Broms (1965) showed that the average crack spacing is less than twice the concrete cover until the stress in the reinforcement exceeds 138 to $200 \mathrm{MPa}$ (for concrete covers between 30 to $75 \mathrm{~mm}$ ). He also concluded that the maximum crack spacing should be less than twice the average crack spacing. In other words, maximum crack spacing is about 4 times the concrete cover. For members under tension, the average crack spacing should be about 20 percent higher than that of the members subjected to flexure.

Increasing the concrete cover has proven to decrease the number of cracks. In fact, when concrete cover is larger, a higher percentage of cracks will remain internal (secondary) but those cracks that reach the surface (primary cracks) will be wider. Therefore, wider cracks form in the concrete member by increasing the concrete cover.

\subsection{Crack width}

Having the maximum crack spacing (4 times the concrete cover), the maximum crack width could be determined by multiplying it by the average steel strain. In case of members under tension with multiple reinforcements, a parameter called "effective concrete cover" could be used instead of concrete cover to reach more precise answers as proposed by Broms (1965) using the following equation:

$t_{e}=d_{c} \sqrt{1+\left(\frac{s}{4 d_{c}}\right)^{2}}$

Where,

$d_{c}=$ Distance from the bar centre to extreme tension fiber (in.);

$\mathrm{S}=$ Bar spacing (in.).

Effective concrete cover is similar to the variable $\sqrt[3]{d_{c} A}$ used in the crack width formulation proposed by Gergely-Lutz for members under flexure (Gergely and Lutz 1968). However "A" in 
this equation is defined as the concrete area symmetric with reinforcement divided by the number of bars (in. ${ }^{2}$ ).

Since the crack with in members under tension has a larger variability, the maximum crack width is likely to be higher for the same steel stress for a member in tension compared to flexure. The narrower cracks in members under flexure compared to tension, could be the result of the crack restraint due to compression zone in flexural members. In fact, in flexural members, the cracks start to develop gradually at the highest stressed location because of the stress gradient as opposed to abrupt cracking in tensile members due to uniform stress distribution. Broms (1965) suggested using the following equation for crack width in tensile members:

$W_{\max }=4 \varepsilon_{s} t_{e}=0.138 f_{s} t_{e} \times 10^{-3}$

Where $t_{e}$ is defined in equation 3-32 and therefore $W_{\max }$ (in inches) could be calculated using Equation 3-34 as follows:

$W_{\text {max }}=0.138 f_{s} d_{c} \sqrt{1+\left(\frac{s}{4 d_{c}}\right)^{2}} \times 10^{-3}$

For a single reinforcement layer, the crack width equation could be simplified as follows:

$W_{\max }=0.10 f_{s}^{3} \sqrt{d_{c} A} \times 10^{-3}$

Equation 3-35 could be used to calculate the crack width in fully cracked members under tension. Since it has been proven that the crack width for tensile members could be highly variable, there is a possibility that the crack width calculated using the proposed equations would be 30 percent larger or smaller than what is measured in real life.

Gergely and Lutz (1968) proposed using the following equation for the maximum crack width in flexural members:

$W_{\text {max }}=0.076 \beta f_{s} \sqrt[3]{d_{c} A} \times 10^{-3}$

In which, 
$\mathrm{W}_{\max }$ : Maximum crack width (mm)

$\beta$ : The distance from neutral axis to tension face divided by the distance between neutral axis and centroid of the reinforcement and could be taken equal to 1.20 in beams.

Taking $\beta$ equal to $1.20,0.076 \beta$ will be 0.091 compared to 0.10 in tensile cracking showing that the maximum tensile crack is about 10 percent wider than the maximum flexural crack in the same section and steel stress. The simplified form of Equation 3-36 assuming $\beta=1.20$ is used in ACI 318-11 (2011) for crack control as presented below:

$z=f_{s} \sqrt[3]{d_{c} A}$

Based on ACI 318-11 (2011), for interior exposure a maximum value of $z=175$ Kips/in (30.6 $\mathrm{MN} / \mathrm{m})$ is allowed which corresponds to a crack width of $0.016(0.41 \mathrm{~mm})$. For exterior exposure z should be limited to $145 \mathrm{Kips} / \mathrm{in}(25.4 \mathrm{MN} / \mathrm{m})$ corresponding to a crack width of 0.013 in $(0.33$ $\mathrm{mm}$ ). For members under tension, the formulation proposed in equation 3-37 could be used only by multiplying the $\mathrm{z}$ factors of 145 and 175 by the ratio of coefficients which is 0.91 . Conclusively, the $\mathrm{z}$ values of 132 and 160 for interior and exterior exposure could be used for tensile members. A formulation proposed by Frosch (1999) is used in this study in order to calculate the width of cracks as presented in Equation 3-38.

$W_{C}=\varepsilon_{C} S_{C}$

Where, $W_{C}$ is the crack width, $\varepsilon_{C}$ is the strain in reinforcement and $S_{C}$ is the spacing between the cracks. This equation is also adapted in the ACI 318-11 Code for calculating the crack width. Based on statistical data, Frosch (1999) also developed an equation for spacing between cracks $\left(S_{C}\right)$ as presented below:

$S_{C}=\psi_{S} d^{*}$ 
Where $\psi_{S}$ is defined as crack spacing factor ( 1 for minimum crack spacing, 1.5 for average crack spacing and 2 for maximum crack spacing) and $d^{*}$ is called "controlling cover distance". Frosch (1999) calibrated the crack spacing factor value based on cracking in flexural members in his model. Here in this study, assuming that the crack width due to volume change is still proportionate to the steel strain at the cracked location, this factor is adjusted based on the experimental results on RC walls. Controlling cover distance $\left(d^{*}\right)$ could be calculated using the following equation having $\mathrm{S}$ as the reinforcement spacing.

$d^{*}=\sqrt{d_{c}^{2}+\left(\frac{S}{2}\right)^{2}}$

\subsection{Material modeling}

Modeling the cracking behavior of RC structures requires nonlinear analysis that makes the $\mathrm{FE}$ model quiet complex. The selected FE program gives the user the possibility to define and simulate the nonlinearity in RC behavior. ABAQUS offers three constitutive models for analyzing concrete in low confining pressure named "the smeared crack concrete model", "concrete damaged plasticity" and "cracking model for concrete". Each model provides different capabilities to simulate different aspects of concrete behavior in different types of structures. Brittle cracking model is chosen for the simulation of the RC walls. This model is meant to be used for the situations where concrete is mainly under tension and compressive failure is of no importance which is suitable for the case of this study.

\subsubsection{Brittle cracking model for concrete}

This model is aimed to be used for simulation of RC members under tension. It considers the behavior of the concrete to be independent of the rebar. The rebar-concrete interactions including bond-slip could not be directly introduced but could be mimicked by making modifications on the 
plain concrete behavior using tension stiffening concept that allows load transfer across cracks using the reinforcements (Hillerborg 1976). Rankine criterion is used for detecting the initiation of crack in this model. Based on this criterion, as soon as the maximum principal stress reaches the concrete tensile strength, the cracks start to form. The surface of the crack would be perpendicular to the maximum principle tensile stress direction. To define the behavior of the RC concrete across cracks after failure of concrete, either a stress-strain relation or a fracture energy criterion could be applied. The post-failure behavior in RC concrete is usually defined by provision of a relationship between post-failure stress and the strain across the crack as shown in Figure 3-1.

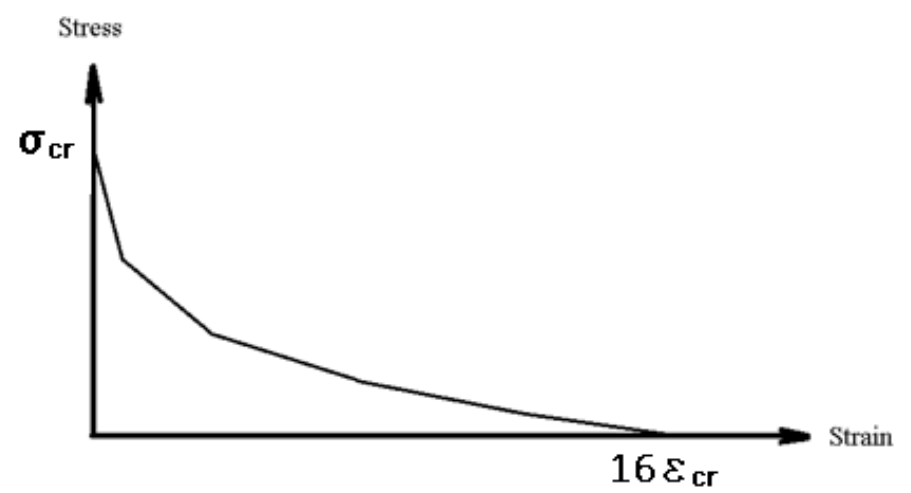

Figure 3-1 Post failure behavior of RC concrete in tension

For a FE simulated RC member, each element contains rebars for most cases. Therefore, if an appropriate tension stiffening is introduced in the cracking model, the rebar-concrete interaction could be defined properly. Reinforcement density, the bond quality between the reinforcement and concrete, the ratio of aggregate size to the bar diameter, and the mesh are the parameters that should be considered in the definition of tension stiffening. For a highly reinforced concrete member that is meshed with fairly fine elements as an example, a fair assumption would be to define the strain softening to reduce the post-failure stress linearly to zero with a strain of about 10 times the failure strain. Therefore, assuming a typical failure strain of $10^{-4}$, a reasonable value for the ultimate strain corresponding to zero stress would be about $10^{-3}$ (Hibbit et al. 2004). For this study, the value of 
ultimate strain is determined based on the tension stiffening model proposed by Massicotte et al. (1990) and the results was verified by comparing the crack widths of the FE model with the experimental study.

When one, two, or all local cracking strain components exceed the failure strain that is defined, all the stress components will be set to zero as the material point fails. The element could be removed from the mesh if all material points in that element fail. In case that the post-failure relation is defined using stress-strain relationship, the strain at failure must be given as the failure criterion, whereas for stress-displacement or stress-fracture energy method, the failure criterion would be the failure displacement.

The brittle cracking model capability to remove elements when they are no longer able to withstand stresses is of significant importance since these elements excessive distortion could cause premature termination of the solution. In a monotonically loaded member, as an example, where a single tensile macro-fracture is expected to be the dominant failure mechanism, removing elements with the use of brittle failure criterion would be reasonable. If the member is expected to go under compression after it fails in tension, it may not be appropriate to eliminate elements since concrete can still carry compression even if it is unable to withstand tension. A wall that is experiencing cyclic loading could be an example of this. It therefore can be concluded that the proper use of the brittle cracking model depends on the structural behavior and failure mechanism.

When an $\mathrm{RC}$ member is simulated using the brittle failure criterion and the concrete reaches the ultimate strain, the brittle cracking contribution to the element stress carrying capacity is removed, while the contribution of the rebar to the element stress capacity remains intact. If the shear failure is defined in the reinforcement material behavior, the steel contribution to the stress carrying capacity of the element is removed when the rebar shear failure criterion is satisfied allowing the 
simulation of progressive failure of an under-reinforced member in which the concrete failure is follows by the ductile steel failure.

\subsection{Case study and FE verification}

\subsubsection{Base restrained wall (creep effect not included)}

In order to verify the selected FE model in ABAQUS, the crack pattern and width of the simulated model is compared with the ones of a case study performed by Kheder (1997). The selected wall is $3.25 \mathrm{~m}$ tall and $12 \mathrm{~m}$ long with a thickness of $150 \mathrm{~mm}$ and $0.2 \%$ reinforcement ratio. The crack width, spacing, height and pattern were recorded using monitoring devices and stress and strain gages. In the FE model, the reinforcement layer is defined to be at the mid-depth of the section in one horizontal and one vertical layer. The bar diameter is $12 \mathrm{~mm}$ with a spacing of $262 \mathrm{~mm}$ for $0.2 \%$ reinforcement ratio as specified in the experimental study. In the FE program, the reinforcement is modeled as a smeared layer meaning that the reinforcement cross section area is evenly distributed among the concrete elements and therefore the bar spacing and size do not directly influence the results. The temperature and shrinkage strain in the case study is modeled by applying the equivalent temperature drop to the walls using the following equation considering the coefficient of thermal expansion $(\alpha)$ of $10 \times 10^{-6}{ }^{\circ} \mathrm{C}$.

$\Delta T=\varepsilon / \alpha$

Since the total volumetric strain of the wall during its exposure period was reported to be $465 \mu \varepsilon$, an equivalent temperature drop of $46.5^{\circ} \mathrm{C}$ is applied to the simulated wall. The material properties as modeled in the FE model is presented in Table 3-5. The symbolic stress-strain behavior of the concrete as modelled in the FE program is demonstrated in Figure 3-2. The descending part of the graph represents the tension stiffening effect after the concrete reaches its tensile strength and that 
is when cracks start to develop. The mesh is selected to be $200 \times 200 \mathrm{~mm}$ after performing the mesh sensitivity analysis on 3D shell elements. Shell elements were used because the thickness of the walls were much smaller than the wall dimensions, the loading was parallel to the plane of the wall and the stress or strain variation within the wall thickness was not significant for this study. The strain contour of the FE model for the selected wall is presented in Figure 3-3 along with the cracking pattern observed in the case study for the same wall. The crack pattern in the FE model could be recognized in the strain contour presented. The widths of cracks are calculated based on the steel strain values collected from the analysis and using Frosch equation. The widest crack in the walls according to the experiment was $0.36 \mathrm{~mm}$ as shown in the figure while the FE simulation shows the widest cracks to be $0.39 \mathrm{~mm}$. The figure demonstrates the crack pattern in addition to the width of major and minor cracks in the actual experiment versus the FE model. Not only the crack widths are in the same range but also the overall crack pattern of the FE study is in good agreement with the case study. Therefore, based on this comparison, the FE model is capable of simulating the $\mathrm{RC}$ walls behavior under volumetric changes.

Table 3-5 Material properties of concrete and steel

\begin{tabular}{|c|c|c|}
\hline Material property & Concrete & Steel \\
\hline Elastic modulus $(\mathrm{MPa})$ & 25000 & 200000 \\
\hline Tensile Strength $(\mathrm{MPa})$ & 3 & -- \\
\hline Yield Strength $(\mathrm{MPa})$ & -- & 400 \\
\hline Density $\left(\mathrm{Kg} / \mathrm{m}^{3}\right)$ & 2400 & 7800 \\
\hline Poisson's ratio & 0.18 & 0.3 \\
\hline$\alpha\left({ }^{\circ} \mathrm{C}\right)$ & $10^{-5}$ & -- \\
\hline
\end{tabular}




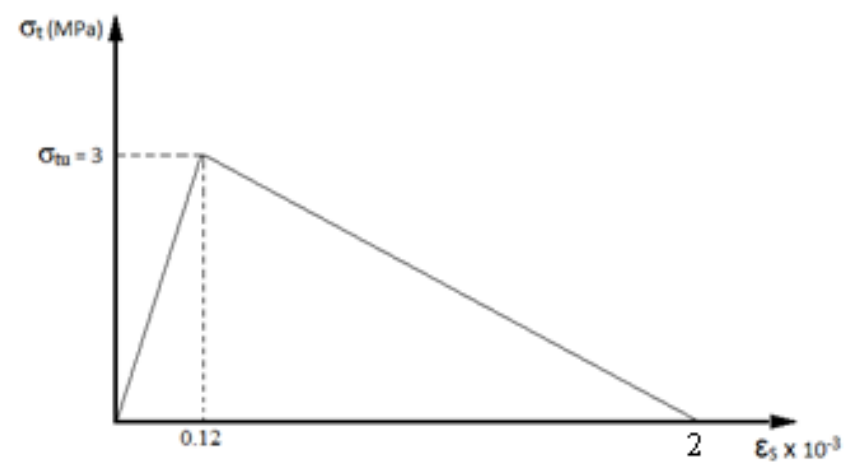

Figure 3-2 Concrete tension stiffening behavior

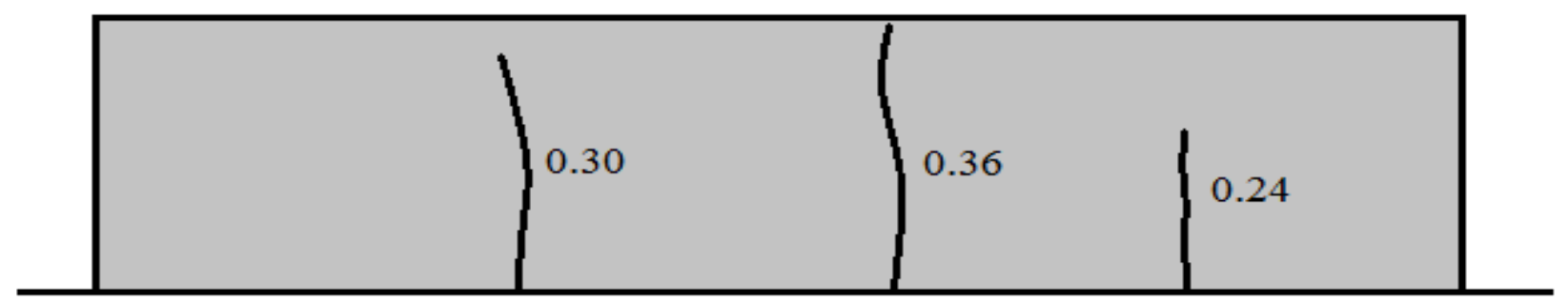

(a) Experimental study

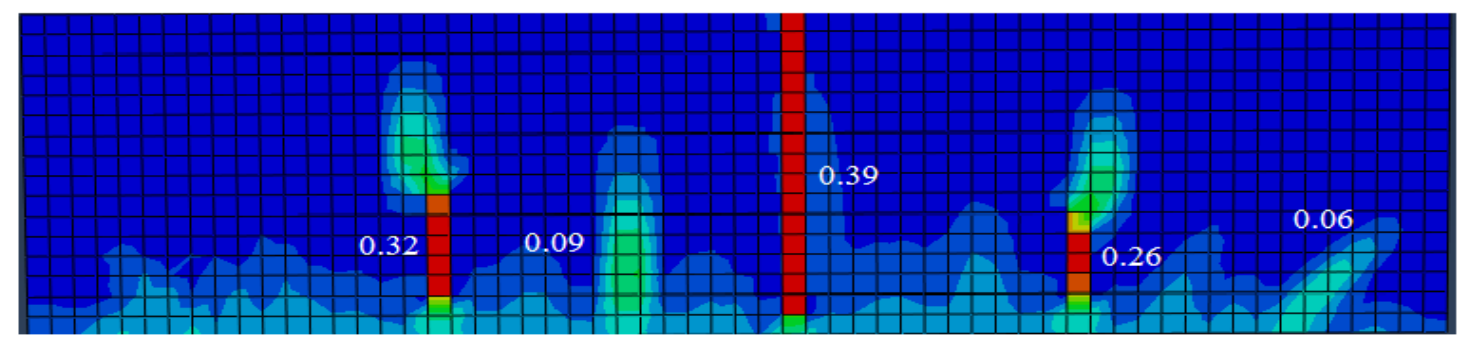

(b) FE model

Figure 3-3 Comparison of crack pattern and width in the experimental study with the FE model

\subsubsection{Base restrained wall (creep effect included)}

The selected wall for this case is $2 \mathrm{~m}$ high and $4 \mathrm{~m}$ long with a thickness of $150 \mathrm{~mm}$ and $0.2 \%$ reinforcement ratio. The total volumetric strain on a sample cast with the same concrete batch and exposed to the identical environment with no restraint was measured to be $1050 \mu \varepsilon$ which is equivalent to $105{ }^{\circ} \mathrm{C}$ temperature drop. The ambient temperature and relative humidity were reported to be about $40{ }^{\circ} \mathrm{c}$ and $20 \%$ respectively. The developed volumetric strain versus time is demonstrated in Figure 3-4 considering a 7 day moist curing period for a total of 60 days that the 
walls was exposed. The equivalent temperature drop as modeled in the FE program is calculated based on Figure 3-4 and presented in Figure 3-5.

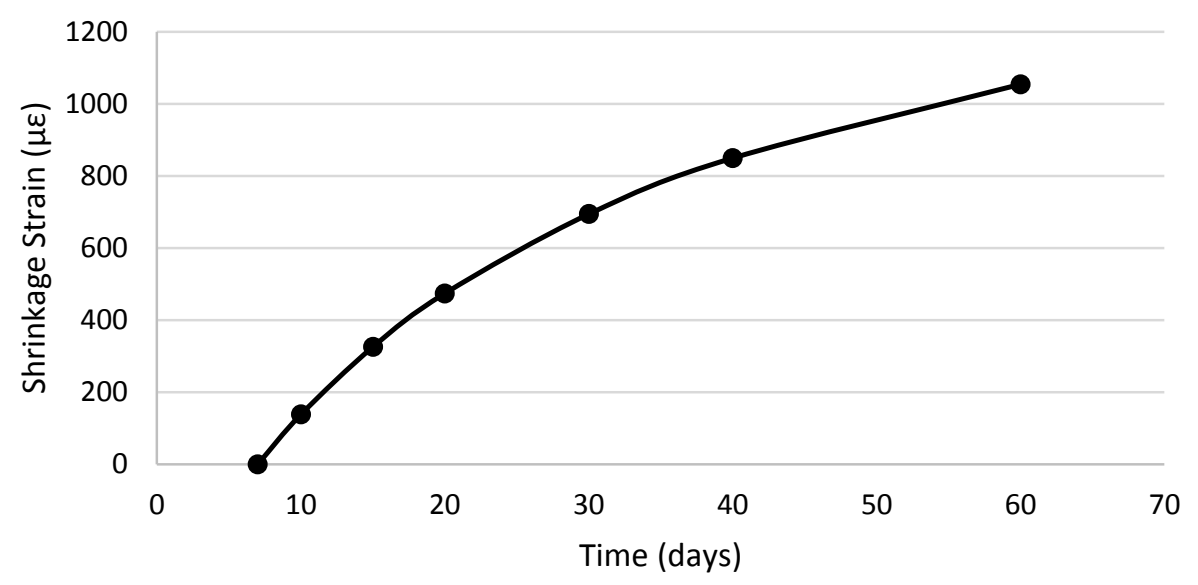

Figure 3-4 Shrinkage strain in the 2 months period after casting

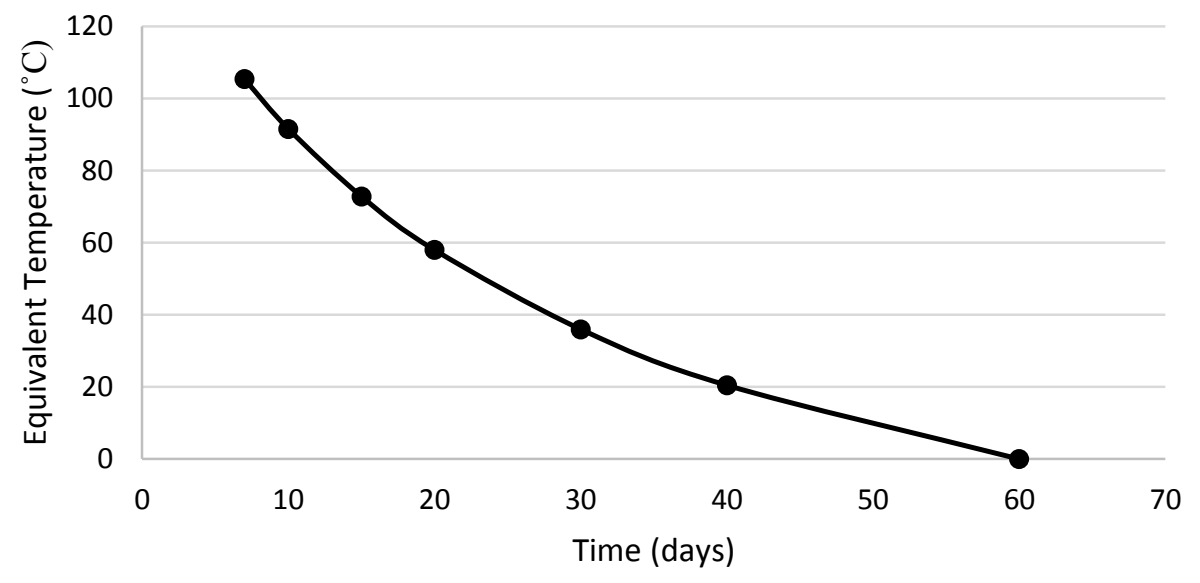

Figure 3-5 Equivalent temperature drop in the 2 months period after casting ACI 209R-92 model is used to calculate the creep coefficient and compliance as explained earlier. Figure 3-6 illustrates the creep coefficient variation with time in the period of 2 months after casting considering 7 days of wet curing. Figure 3-7 presents the compliance calculated having the time dependent creep coefficient. 


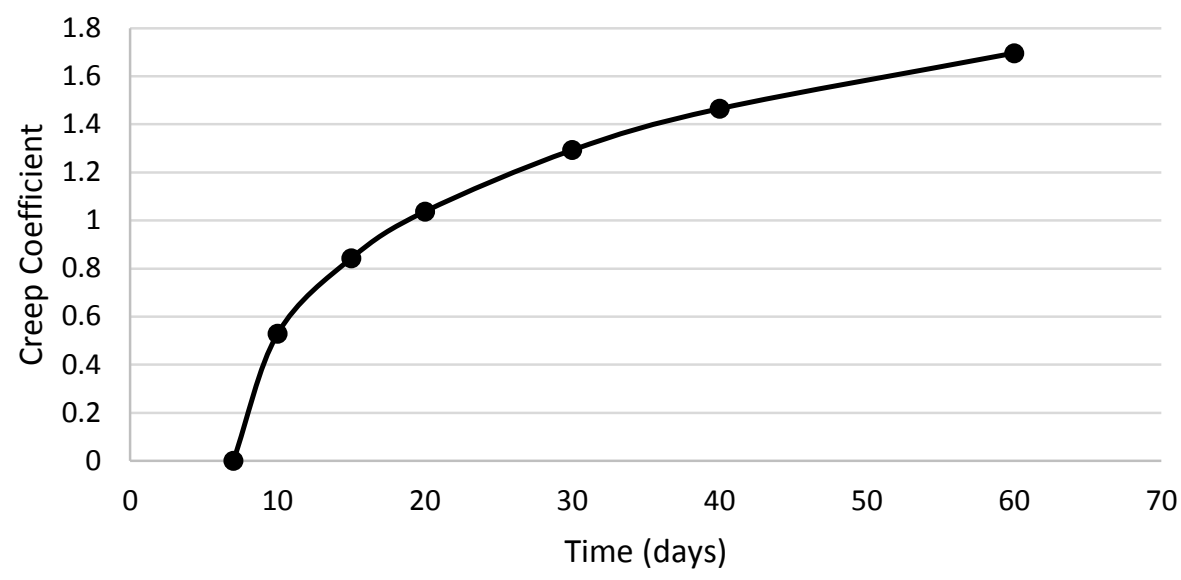

Figure 3-6 Creep coefficient variation with time over the 2 months exposure

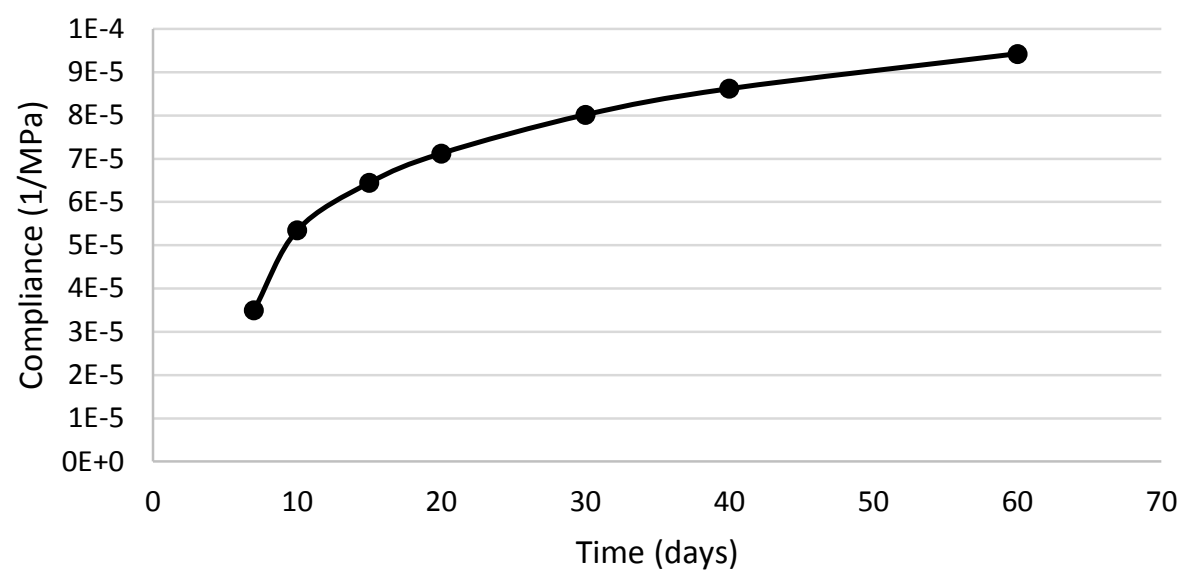

Figure 3-7 Compliance variation with time over the 2 months exposure

The mesh is selected to be $200 \times 200 \mathrm{~mm}$ after performing the mesh sensitivity analysis on $3 \mathrm{D}$ shell elements. The strain contour of the FE model for the selected wall is presented in Figure 3-8 along with the cracking pattern observed in the experimental study. The figure demonstrates the crack pattern in addition to the width of major and minor cracks in the actual experiment versus FE model. Not only the cracks widths are in the same range but also the overall crack pattern of the FE study is in good agreement with the case study. Therefore, it can be concluded that the selected FE model is able to simulate the cracking behavior of base restrained $\mathrm{RC}$ walls under restrained volumetric strains. 


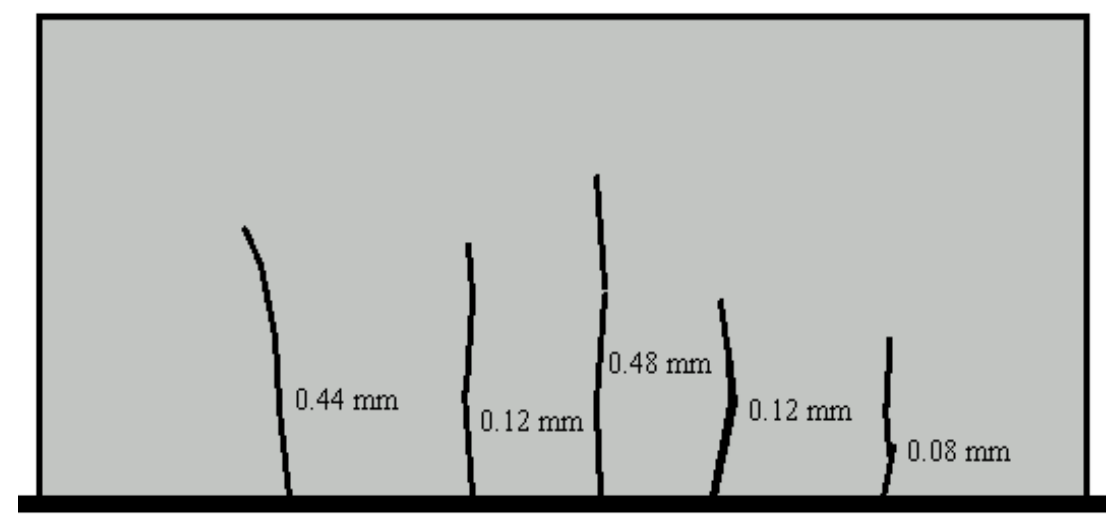

(a) Experimental study

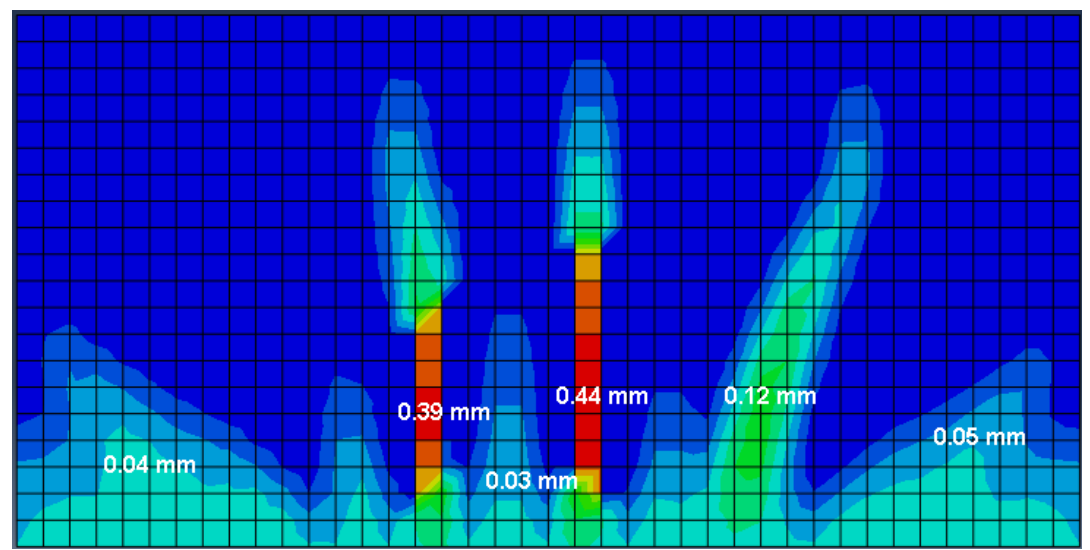

(b) FE Model

Figure 3-8 Comparing the crack pattern and width in experimental study with the FE model

\subsection{Temperature and shrinkage strain}

The shrinkage strain can be calculated using the procedure proposed by ACI 209R-82 as explained earlier in this chapter using Equation (3-5). In order to find the time dependent shrinkage strain, the ultimate shrinkage needs to be computed using Equation (3-6) and (3-7). Since three different climate conditions (tropical, cold and humid, and hot and dry) are considered in this study, three different values are calculated for the relative humidity coefficient using Equation 3-8. The relative humidity for dry, humid, and tropical climates are assumed to be $20 \%, 70 \%$, and $90 \%$ respectively. The concrete is assumed to be wet cured for 7 days. Slump, fine aggregate and cement content factors are taken to be equal to be 1.0 assuming they are in the standard range. The average ultimate 
shrinkage strain is calculated to be $150 \mu \varepsilon, 300 \mu \varepsilon$ and $500 \mu \varepsilon$ for tropical, cold and humid, and hot and dry climates respectively.

It has been proven that summer concreting could be a lot more critical in terms of thermal and shrinkage strain to the point that the volumetric strain for structures poured in the summer could be twice as much the ones cast in the winter for the period of a year (Kheder et al. 1994). Therefore, it is assumed that the concrete is cast in the summer and consdering the most critical situation, a period of 6 months is considered for the calculation of total volumetric strains since after that point the weather starts to warm up again and the thermal strains will reduce. In order to determine the thermal strain, the maximum and minimum temperatures need to be determined during this period. The maximum temperature could be taken as the ambient temperature during casting and for the minimum temperature assuming the wall is exposed to water since the water temperature rarely goes below $0^{\circ} \mathrm{C}$, the minimum is assumed to be zero for both cold and humid and hot and dry climate. The total temperature variation in the 6 months period is assumed to be $40{ }^{\circ} \mathrm{C}$ and $30^{\circ} \mathrm{C}$ for the hot and cold climates respectively given their minimum temperature is zero. For the tropical climate a total temperature variation of $15^{\circ} \mathrm{C}$ is assumed since there is not much temperature variation throughout the year. Therefor the total thermal strain caused by temperature drop from the summer to the winter ( 6 months period) would be $400 \mu \varepsilon, 300 \mu \varepsilon$, and $150 \mu \varepsilon$ for hot and dry, cold and humid, and tropical environments respectively.

The summation of thermal strain and shrinkage strain would be required for the analysis. In case of time-independent models in which the creep effect is ignored, the summation of thermal and shrinkage strain is applied to the walls as the ultimate strain. Therefore, the walls are assumed to be exposed to a total strain of $900 \mu \varepsilon, 600 \mu \varepsilon$, and $300 \mu \varepsilon$ for hot and dry, cold and humid, and tropical climates respectively. 
For the models that include the creep effect, the shrinkage strain values need to be determined using Equation (3-5) for the six months period of exposure. Figure 3-9 (a) presents the shrinkage strain for the three climates over the period of 6 months. The reason behind choosing a six months exposure period as opposed to two years was that the difference between the crack widths in six months and two years is less than $10 \%$ considering the shrinkage strain reaches about $85 \%$ of its ultimate in six months. Figure 3-9 (b) presents the thermal strain caused by temperature drop for each climate assuming a linear temperature decrease. Adding the thermal and shrinkage strain gives the total volumetric strain which is presented in Figure 3-9 (c) for the 6 months period in each climate condition.

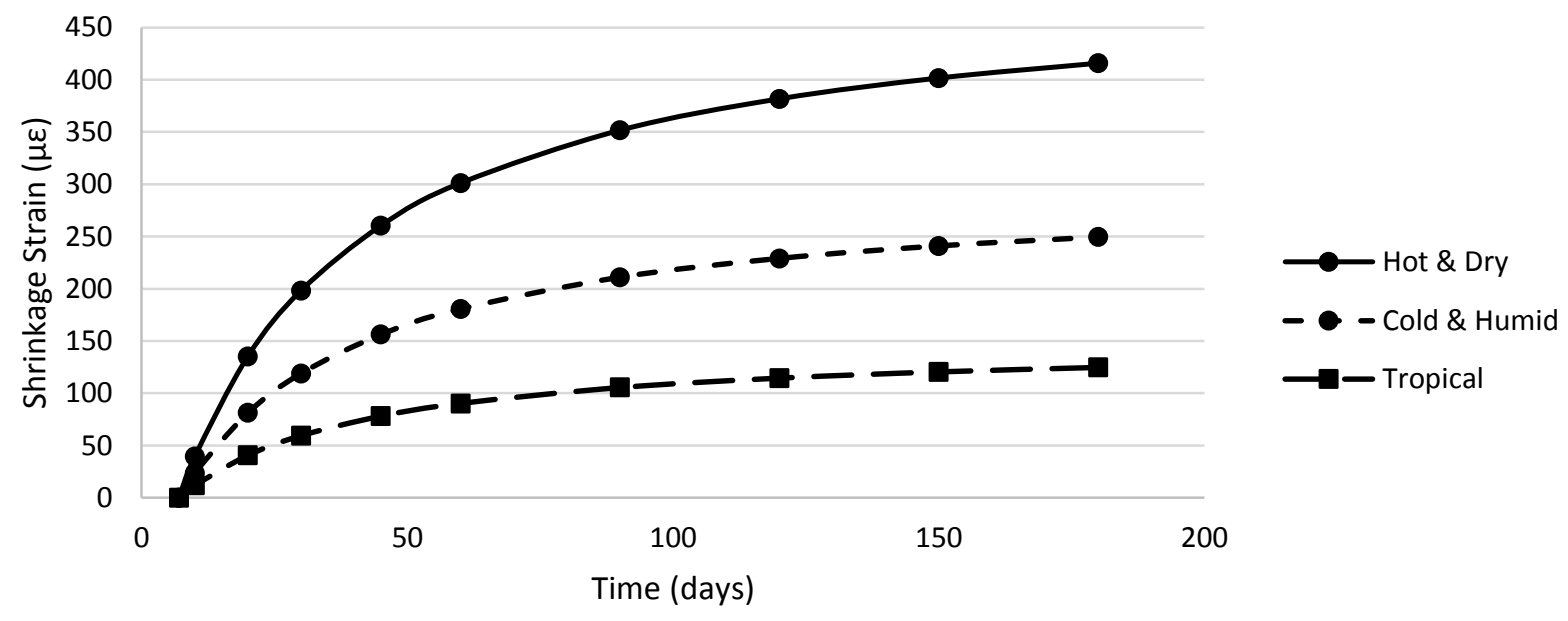

(a) Shrinkage strain 


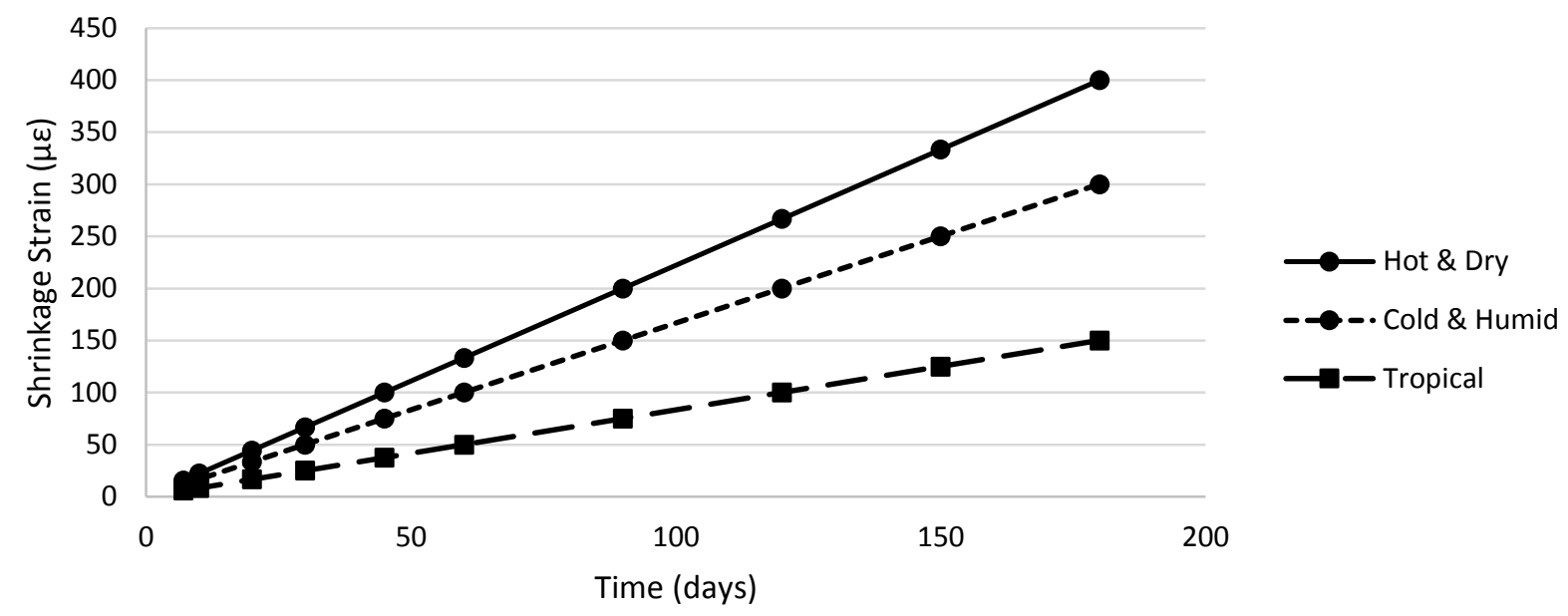

(b) Thermal strain

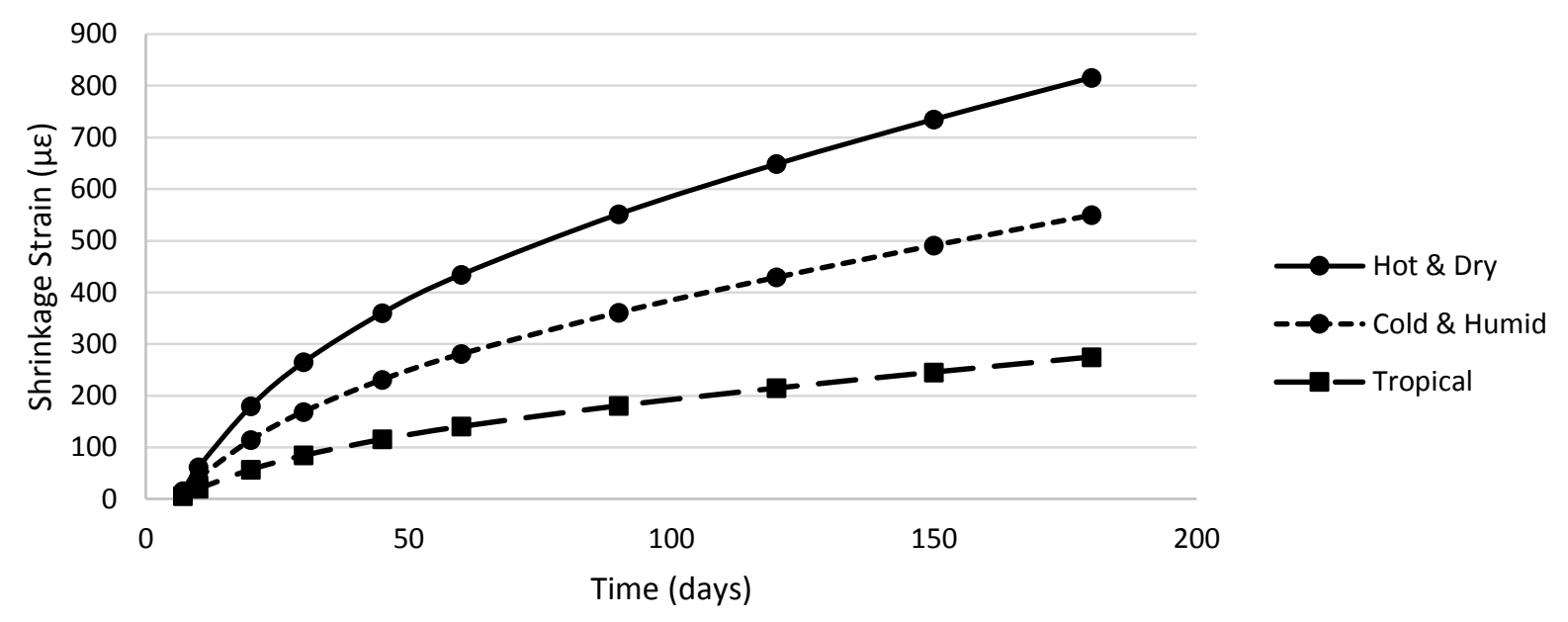

(c) Total volumetric strain

Figure 3-9 Shrinkage and thermal strain versus time in the 6 months period of exposure

\subsection{Creep}

Concrete creep is considered using the concept of compliance as defined in Equation (3-15). In order for that to be calculated, the secant elastic modulus of concrete $E_{c m t o}$ at the time of loading and the creep coefficient needs to be determined using Equation (3-16) and (3-18) respectively. Having the concrete unit weight of $24 \mathrm{~kg} / \mathrm{m}^{3}$ and the mean compressive strength of $25 \mathrm{MPa}$ after curing, the secant elastic modulus at 7 days is calculated to be $2780 \mathrm{MPa}$. 
The ultimate creep coefficient could be determined using Equation (3-19) and (3-20) introducing 6 correction factors. The age of loading factor is applicable when the age at which the loading starts is more than 7 days. Therefore, assuming a 7 days curing period and given the fact that the thermal and shrinkage loading to start right after the curing period, this coefficient would be equal to 1 .

The relative humidity factor could be calculated using Equation (3-22). Assuming 90\%, 70\% and $20 \%$ relative humidity for tropical, cold and humid, and hot and dry climate. The member size and shape is accounted for with a correction factor as presented in Equation (3-23) which is calculated to be an average of 0.65 given the dimensions of the walls. The rest of the correction coefficients including slump, air content and fine aggregate factors are considered to be 1 for this case. Figure 3-10 and Figure 3-11 demonstrate the creep coefficient and compliance versus time as calculated.

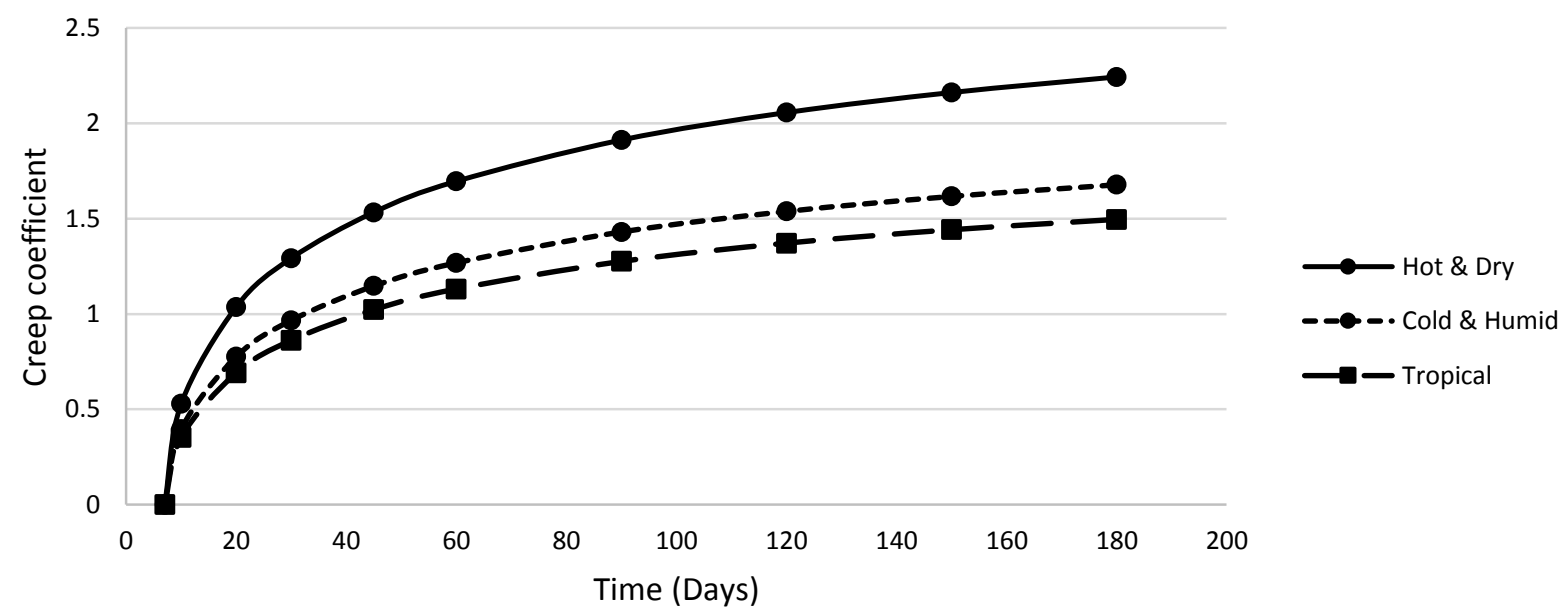

Figure 3-10 Creep coefficient versus time in a period of 6 months after casting 


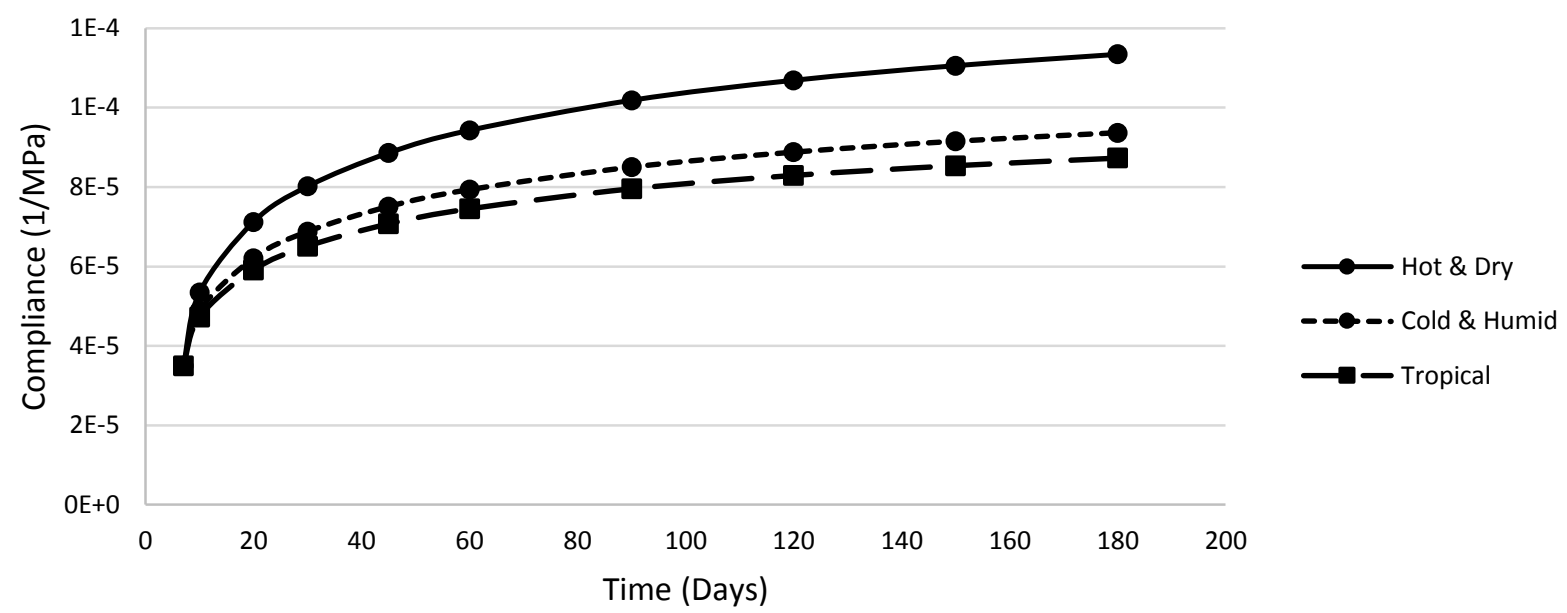

Figure 3-11 Compliance versus time in a period of 6 months after casting

\subsection{Summary}

In this chapter, ACI 209 model for the prediction of shrinkage and creep was presented. A number of crack width and spacing prediction models were reviewed. FE modeling and the material behavior which is used for simulation of concrete was explained. The FE model was verified with an existing experimental study by comparing their crack width and pattern. Finally, the shrinkage and thermal strains were calculated and the creep was determined to be used in the parametric study. 


\section{RESPONSE OF BASE RESTRAINED WALLS}

\subsection{General}

This chapter presents the results of the FE study performed on simulated base restrained RC walls to investigate their cracking behavior due to moisture and temperature variations. The influence of wall length, height, $\mathrm{L} / \mathrm{H}$ ratio and thickness have been studied on the crack width. In addition, the effect of reinforcement ratio, applied volumetric strain, concrete tensile strength, and steel yield strength is discussed. The ultimate shrinkage strain is applied to the walls and neither the variation of shrinkage with time nor the effect of creep has been considered in this chapter. In addition to the maximum crack width value, the width of cracks over the wall height is discussed.

\subsection{Maximum Crack Width}

\subsubsection{Effect of wall geometry}

Walls are modeled with lengths varying from $4 \mathrm{~m}$ to $30 \mathrm{~m}$ and heights of $4 \mathrm{~m}, 6 \mathrm{~m}$ and $8 \mathrm{~m}$ and $300 \mathrm{~mm}, 500 \mathrm{~mm}$, and $700 \mathrm{~mm}$ thickness. Since the possibility of having a wall with a length of more than $30 \mathrm{~m}$ without any movement joints is very low in practice, walls are modelled with lengths up to $30 \mathrm{~m}$. The volumetric strain and reinforcement ratio are kept constant at $600 \mu \varepsilon$ (representing cold and humid condition) and $0.3 \%$ respectively. The $0.3 \%$ reinforcement ratio is chosen as the minimum steel ratio based on the ACI 350-06 Code recommendation. Figure 4-1 presents the effect of wall geometry on the width of cracks. Figure 4-1 (a) shows the influence of the wall length on the crack width. The lowest crack width which is about $0.1 \mathrm{~mm}$ occurs in the 4x4 m (length $\mathrm{x}$ height) wall while $4 \times 30 \mathrm{~m}$ wall experiences the widest crack of about $1 \mathrm{~mm}$. It clearly demonstrates that the longer walls experience wider cracks. This conclusion can also be made for $6 \mathrm{~m}$ and $8 \mathrm{~m}$ tall walls. The effect of $\mathrm{L} / \mathrm{H}$ ratio on the width of cracks is shown in Figure 4-1 (b) with $\mathrm{L} / \mathrm{H}$ ratios varying from 1 to 3.5 . It is shown that wider cracks occur in walls with 
larger $\mathrm{L} / \mathrm{H}$ ratios irrespective of the wall height. Considering $4 \mathrm{~m}$ tall walls as an example, the crack width varies from $0.08 \mathrm{~mm}$ to $0.49 \mathrm{~mm}$ as the $\mathrm{L} / \mathrm{H}$ ratio increases from 1 to 3.5 .

The influence of wall height on the crack width considering constant wall lengths does not have a trend that could lead to a conclusion as shown in Figure A-1 in Appendix A. Therefore, the wall height effect is demonstrated with $\mathrm{L} / \mathrm{H}$ ratios kept constant in Figure 4-1(c). Each graph compares the crack width for 3 different heights $(4 \mathrm{~m}, 6 \mathrm{~m}$, and $8 \mathrm{~m}$ ) with a constant $\mathrm{L} / \mathrm{H}$ ratio. It shows that wider cracks occur in higher walls. As an example, for $\mathrm{L} / \mathrm{H}=1$, the crack width is $0.07 \mathrm{~mm}, 0.19$ $\mathrm{mm}$, and $0.251 \mathrm{~mm}$ for $4 \mathrm{~m}, 6 \mathrm{~m}$ and $8 \mathrm{~m}$ tall walls respectively.

Figure 4-1 (d) presents the effect of wall thickness on the crack width considering different wall lengths and heights. It should be noted that the influence of gradient temperature and shrinkage which could affect the results especially in thicker walls is not considered in this study. The results as presented in the graphs show that thickness is of no significant influence on the crack width. This could be attributed to the selection of shell element for this study given the fact that it does not consider stress and strain variations within the thickness of the walls and the unrealistic boundary condition of the shell element which considers an edge as opposed to a surface at the bottom. 

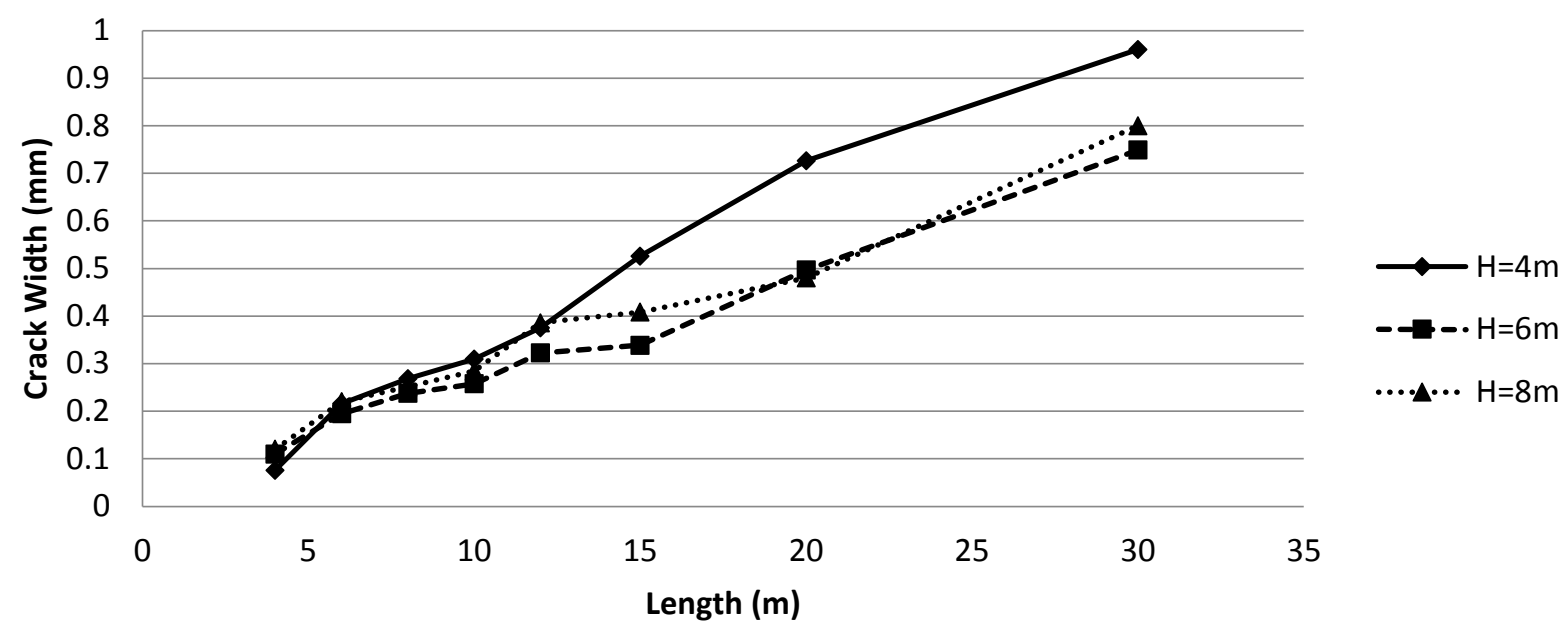

(a) Effect of wall length
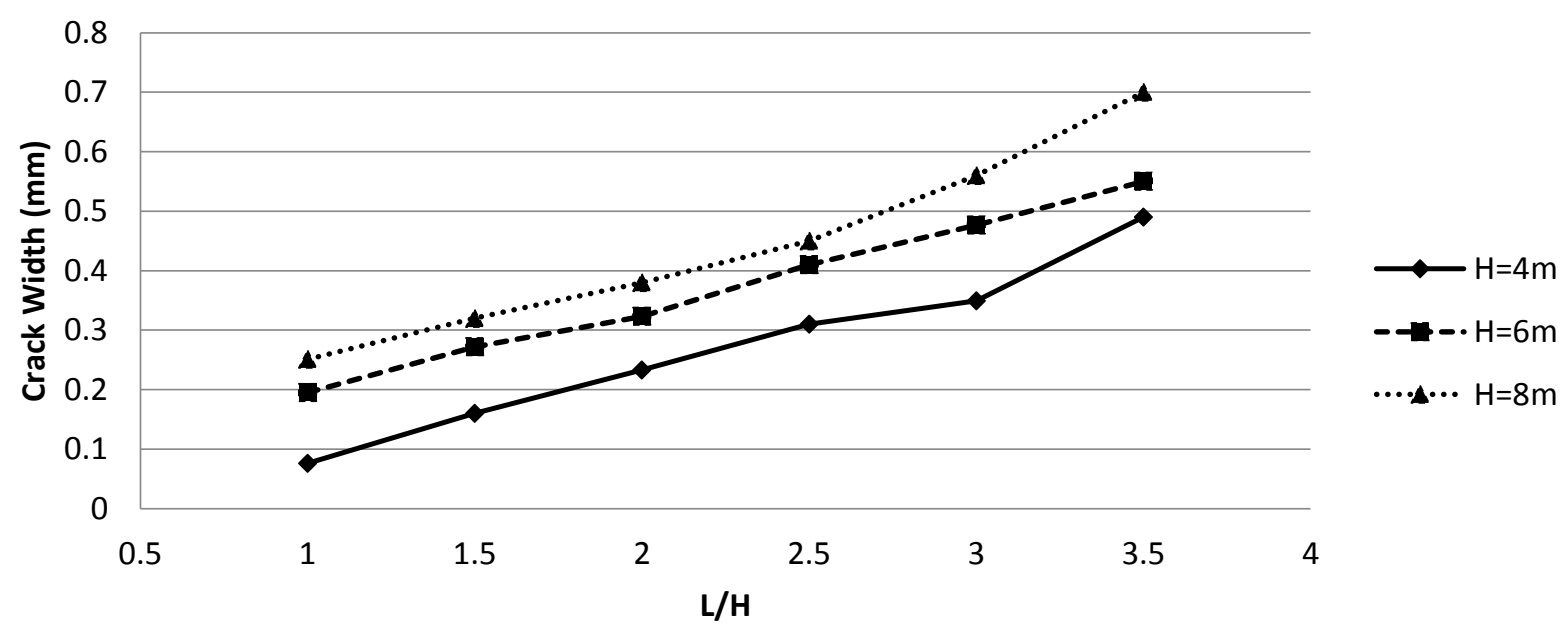

(b) Effect of $\mathrm{L} / \mathrm{H}$ ratio

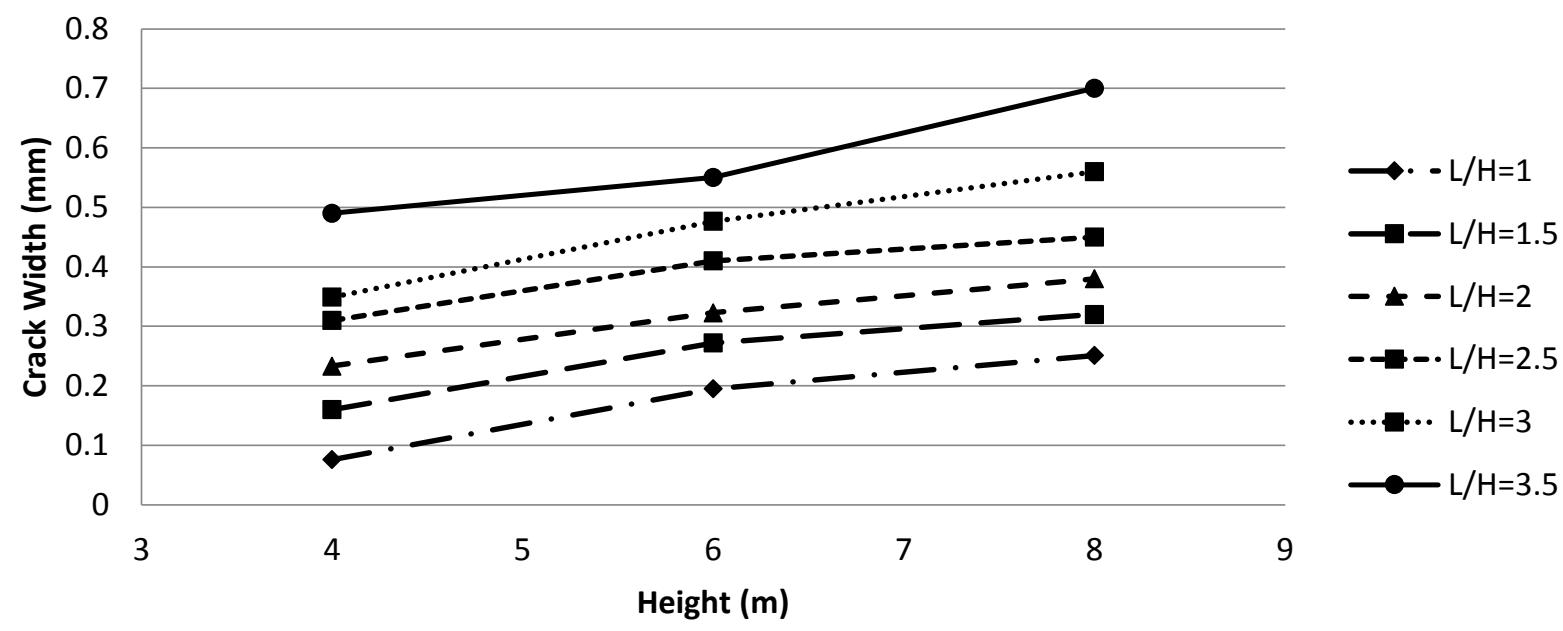

(c) Effect of wall height 


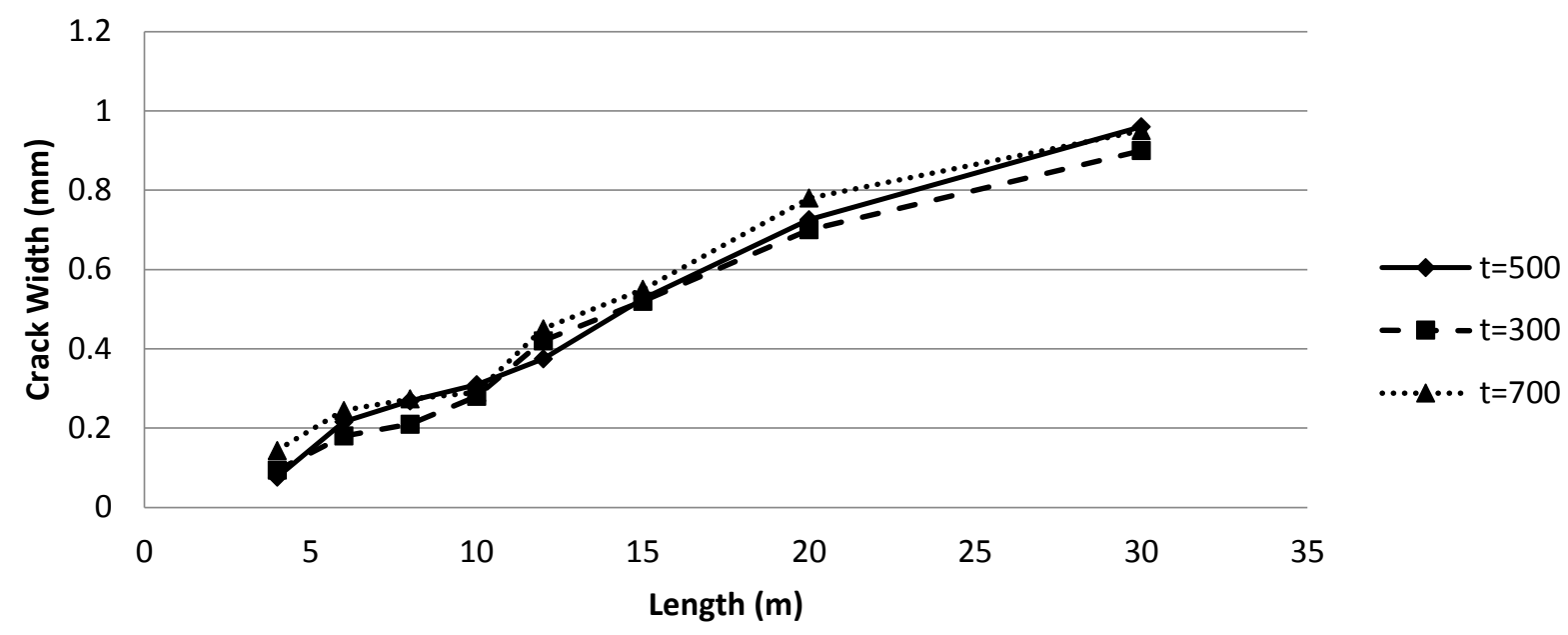

(d) Effect of wall thickness

Figure 4-1 Effect of wall length, L/H, height, and thickness on the crack width

\subsubsection{Effect of reinforcement ratio}

The effect of reinforcement ratio on the width of cracks is investigated by simulating the walls with reinforcement ratios varying from $0.3 \%$ to $0.7 \%$. The $0.3 \%$ is chosen since it is the lowest reinforcement ratio proposed by the ACI $350-06$ Code and $0.7 \%$ is selected since it limits the crack widths of the modelled walls to less than $0.1 \mathrm{~mm}$. Figure 4-2 presents the crack width versus reinforcement ratio for $4 \mathrm{~m}$ tall walls subjected to $600 \mu \varepsilon$ volumetric strain with concrete tensile strength of $3 \mathrm{MPa}$. Each graph in this figure is developed for a constant length. It can be concluded that irrespective of the wall length, increasing the reinforcement ratio decreases the width of cracks. It also shows that the most significant crack width reduction due to reinforcement ratio increase occurs in the longest wall $(\mathrm{L}=30 \mathrm{~m})$ in which the crack width reduces from $0.95 \mathrm{~mm}$ to almost $0.1 \mathrm{~mm}$ by increasing the steel ratio from $0.3 \%$ to $0.7 \%$. 


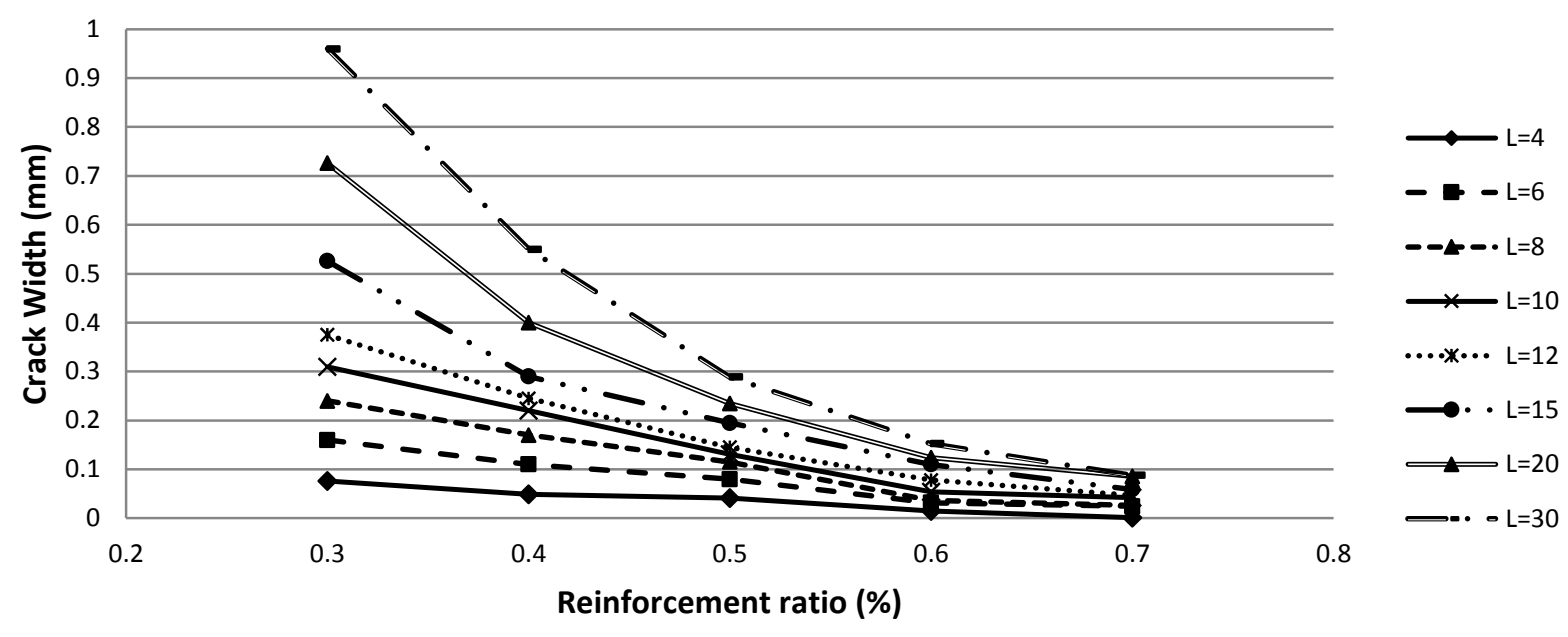

Figure 4-2 Effect of reinforcement ratio on the crack width

Figures A-2 to A-4 in Appendix A present the crack width versus wall length demonstrating the influence of reinforcement ratio considering different wall lengths, heights and volumetric strains. It can be seen in all these graphs that increasing the reinforcement ratio from $0.3 \%$ to $0.7 \%$ leads to a crack width reduction. Walls reinforced with only $0.3 \%$ steel have the potential to form cracks that could endanger their performance even under low volumetric strain values especially if their length exceed 10 meters. Considering 4 × 30 m walls as an example, the crack width can be about $0.7 \mathrm{~mm}, 0.95 \mathrm{~mm}$, and $1.2 \mathrm{~mm}$ for walls subjected to $300 \mu \varepsilon, 600 \mu \varepsilon$, and $900 \mu \varepsilon$ respectively. The significance of the effect of steel ratio increment on the crack width seems to gradually decrease by increasing reinforcement ratio from $0.3 \%$ to $0.7 \%$.

\subsubsection{Effect of climate condition}

The influence of climate condition on the crack width is illustrated in Figure 4-3 for 4 m tall walls with a reinforcement ratio of $0.3 \%$. Volumetric strain values of $300 \mu \varepsilon, 600 \mu \varepsilon$, and $900 \mu \varepsilon$ represent the tropical, cold and humid, and hot and dry climates respectively. It is clearly shown that the crack width increases by increasing the volumetric strain values. It also appears that the volumetric strain has a more substantial influence on the crack width of longer walls as the 
difference between the results increase by increasing the length of the walls. Figures A-5 to A-7 in Appendix A are presented to further discuss the impact of applied temperature/shrinkage strain on the width of cracks for different heights and steel ratios. Each figure shows the crack width versus wall length for different climate conditions considering constant wall heights and steel ratios. It could be seen in all these figures that wider cracks occur in the walls under higher applied strain. Therefore, it can be concluded that hot and dry weather is the most critical among all climate conditions and would need the largest amount of reinforcement while tropical climate requires the least amount of steel.
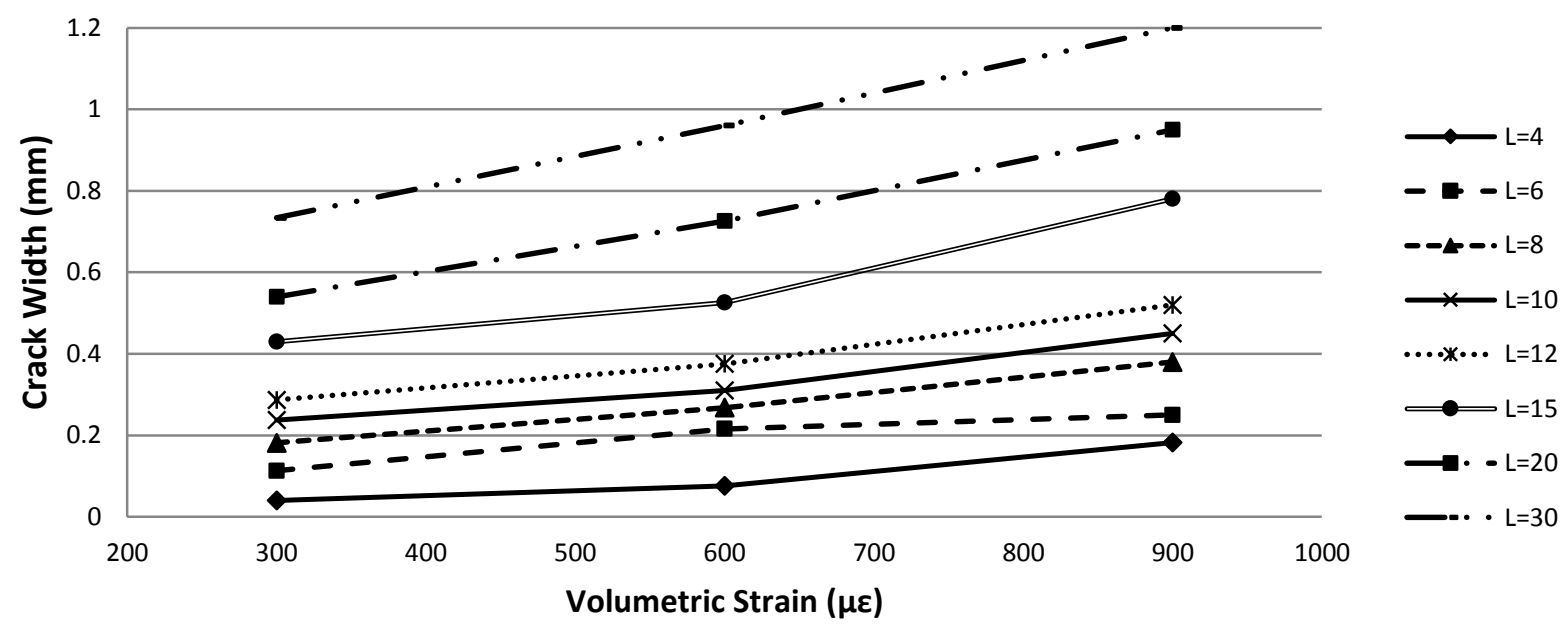

(a) Crack width vs. volumetric strain

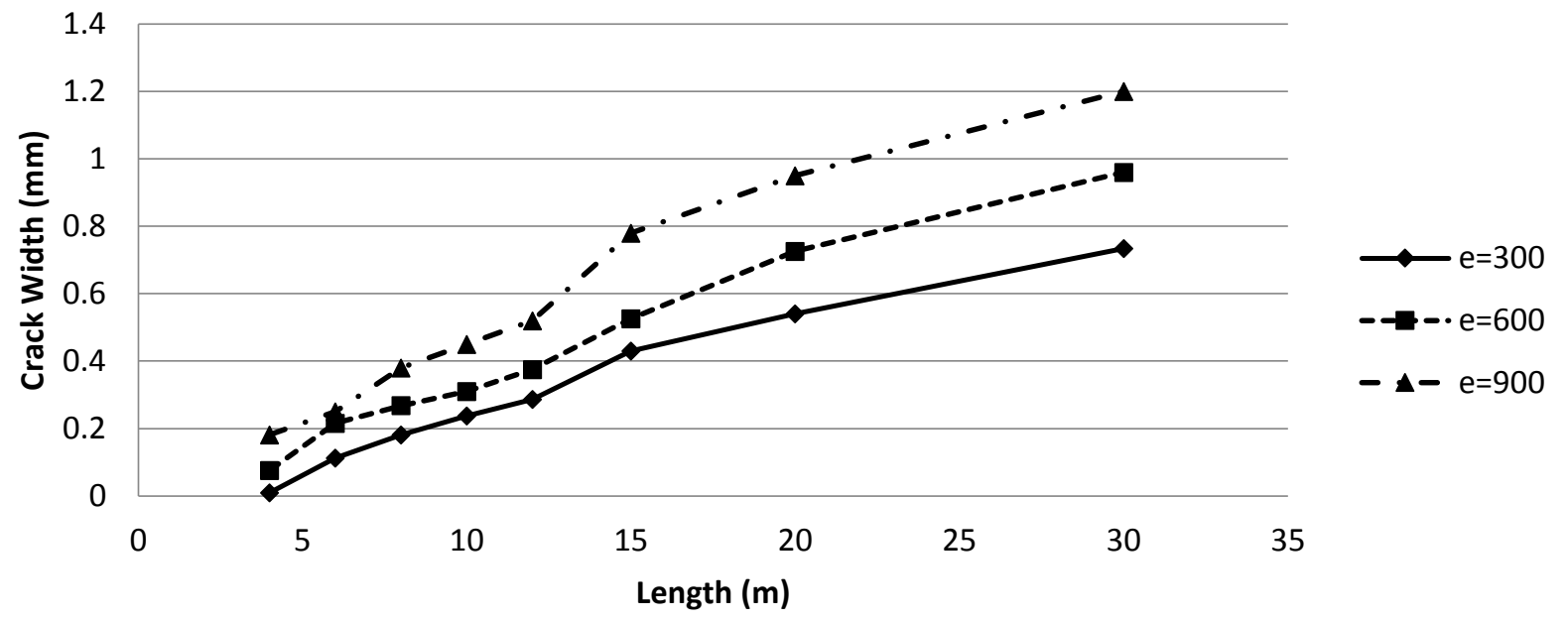

(b) Crack width vs. wall length 
Figure 4-3 Effect of volumetric strain (climate) on the crack width

\subsubsection{Effect of concrete tensile strength}

Figure 4-4 illustrates the influence of concrete tensile strength on the crack width. The concrete tensile strength values are chosen to be 2.5 $\mathrm{MPa}, 3 \mathrm{MPa}$ and $3.5 \mathrm{MPa}$ representing the tensile strength of normal strength concrete corresponding to a compressive strength in the range of 25 MPa to $35 \mathrm{MPa}$. It appears that wider cracks occur in the walls made of higher tensile strength concrete. This difference is more apparent in longer walls as can be seen in the figure. The reason behind this is that the higher the tensile strength, the longer it takes for the cracks to form. Therefore, walls made of weaker concrete crack sooner (under a lower stress) leading to a stress relief in the member because of crack. Consequently they will experience a higher number of narrower cracks under the same volumetric strain as opposed to walls made of stronger concrete which crack under a higher stress level developing less but wider cracks. It should be noted that this conclusion may not be applied to high strength concrete or any concrete with tensile strength values in excess of this range.

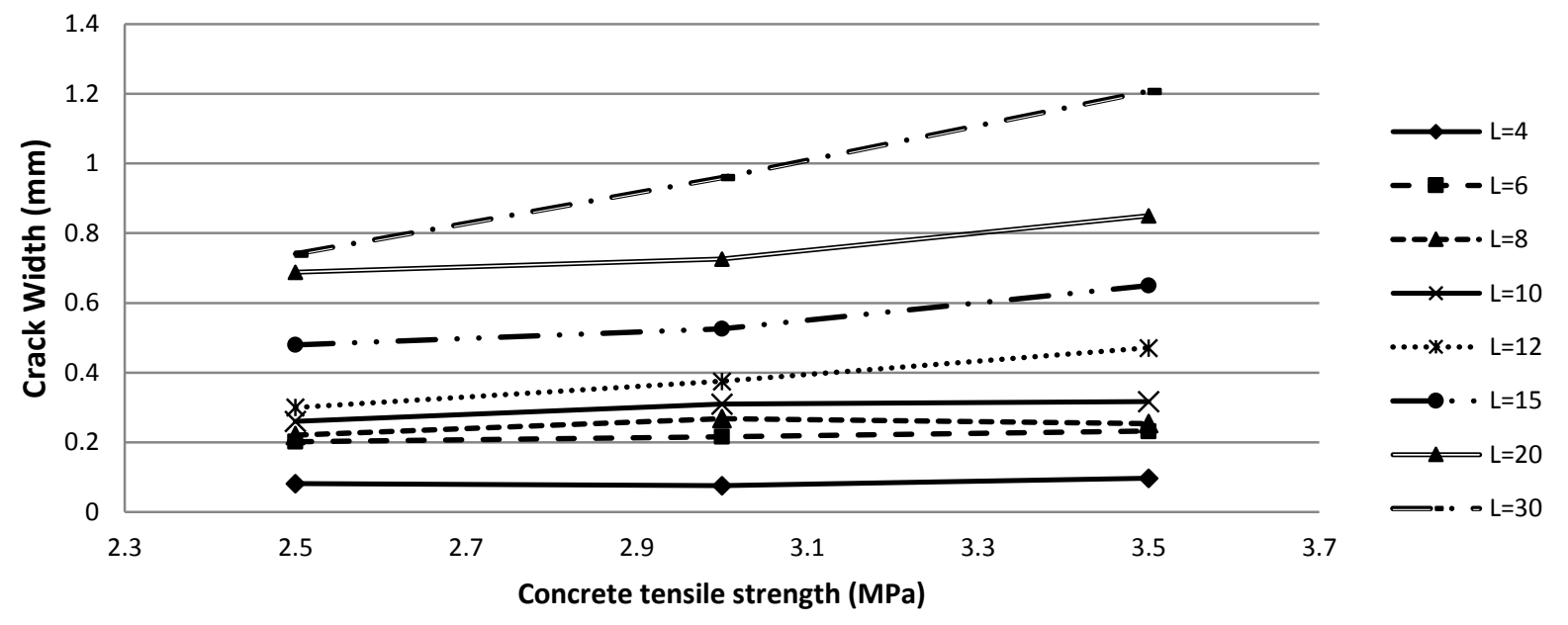

(a) Crack width vs. Concrete tensile strength 


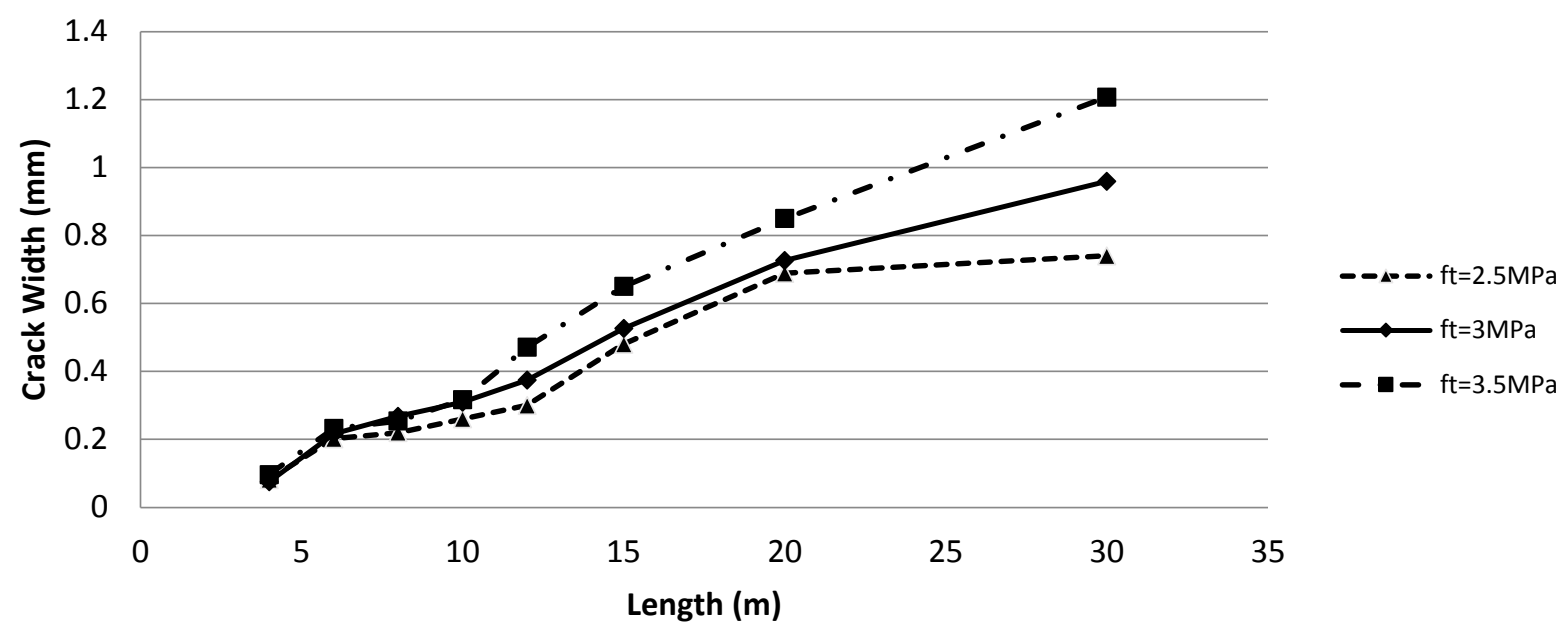

(b) Crack width vs. wall length

Figure 4-4 Effect of concrete tensile strength on crack width

Figures A-8 and A-9 in Appendix A illustrate the influence of concrete tensile strength on the crack width of $6 \mathrm{~m}$ and $8 \mathrm{~m}$ walls and $4 \mathrm{~m}$ walls with different reinforcement ratios. It could clearly be concluded from the graphs that wider cracks develop in walls made of higher tensile strength concrete irrespective of their height or reinforcement ratio.

\subsubsection{Effect of steel behavior}

The influence of steel behavior on the crack width of modelled RC walls is discussed in this part. As mentioned earlier, an elasto-plastic behavior was defined for the steel in the FE models. In this part, for the sake of comparison, the steel is assumed to behave linearly without defining the yield stress and strain in its constitutive model meaning that it never reaches a plastic stage. Figure 4-5 shows the crack widths of $4 \mathrm{~m}$ tall walls with $0.3 \%$ and $0.5 \%$ reinforcement ratios reinforced with linear and non-linear steel. Figure A-10 in Appendix A presents the crack width of $6 \mathrm{~m}$ and $8 \mathrm{~m}$ tall walls reinforced with $0.3 \%$ steel and Figure A-11 shows the results of $4 \mathrm{~m}$ tall walls reinforced with $0.4 \%, 0.6 \%$ and $0.7 \%$ steel. It can be seen that for the walls reinforced with $0.3 \%$ steel, the steel behavior has no influence on the crack width when the wall length is less than $10 \mathrm{~m}$. However, the difference between the crack width of walls reinforced with linear and non-linear steel becomes 
more significant as the wall length increases. As an example, the crack width in the $4 \times 15 \mathrm{~m}$ wall reinforced with $0.3 \%$ steel (Figure 4-5) is $0.42 \mathrm{~mm}$ and $0.52 \mathrm{~mm}$ for linear and non-linear steel respectively which corresponds to a roughly $20 \%$ difference. While for $4 \times 30 \mathrm{~m}$ wall, the crack width values are $0.56 \mathrm{~mm}$ and $0.96 \mathrm{~mm}$ for linear and non-linear steel corresponding to a difference of about $40 \%$. This could be rationalized by considering the fact that increasing the wall length leads to an increase in the stress and strain level as demonstrated earlier by a higher crack width in longer walls. Therefore, with this low amount of reinforcement ratio $(0.3 \%)$, the steel in longer walls yields and enter the plastic phase causing larger deformation. If this non-linearity is not defined, the crack width will be considerably smaller than its real magnitude as shown in these figures. Considering the steel yield strength of $400 \mathrm{MPa}$ and elastic modulus of $200000 \mathrm{MPa}$, the yield strain could be calculated as 0.002. Taking the steel strain into Frosch crack width formulation by having a clear cover of $50 \mathrm{~mm}$ and reinforcement spacing of 200 , the crack width that the steel yields at can be calculated as $0.224 \mathrm{~mm}$. Looking more closely into these figures verifies this calculation and can lead to conclusion that for this reinforcement spacing and clear cover, when the crack width exceeds $0.224 \mathrm{~mm}$, the steel yields. Therefore, for those cases with crack widths of less than $0.244 \mathrm{~mm}$ definition of steel nonlinearity is of no importance. 


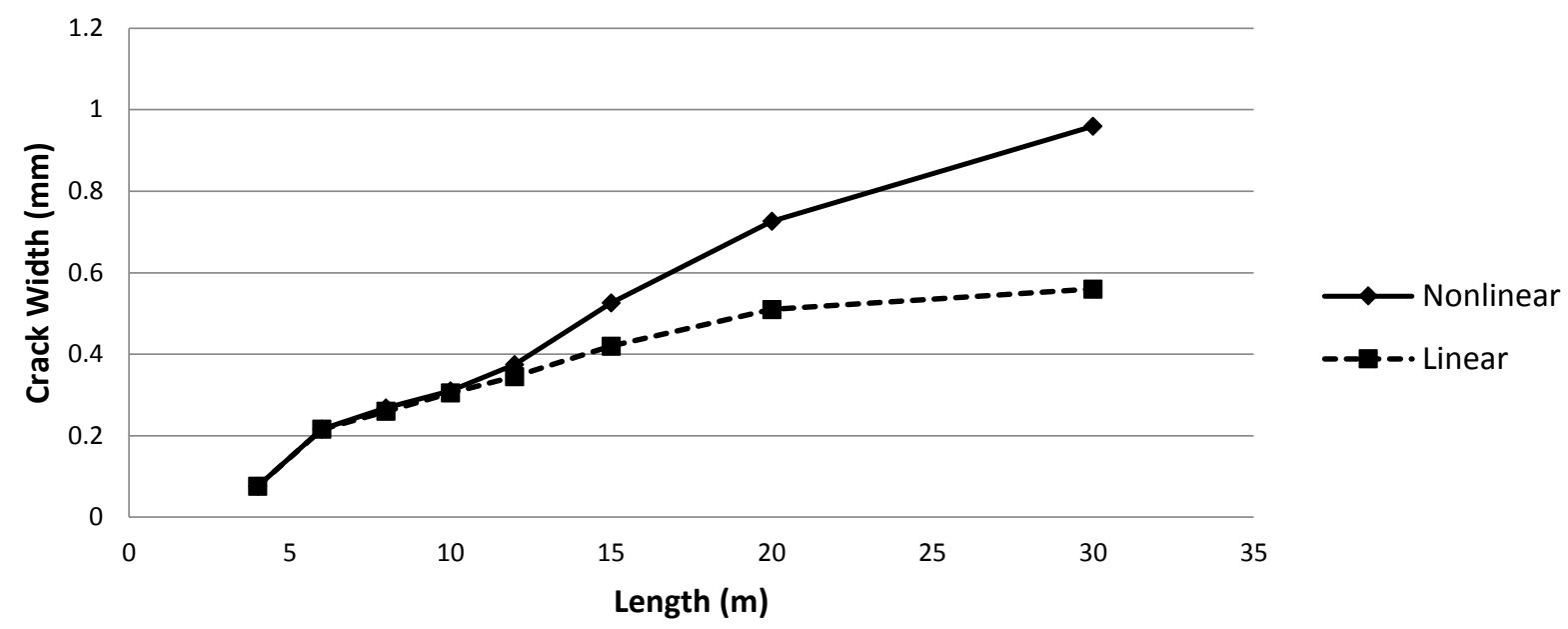

(a) $\rho=0.3 \%$

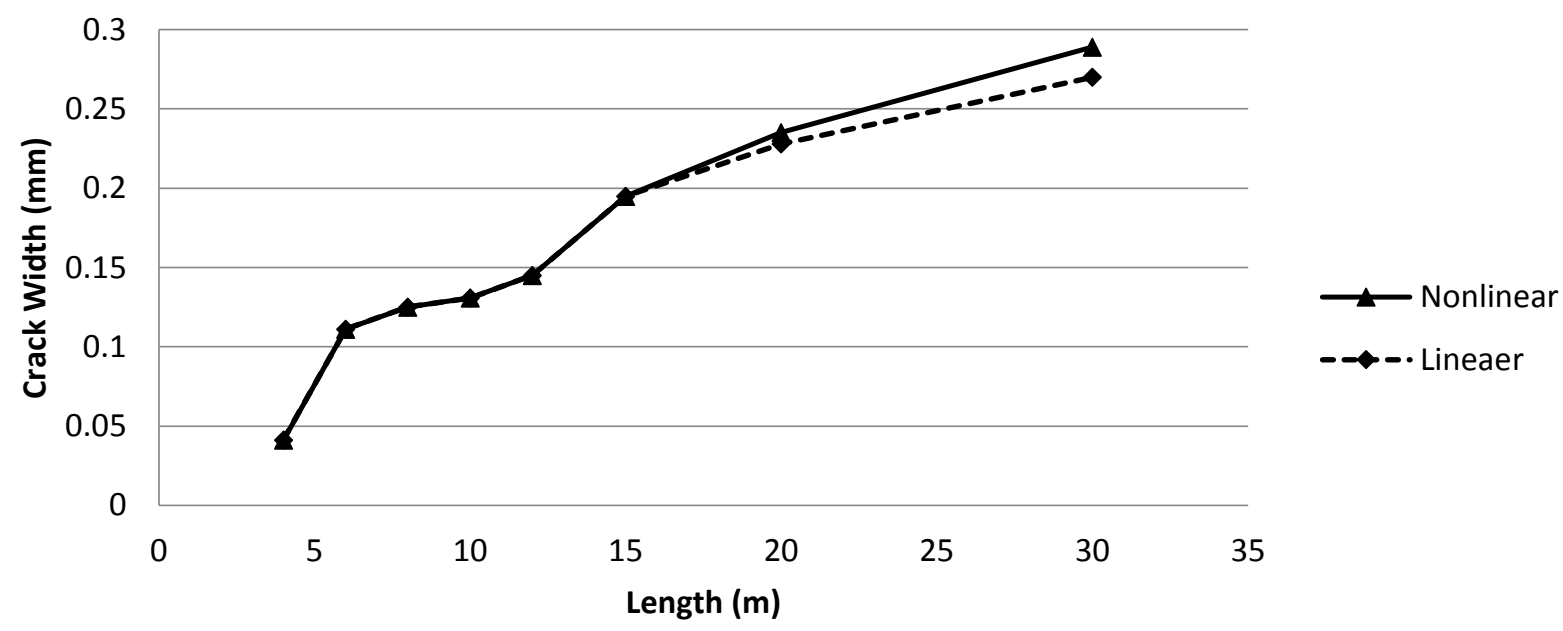

(b) $\rho=0.5 \%$

Figure 4-5 The influence of steel behavior on the crack width

Figure A-11 in Appendix A shows the influence of steel behavior along with the reinforcement ratio on $4 \mathrm{~m}$ tall walls with steel ratios varying between $0.4 \%$ and $0.7 \%$. It can be seen that by increasing the reinforcement ratio, the difference between the crack widths of walls reinforced with linear and nonlinear steel has decreased. In fact for $0.6 \%$ and $0.7 \%$ reinforcement ratio, there is no difference in the crack width results between linear and nonlinear steel as the crack width is below 0.224 , therefore steel never yields and remains in the elastic stage. 


\subsubsection{Effect of steel yield strength on crack width}

The influence of steel strength on the crack width of RC walls is discussed by comparing the crack width of walls reinforced with $300 \mathrm{MPa}$ and $400 \mathrm{MPa}$ steel. All previous analyses were performed on walls reinforced with $400 \mathrm{MPa}$ steel. Figure 4-6 compares the results of $300 \mathrm{MPa}$ and $400 \mathrm{MPa}$ steel with $0.3 \%$ and $0.5 \%$ reinforcement ratios considering $4 \mathrm{~m}$ tall walls. Figure A-12 in Appendix A shows the crack width values for $6 \mathrm{~m}$ and $8 \mathrm{~m}$ tall walls reinforced with $0.3 \%$ steel and Figure A-13 (Appendix A) demonstrates the results of walls reinforced with varying steel ratios from $0.4 \%$ to $0.7 \%$.

In general, these figures show that the walls reinforced with grade 300 steel experience wider cracks in comparison with those containing $400 \mathrm{MPa}$ rebars. This is because of the fact that 300 MPa rebars yield under a lower stress. Therefore, in an identical situation, the $300 \mathrm{MPa}$ steel may yield and go into plastic stage and consequently experience larger deformation while the $400 \mathrm{MPa}$ steel is still in elastic phase.

Based on the figures, the steel strength has little to no influence on the crack width of walls that are shorter than about $8 \mathrm{~m}$ in length. While, as the wall length increases the steel strength effect becomes more apparent. In Figure 4-6 (a) as an example, the crack width in the 4x10 m wall reinforced with $0.3 \%$ steel is $0.34 \mathrm{~mm}$ and $0.31 \mathrm{~mm}$ for $300 \mathrm{MPa}$ and $400 \mathrm{MPa}$ steel respectively which corresponds to an approximate difference of $8 \%$. Whereas, for $4 \times 30 \mathrm{~m}$ wall with the same steel percentage, the crack width values are $1.3 \mathrm{~mm}$ and $0.96 \mathrm{~mm}$ for $300 \mathrm{MPa}$ and $400 \mathrm{MPa}$ steel corresponding to $25 \%$ difference. Therefore, the longer the wall, the higher the stress level and the further the crack width difference will be between the walls reinforced with different steel grades. For $300 \mathrm{MPa}$ steel, having the elastic modulus of $200000 \mathrm{MPa}$, the yield strain is 0.0015 as opposed to 0.002 for grade 400 steel. Using Frosch equation and considering the clear cover of $50 \mathrm{~mm}$ and bar spacing of $200 \mathrm{~mm}$, the crack width that the steel yields at would be $0.168 \mathrm{~mm}$ for grade 300 
steel while this value was calculated earlier to be equal to $0.224 \mathrm{~mm}$ for grade 400 steel. Therefore, walls that are reinforced with $300 \mathrm{MPa}$ steel get into plastic stage as soon as their crack width reaches $0.168 \mathrm{~mm}$ while those reinforced with $400 \mathrm{MPa}$ rebars remain in elastic stage up to the point that the width of crack exceeds $0.224 \mathrm{~mm}$. Looking more closely into these figures show that when the crack widths is below $0.168 \mathrm{~mm}$ both walls seem to experience the same crack widths. However, when the crack width exceeds beyond this point the $300 \mathrm{MPa}$ steel wall shows wider cracks and this difference becomes more significant as the length of the walls increase.

It can be seen in Figure 4-6 (see also Appnedix A, Figure A-12) that by increasing the steel percentage the difference between the crack widths of walls reinforced with different steel grades decreases. In fact for $0.6 \%$ and $0.7 \%$ reinforcement ratio, there is no difference in the crack width results between grade 300 and 400 steel as they never yield.

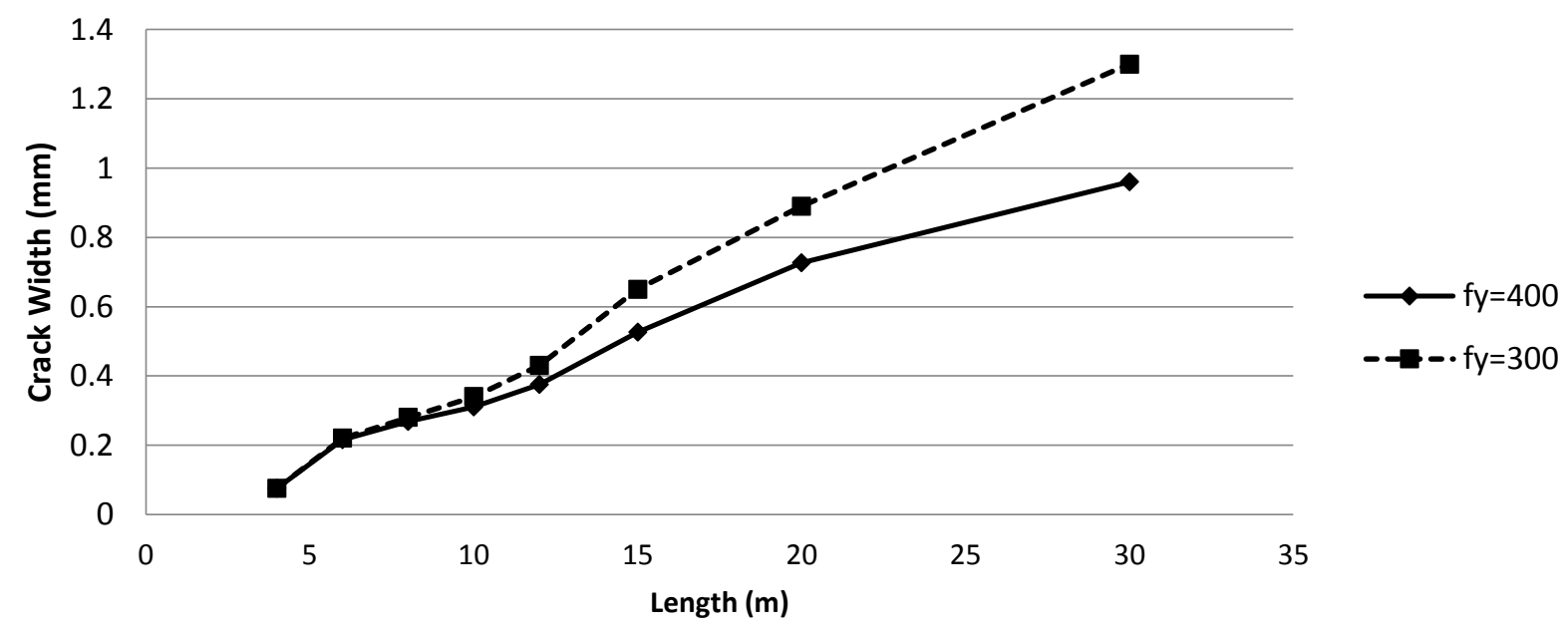

(a) $\rho=0.3 \%$ 


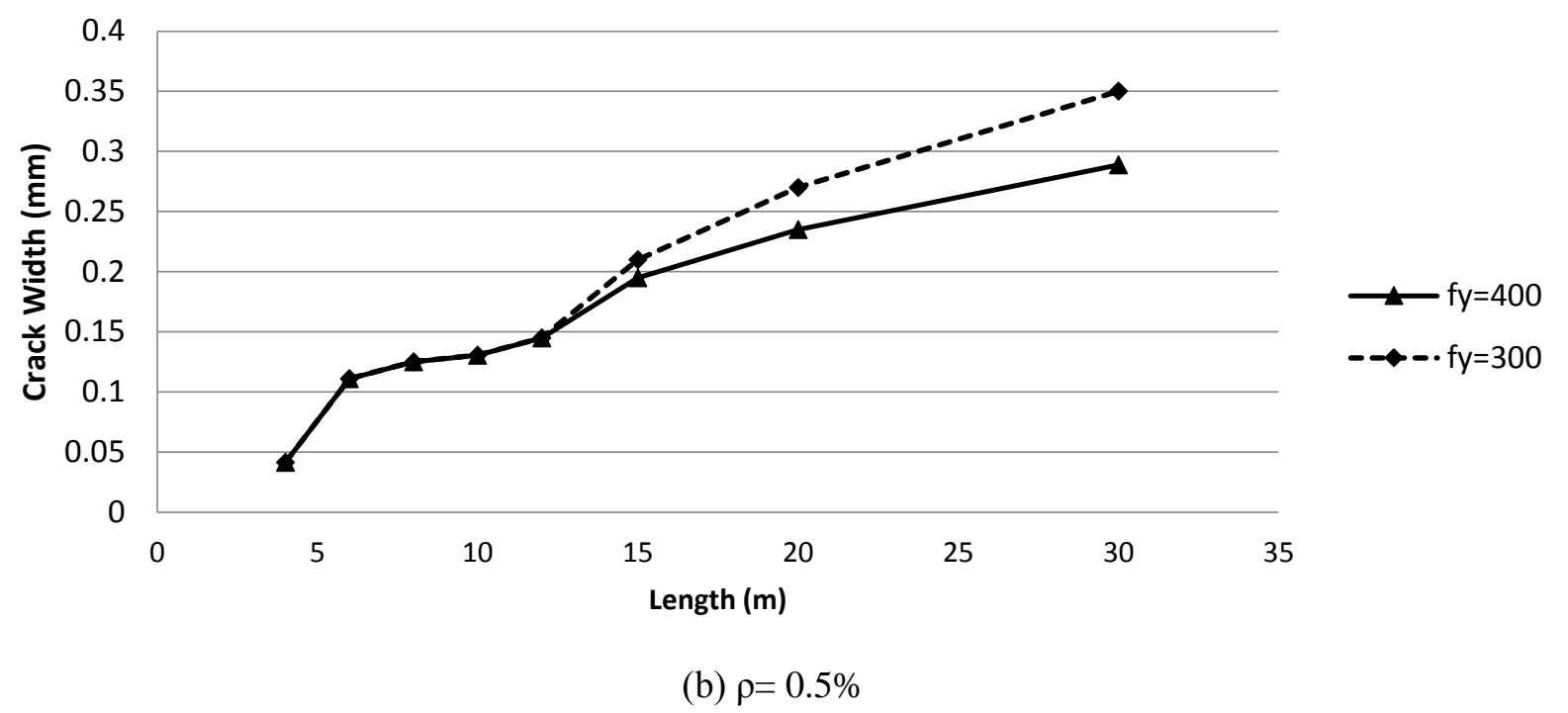

Figure 4-6 The effect of steel yield strength on the crack width

\subsection{Crack width variation over the wall length}

\subsubsection{Effect of wall dimensions}

The variation of crack width over the wall height is discussed here in this part. Figure 4-7 demonstrates the crack width for $4 \mathrm{~m}$ tall walls with $0.3 \%$ reinforcement subjected to $600 \mu \varepsilon$ thermal and shrinkage strain. The figure contains 8 graphs and each graph shows the crack width variation along the height of the wall. It is noticeable in these graphs that by increasing the wall length, the crack also extends further towards the top of the wall. For $4 \times 4 \mathrm{~m}$ wall, the maximum width of crack is about $0.076 \mathrm{~mm}$ which happens at about $10 \%$ of the wall height $(0.4 \mathrm{~m}$ from the bottom). The crack itself starts from about $0.2 \mathrm{~m}$ from the bottom and ends at $0.6 \mathrm{~m}$. Considering the $4 \times 30 \mathrm{~m}$ wall in the same figure, the crack seems to widen with height and reach its maximum at the top of the wall to a value of $0.96 \mathrm{~mm}$. In general, by increasing the wall length, the cracks extend further into the wall as shown in the figure. In addition, the maximum width of crack seems to move up in the wall by as the wall length increases. Figure A-14 (Appendix A) shows the effect of wall length on the crack width over the wall height for $6 \mathrm{~m}$ and $8 \mathrm{~m}$ tall walls. Comparing the results of $4 \mathrm{~m}, 6 \mathrm{~m}$ and $8 \mathrm{~m}$ tall walls, the elevation at which the maximum crack width occurs is 
the highest in $4 \mathrm{~m}$ high wall and lowest in $8 \mathrm{~m}$ high wall considering the same length. It suggests that the height of the maximum crack width depends on the $\mathrm{L} / \mathrm{H}$ ratio more than the length of the wall.

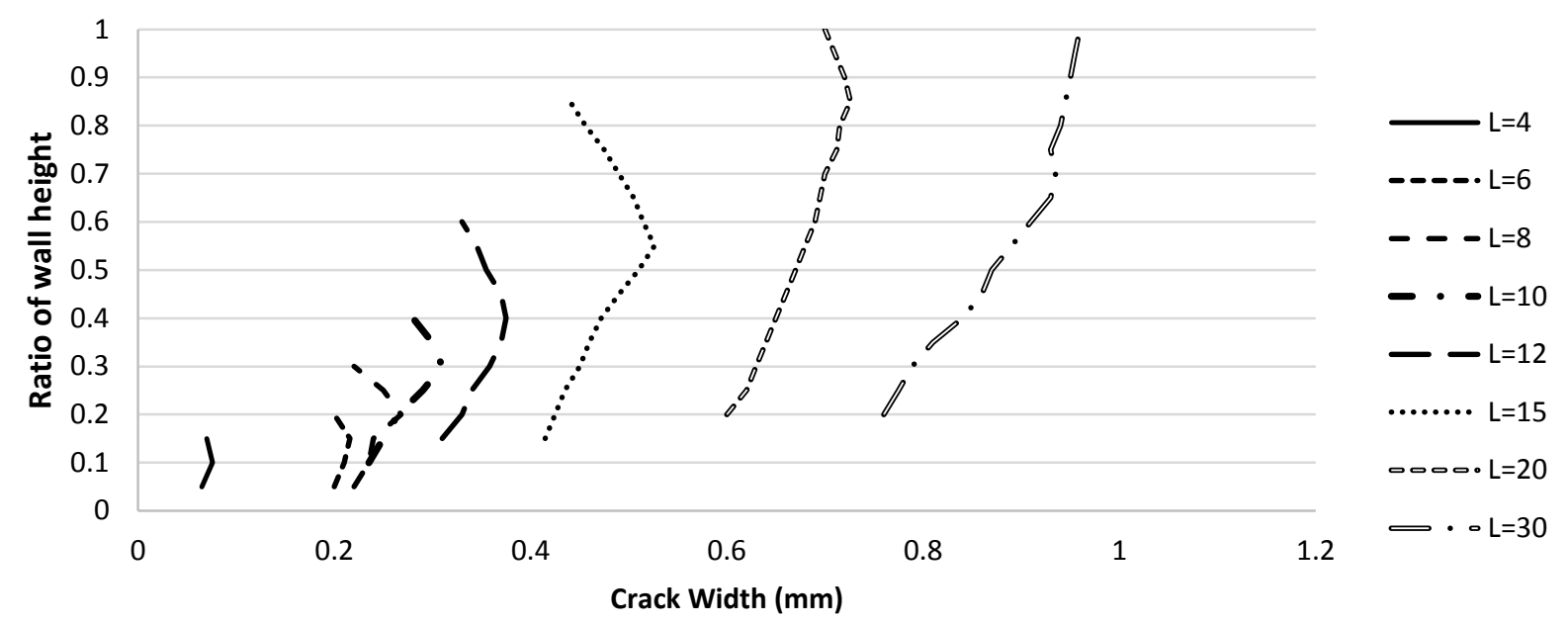

Figure 4-7 Effect of wall length on the crack width along the wall height

Given the conclusion that was made comparing walls with different heights, the crack width is presented considering constant L/H ratios in Figure 4-7 (see also Appendix A, Figure A-15). Each of these figures shows the crack width in walls with a constant $\mathrm{L} / \mathrm{H}$ value and 3 different heights while the reinforcement ratio is kept constant $(0.3 \%)$. Since the trend was quite similar, only the results of $\mathrm{L} / \mathrm{H}$ ratios of 1, 2, 3 and 5 has been demonstrated here in Figure 4-8 and the rest of the graphs are presented in Appendix A, Figure A-15. It can be seen that walls with higher L/H ratios have their cracks extended further towards the top. In addition, for higher $\mathrm{L} / \mathrm{H}$ values, the location of the maximum crack width is higher on the wall. The maximum width of cracks move up from $10 \%$ of the height when $\mathrm{L} / \mathrm{H}=1$ to about $85 \%$ of it for $\mathrm{L} / \mathrm{H}=5$. These graphs show that the extension of these cracks and the elevation of the maximum width mainly depend on the $\mathrm{L} / \mathrm{H}$ ratio. 


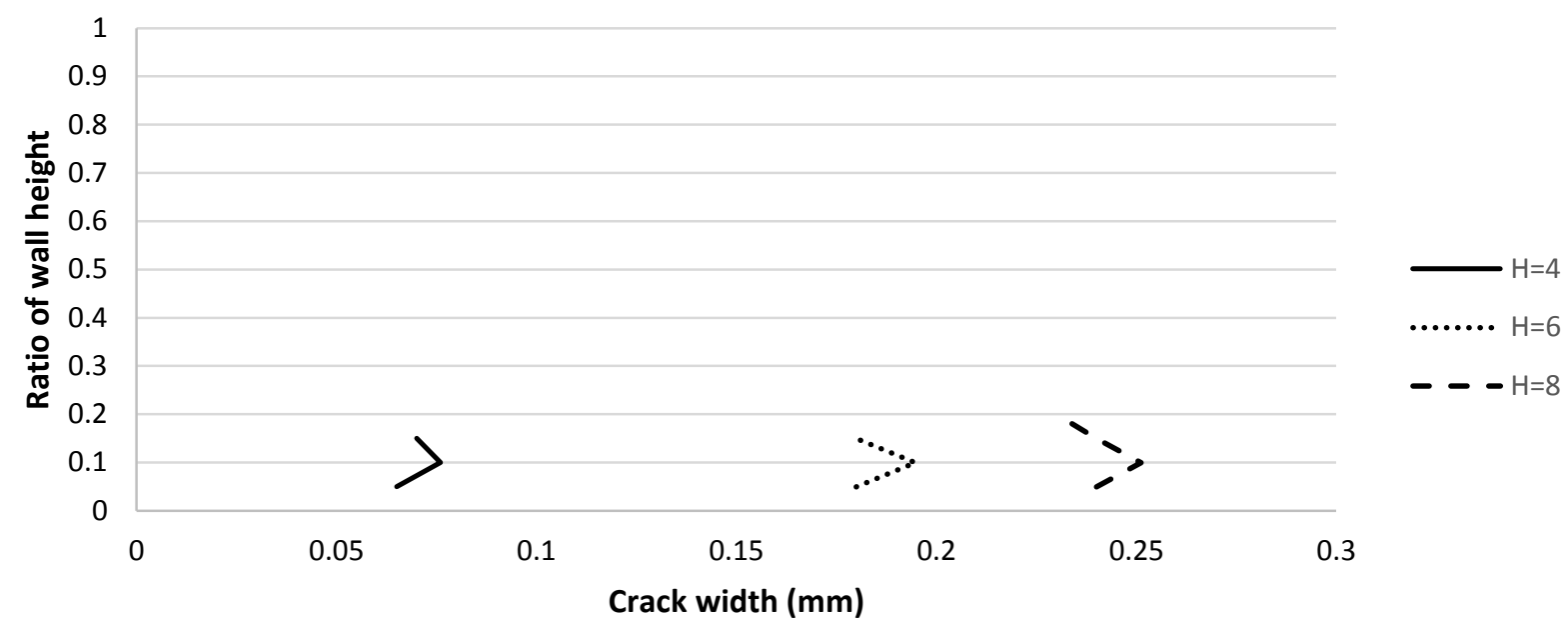

(a) $\mathrm{L} / \mathrm{H}=1$

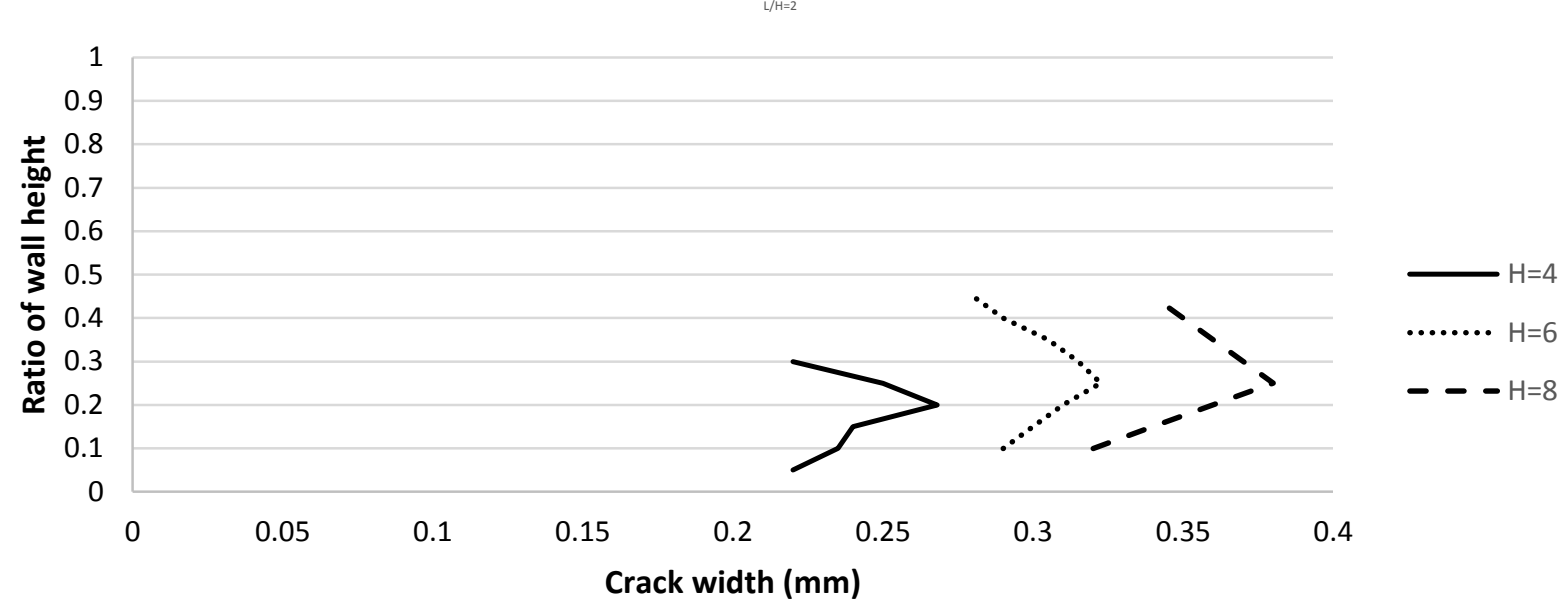

(b) $\mathrm{L} / \mathrm{H}=2$
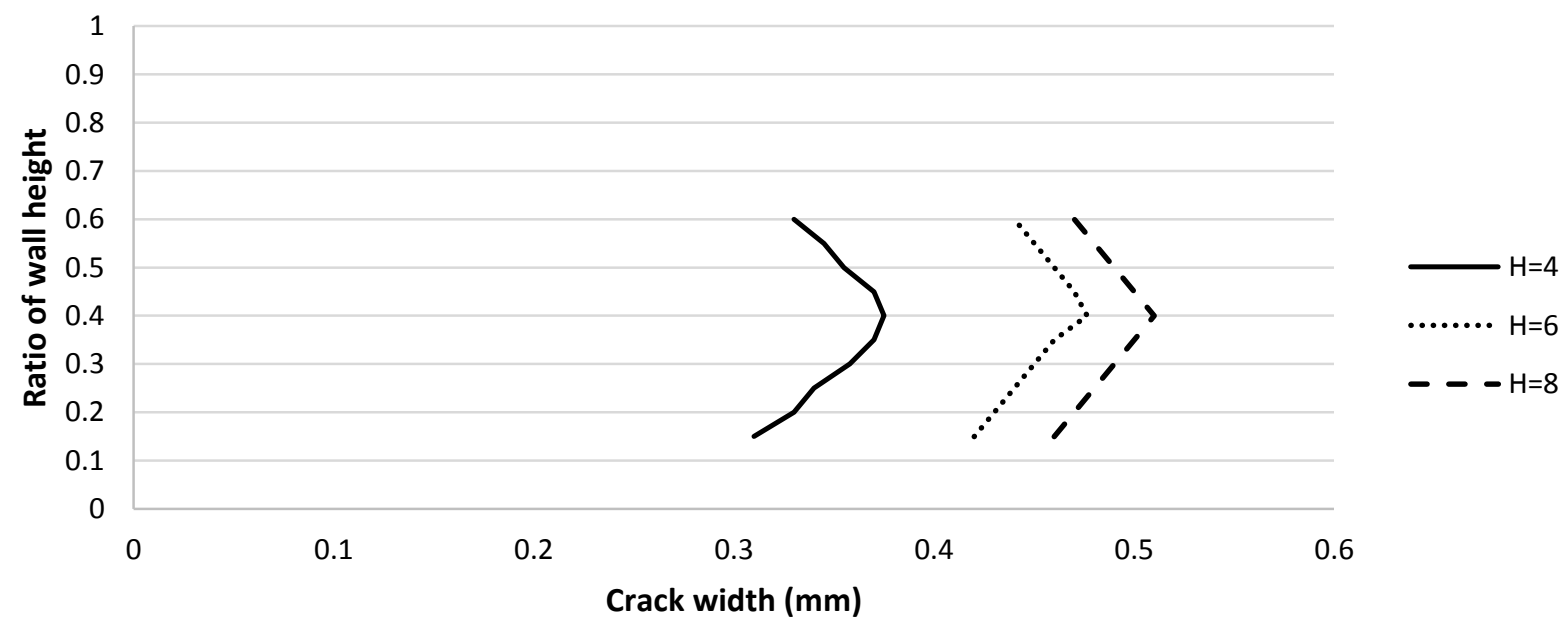

(c) $\mathrm{L} / \mathrm{H}=3$ 


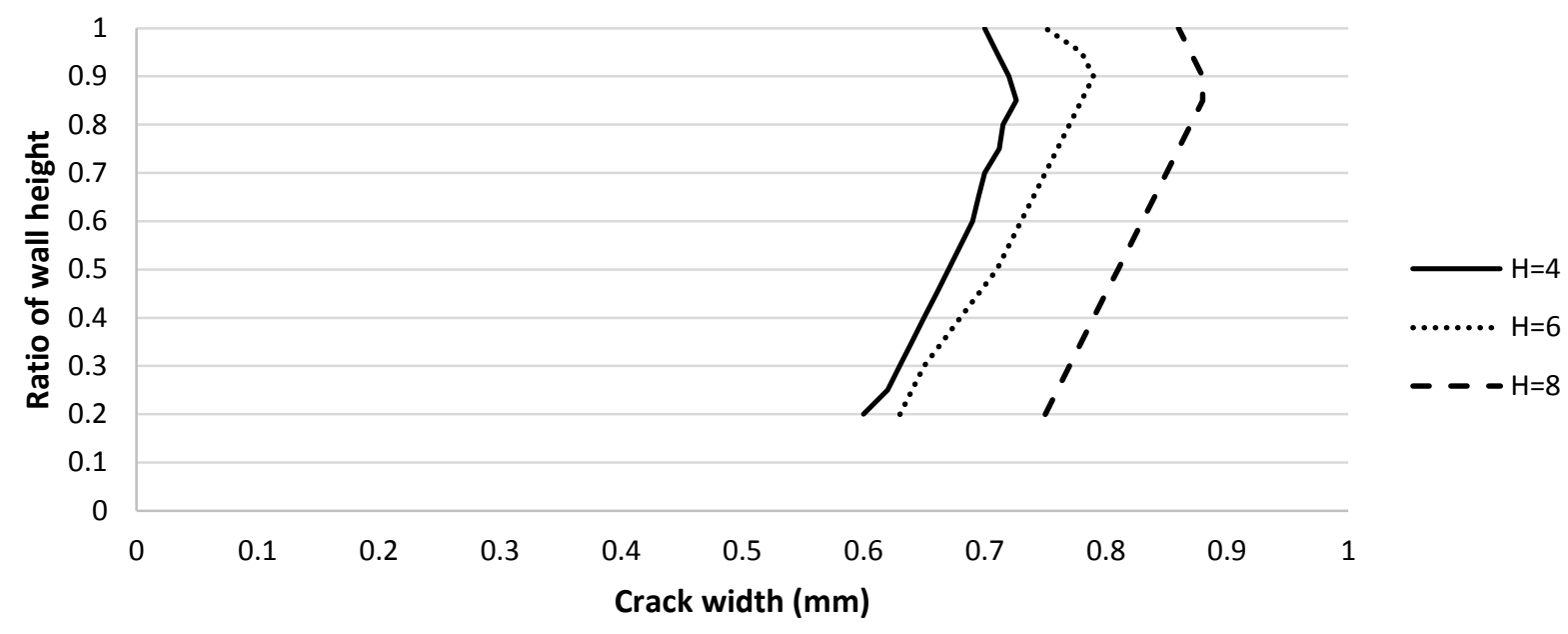

(d) $\mathrm{L} / \mathrm{H}=5$

Figure 4-8 Crack width along the wall height $(\mathrm{L} / \mathrm{H}=5, \rho=0.3 \%)$

\subsubsection{Effect of reinforcement ratio}

Figure 4-9 represents the effect of reinforcement ratio on the crack width along the wall height. It only demonstrates the results of 4 x $30 \mathrm{~m}$ wall reinforced with different steel percentages. The rest of the results are presented in Appendix A, Figure A-16 with a constant height of $4 \mathrm{~m}$ and varying length from $4 \mathrm{~m}$ to $20 \mathrm{~m}$. Each figure contains 5 graphs for reinforcement ratios varying from $0.3 \%$ to $0.7 \%$. They show that the elevation of the maximum crack width and the length of cracks are not influenced by the steel percentage. It also confirms that the higher $\mathrm{L} / \mathrm{H}$ ratio the higher these cracks extend into the walls. Figure 4-9 shows that the crack width increases from the bottom to the top for all reinforcement ratios. It is in line with previous studies done by Kheder (1997) that if $\mathrm{L} / \mathrm{H}$ ratios are above 5, the crack widens along the height and reaches its maximum width at the top of the wall. 


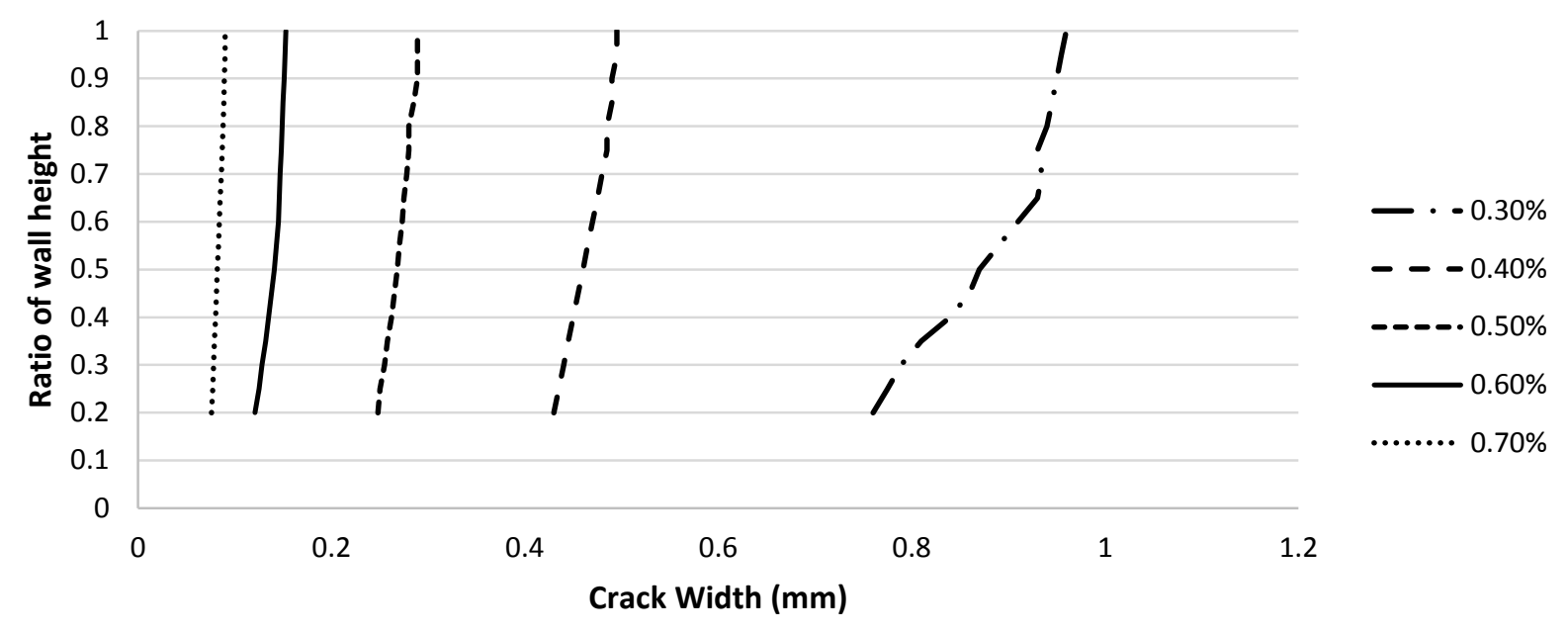

Figure 4-9 crack width along the wall height $(\mathrm{H}=4 \mathrm{~m}, \mathrm{~L}=30 \mathrm{~m})$

\subsection{Summary}

In this chapter, the results of the parametric study performed on base restrained RC walls due to moisture and temperature variations were presented. The effect of creep was not considered in this chapter and walls were solely restrained at the base. It was shown that increasing the wall length, $\mathrm{L} / \mathrm{H}$ ratio, height, and concrete tensile strength increases the maximum crack width. The crack width increased from less than $0.1 \mathrm{~mm}$ to slightly below $1 \mathrm{~mm}$ by increasing the length of the wall from $4 \mathrm{~m}$ to $30 \mathrm{~m}$. Increasing the height of the wall increased the crack width between $10 \%$ and $20 \%$. The reinforcement ratio had a significant influence on reducing the crack width especially in $30 \mathrm{~m}$ long walls in which the crack width is reduced to about $90 \%$ by increasing the steel ratio from $0.3 \%$ up to $0.7 \%$. 


\section{RESPONSE OF BASE RESTRAINED RC WALLS WITH PARTIAL SIDE RESTRAINT}

\subsection{General}

The cracking behavior of RC walls fully restrained at the base and partially restrained at the sides is discussed in this chapter. Such a condition could commonly occur in basement walls and walls in rectangular tanks in liquid containing structures. The side walls provide some restraining effect to the perpendicular walls which could influence the cracking behavior of the member under thermal and shrinkage strains. The influence of the wall height, length, L/H ratio, thickness, reinforcement ratio, climate conditions, steel yield strength and concrete tensile strength are investigated on the width of cracks. The influence of creep and time dependent volumetric strain variation has not been considered in this part of the study.

\subsection{Maximum Crack Width}

\subsubsection{Effect of wall geometry}

Figure 5-1 (a) presents the influence of the wall length on the crack width. The applied volumetric strain is $600 \mu \varepsilon$, reinforcement ratio is $0.3 \%$, and the concrete tensile strength is considered to be $3 \mathrm{MPa}$. The lowest crack width which is about $0.1 \mathrm{~mm}$ occurs in the $4 \times 4 \mathrm{~m}$ wall and the widest crack (around $1.1 \mathrm{~mm}$ ) form in the $4 \times 30 \mathrm{~m}$ wall. It clearly demonstrates that longer walls experience wider cracks.

The influence of $\mathrm{L} / \mathrm{H}$ ratio on the crack width is shown in Figure 5-1 (b) with $\mathrm{L} / \mathrm{H}$ ratios varying from 1 to 4.5. It shows that wider cracks occur in walls with larger $\mathrm{L} / \mathrm{H}$ ratios. As an example, for $4 \mathrm{~m}$ tall walls, the crack width varies from about $0.1 \mathrm{~mm}$ to $0.75 \mathrm{~mm}$ by increasing the $\mathrm{L} / \mathrm{H}$ ratio from 1 to 4.5. Figure B-1 (Appendix B) shows the crack width versus wall height for different wall lengths. This graph does not seem to have a conclusive trend on the effect of wall height on the 
crack width. Therefore, the influence of wall height is demonstrated with $\mathrm{L} / \mathrm{H}$ ratios kept constant in Figure 5-1 (c). Each graph in this figure compares the crack width of walls with different heights $(4 \mathrm{~m}, 6 \mathrm{~m}$, and $8 \mathrm{~m})$ in a single $\mathrm{L} / \mathrm{H}$ ratio. It can be seen that wider cracks occur in taller walls when the $\mathrm{L} / \mathrm{H}$ is kept constant. As an example, when $\mathrm{L} / \mathrm{H}$ is equal to 4 , the crack width is about $0.65 \mathrm{~mm}, 0.75 \mathrm{~mm}$, and $0.88 \mathrm{~mm}$ for $4 \mathrm{~m}, 6 \mathrm{~m}$ and $8 \mathrm{~m}$ tall walls respectively. Effect of wall thickness is another parameter that is considered in this parametric study. Figure 5-1 (d) presents the crack width versus wall length considering three different thicknesses $(300 \mathrm{~mm}, 500 \mathrm{~mm}$, and $700 \mathrm{~mm}$ ). It shows that the thickness does not have a significant influence on the crack width since there seem to be very little difference in the crack widths of the simulated walls with different thicknesses.

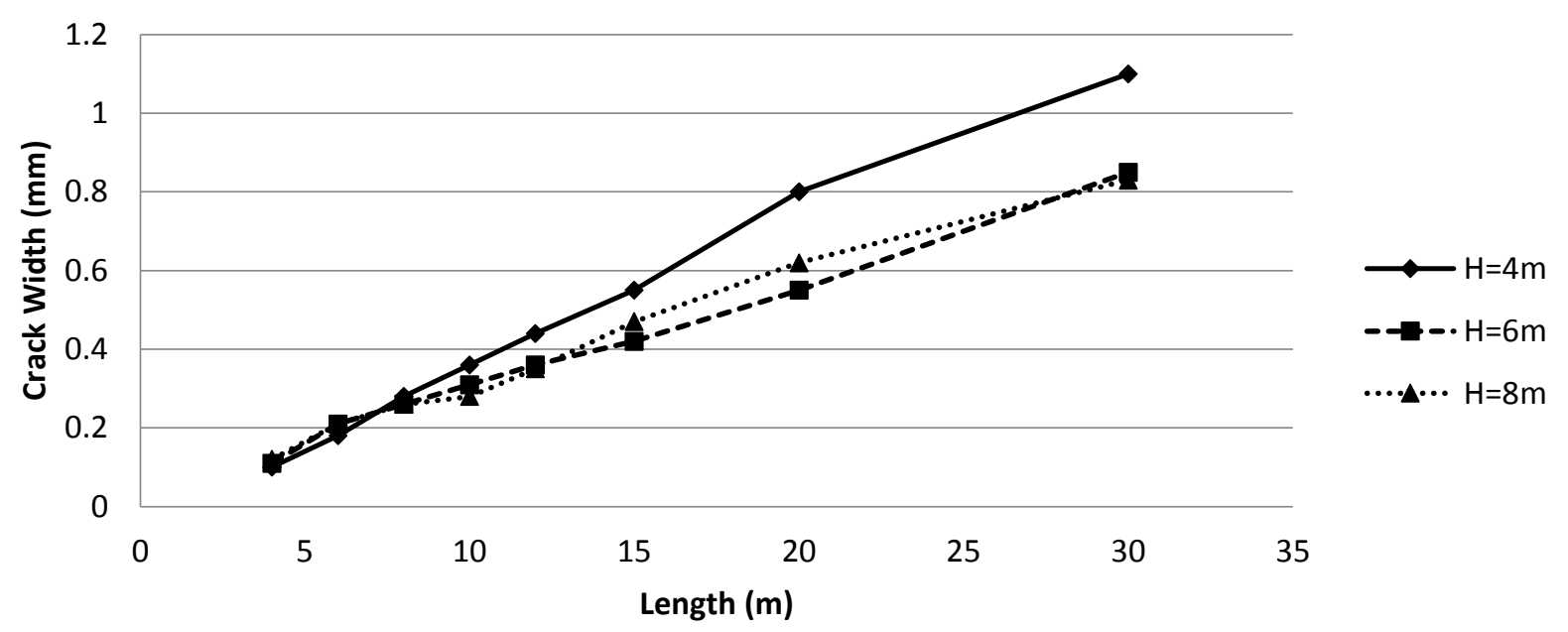

(a) Effect of wall length 


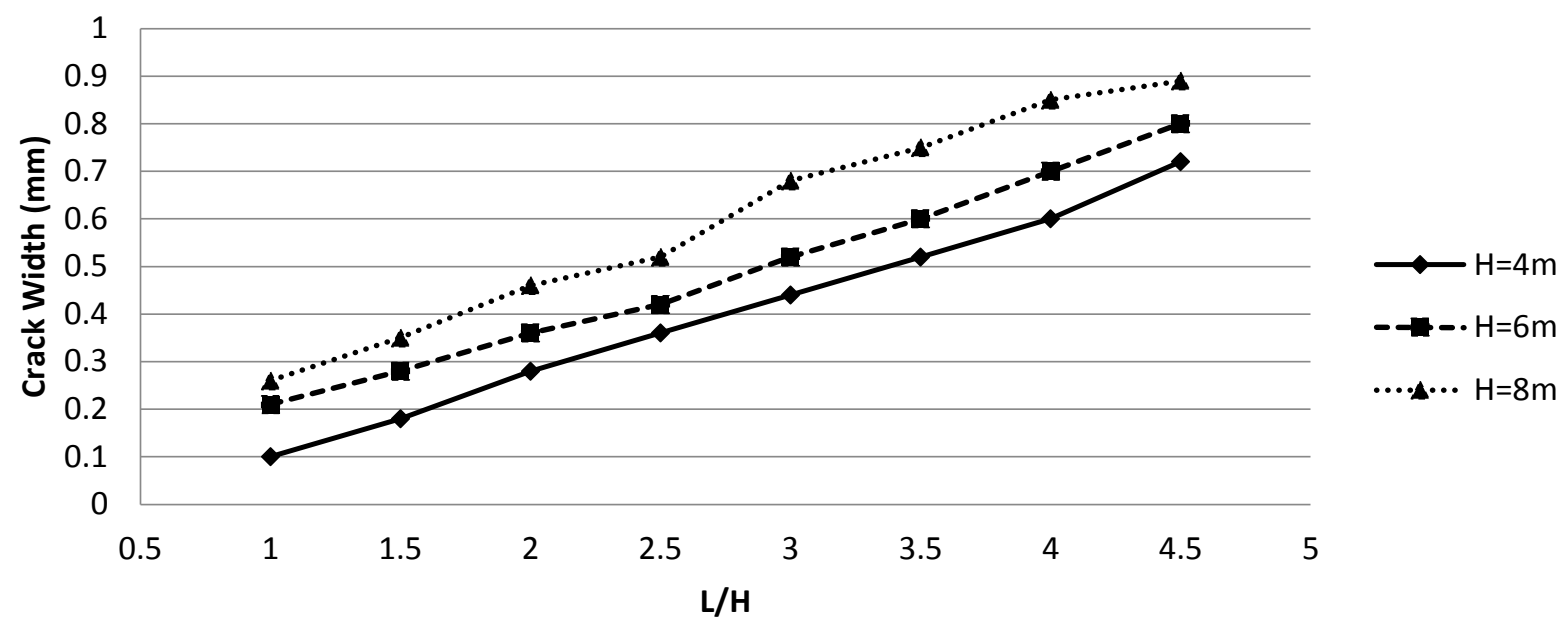

(b) Effect of $\mathrm{L} / \mathrm{H}$ ratio
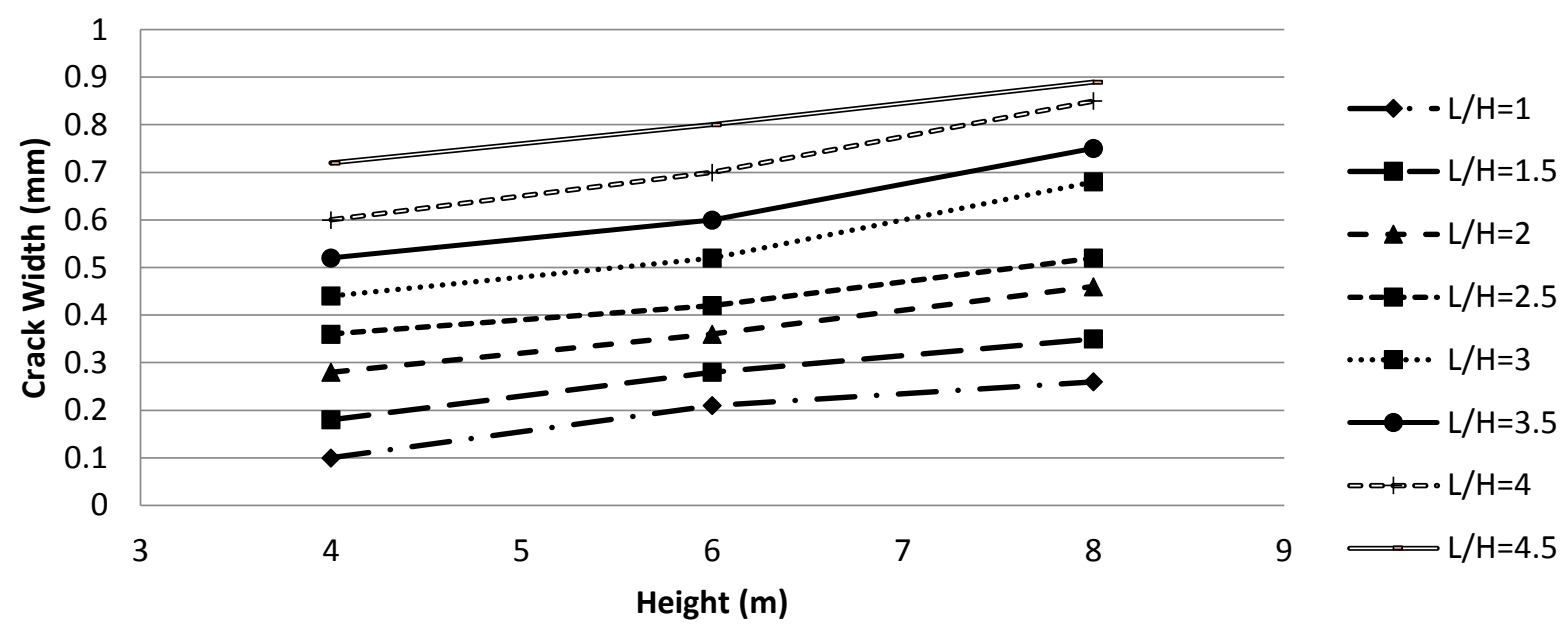

(c) Effect of wall height
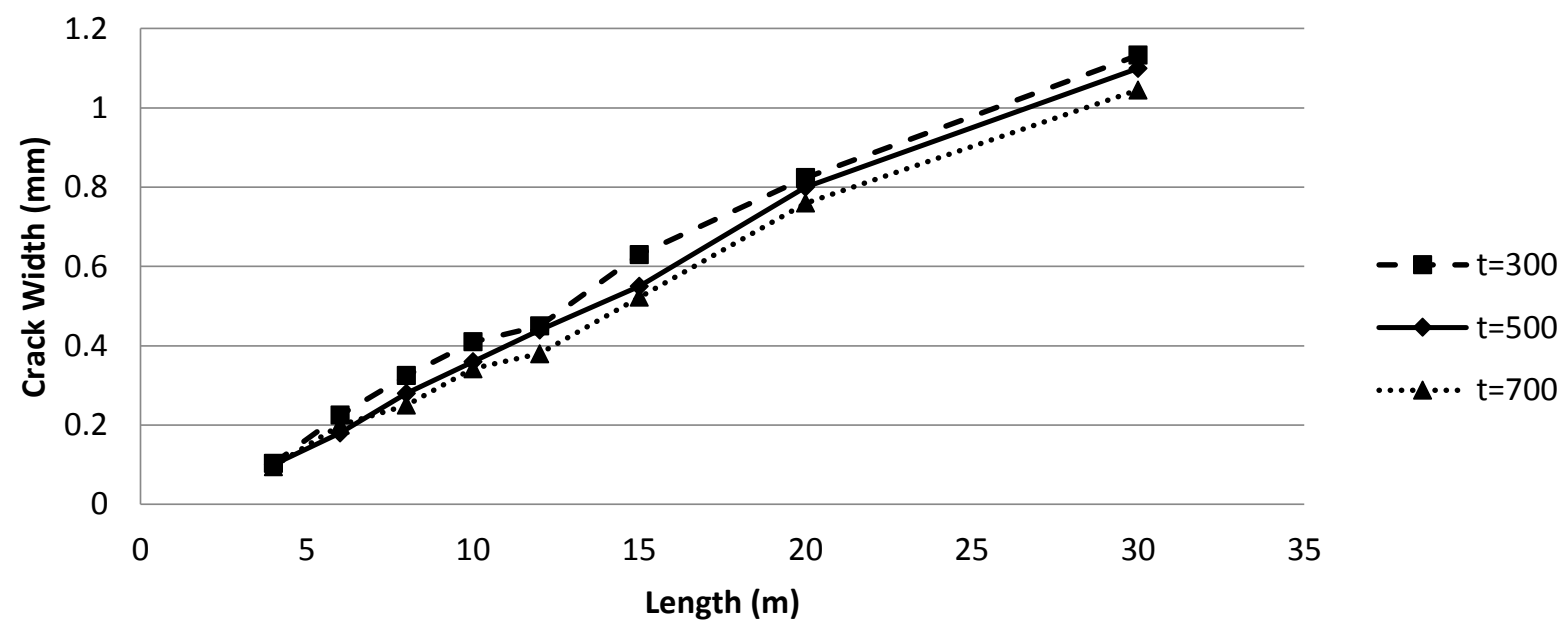

(d) Effect of wall thickness

Figure 5-1 Effect of wall length, L/H ratio, height and thickness on crack width 


\subsubsection{Effect of reinforcement ratio}

The effect of reinforcement ratio on the crack width is discussed with walls reinforced with steel percentages varying from $0.3 \%$ to $0.7 \%$ as presented in Figure 5-2 (see also Appendix B, Figures B-2, B-3, and B-4). Figure 5-2 shows the crack width versus reinforcement ratio for $4 \mathrm{~m}$ tall walls subjected to $600 \mu \varepsilon$ volumetric strain. Each graph in this figure presents the crack width of a wall with its reinforcement ratio increasing while the length is kept constant. It shows that irrespective of the wall length, increasing the reinforcement ratio from $0.3 \%$ to $0.7 \%$ decreases the width of cracks. It also shows that the most significant crack width reduction happens in the $30 \mathrm{~m}$ long wall in which the crack width reduces from $1.1 \mathrm{~mm}$ to almost $0.1 \mathrm{~mm}$ by increasing the steel ratio from $0.3 \%$ to $0.7 \%$.

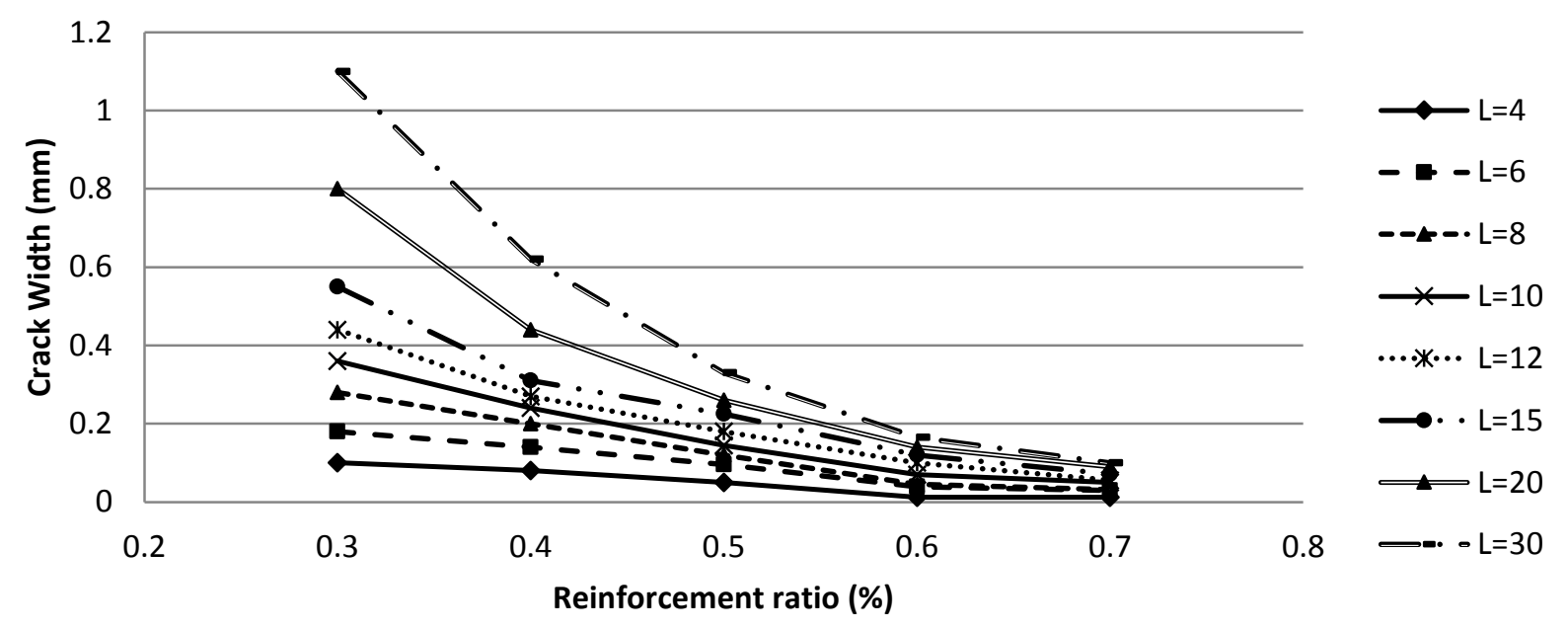

Figure 5-2 Effect of reinforcement ratio on the crack width of $4 \mathrm{~m}$ tall walls

Figures B-2, B-3, and B-4 (Appendix B) present the effect of steel ratio on the crack width of $4 \mathrm{~m}$, $6 \mathrm{~m}$, and $8 \mathrm{~m}$ tall walls respectively considering different volumetric strains. It is shown in all these graphs that increasing the reinforcement ratio narrows the cracks. Considering $4 \times 30 \mathrm{~m}$ wall as an example the crack width can be as large as about $0.8 \mathrm{~mm}, 1.1 \mathrm{~mm}$, and $1.25 \mathrm{~mm}$ for walls subjected 
to $300 \mu \varepsilon, 600 \mu \varepsilon$, and $900 \mu \varepsilon$ respectively. The figures also show that the rate of crack width reduction gradually decreases by increasing the reinforcement ratio.

\subsubsection{Effect of climate conditions}

The influence of climate condition on the crack width is illustrated in Figure 5-3 for $4 \mathrm{~m}$ tall walls with a reinforcement ratio of $0.3 \%$. Three different climate conditions has been considered corresponding to the volumetric strain values of $900 \mu \epsilon, 600 \mu \epsilon$, and $300 \mu \epsilon$. It is clearly shown that wider crack occur in walls under higher volumetric strains. Figures B-5, B-6, and B-7 (Appendix B) are presented to further discuss the impact of applied thermal and shrinkage strain on the width of cracks for $4 \mathrm{~m}, 6 \mathrm{~m}$, and $8 \mathrm{~m}$ tall walls respectively. It can be seen in all these figures that the higher the applied strain, the wider cracks will form in the RC walls. It also appears that the volumetric strain has a more substantial influence on the crack width of longer walls as the difference between the results increase by increasing the length of the walls.

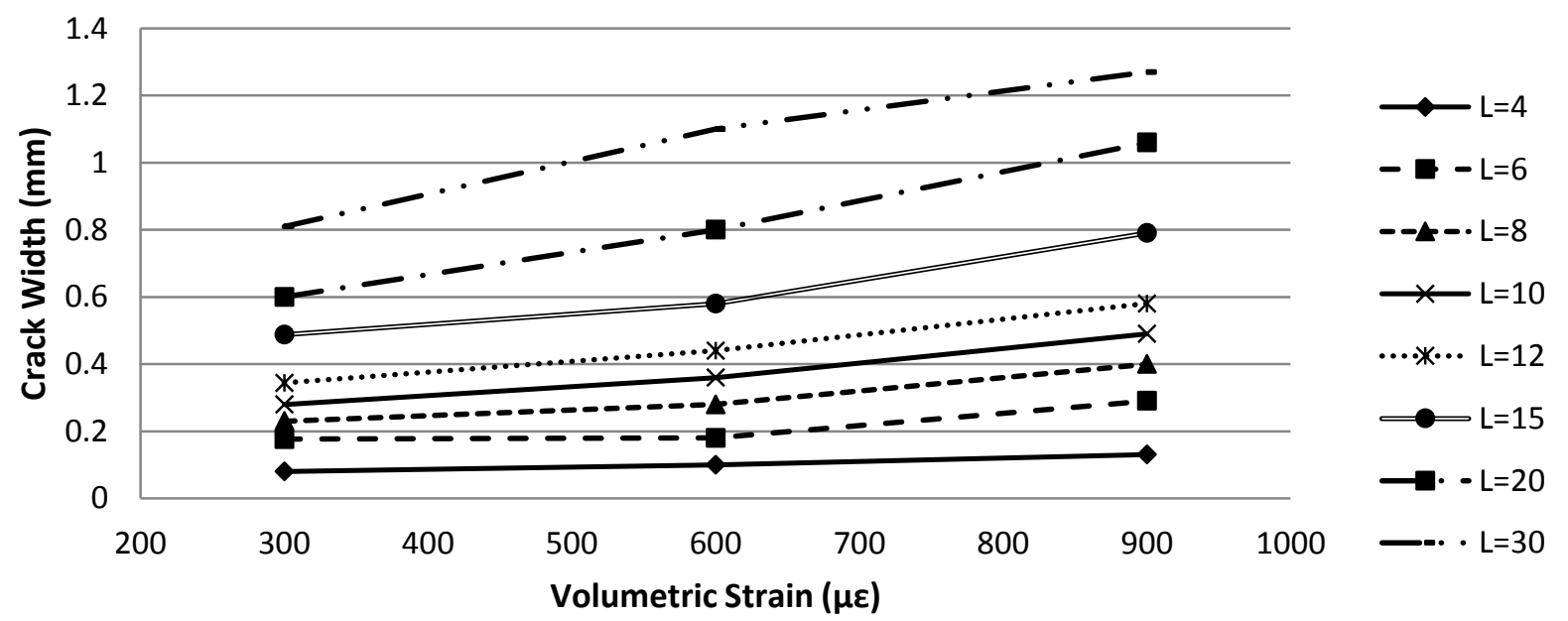

Figure 5-3 Effect of volumetric strain on the crack width of $4 \mathrm{~m}$ tall walls 


\subsubsection{Effect of concrete tensile strength}

Figure 5-4 (see also Appendix B, Figures B-8 and B-9) illustrates the effect of concrete tensile strength on the crack width. Figure 5-4 presents the results of $4 \mathrm{~m}$ tall walls reinforced with $0.3 \%$ steel. It appears that increasing the tensile strength of concrete leads to formation of wider cracks. This is due to the fact that stronger concrete cracks under a higher stress level and therefore a lower number of wide cracks occur in it. While the weaker concrete experiences a higher number of narrower cracks since it cracks under a lower stress level and as the cracks form, the existing cracks narrow due to stress relief.

Figure B-8 (Appendix B) is presented to discuss the influence of concrete tensile strength considering different wall heights. Figure B-9 (Appendix B) shows the effect of concrete tensile strength on the crack widths of walls with varying reinforcement ratios. It can be concluded from the graphs that wider cracks form in walls made of higher tensile strength concrete irrespective of their height or reinforcement ratio.

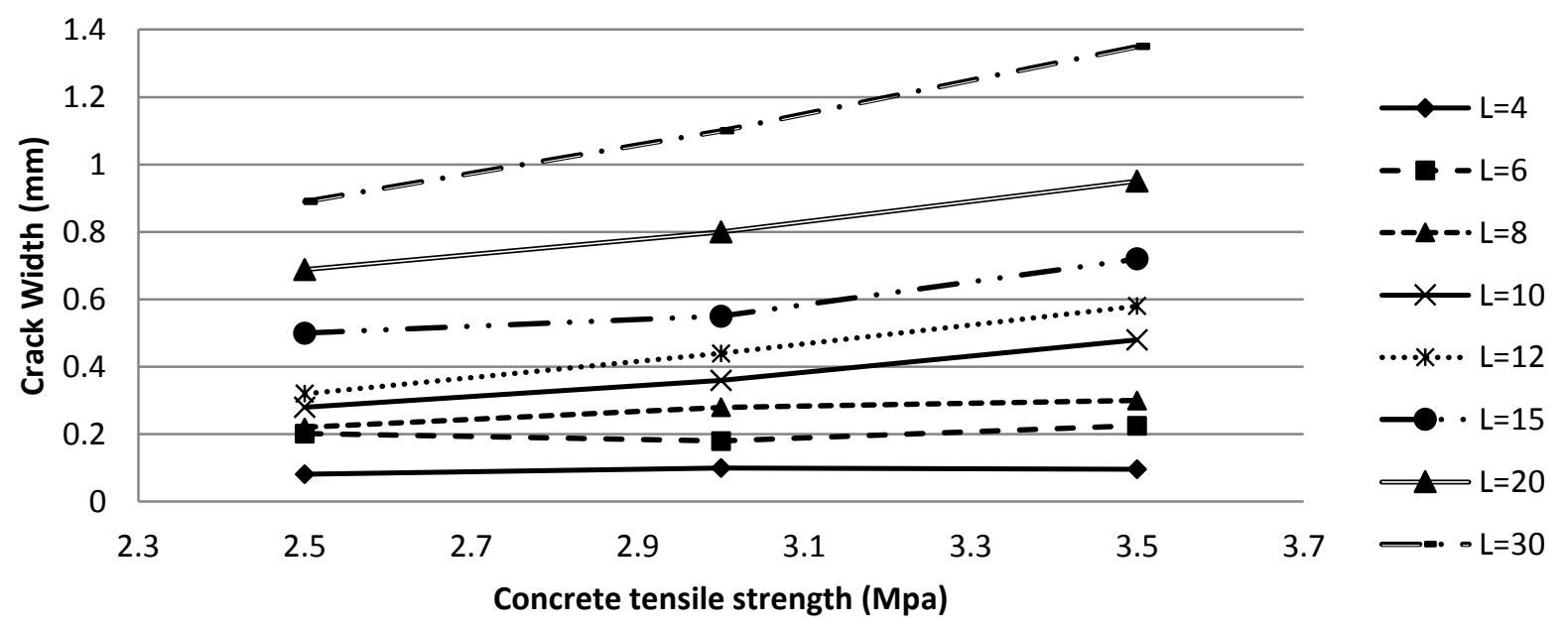

Figure 5-4 Effect of concrete tensile strength on the crack width 


\subsubsection{Effect of steel nonlinearity on the crack width}

Figure 5-5 (see also Appendix B, Figures B-10 and B-11) presents the effect of steel behavior on the crack width of RC walls. Figure 5-5 shows the crack width for $4 \mathrm{~m}$ tall walls reinforced with $0.3 \%$ and $0.5 \%$ comparing the crack width of walls reinforced with linear and non-linear steel. It shows that the difference between the crack width values gradually increase by increasing the wall length. As an example, the crack width in the $4 \times 15 \mathrm{~m}$ wall reinforced with $0.3 \%$ steel is $0.45 \mathrm{~mm}$ and $0.55 \mathrm{~mm}$ for linear and non-linear steel respectively. While, for $4 \times 30 \mathrm{~m}$ wall the crack width values are $0.6 \mathrm{~mm}$ and $1.1 \mathrm{~mm}$ for linear and non-linear steel respectively. Therefore, if steel nonlinearity is not defined, the crack width can be considerably lower than its real magnitude especially in longer walls reinforced with low steel percentages. Using Frosch equation with clear cover of $50 \mathrm{~mm}$ and reinforcement spacing of $200 \mathrm{~mm}$, the crack width at which the steel yields would be equal to $0.224 \mathrm{~mm}$. Therefore, when the crack width is less than $0.244 \mathrm{~mm}$, the definition of steel nonlinearity does not make any changes on the crack width results since the steel is in elastic stage.

Figure B-11 (Appendix B) shows the influence of steel behavior with reinforcement ratios varying between $0.4 \%$ and $0.7 \%$. It can be seen that by increasing the reinforcement ratio the difference between the crack widths of walls reinforced with linear and nonlinear steel has decreased. In fact for $0.6 \%$ and $0.7 \%$ reinforcement ratios, the non-linearity of steel has no effect on the results since the crack width is below $0.224 \mathrm{~mm}$ and steel remains in the elastic stage. 


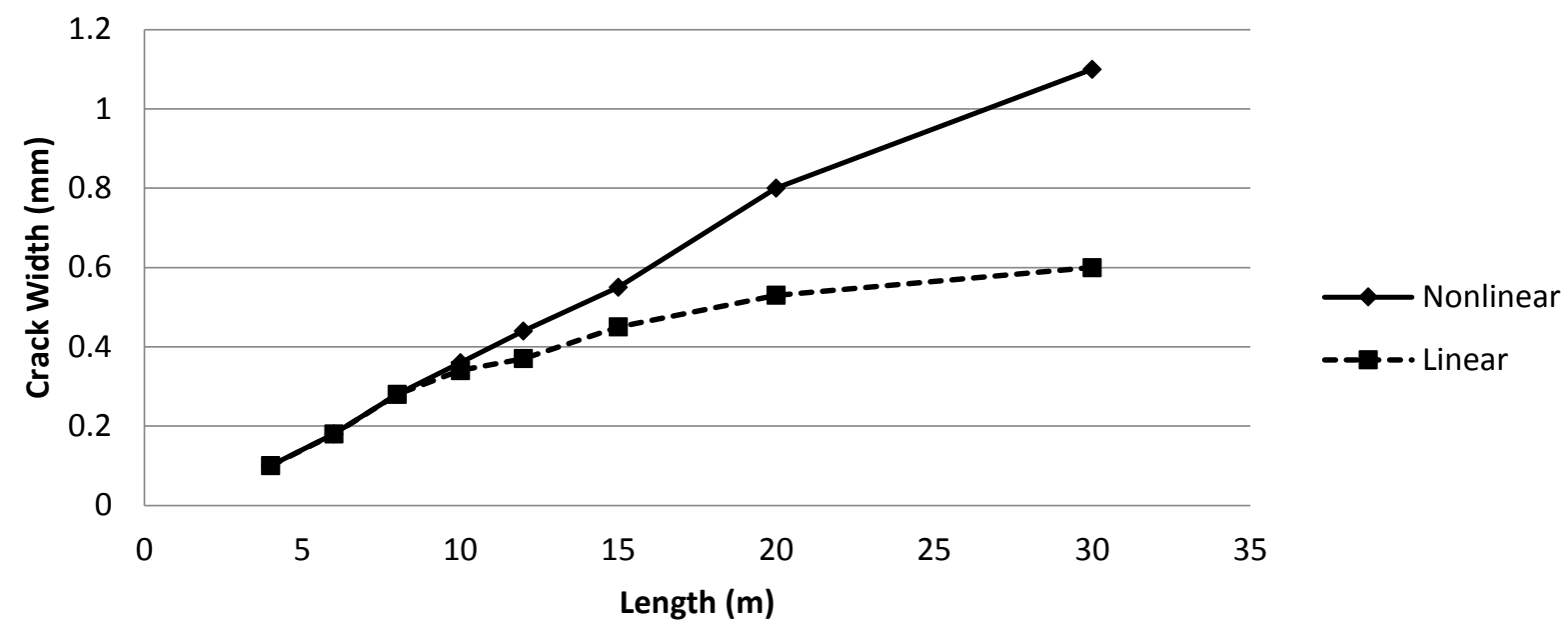

(a) $\rho=0.3 \%$

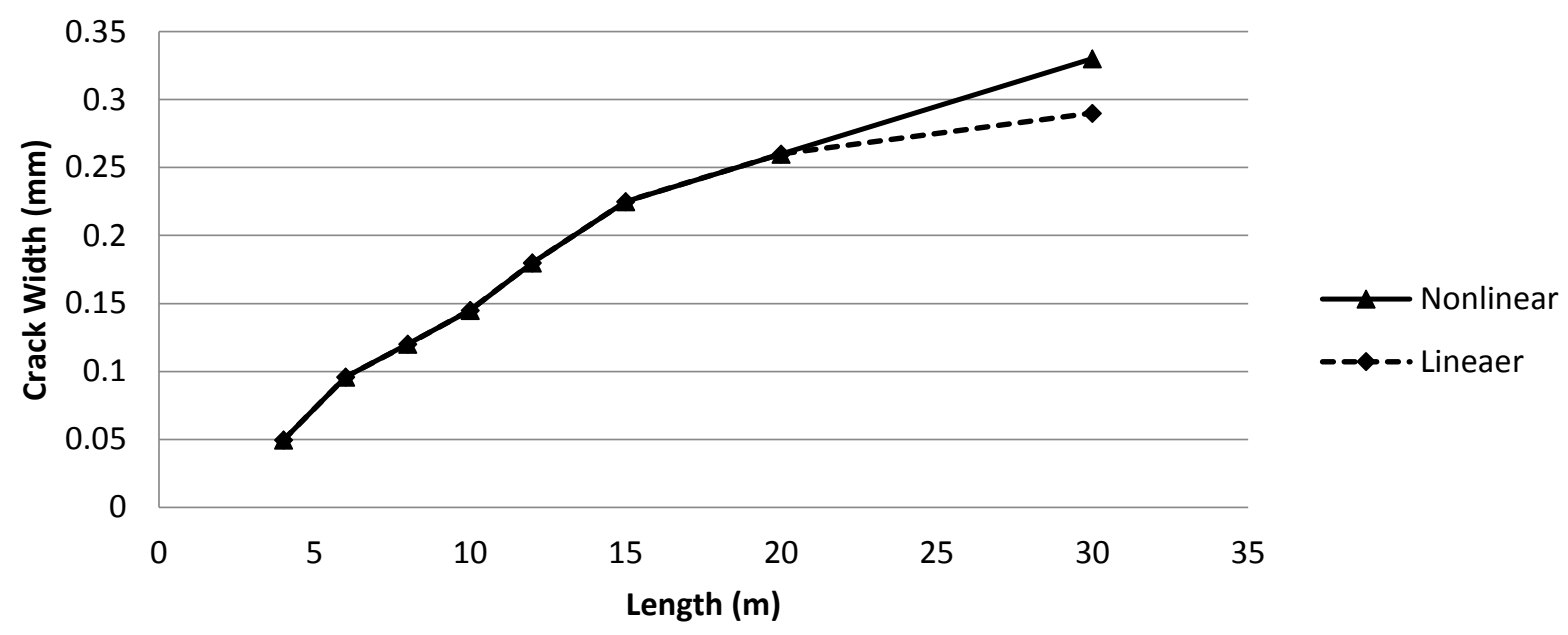

(b) $\rho=0.5 \%$

Figure 5-5 Effect of steel behavior on the crack width

\subsubsection{Effect of steel yield strength on crack width}

The influence of steel strength on the crack width of modelled RC walls is discussed in this part by comparing the crack width of walls reinforced with $300 \mathrm{MPa}$ and $400 \mathrm{MPa}$ steel. Figure 5-6 illustrates the results of the FE analyses on $4 \mathrm{~m}$ tall walls with $0.3 \%$ and $0.5 \%$ steel ratios. Figure B-12 (Appendix B) presents the crack width of $6 \mathrm{~m}$ and $8 \mathrm{~m}$ walls reinforced with $0.3 \%$ steel and Figure B-13 (Appendix B) illustrates the results of $4 \mathrm{~m}$ tall walls reinforced with steel percentages varying from $0.4 \%$ up to $0.7 \%$. 
In general, the walls reinforced with grade 300 steel experience wider cracks in comparison with those containing $400 \mathrm{MPa}$ rebars. It is shown that as the wall length increases, the effect of steel strength becomes more apparent. Figure 5-6 (a) shows that the crack widths of the 4x10 m wall reinforced with $300 \mathrm{MPa}$ and $400 \mathrm{MPa}$ steel are $0.4 \mathrm{~mm}$ and $0.36 \mathrm{~mm}$ respectively. For $4 \times 30 \mathrm{~m}$ wall the crack width values are $1.25 \mathrm{~mm}$ and $1.1 \mathrm{~mm}$ for $300 \mathrm{MPa}$ and $400 \mathrm{MPa}$ steel respectively. When the wall is short, the stress level is low and both $300 \mathrm{MPa}$ and $400 \mathrm{MPa}$ rebars are in the elastic phase. However, by increasing the length, the stress level increases and as soon as it reaches $300 \mathrm{MPa}$, grade 300 steel yields and goes into plastic stage causing large deformation and wide cracks while the $400 \mathrm{MPa}$ steel is still in elastic stage until the stress exceeds $400 \mathrm{MPa}$. Using Frosch equation and considering the clear cover of $50 \mathrm{~mm}$ and bar spacing of $200 \mathrm{~mm}$, the crack width at which the steel yields would be $0.168 \mathrm{~mm}$ and $0.224 \mathrm{~mm}$ for grade 300 and 400 steel respectively. Therefore, the $300 \mathrm{MPa}$ steel goes into plastic stage as soon as the crack width reaches $0.168 \mathrm{~mm}$ while those reinforced with $400 \mathrm{MPa}$ rebars would be in the elastic stage up to the point that the width of crack exceeds $0.224 \mathrm{~mm}$.

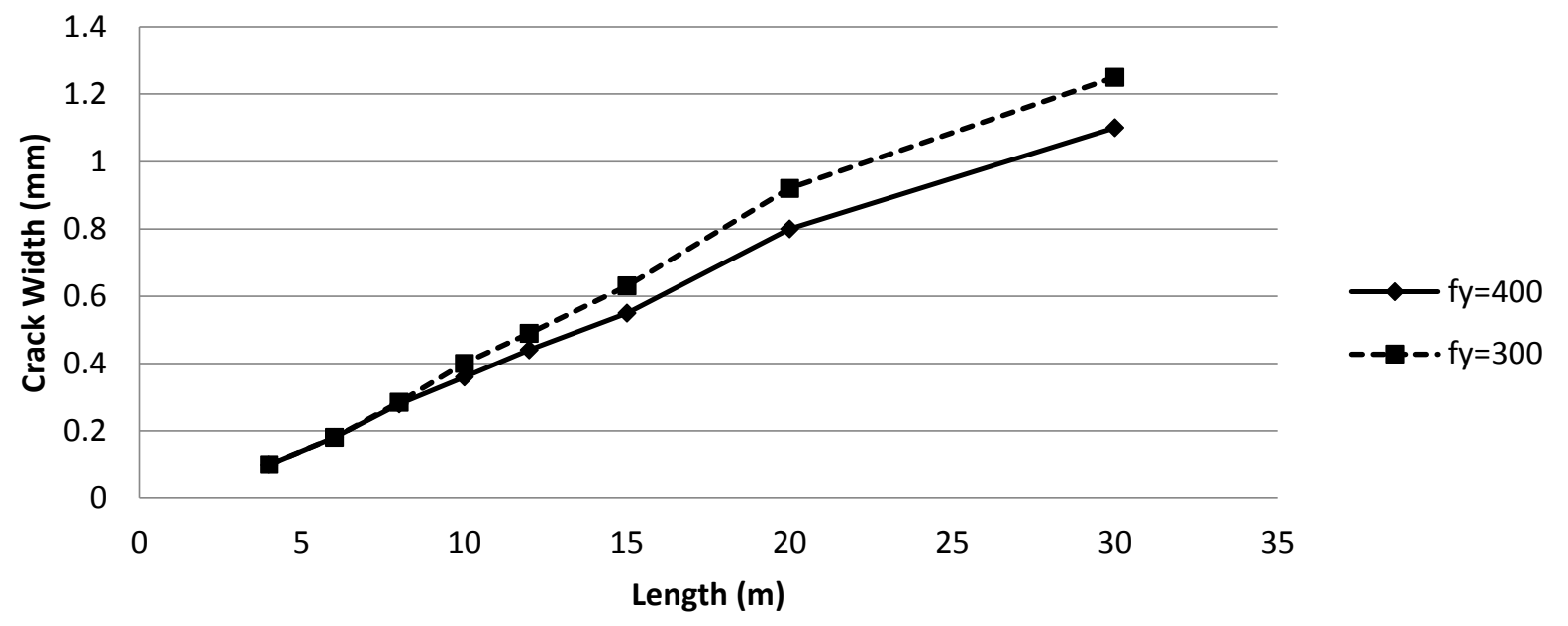

(a) $\rho=0.3 \%$ 


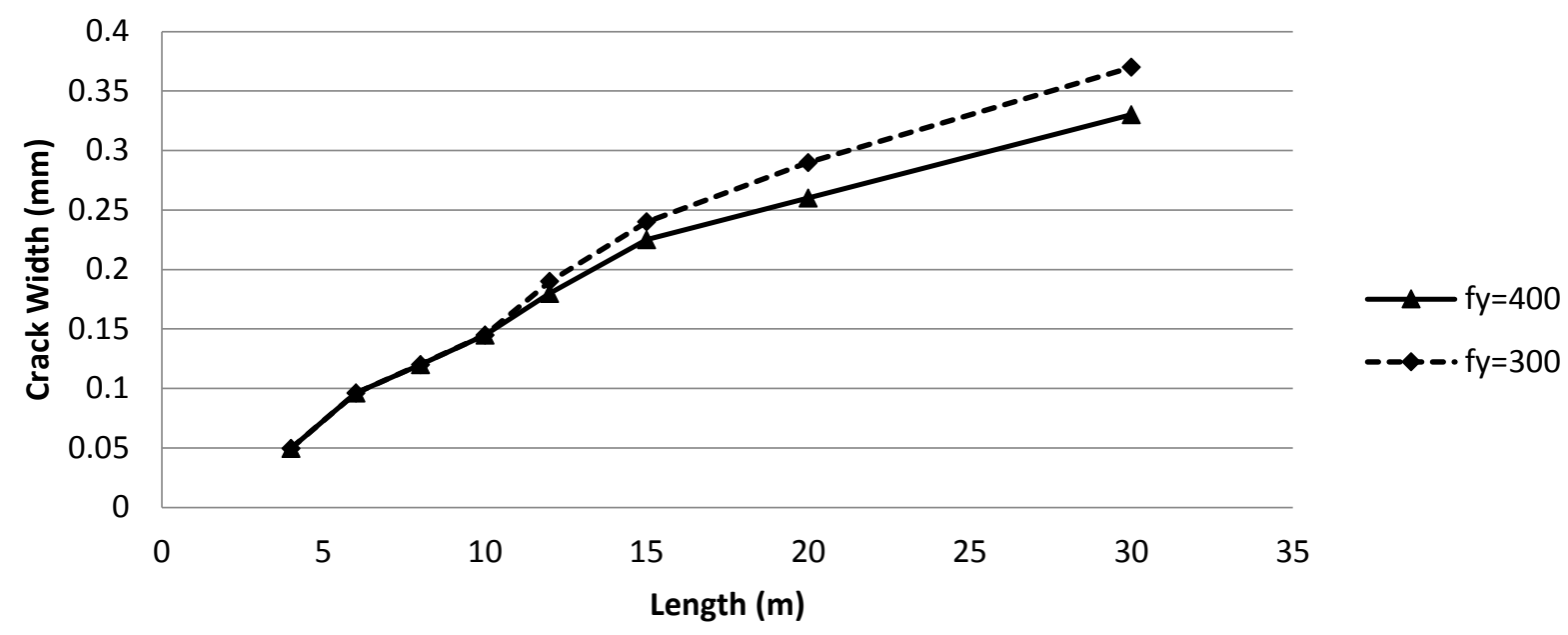

(a) $\rho=0.5 \%$

Figure 5-6 Influence of steel yield strength on the crack width

Figure B-13 (Appendix B) shows that by increasing the steel percentage, the difference between the crack widths of walls reinforced with different steel grades decreases. In fact for $0.6 \%$ and $0.7 \%$ reinforcement ratio, there is no difference in the crack width outcomes of the grade 300 and 400 steel reinforcement as they do not yield since the crack width does not exceed $0.168 \mathrm{~mm}$.

\subsection{Crack width along the wall height}

\subsubsection{Effect of length and height}

Figures 5-7 (see also appendix B, Figure B-14) demonstrate the variation of crack width along the wall height. The reinforcement ratio is $0.3 \%$ and assumed thermal and shrinkage strain is $600 \mu \varepsilon$. It is noticeable in these graphs that by increasing the length of the wall, the maximum crack width and the crack extent move towards the top of the wall. In figure 5-7 as an example, for $4 \mathrm{~m}$ long wall, the maximum width of crack happens at about $10 \%$ of the wall height $(0.4 \mathrm{~m}$ from the bottom in this case). The crack itself start from about $0.2 \mathrm{~m}$ from the bottom and ends at $0.6 \mathrm{~m}$. Considering the $4 \times 15 \mathrm{~m}$ wall, the maximum crack width occurs at about $65 \%$ of the wall height and the crack ends at about $85 \%$ of the wall height. For $4 \times 30 \mathrm{~m}$ wall the crack widens all the way to reach its maximum at the top of the wall. Comparing the results of these graphs for different heights, the 
maximum crack width is highest in $4 \mathrm{~m}$ tall wall and lowest in $8 \mathrm{~m}$ tall wall considering the same length. It suggests that the maximum crack width location could depend on the $\mathrm{L} / \mathrm{H}$ ratio more than the length of the wall solely.

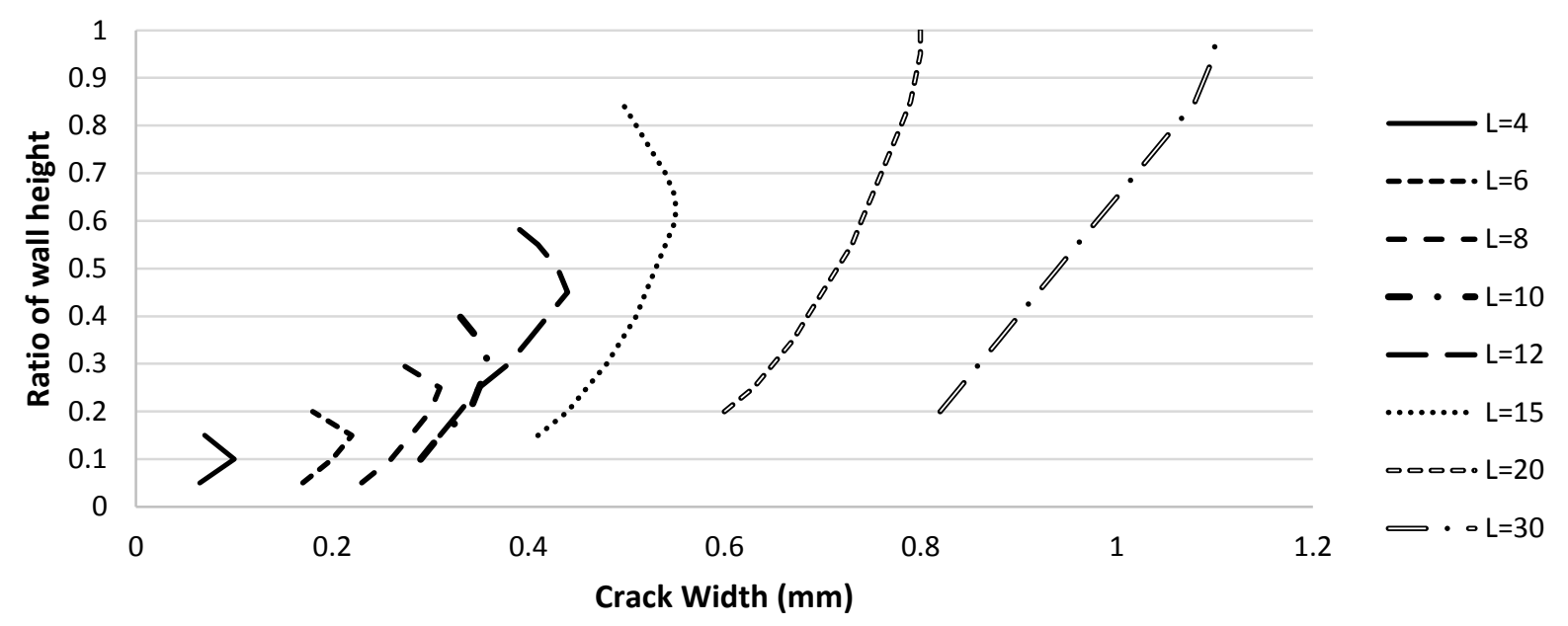

Figure 5-7 Effect of wall length on the crack width over the wall height

The effect of wall height and $\mathrm{L} / \mathrm{H}$ ratio on the crack width over the wall height is presented in Figures 5-8 (see also appendix B, Figure B-15). As the $\mathrm{L} / \mathrm{H}$ ratio increases the location of maximum crack width moves towards the top of the wall. The maximum width of cracks move up from about $10 \%$ of the height when $\mathrm{L} / \mathrm{H}=1$ to the top of the wall for $\mathrm{L} / \mathrm{H}=5$. These graphs mainly show that the extension of these cracks and the location of the maximum width mainly depend on the $\mathrm{L} / \mathrm{H}$ ratio. The wall height does not seem to influence the crack width variation over the wall height. 

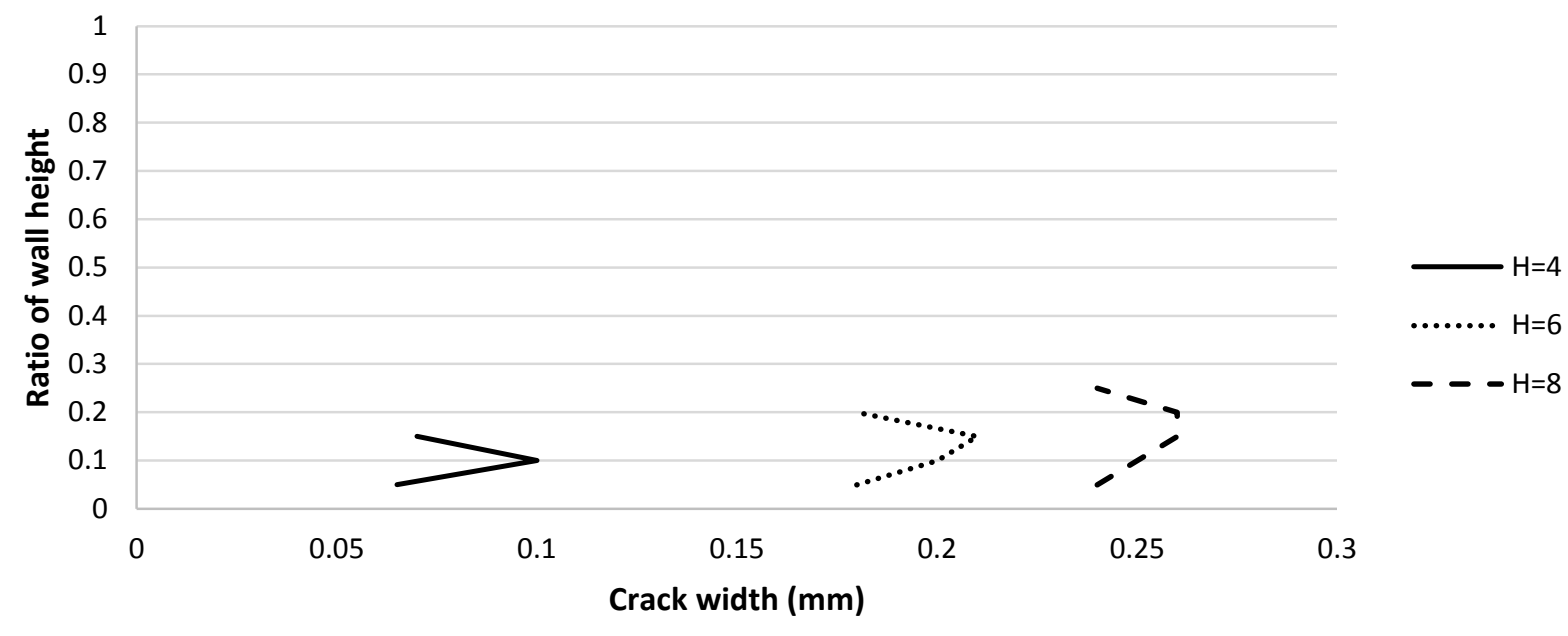

(a) $\mathrm{L} / \mathrm{H}=1$
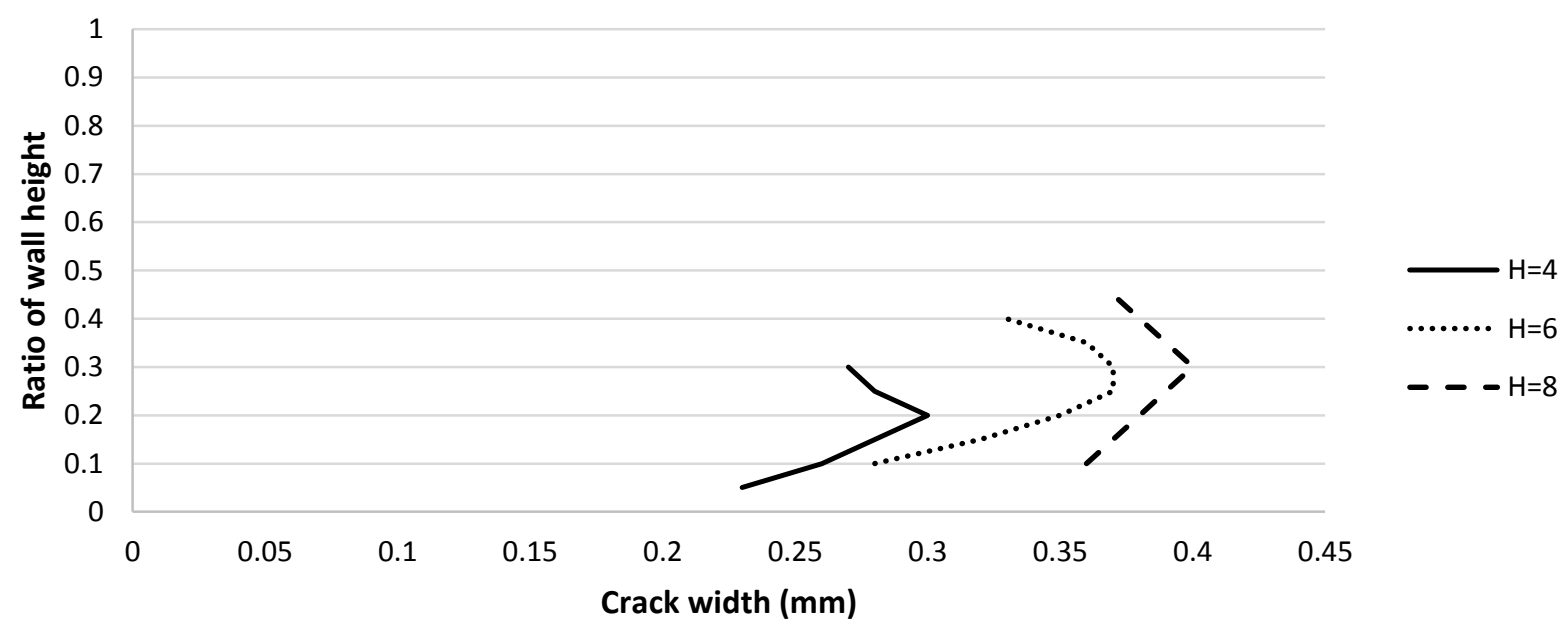

(b) $\mathrm{L} / \mathrm{H}=2$

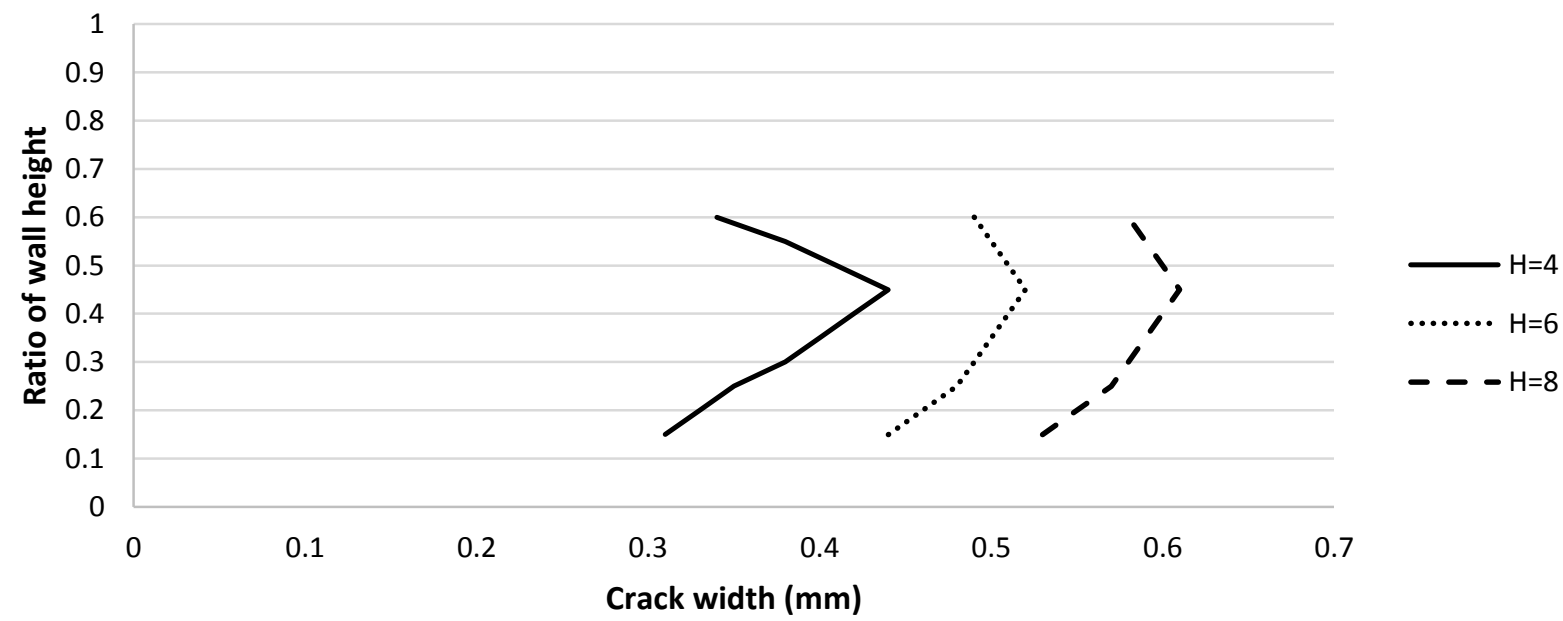

(c) $\mathrm{L} / \mathrm{H}=3$ 


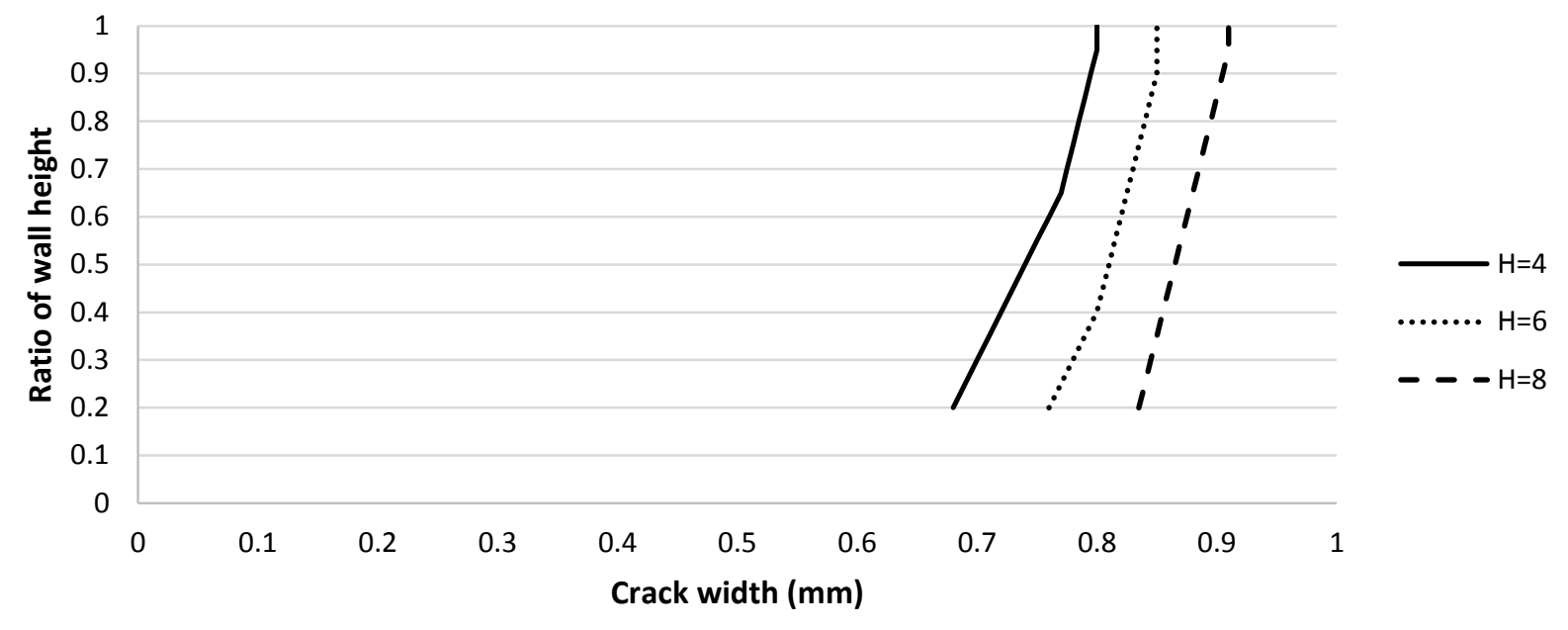

(d) $\mathrm{L} / \mathrm{H}=5$

Figure 5-8 Effect of wall height on the crack width along the wall height

\subsubsection{Effect of reinforcement ratio}

Figure 5-9 demonstrates the effect of reinforcement ratio on the crack width along the wall height. This figure contains 5 graphs for reinforcement ratios varying from $0.3 \%$ to $0.7 \%$ while the wall length and height are kept constant at $30 \mathrm{~m}$ and $4 \mathrm{~m}$ respectively. Figure B-16 in Appendix B shows the effect of steel ratio on the crack width of $4 \mathrm{~m}$ high walls with lengths varying from $4 \mathrm{~m}$ up to $20 \mathrm{~m}$. The figures show that the maximum crack width and the extension of the cracks do not seem to be influenced by the steel percentage. Figure 5-9 shows that the crack width increases from the bottom to the top of the wall for all reinforcement ratios. This is in agreement with previous studies done by Kheder (1997) that if L/H ratios is larger than 5, the crack widens along the height and reaches its maximum width at the top of the wall. 


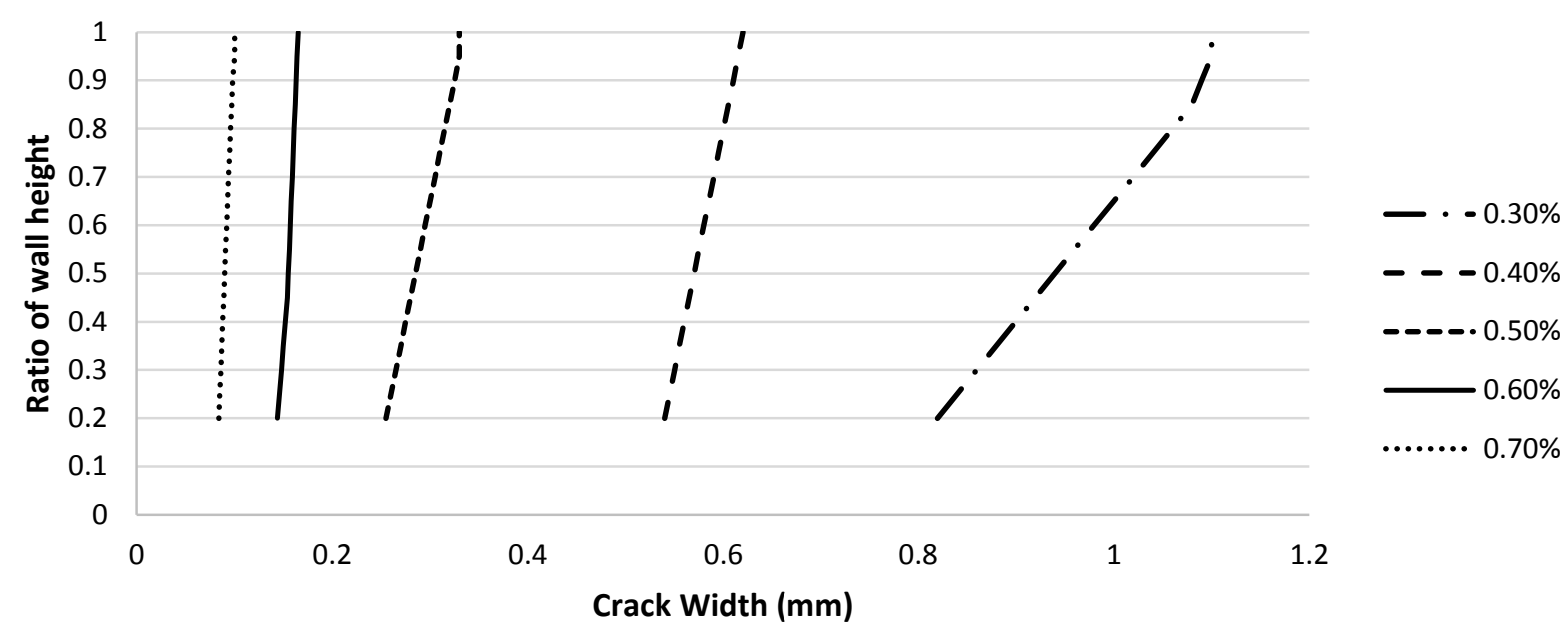

Figure 5-9 crack width along the wall height $(\mathrm{H}=4 \mathrm{~m}, \mathrm{~L}=30 \mathrm{~m})$

\subsection{Summary}

In this chapter, the results of the parametric study on $\mathrm{RC}$ walls with full restraint at the base and partial restraint at the sides were presented. The creep effect was not included in the models. The results of the parametric study showed similar trends as in Chapter 4 for base restrained walls. In fact by increasing the wall length, $\mathrm{L} / \mathrm{H}$ ratio, height, and concrete tensile strength, the maximum crack width increased. Widest cracks occurred in hot and dry climate due to higher shrinkage strain values in this climate and increasing the reinforcement ratio reduced the crack width. The crack width values were in the range of $0.1 \mathrm{~mm}$ to slightly above $1 \mathrm{~mm}$. The crack widths were slightly larger compared to the crack width of walls with base restraint only. 


\section{RESPONSE OF BASE RESTRAINED WALLS CONSIDERING THE EFFECT OF CREEP}

\subsection{General}

This chapter presents the cracking behavior of base restrained $\mathrm{RC}$ walls with no side restraint. The effect of creep is included in the simulation of the RC walls in this chapter. The influence of geometrical parameters including the wall height, length, $\mathrm{L} / \mathrm{H}$ ratio and thickness have been studied on the width of cracks. In addition, the effect of reinforcement ratio, climate condition, concrete tensile strength and steel yield strength is discussed. The effect of creep is considered using the concept of effective elastic modulus.

\subsection{Maximum crack width}

\subsubsection{Effect of wall geometry}

Walls are modeled with lengths varying from $4 \mathrm{~m}$ to $30 \mathrm{~m}$ and heights of $4 \mathrm{~m}, 6 \mathrm{~m}$ and $8 \mathrm{~m}$ considering three different values for their thickness $(300 \mathrm{~mm}, 500 \mathrm{~mm}$, and $700 \mathrm{~mm})$. The time dependent volumetric strain that is applied to these walls is based on the calculations that was done in chapter 3. In this part, the walls are assumed to be exposed to cold and humid conditions and reinforced with $0.3 \%$ steel. Figure 6-1 shows the effect of wall length, L/H ratio, height, and thickness. Figure 6-1 (a) presents the influence of wall length on the crack width. It is evident in this figure that longer walls experience wider cracks. The lowest crack width which is about 0.05 mm occurs in the $4 \times 4 \mathrm{~m}$ wall and $4 \times 30 \mathrm{~m}$ wall seems to experience the widest crack of about 0.7 $\mathrm{mm}$.

Figure 6-1 (b) demonstrates the influence of $\mathrm{L} / \mathrm{H}$ ratio on the width of cracks with $\mathrm{L} / \mathrm{H}$ varying between 1 and 3.5 considering 3 different wall heights. It is shown in this figure that walls with 
larger $\mathrm{L} / \mathrm{H}$ ratios experience wider cracks. Considering $4 \mathrm{~m}$ tall walls as an example, the crack width varies from about $0.05 \mathrm{~mm}$ to $0.4 \mathrm{~mm}$ as the $\mathrm{L} / \mathrm{H}$ ratio increases from 1 to 3.5 .

Effect of wall height on the crack width considering constant lengths is shown in Figure C-1 (Appendix C). However, since the graphs do not seem to have a constant trend, this effect is discussed in Figure 6-1 (c) considering constant L/H ratios. It clearly shows that in walls with the same $\mathrm{L} / \mathrm{H}$ ratio, taller walls experience wider cracks.

Effect of the wall thickness is also investigated on the width of cracks as presented in Figure 6-1 (d). Based on this graphs, thickness is of no significance on the crack width of RC walls.

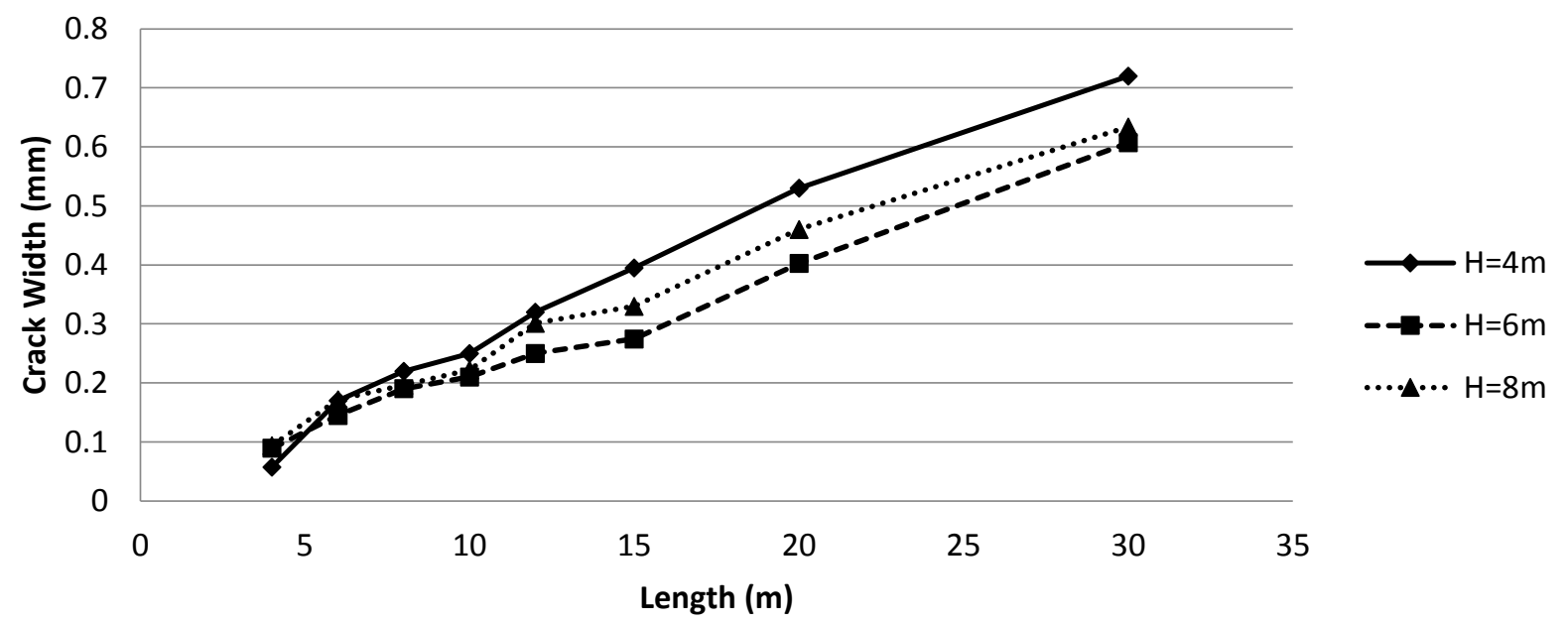

(a) Effect of wall length

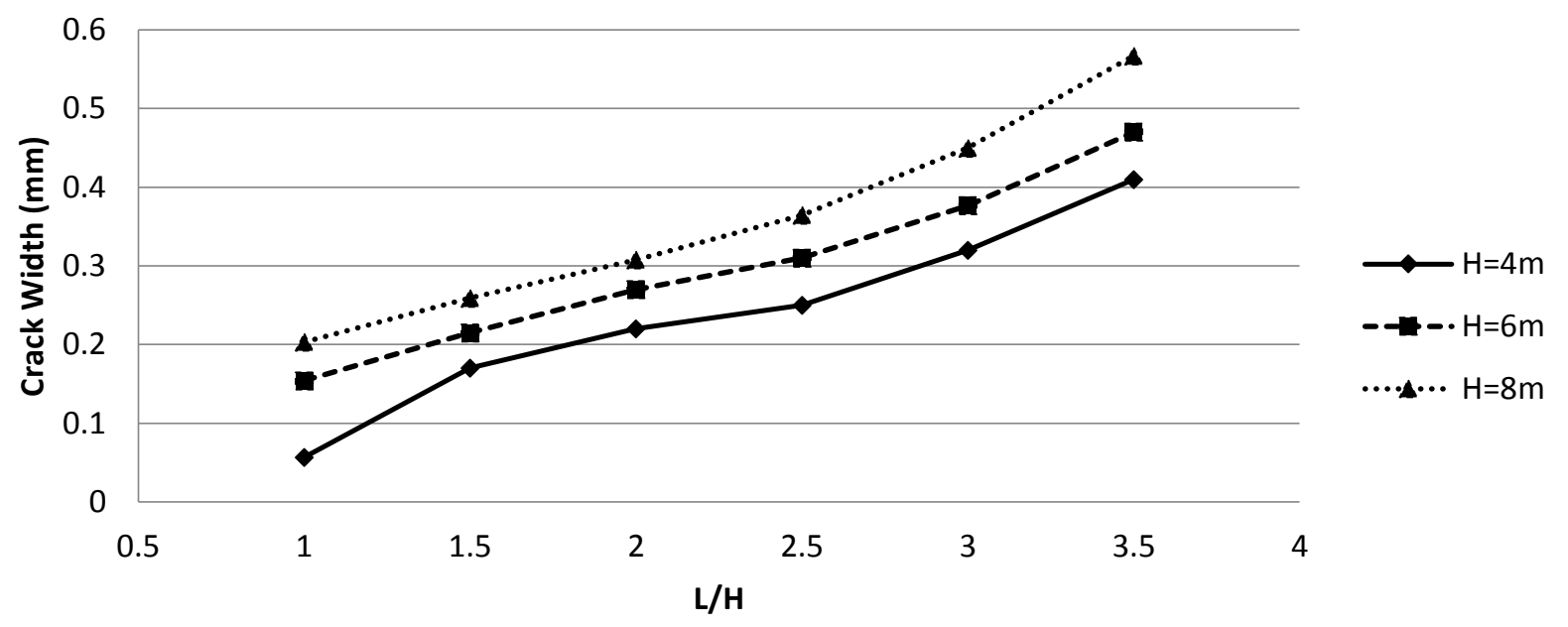

(b) Effect of L/H 


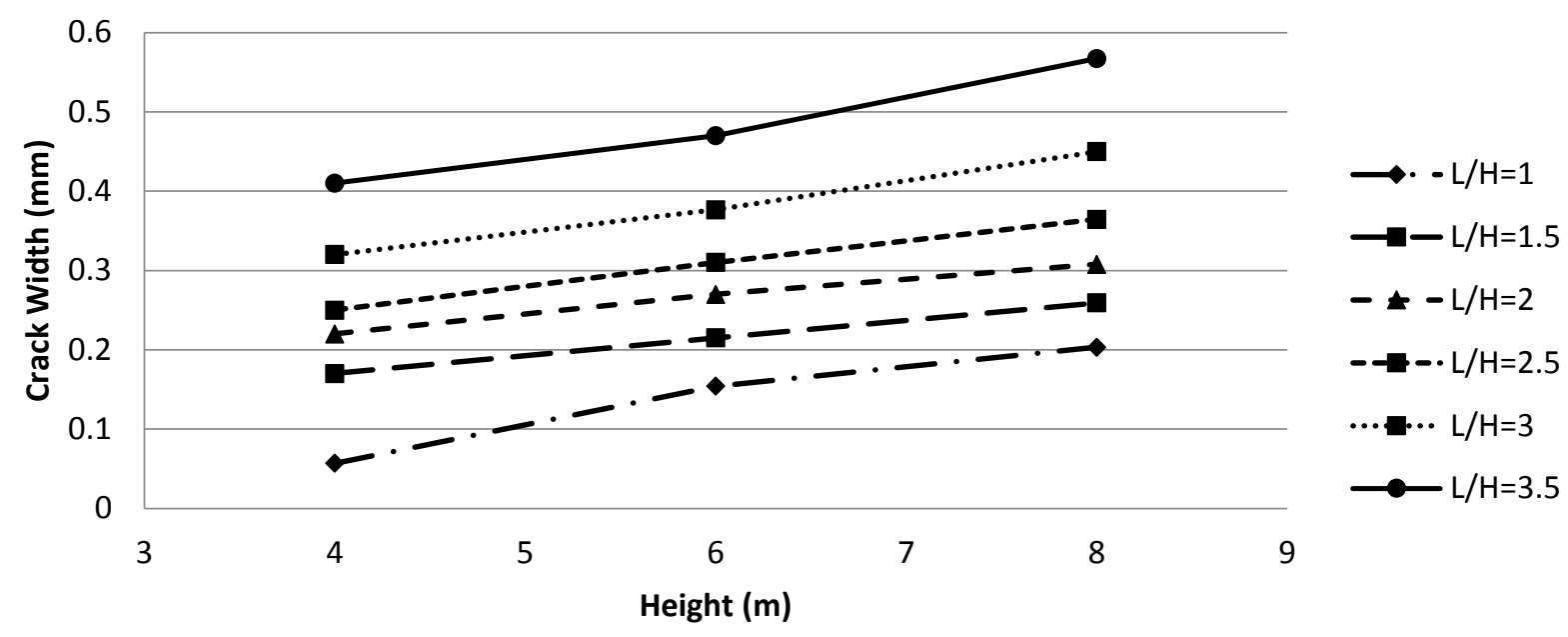

(c) Effect of wall height

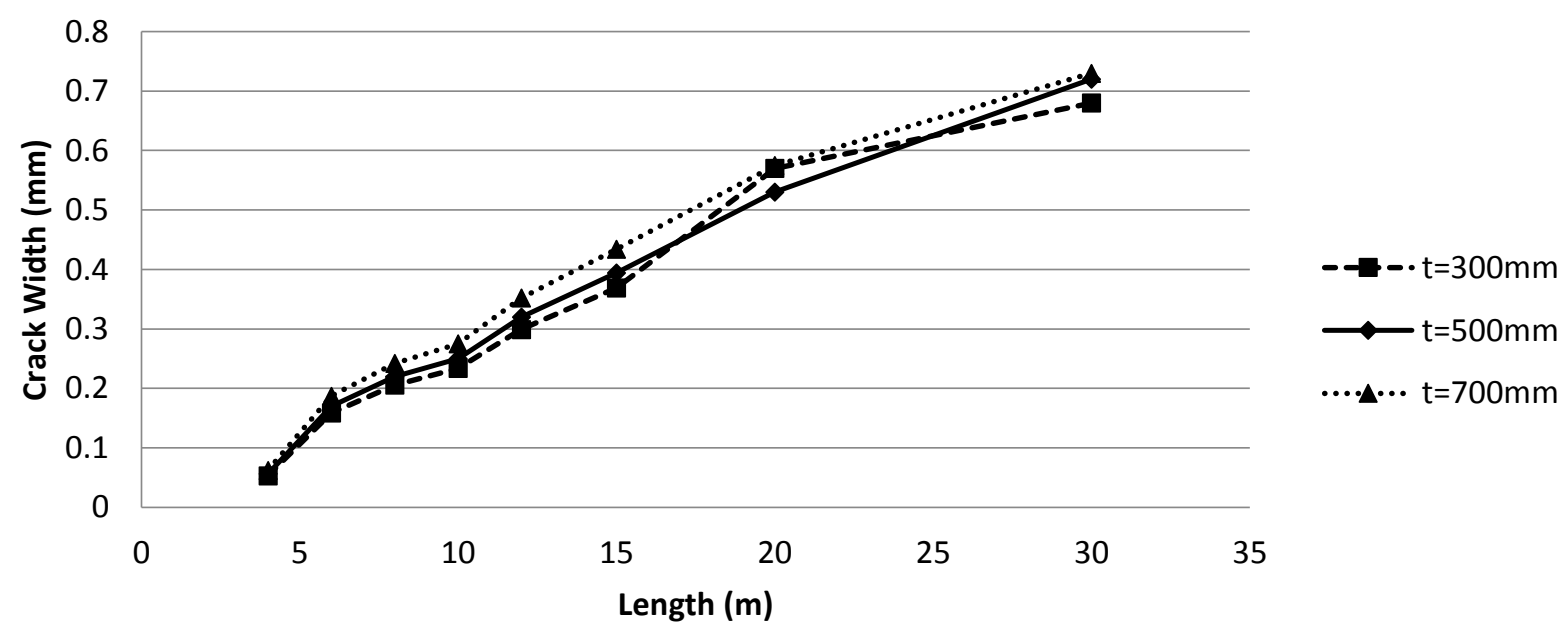

(d) Effect of wall thickness

Figure 6-1 Effect of wall length, L/H, height and thickness on the crack width

\subsubsection{Effect of reinforcement ratio}

Effect of reinforcement ratio on the crack width is discussed by simulating walls reinforced with steel ratios varying from $0.3 \%$ up to $0.7 \%$. Figure $6-2$ shows the influence of steel ratio on $4 \mathrm{~m}$ tall walls in cold and humid climate. Figures C-2, C-3 and C-4 (Appendix C) illustrate this effect on 4 $\mathrm{m}, 6 \mathrm{~m}$, and $8 \mathrm{~m}$ tall walls considering three volumetric strains for each height. It can be seen in each figure that increasing the reinforcement ratio reduces the maximum crack width. In Figure 62 as an example, the crack width in $30 \mathrm{~m}$ long walls is reduced from $0.72 \mathrm{~mm}$ to about $0.07 \mathrm{~mm}$ by increasing the steel percentage from $0.3 \%$ to $0.7 \%$. It is shown that a reinforcement ratio of 
$0.7 \%$ could maintain the crack widths below $0.1 \mathrm{~mm}$ for all modeled walls. It also shows that longer walls under higher volumetric strain need more steel percentage to satisfy crack control requirements.

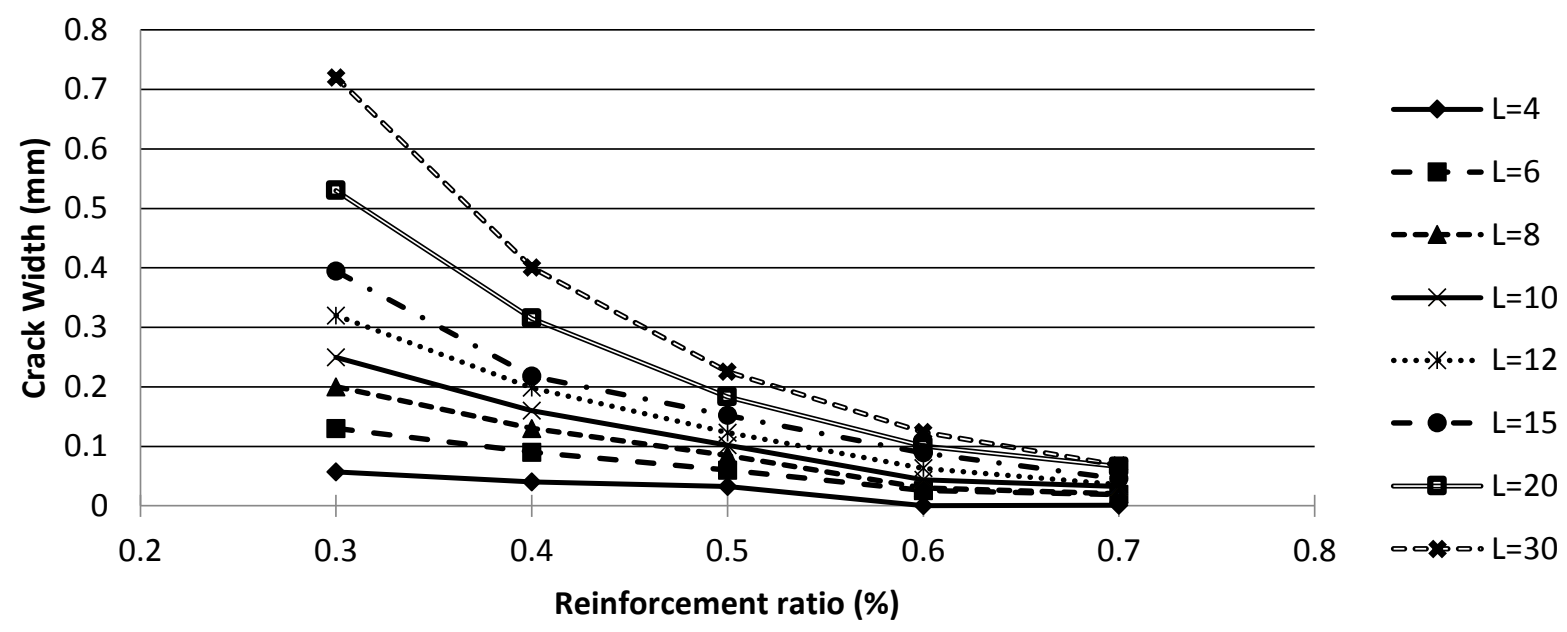

Figure 6-2 Effect of reinforcement ratio on the crack width

\subsubsection{Effect of climate conditions}

Figure 6-3 presents the influence of volumetric strain on the crack width considering different heights, lengths, and reinforcement ratios. Figure 6-3 shows the effect of volumetric strain on the crack width of $4 \mathrm{~m}$ tall walls reinforced with $0.3 \%$ steel. Figures C-5, C-6, and C-7 (Appendix C) demonstrate this effect on $4 \mathrm{~m}, 6 \mathrm{~m}$, and $8 \mathrm{~m}$ tall walls respectively. In general, it can be seen that walls experience wider cracks as the volumetric strain increases. Therefore, the widest cracks occur in walls exposed to hot and dry climate and the narrowest cracks form in the walls cast in the tropical environment. The trend is quite similar irrespective of the walls height and reinforcement ratio. However, it is noticeable that the influence of climate condition on the crack width increases with increasing the wall length. It can also be concluded that the walls exposed to the hot and dry climate will need the highest reinforcement ratio and the walls cast in tropical zones could be reinforced with less steel. 


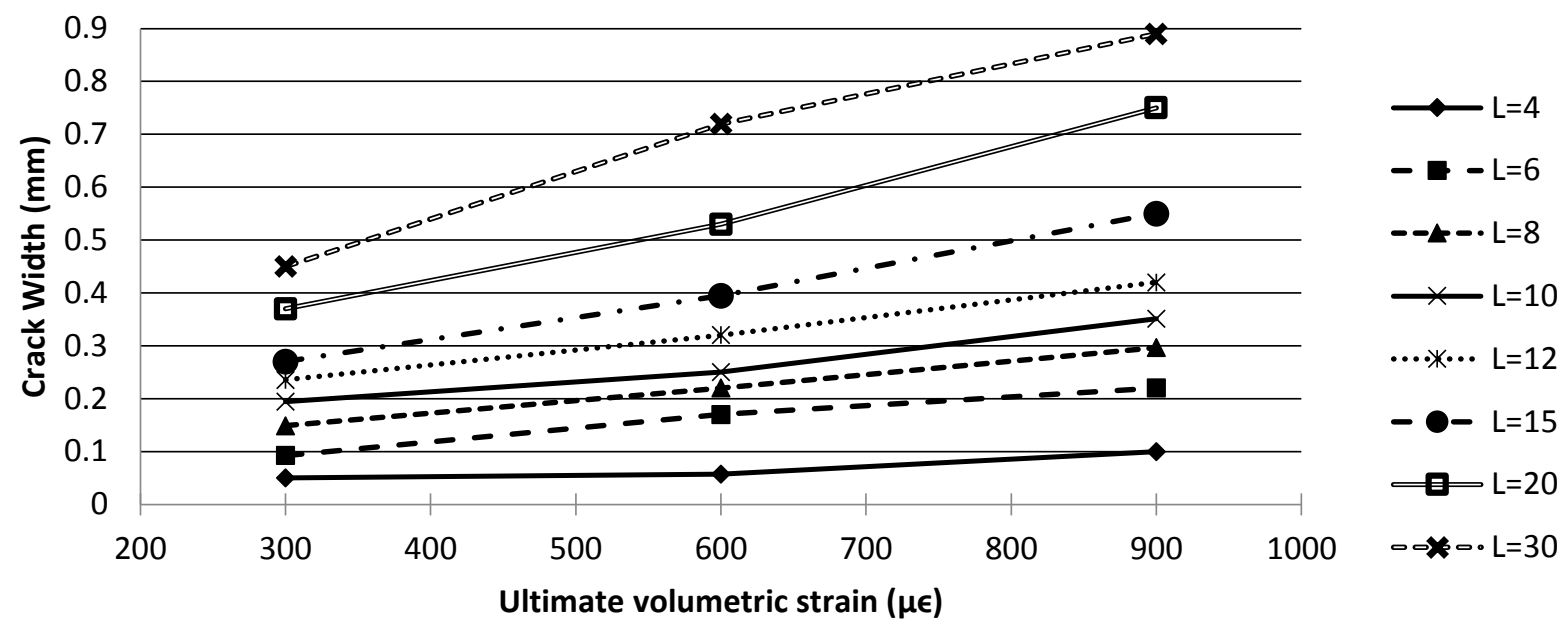

Figure 6-3 Effect of climate condition on the crack width

\subsubsection{Effect of concrete tensile strength}

Figure 6-4 (see also Appendix C, Figure C-8 and C-9) is presented to discuss the effect of concrete tensile strength on width of cracks. Figure 6-4 demonstrates the crack width of $4 \mathrm{~m}$ tall wall reinforced with $0.3 \%$ steel. It can be seen in this figure that wider cracks develop in walls made of higher tensile strength concrete. This trend is similar in Figure C-8 (Appendix C) which contains the results of $6 \mathrm{~m}$ and $8 \mathrm{~m}$ walls. This could be explained by the fact that walls made of stronger concrete need a higher stress level to crack and therefore develop a lower number but wider cracks as opposed to the walls cast with weaker concrete which experience more but narrower cracks. Figure C-9 (Appendix C) shows the effect of concrete tensile strength considering different reinforcement ratios. It can be concluded that wider cracks form in walls made of stronger concrete irrespective of the reinforcement ratio. 


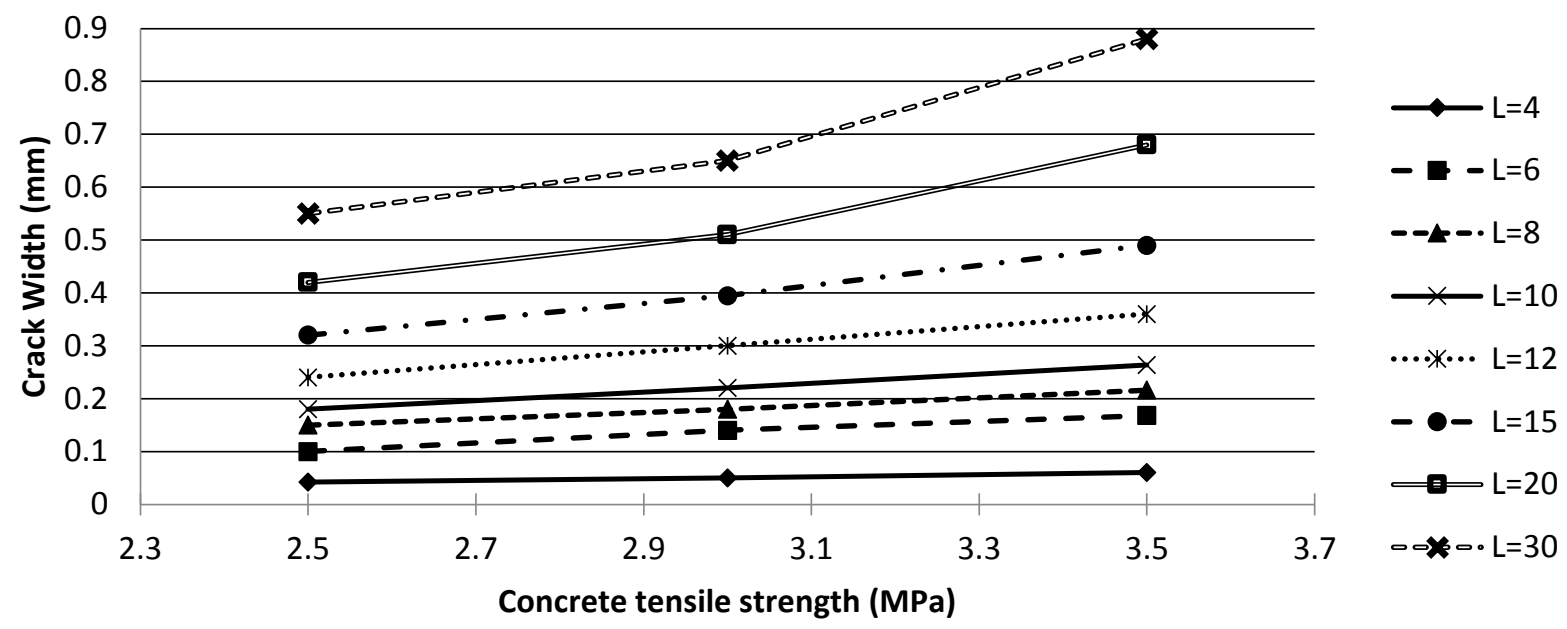

Figure 6-4 Effect of concrete tensile strength on the crack width

\subsubsection{Effect of steel nonlinearity on crack width}

Figure 6-5 demonstrates the crack width of $4 \mathrm{~m}$ tall $\mathrm{RC}$ walls reinforced with $0.3 \%$ and $0.5 \%$ linear and non-linear steel. Figure C-10 (Appendix C) shows this effect on $6 \mathrm{~m}$ and $8 \mathrm{~m}$ tall walls reinforced with $0.3 \%$ steel. The walls are exposed to cold and humid environment with concrete tensile strength of $3 \mathrm{MPa}$. It can be seen that the effect of steel nonlinearity becomes more apparent by increasing the wall length which is because of the stress and stress level increase. Considering the steel yield strength of $400 \mathrm{MPa}$ and elastic modulus of $200000 \mathrm{MPa}$, the yield strain could be calculated as 0.002 . Taking the steel strain into Frosch crack formulation by having a clear cover of $50 \mathrm{~mm}$ and reinforcement spacing of 200 , the crack width at which the steel yields would be $0.224 \mathrm{~mm}$. In other words, the steel yields as soon as the crack width exceeds $0.224 \mathrm{~mm}$. Therefore, when the crack width is less than $0.244 \mathrm{~mm}$, the definition of steel nonlinearity is of no importance. The influence of steel behavior on the crack width of RC walls with different reinforcement ratios is demonstrated in Figure C-11 (Appendix C). It can be seen that by increasing the reinforcement ratio from $0.4 \%$ to $0.7 \%$, the difference between the crack widths in walls reinforced with linear and nonlinear steel has decreased. In fact for $0.6 \%$ and $0.7 \%$ steel, there is no difference in the crack width results between linear and nonlinear steel as the crack width is below 0.224 and steel 
is never yields. For $0.5 \%$ reinforcement ratio (Figure 6-5 b), the significance of steel nonlinearity on crack width could only be seen in the walls longer than $20 \mathrm{~m}$ as the steel goes into plastic phase. It can be concluded that the steel nonlinearity is only of substantial effect for lower reinforcement ratios and longer walls.

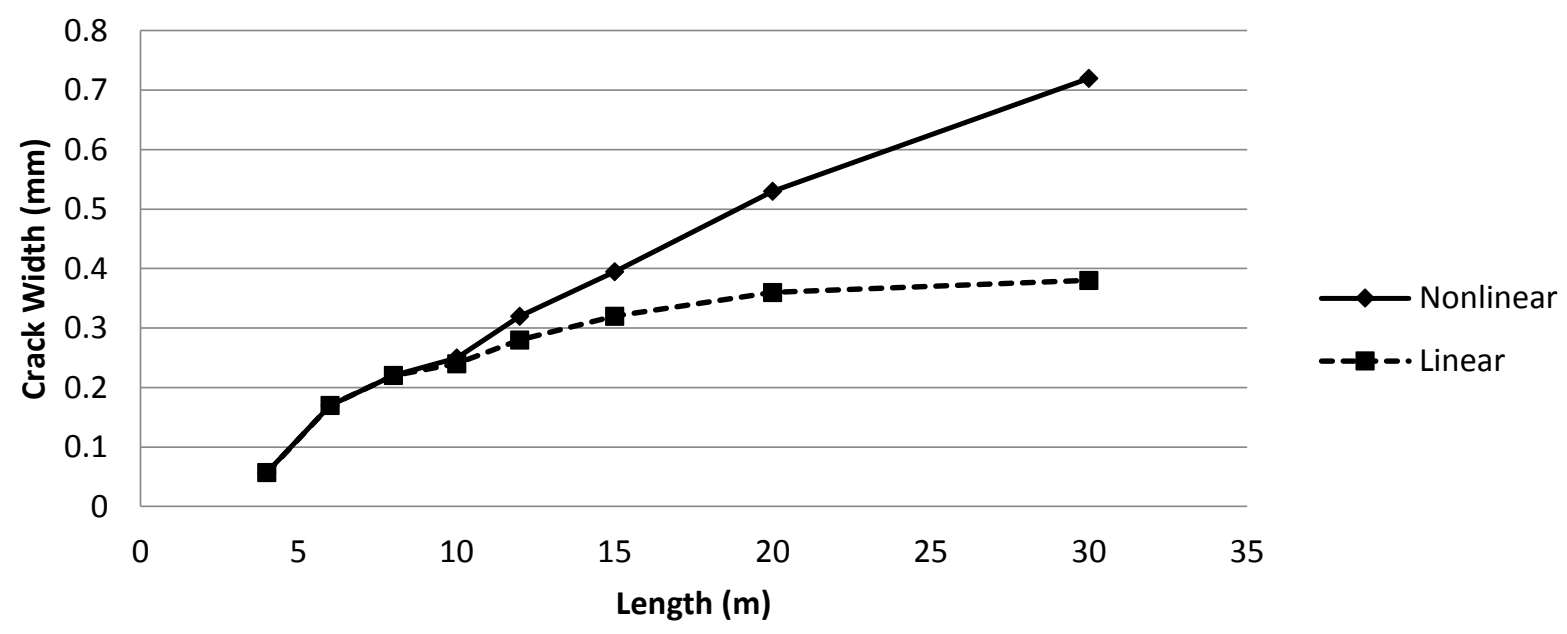

(a) $\rho=0.3 \%$

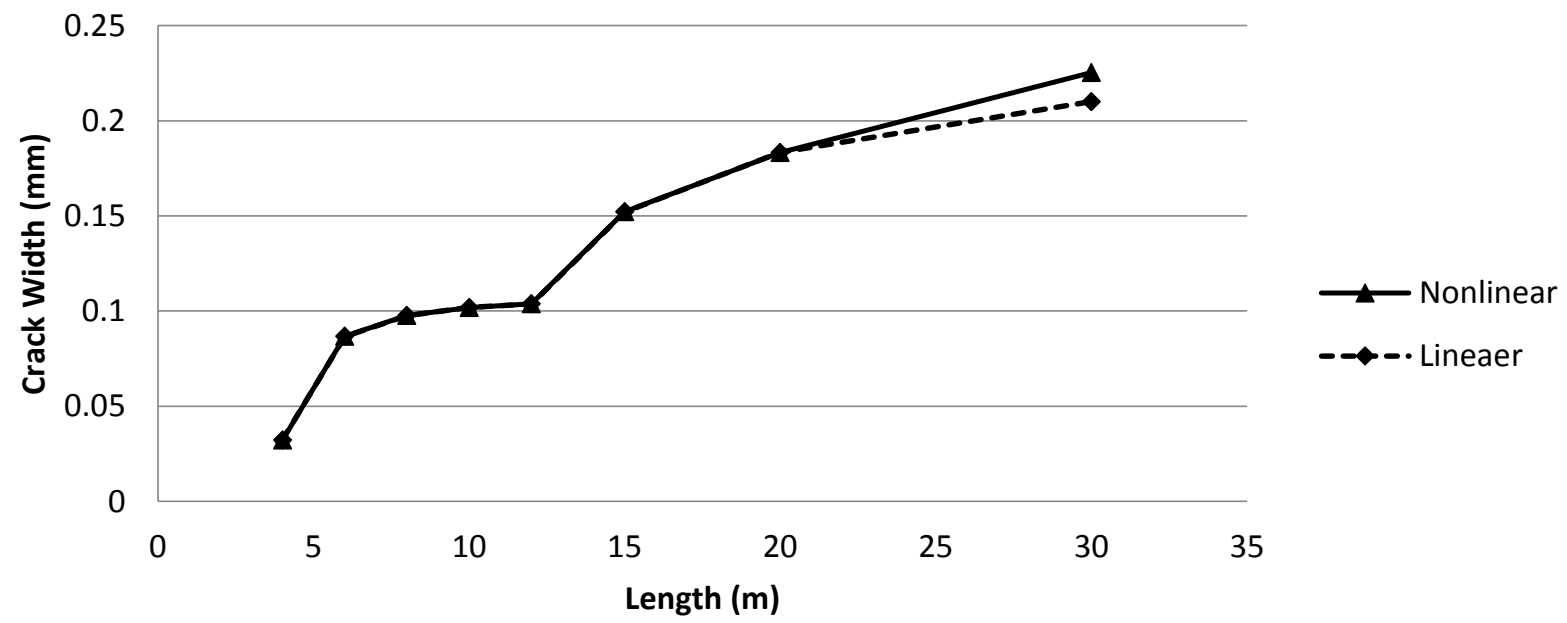

(b) $\rho=0.5 \%$

Figure 6-5 Effect of steel nonlinearity on the crack width 


\subsubsection{Effect of steel yield strength on the crack width}

Figure 6-6 shows the results of $4 \mathrm{~m}$ tall walls reinforced with $0.3 \%$ and $0.5 \%$ steel comparing the $300 \mathrm{MPa}$ and $400 \mathrm{MPa}$ steel. Figure C- 12 (Appendix C) shows the results of $6 \mathrm{~m}$ and $8 \mathrm{~m}$ tall walls and Figure C-13 (Appendix C) presents the crack width values considering different reinforcement ratios. It can be seen that the walls reinforced with grade 300 steel experience wider cracks in comparison with those containing $400 \mathrm{MPa}$ rebars. This is due to the fact that $300 \mathrm{MPa}$ rebars yield under a lower stress and therefore, in identical situation, the $300 \mathrm{MPa}$ steel may yield and go into plastic stage and consequently deform dramatically while the $400 \mathrm{MPa}$ steel is remaining in the elastic phase. Since increasing the wall length leads to an increase in the stress and strain level in the walls, the longer the walls, the higher the stress level and the further the crack width difference will be among walls reinforced with different steel grades.

For $300 \mathrm{MPa}$ steel, having the elastic modulus of $200000 \mathrm{MPa}$, the yield strain will be 0.0015 . Using Frosch equation and considering the clear cover of $50 \mathrm{~mm}$ and bar spacing of $200 \mathrm{~mm}$, the crack width at which the $300 \mathrm{MPa}$ steel yields would be $0.168 \mathrm{~mm}$ as opposed to $0.224 \mathrm{~mm}$ for $400 \mathrm{MPa}$ steel. Therefore, $300 \mathrm{MPa}$ steel yields as soon as their crack width reaches $0.168 \mathrm{~mm}$ while $400 \mathrm{MPa}$ rebars are in elastic stage up to the point that the width of crack exceeds $0.224 \mathrm{~mm}$. Figure 6-6 also shows that when the crack width exceeds $0.168 \mathrm{~mm}$, the $300 \mathrm{MPa}$ steel shows wider cracks and this difference becomes more significant as the length of the walls increase.

Figure C-13 (Appendix C) shows the influence of steel strength for different reinforcement ratios on crack width of $4 \mathrm{~m}$ tall walls. It can be seen that by increasing the steel percentage the difference between the crack widths of walls reinforced with different steel grades decreases. In fact for $0.6 \%$ and $0.7 \%$ reinforcement ratios, there is no difference in the crack width results between grade 300 and 400 steel as they do not reach the yield stress. It can be concluded that the steel grade is only 
of substantial influence for lower reinforcement ratios $(0.3 \%, 0.4 \%$ and $0.5 \%)$ especially in walls longer than $12 \mathrm{~m}$ in length.

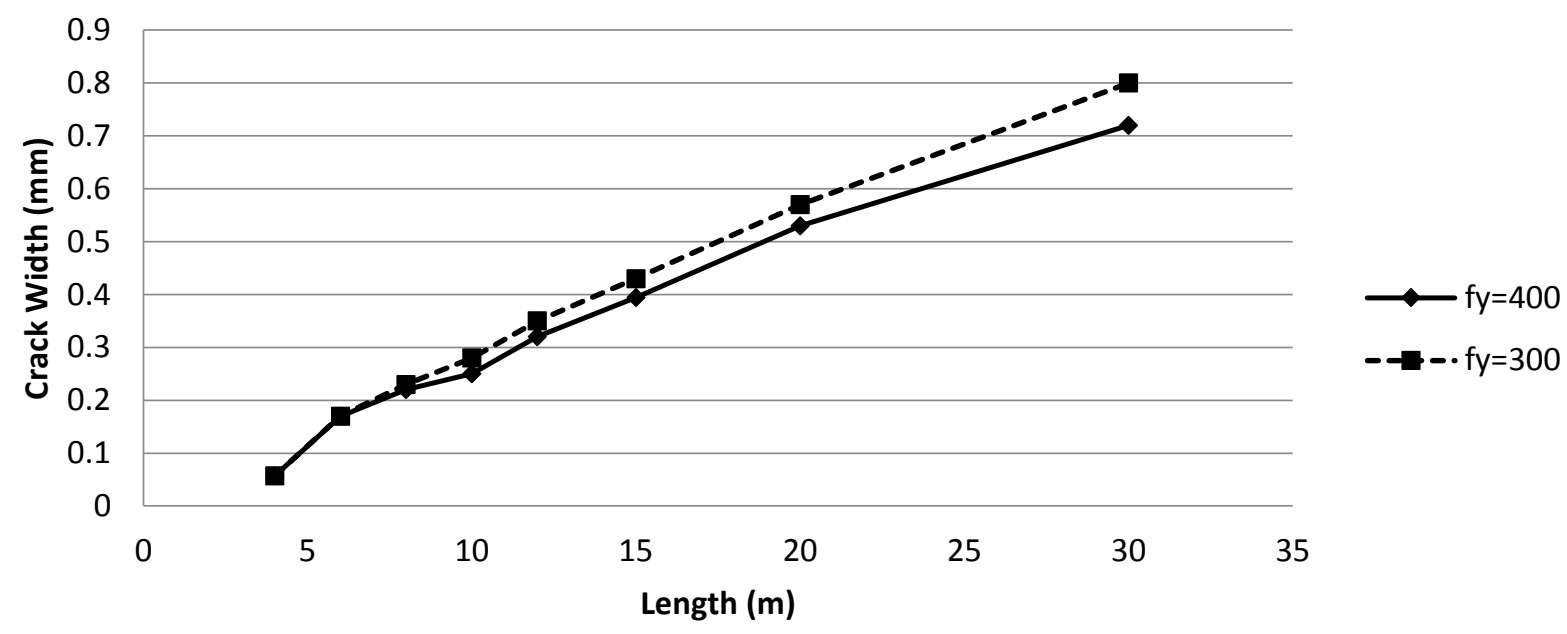

(a) $\rho=0.3 \%$

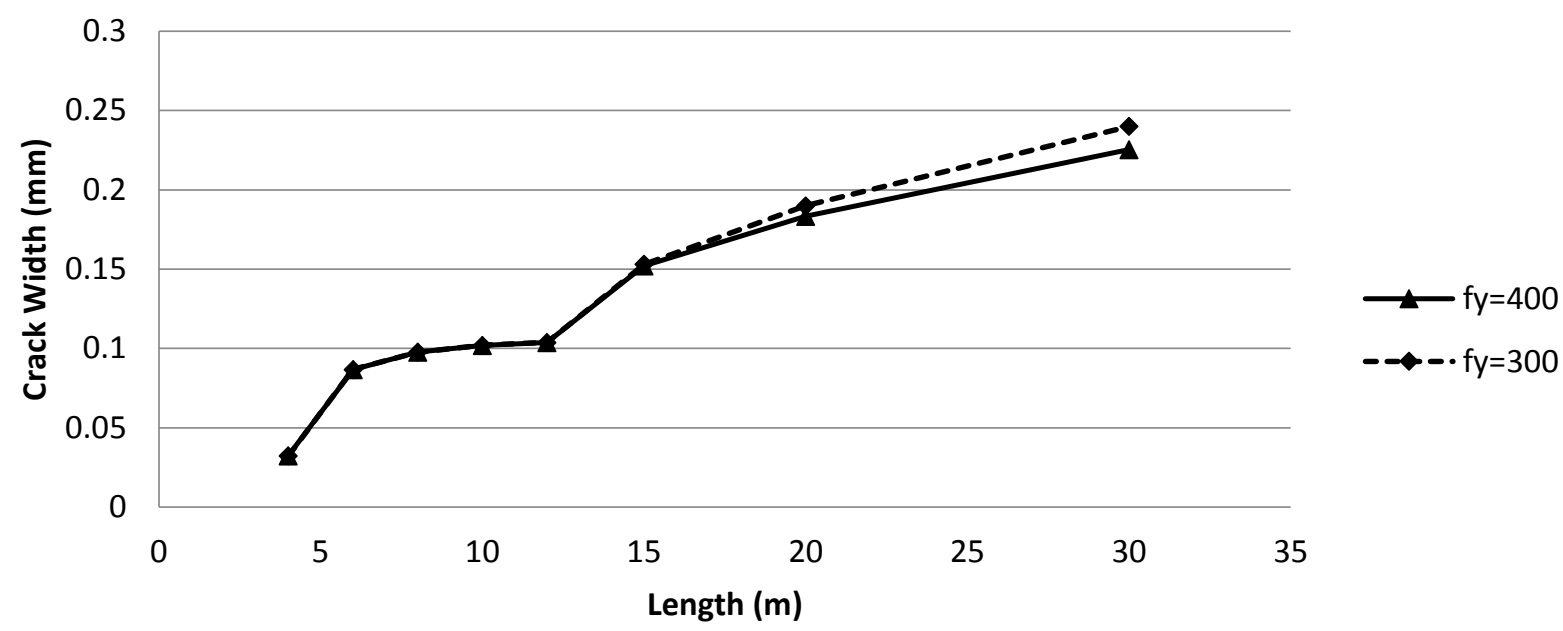

(b) $\rho=0.3 \%$

Figure 6-6 Effect of steel yield strength on the crack width

\subsection{Crack width variation along the wall length}

\subsubsection{Effect of wall length and height}

The variation of crack width along the wall height is presented in Figure 6-7 and Figure C-14 (see Appendix C). The reinforcement ratio is $0.3 \%$ and the climate condition is assumed to be cold and humid. Each figure contains 8 graphs and each graph shows the crack width variation over the 
height of the wall. It is noticeable that by increasing the length of the walls the crack extends further towards the top of the wall. In figure 6-7 as an example, for $4 \mathrm{~m}$ long wall, the maximum width of crack is about $0.05 \mathrm{~mm}$ which happens at about $10 \%$ of the wall height $(0.4 \mathrm{~m}$ from the bottom in this case). The crack itself start from about $0.2 \mathrm{~m}$ from the bottom and ends at $0.6 \mathrm{~m}$. Considering the $4 \times 30 \mathrm{~m}$ wall in the same figure, the crack seems to widen from the bottom to reach its maximum width at the top of the wall to a value of $0.72 \mathrm{~mm}$. It can be concluded that the longer the wall, the higher the cracks extend into the wall. In addition, the height at which the crack reaches its maximum width moves further towards the top of the wall by increasing the wall length. It is worth mentioning that comparing the results of these graphs for different heights (Figure 6-7 and Figure C-14 in Appendix C), the maximum crack width is highest in $4 \mathrm{~m}$ wall and lowest in 8 $\mathrm{m}$ wall considering the same length. It suggests that the height at which the crack reaches its maximum width mainly depends on the $\mathrm{L} / \mathrm{H}$ ratio rather than the length of the wall.

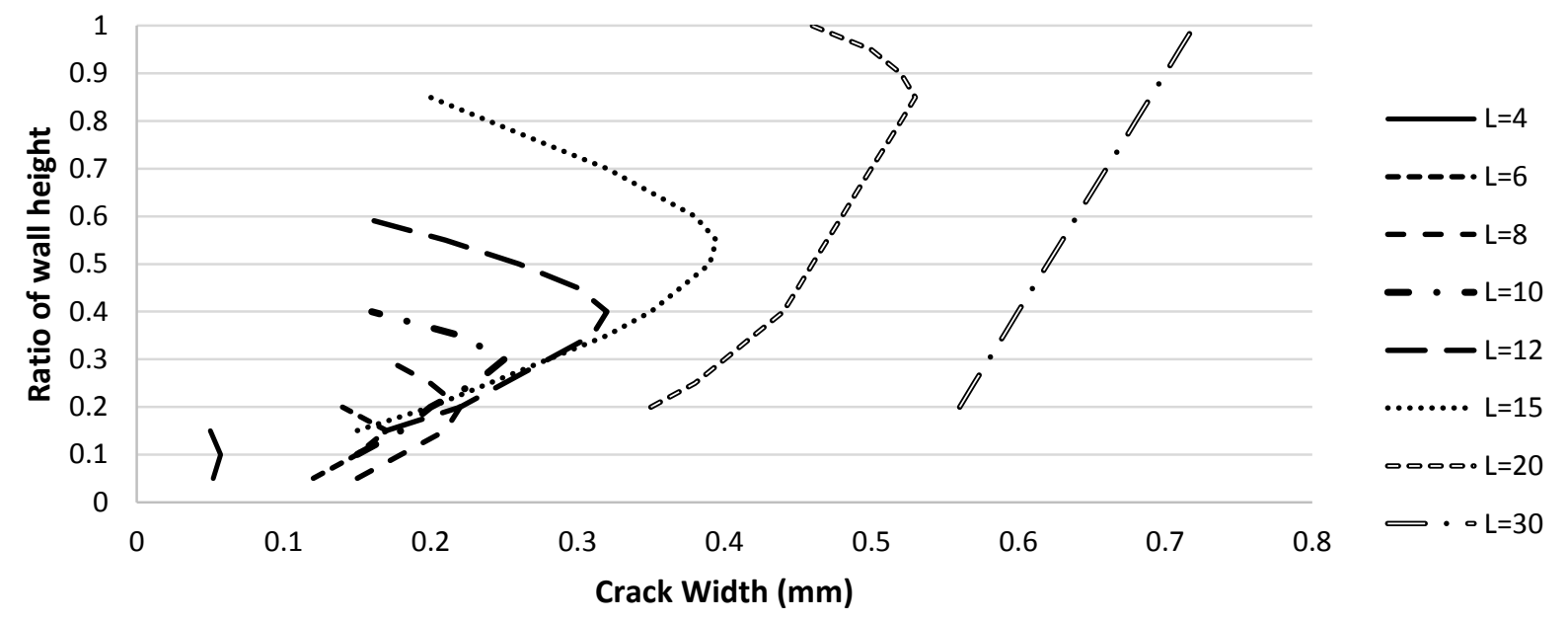

Figure 6-7 Effect of wall length on the crack width along the wall height

The influence of wall height and $\mathrm{L} / \mathrm{H}$ ratio on the crack width over the wall length is presented in Figure 6-8 and Figure C-15 (see Appendix C). Each of these figures contains the crack width of walls with an $\mathrm{L} / \mathrm{H}$ value and 3 different heights while the reinforcement ratio is kept constant 
$(0.3 \%)$. It can be seen that the height does not have a significant effect on the extent of the cracks when the $\mathrm{L} / \mathrm{H}$ ratio is kept constant. However, comparing these figures shows that by increasing the $\mathrm{L} / \mathrm{H}$ ratio the location of maximum crack width and also the extension of the crack into the wall move further towards the top of the wall. The maximum crack width moves up from about $10 \%$ of the height when $\mathrm{L} / \mathrm{H}=1$ to about $85 \%$ of it for $\mathrm{L} / \mathrm{H}=5$. Therefore, it can be concluded that the extension of the cracks into the wall and the location of the maximum crack width mainly depends on the $\mathrm{L} / \mathrm{H}$ ratio.

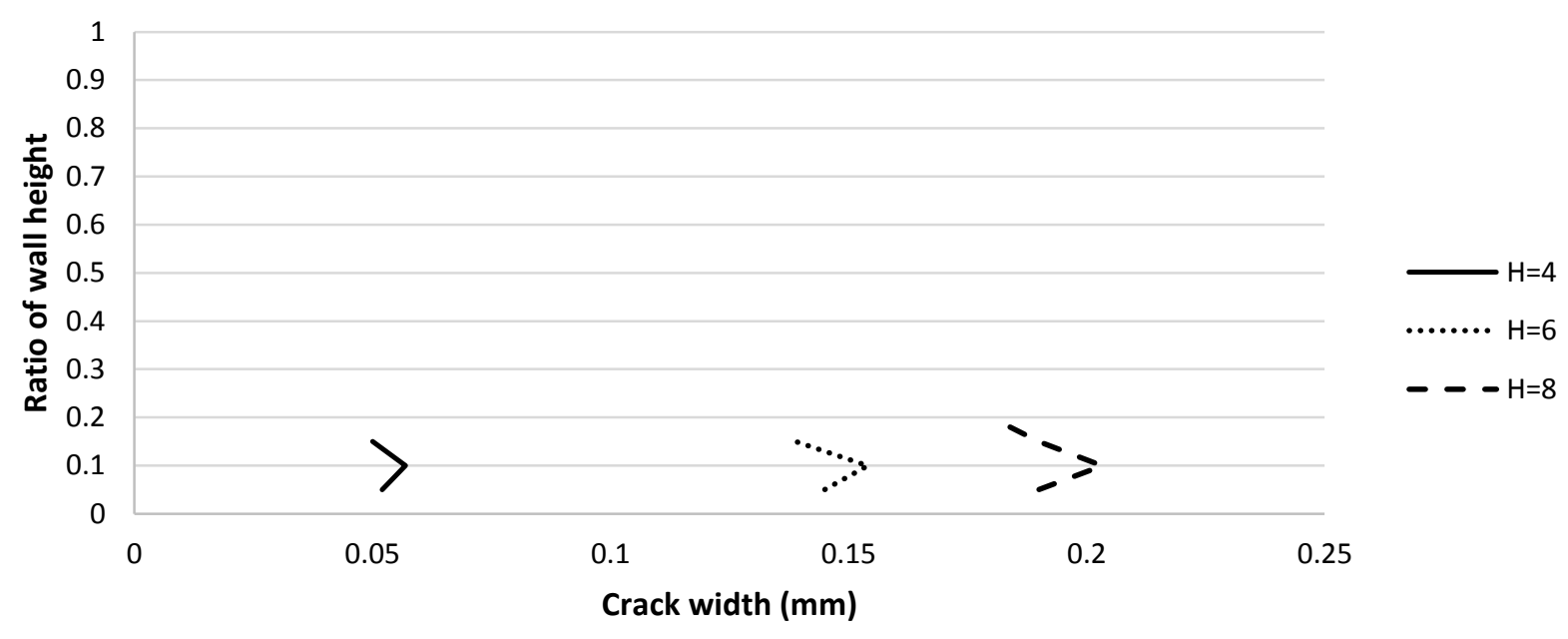

(a) $\mathrm{L} / \mathrm{H}=1$

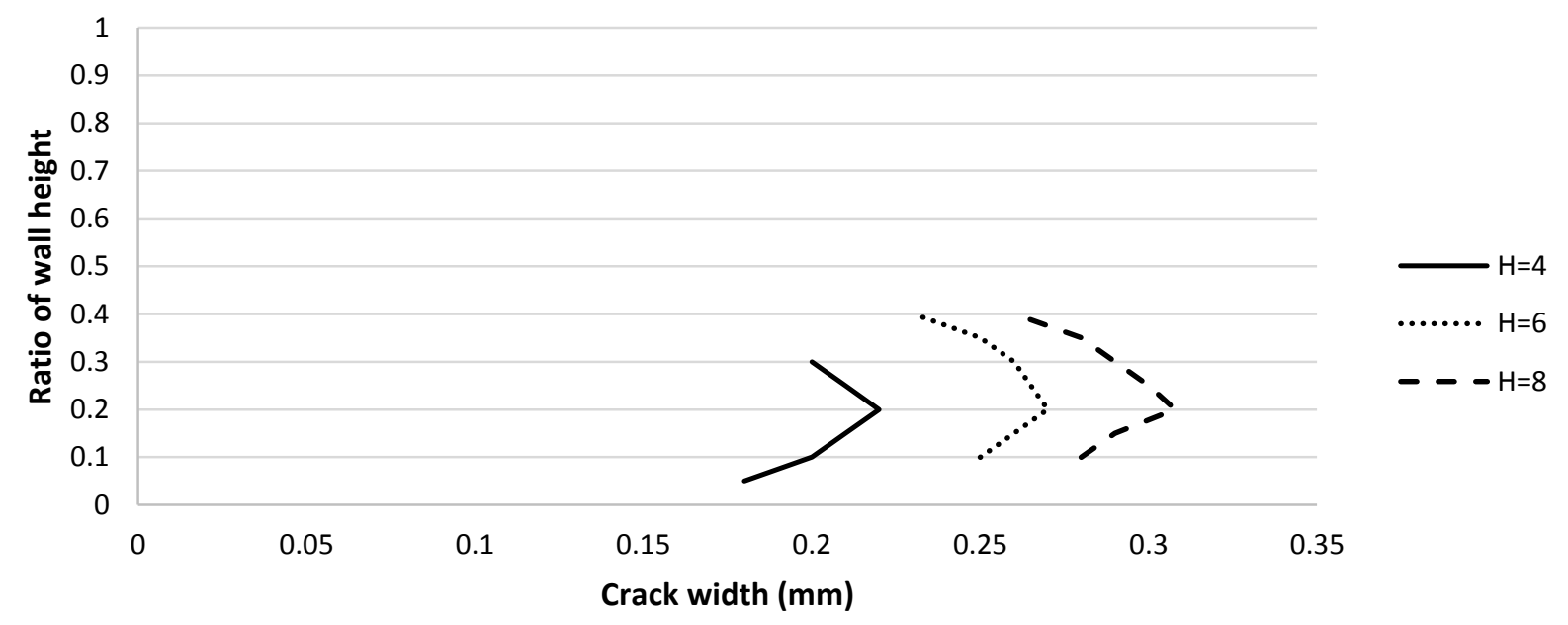

(b) $\mathrm{L} / \mathrm{H}=2$ 


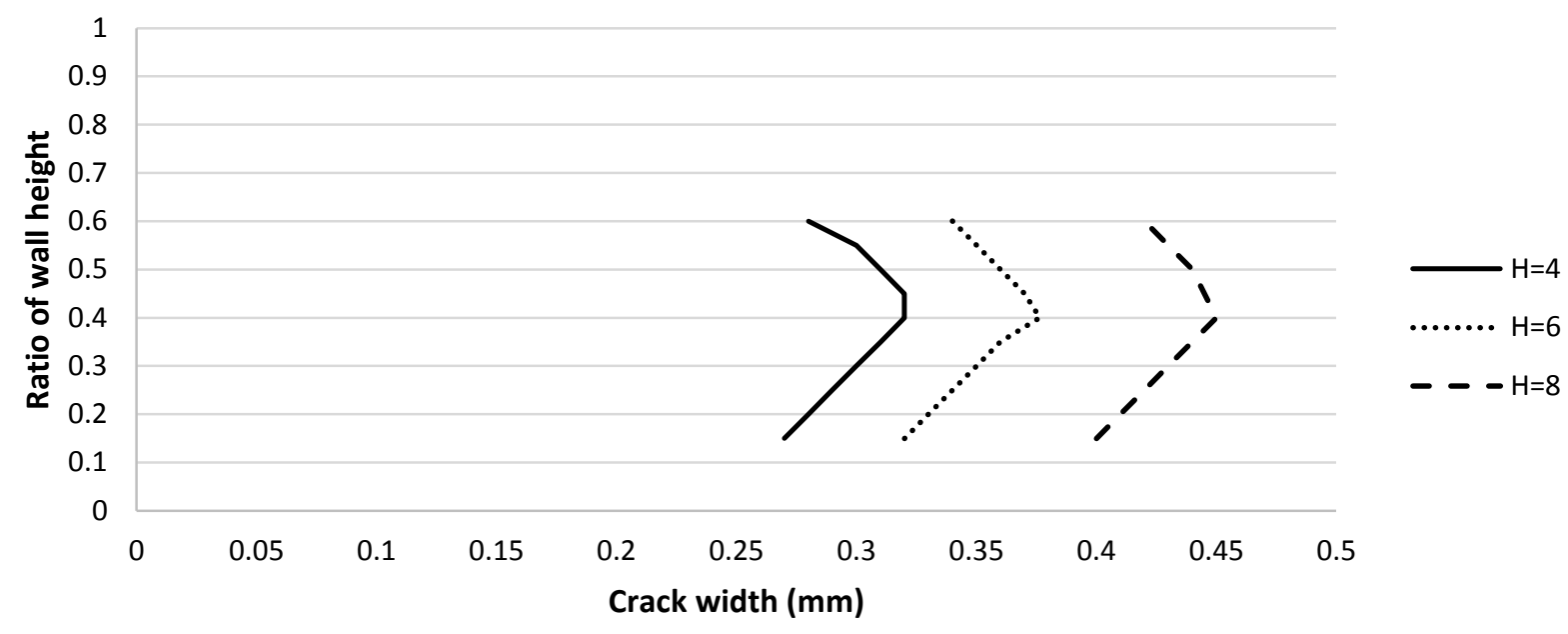

(c) $\mathrm{L} / \mathrm{H}=3$

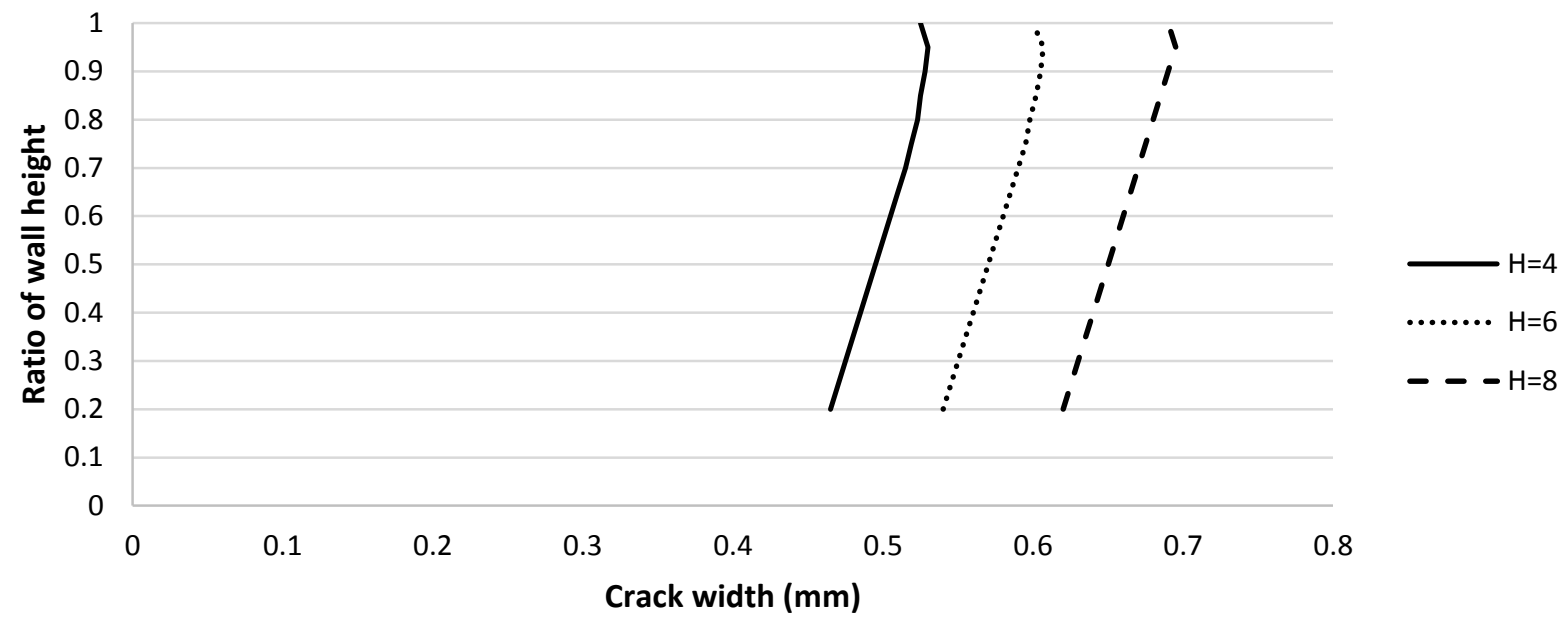

Figure 6-8 Effect of wall height on the crack width over the wall height

\subsubsection{Effect of reinforcement ratio}

Figures 6-9 and Figure C-16 (see Appendix C) illustrate the effect of reinforcement ratio on the crack width along the wall height. Each figure contains 5 graphs for reinforcement ratios from $0.3 \%$ to $0.7 \%$ while the height of the wall is kept constant $(\mathrm{H}=4 \mathrm{~m})$. The location of maximum crack width and the crack extent do not seem to be influenced by the steel percentage. It can be seen that for larger $\mathrm{L} / \mathrm{H}$ ratios the cracks extend higher in the walls. Figure 6-9 shows that the crack width increases from the bottom to the top for all reinforcement ratios. It is in agreement with the 
experimental study performed by Kheder (1997) that for L/H ratios larger than 5, the crack widens along the height and reach its maximum width at the top of the wall.

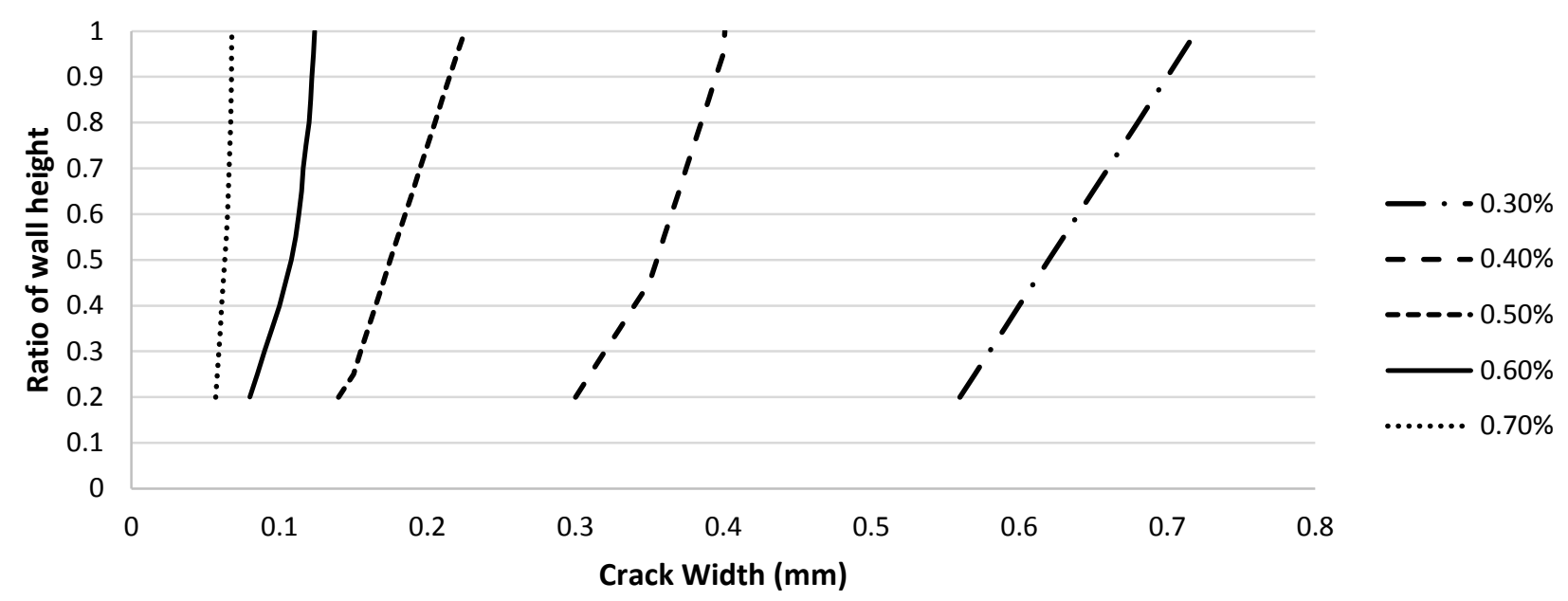

Figure 6-9 Effect of reinforcement ratio on the crack width along the wall height

\subsection{Summary}

In this chapter, the results of the parametric study on base restrained RC walls considering the effect of creep were presented. The walls were only restrained at the base with no side restraint. The shrinkage and creep was considered for a period of six months. The crack widths were in the range of $0.1 \mathrm{~mm}$ to about $0.7 \mathrm{~mm}$ which is smaller than those reported in the previous chapter. This could be rationalized by considering the fact that tensile stresses caused by shrinkage strain were relaxed because of creep. Similar to Chapters 4 and 5, it was shown that by increasing the wall length, $\mathrm{L} / \mathrm{H}$ ratio, height, and concrete tensile strength the maximum crack width increases. The reinforcement ratio had the same significance on the response as in the previous chapters. The crack width was reduced from about $0.7 \mathrm{~mm}$ to below $0.1 \mathrm{~mm}$ by increasing the steel ratio from $0.3 \%$ to $0.7 \%$ in $4 \times 30 \mathrm{~m}$ wall. It was also shown that the dry climate with high seasonal temperature variations and low humidity is the most critical case among all showing the largest crack widths. 


\section{COMPARISON OF CRACK WIDTH IN DIFFERENT FE MODELS AND DESIGN RECOMMENDATION}

\subsection{General}

This chapter begins by comparing the results collected from Chapters 4, 5, and 6. The effect of each parameter is discussed separately and compared in each model. The recommended minimum reinforcement ratios from different codes are reviewed and discussed. Walls which are modelled with such recommended steel ratios are evaluated and the results are compared with the crack width limitations. Finally, a new procedure is proposed to determine the minimum reinforcement ratio in $\mathrm{RC}$ walls. This new formulation considers the major parameters that affect the crack width in base restrained $\mathrm{RC}$ walls.

\subsection{Comparison of crack width in different models}

Table 7-1 contains the models and their descriptions as presented in Chapters 4,5 , and 6. The difference between these models is the presence of partial side restraint and the creep effect. In this section, the crack width of these three models are compared with respect to each parameter.

Table 7-1 Simulated FE models and their descriptions

\begin{tabular}{|c|c|}
\hline Model & Description \\
\hline A & Base restrained wall with no side restraint ignoring the effect of creep (Chapter 4) \\
\hline B & Base restrained wall with no side restraint considering the effect of creep (Chapter 6) \\
\hline C & $\begin{array}{c}\text { Base restrained wall with partial side restraint (perpendicular to the wall surface at } \\
\text { the sides) ignoring the effect of creep (Chapter 5) }\end{array}$ \\
\hline
\end{tabular}

\subsubsection{Effect of wall dimensions}

Figures 7-1 (a), (b) and (c) compares the crack width of the three different models considering wall heights of $4 \mathrm{~m}, 6 \mathrm{~m}$, and $8 \mathrm{~m}$ respectively. It is assumed in all cases that the wall thickness is 500 
$\mathrm{mm}$, reinforcement ratio is $0.3 \%$, concrete tensile strength is $3 \mathrm{MPa}$ and the walls are exposed to the cold and humid climate. In general, the trend is similar for all models in the sense that crack width increases by increasing the wall length. It can also be seen that the crack width in Model B is between 20 to 40 percent less compared to Model A. This difference is due to the effect of creep that is considered in Model B which reduces the stress level and causes narrower cracks to occur. Comparison of Models A and C shows that the crack width is between 5\% and 15\% less in Model A. The only difference between these two models is that Model C is partially restrained at the sides and that is causing a slight increase in the width of cracks compared to Model A.

Figure 7-2 shows the crack width versus $\mathrm{L} / \mathrm{H}$ ratio of the three models considering different wall heights. It demonstrates that Model B experiences the narrowest cracks due to the creep effect while the widest cracks occur in Model C with the partial side restraint.

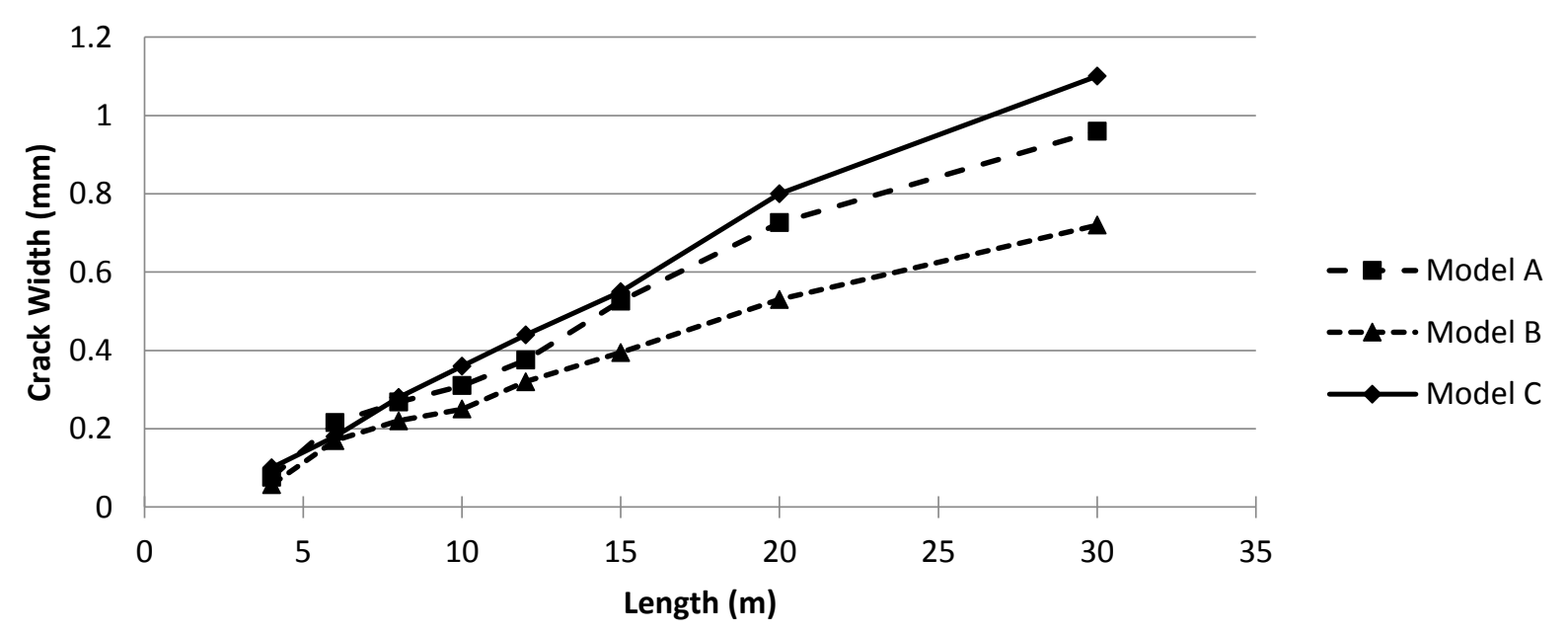

(a) $\mathrm{H}=4 \mathrm{~m}$ 


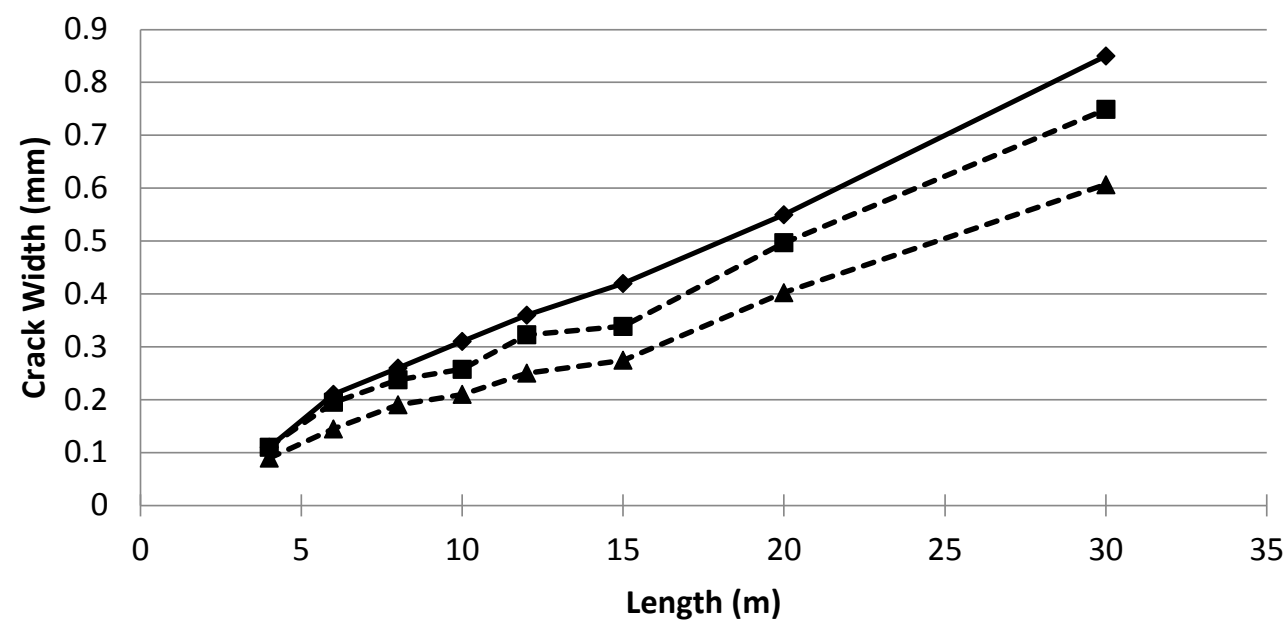

$-\rightarrow-. M$ Model A

$--1-\cdot$ Model B

$\longrightarrow$ Model C

(b) $\mathrm{H}=6 \mathrm{~m}$

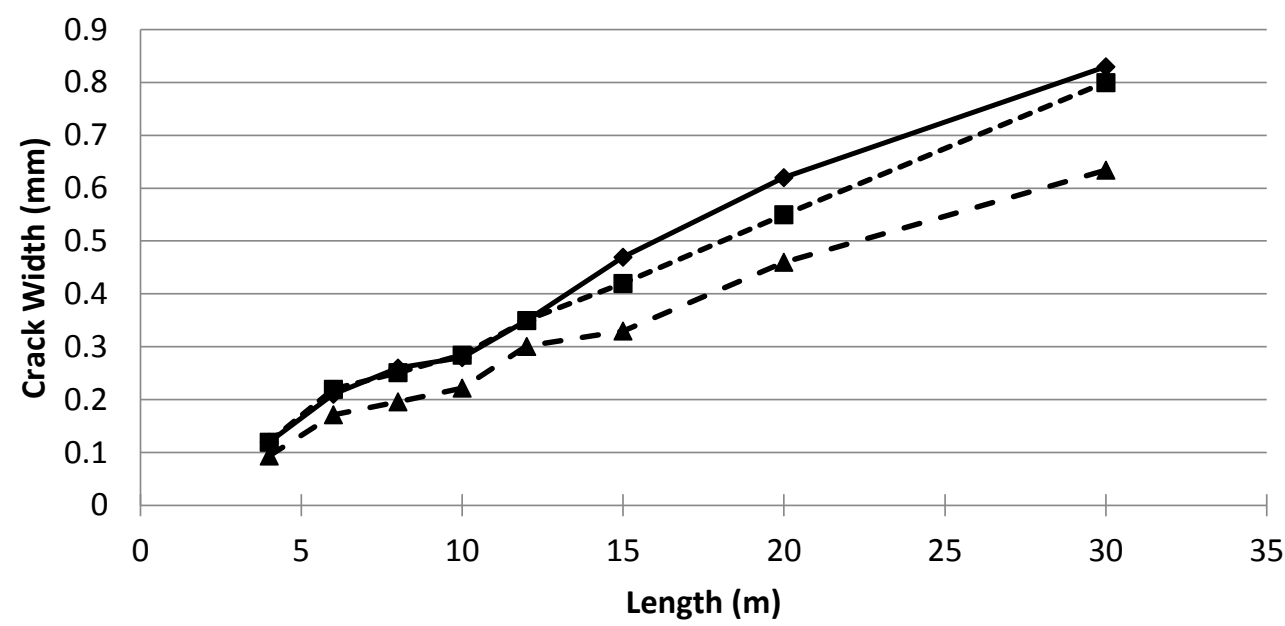

$-\rightarrow-\cdot$ Model A

$-\leftarrow-$ Model B

$\longrightarrow$ Model C

(c) $\mathrm{H}=8 \mathrm{~m}$

Figure 7-1 Comparing the effect of wall length on the crack width

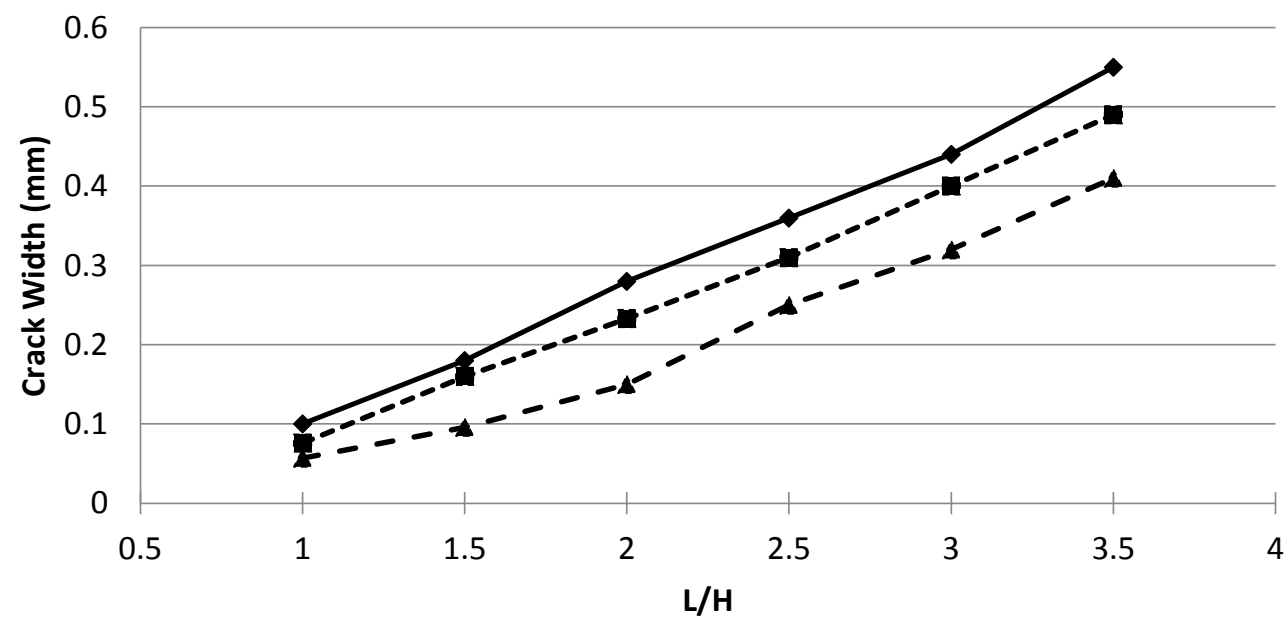

$-\rightarrow-\cdot$ Model A

$-\star-$ Model B

$\longrightarrow$ Model C

(a) $\mathrm{H}=4 \mathrm{~m}$ 


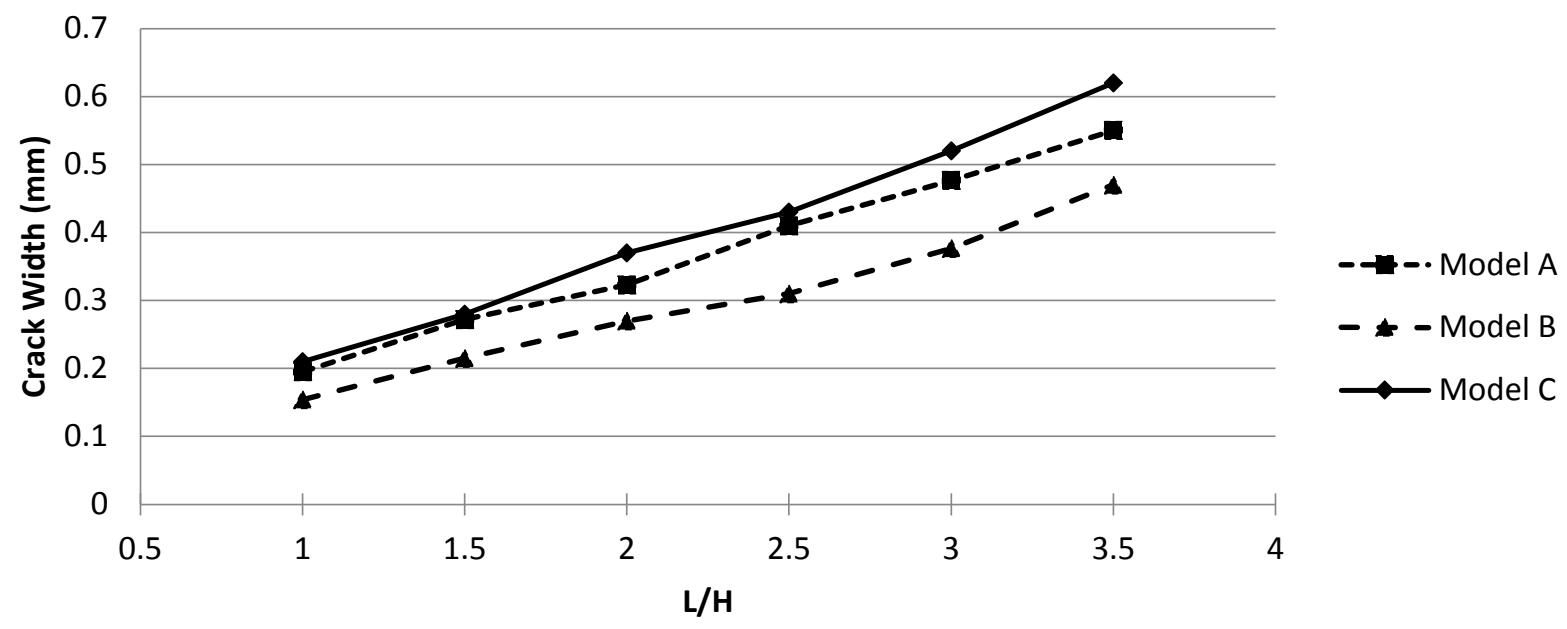

(b) $\mathrm{H}=6 \mathrm{~m}$

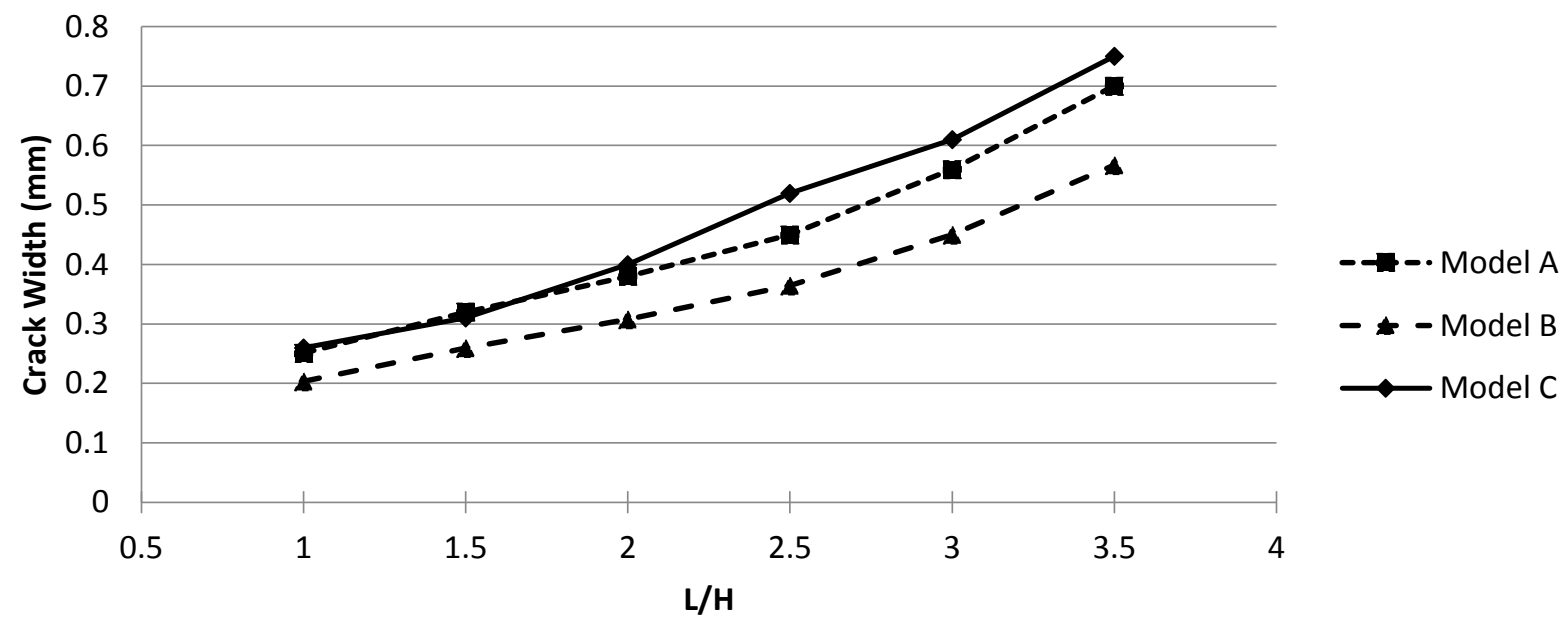

(c) $\mathrm{H}=8 \mathrm{~m}$

Figure 7-2 Comparing the effect of $\mathrm{L} / \mathrm{H}$ on the crack width

\subsubsection{Effect of climate conditions}

Figures 7-3 (a), (b) and (c) demonstrate the crack width of the three modeled walls in tropical, cold and humid, and hot and dry climates respectively. The modelled walls are $4 \mathrm{~m}$ tall with $0.3 \%$ steel ratio and $3 \mathrm{MPa}$ concrete tensile strength. The trend is similar in all climates and it could be seen that the crack width is highest in hot and dry climate and lowest in tropical climate when comparing three graphs. It is also shown that Model C experiences the largest crack widths due to the partial restraint (about 10\% more than Model A and 40\% more than Model B) and the creep effect reduces the crack width in Model B between $20 \%$ to $40 \%$ compared to Model A. 


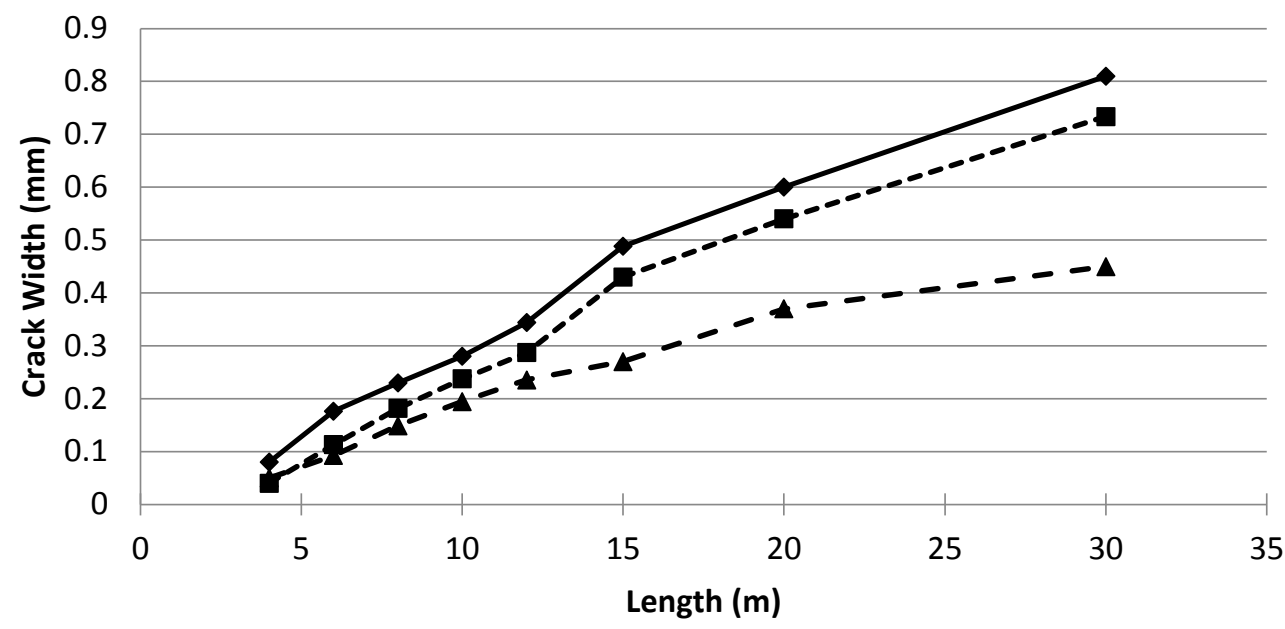

$-\rightarrow-\cdot$ Model A

- \pm- Model B

$\longrightarrow$ Model C

(a) Tropical climate

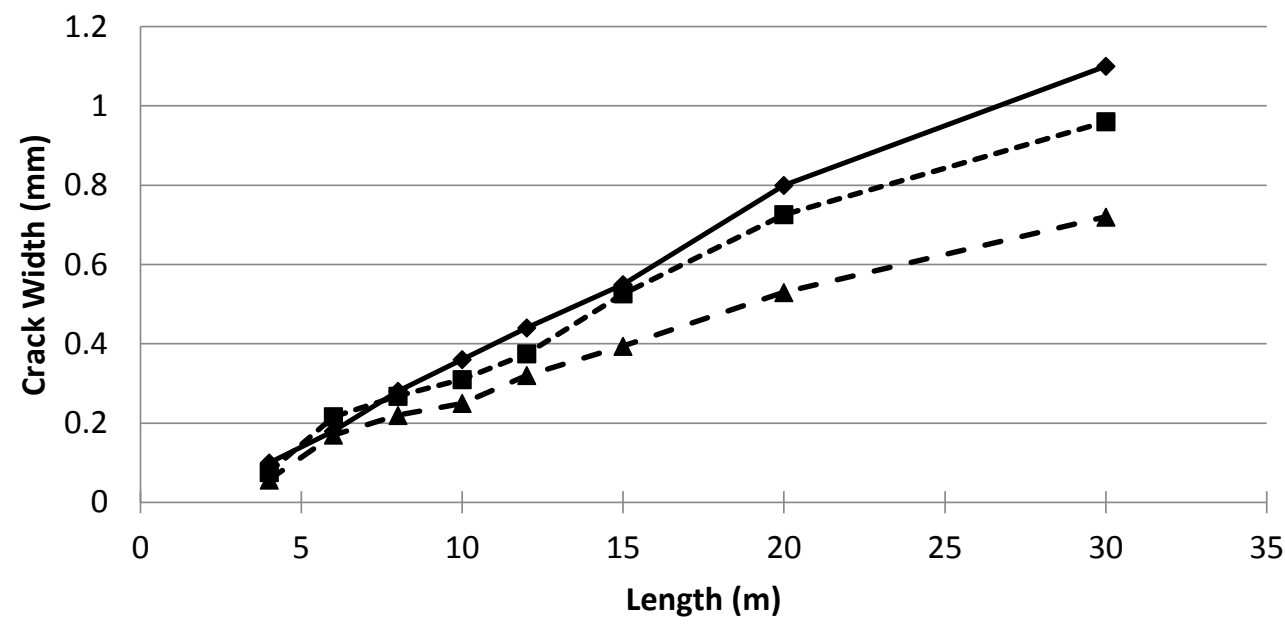

$-\rightarrow-\cdot$ Model A

$-\star-$ Model B

$\longrightarrow$ Model C

(b) Cold and humid climate

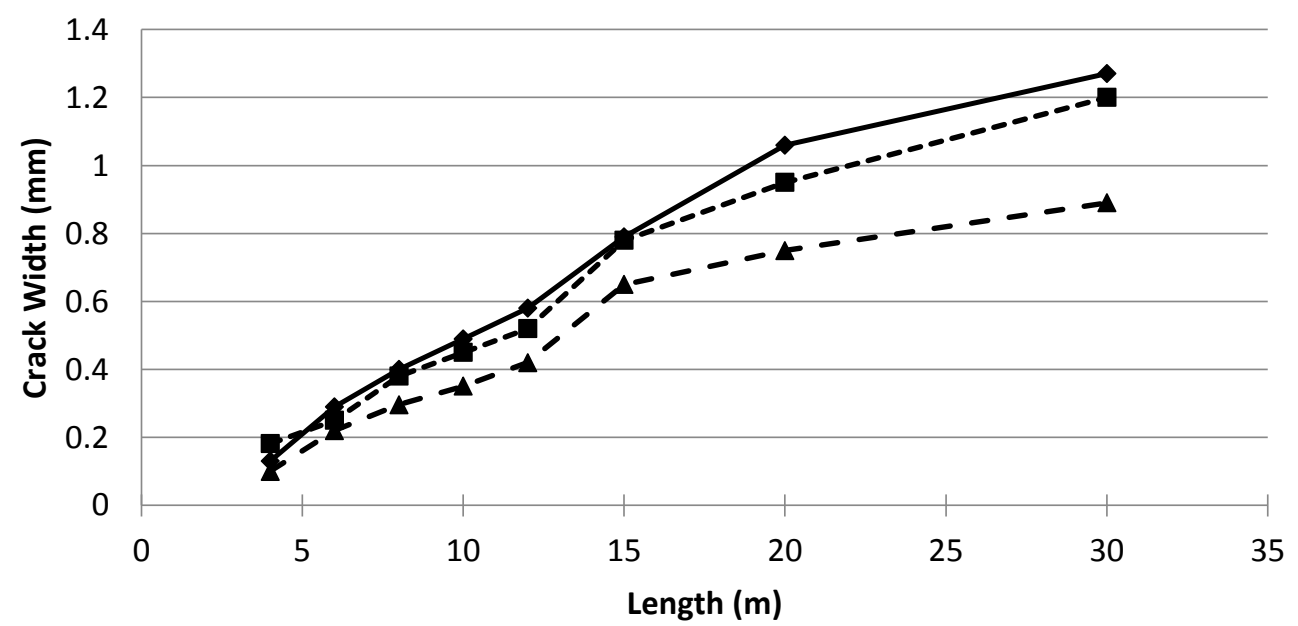

$-\rightarrow-\cdot$ Model A

$-\star-$ Model B

$\longrightarrow$ Model C

(c) Hot and dry climate

Figure 7-3 Comparing the effect of climate condition 


\subsubsection{Effect of reinforcement ratio}

Figure 7-4 presents the crack width versus wall length for reinforcement ratios varying from $0.4 \%$ to $0.7 \%$ while comparing the results of each model. The walls are $4 \mathrm{~m}$ high with varying lengths from $4 \mathrm{~m}$ to $30 \mathrm{~m}$ and concrete tensile strength of $3 \mathrm{Mpa}$, exposed to the cold and humid climate. In general, the trend seems to be the same for all reinforcement ratios and the difference between the crack widths in the models does not seem to be influenced by the steel percentage. Therefore, the widest and narrowest cracks occur in Model C and Model A respectively.

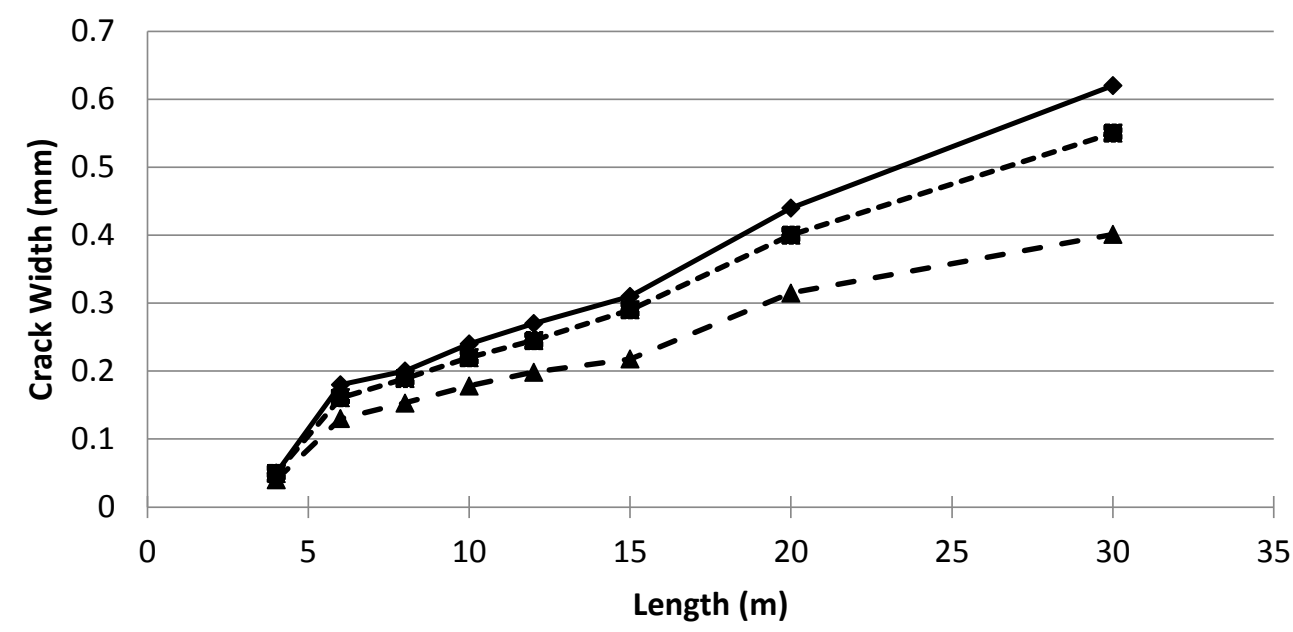

$-\rightarrow-\cdot$ Model A

- \pm- Model B

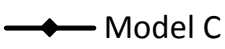

(a) $\rho=0.4 \%$
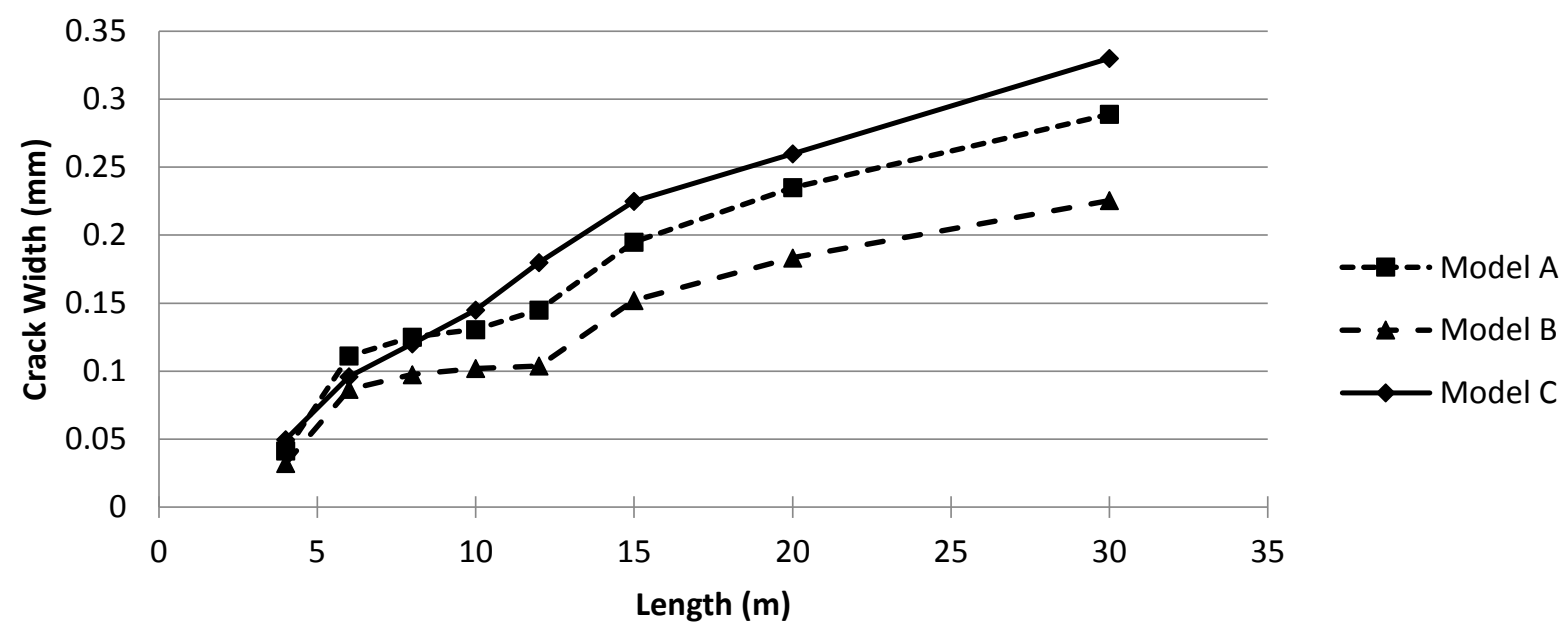

(b) $\rho=0.5 \%$ 


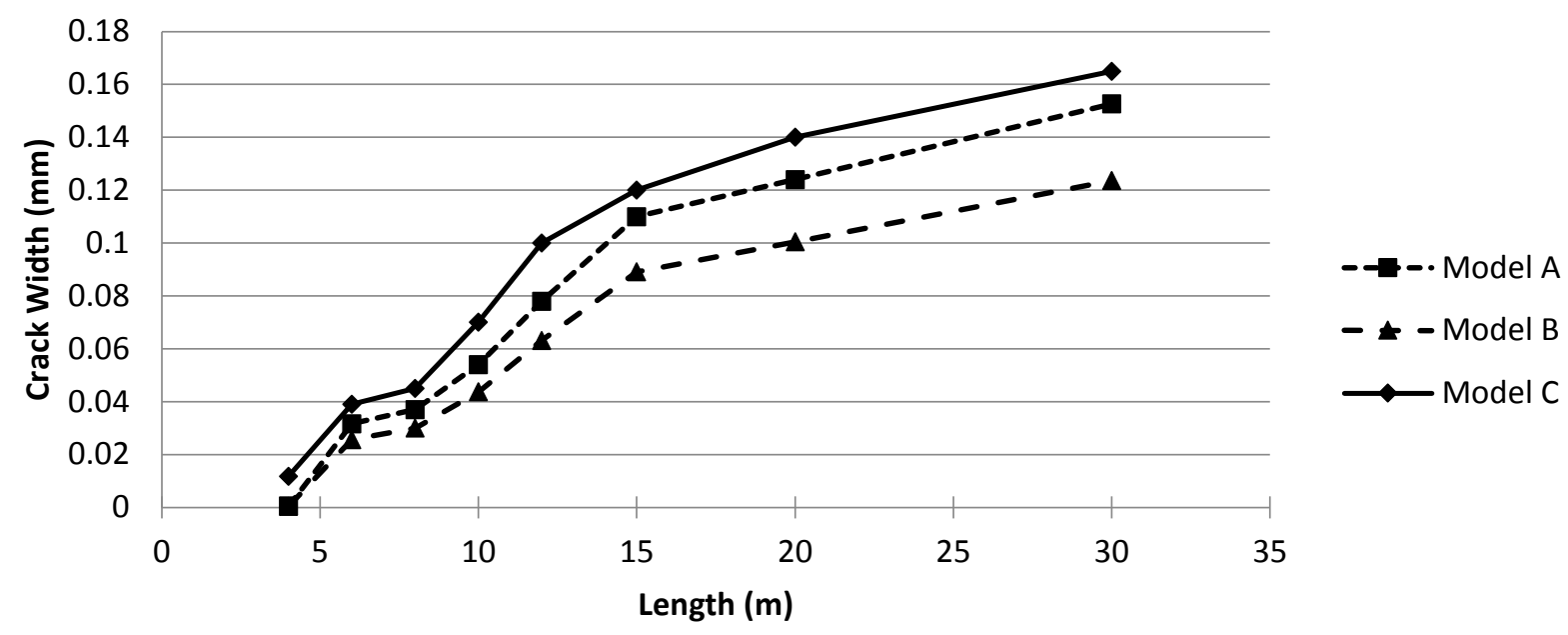

(c) $\rho=0.6 \%$

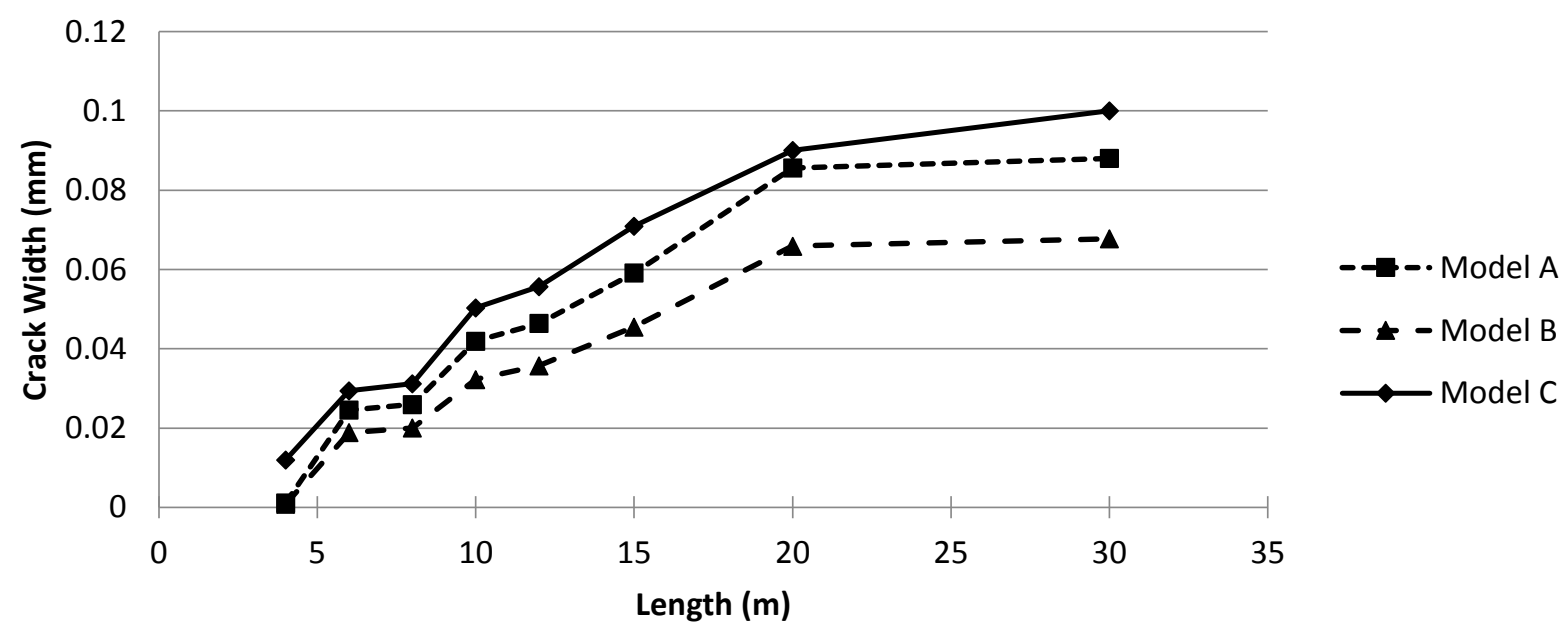

(d) $\rho=0.7 \%$

Figure 7-4 Comparing the effect of reinforcement ratio on the crack width

\subsubsection{Effect of concrete tensile strength}

Figure 7-5 illustrates the influence of concrete tensile strength on the crack width comparing three different models. The walls are $4 \mathrm{~m}$ high, reinforced with $0.3 \%$ steel and exposed to the cold and humid climate. The figure shows similar trend for all models irrespective of the concrete tensile strength. It can be seen that the difference between the crack widths in the models are in the same range as in previous sections with Model $\mathrm{C}$ experiencing the widest and Model $\mathrm{B}$ showing the narrowest cracks. 


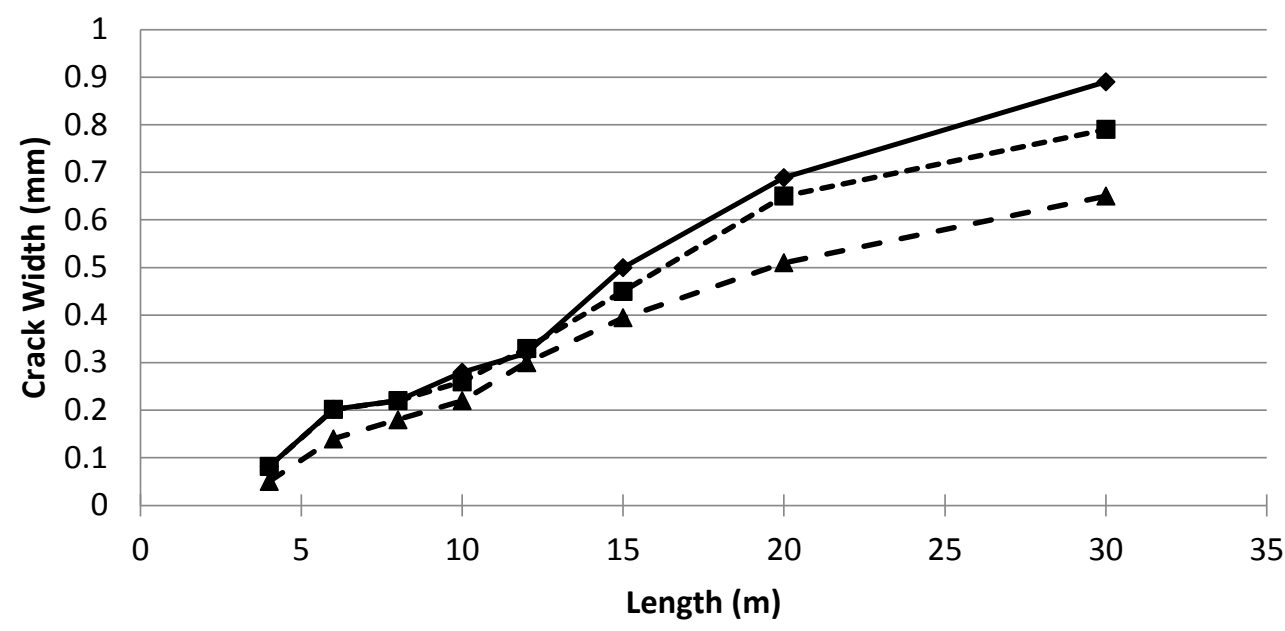

$-\rightarrow-\cdot$ Model A

$-\_-$Model B

$\longrightarrow$ Model C

(a) $\mathrm{f}_{\mathrm{t}}=2.5 \mathrm{Mpa}$

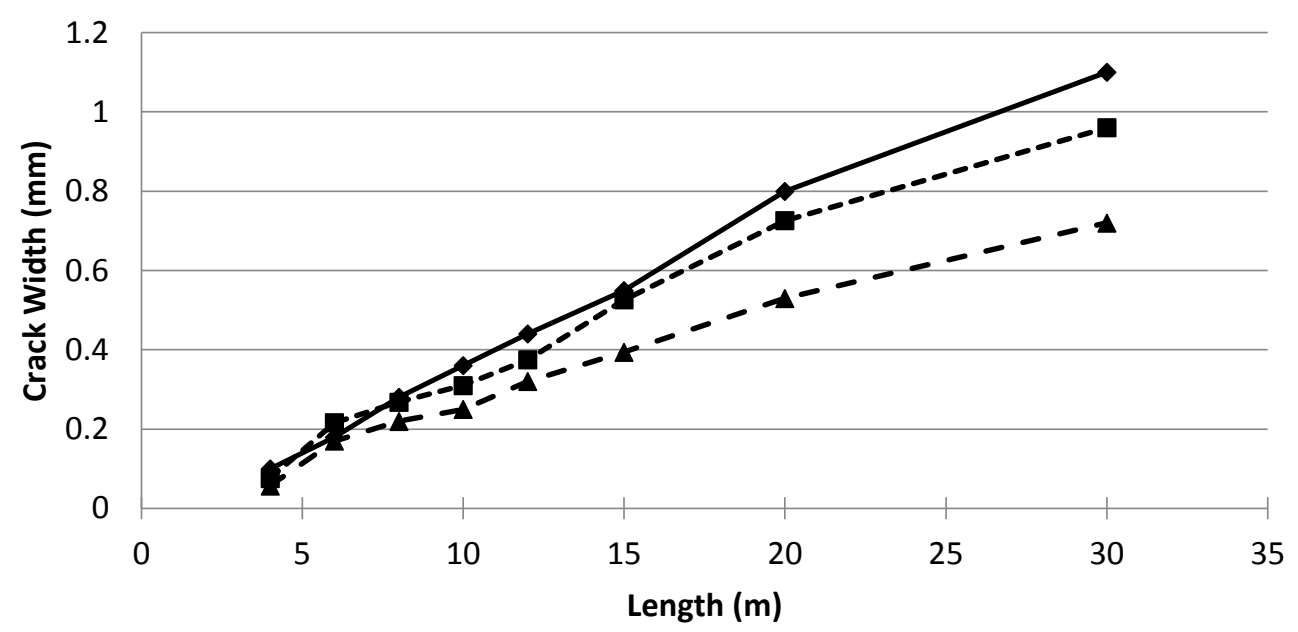

$-\rightarrow-\cdot$ Model A

$-\star-$ Model B

$\longrightarrow$ Model C

(b) $\mathrm{f}_{\mathrm{t}}=3 \mathrm{Mpa}$

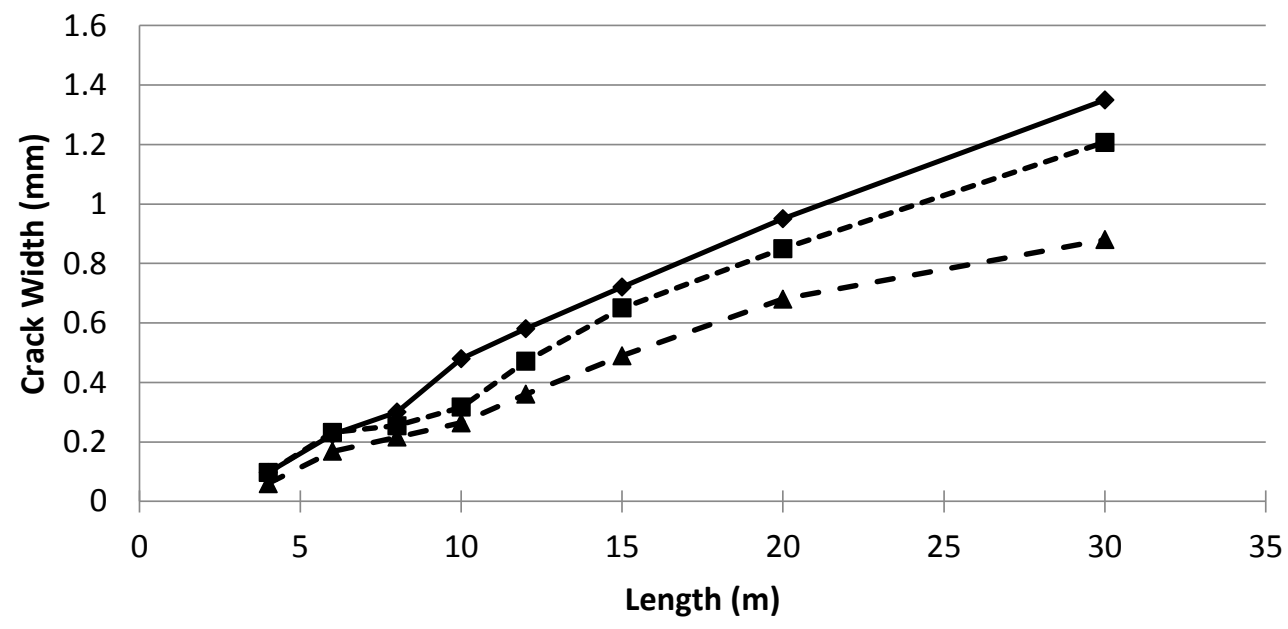

$-\rightarrow-\cdot$ Model A

$-\star-$ Model B

$\longrightarrow$ Model C

(c) $\mathrm{f}_{\mathrm{t}}=3.5 \mathrm{Mpa}$

Figure 7-5 Comparing the effect of reinforcement ratio on the crack width 


\subsection{Minimum reinforcement ratios in different codes}

The minimum reinforcement ratios recommended by different codes are reviewed, evaluated and discussed in this part. Walls are modelled with the proposed steel ratios and the resulting crack widths are compared with the allowable crack width suggested by ACI 224R-01 (2008) as presented in Table 7-2. This table contains the crack width limits based on exposure conditions. The abbreviations for each case is also shown in this table which are used for comparison later in the figures. The modelled walls in this section are assumed to be base restrained only with no side restraints. The effect of creep is considered for all cases.

Table 7-2 ACI 224R allowable crack width based on exposure conditions

\begin{tabular}{|c|c|c|}
\hline Exposure condition & Symbol & Crack width (mm) \\
\hline Dry air or protective membrane & D & 0.41 \\
\hline Humidity, moist air, soil & H & 0.30 \\
\hline De-icing chemical & De-I & 0.18 \\
\hline Seawater and seawater spray, wetting and drying & SW & 0.15 \\
\hline Water-retaining structures & WRS & 0.10 \\
\hline
\end{tabular}

\subsubsection{CSA A23.3 and S474}

Design of concrete structures, CSA A23.3 Code (CSA A23.3-14) suggests using $0.2 \%$ and $0.15 \%$ steel in horizontal and vertical directions respectively. Figure 7-6 shows the crack width of walls reinforced with the proposed CSA minimum steel ratio exposed to different climate conditions. The horizontal lines illustrated in the figures represent the allowable crack widths as presented by Table 7-2. 


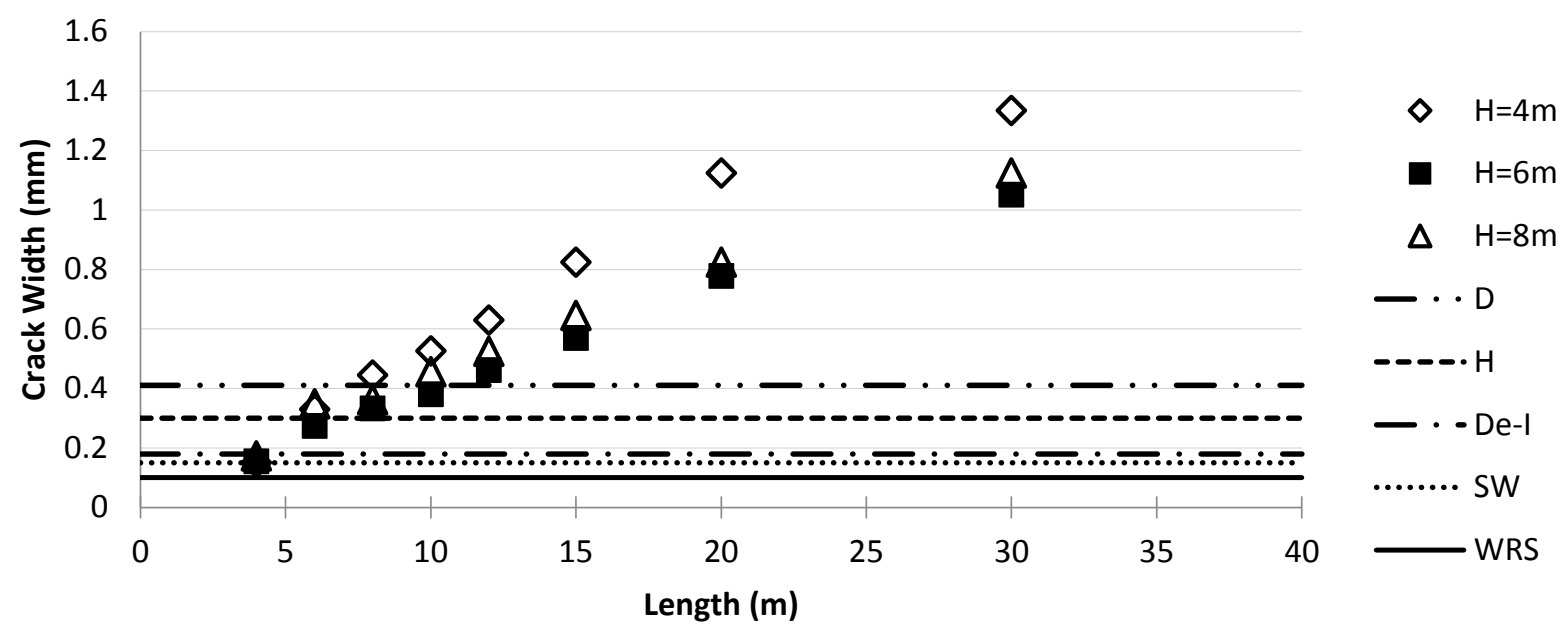

(a) Hot and dry climate
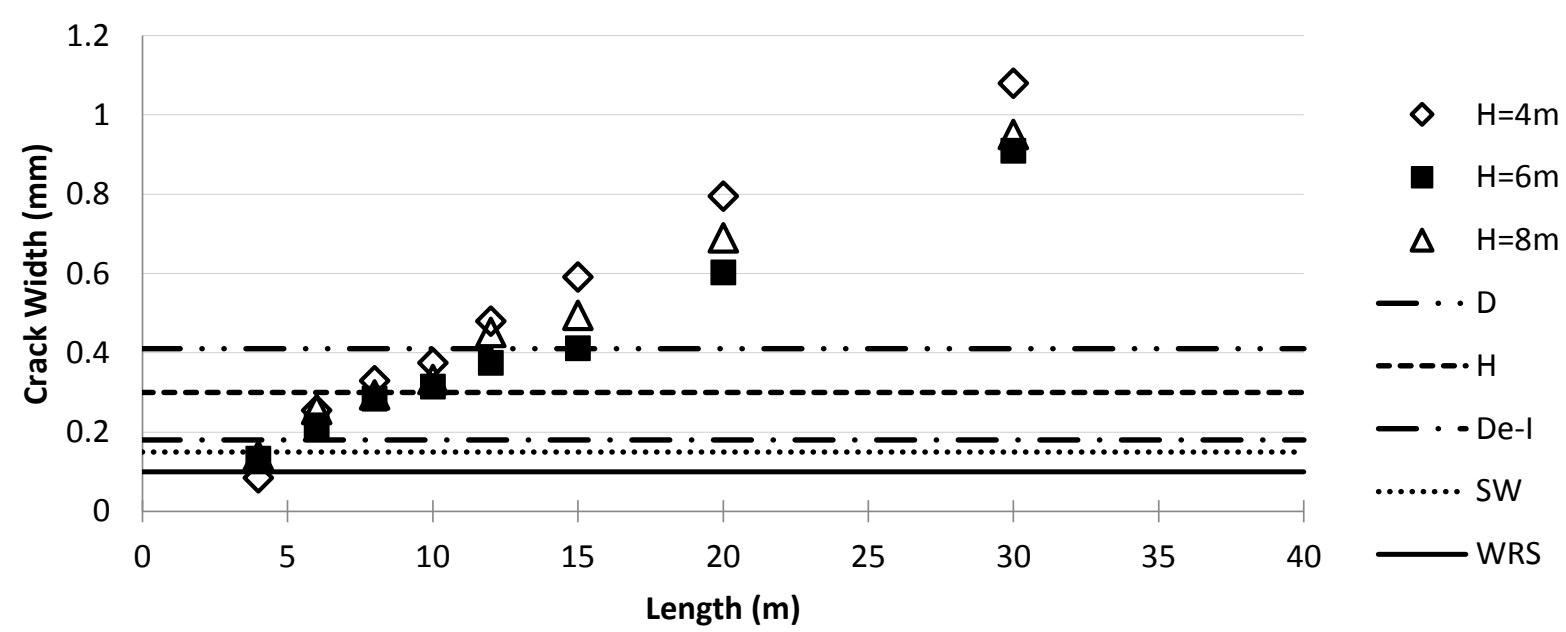

(b) Cold and humid climate

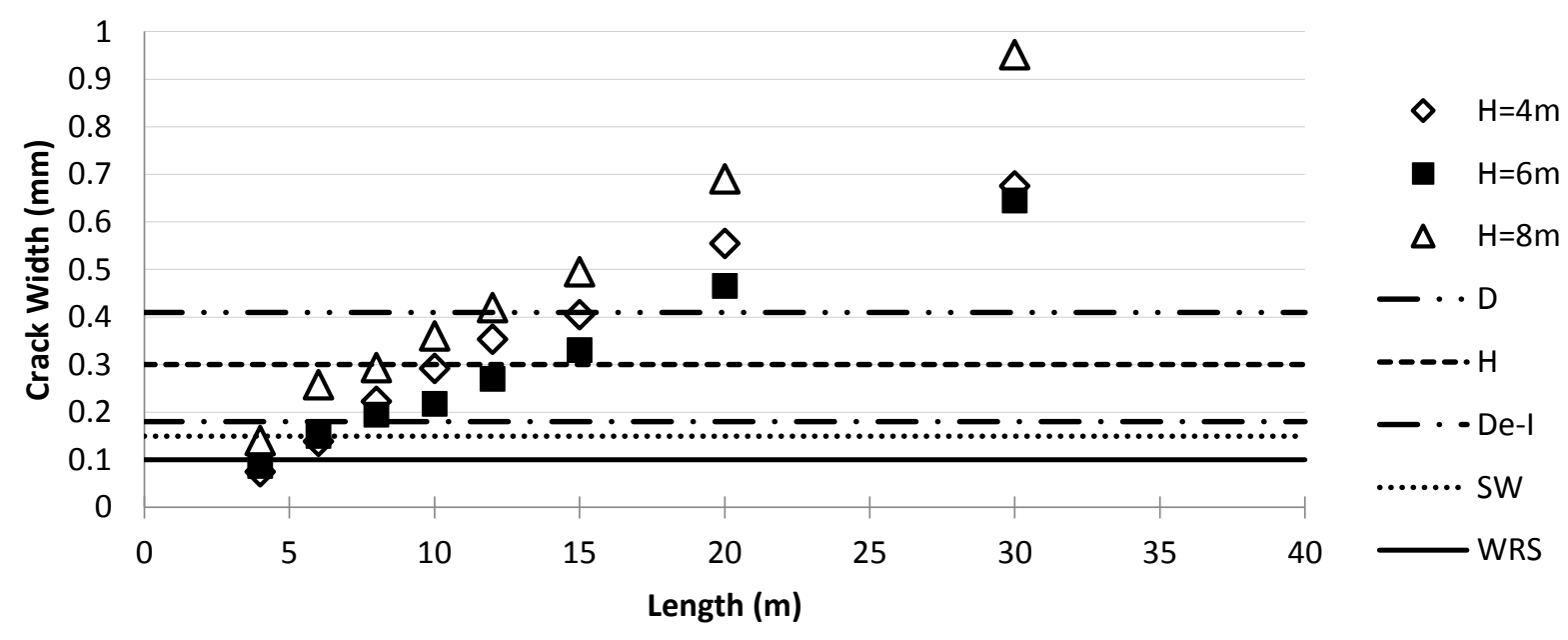

(c) Tropical climate

Figure 7-6 Crack width of walls reinforced based on CSA 23.3 minimum reinforcement ratio 
These figures show that the CSA A23.3 is not able to satisfy the crack width limit for the water retaining structures. However, considering dry or humid exposure condition, the proposed reinforcement ratio can limit the crack width for most walls shorter than $10 \mathrm{~m}$ in length especially in the tropical climate.

In CSA S474-04 (2004) that is issued specifically for design of offshore concrete structures, a minimum reinforcement ratio of $0.3 \%$ is suggested to be used for crack control. Figures 6-1 (from chapter 6) shows the crack widths of walls reinforced with $0.3 \%$ steel suggesting that this amount of reinforcement ratio is not nearly sufficient to limit the crack width to $0.1 \mathrm{~mm}$ (for WRS) or even $0.15 \mathrm{~mm}$ (for SW). However, CSA S474-04 suggests limiting the width of cracks to $0.25 \mathrm{~mm}$ and $0.5 \mathrm{~mm}$ for the splash zone and other zones respectively. Therefore, the proposed $0.3 \%$ steel might be able to satisfy these crack width limits to some extent.

\subsubsection{ACI 318}

ACI 318M-11 (2011) proposes minimum reinforcement ratios for walls in both horizontal and vertical directions. A minimum vertical steel ratio of $0.12 \%$ is recommended for $420 \mathrm{MPa}$ steel bars (smaller than No. 16 or $15.875 \mathrm{~mm}$ nominal diameter) and $0.15 \%$ reinforcement ratio for other rebars. For the horizontal reinforcement, this code suggests using $0.2 \%$ steel if the yield strength is more than $420 \mathrm{MPa}$ or $0.25 \%$ for a lower grade steel. This reinforcement ratio is quite similar to CSA A 23.3 and obviously not sufficient for SW or WRS crack width limitations.

\subsubsection{ACI 350}

The ACI 350-06 Code provides a recommendation for the minimum reinforcement ratio based on the steel grade and distance between the movement joints as presented in Table 7-3. Figure 7-7 (see also appendix D, Figures D-1 and D-2) illustrates the crack width of the simulated walls with different lengths and heights considering different climate conditions and crack width limits. It can 
be seen in the figures that the proposed reinforcement ratio is sufficient to limit the cracks to 0.15 mm (SW exposure) in tropical climate. However, considering cold and humid and hot and dry climate, the steel ratio can only limit the crack width to $0.3 \mathrm{~mm}$ (H exposure) and not for all cases.

Table 7-3 ACI 350-06 proposed minimum reinforcement ratio

\begin{tabular}{|c|c|c|}
\hline \multirow{2}{*}{$\begin{array}{c}\text { Length between joints } \\
(\mathrm{m})\end{array}$} & \multicolumn{2}{|c|}{ Minimum shrinkage and temperature reinforcement ratio } \\
\cline { 2 - 3 } & Grade 300 & Grade 420 \\
\hline Less than 6 & 0.003 & 0.003 \\
\hline 6 to less than 9 & 0.004 & 0.003 \\
\hline 9 to less than 12 & 0.005 & 0.004 \\
\hline 12 and greater & 0.006 & 0.005 \\
\hline
\end{tabular}

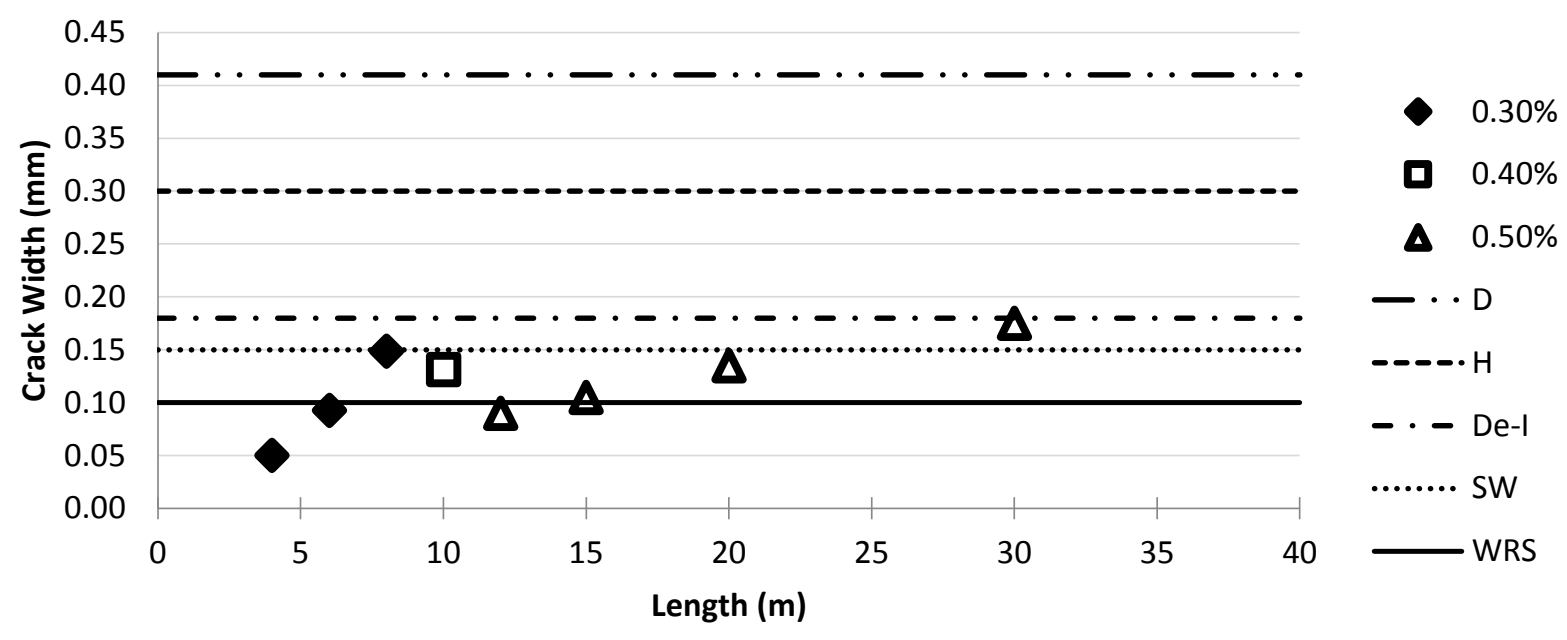

(a) Tropical climate

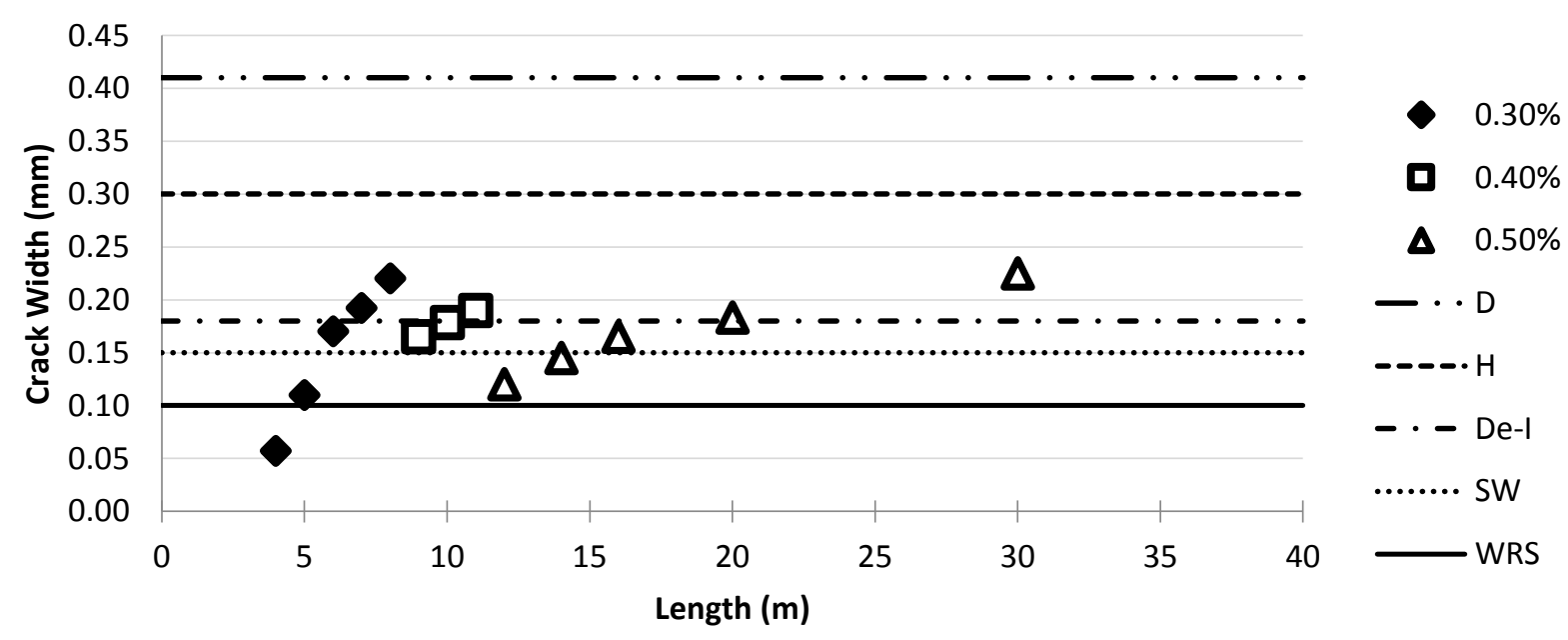

(b) Cold and humid climate 


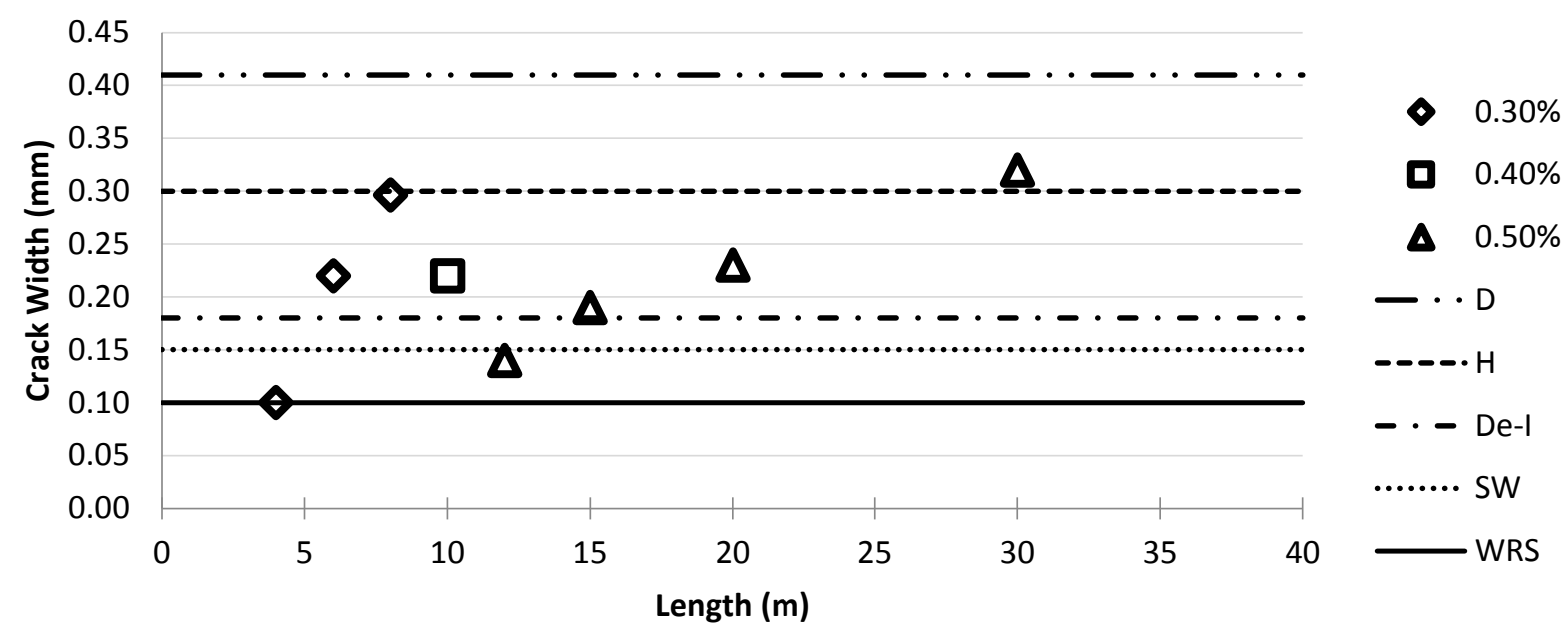

(c) Hot and dry climate

Figure 7-7 Crack widths of walls reinforced based on ACI 350-06 $(\mathrm{H}=4 \mathrm{~m}, \mathrm{e}=900 \mu \epsilon)$

\subsubsection{Alternative ACI 350 Committee recommendations}

Recently ACI 350 Committee has proposed some changes to the provision of ACI 350-06 to replace the minimum reinforcement requirements. Two different procedures for the minimum steel ratio are being evaluated. The first procedure suggests the minimum reinforcement based on the degree of restraint which has been classified into three categories of reduced, normal, and maximum restraint. In case of base restrained walls, the horizontal reinforcement in the lower half and upper half of the wall are considered in the maximum and normal restraint categories respectively. The vertical rebars which are exposed to a lower level of restraint are classified as reduced restraint. The reinforcement ratio for each restraint category can be calculated using the formulas presented in Table 7-4 based on the size of reinforcing steel (in inches). The values for the reinforcement ratios provided in the third column of this table are computed for 10M rebar.

The second recommendation suggests using $1 \%$ horizontal reinforcement for the bottom $1220 \mathrm{~mm}$ (4ft) of the wall while the remaining horizontal reinforcement is to be placed based on ACI350-06 as presented in Table 7-4. The vertical reinforcement ratio in this case is calculated based on the 
second recommendation using the formula suggested for reduced restraint condition which would be $0.28 \%$ for $10 \mathrm{M}$ bars.

Table 7-4 ACI 350 recommended reinforcement ratio (Rec. I)

\begin{tabular}{|c|c|c|}
\hline Restraint & Minimum reinforcement ratio & $\begin{array}{c}\text { Calculated reinforcement } \\
\text { ratio for } 10 \mathrm{M} \text { bars }\end{array}$ \\
\hline Reduced & $\mathrm{A}_{\mathrm{s}} / \mathrm{A}_{\mathrm{g}}=0.7\left[0.0023\left(\mathrm{~d}_{\mathrm{b}}+1.25\right)\right]$ & $0.28 \%$ \\
\hline Normal & $\mathrm{A}_{\mathrm{s}} / \mathrm{A}_{\mathrm{g}}=0.0023\left(\mathrm{~d}_{\mathrm{b}}+1.25\right)$ & $0.40 \%$ \\
\hline Maximum & $\mathrm{A}_{\mathrm{s}} / \mathrm{A}_{\mathrm{g}}=2\left[0.0023\left(\mathrm{~d}_{\mathrm{b}}+1.25\right)\right]$ & $0.80 \%$ \\
\hline
\end{tabular}

Table 7-5 ACI 350 recommended reinforcement ratio (Rec. II)

\begin{tabular}{|c|c|c|c|}
\hline \multirow{2}{*}{$\begin{array}{c}\text { Length between } \\
\text { joints }(\mathrm{m})\end{array}$} & \multicolumn{3}{|c|}{ Minimum shrinkage and temperature reinforcement ratio } \\
\cline { 2 - 4 } & $\begin{array}{c}\text { Horizontal bottom } \\
1220 \mathrm{~mm}(4 \mathrm{ft} .)\end{array}$ & $\begin{array}{c}\text { Horizontal } \\
\text { remaining }\end{array}$ & $\begin{array}{c}\text { Vertical (for 10 M } \\
\text { rebars) }\end{array}$ \\
\hline Less than 6 & 0.01 & 0.003 & 0.0028 \\
\hline 6 to less than 9 & 0.01 & 0.004 & 0.0026 \\
\hline 9 to less than 12 & 0.01 & 0.005 & 0.0026 \\
\hline 12 and greater & 0.01 & 0.006 & 0.0026 \\
\hline
\end{tabular}

Figures 7-8 presents the crack width of walls reinforced based on Table 7-4 considering different lengths, heights and climates. The figures show that the crack width is kept below $0.1 \mathrm{~mm}$ for the walls shorter than about $10 \mathrm{~m}$ in length but it increases exponentially by increasing the length of the wall in excess of $15 \mathrm{~m}$. This is because the proposed reinforcement ratio is independent of the wall dimensions while it was shown that longer and taller walls require more reinforcement since they experience wider cracks. On the other hand, considering the crack width along the wall height as the $\mathrm{L} / \mathrm{H}$ ratio increases, the cracks tend to extend towards the top of the wall and for $\mathrm{L} / \mathrm{H}$ ratios larger than 3.5, the cracks develop their maximum width in the upper half of the wall. Therefore, the assumption that the upper half of the wall is under so called normal restraint and could contain less reinforcement than the lower half may not be appropriate when $\mathrm{L} / \mathrm{H}$ ratios exceed 3.5.

Comparing the results of this ACI proposed recommendation with those of ACI 350-06 Code shows that the crack width of walls shorter than $10 \mathrm{~m}$ in length can be reduced substantially but, 
the longer walls will experience even wider cracks since the upper half of the wall contains less reinforcement.

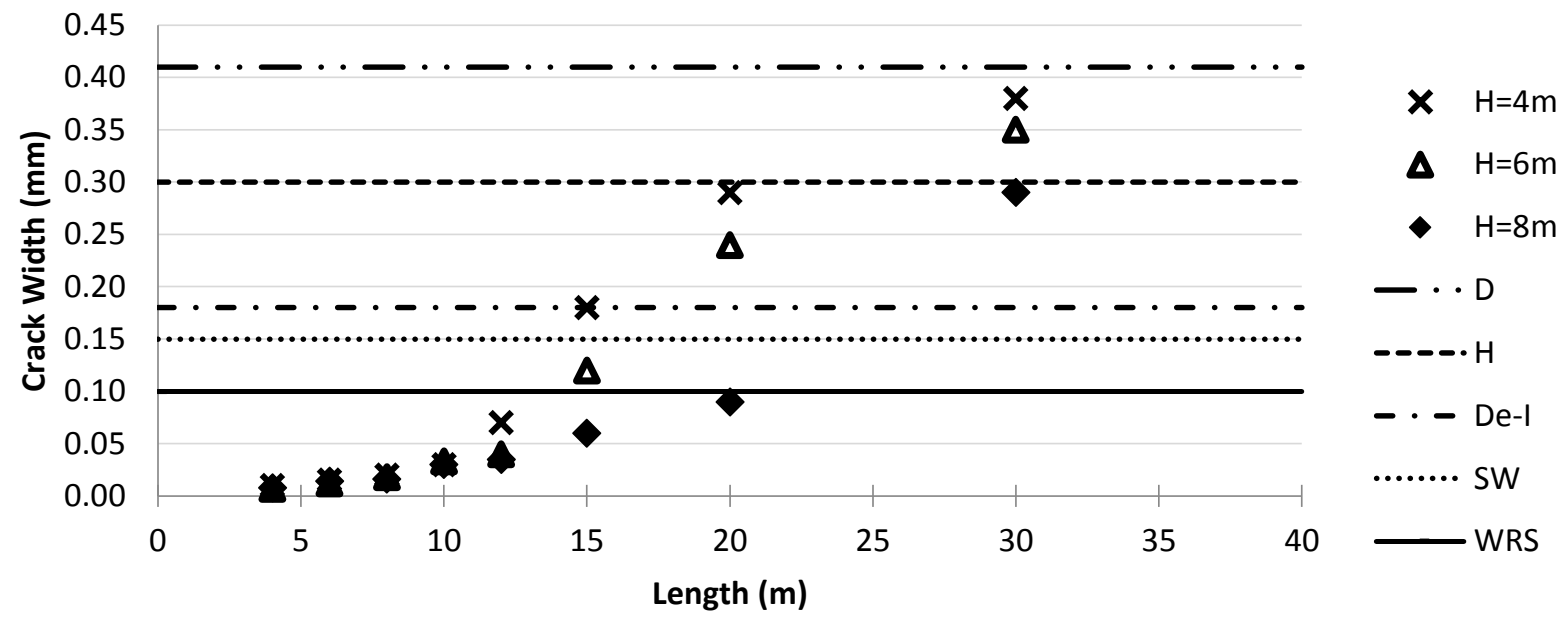

(a) Tropical climate

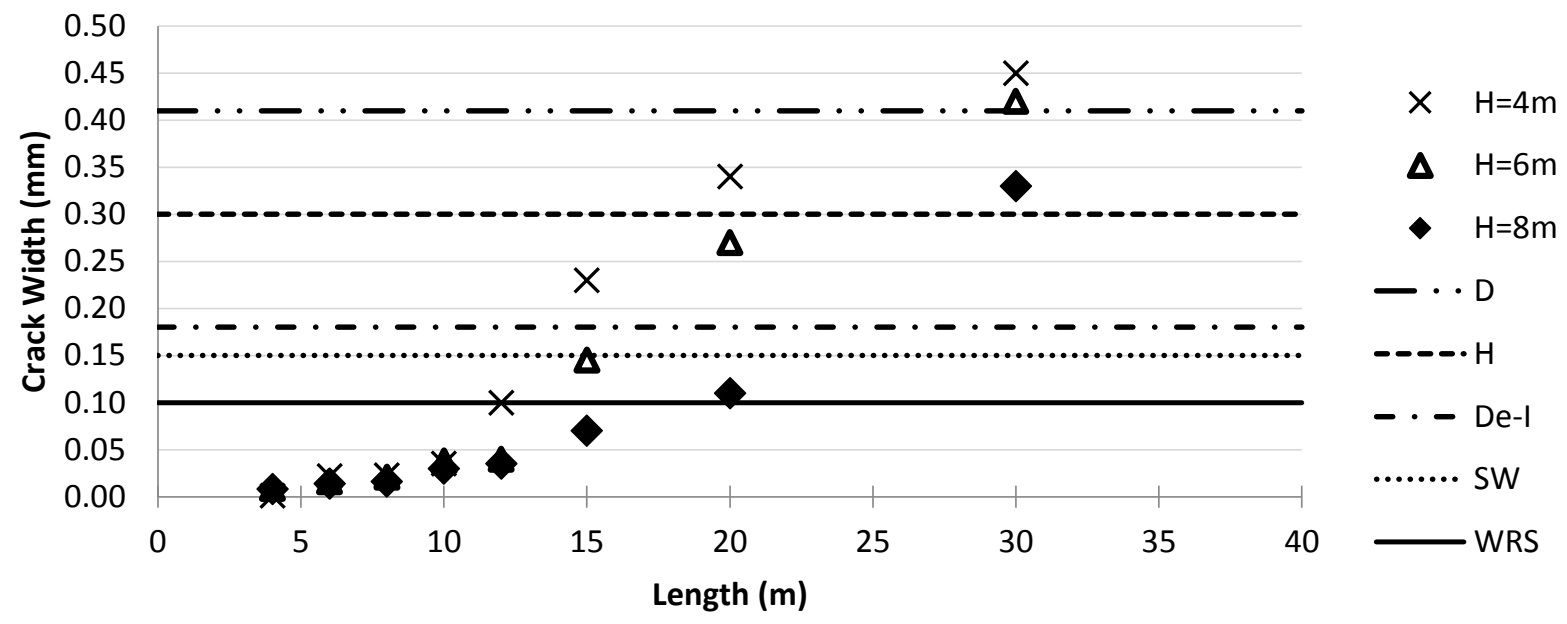

(b) Cold and humid climate 


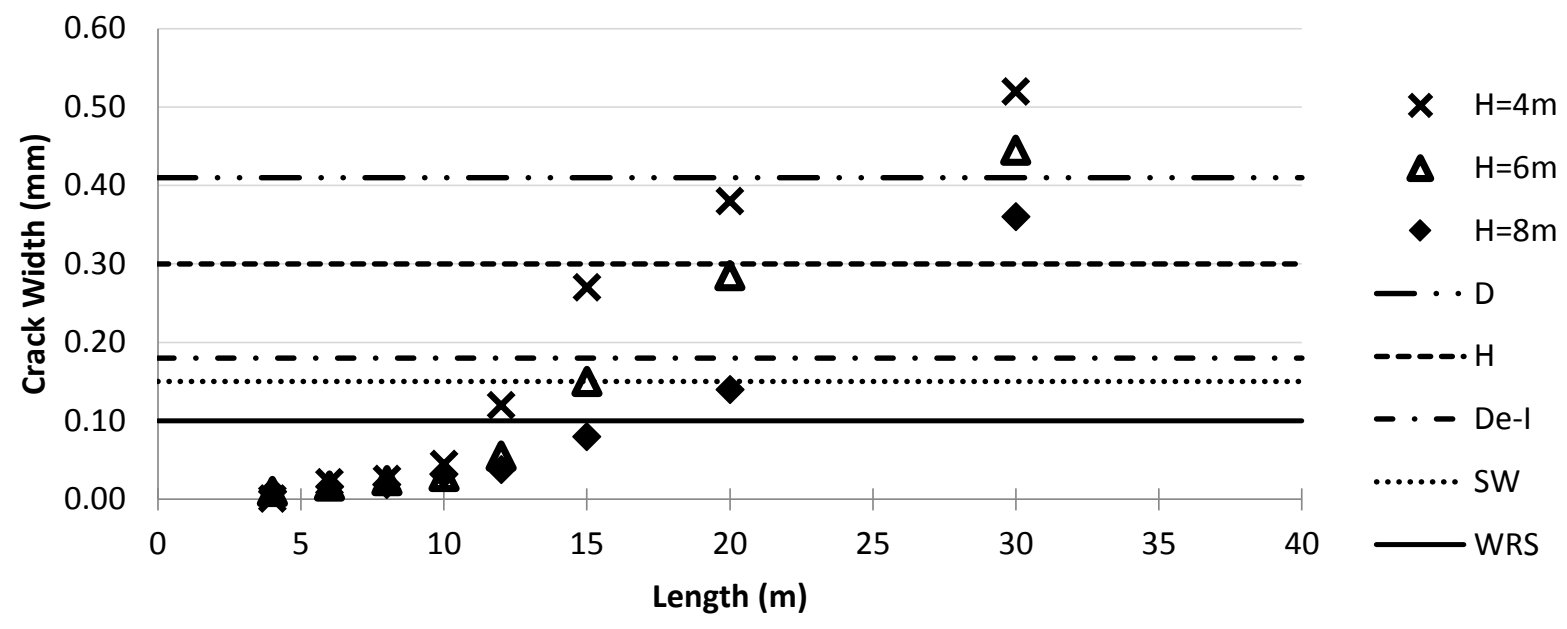

(c) Hot and dry climate

Figure 7-8 Crack width of $6 \mathrm{~m}$ high RC walls reinforced based on ACI 350 Rec I

Figure 7-9 (see also Appendix D, Figures D-3 and D-4) presents the crack widths of 4 m, $6 \mathrm{~m}$, and $8 \mathrm{~m}$ tall walls reinforced based on Table 7-5. In general, since the lower part of the walls are reinforced with such high reinforcement ratio, the crack width is very small for short walls (L less than about $8 \mathrm{~m}$ ) since they tend to crack in the lower part close to the foundation. However, by increasing the length and $\mathrm{L} / \mathrm{H}$ ratio, the cracks tend to extend higher in the wall and the high steel density in the lower part is of little benefit to limit the crack width.

Comparing the results of this recommendation with the ones of ACI 350-06 shows that the width of cracks is almost identical in two cases after the length of the walls exceed $10 \mathrm{~m}$ since the upper part of the wall is reinforced with the same steel percentage and the maximum crack width occurs above the bottom $4 \mathrm{ft}$ of the walls for the most part. Overall, none of the two alternative recommendations is appropriate for crack control of walls considering the WRS exposure. However, Rec I can be used only for walls shorter than about $10 \mathrm{~m}$ to limit the cracks to $0.1 \mathrm{~mm}$. 


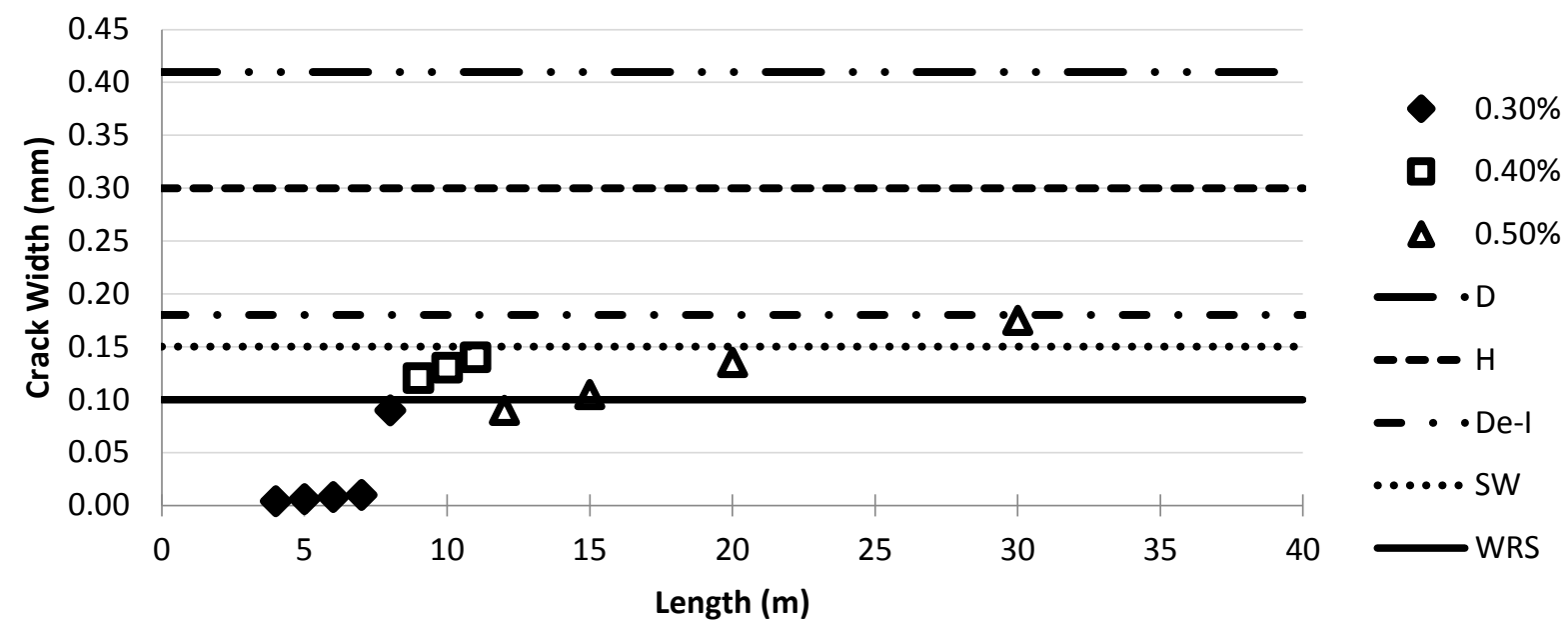

(a) Tropical climate

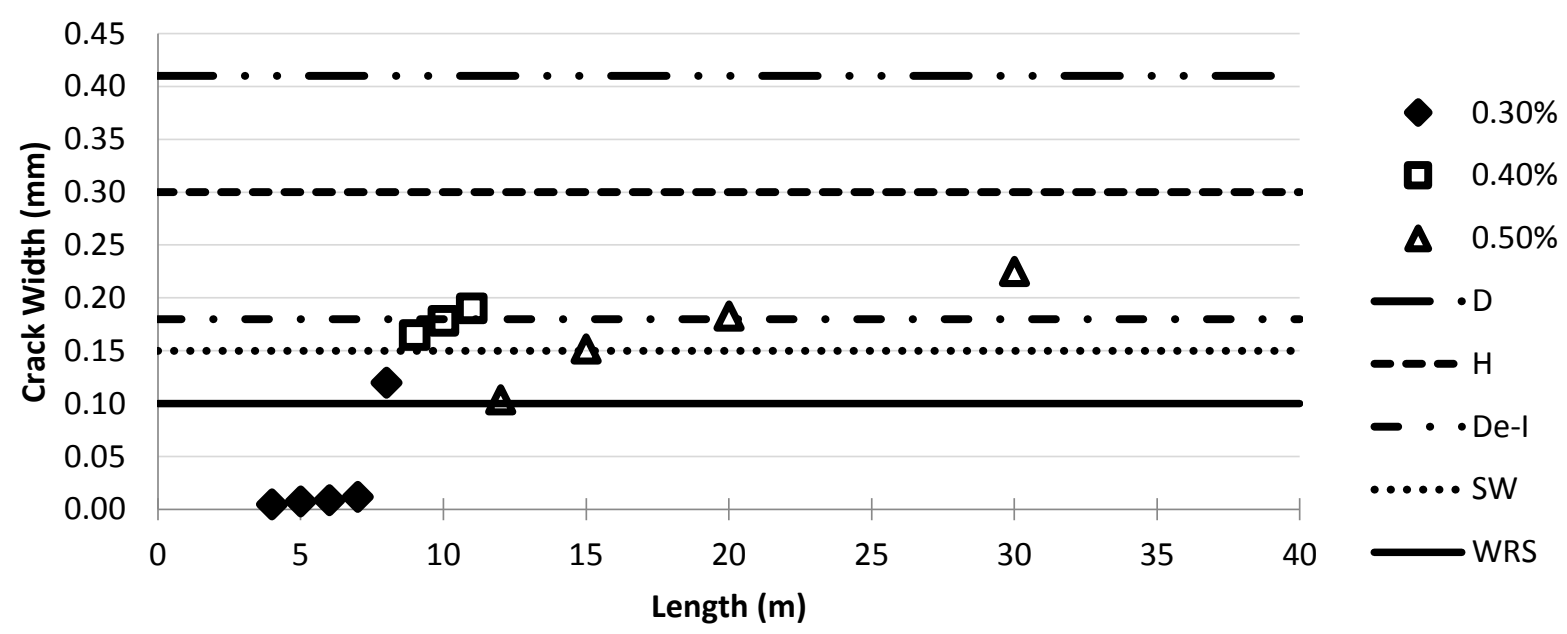

(b) Cold and humid climate

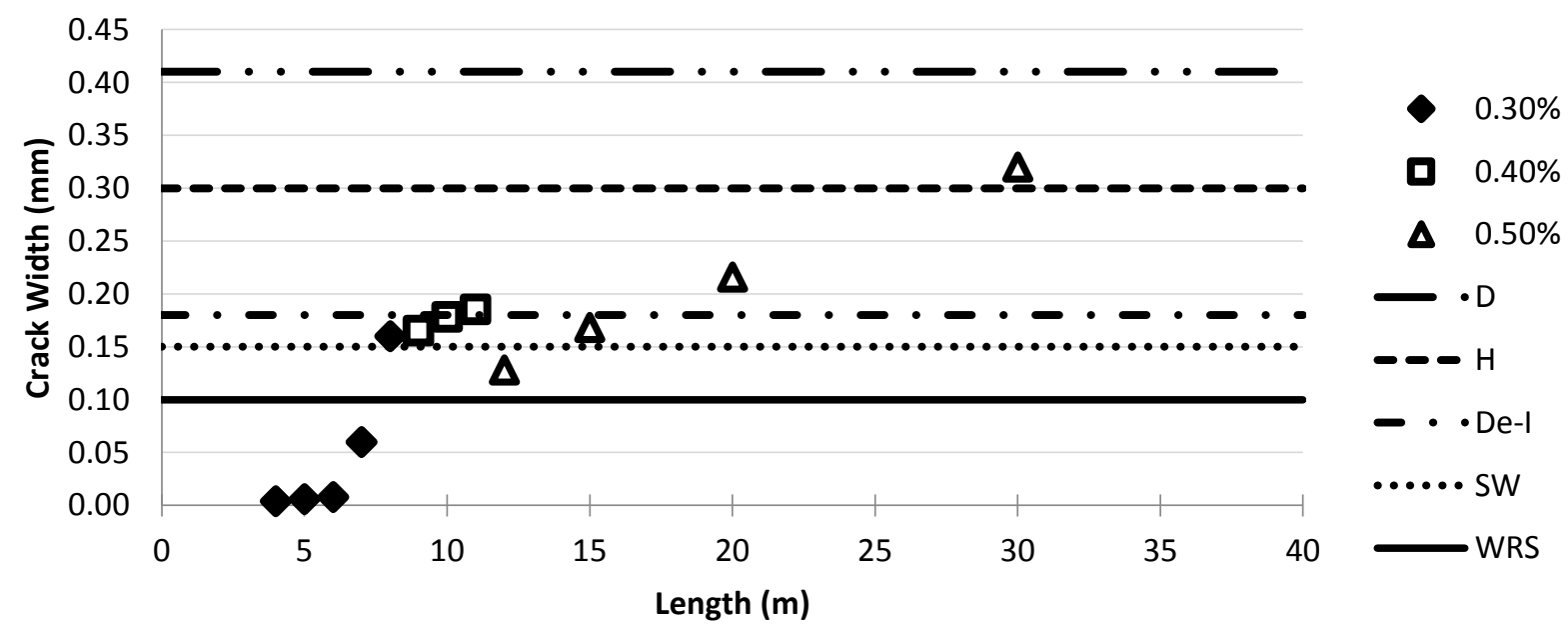

(c) Hot and dry climate

Figure 7-9 Crack width of $4 \mathrm{~m}$ high RC walls reinforced based on ACI 350 Rec II 


\subsubsection{CEB-FIP}

CEB-FIP Model Code (1990) proposes a formulation for the minimum reinforcement ratio for crack control as shown in Equation 7- 1.

$A_{s, \min }=K_{c} K f_{c t, \max } A_{c t} / \sigma_{s 2}$

In which, $A_{c t}$ is the area of concrete tension zone before cracking, $\sigma_{s 2}$ is the steel stress which could be equal to yield strength in case of secured adequate anchorage. $f_{c t \text {, max }}$ is the concrete tensile strength, $\mathrm{K}$ is the correction factor that is taken to be 0.5 for intrinsic imposed deformation for sections with a height of more than $0.8 \mathrm{~m} . \mathrm{K}_{\mathrm{c}}$ varies between 0.4 for flexural members and 1 for pure tension which is assumed to be 0.8 here for the base restrained wall. Considering the steel yield strength of $400 \mathrm{MPa}$, the minimum reinforcement ratios would be equal to $0.25 \%, 0.3 \%$, and $0.35 \%$ for concrete tensile strengths of $2.5 \mathrm{MPa}, 3 \mathrm{MPa}$ and $3.5 \mathrm{MPa}$. It is noticeable that this code considers a linear relationship between reinforcement ratio and concrete tensile strength and therefore members made of stronger concrete need to be reinforced with a higher steel percentage. Figure 7-10 present the crack width of $4 \mathrm{~m}$ tall walls with varying lengths exposed to different climate conditions having their concrete tensile strength equal to $2.5 \mathrm{MPa}, 3 \mathrm{MPa}$, and $3.5 \mathrm{MPa}$ respectively. Overall, the reinforcement ratio is not sufficient to meet the WRS crack width limit. Considering the $\mathrm{D}$ exposure condition, the walls shorter than $10 \mathrm{~m}$ to $12 \mathrm{~m}$ experience cracks less than $0.41 \mathrm{~mm}$ limit. 


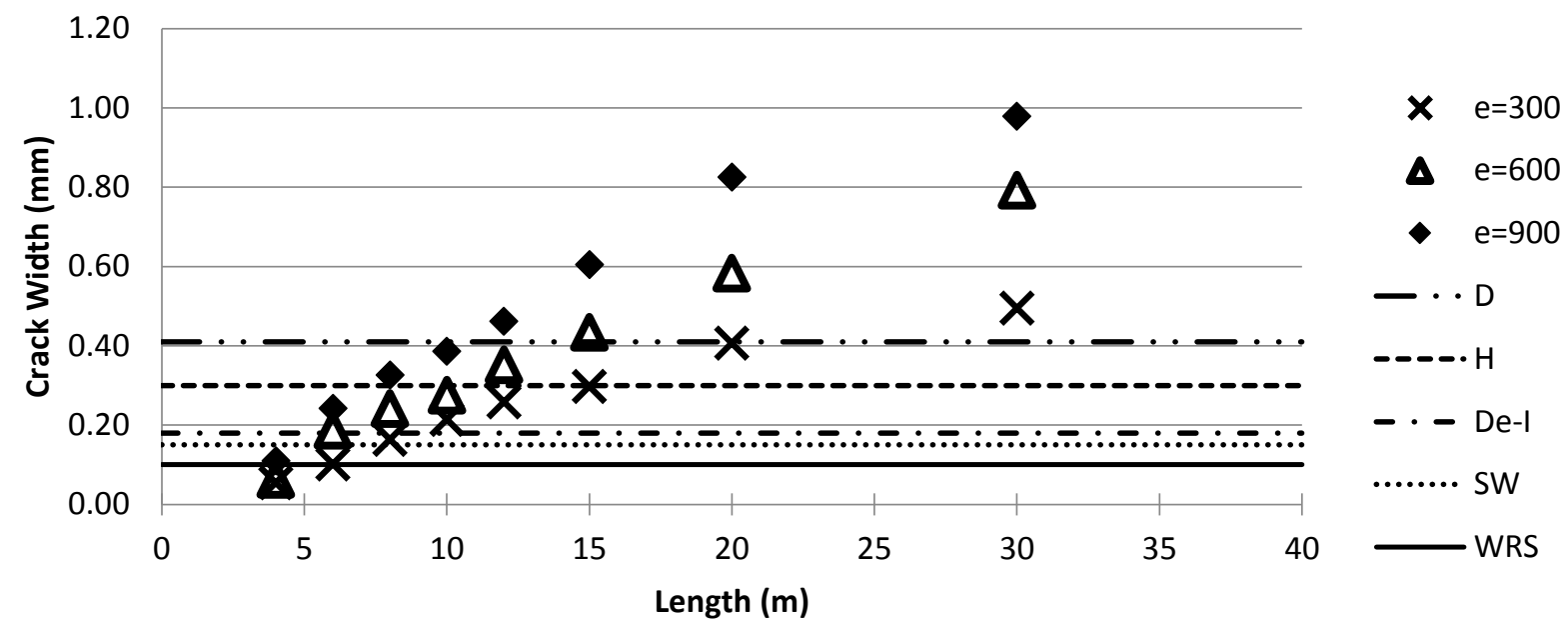

(a) $\mathrm{ft}=2.5 \mathrm{MPa}$

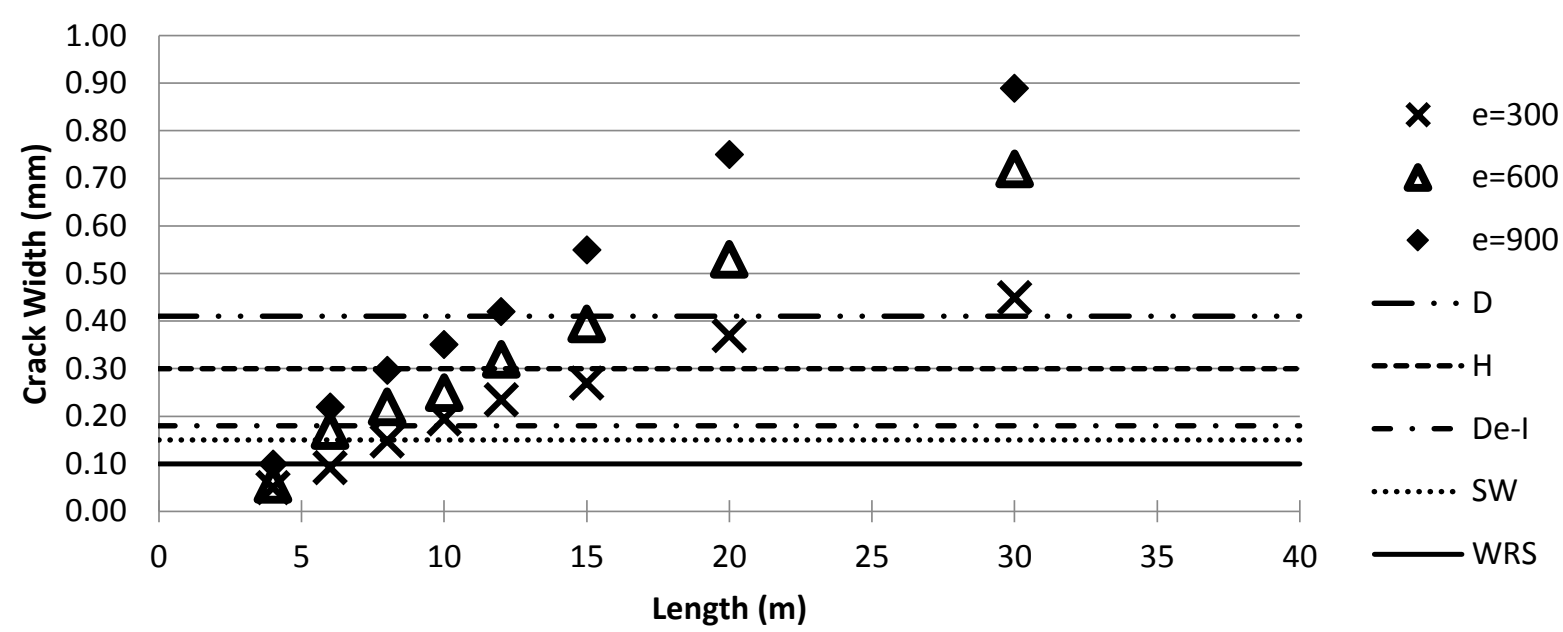

(b) $\mathrm{ft}=3 \mathrm{MPa}$

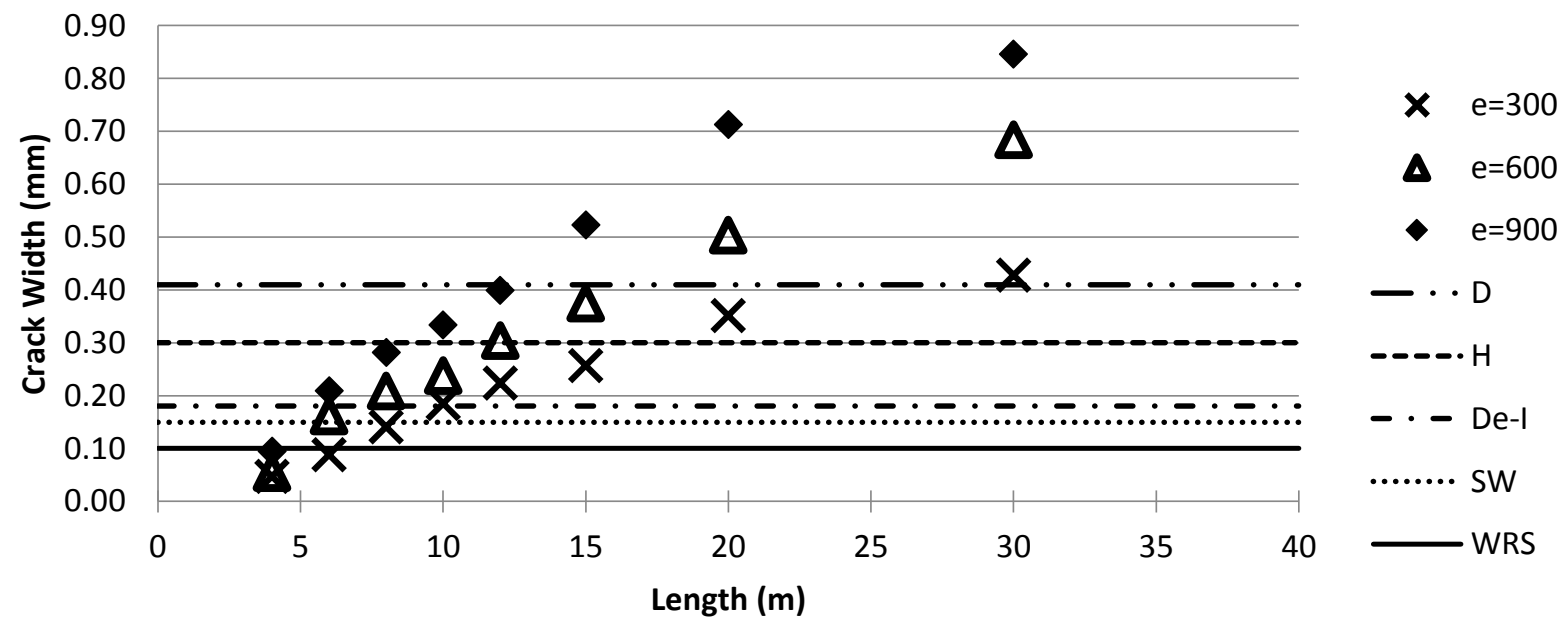

(c) $\mathrm{ft}=3.5 \mathrm{MPa}$

Figure 7-10 Crack widths in $\mathrm{RC}$ walls reinforced based on CEB-FIP $(\mathrm{H}=4 \mathrm{~m}, \mathrm{ft}=3.5 \mathrm{MPa})$ 


\subsubsection{AS 3600}

The Australian standard (AS 3600, 2001) suggests using minimum reinforcement ratios for restrained shrinkage and temperature strain based on the required degree of crack control. Minimum horizontal reinforcement ratios of $0.25 \%, 0.35 \%$, and $0.6 \%$ are recommended for minor, moderate and strong degrees of control over cracking respectively. A reinforcement ratio of $0.15 \%$ is recommended to be placed in the vertical direction. Given the results of the FE simulations in the previous chapters, these reinforcement ratios may not be sufficient for some cases.

\subsubsection{Other codes}

British Standard (BS 8110-1, 1997) suggests using the minimum reinforcement ratios of $0.25 \%$ and $0.3 \%$ in both directions for grade 460 and grade 250 steel respectively. It also mentions that the bars should be small and closely spaced but does not give further details on it. The code of New Zealand (NZS 3110 2006) suggests using minimum reinforcement ratio of $0.7 / f_{\mathrm{y}}$ which should be greater than $0.14 \%$. For large members, this code suggests provision of at least 1000 $\mathrm{mm}^{2}$ of steel per meter width with bar spacing of less than $300 \mathrm{~mm}$. Considering the $400 \mathrm{MPa}$ steel, the value of $0.7 / \mathrm{f}_{\mathrm{y}}$ would be $0.175 \%$ and the providing $1000 \mathrm{~mm}^{2}$ in a meter long of $500 \mathrm{~mm}$ thick wall gives a reinforcement ratio of $0.2 \%$.

\subsection{Minimum reinforcement ratio}

Based on the results of the FE analyses presented in this dissertation, it was concluded that the $\mathrm{L} / \mathrm{H}$ ratio (length), height, reinforcement ratio, climate condition, and concrete tensile strength are the major parameters that influence the width of cracks in base restrained RC walls. A formula is proposed to determine the minimum required steel based on the acceptable crack widths proposed by ACI 224R-01 (2008). The proposed empirical formula is developed based on the FE results of this study and takes into account the major parameters that affect the crack width. 
$\rho_{\min }=\rho_{e} \gamma_{L / H} \gamma_{H} \gamma_{c l} \gamma_{f t} \geq 0.002$

In which, $\rho_{\min }$ is the proposed minimum steel ratio, $\rho_{e}$ is the base steel ratio based on exposure conditions and $\gamma_{L / H}, \gamma_{H}, \gamma_{c l}$ and $\gamma_{f t}$ are factors to account for $\mathrm{L} / \mathrm{H}$ ratio, height, climate and concrete tensile strength respectively. Table 7-6 presents the base steel ratio and correction factors for $\mathrm{L} / \mathrm{H}$, height, and climate conditions and the concrete tensile strength factor could be computed using Equation 7-3.

Table 7-6 Modification factors for the proposed minimum reinforcement (a) reinforcement ratio based on exposure conditions

\begin{tabular}{|c|c|}
\hline Exposure condition & $\rho_{e}$ \\
\hline Dry air or protective membrane & 0.14 \\
\hline Humidity, moist air, soil & 0.16 \\
\hline De-icing chemical & 0.19 \\
\hline $\begin{array}{c}\text { Seawater and seawater spray, wetting and } \\
\text { drying }\end{array}$ & 0.21 \\
\hline Water-retaining structures & 0.25 \\
\hline
\end{tabular}

(b) $\mathrm{L} / \mathrm{H}$ modification factor

\begin{tabular}{|c|c|}
\hline L/H Categories & $\gamma_{L / H}$ \\
\hline$L / H<1.5$ & 1.0 \\
\hline $1.5 \leq L / H<2$ & 1.5 \\
\hline $2 \leq L / H<3$ & 2.0 \\
\hline $3 \leq L / H<4$ & 2.5 \\
\hline$L / H \geq 4$ & 3.0 \\
\hline
\end{tabular}

(c) Height modification factor

\begin{tabular}{|c|c|}
\hline Height Categories & $\gamma_{H}$ \\
\hline$H \leq 2$ & 0.8 \\
\hline $2 \leq H<4$ & 0.9 \\
\hline $4 \leq H<6$ & 1.0 \\
\hline $6 \leq H<8$ & 1.1 \\
\hline$H \geq 8$ & 1.2 \\
\hline
\end{tabular}

(d) Climate modification factor

\begin{tabular}{|c|c|}
\hline Climate Categories & $\gamma_{c l}$ \\
\hline Tropical & 0.75 \\
\hline Cold/Humid & 1.0 \\
\hline Hot/Dry & 1.2 \\
\hline
\end{tabular}


$\gamma_{f t}=f_{t} / 3(2 \leq f t \leq 4)$

Figure 7-11 shows the crack widths of $4 \mathrm{~m}$ high $\mathrm{RC}$ walls reinforced based on the minimum reinforcement ratio as presented in Equation 7-2 for different wall lengths, concrete tensile strength values, climates and exposure conditions. It can be seen that the recommended reinforcement ratio can limit the width of cracks to the proposed values presented in Table 7-2.

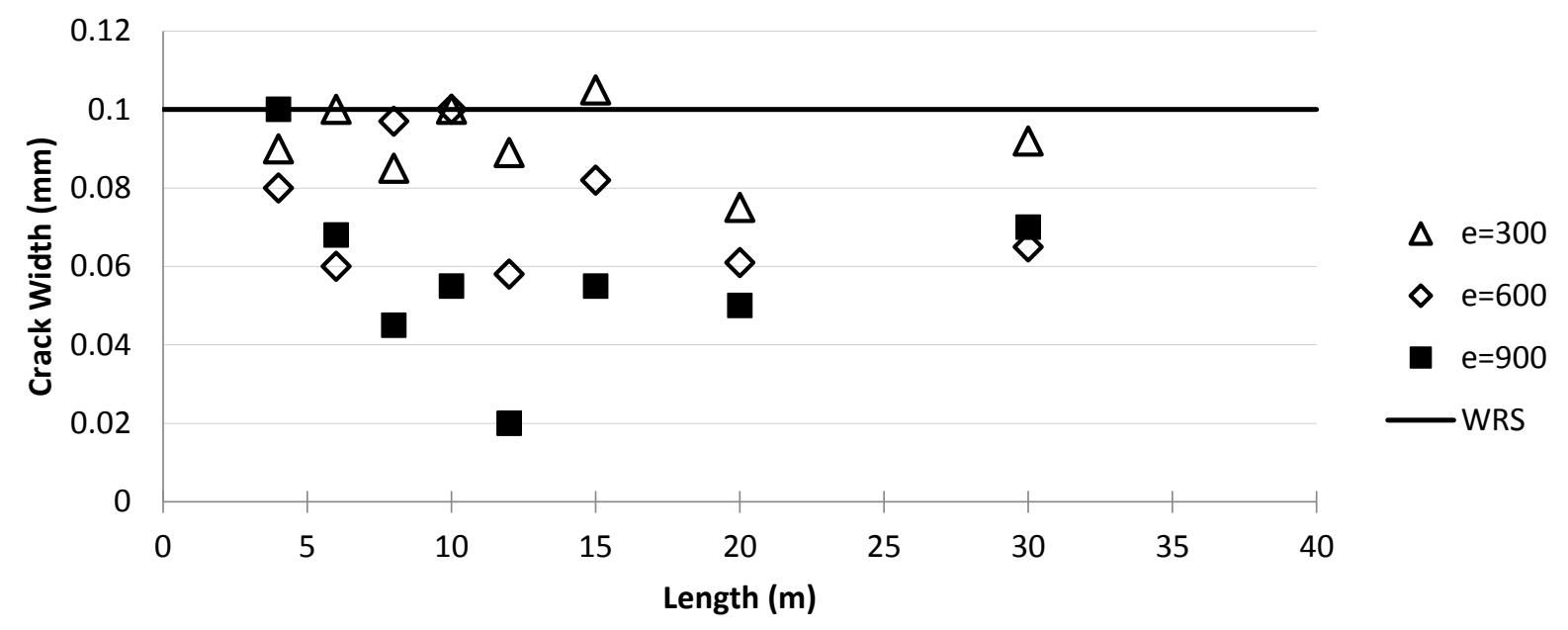

(a) $\mathrm{f}_{\mathrm{t}}=3 \mathrm{MPa}, \mathrm{H}=4 \mathrm{~m}, \mathrm{WRS}$ exposure

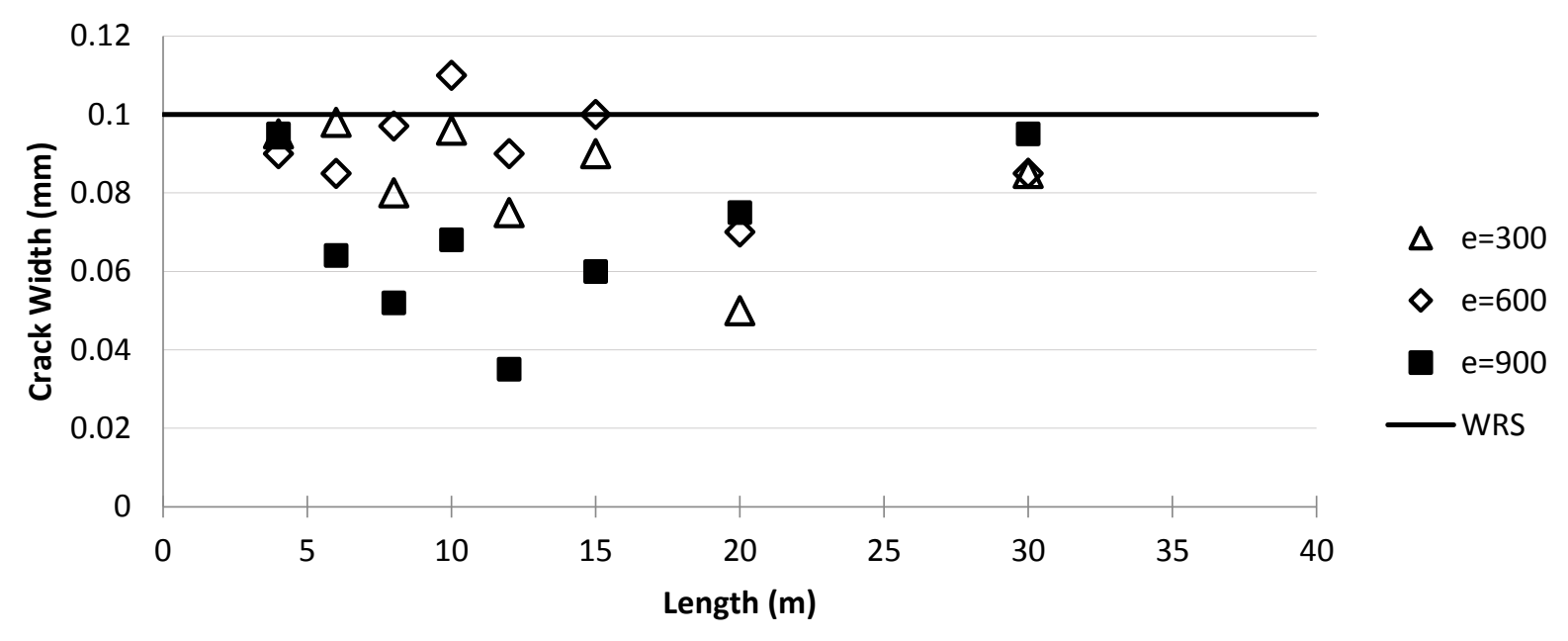

(b) $\mathrm{f}_{\mathrm{t}}=2.5 \mathrm{MPa}, \mathrm{H}=4 \mathrm{~m}$, WRS exposure 


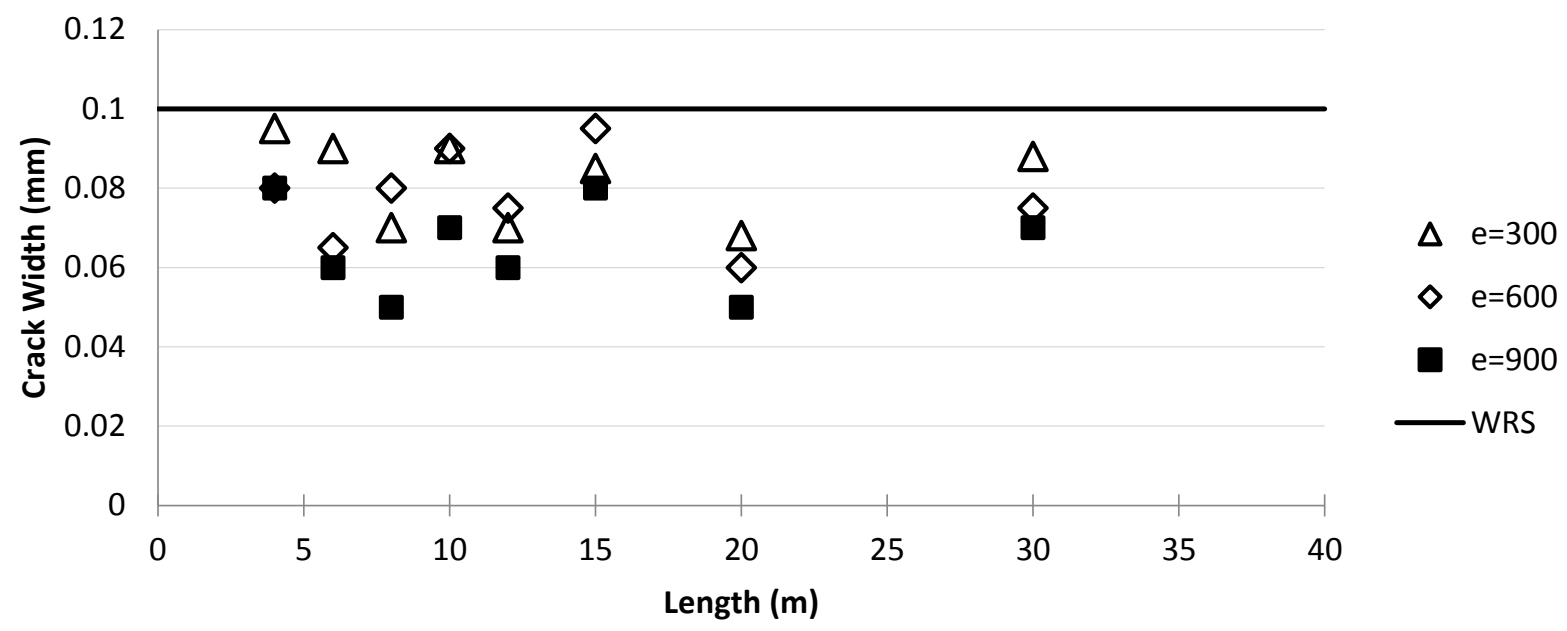

(c) $\mathrm{f}_{\mathrm{t}}=3.5 \mathrm{MPa}, \mathrm{H}=4 \mathrm{~m}$, WRS exposure

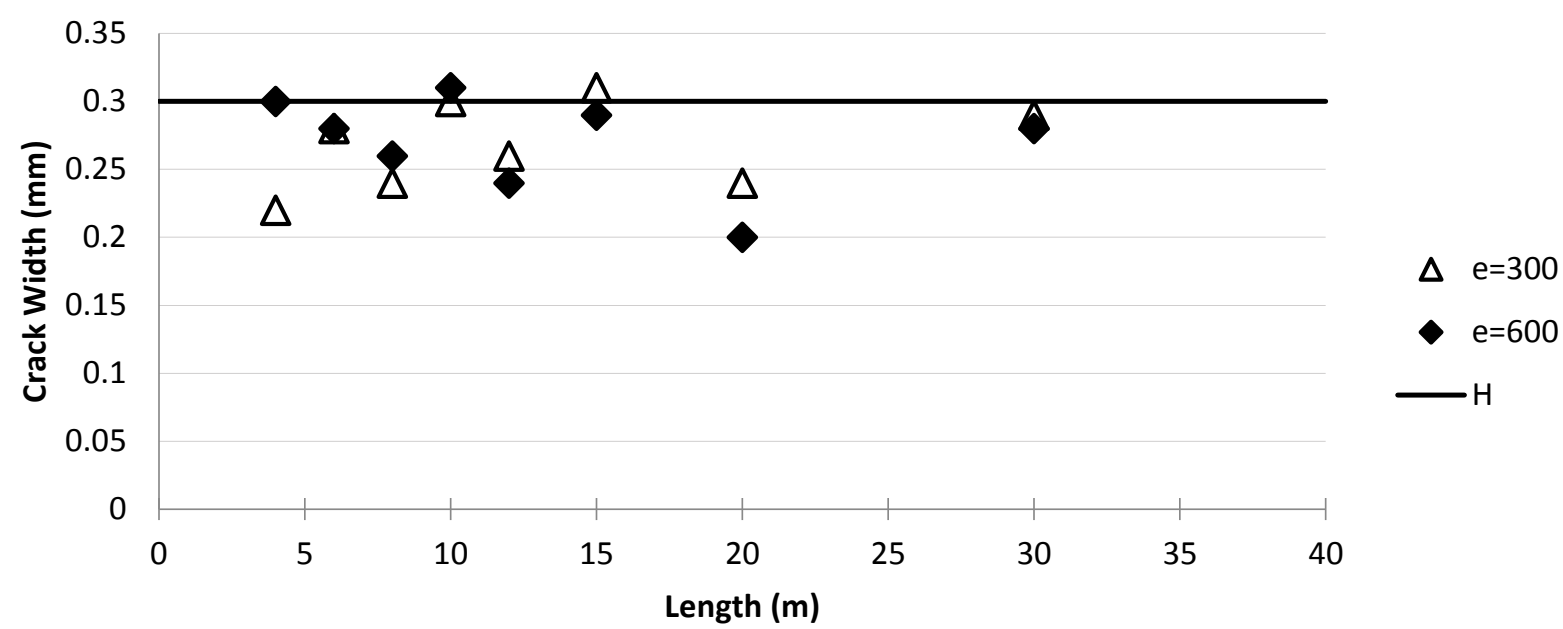

(d) $\mathrm{f}_{\mathrm{t}}=3 \mathrm{MPa}, \mathrm{H}=4 \mathrm{~m}, \mathrm{H}$ exposure class

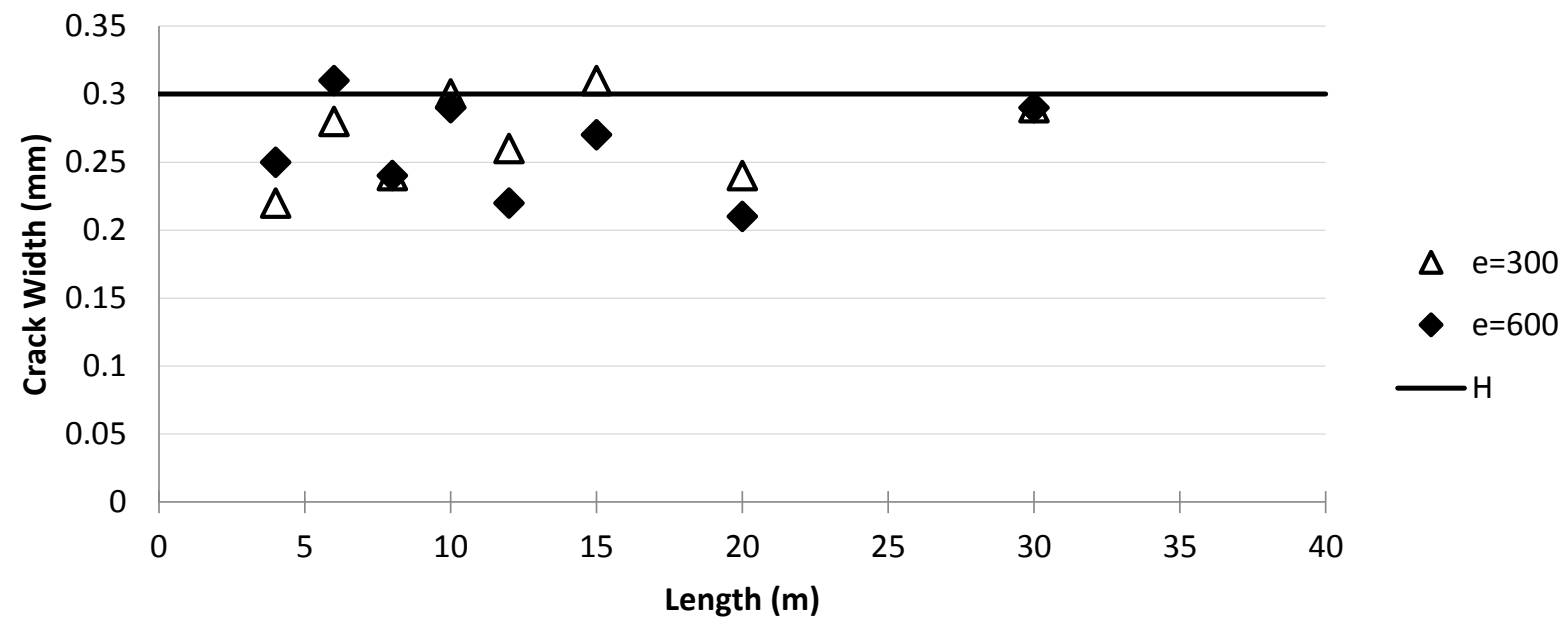

(e) $\mathrm{f}_{\mathrm{t}}=2.5 \mathrm{MPa}, \mathrm{H}=4 \mathrm{~m}, \mathrm{H}$ exposure class 


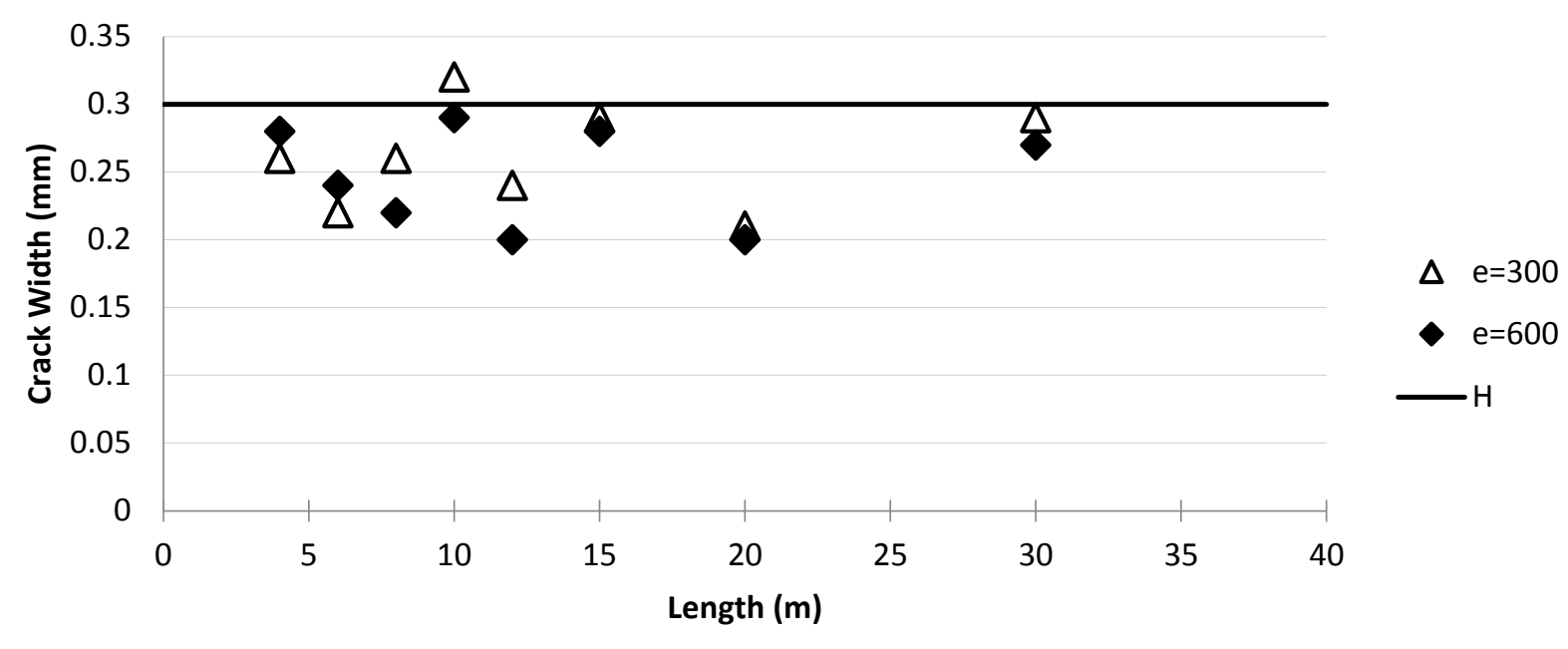

(f) $\mathrm{f}_{\mathrm{t}}=3.5 \mathrm{MPa}, \mathrm{H}=4 \mathrm{~m}, \mathrm{H}$ exposure class

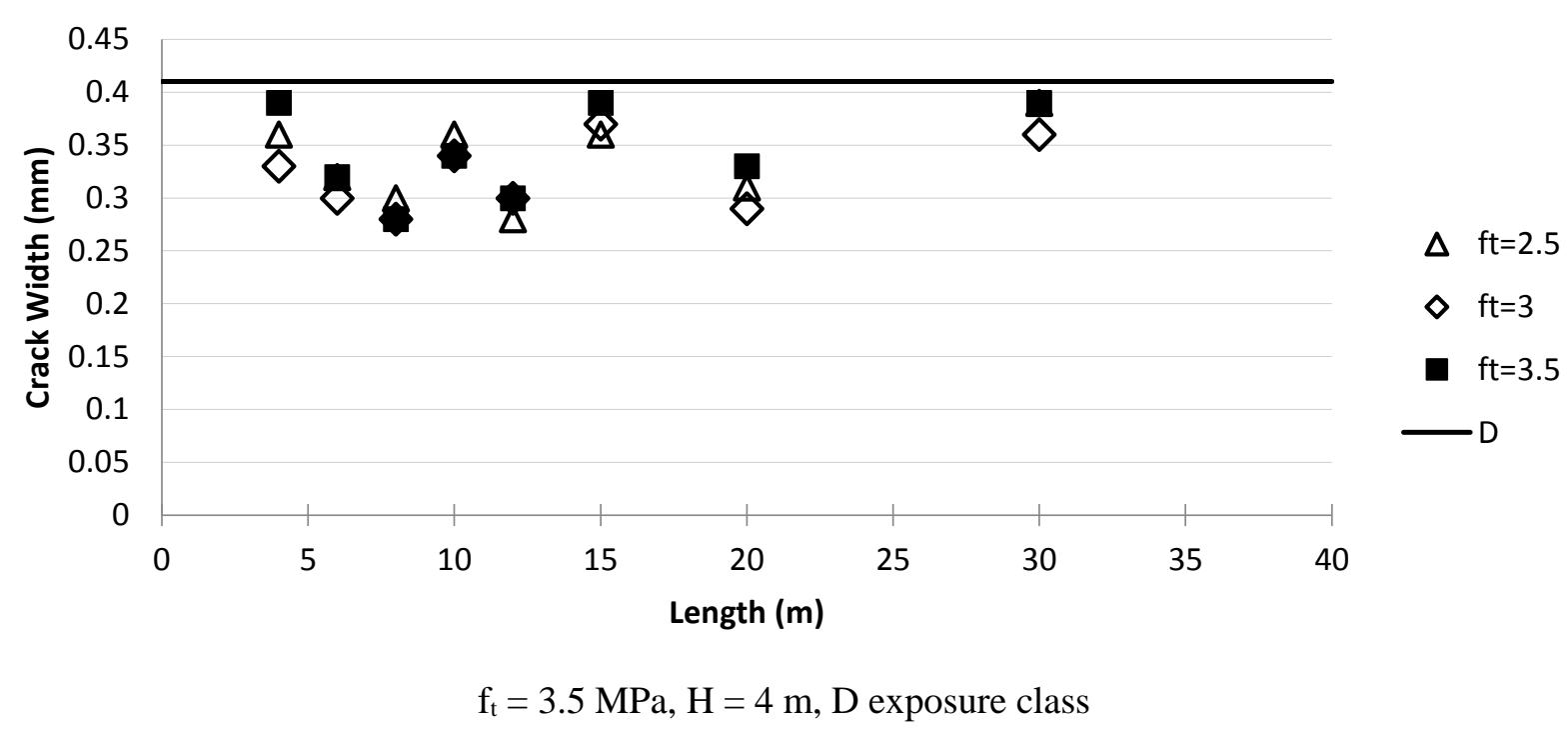

Figure 7-11 Crack widths of walls reinforced based on the proposed steel ratio

\subsection{Summary}

In this chapter, the results of the three different models as presented in Chapters 4,5 , and 6 were compared. It was shown that considering the effect of creep can reduce the maximum crack width for up to $40 \%$. It was also concluded that the partial side restraint causes an increase of about $10 \%$ in the crack width. The evaluation of the recommended minimum steel ratios from different codes demonstrated that none of them are able to meet the WRS crack width limitation. Finally a new procedure was recommended to determine the minimum reinforcement ratio in RC walls. 


\section{CONCLUSIONS AND RECOMMENDATIONS}

\subsection{Summary}

The cracking behavior of base restrained RC walls subjected to restrained shrinkage and thermal strain was studied using the FE method. The FE model was first verified by comparing the crack width and pattern of the simulated walls with the ones of an experimental study. For the first part of the FE study, the walls were assumed to be fully restrained at the base without considering the creep effect. The second part contained the results of walls fully restrained at the base and partially restrained at the sides without the creep effect. In the third part the effect of creep was introduced to the model with full base restraint and no side restraint. The calculated volumetric strain which is the summation of thermal and shrinkage strain was applied in form of a temperature drop and the crack width was determined using the steel strain from the FE program. The influence of a series of parameters including the wall height, length, length/height ratio, and thickness in addition to the climate condition, steel and concrete strength, and reinforcement ratio was studied on the maximum crack width and variation of the crack width over the wall height.

Walls were modelled with lengths varying from $4 \mathrm{~m}$ to $30 \mathrm{~m}$, heights of $4 \mathrm{~m}, 6 \mathrm{~m}$, and $8 \mathrm{~m}$, and thicknesses of $300 \mathrm{~mm}, 500 \mathrm{~mm}$, and $700 \mathrm{~mm}$. Three climate conditions were considered including hot and dry, cold and humid and tropical with three different volumetric strain values corresponding to each climate condition. The effect of reinforcement ratio was discussed with steel ratios varying from $0.3 \%$ to $0.7 \%$ and the influence of concrete tensile strength was investigated by considering three different concrete tensile strengths of $2.5 \mathrm{MPa}, 3 \mathrm{MPa}$, and $3.5 \mathrm{MPa}$. The reinforcement yield strengths of $300 \mathrm{MPa}$ and $400 \mathrm{MPa}$ were considered to discuss the effect of steel yield strength on the crack width. 
After conducting the parametric study, the results of these three models were compared to each other in order to investigate the effect of creep and presence of partial side restraint on the results. The minimum reinforcement ratios proposed by different codes were reviewed. A number of base restrained walls were simulated on the basis of these recommendations to examine if they meet the crack control requirement. Finally, a procedure was suggested to determine the minimum reinforcement ratio for crack control of base restrained $\mathrm{RC}$ walls which takes into account the major parameters that affect the crack width.

\subsection{Outcomes and conclusions}

Based on the results of this study, the following conclusions are drawn:

- Increasing the wall length, $\mathrm{L} / \mathrm{H}$ ratio and height increase the width of cracks while the wall thickness does not have a significant effect on the crack width.

- The widest cracks develop in hot and dry climate while the narrowest cracks form under tropical climate condition.

- Increasing the reinforcement ratio from $0.3 \%$ up to $0.7 \%$ reduces the crack width significantly.

- The crack width increases with increasing the concrete tensile strength. In fact, weaker concrete experiences a higher number of narrower cracks as opposed to fewer number of wide cracks in walls made of stronger concrete.

- Walls reinforced with $300 \mathrm{MPa}$ steel experience wider cracks in comparison with those reinforced with $400 \mathrm{MPa}$ steel. The effect of steel yield strength is more noticeable in reinforcement ratios lower than $0.5 \%$ and walls longer than $10 \mathrm{~m}$.

- The effect of steel behavior was discussed by comparing the crack width of walls assuming both linear and non-linear behavior for the steel reinforcement. It was shown that by increasing the wall length (L/H ratio) especially in walls reinforced with lower steel ratios (less than 
$0.5 \%$ ), the difference between the crack width values became more apparent which is due to the fact that steel yields when the reinforcement ratio is small.

- Increasing the $\mathrm{L} / \mathrm{H}$ ratio causes the maximum crack width to occur at a higher elevation in the wall and also the cracks extend further towards the top of the wall.

- For the walls considered in this study, it was shown that the effect of creep resulted in a decrease in the width of cracks ranging from $20 \%$ to $40 \%$. It was also shown that having the partial (out of plane) side restraint which could be caused by perimeter walls in a rectangular tank can cause the crack width to increase from $5 \%$ to up to $15 \%$.

- The proposed steel ratios by ACI 350-06 may not be appropriate considering the $0.1 \mathrm{~mm}$ crack width limit for WRS.

- Other codes including the CSA 23, Australian, New Zealand, British Standard, and CEB-FIP, do not take into account the effect of the parameters that influence the temperature and shrinkage cracking. In addition, the steel percentages recommended by these codes are not sufficient for WRS.

- The suggested minimum steel ratio in this study takes into account major factors that could affect the crack width including the $\mathrm{L} / \mathrm{H}$ ratio (wall length), wall height, climate condition, and concrete tensile strength along with the degree to which the crack control is needed (exposure condition).

\subsection{Recommendations for future research}

Future research related to the work described in this thesis can be carried out as follows:

- Early age thermal and shrinkage cracking behavior of RC can be investigated using the FE method. This includes the cracking behavior of concrete in the first few days which mostly occurs because of the heat of hydration and subsequent cooling of the concrete. 
- The effect of reinforcement layout including bar spacing and diameter, in addition to the clear cover could be considered on the cracking behavior of RC walls.

- The effect of temperature and moisture gradient could be considered in the models and their influence on the cracking behavior especially in thick concrete walls.

- Conducting experiments on RC walls with different restraints exposed to different temperatures and humidity levels representing climate conditions could provide a better understanding of the behavior. Effect of different parameters between the experimental walls and those obtained using this study could be compared.

- Provision of monitoring devices on real life projects and monitoring the stress and strain levels in addition to cracking behavior including the crack width, spacing and pattern gives a better insight into the temperature and shrinkage effects. 


\section{References}

ACI Committee 224. 1992. Cracking of concrete members in direct tension. ACI 224.2R- 92. American Concrete Institute, Detroit.

ACI Committee 224. 2001. Control of cracking in concrete structures, ACI 224.2R-92, American Concrete Institute, Detroit.

ACI Committee 224. 2001. American Concrete Institute. Control of cracking in concrete structures. ACI 224R-01, American Concrete Institute, Detroit.

ACI Committee 207. 2007. American Concrete Institute. Report on Thermal and Volume Change Effects on Cracking of Mass Concrete. ACI 207.2R-07, American Concrete Institute, Detroit.

ACI Committee 209. 2008, Prediction of creep, shrinkage and temperature effects in concrete structures, ACI 209.R-08, American Concrete Institute, Detroit.

ACI Committee 209. 2008. Guide for Modeling and Calculating Shrinkage and Creep in Hardened Concrete. ACI 209.2R-08, American Concrete Institute, Detroit.

ACI committee 318. 2011. American Concrete Institute. Building code requirements for structural concrete and commentary. ACI 318M-11.

ACI Committee 350. 2006. American Concrete Institute. Code requirements for environmental engineering concrete structure (ACI 350M-06) and commentary. ACI 350RM-06.

Al Rawi, R.S. and Kheder G.F. 1990. Control of cracking due to volume change in base-restrained concrete members. ACI Structural Journal. 87(4): 397-405.

Al-Manaseer, A. and Prado, A. 2015. Statistical comparisons of creep and shrinkage prediction models using RILEM and NU-ITI database. ACI Materials Journal. 112(1): 125-135.

Andersen, M. E. 1998. Design and construction of concrete structures using temperature and stress calculations to evaluate early age thermal effects. G. M. Idorn Consult, Ramboll, Denmark. 
Material Science of Concrete V, Published by The American Ceramic Society, 735 Ceramic Place Westerville, Ohio 43081.

Ayotte, E., Massicotte, B., Houde, J., and Gocevski, V. 1997. Modeling the thermal stresses at early ages in a concrete monolith, ACI Materials Journal, V. 94, No. 6, Nov.-Dec. 1997, Title No. 94-M65, pp. 577-587.

Bosnjak, D., Kanstad, T. 2001. Structural behavior numerical simulation of the maridal culvert. Published by Department of Civil \& Mining Engineering NTNU, Norway, IPACS report BE963843/2001:33-8.

Branco, F. A., Mendes, P. A., and Mirabell, E. 1992. Heat of hydration effects in concrete structures V. 89, No. 2, March-April, pp. 139-145.

Branson, D. E., and Christiason, M. L. 1971. Time Dependent Concrete Properties Related to Design—Strength and Elastic Properties, Creep and Shrinkage. Creep, Shrinkage and Temperature Effects, SP-27, American Concrete Institute, Farmington Hills, MI, pp. 257-277.

Broms, B. B., 1965. Crack Width and Crack Spacing in Reinforced Concrete Members. ACI JOURNAL, Proceedings V. 62, No. 10, Oct., pp. 1237-1256.

Carlson, R.W. and Reading T.J. 1988. Model study of shrinkage cracking in concrete building walls. ACI Structural Journal. (July-August): 395-404.

CEB-FIP Model Code. 2010. Model Code for Concrete Structures, Comite Euro-International due Beton/Federation Internaitonale de la Precontrainte, Paris.

Chantelois, A., Leger, P., Tinawi, R., and Vielleux, M. 1999. Experimental and Numerical predictions of critical cooling temperature for crack propagation in concrete structures. ACI Structural Journal, V. 96, No. 2, March-April 1999, Title No. 96-s22, pp. 203-211. 
Elbadry, M. and Ghali, A. 1995. Control of thermal cracking of concrete structures. ACI Structural Journal. 92(4):435-50.

Environment Canada. Meteorological Service of Canada. Canadian Climate Normals. 1981-2010 Climate Normals \& Averages (http://climate.weather.gc.ca)

Frosch R. J. 1999. Another look at cracking and crack control in reinforced concrete. ACI Structural Journal. 96(3): 437-42.

General conditions standard specifications and supplemental specifications. 1983. Ontario Provincial Standard Specifications. Ontario: Ministry of Transportation and Communications.

Gergely, P., and Lutz, L. A. 1968. Maximum Crack Width in Reinforced Concrete Flexural Members. Causes, Mechanism, and Control of Cracking in Concrete, SP-20, American Concrete Institute, Farmington Hills, pp. 87-117.

Gilbert, R.I. 1992. Shrinkage cracking in fully restrained concrete members. ACI Structural Journal. 89(2):141-9.

Harrison, T.A. Early-age thermal crack control in concrete. 1981. CIRIA, Report No. 91. London: Construction, Industry, Research and Information Association. p. 48.

Hibbitt HD, Karlson BI, Sorenson EP. 2004. ABAQUS version 6.4, Finite Element Program. Providence (RI): Hibbitt, Karlson \& Sorenson, Inc.

Hillerborg, A.; Modeer, M; and Petersson, P. E., 1976, “Analysis of Crack Formation and Crack Growth by Means of Fracture Mechanics and Finite Elements," Concrete Research, V. 6, pp. 773782.

Huang, C. X. 1999. The three dimensional modeling of thermal cracks in concrete structures. Material and Structures/Materaux et Constructions, Vol. 32, Nov., pp 673-678. 
Kheder, G.F., Rawi R.S.A., Dhahi, J.K.A. 1994. Study of the behavior of volume change cracking in base-restraint concrete walls. ACI Materials Journal. 91(2):150-7.

Kheder, G.H. 1997. A new look at the control of volume change cracking of base restrained concrete walls. ACI Structural Journal. 94(3): 262-71.

Kianoush, M.R., Acarcan, M., Ziari, A. 2008. Behaviour of base restrained reinforced concrete walls under volumetric change. Engineering Structures, 30: 1526-1534.

Klein, F., Hoffman, E.S. and Rice, P.F. 1981. Application of strength design methods to sanitary structures. Concrete International. (April): 35-40.

Liou, D. D. 1999. Thermal effects in large-sized diaphragm wall. Journal of performance of constructed facilities. Vol. 13, No. 1, Feb., pp. 17-21.

Nejadi, S. and Gilbert, R.I. 2004. Shrinkage cracking and crack control in restrained reinforced concrete members. ACI Structural Journal. 101(6): 840-845.

Pettersson, D., Thelandersson, S. 2001. Crack development in concrete structures due to imposed strains-part 1: Modeling. Materials and Structures/Materiaux et Constructions. 34(Jan-Feb): 7-13. Pettersson, D, Thelandersson, S. 2001. Crack development in concrete structures due to imposed strains-part 2: Parametric study of a wall fully restrained at the base. Materials and Structures/Materiaux et Constructions. 34(January-February):14-20.

Saetta, A., Scotta, R., and Vitaliani, R. 1995. Stress anlysis of concrete subjected to variable thermal loads. Journal of Structural Engineering, Vol. 121, No. 3, March, pp. 446-457.

Thelandersson, S., Alemo, J. and Nagy, A. 1998. Cracking of concrete structures due to imposed strains with regard to design of reinforcement. Materials and Structures. 31:442-50. 
Vitharana, N. D., Priestley, M. J. N., and Dean J. A. 1998. Behavior of reinforced concrete structures reservoir wall elements under applied and thermally-induced loading. ACI Structural Journal, Vol. 95, No. 3, May-June, pp. 238-248. 


\section{APPENDIX A - RESULTS OF BASE RESTARAINED WALLS}

\section{A.1 General}

This Appendix presents the remaining results of the parametric study on base restrained walls with no partial side restraint as in Chapter 4. The effect of creep is not considered in the results that are presented in this Appendix. These graphs are demonstrated in order to further discuss the influence of each parameter on the crack width and its variation along the wall length.

\section{A.2 Results of the parametric study}

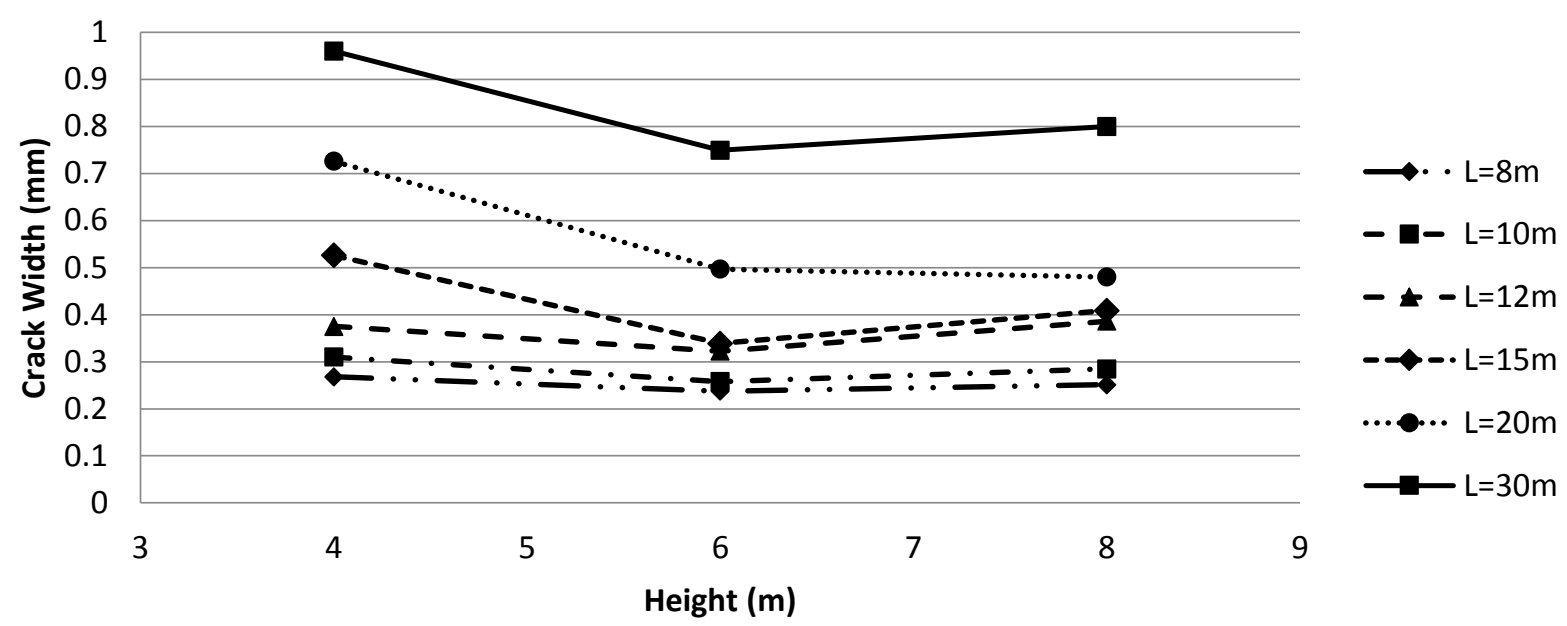

Figure A-1 Effect of wall height on the crack width considering constant wall lengths

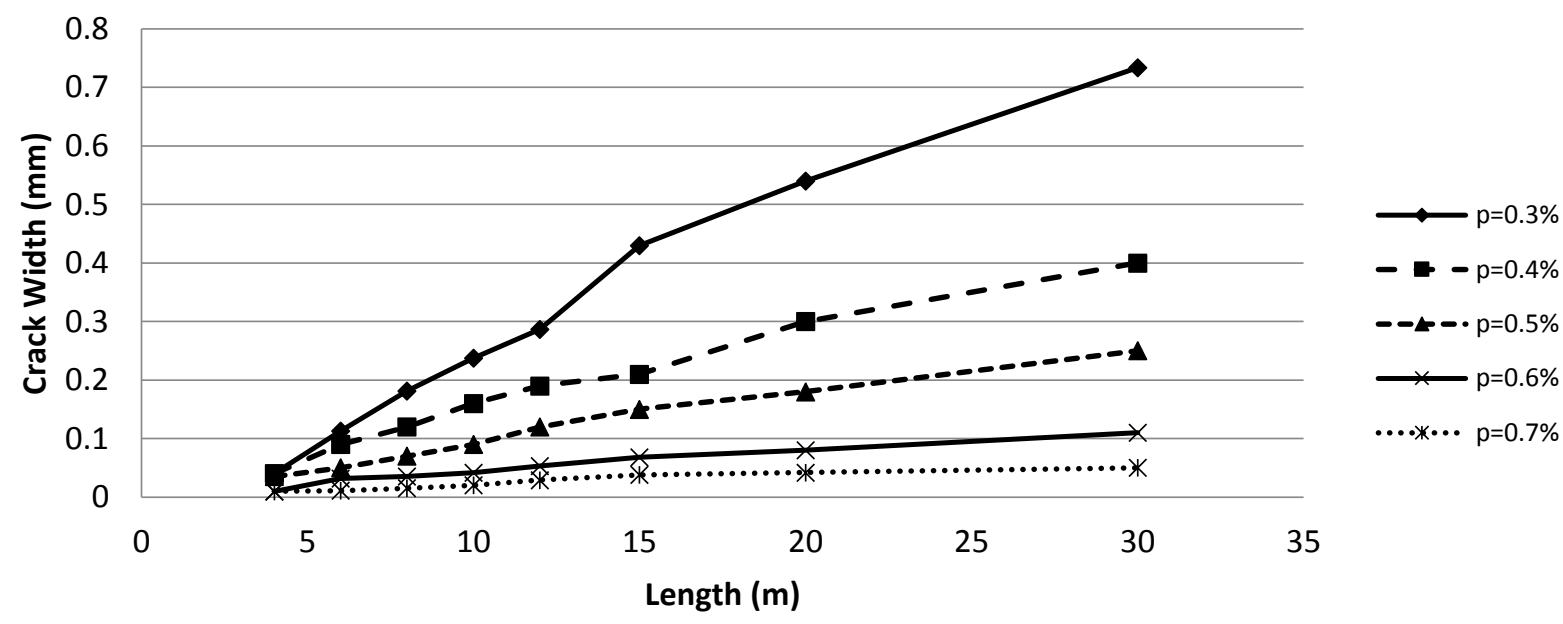

(a) $\mathrm{e}=300 \mu \varepsilon$ 

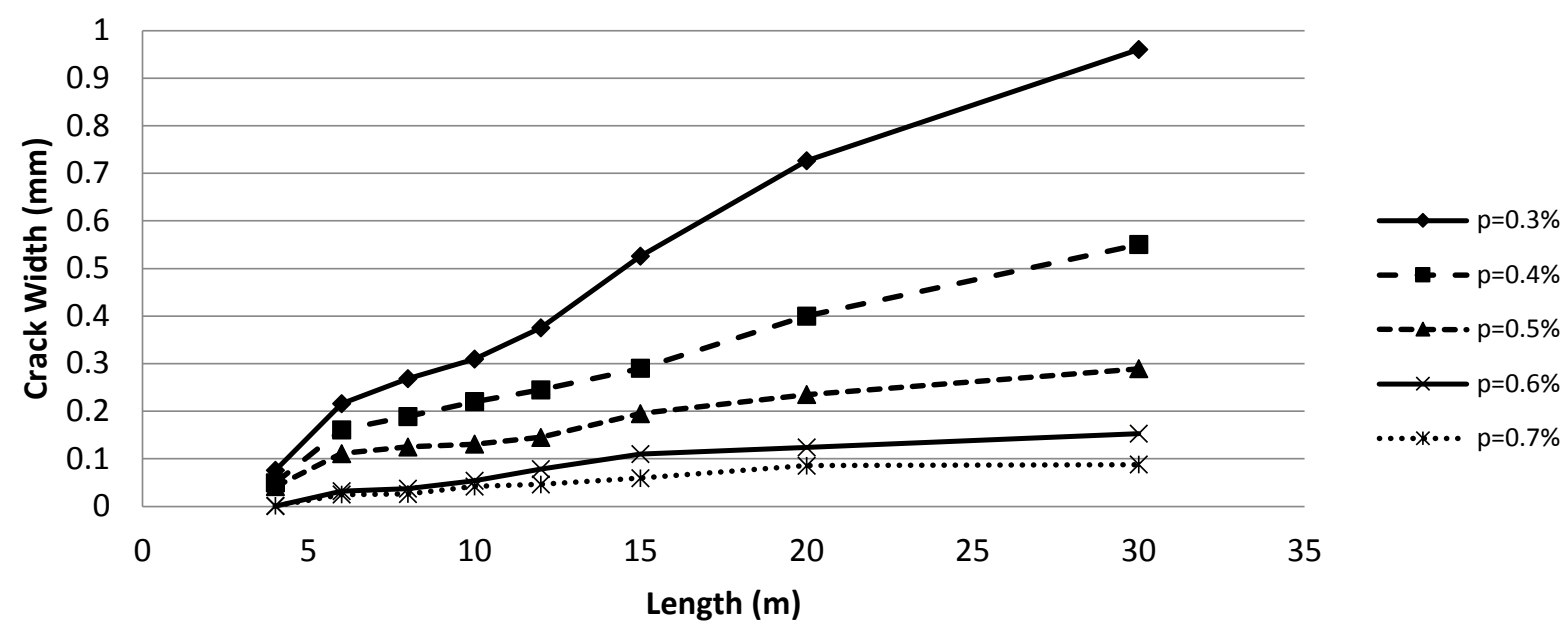

(b) $\mathrm{e}=600 \mu \varepsilon$
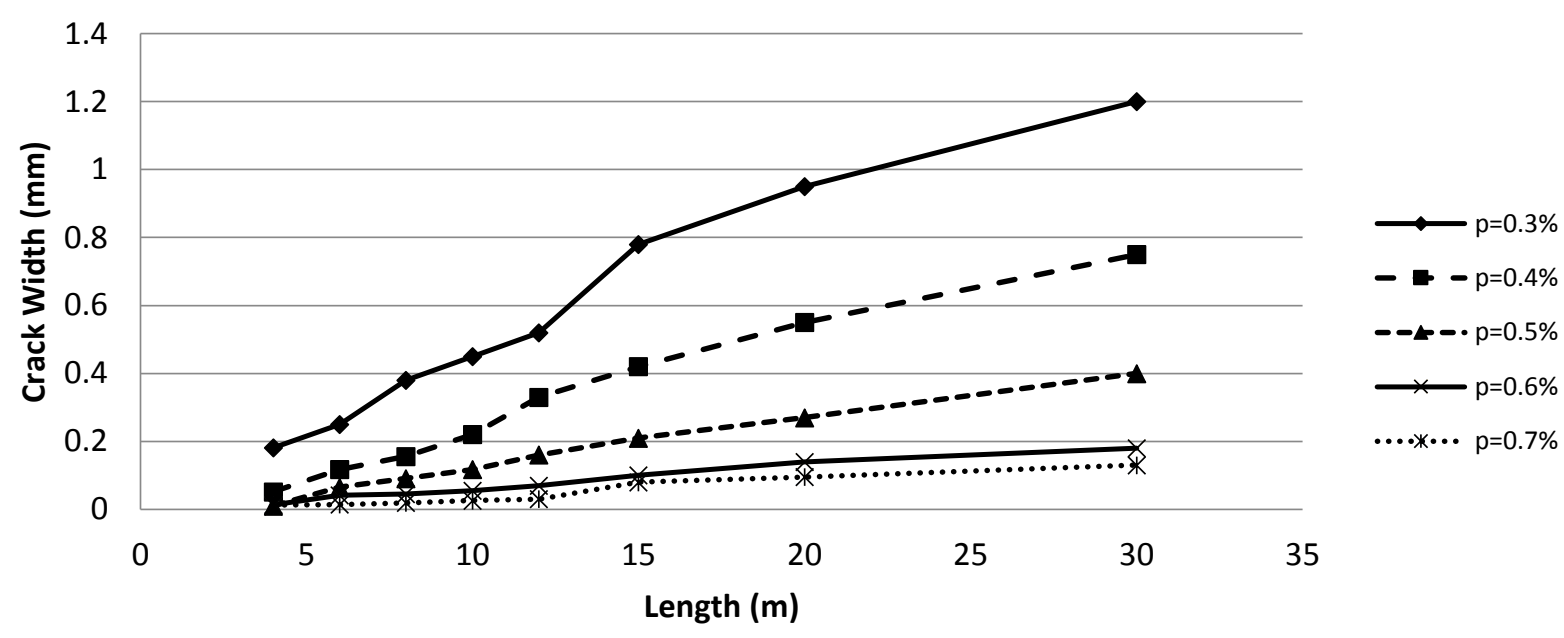

(c) $\mathrm{e}=900 \mu \varepsilon$

Figure A-2 Effect of reinforcement ratio on the crack width considering different climates $(\mathrm{H}=4 \mathrm{~m})$
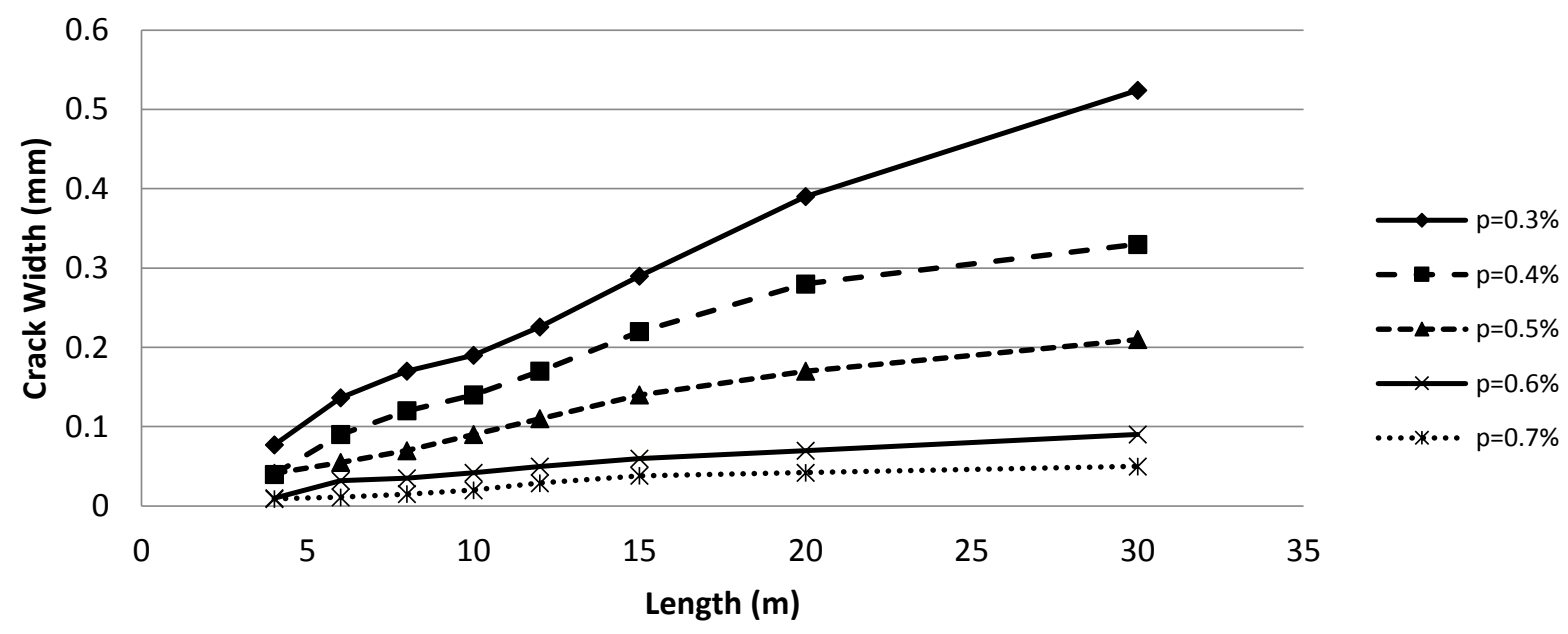

(a) $\mathrm{e}=300 \mu \varepsilon$ 

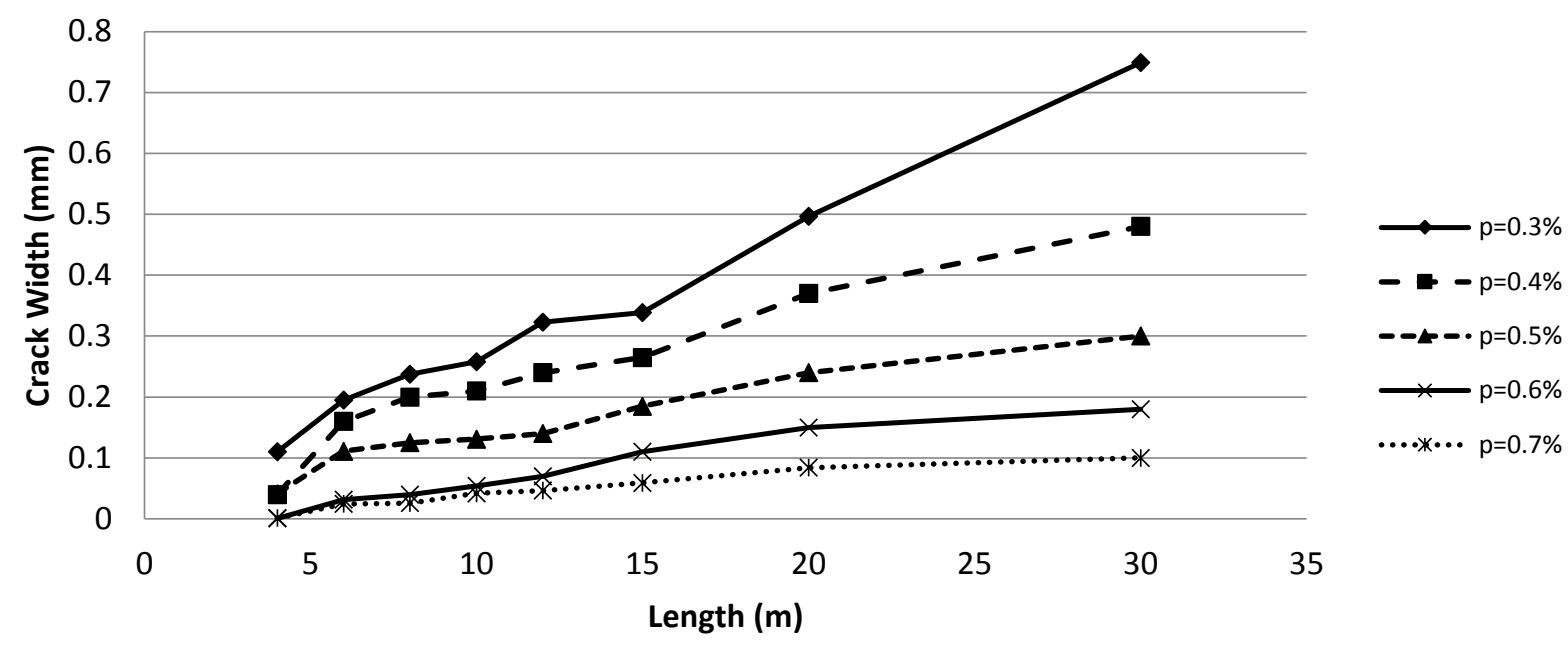

(b) $\mathrm{e}=600 \mu \varepsilon$
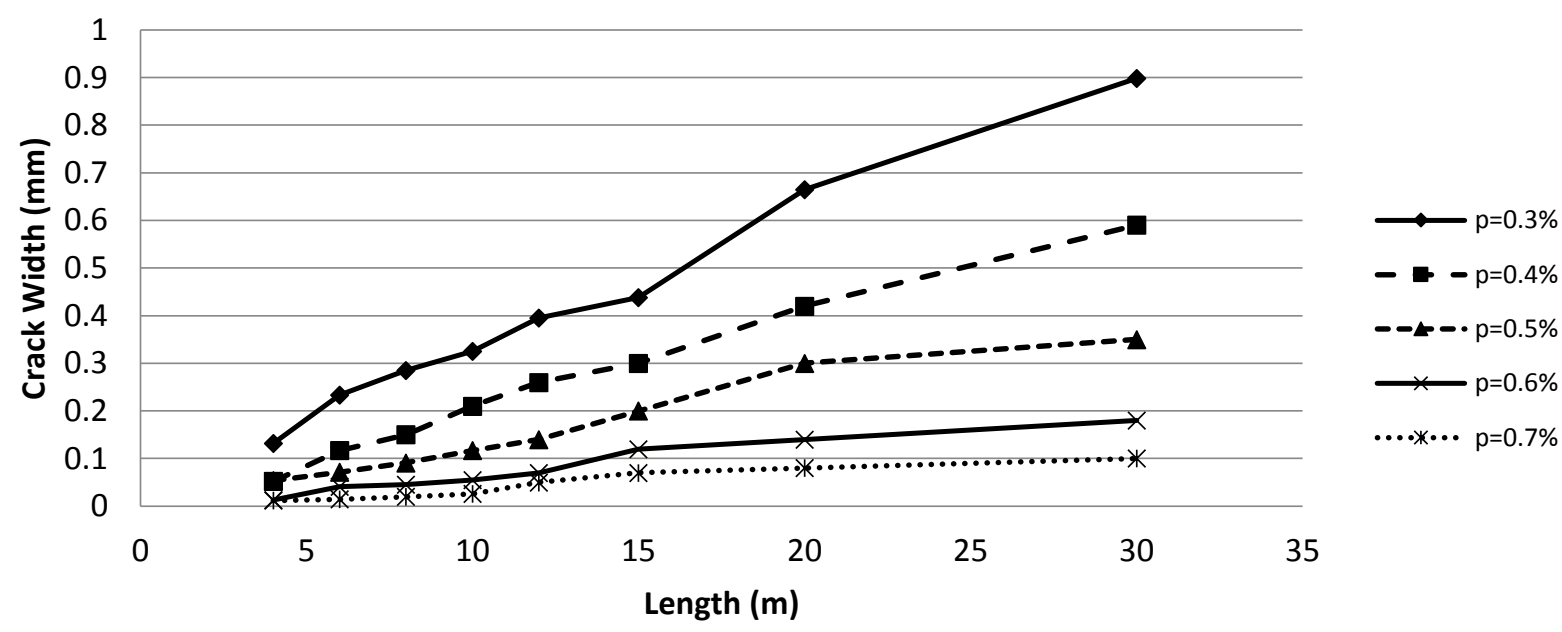

(c) $\mathrm{e}=900 \mu \varepsilon$

Figure A-3 Effect of reinforcement ratio on the crack width considering different climates $(\mathrm{H}=6 \mathrm{~m})$

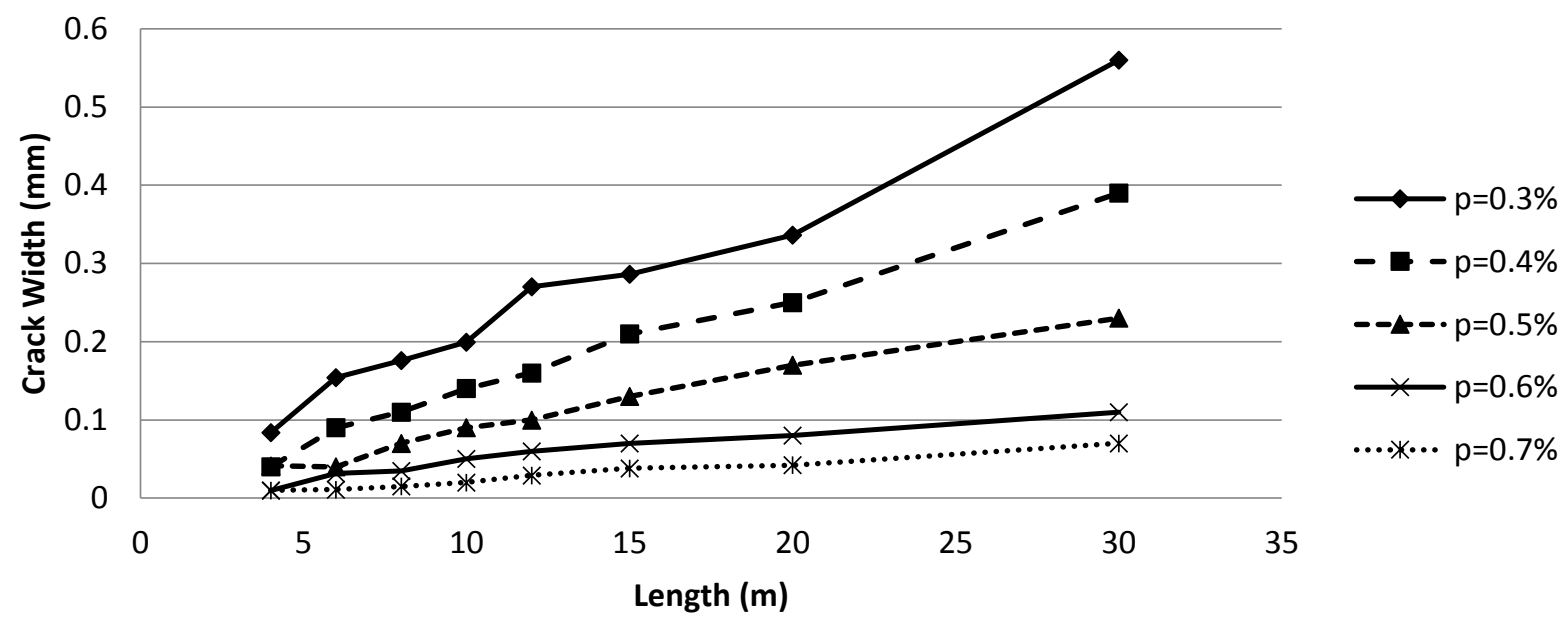

(a) $\mathrm{e}=300 \mu \varepsilon$ 


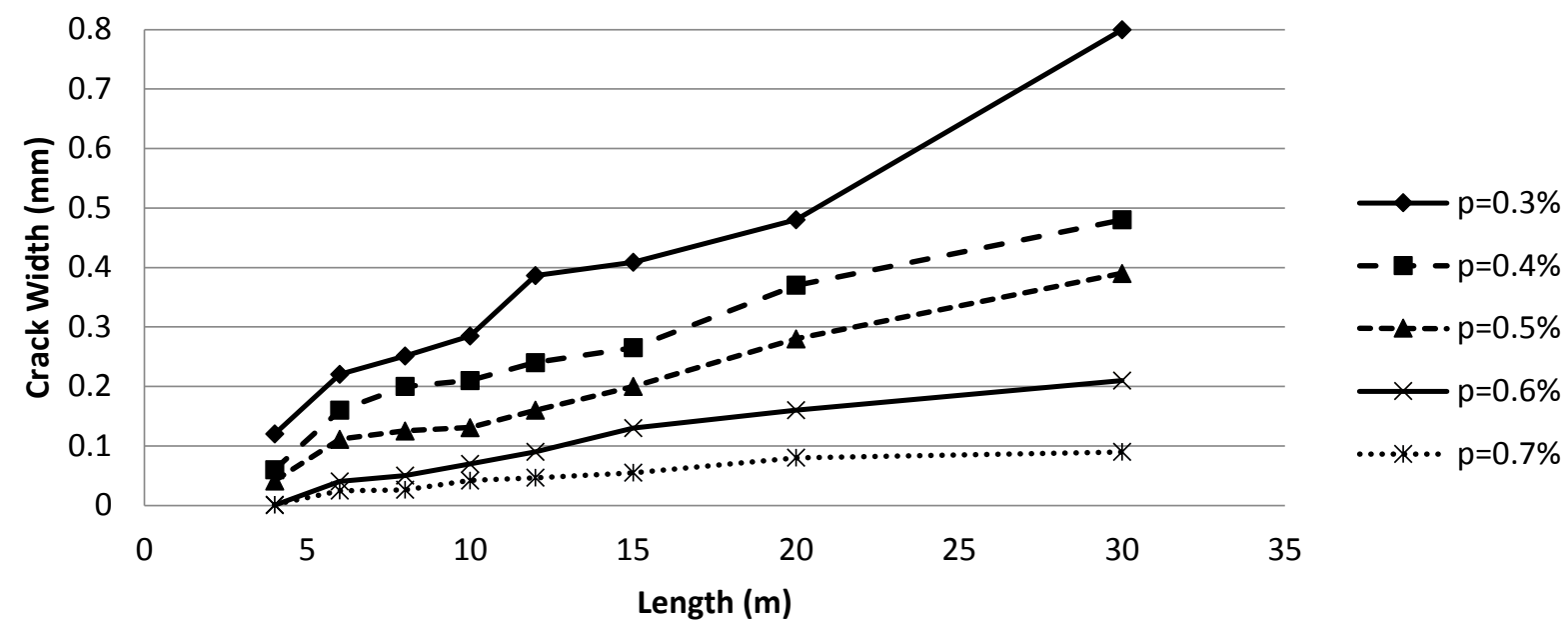

(b) $\mathrm{e}=600 \mu \varepsilon$

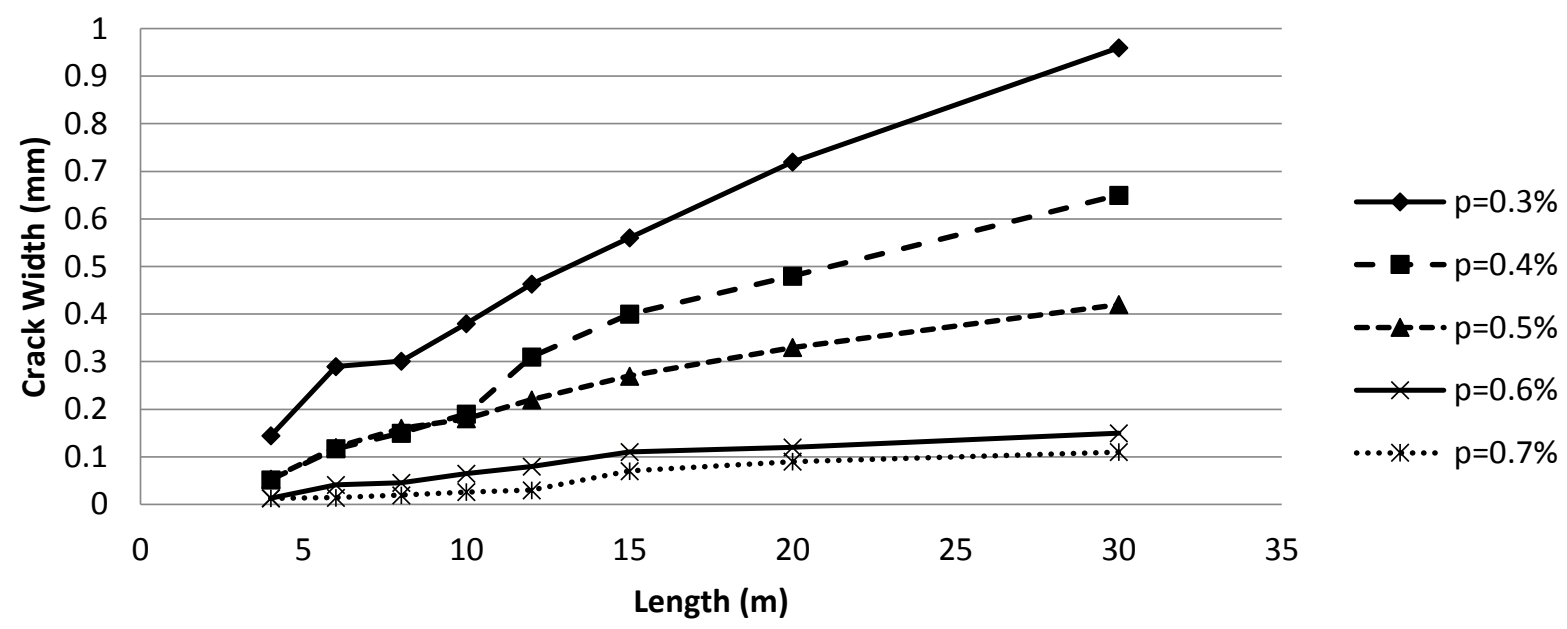

(c) $\mathrm{e}=900 \mu \varepsilon$

Figure A-4 Effect of reinforcement ratio on the crack width considering different climates $(\mathrm{H}=8 \mathrm{~m})$

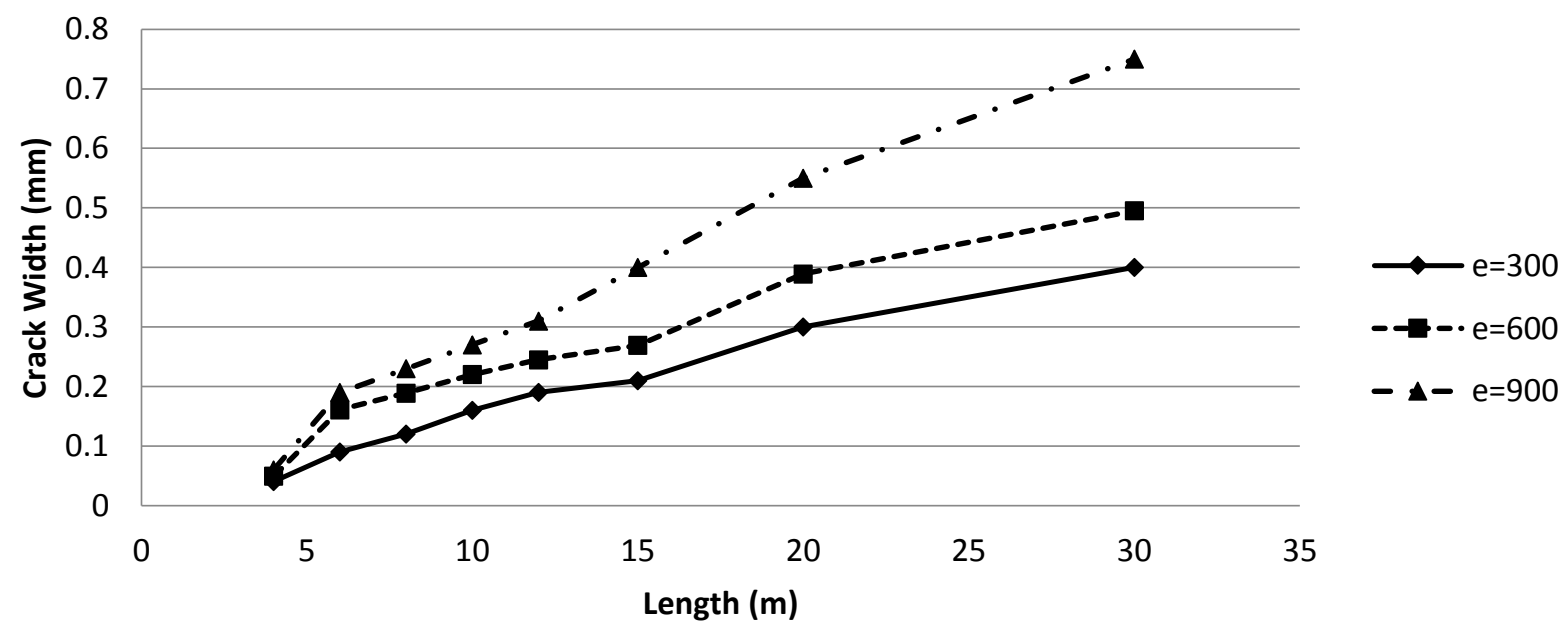

(a) $\rho=0.4 \%$ 

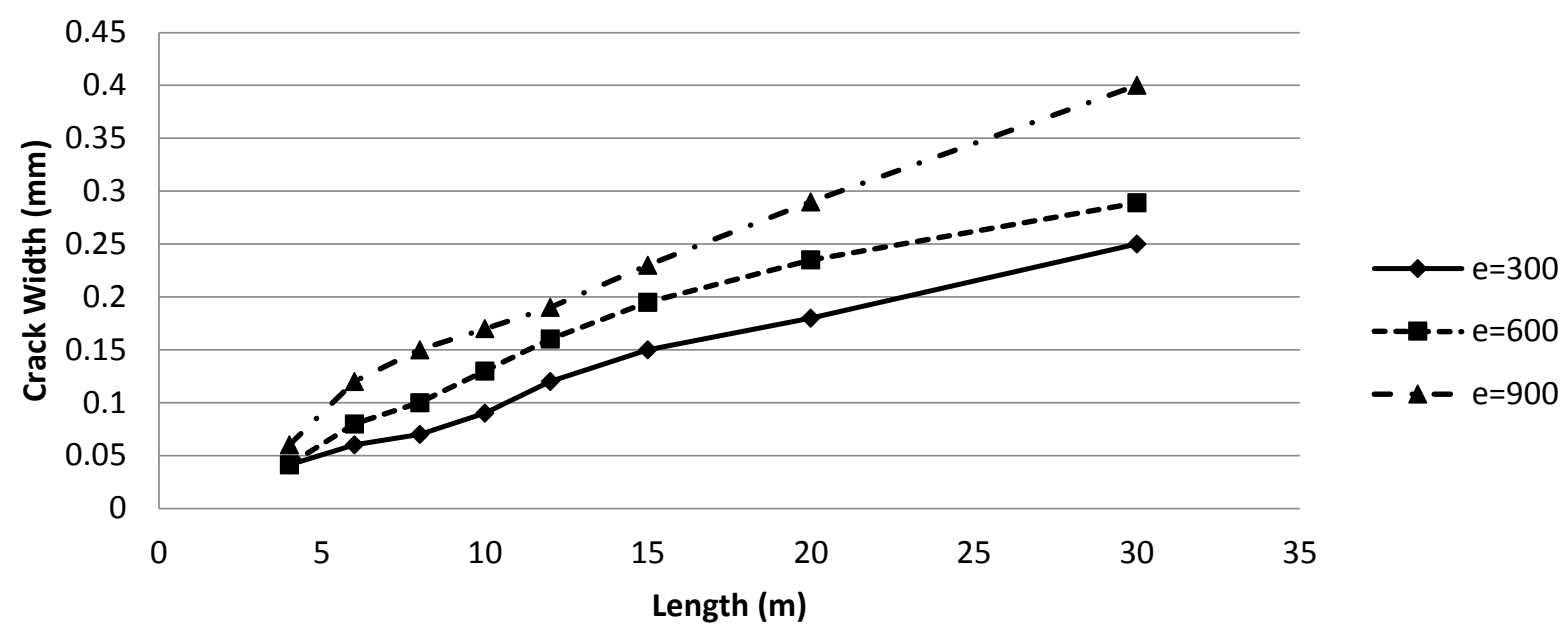

(b) $\rho=0.5 \%$
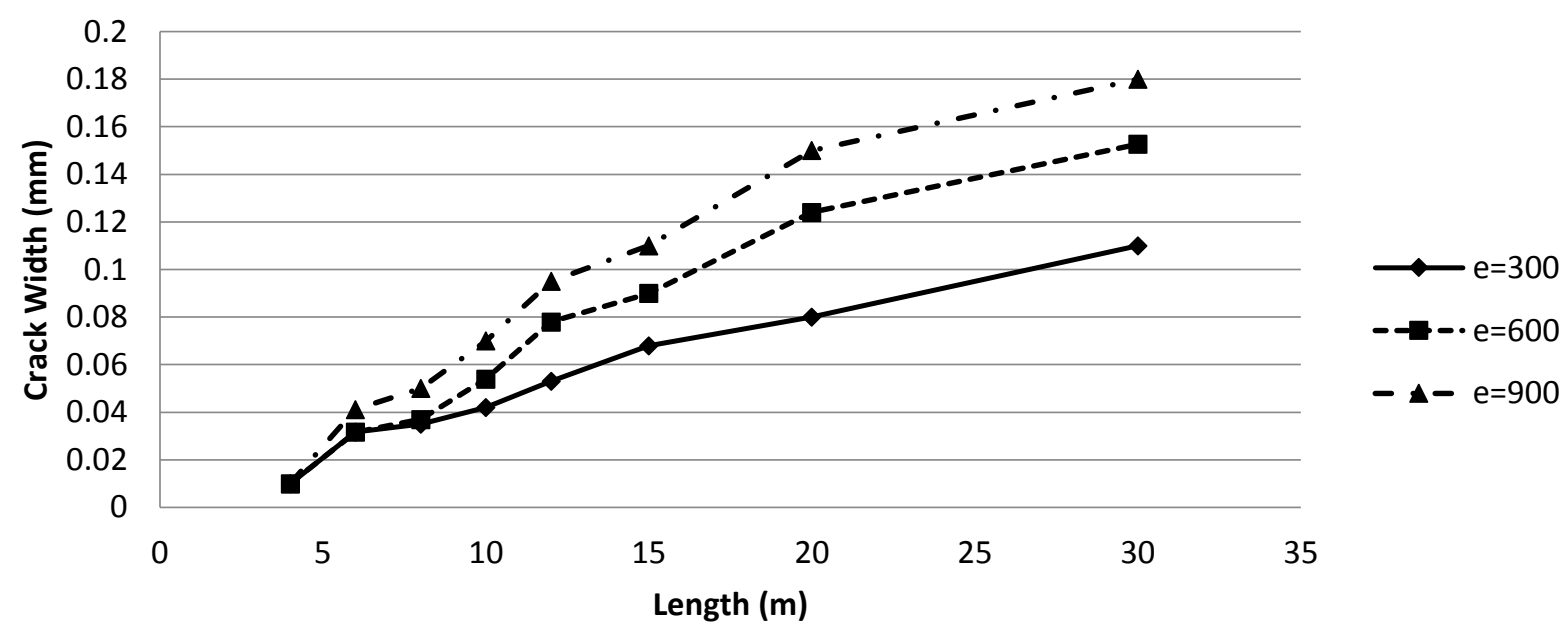

(c) $\rho=0.6 \%$

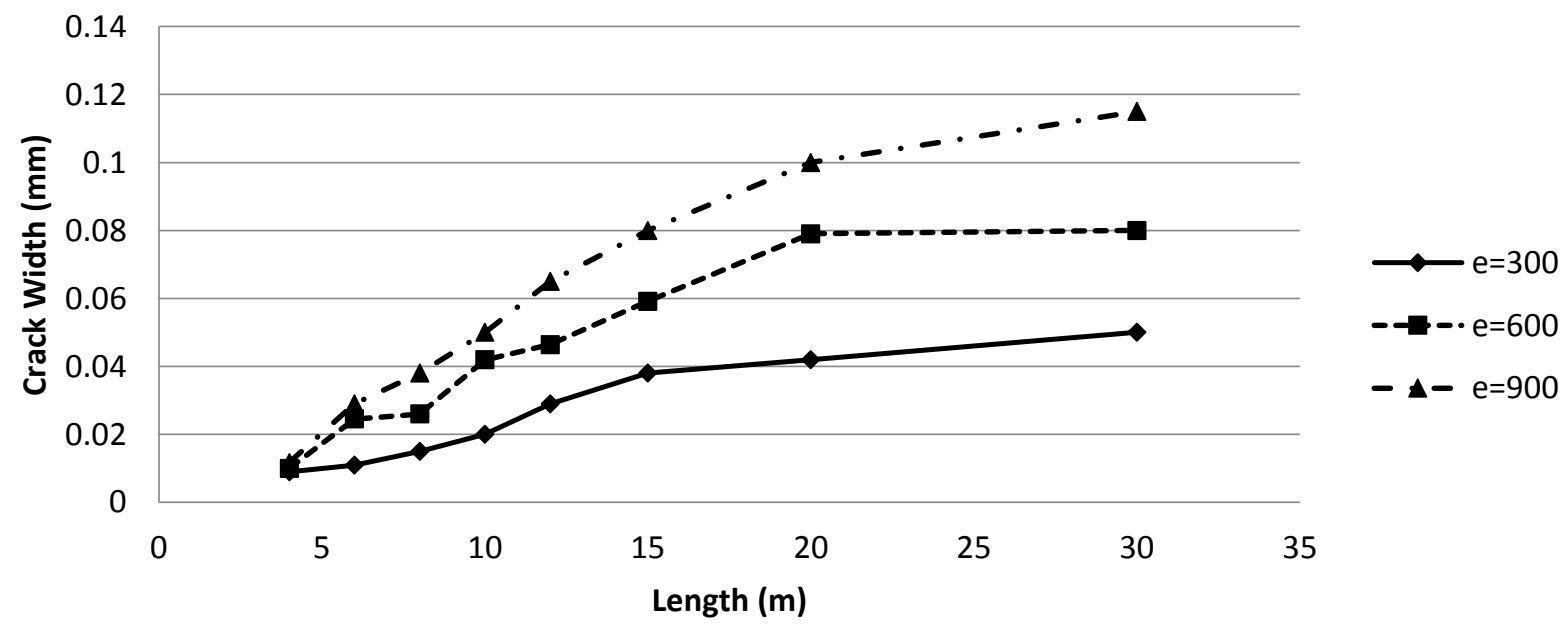

(d) $\rho=0.7 \%$

Figure A-5 Effect of volumetric strain on the crack width considering different steel ratios $(\mathrm{H}=4 \mathrm{~m})$ 

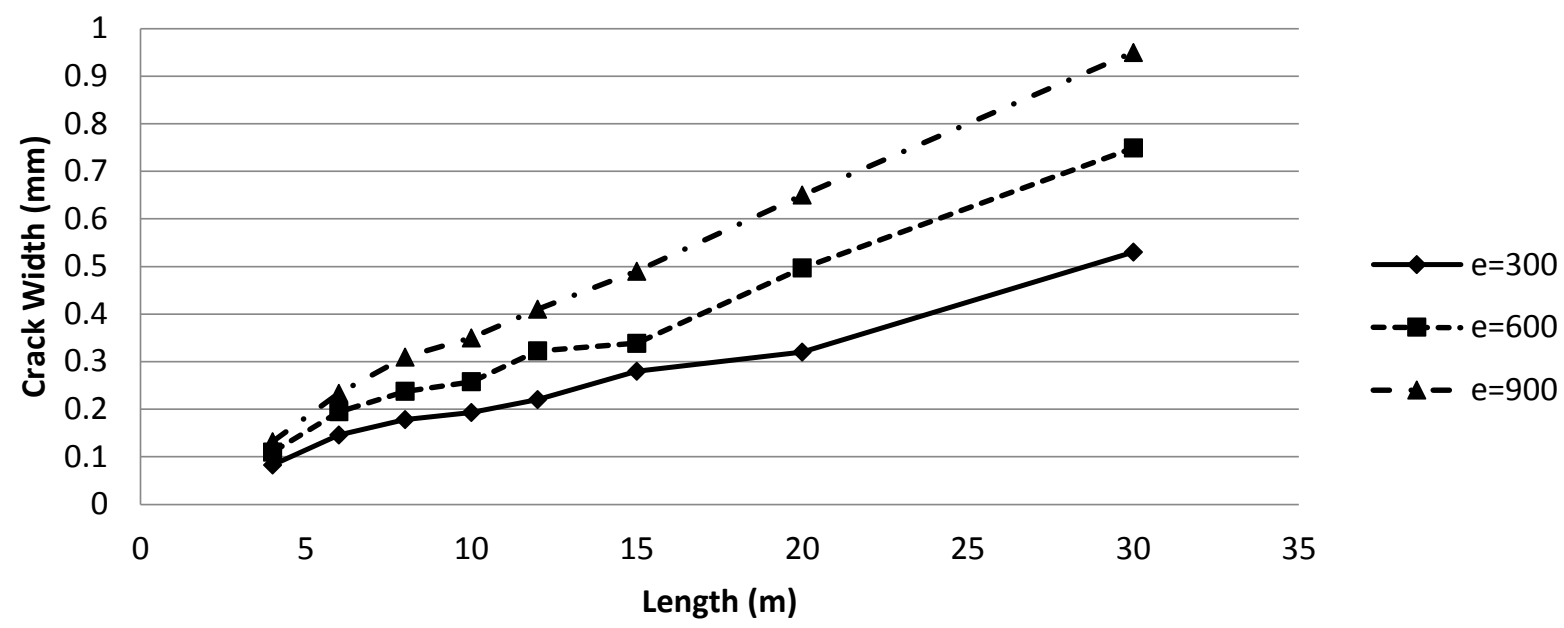

(a) $\rho=0.3 \%$
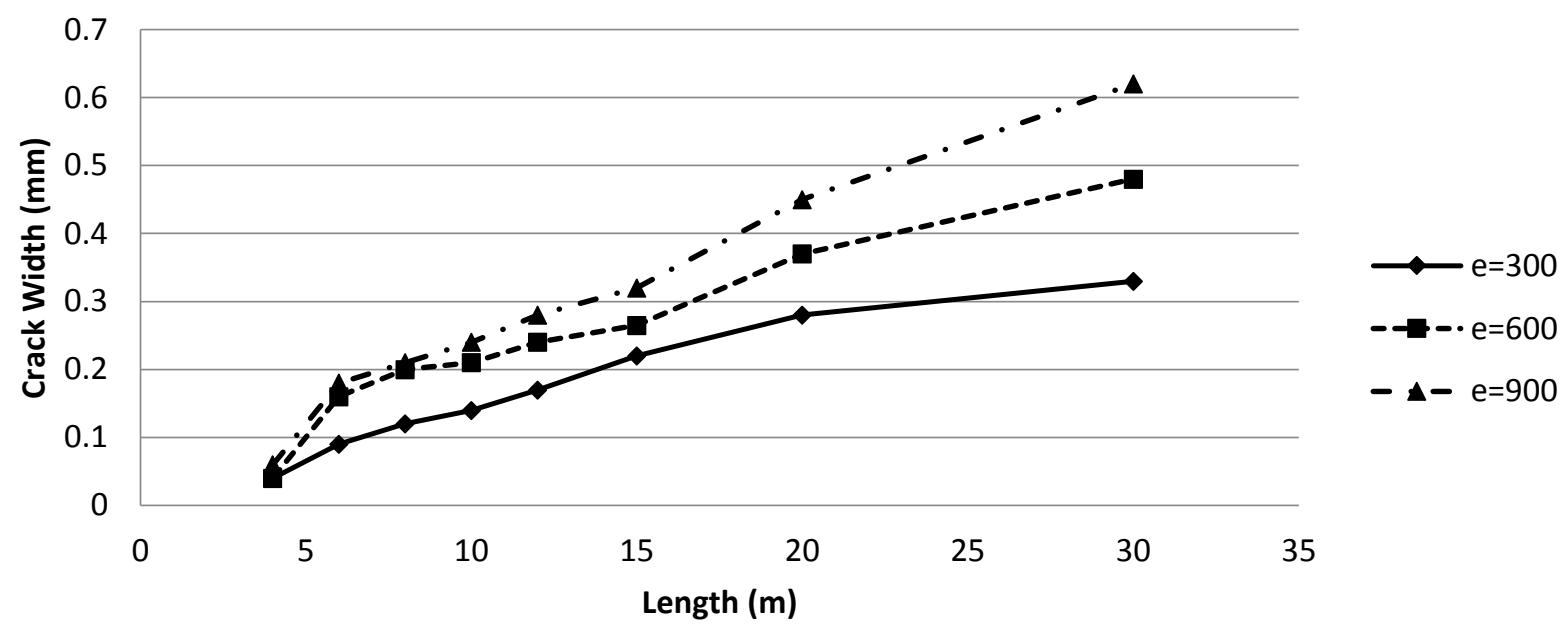

(b) $\rho=0.4 \%$
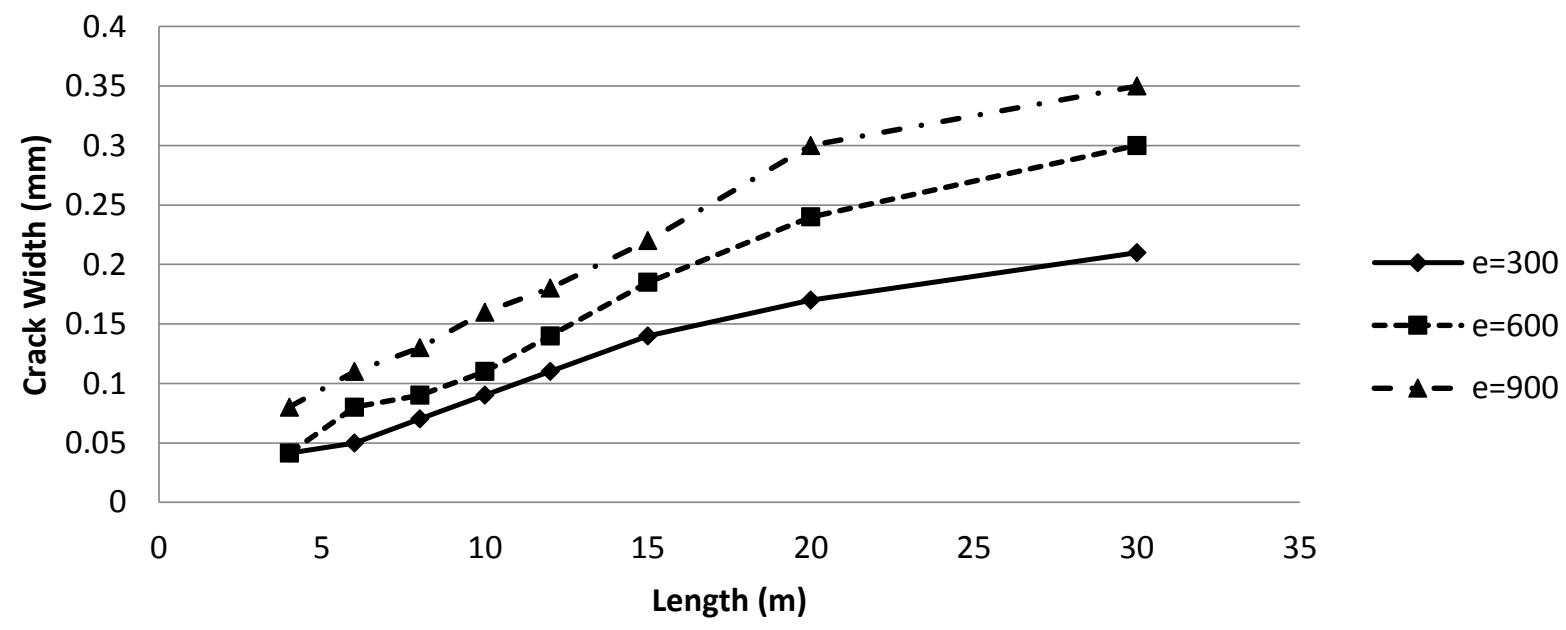

(c) $\rho=0.5 \%$ 

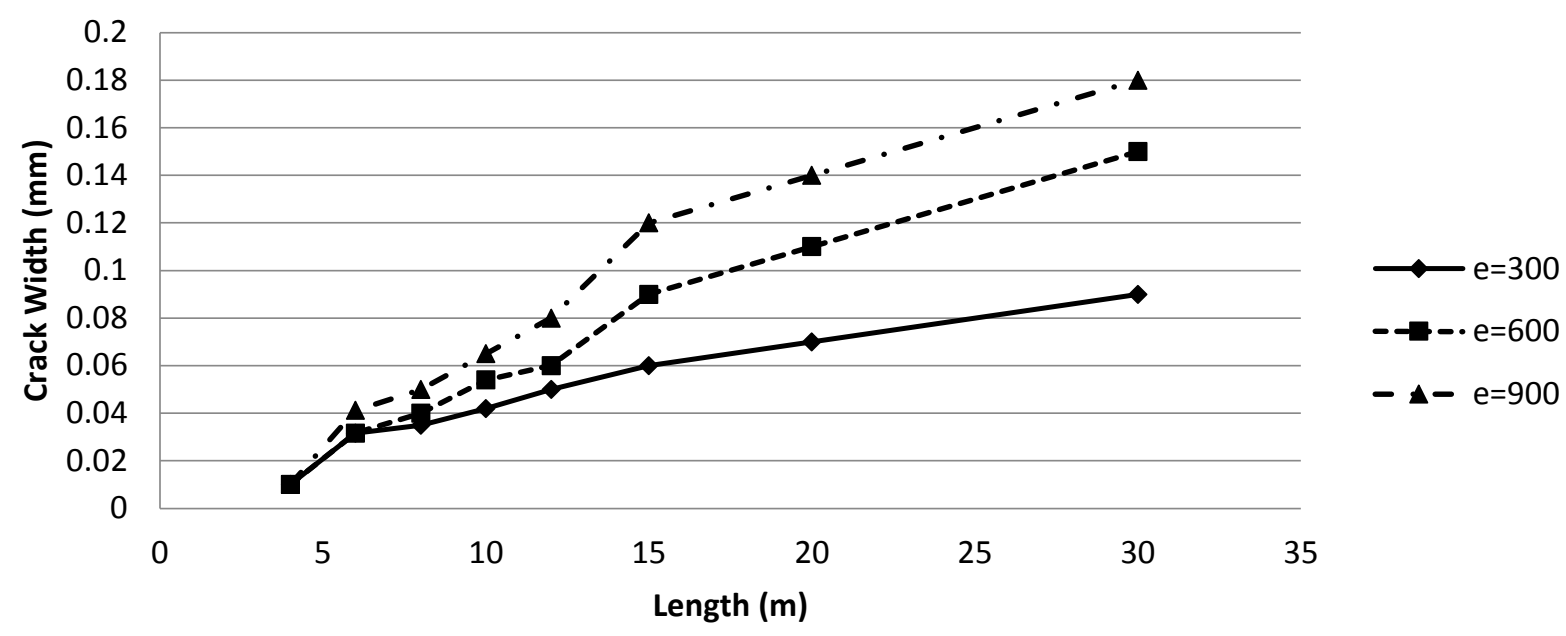

(d) $\rho=0.6 \%$

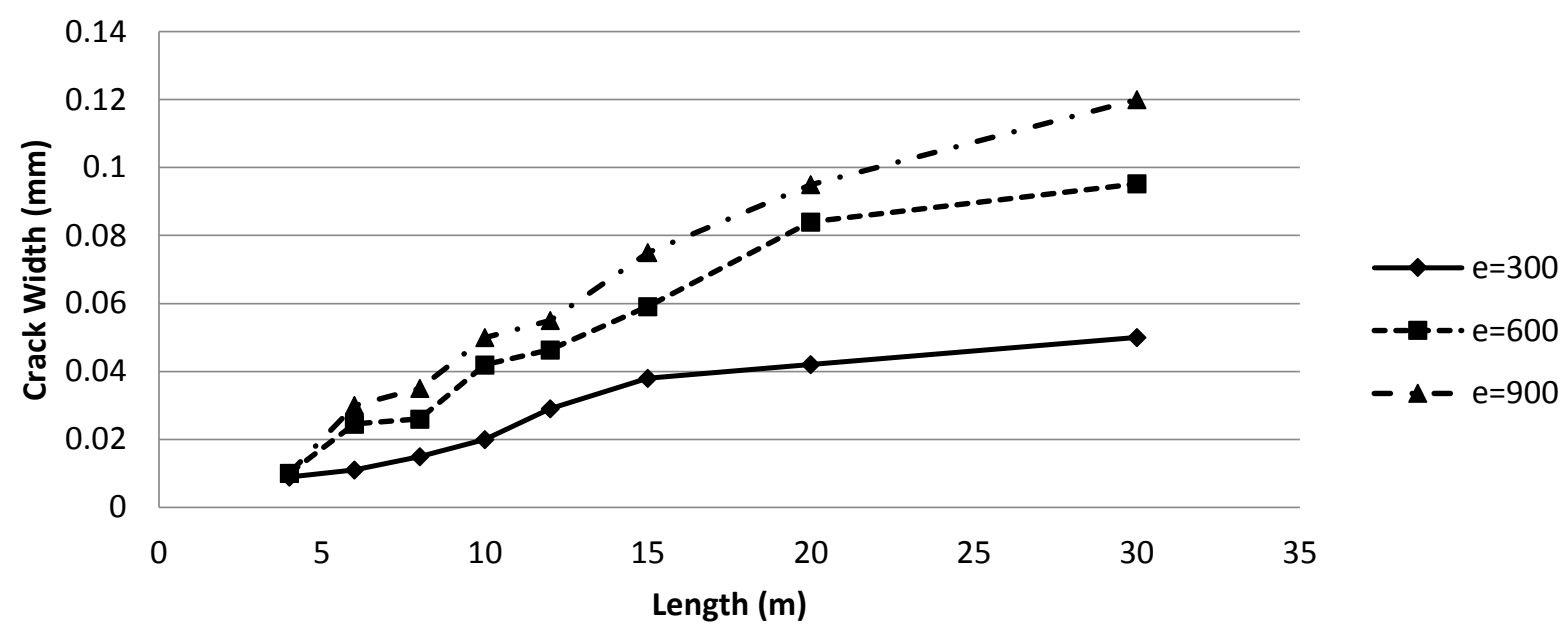

(e) $\rho=0.7 \%$

Figure A-6 Effect of volumetric strain on the crack width considering different steel ratios $(\mathrm{H}=6 \mathrm{~m})$

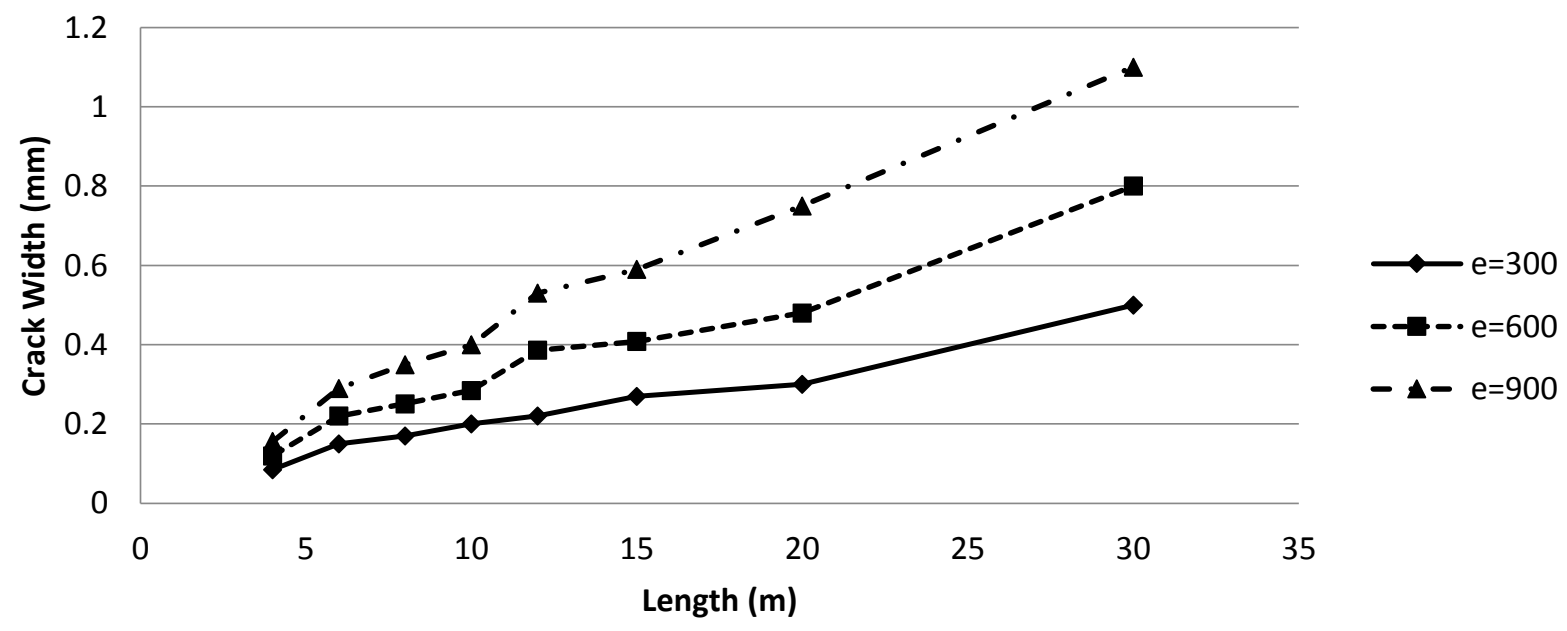

(a) $\rho=0.3 \%$ 

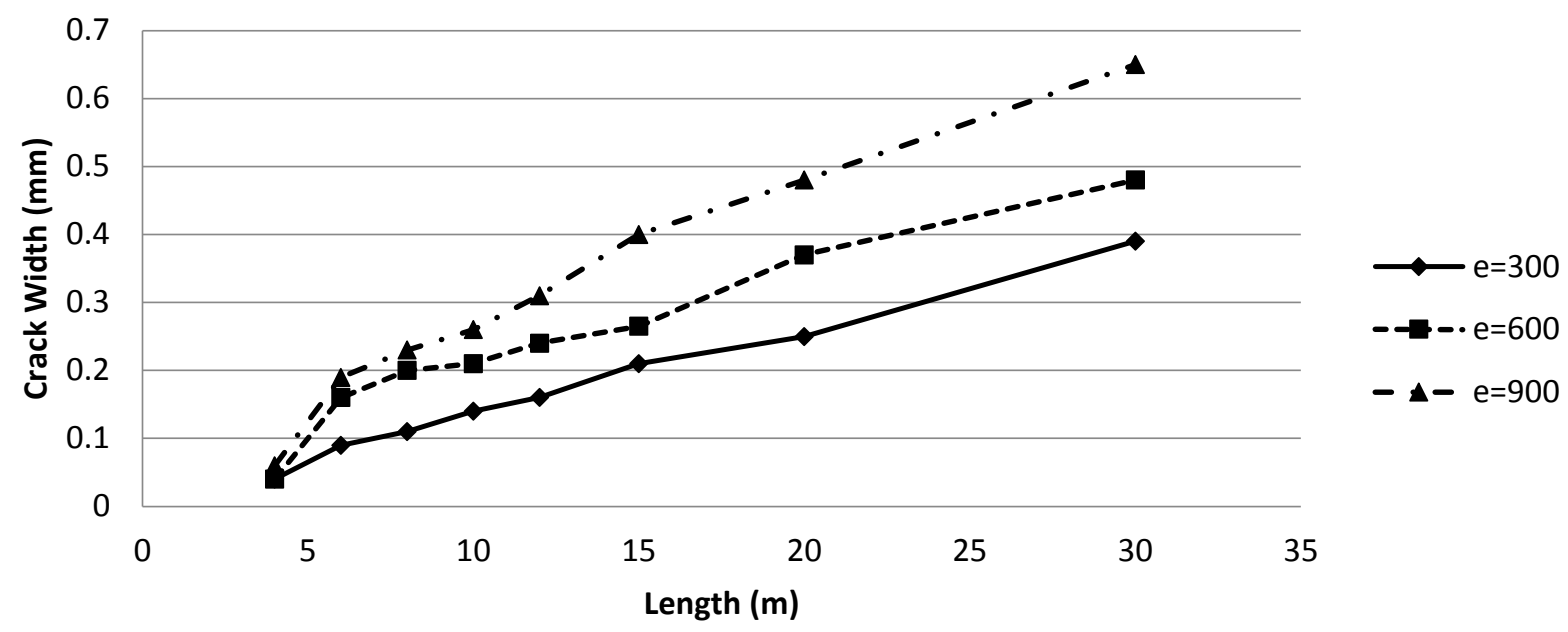

(b) $\rho=0.4 \%$
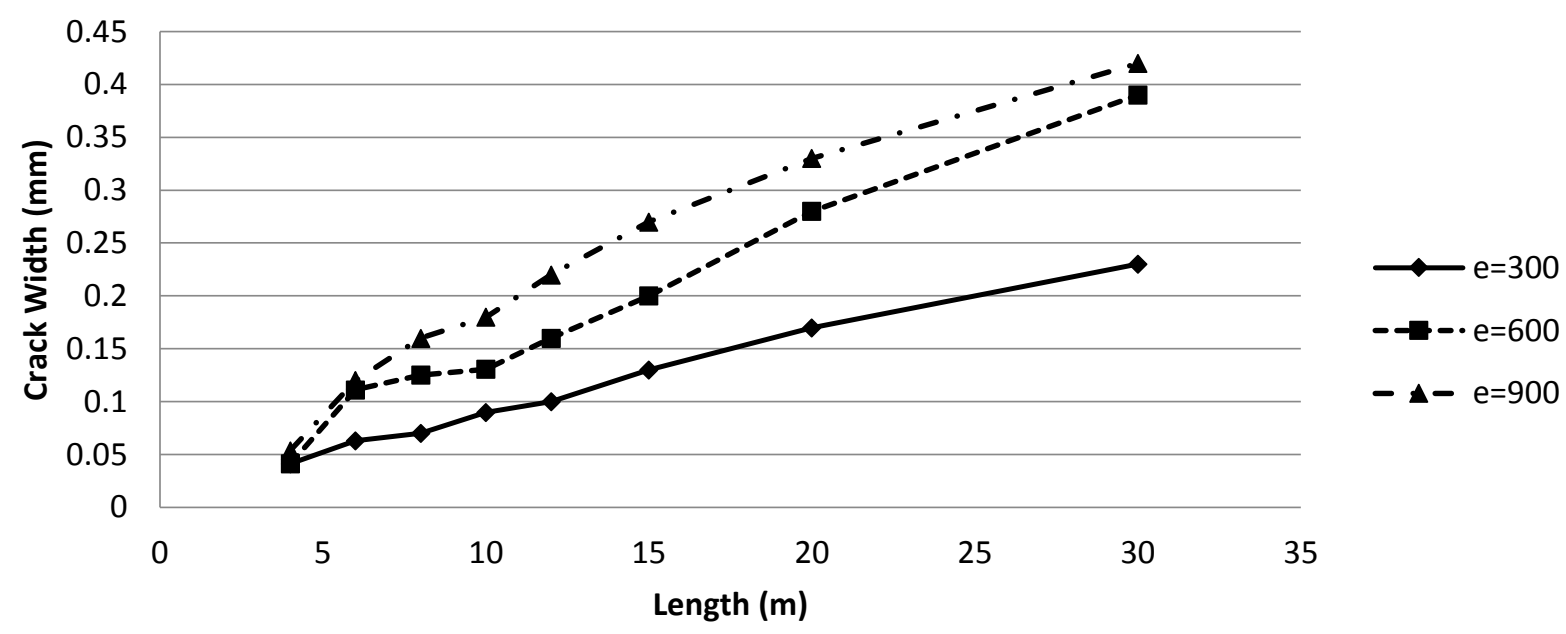

(c) $\rho=0.5 \%$
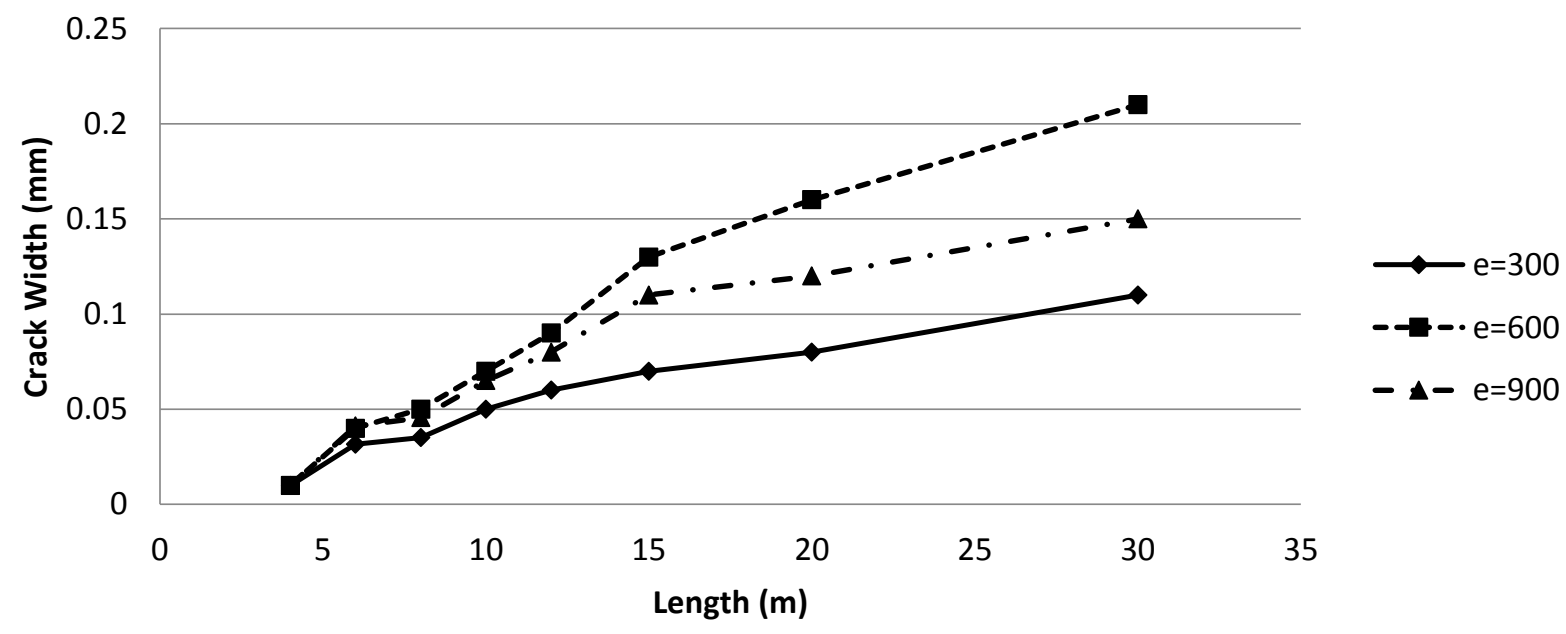

(d) $\rho=0.6 \%$ 


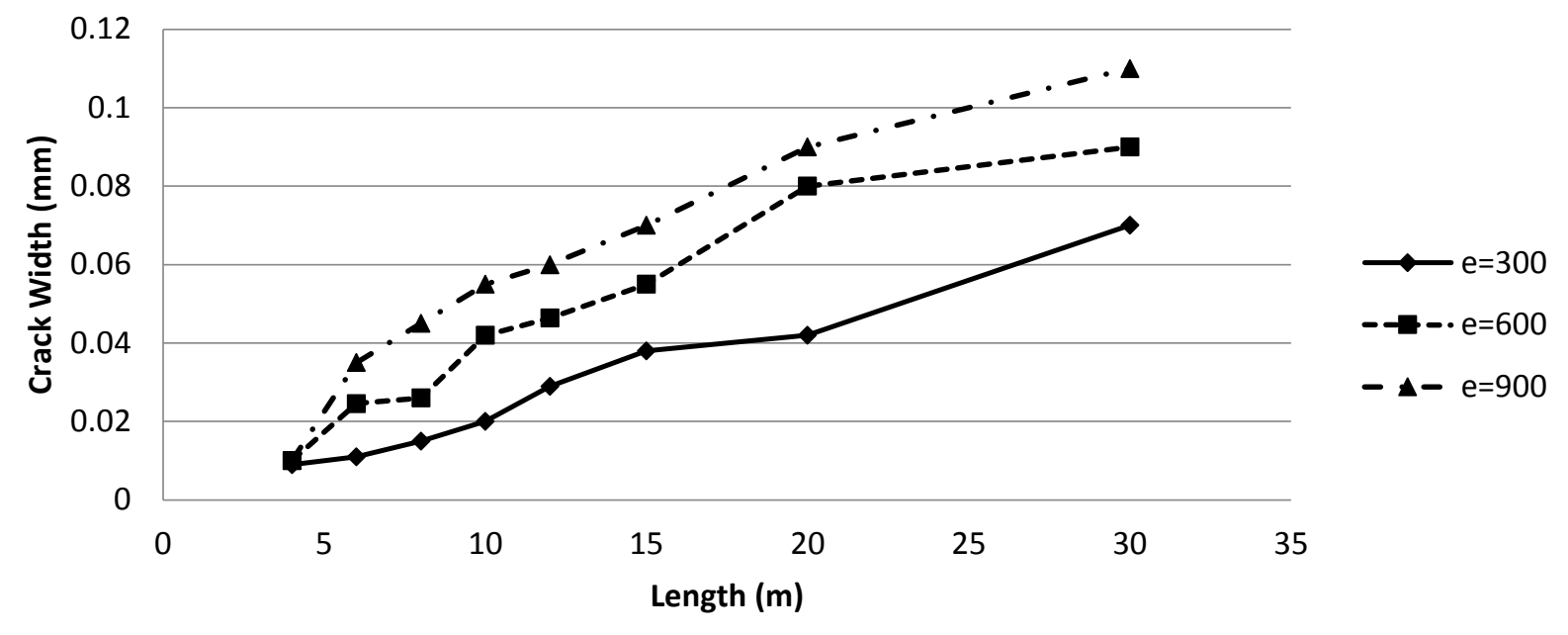

(e) $\rho=0.7 \%$

Figure A-7 Effect of volumetric strain on the crack width considering different steel ratios $(\mathrm{H}=8 \mathrm{~m})$
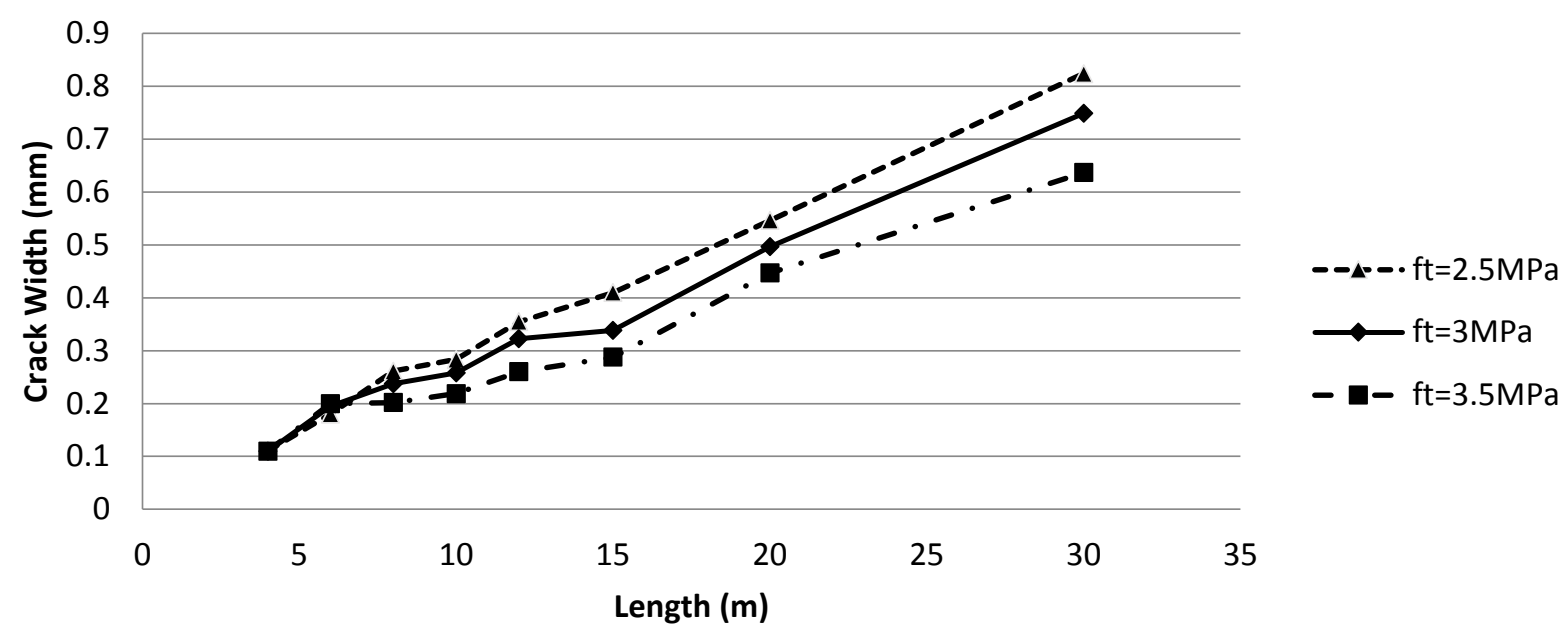

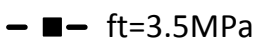

(a) $\mathrm{H}=6 \mathrm{~m}$
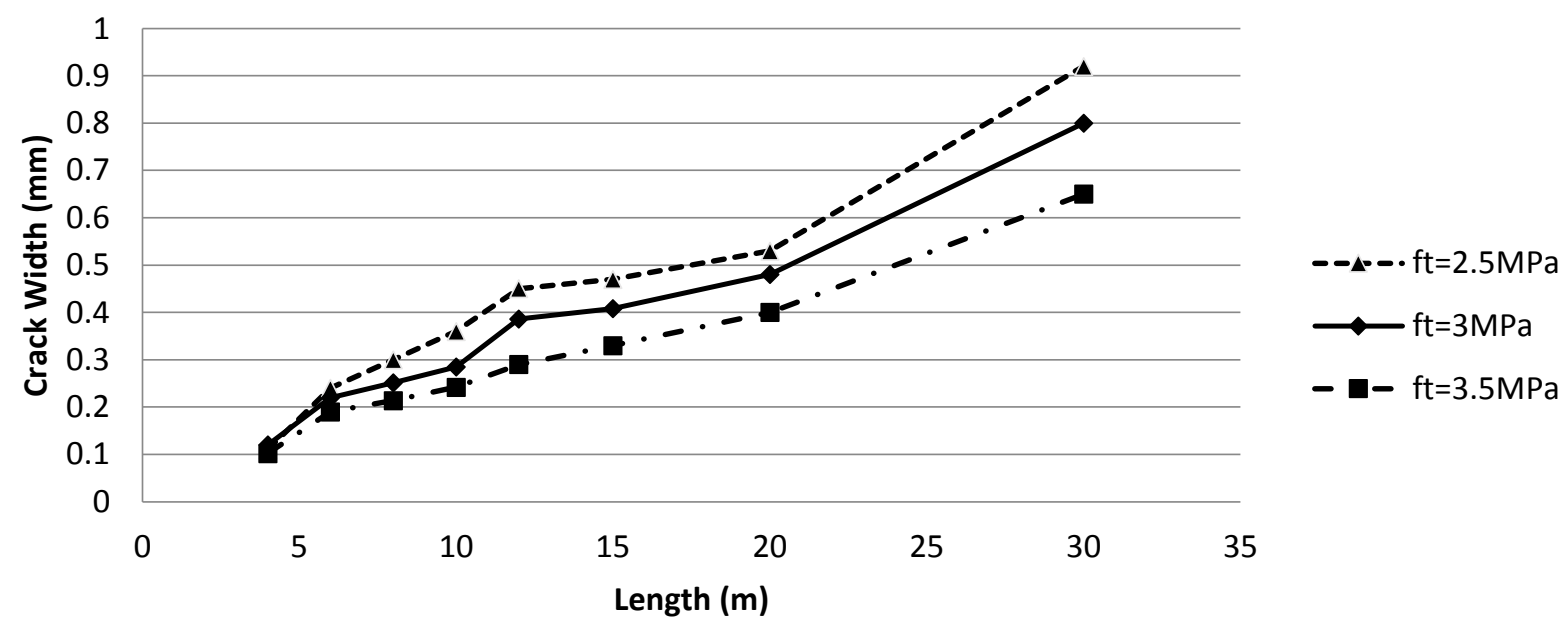

(b) $\mathrm{H}=8 \mathrm{~m}$

Figure A-8 Effect of concrete tensile strength on the crack width $(\rho=0.3 \%)$ 

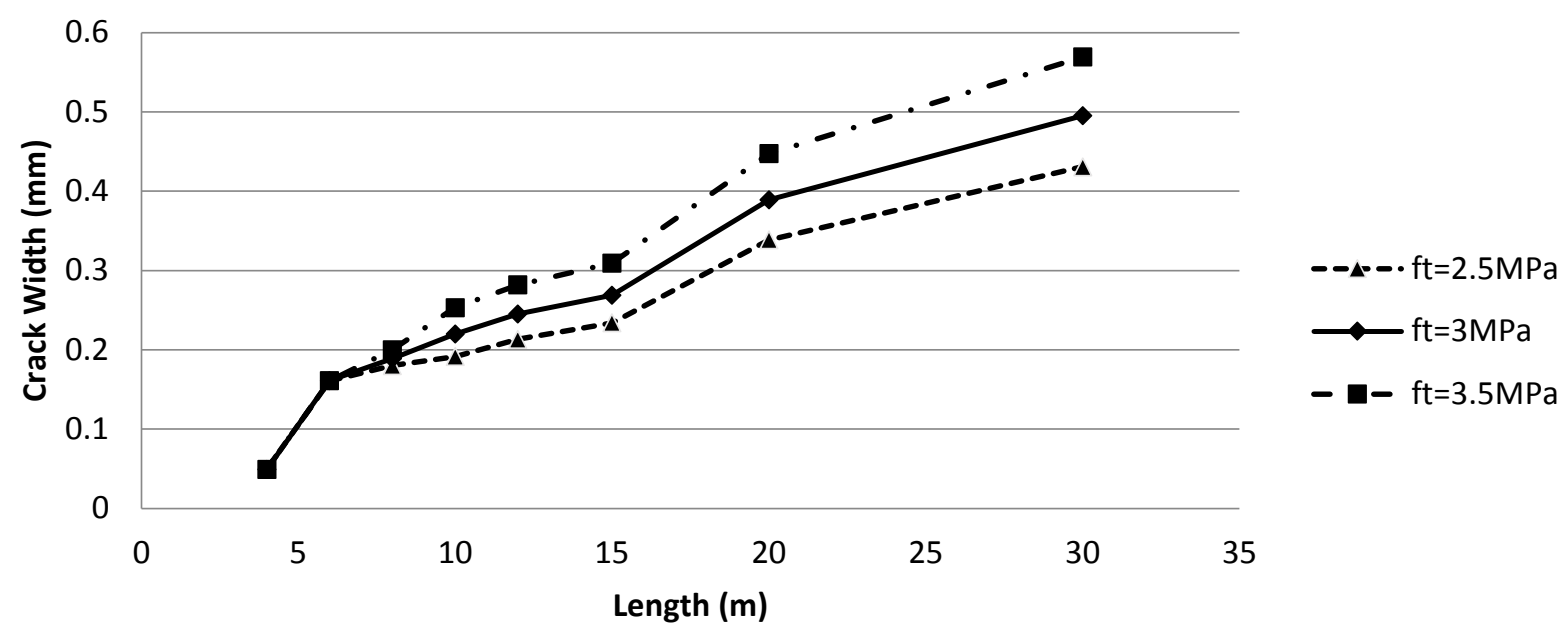

(a) $\rho=0.4 \%$
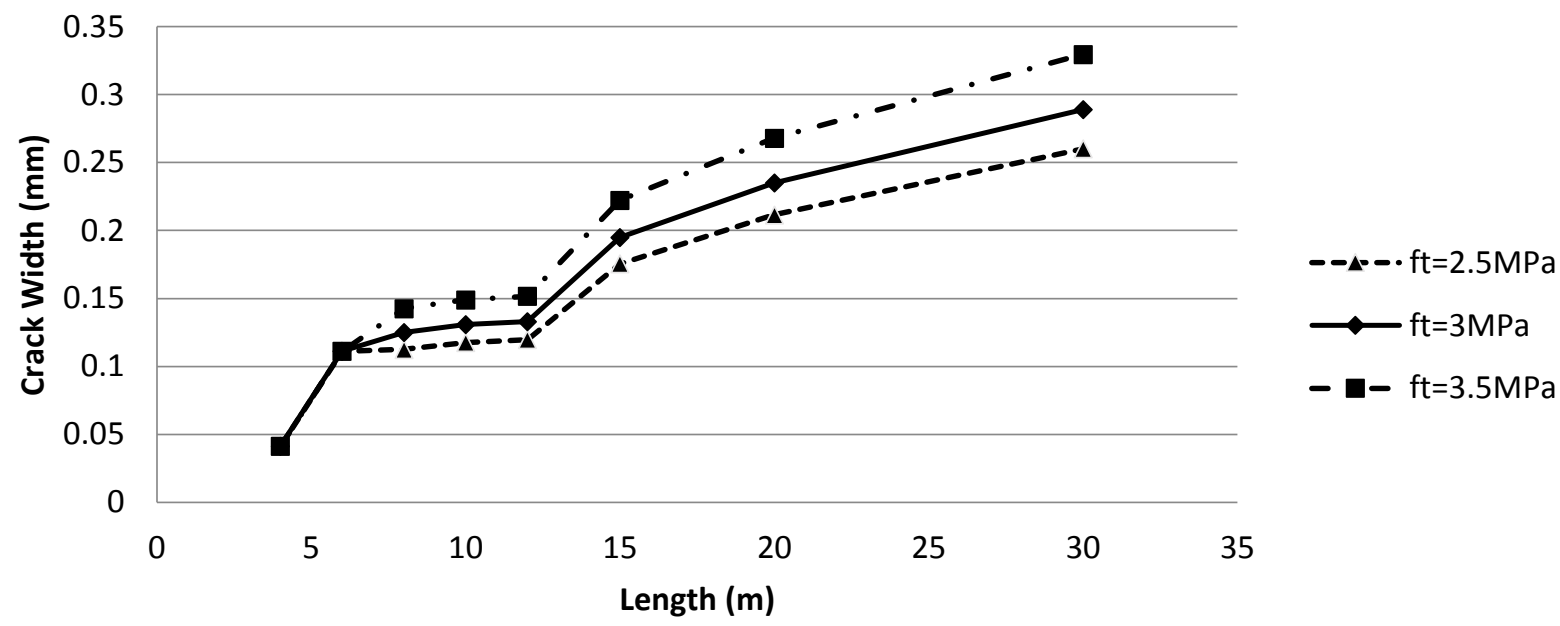

(b) $\rho=0.5 \%$

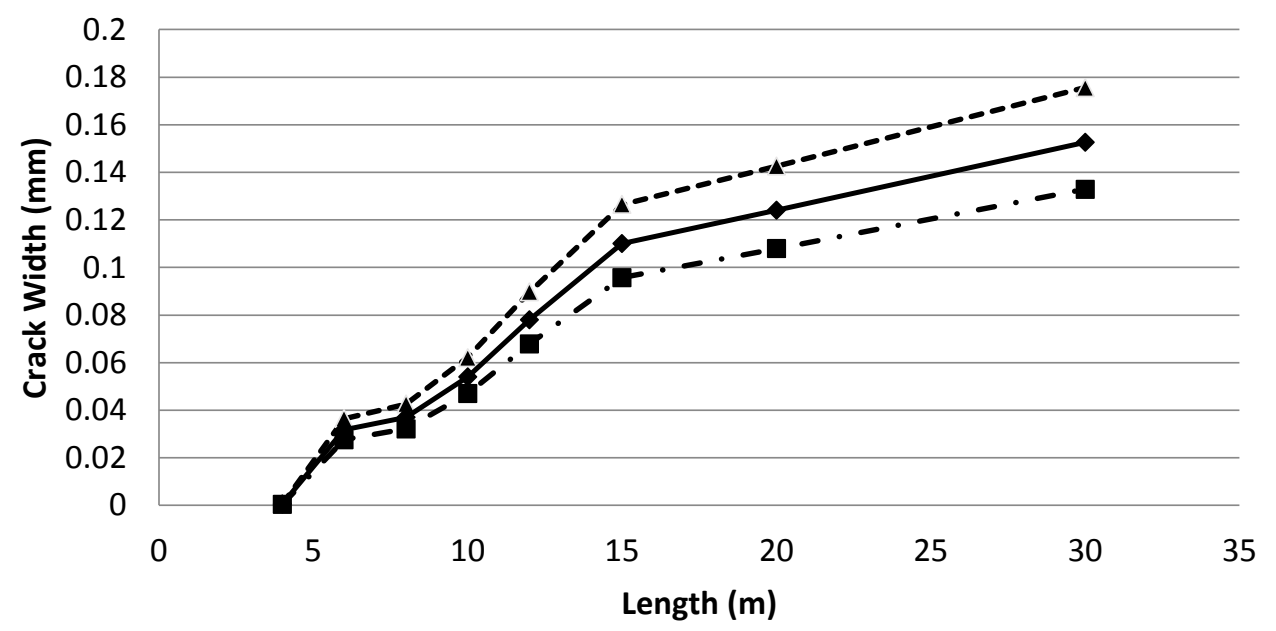

$--\Delta \cdot-\cdot \mathrm{ft}=2.5 \mathrm{MPa}$

$\longrightarrow \mathrm{ft}=3 \mathrm{MPa}$

- $\mathbf{-} \mathrm{ft}=3.5 \mathrm{MPa}$

(c) $\rho=0.6 \%$ 


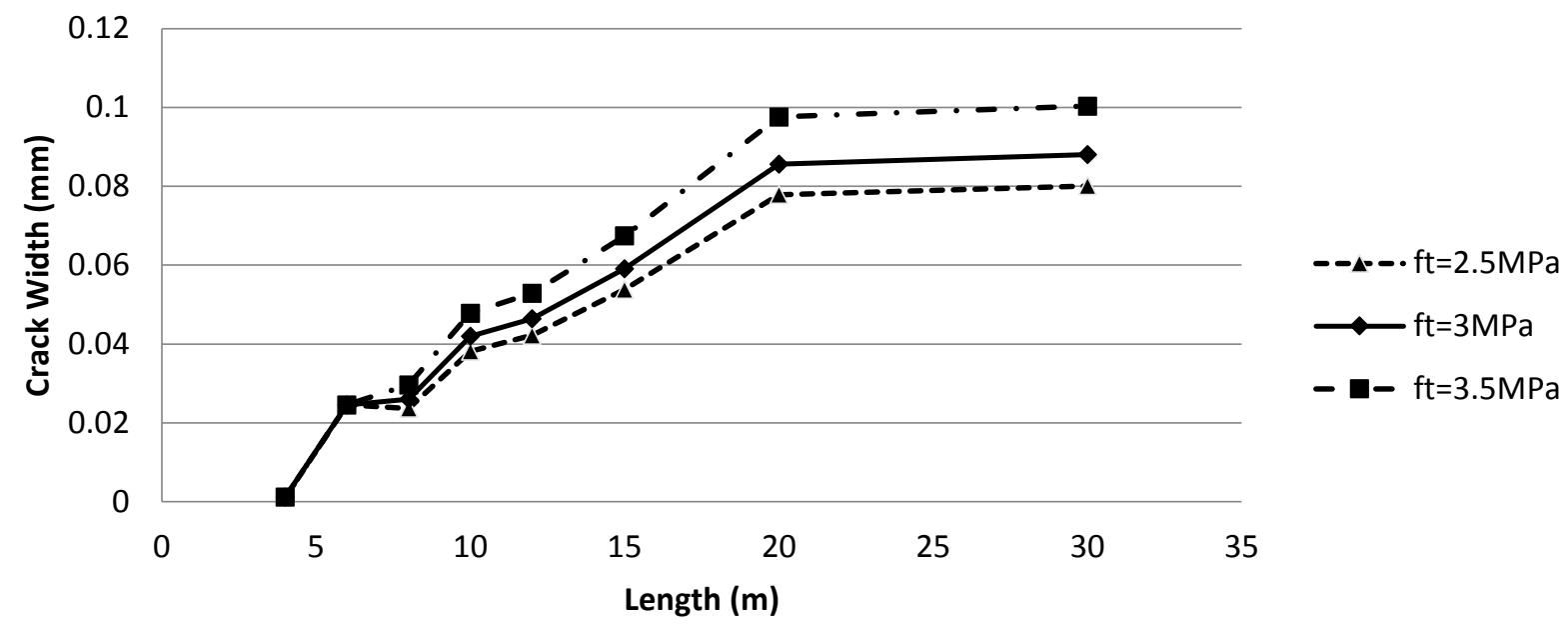

(d) $\rho=0.7 \%$

Figure A-9 Effect of concrete tensile strength on the crack width $(\mathrm{H}=4 \mathrm{~m})$
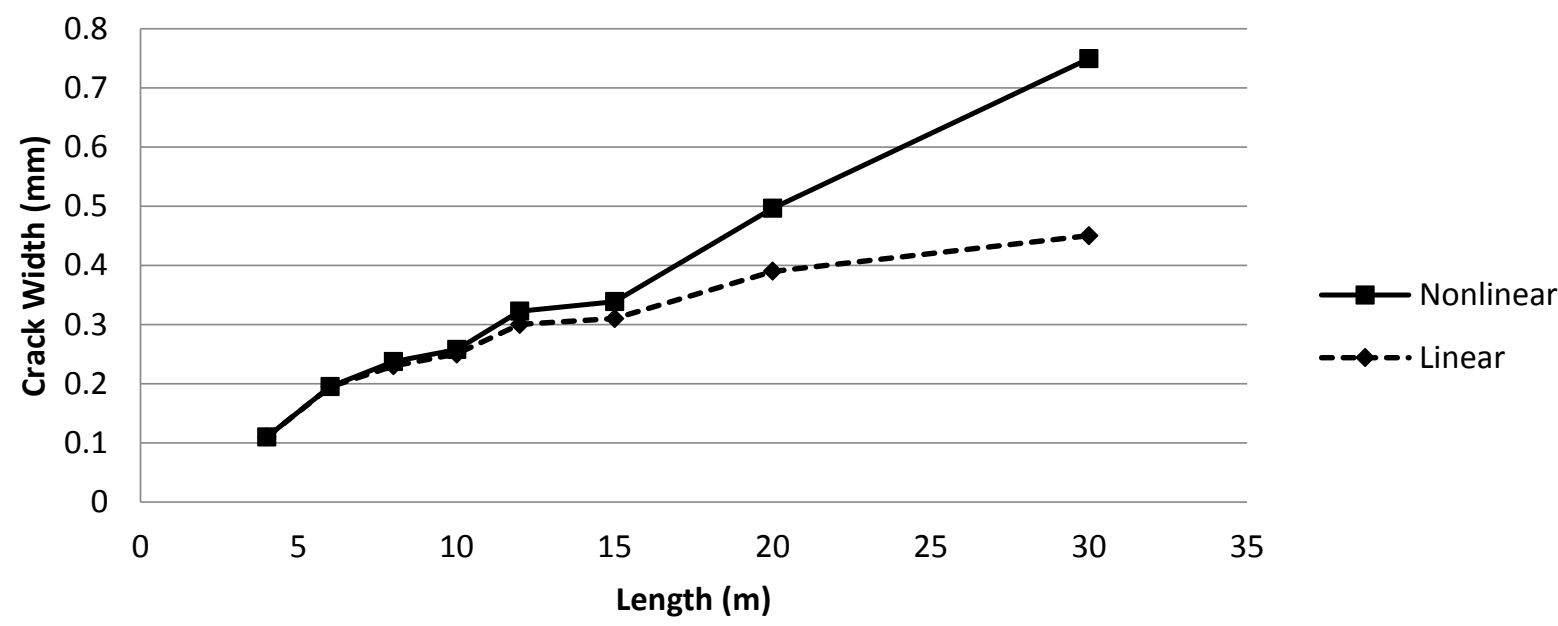

(a) $\mathrm{H}=6 \mathrm{~m}$

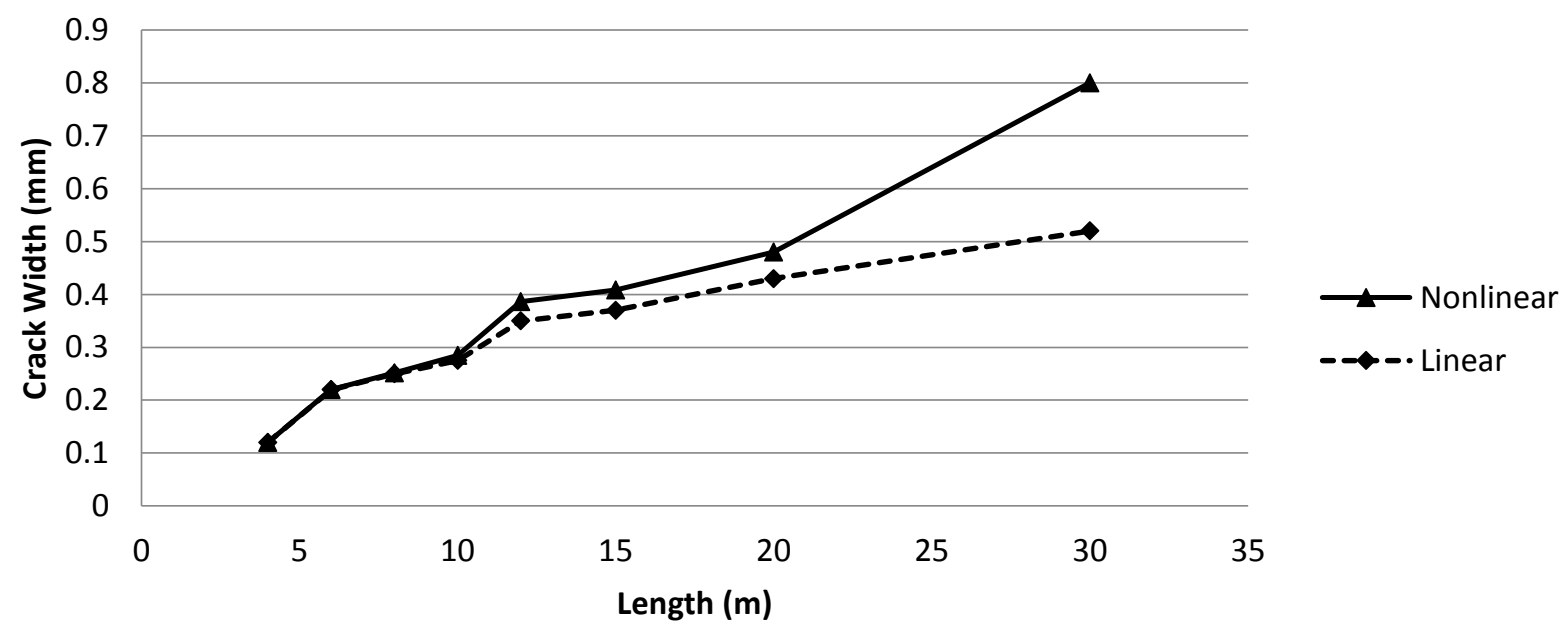

(b) $\mathrm{H}=8 \mathrm{~m}$

Figure A-10 Effect of steel behavior on the crack width $(\rho=0.3 \%)$ 


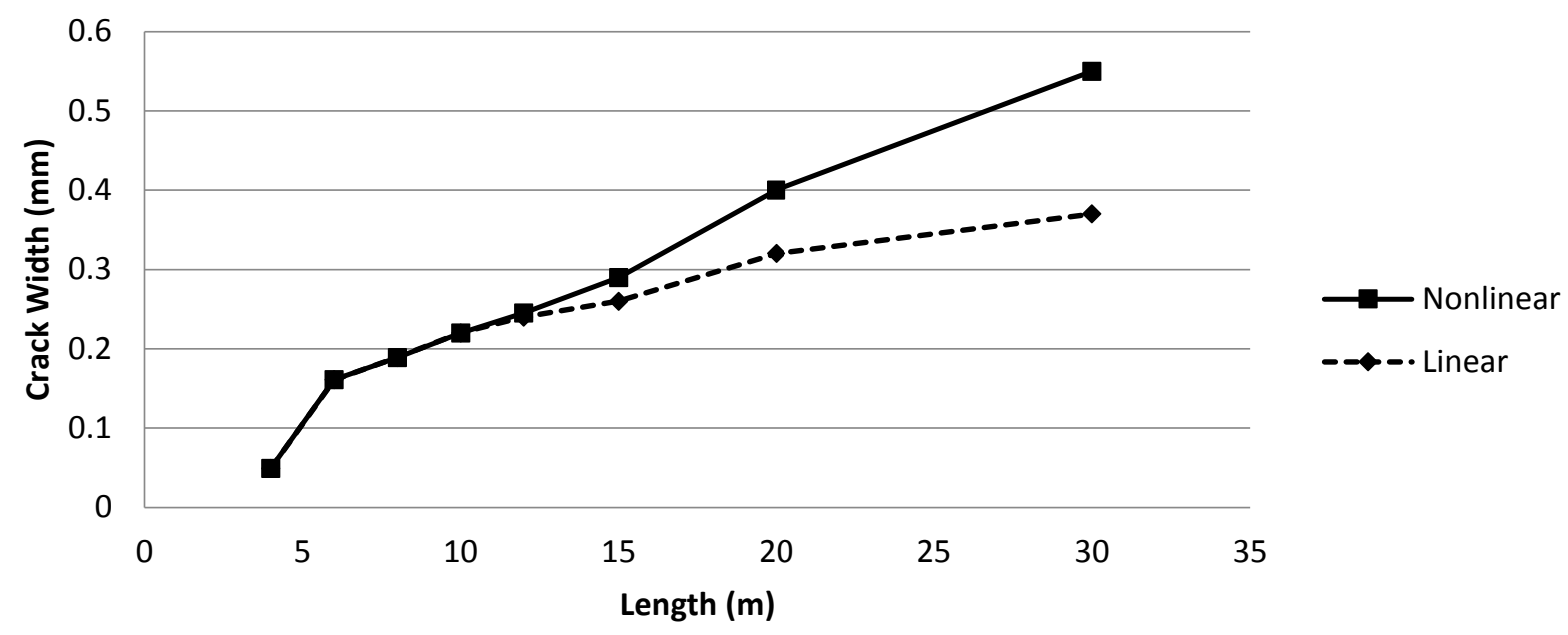

(a) $\rho=0.4 \%$
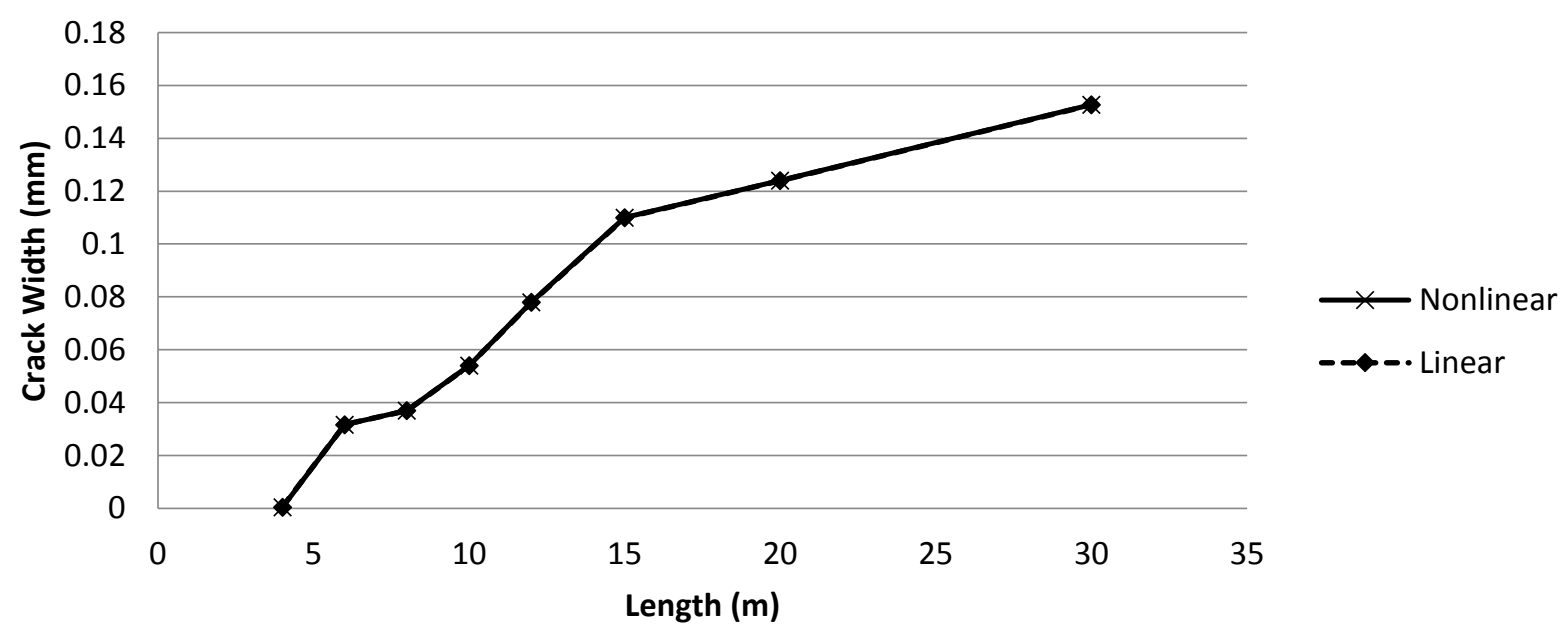

(b) $\rho=0.6 \%$

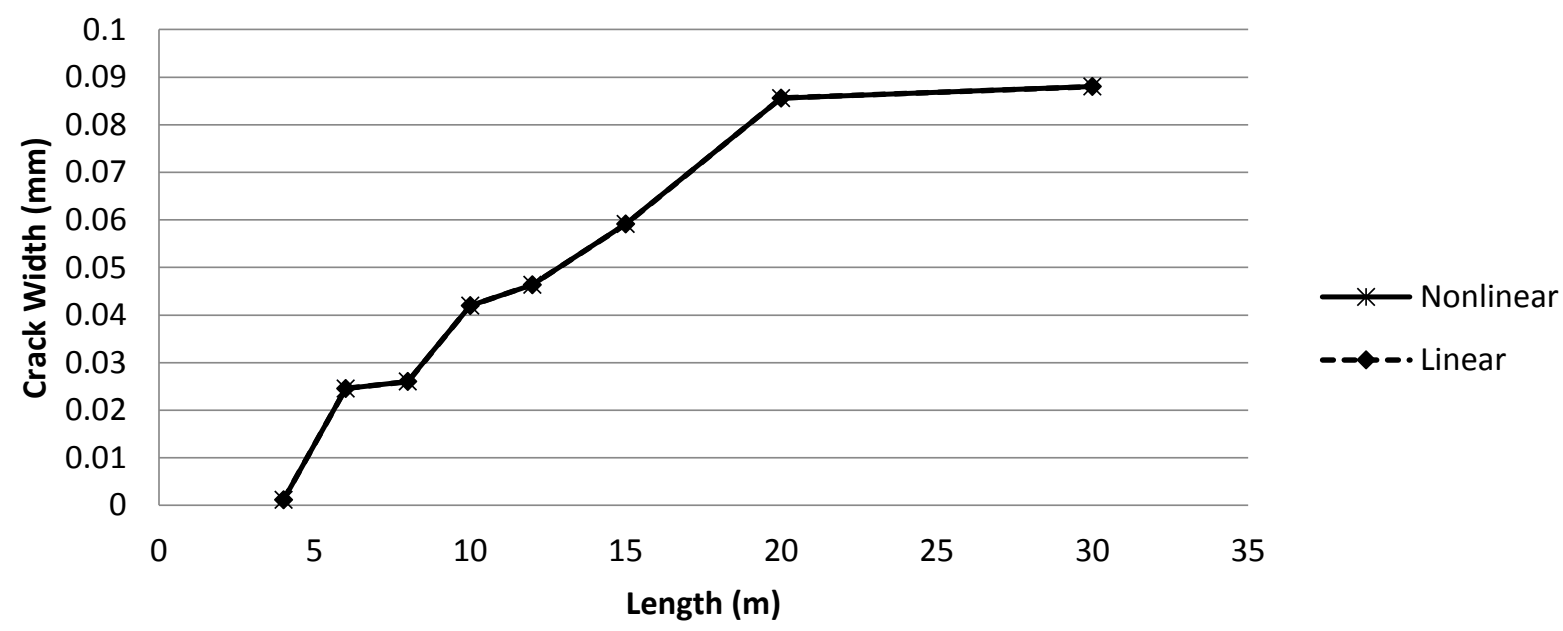

(c) $\rho=0.7 \%$

Figure A-11 Effect of steel behavior on the crack width reinforced with different steel ratios $(\mathrm{H}=4 \mathrm{~m})$ 


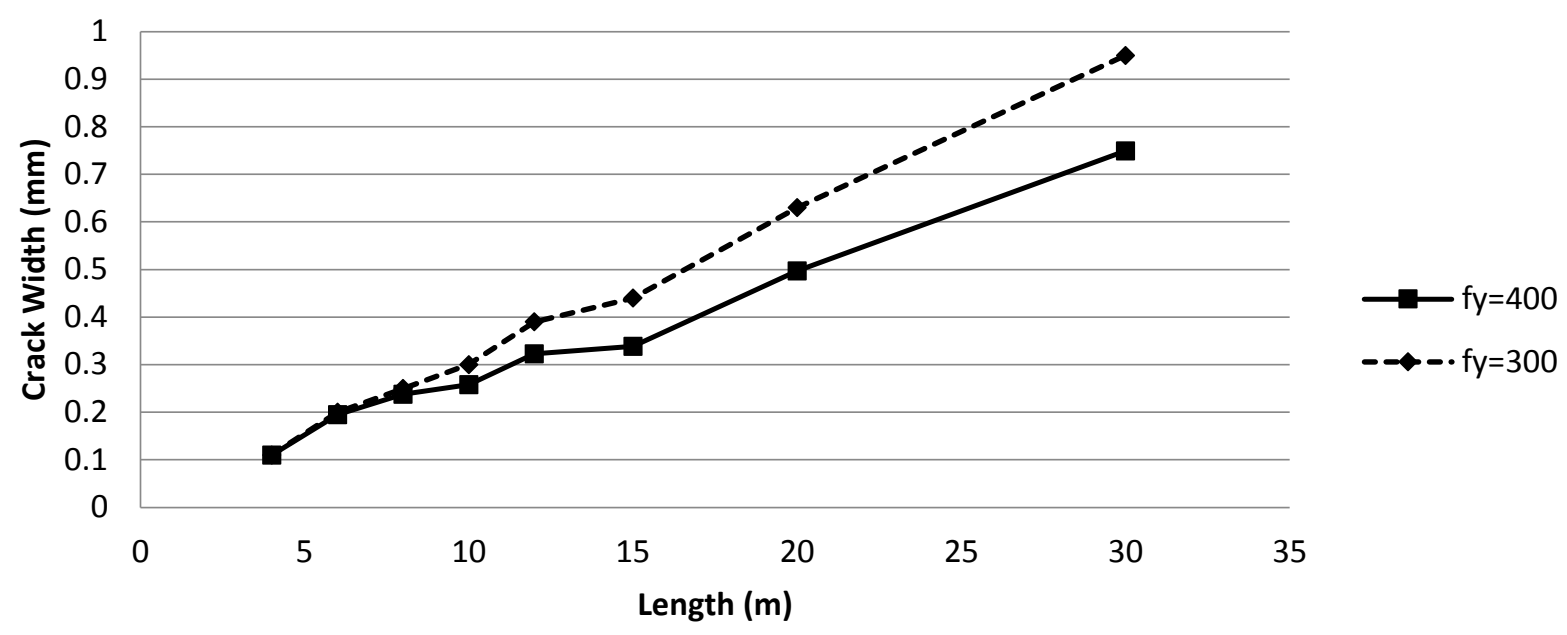

(a) $\mathrm{H}=6 \mathrm{~m}$

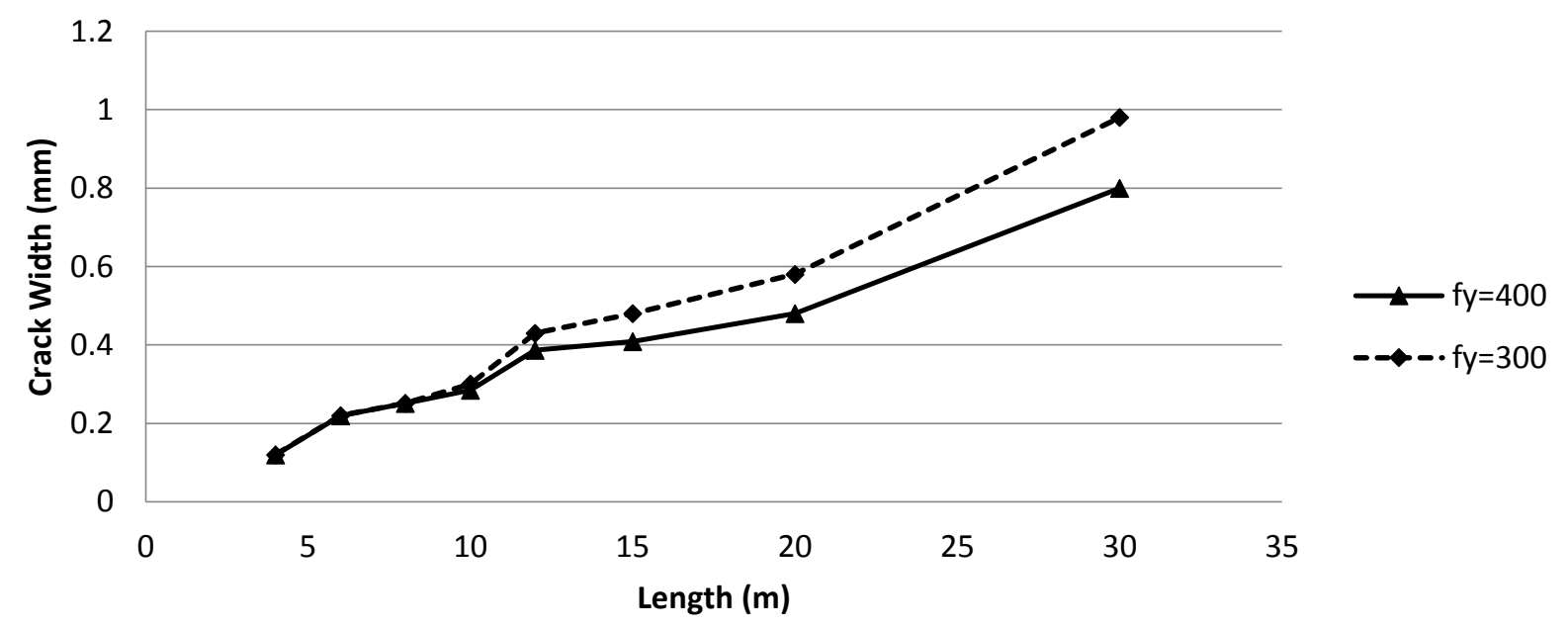

(b) $\mathrm{H}=8 \mathrm{~m}$

Figure A-12 Effect of steel yield strength on the crack width of walls with different heights $(\rho=0.3 \%)$

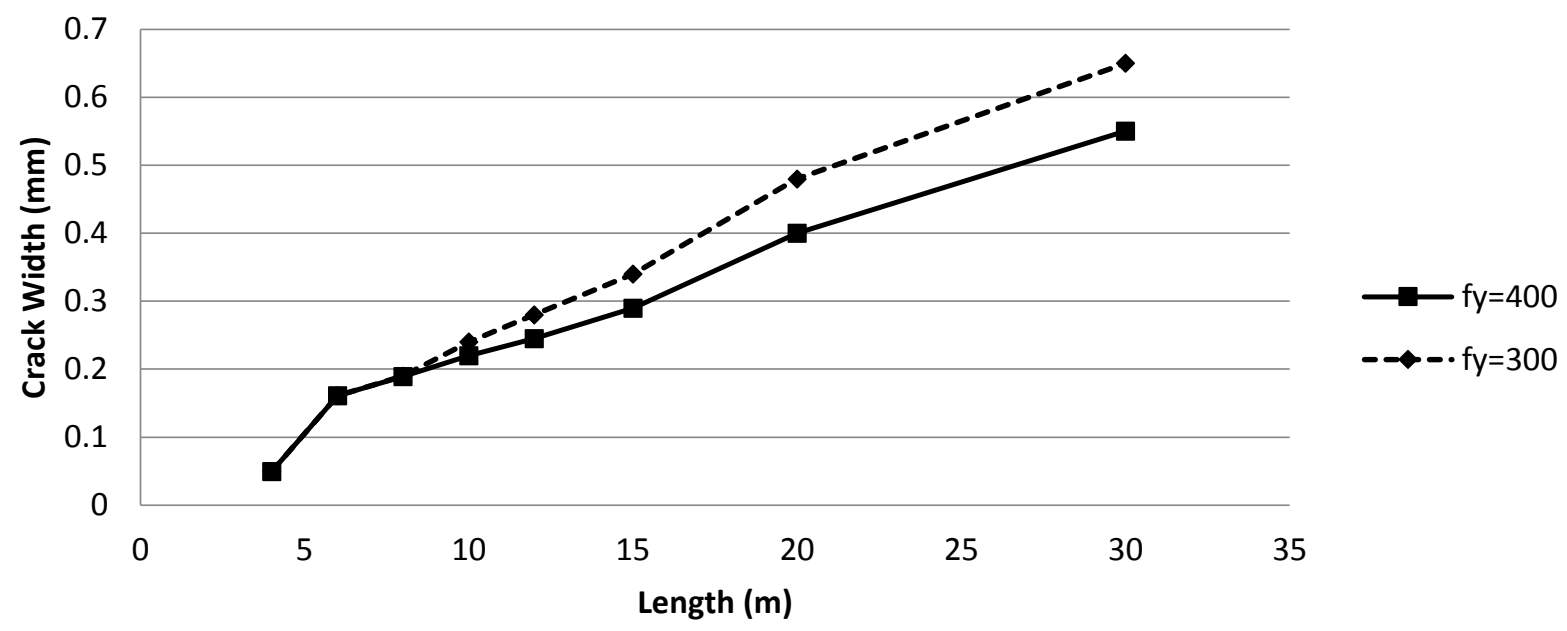

(a) $\rho=0.4 \%$ 

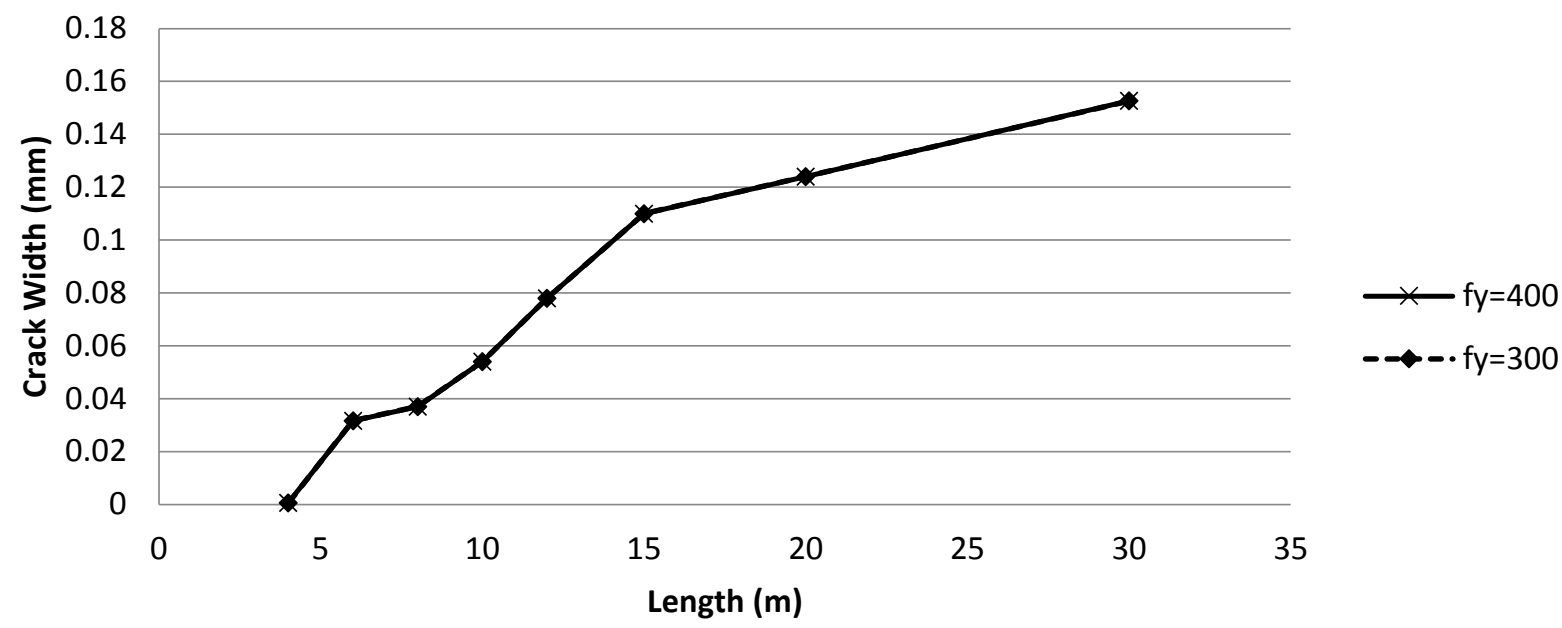

(b) $\rho=0.6 \%$
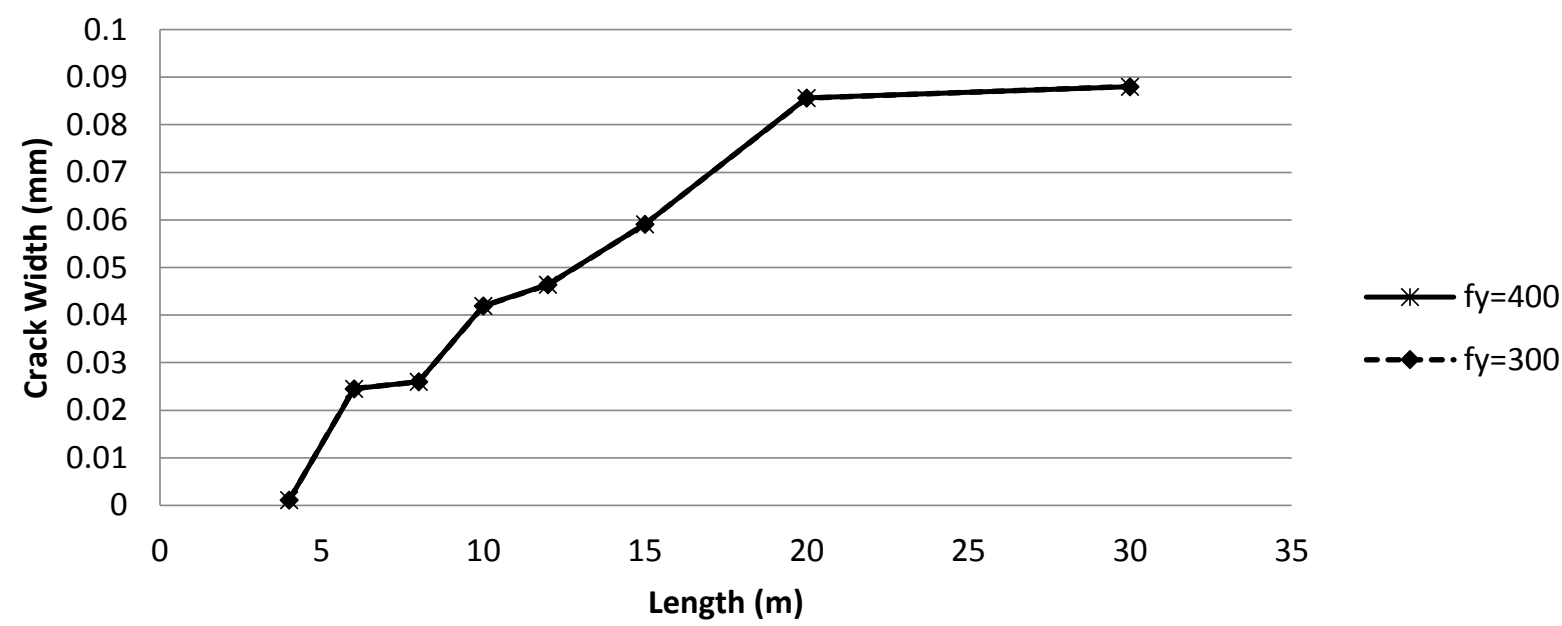

(c) $\rho=0.6 \%$

Figure A-13 Effect of steel yield strength on the crack width $(\mathrm{H}=4 \mathrm{~m})$

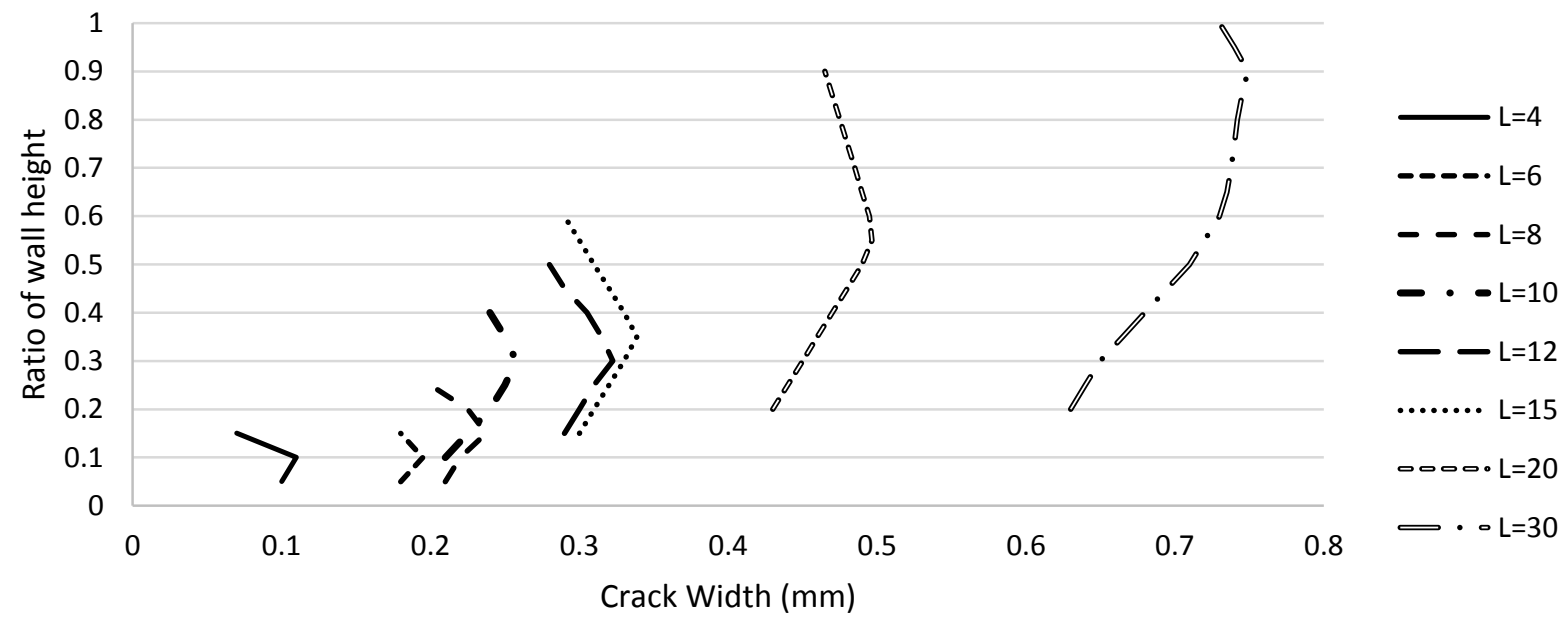

(a) $\mathrm{H}=6 \mathrm{~m}$ 


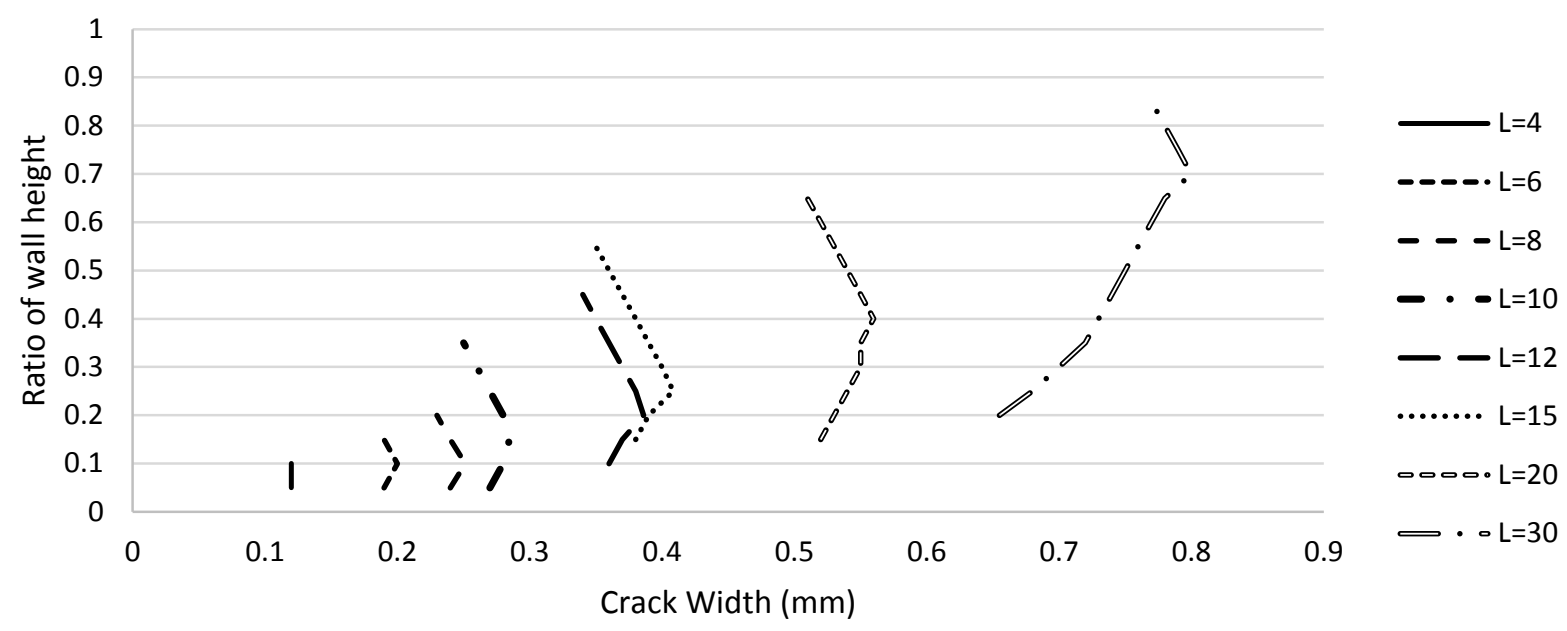

(b) $\mathrm{H}=8 \mathrm{~m}$

Figure A-14 Effect of wall length on the crack width over the wall height $(\rho=0.3 \%)$
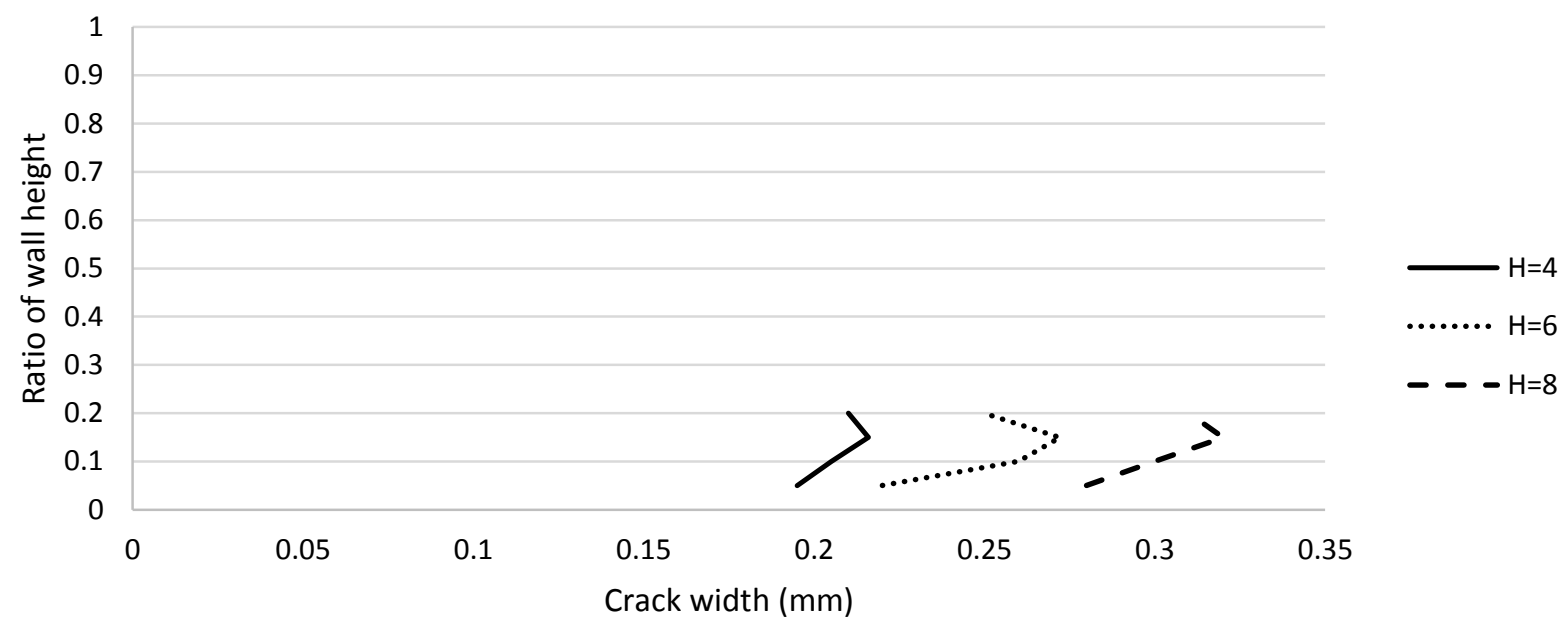

(a) $\mathrm{L} / \mathrm{H}=1.5$

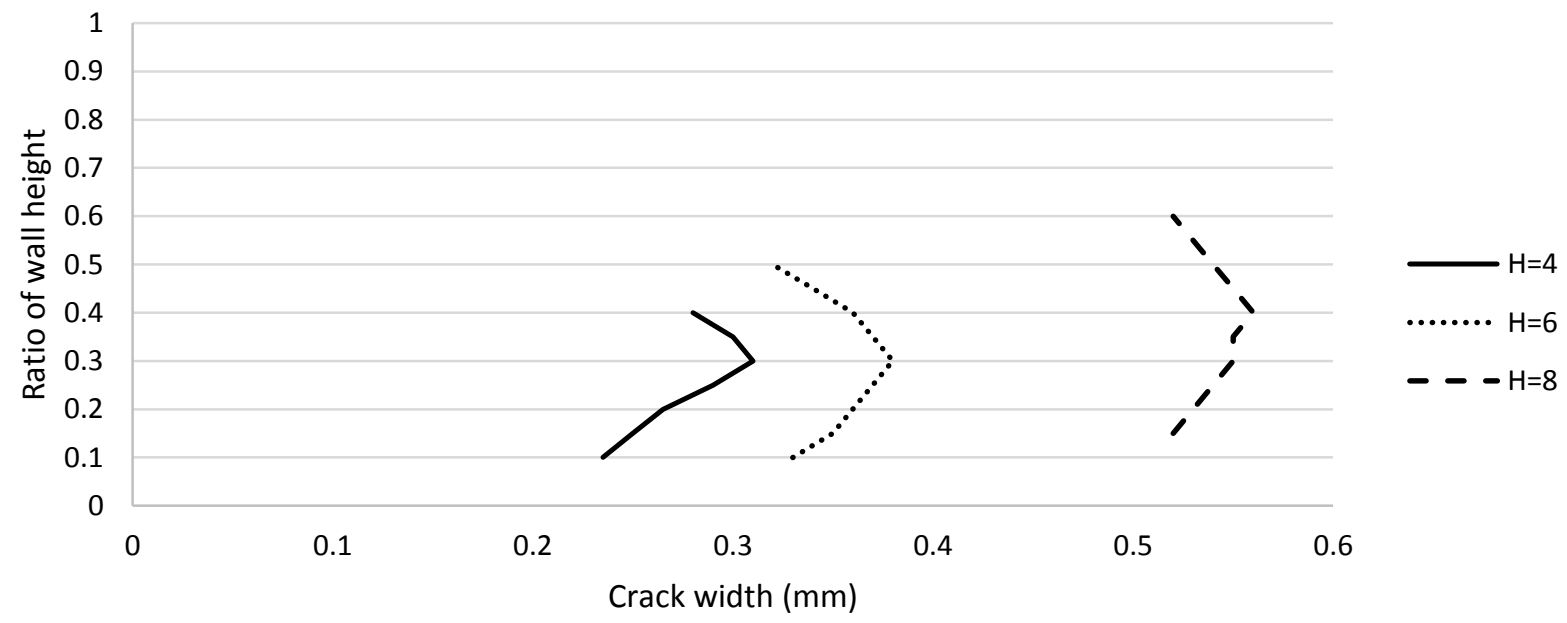

(b) $\mathrm{L} / \mathrm{H}=2.5$ 


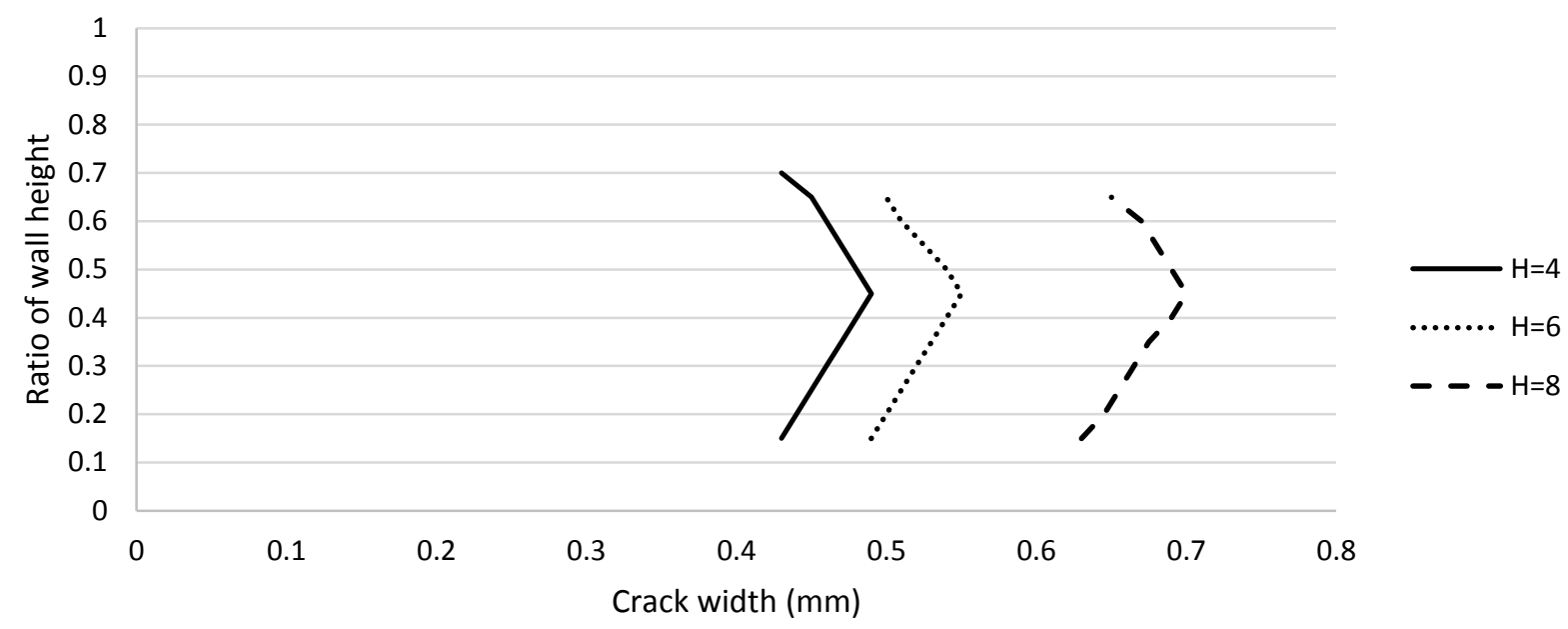

(c) $\mathrm{L} / \mathrm{H}=3.5$

Figure A-15 Effect of $\mathrm{L} / \mathrm{H}$ ratio on the crack width over the wall height $(\rho=0.3 \%)$
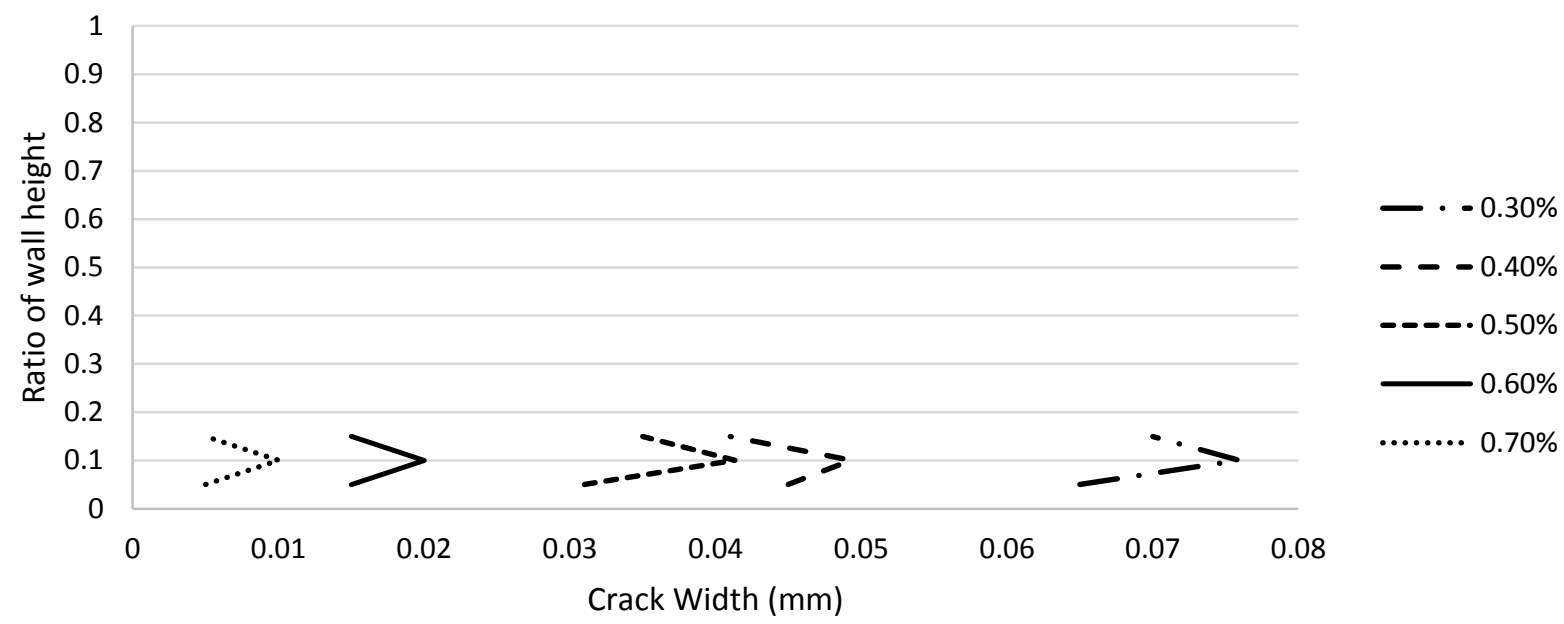

(a) $\mathrm{L}=4 \mathrm{~m}$

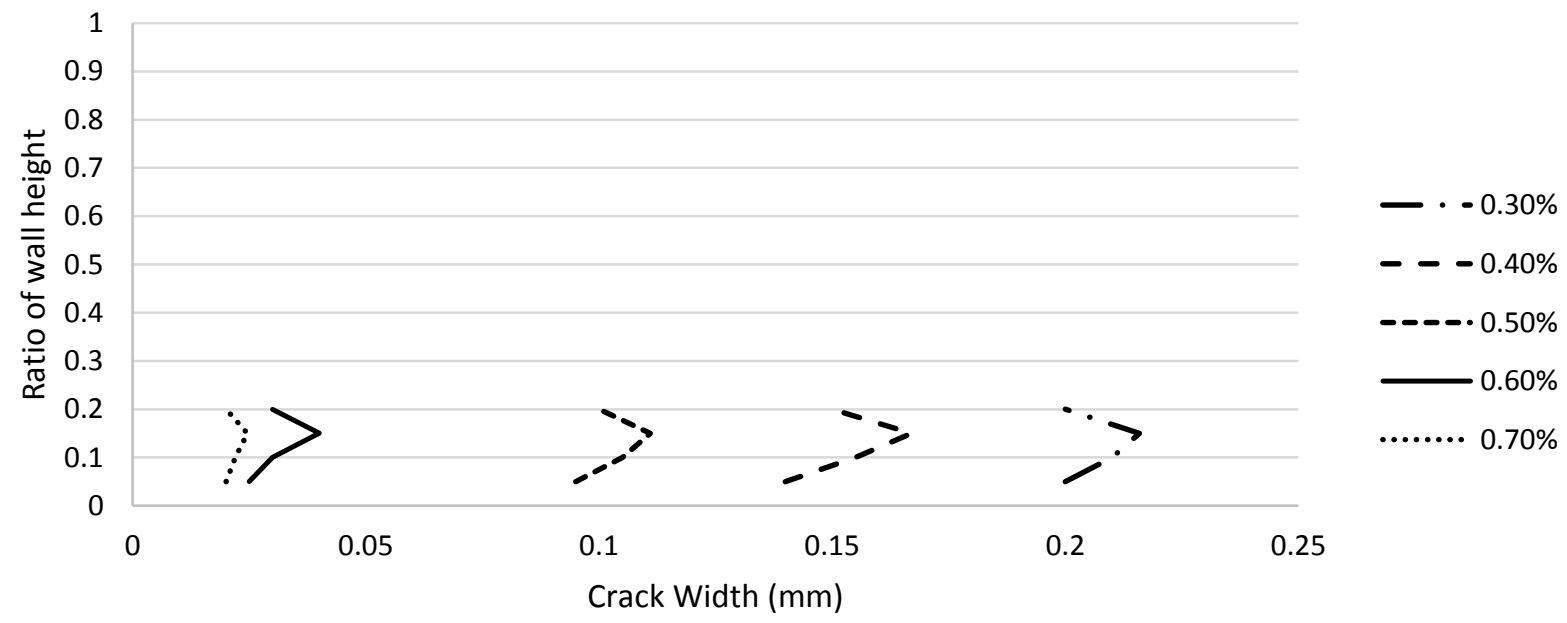

(b) $\mathrm{L}=6 \mathrm{~m}$ 

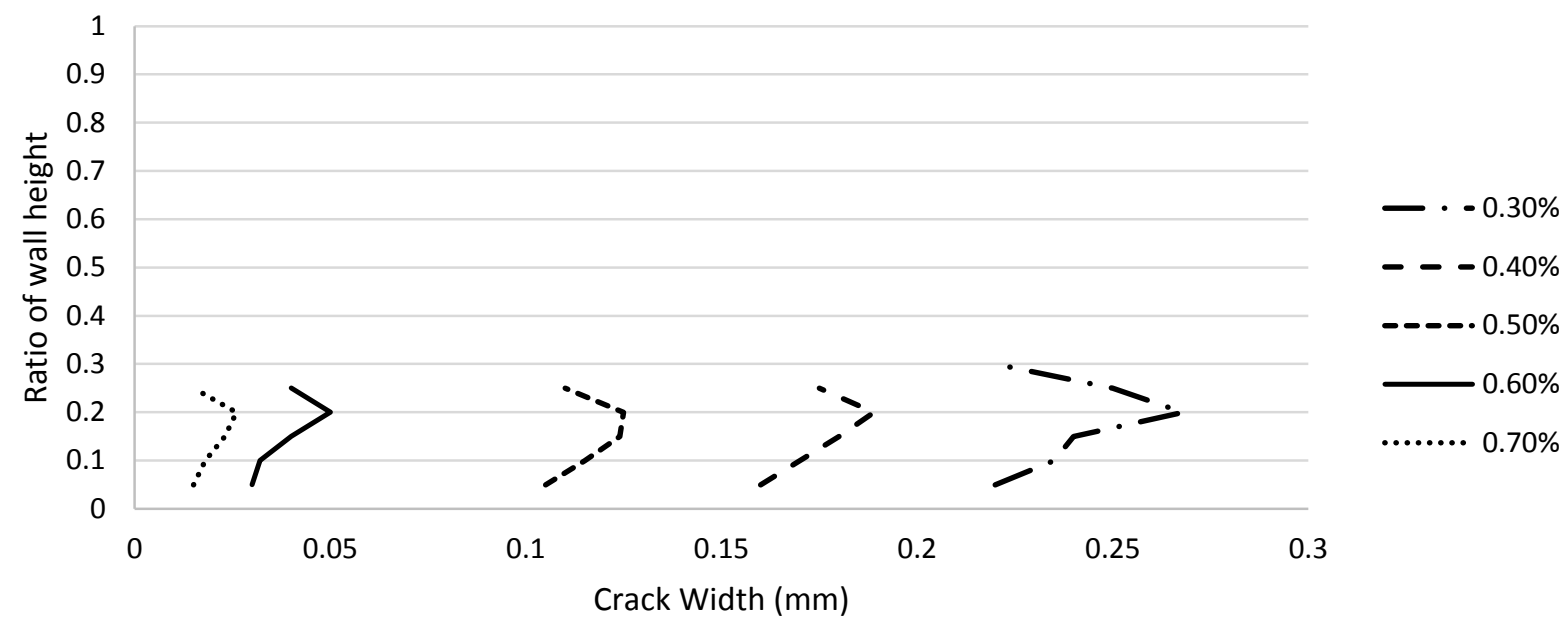

(c) $\mathrm{L}=8 \mathrm{~m}$
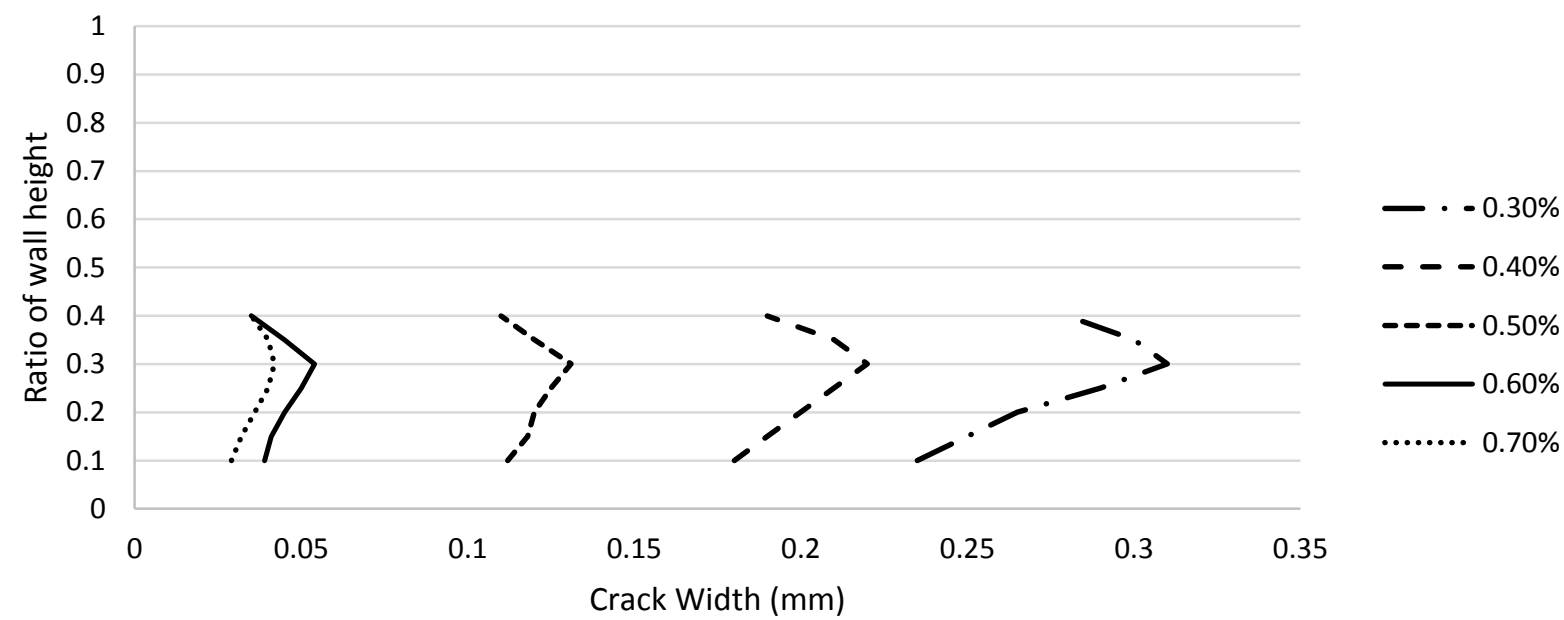

(d) $\mathrm{L}=10 \mathrm{~m}$

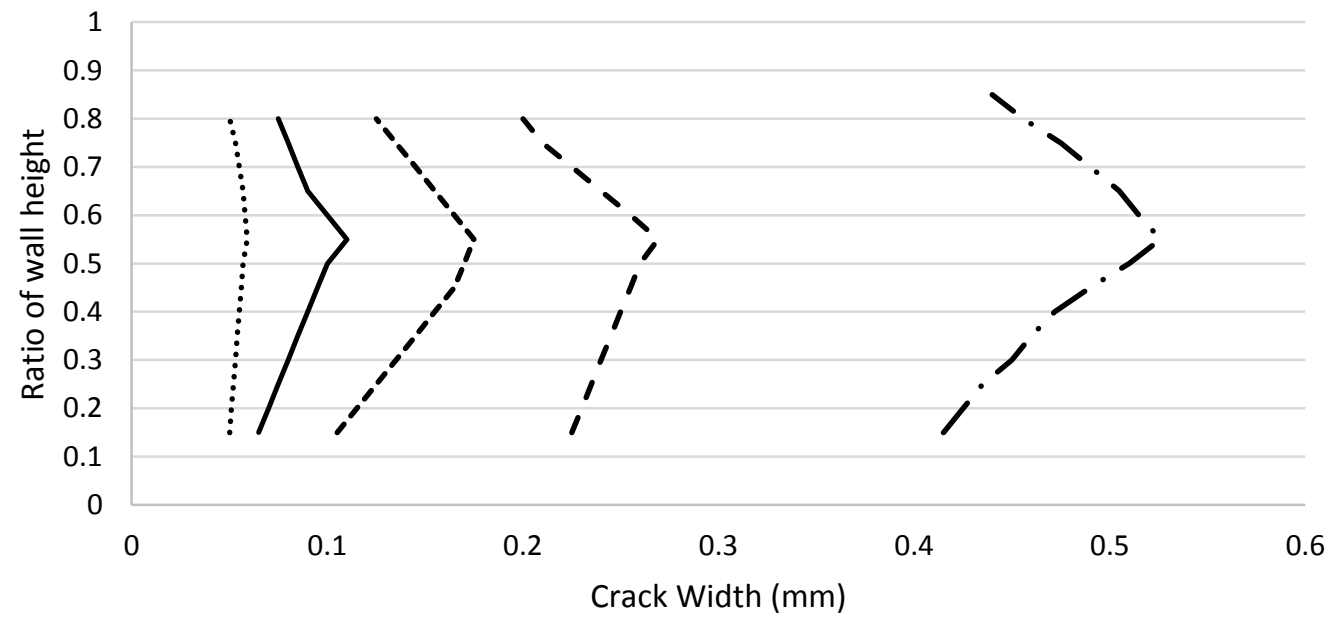

- - $-0.30 \%$

- - $0.40 \%$

---.-0.50\%

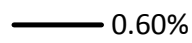

......... $0.70 \%$

(e) $\mathrm{L}=15 \mathrm{~m}$ 


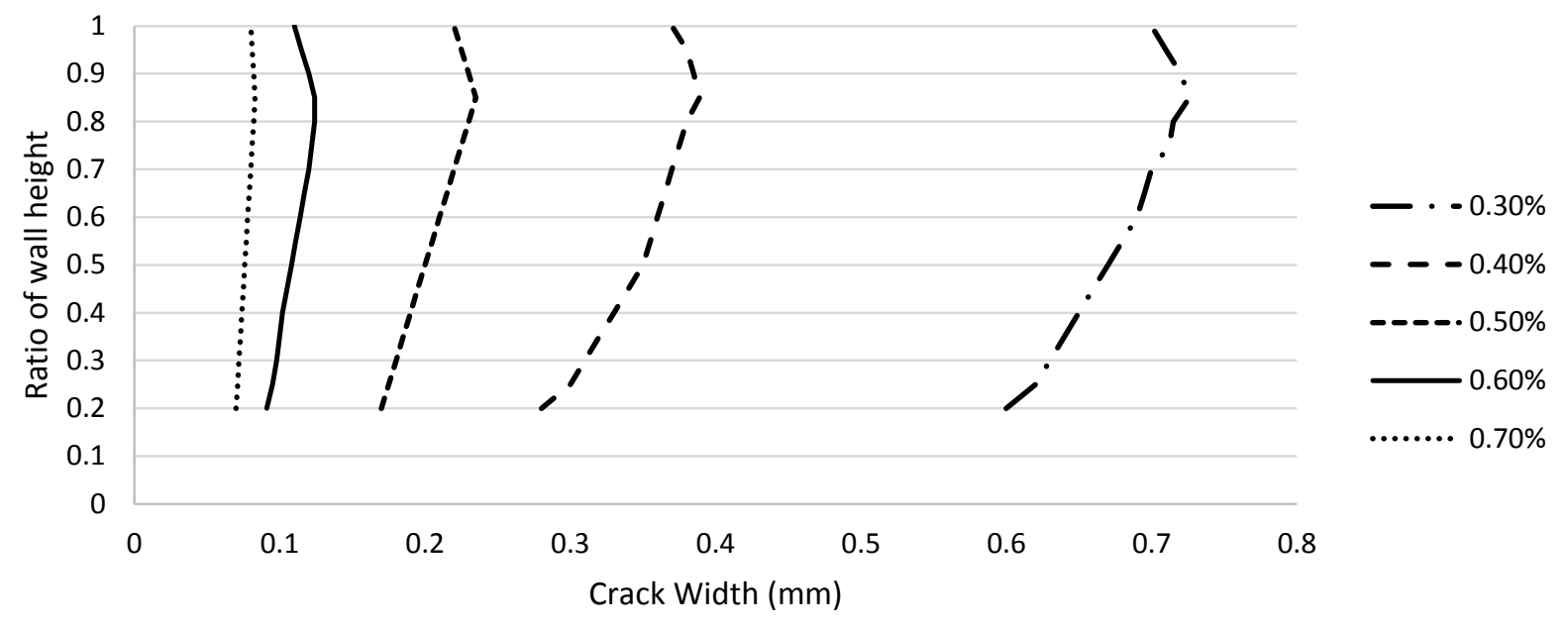

(f) $\mathrm{L}=20 \mathrm{~m}$

Figure A-16 Effect of steel ratio on the crack width over the wall height $(\mathrm{H}=4 \mathrm{~m})$ 


\section{APPENDIX B - RESULTS OF BASE RESTRAINED WALLS WITH PARTIAL RESTRAINT AT THE SIDES}

\section{B.1 General}

This Appendix presents the remaining results of the parametric study on base restrained walls with partial side restraint as in Chapter 5. The effect of creep is not considered in the results that are presented in this Appendix. These graphs are demonstrated in order to further discuss the influence of each parameter on the crack width and its variation along the wall length.

\section{B.2 Results of the parametric study}

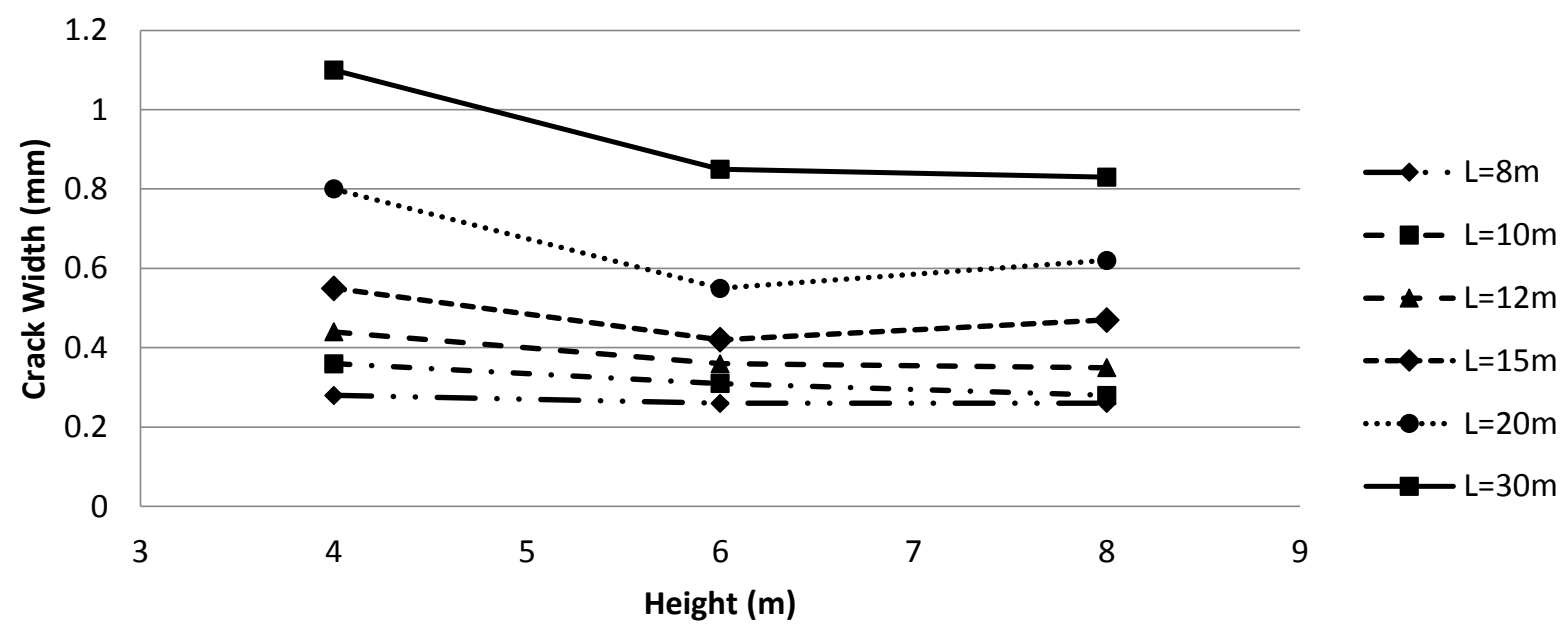

Figure B-1 Effect of wall height on the crack width considering constant wall lengths
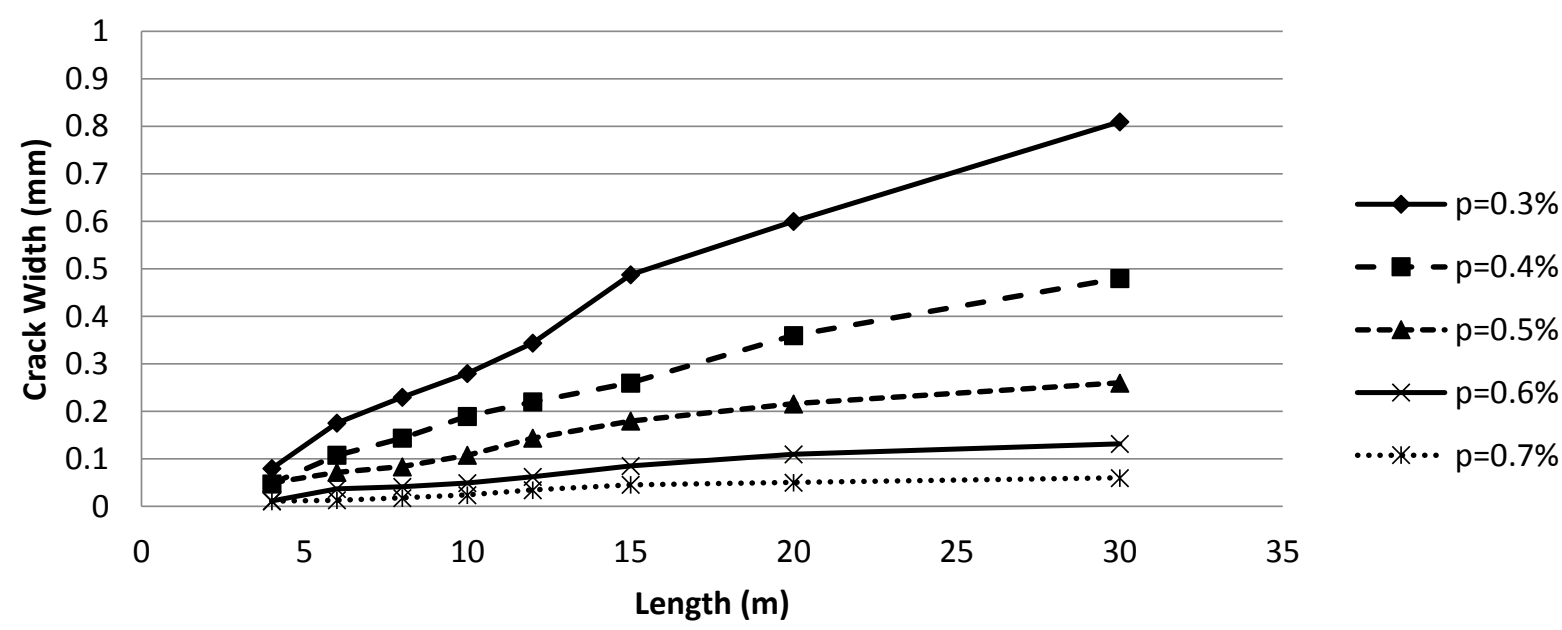

$-p=0.4 \%$

$--\llcorner-\cdot p=0.5 \%$

$\simeq p=0.6 \%$

…*...p $=0.7 \%$

(a) $\mathrm{e}=300 \mu \varepsilon$ 


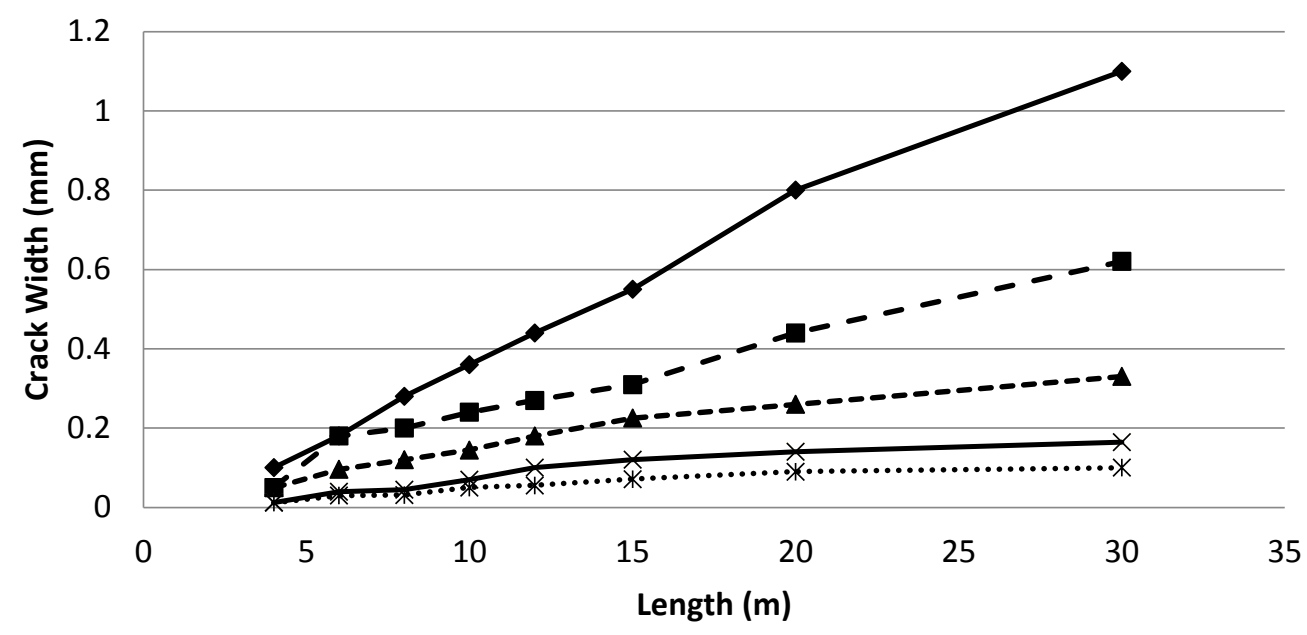

$\longrightarrow p=0.3 \%$

- $-p=0.4 \%$

- $-\mathbf{s}-p=0.5 \%$

$\longrightarrow p=0.6 \%$

...*...p $p=0.7 \%$

(b) $\mathrm{e}=600 \mu \varepsilon$

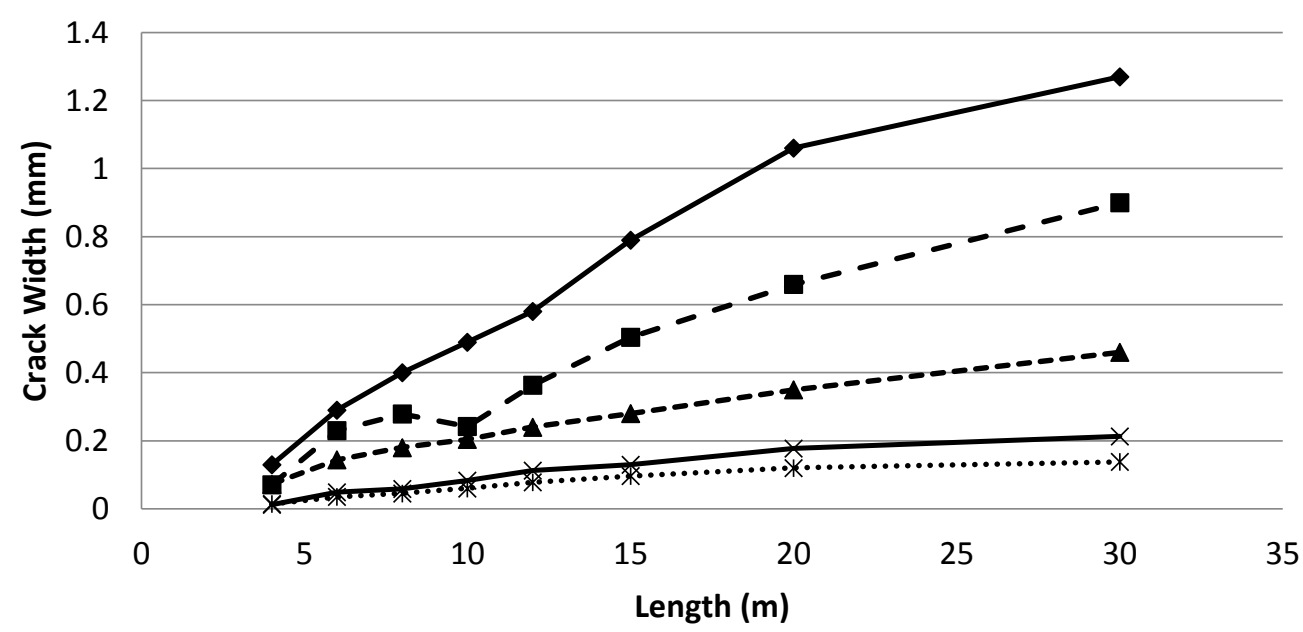

$\longrightarrow p=0.3 \%$

- - $p=0.4 \%$

- $\mathbf{p}-\cdot p=0.5 \%$

$\longrightarrow p=0.6 \%$

$\cdots * \cdots \cdot p=0.7 \%$

(c) $\mathrm{e}=900 \mu \varepsilon$

Figure B-2 Effect of reinforcement ratio on the crack width considering different climates $(\mathrm{H}=4 \mathrm{~m})$
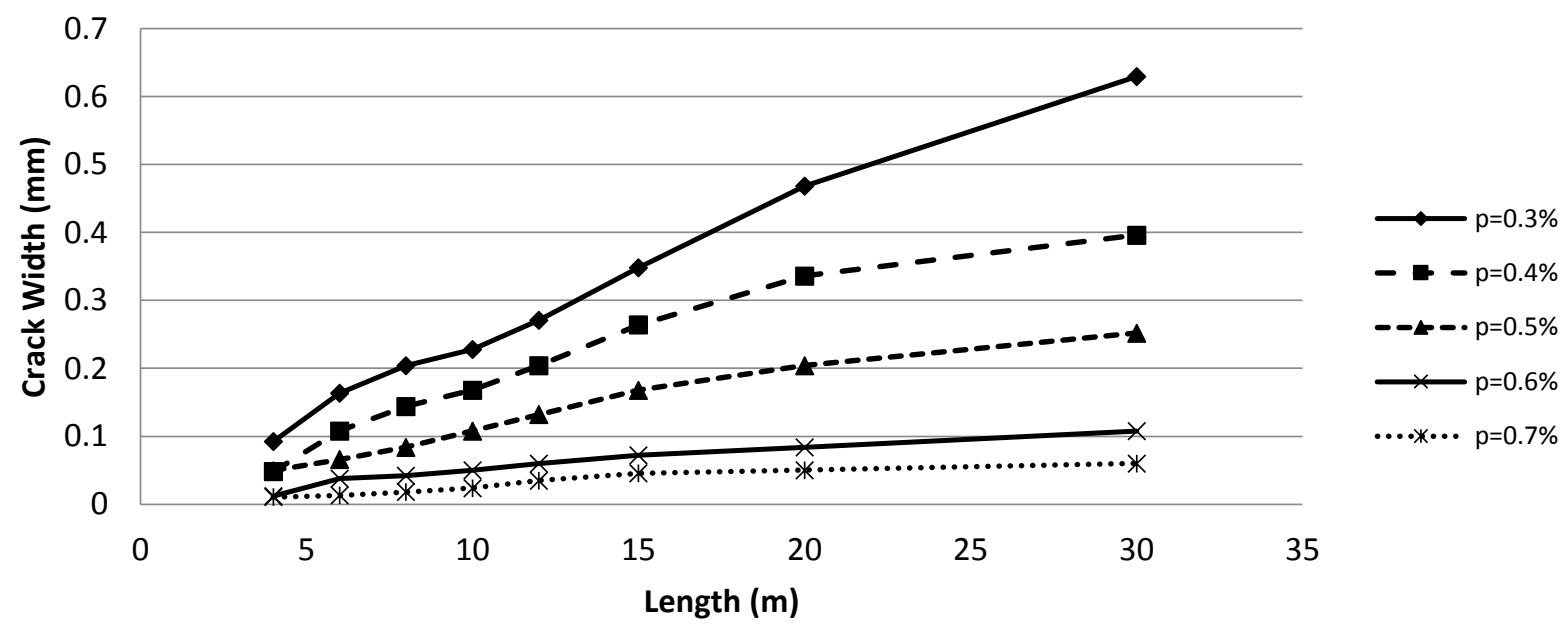

- - $p=0.4 \%$

$--\leftarrow-\cdot p=0.5 \%$

$\longrightarrow p=0.6 \%$

$\cdots \cdots \cdots \cdots p=0.7 \%$

(a) $\mathrm{e}=300 \mu \varepsilon$ 

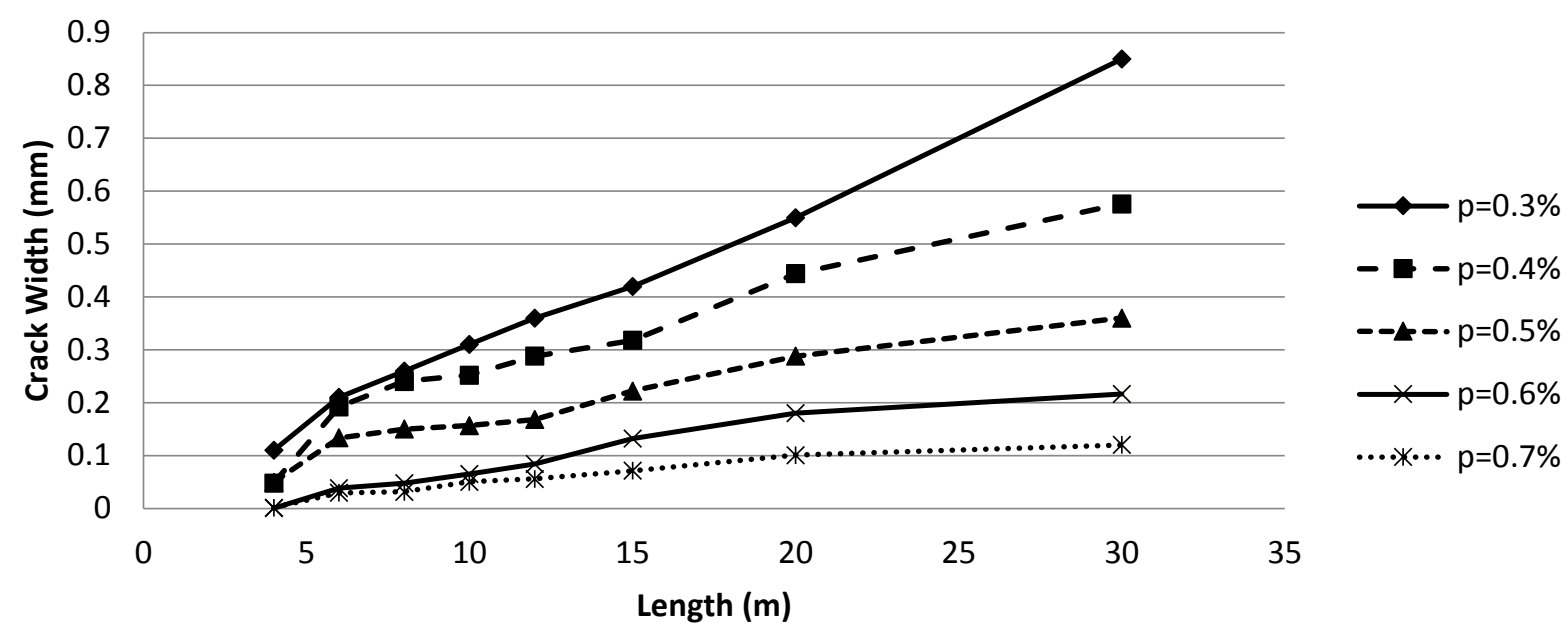

(b) $\mathrm{e}=600 \mu \varepsilon$

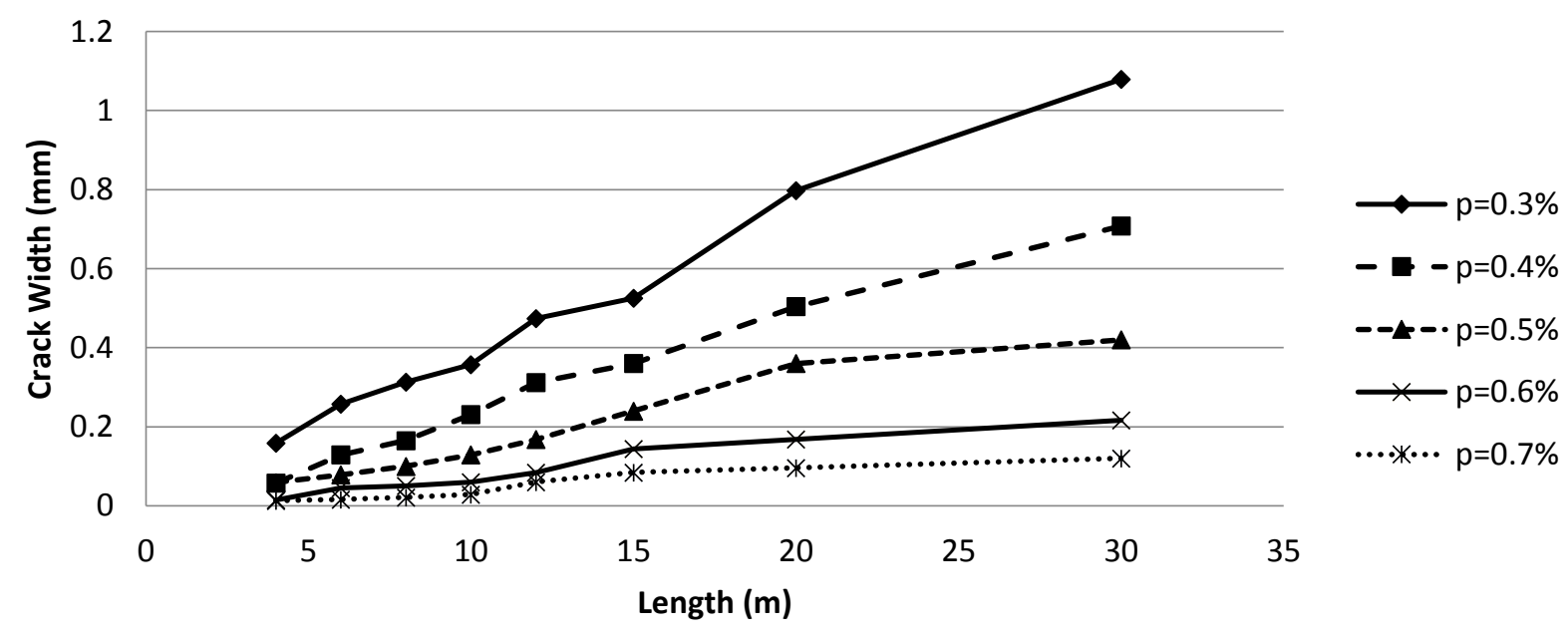

(c) $\mathrm{e}=900 \mu \varepsilon$

Figure B-3 Effect of reinforcement ratio on the crack width considering different climates $(\mathrm{H}=6 \mathrm{~m})$

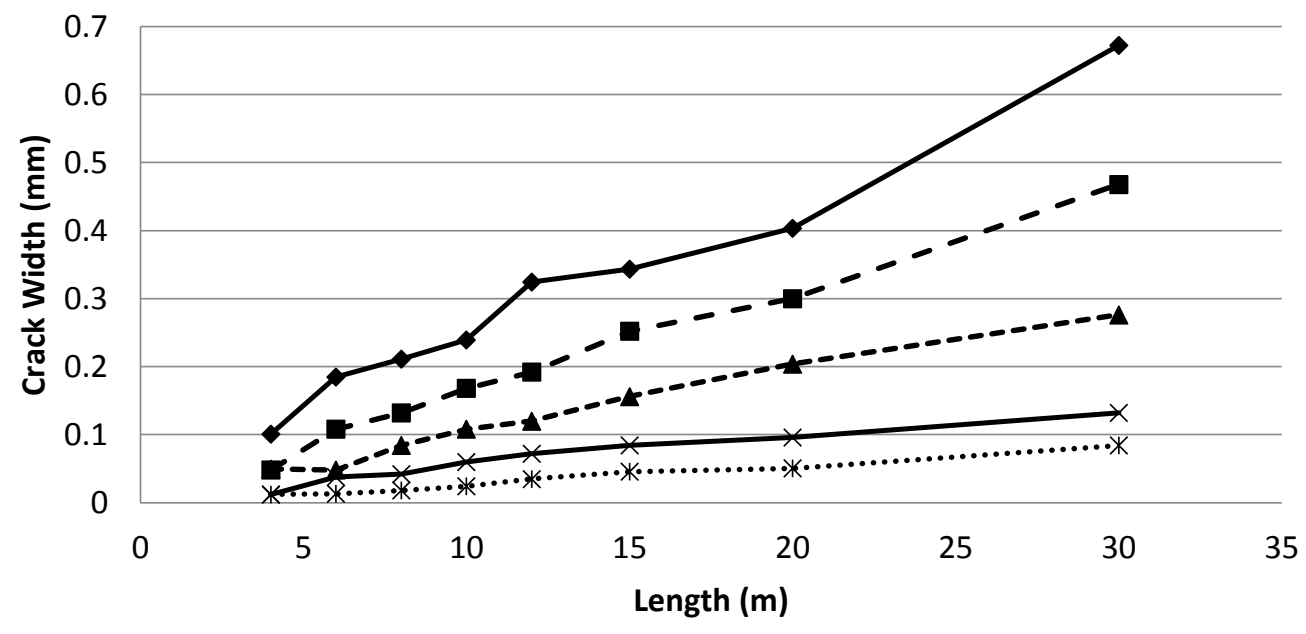

$\longrightarrow p=0.3 \%$

- $-p=0.4 \%$

- - $\mathbf{-}-\cdot p=0.5 \%$

$\longrightarrow p=0.6 \%$

…*...p $p=0.7 \%$

(a) $\mathrm{e}=300 \mu \varepsilon$ 

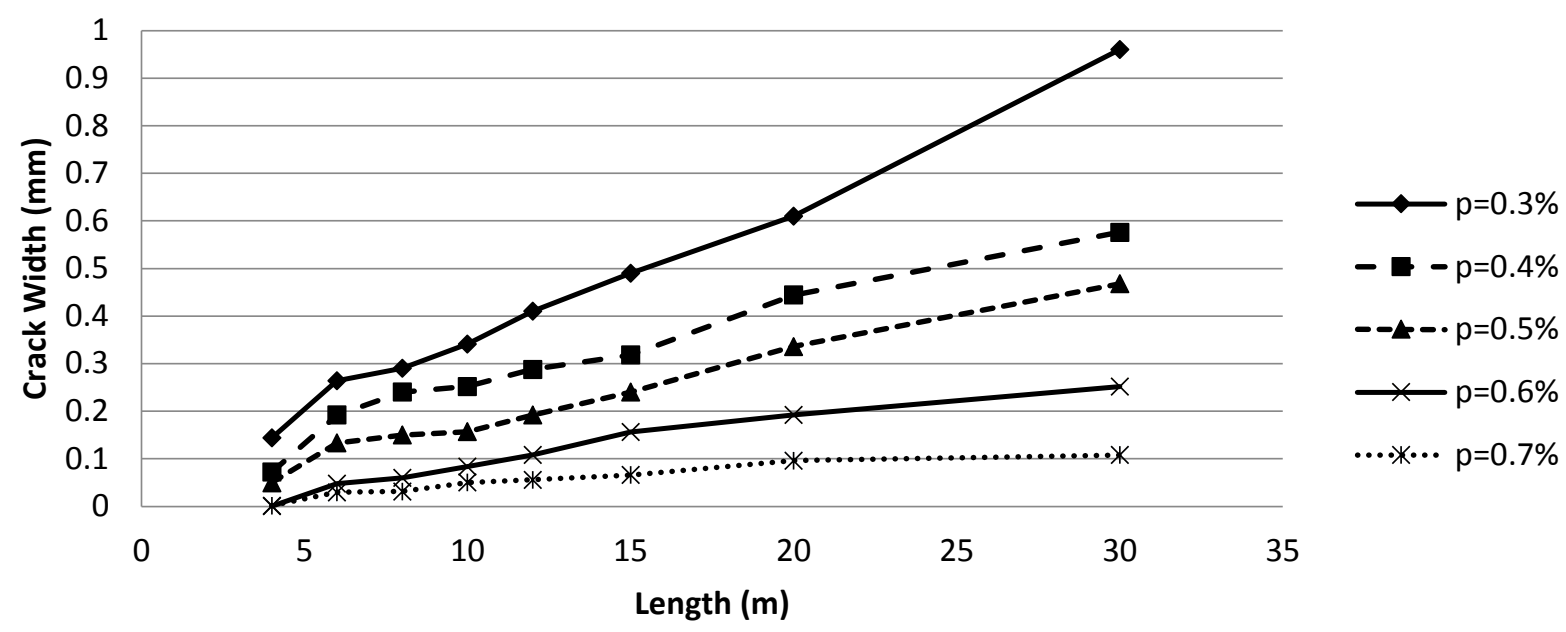

(b) $\mathrm{e}=600 \mu \varepsilon$

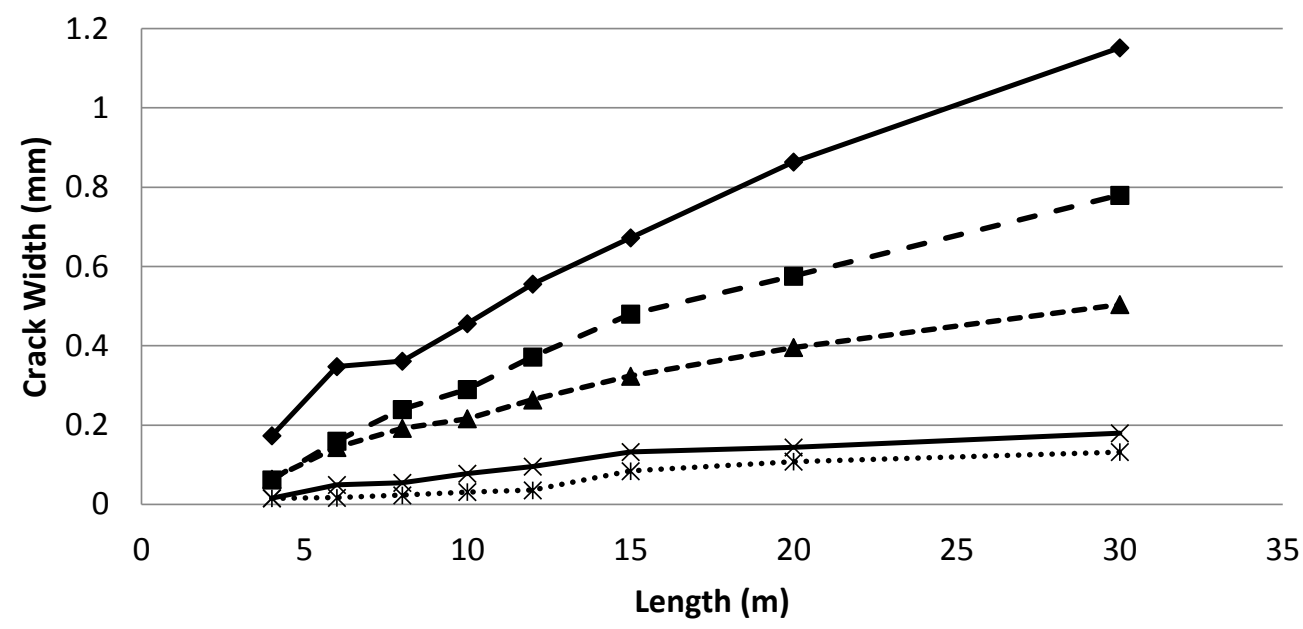

$\longrightarrow p=0.3 \%$

$-p=0.4 \%$

$--4-\cdot p=0.5 \%$

$\longrightarrow p=0.6 \%$

$\cdots * \cdots p=0.7 \%$

(c) $\mathrm{e}=900 \mu \varepsilon$

Figure B-4 Effect of reinforcement ratio on the crack width considering different climates $(\mathrm{H}=8 \mathrm{~m})$

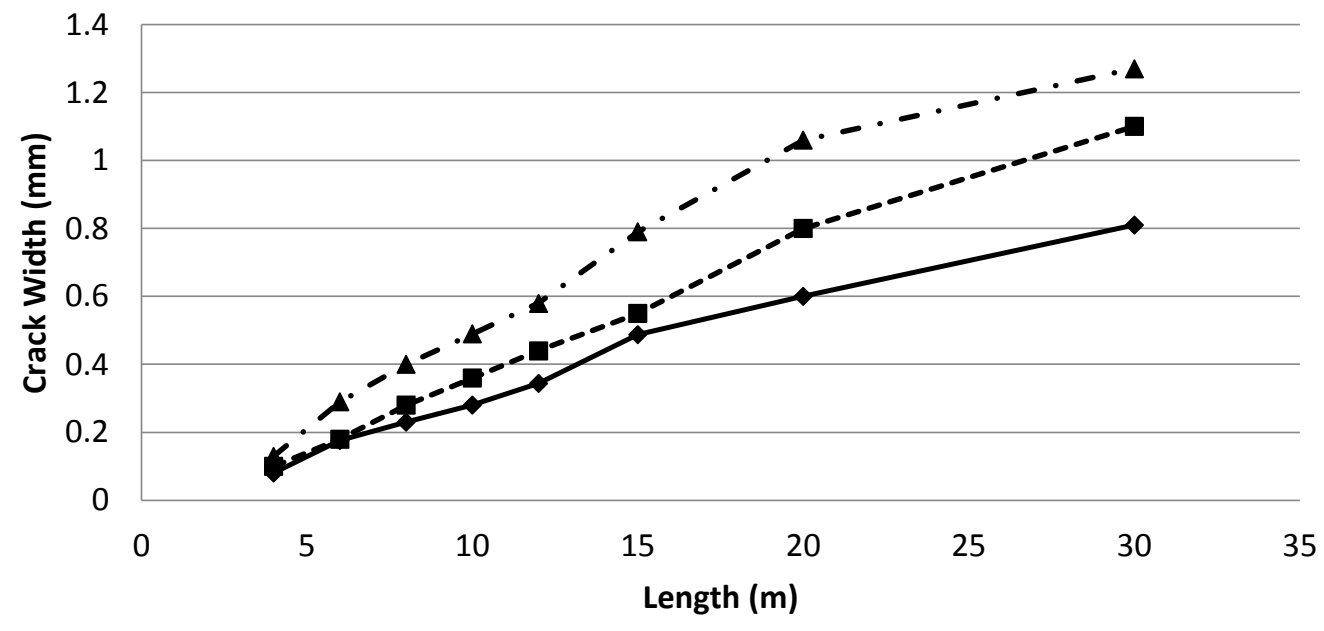

$\longrightarrow \mathrm{e}=300$

$-\rightarrow-\cdot e=600$

- $\Delta-\mathrm{e}=900$

(a) $\rho=0.3 \%$ 

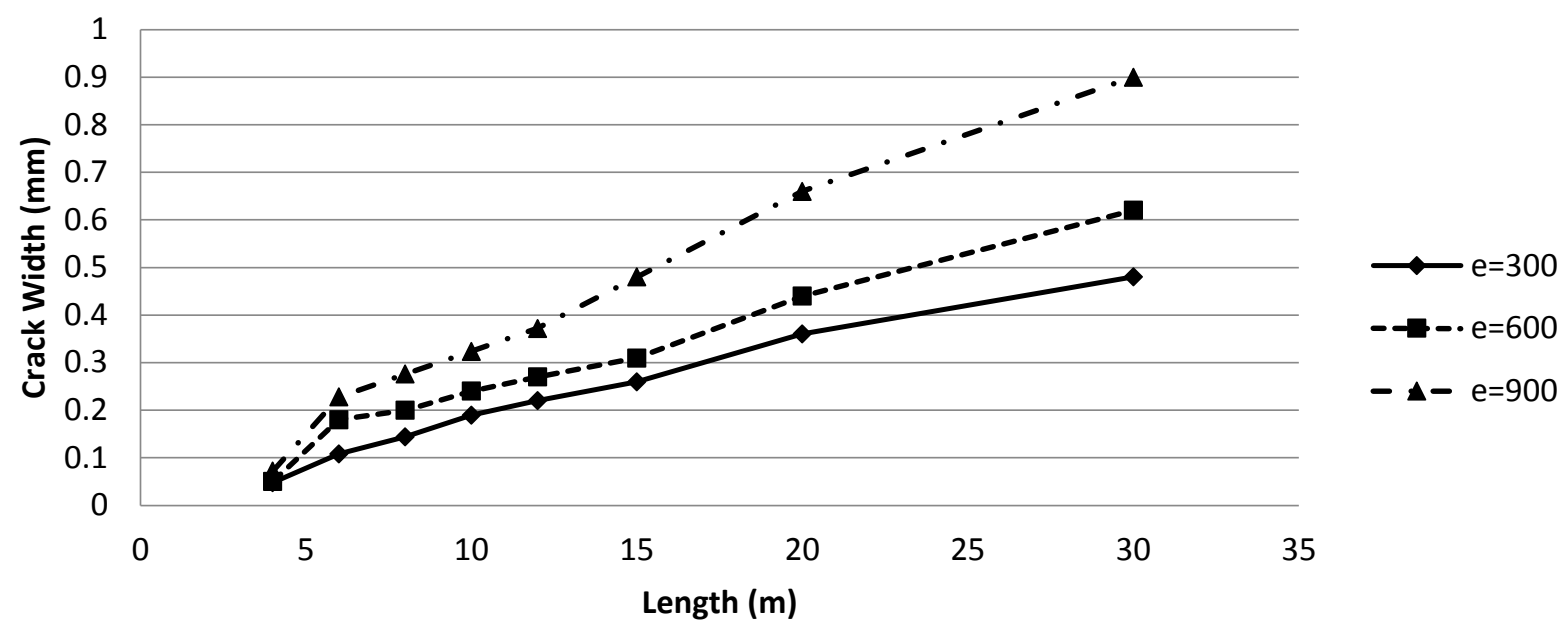

(b) $\rho=0.4 \%$
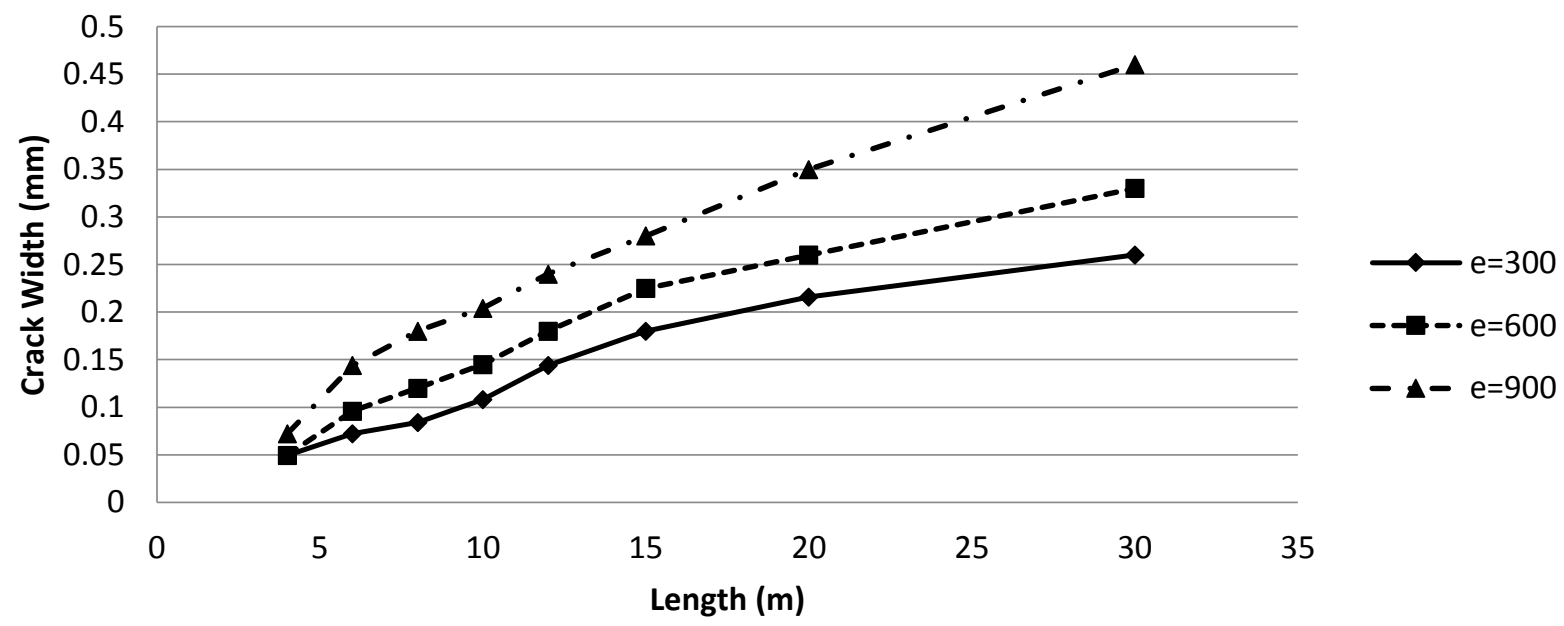

(c) $\rho=0.5 \%$
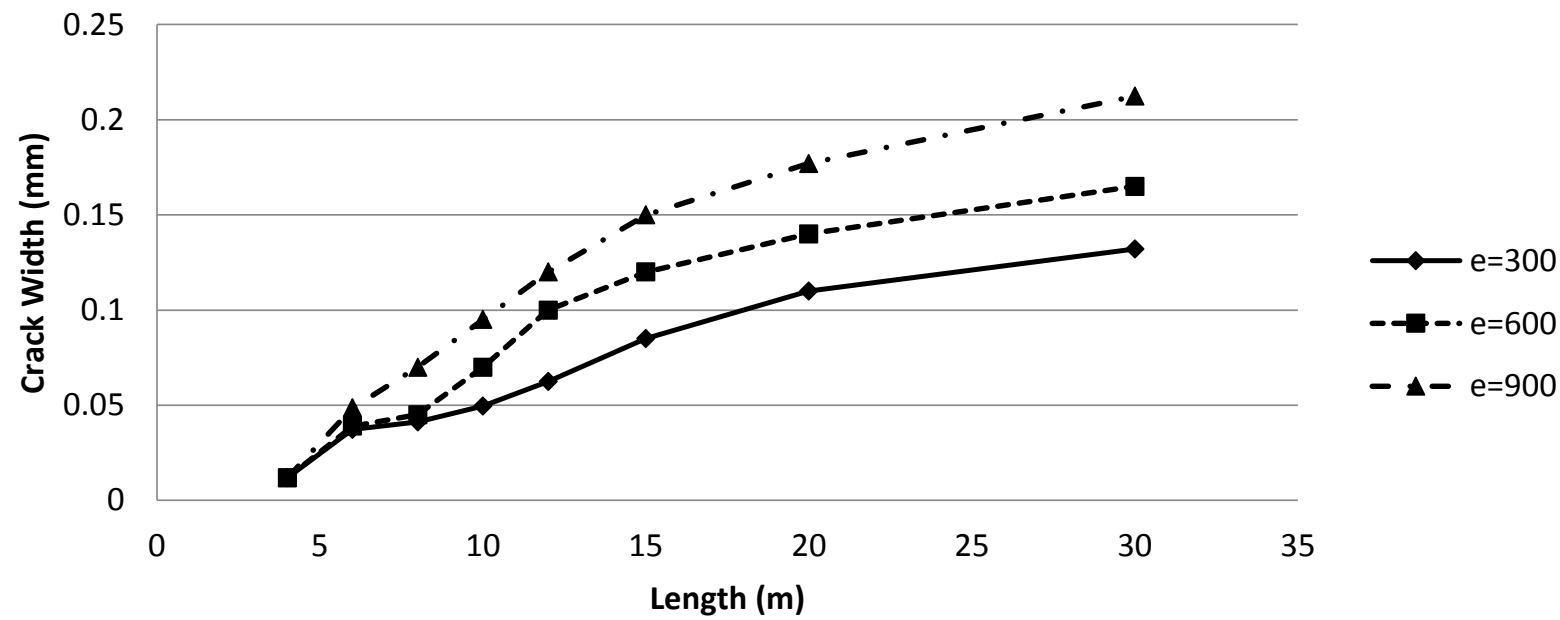

(d) $\rho=0.6 \%$ 


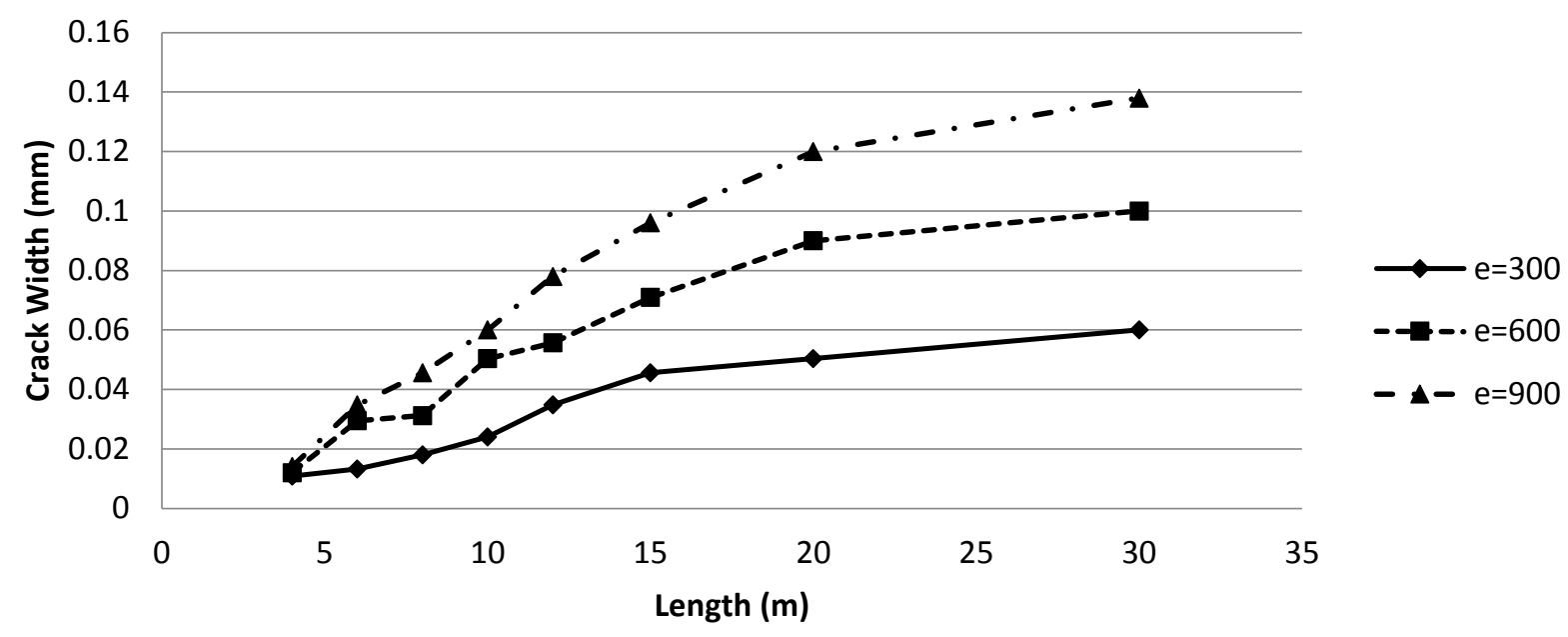

(e) $\rho=0.7 \%$

Figure B-5 Effect of volumetric strain on the crack width considering different steel ratios $(\mathrm{H}=4 \mathrm{~m})$
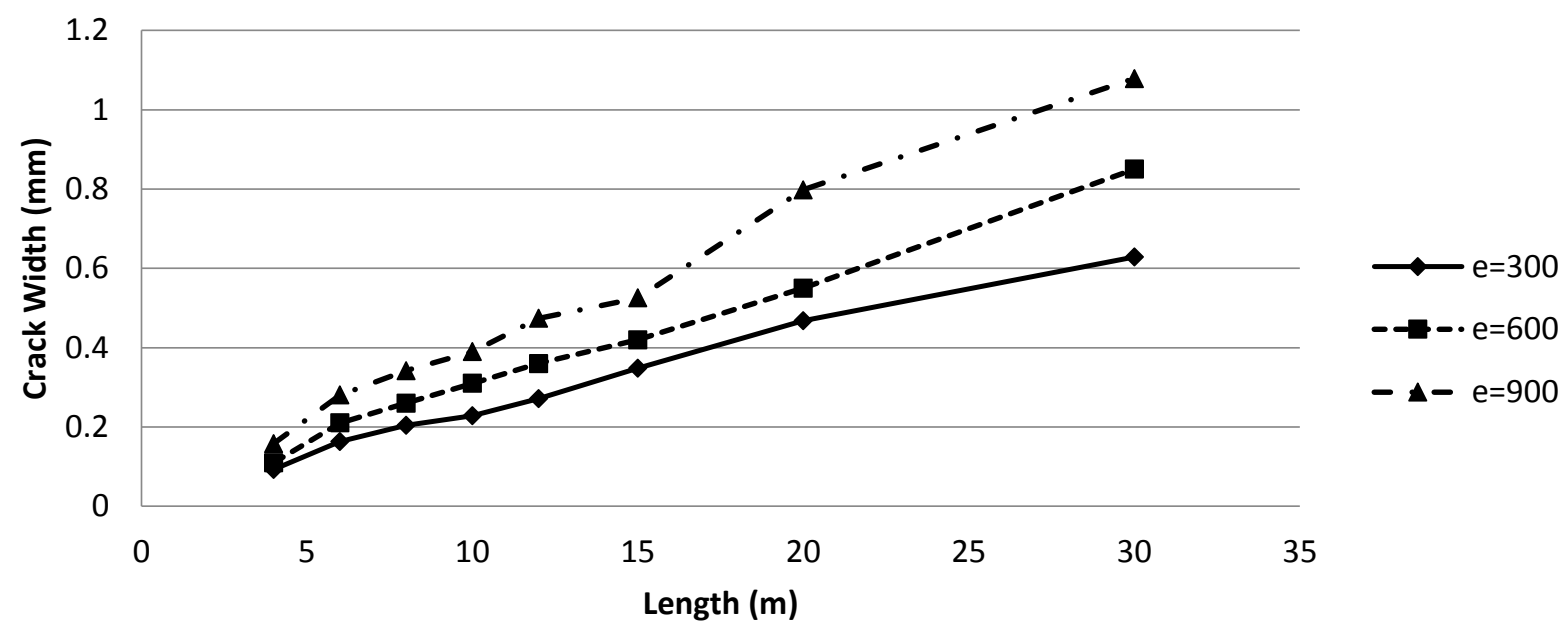

(a) $\rho=0.3 \%$
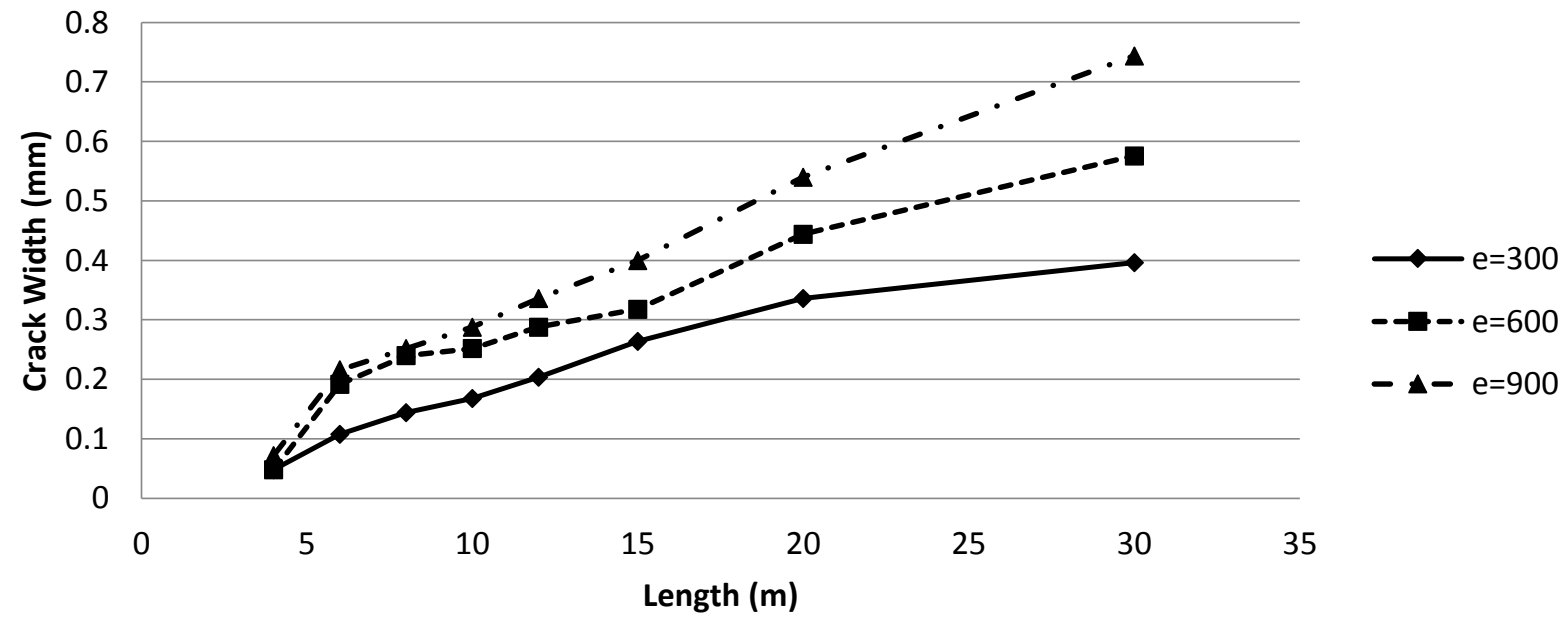

(b) $\rho=0.4 \%$ 

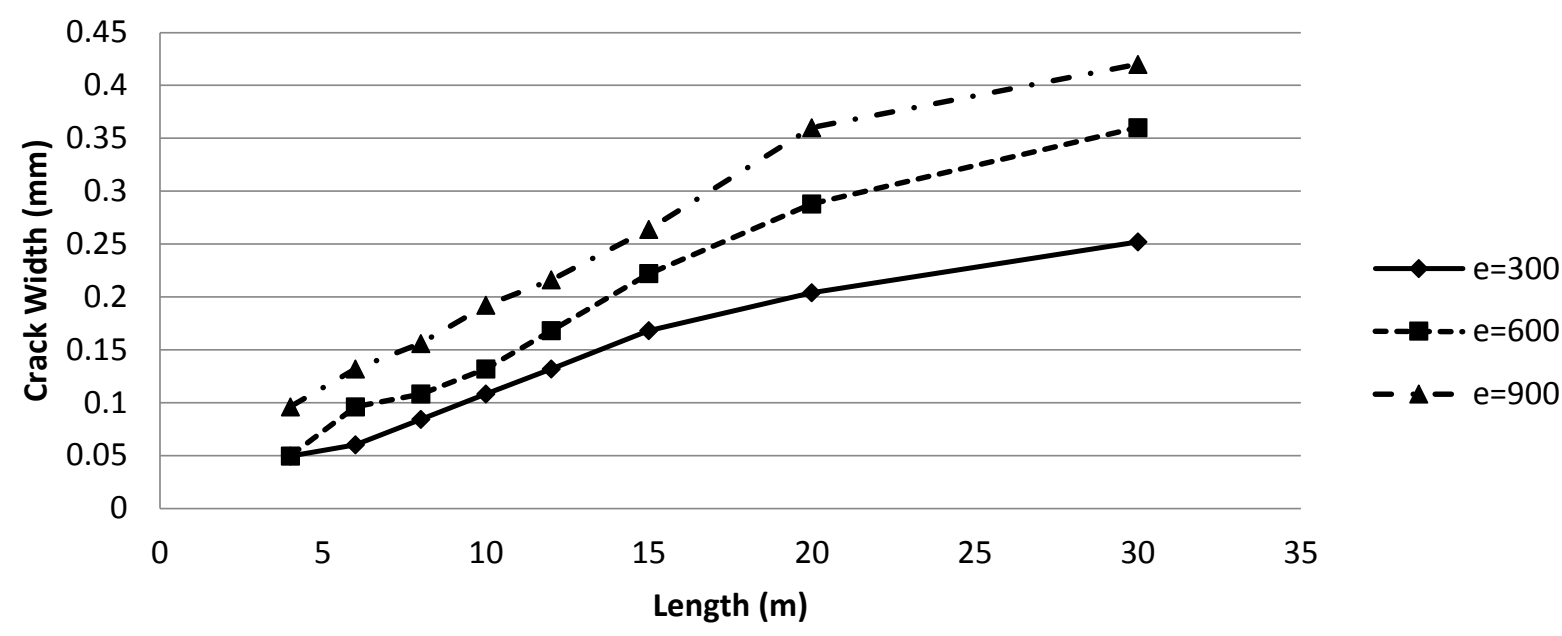

(c) $\rho=0.5 \%$
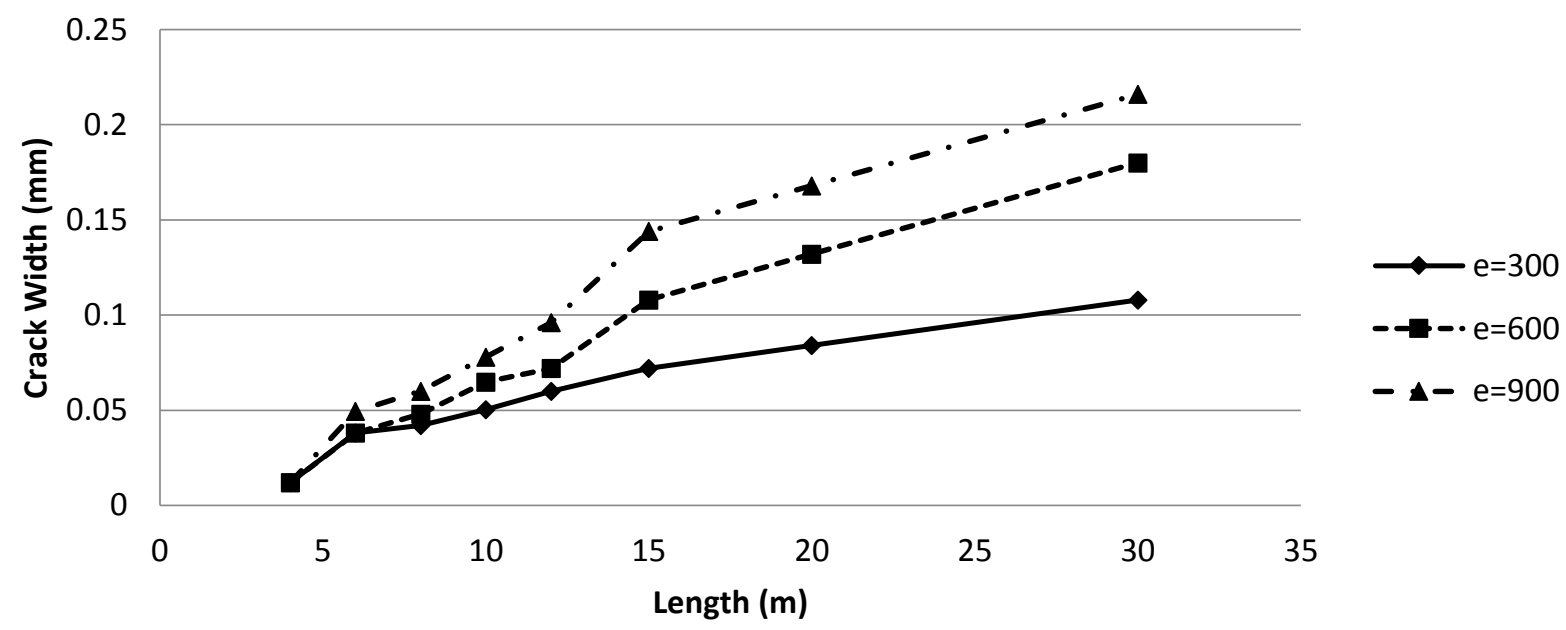

(d) $\rho=0.6 \%$

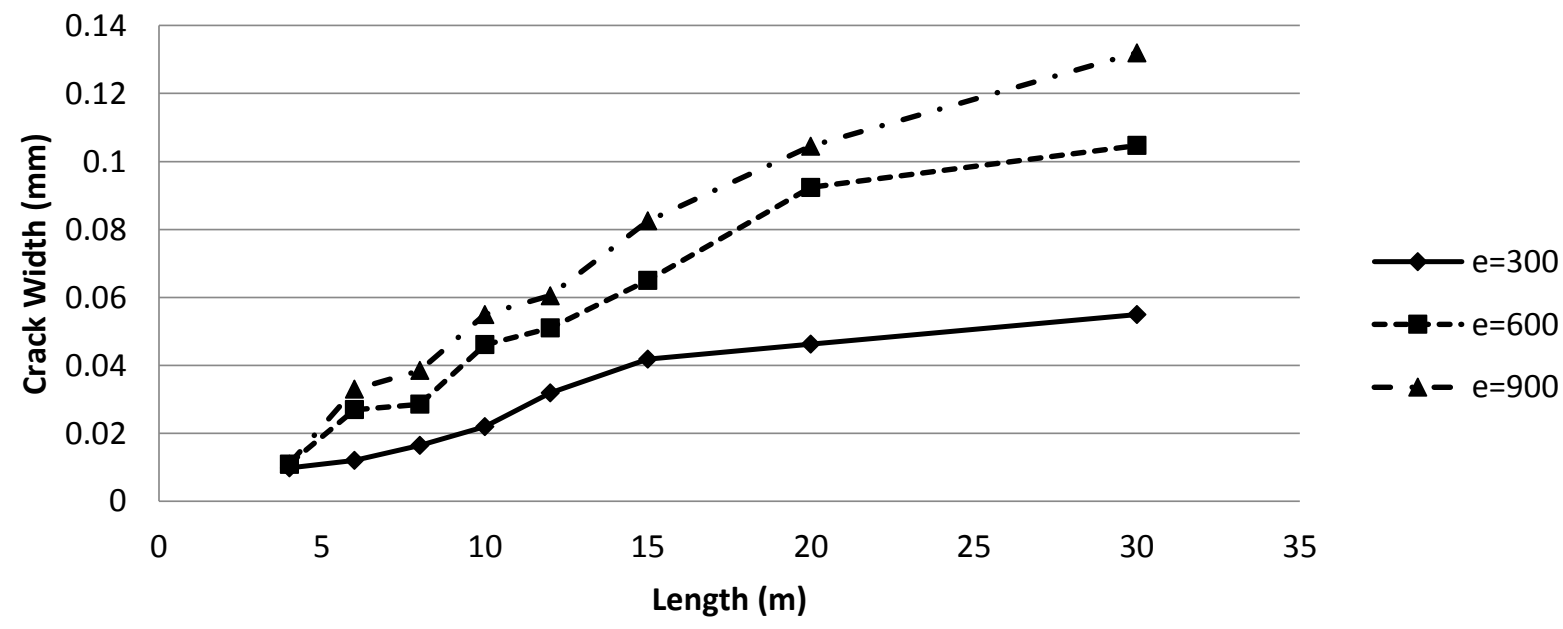

(e) $\rho=0.7 \%$

Figure B-6 Effect of volumetric strain on the crack width considering different steel ratios $(\mathrm{H}=6 \mathrm{~m})$ 

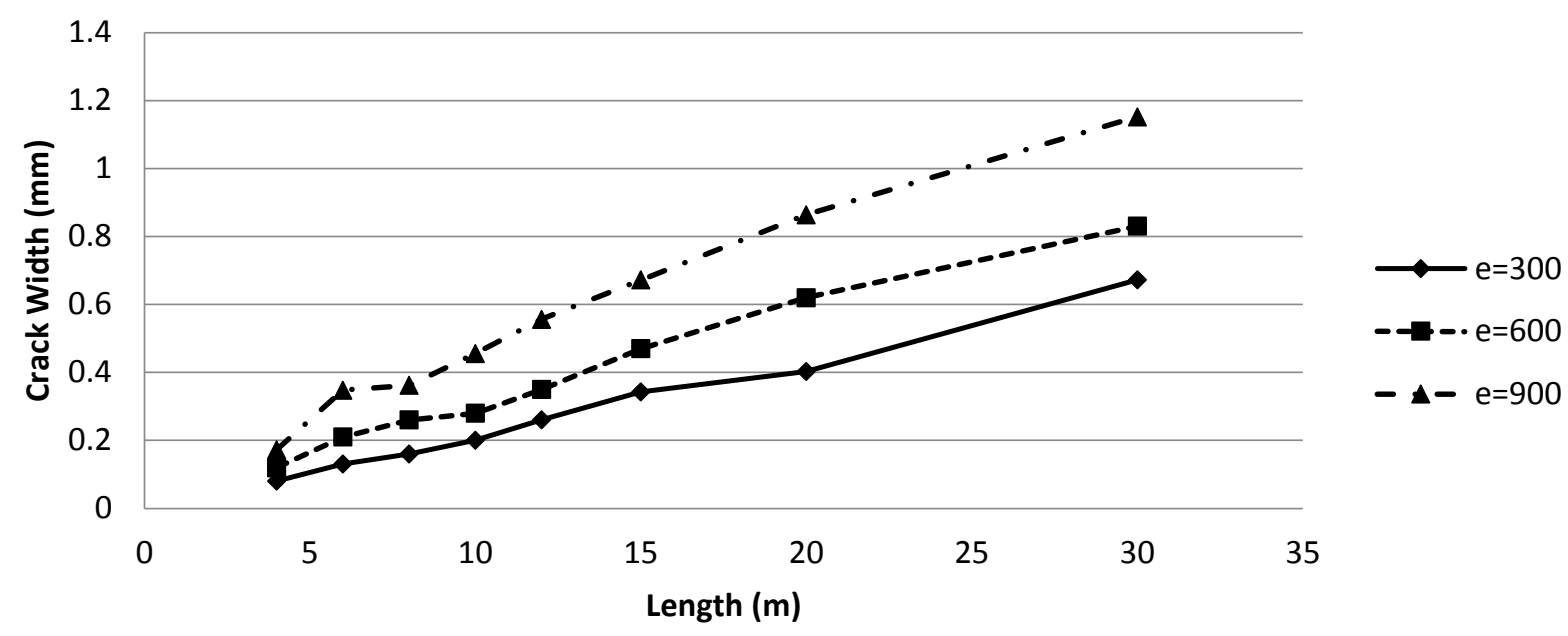

(a) $\rho=0.3 \%$
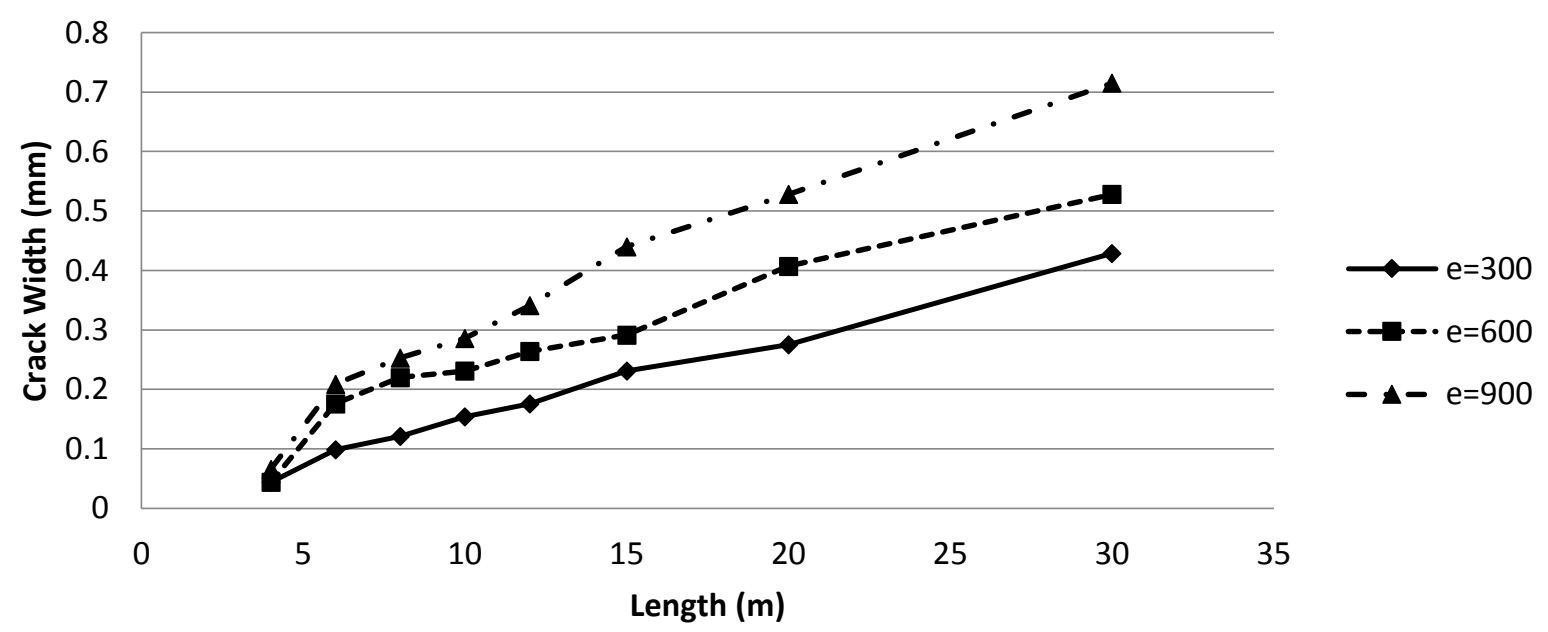

(b) $\rho=0.4 \%$
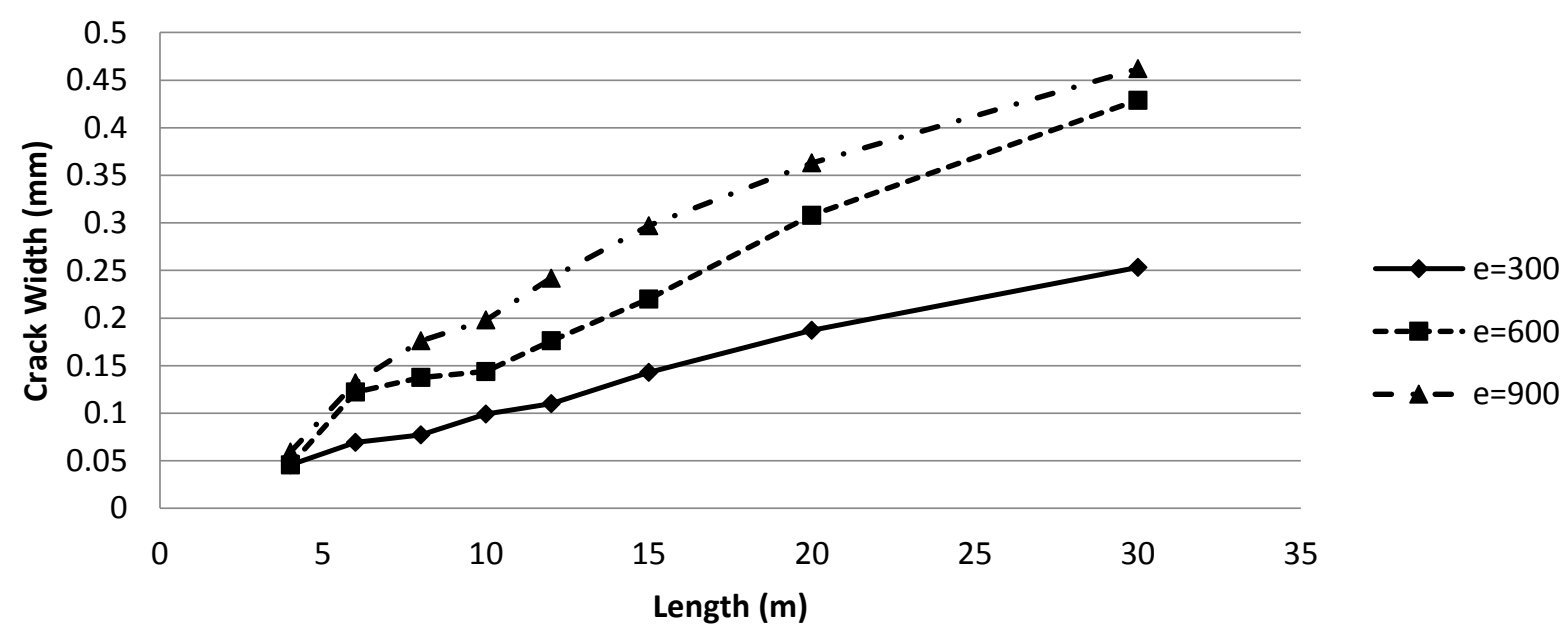

(c) $\rho=0.5 \%$ 

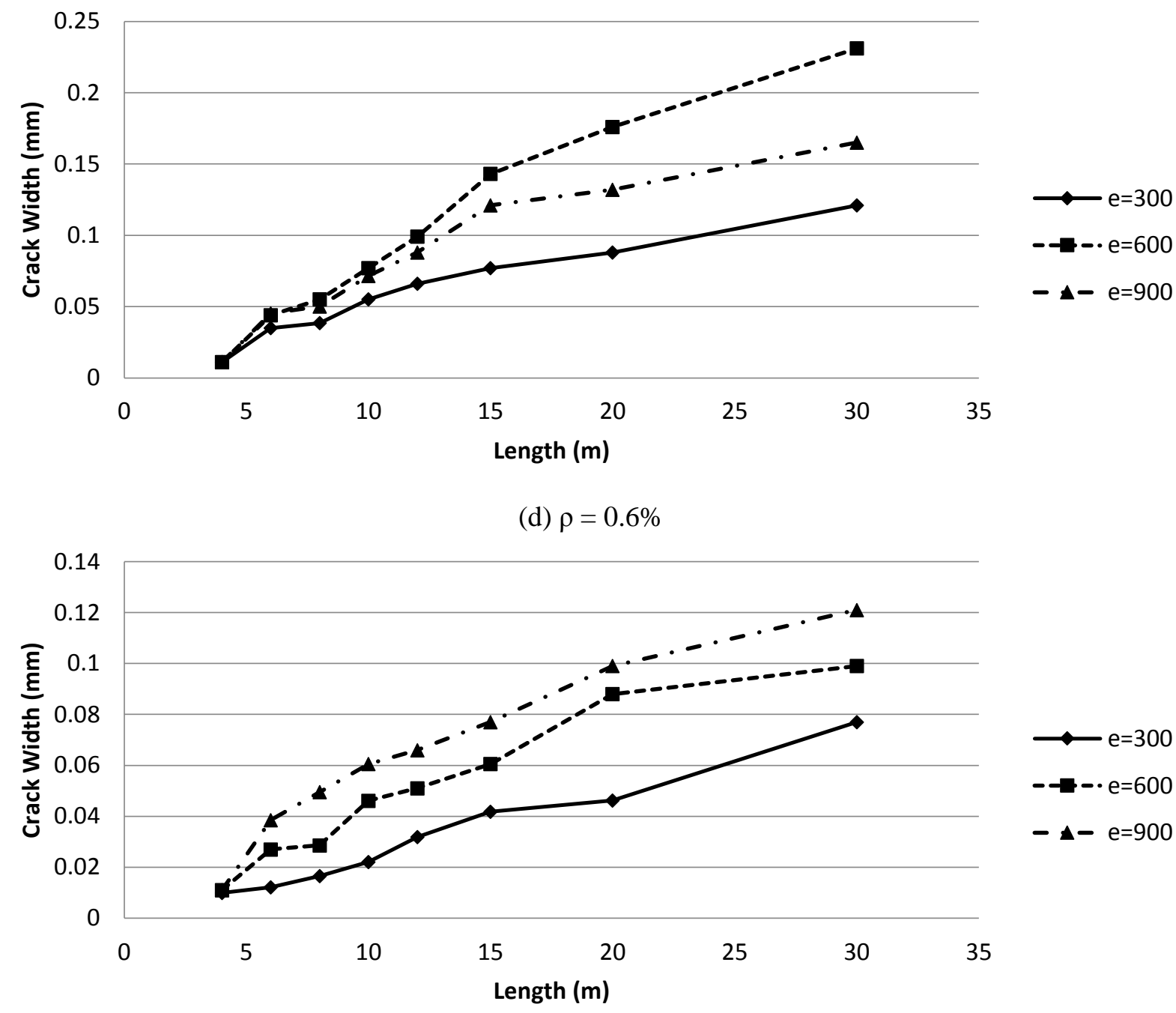

(e) $\rho=0.7 \%$

Figure B-7 Effect of volumetric strain on the crack width considering different steel ratios $(\mathrm{H}=8 \mathrm{~m})$

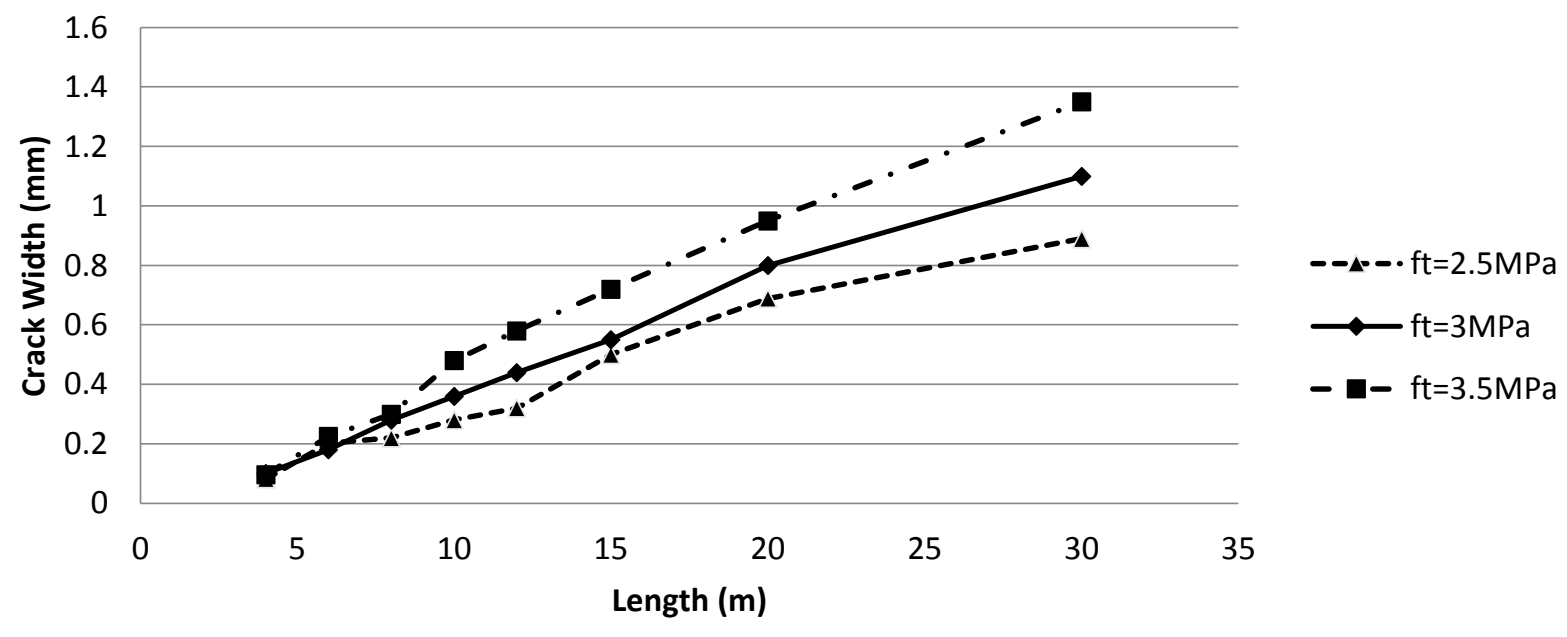

(a) $\mathrm{H}=4 \mathrm{~m}$ 


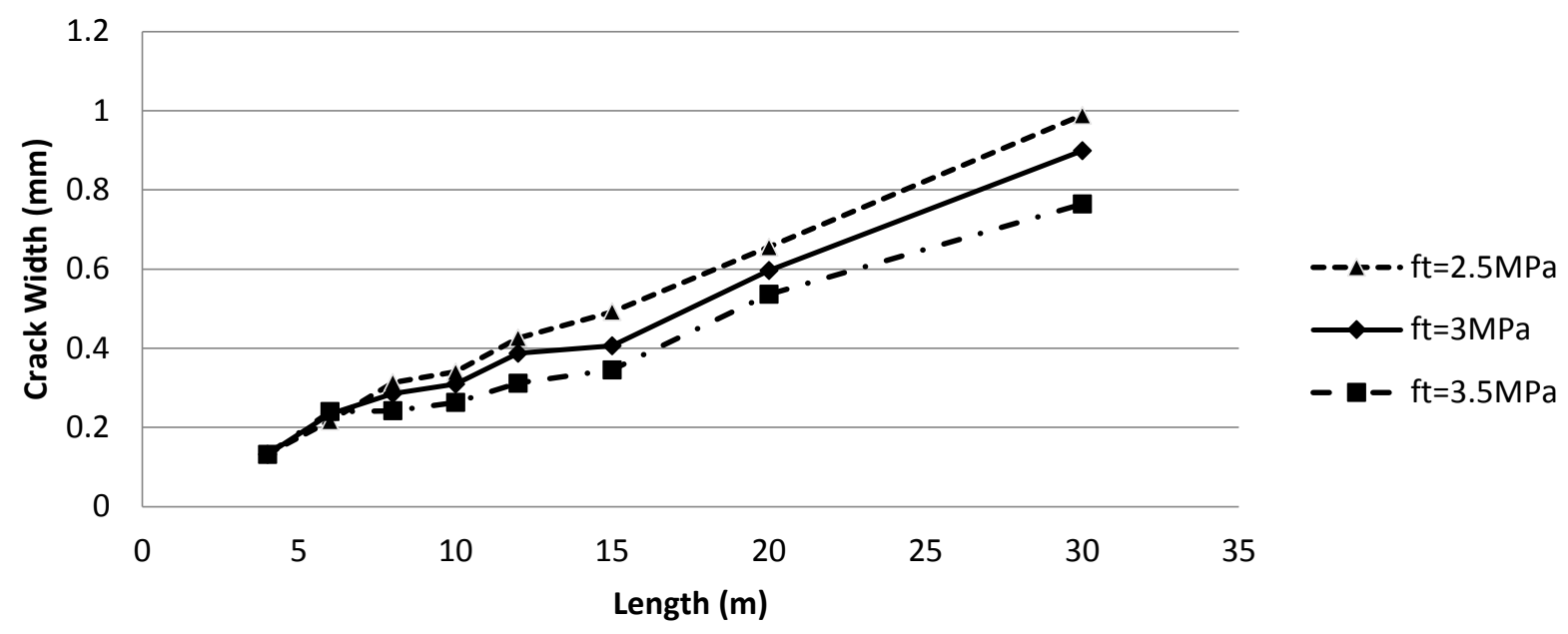

(b) $\mathrm{H}=6 \mathrm{~m}$

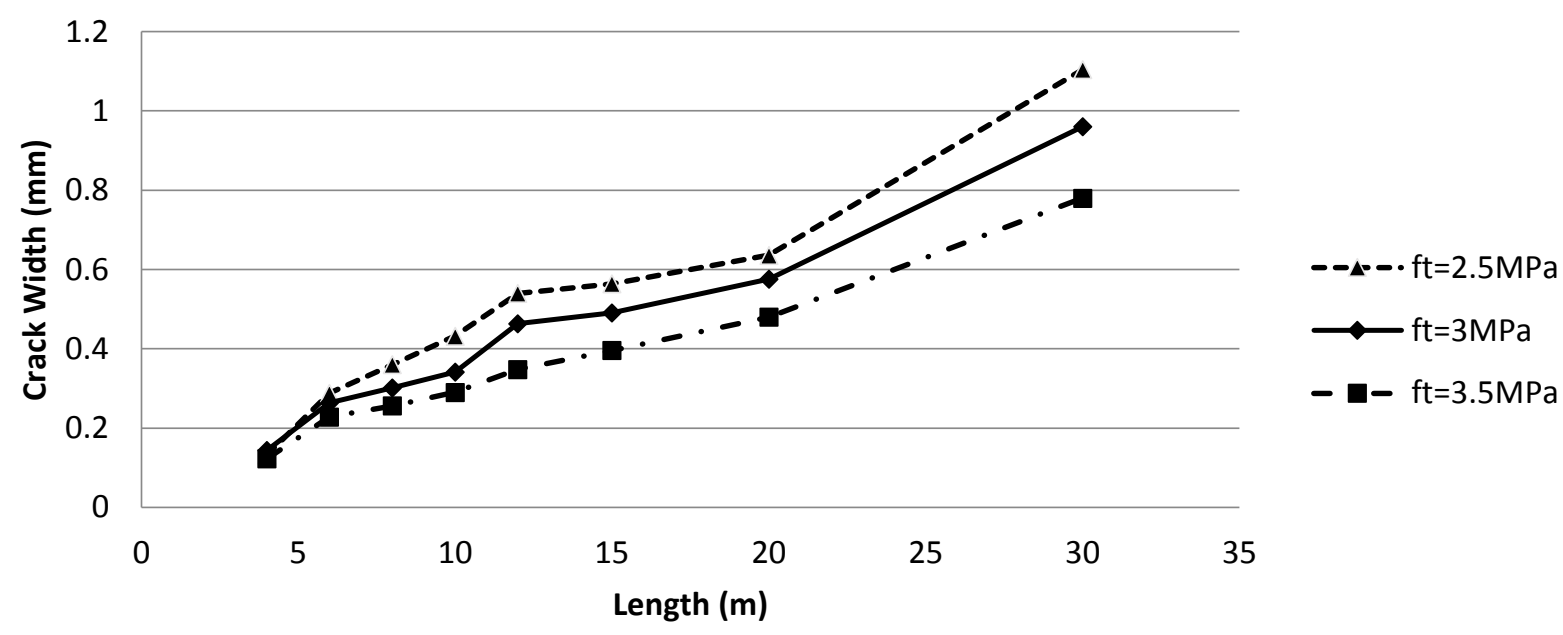

(c) $\mathrm{H}=8 \mathrm{~m}$

Figure B-8 Effect of concrete tensile strength on the crack width $(\rho=0.3 \%)$

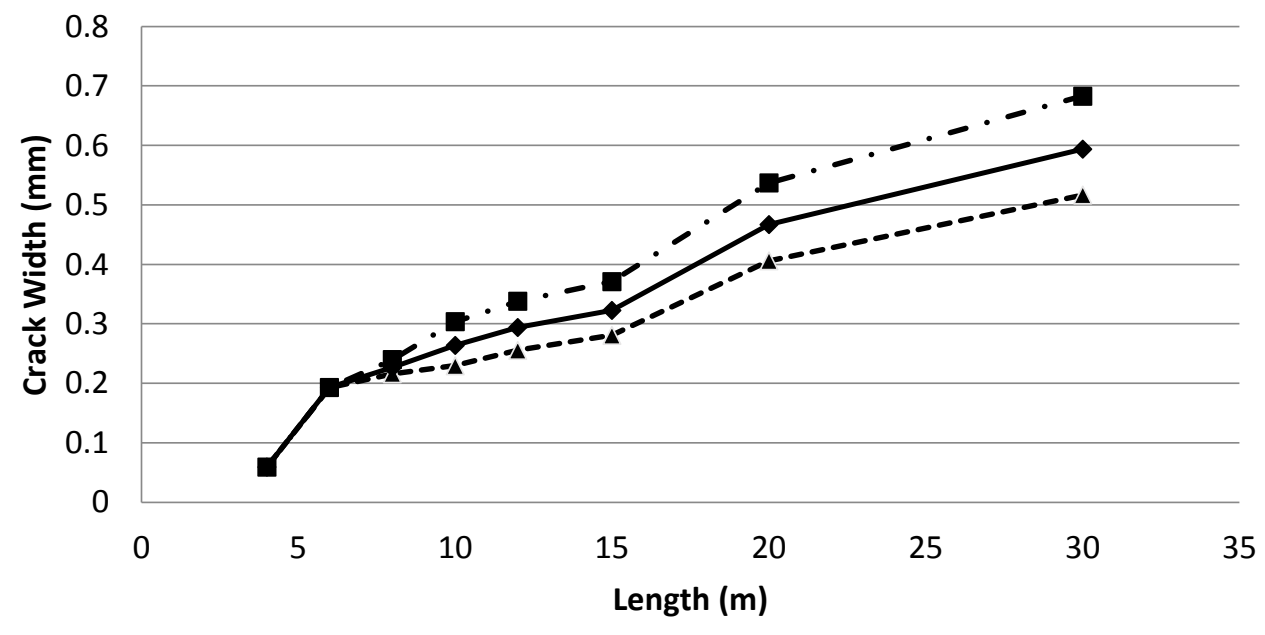

$--1-\cdot \cdot \mathrm{ft}=2.5 \mathrm{MPa}$

$\longrightarrow \mathrm{ft}=3 \mathrm{MPa}$

- $\mathbf{- n} \mathrm{ft}=3.5 \mathrm{MPa}$

(a) $\rho=0.4 \%$ 

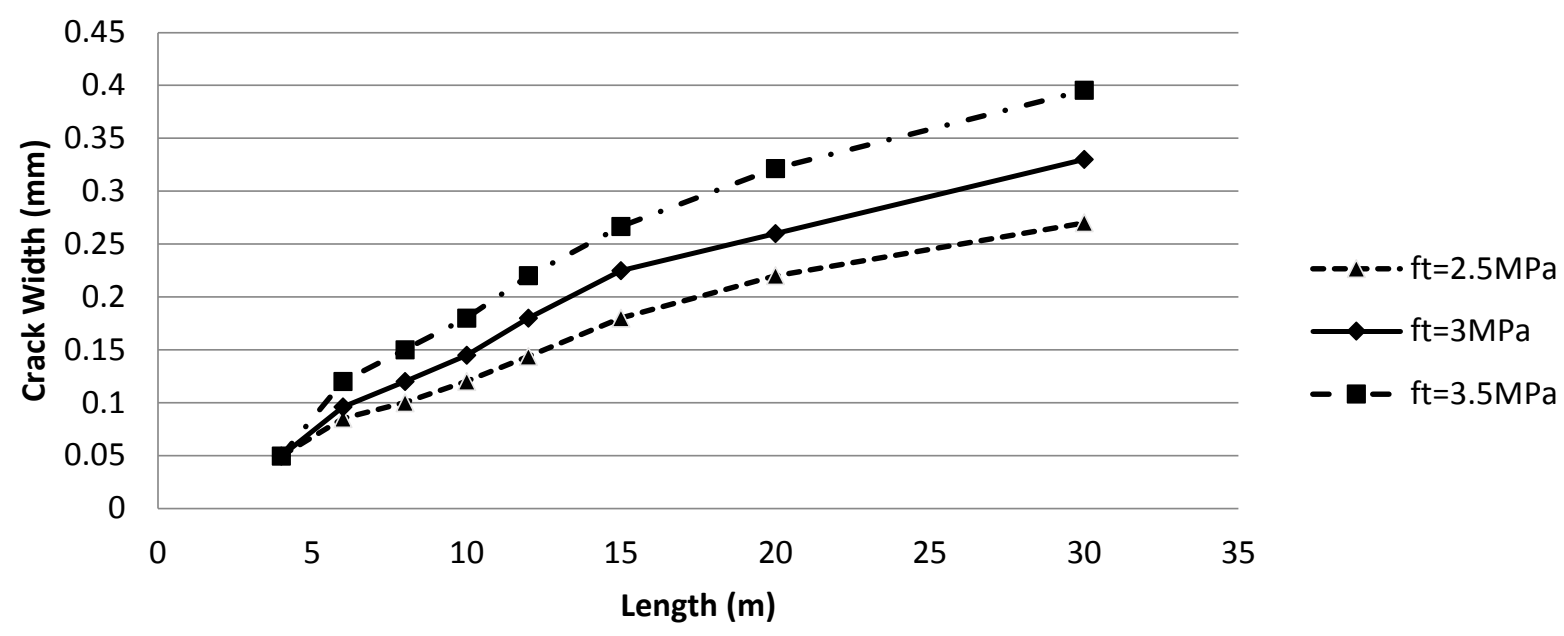

(b) $\rho=0.5 \%$
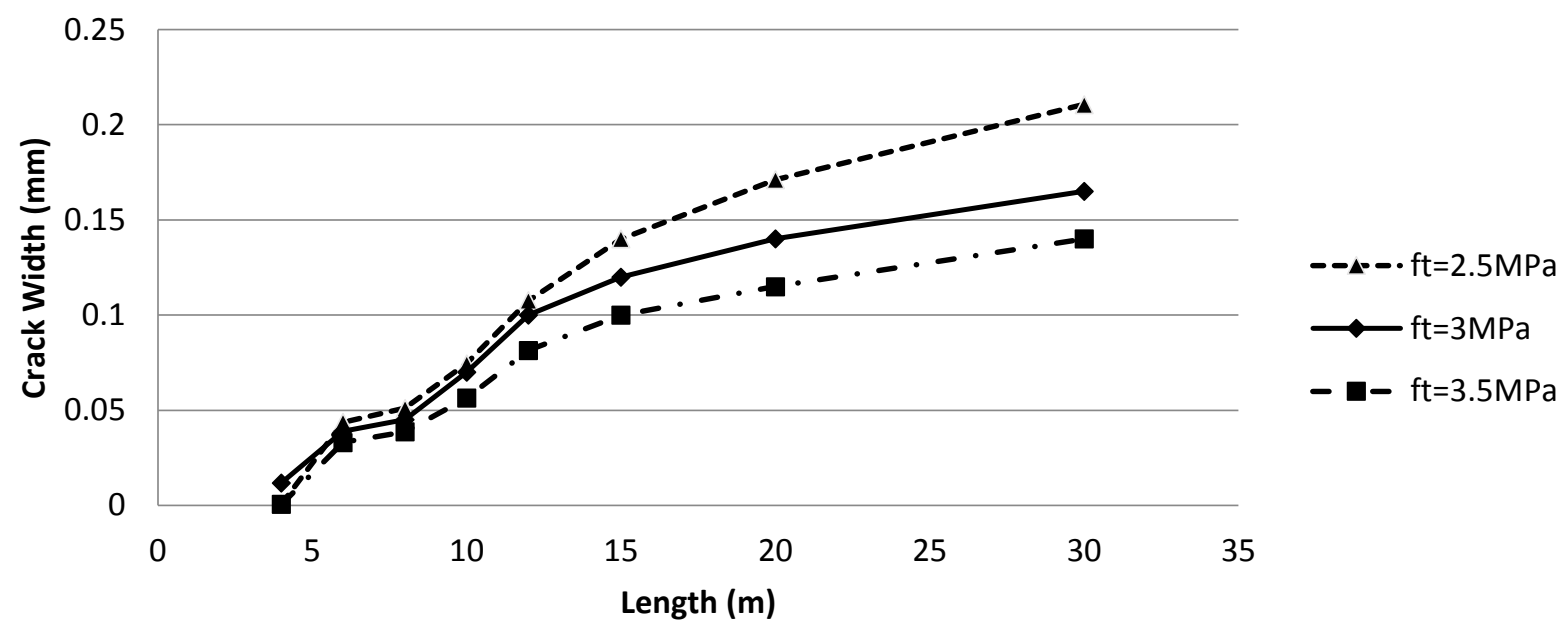

(c) $\rho=0.6 \%$

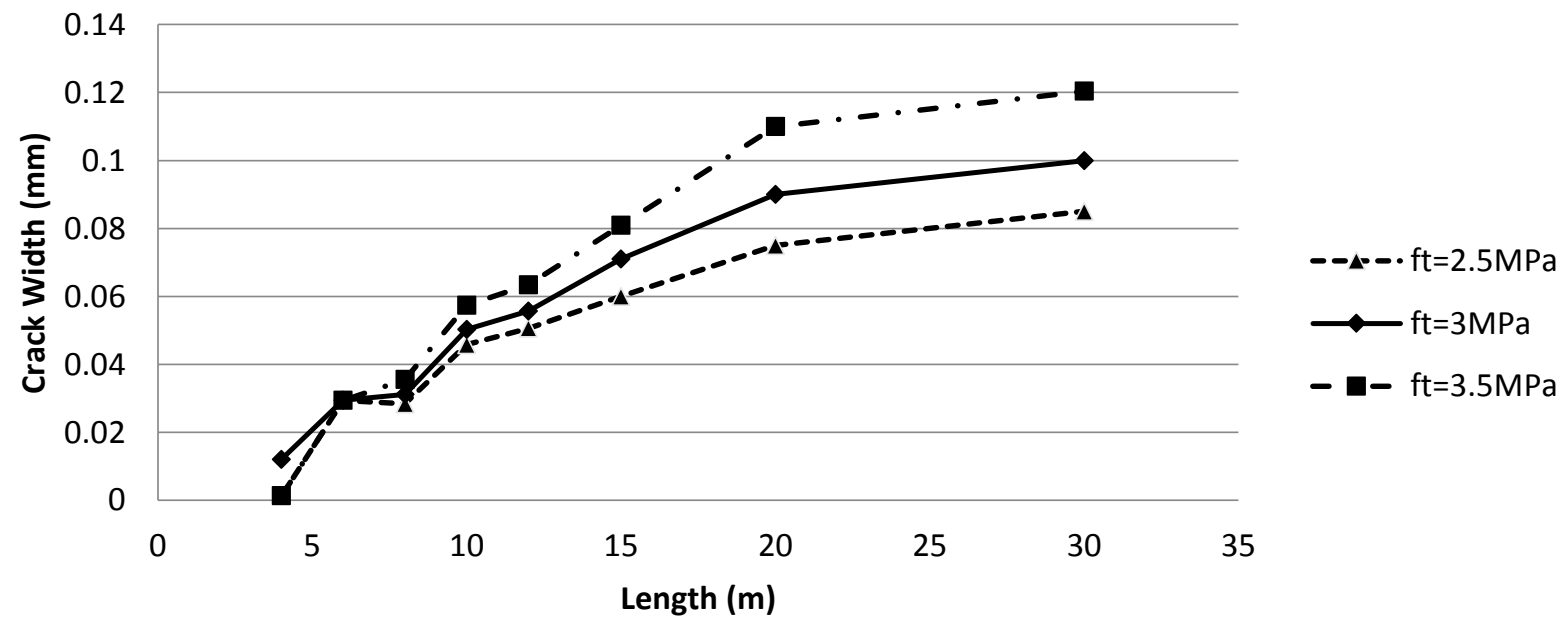

(d) $\rho=0.7 \%$

Figure B-9 Effect of concrete tensile strength on the crack width with different steel ratios $(\mathrm{H}=4 \mathrm{~m})$ 


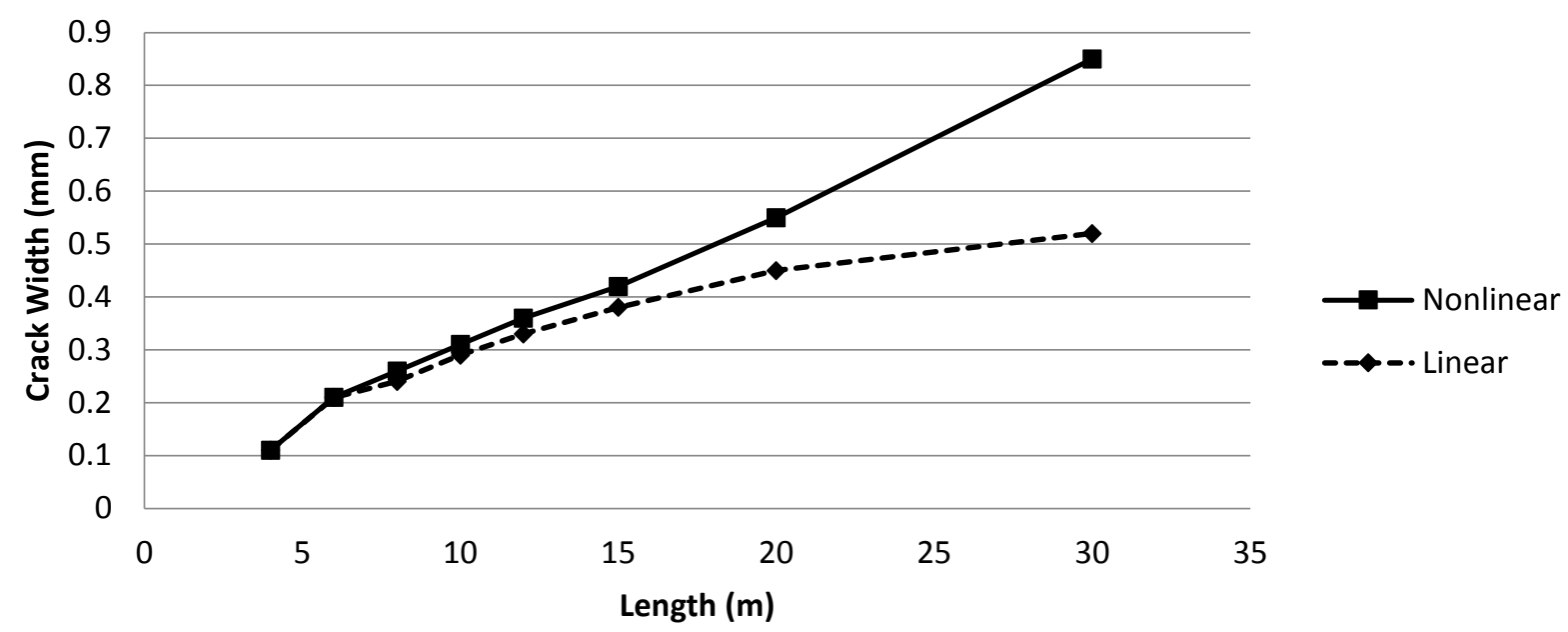

(a) $\mathrm{H}=6 \mathrm{~m}$

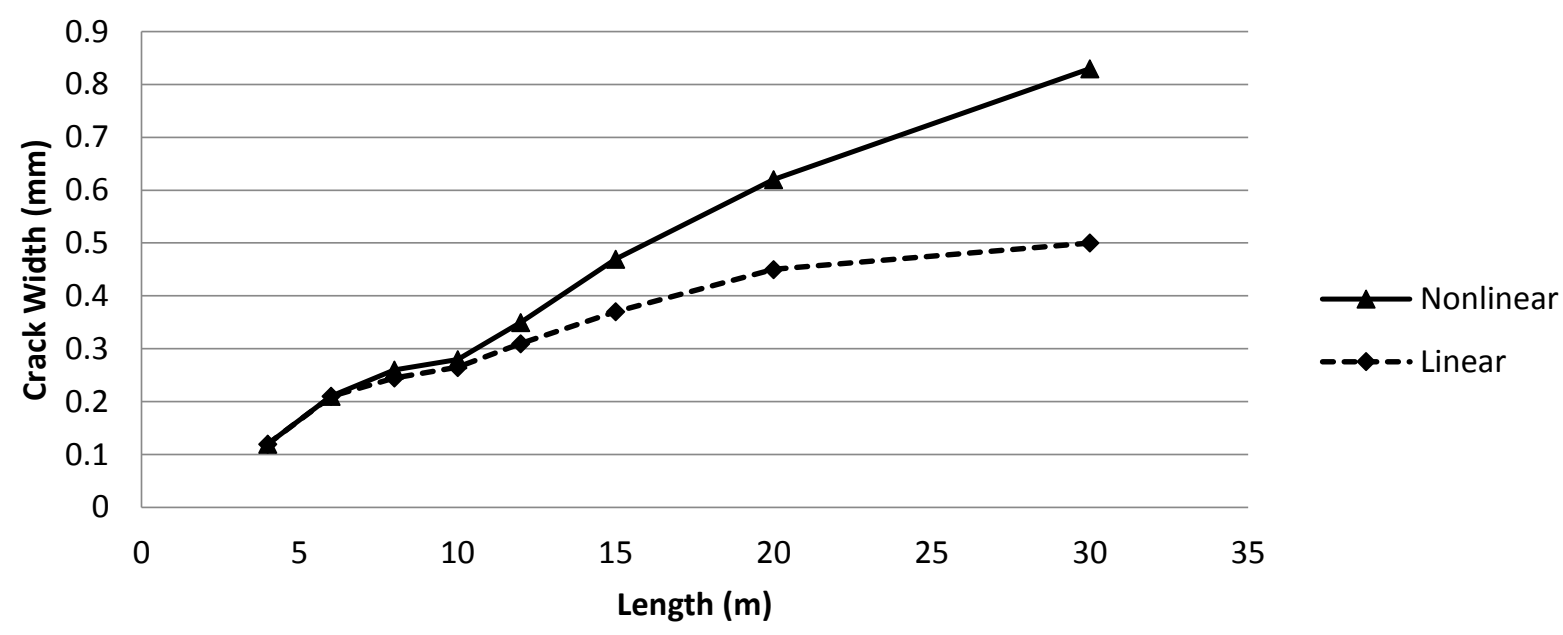

(b) $\mathrm{H}=8 \mathrm{~m}$

Figure B-10 Effect of steel behavior on the crack width considering different wall heights $(\rho=0.3 \%)$

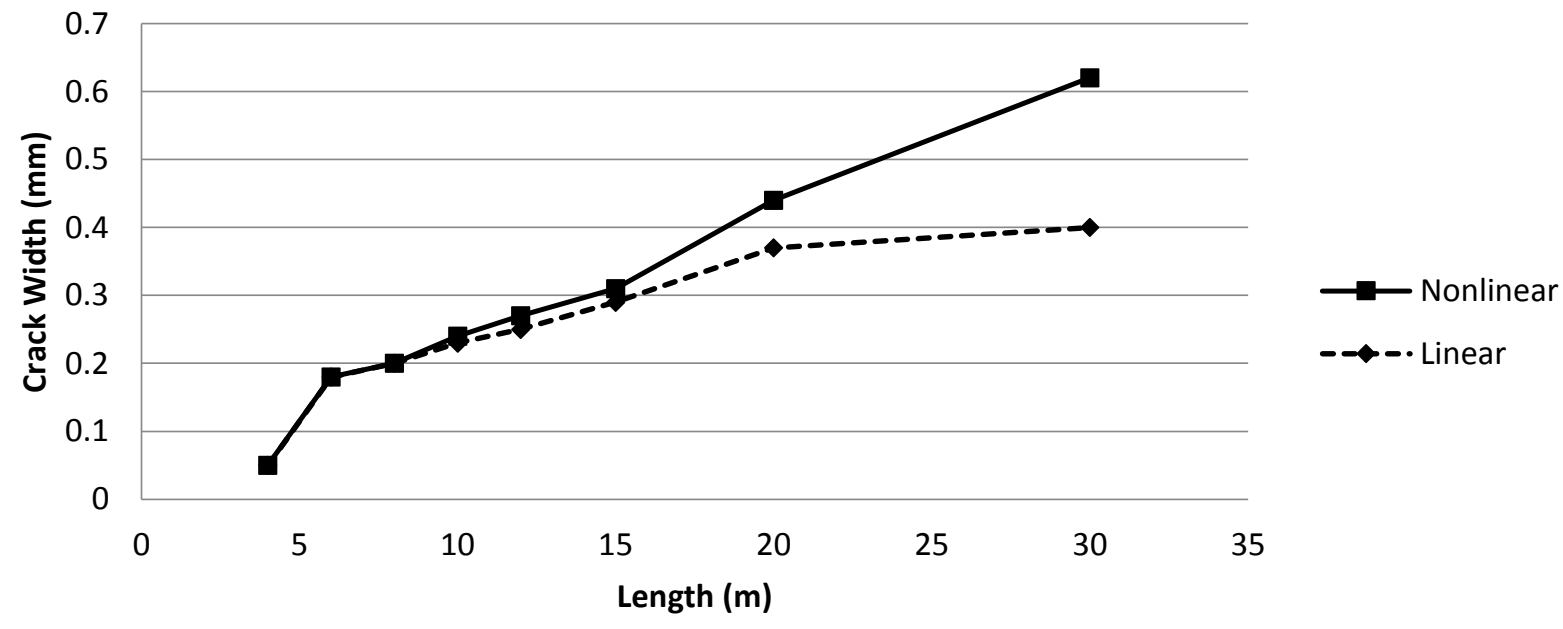

(a) $\rho=0.4 \%$ 


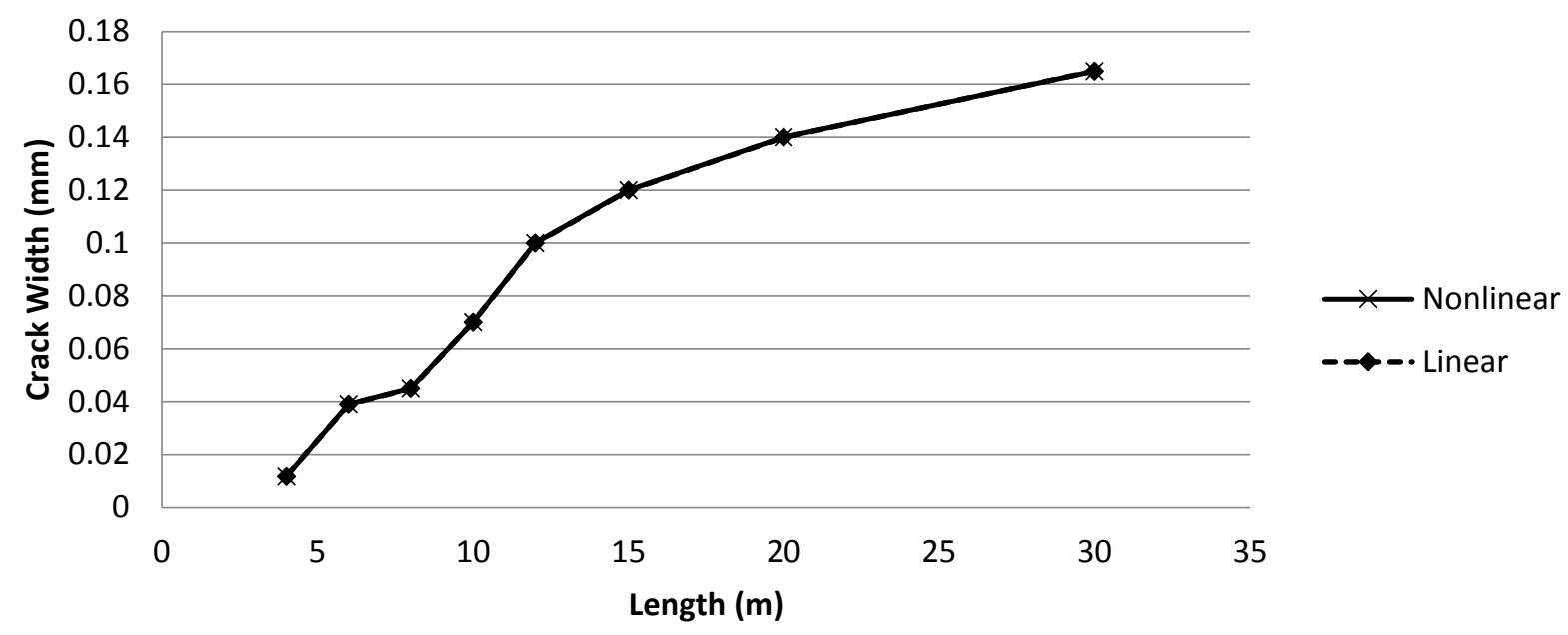

(b) $\rho=0.6 \%$

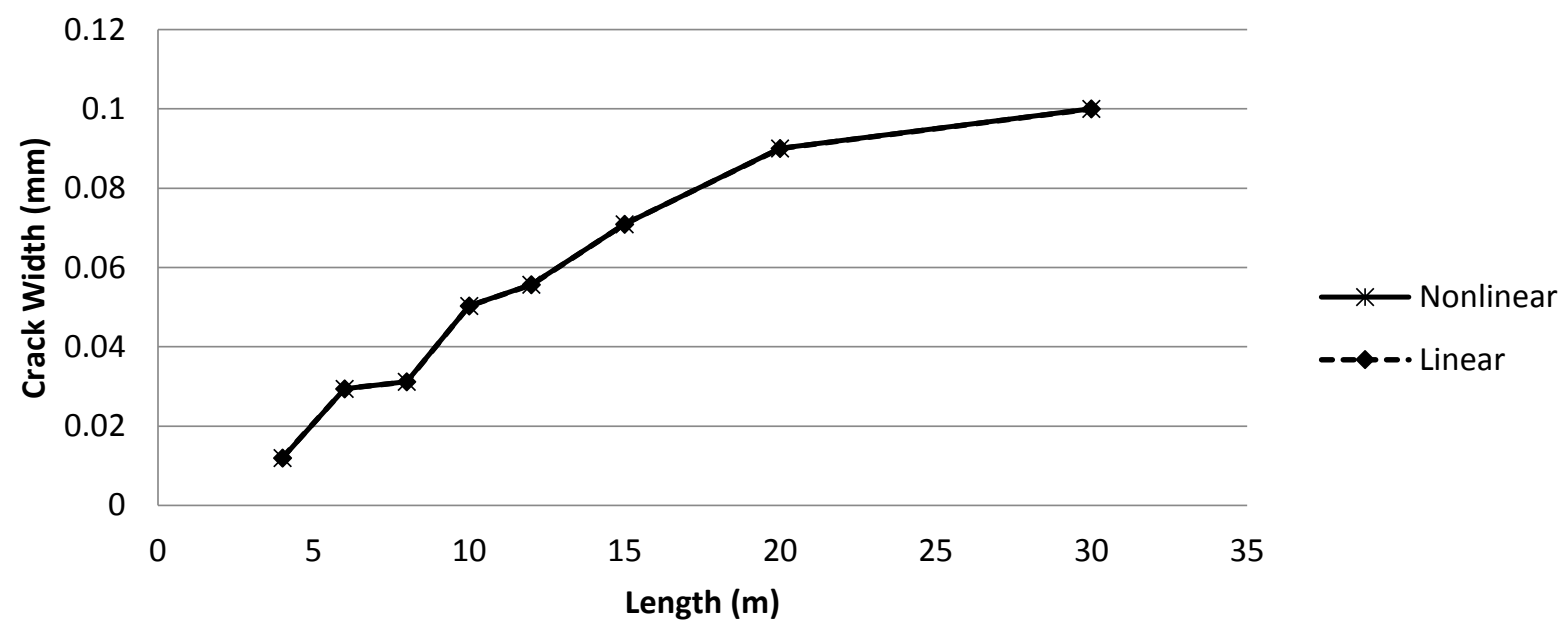

(c) $\rho=0.7 \%$

Figure B-11 Effect of steel behavior on the crack width considering different steel ratios $(\mathrm{H}=4 \mathrm{~m})$

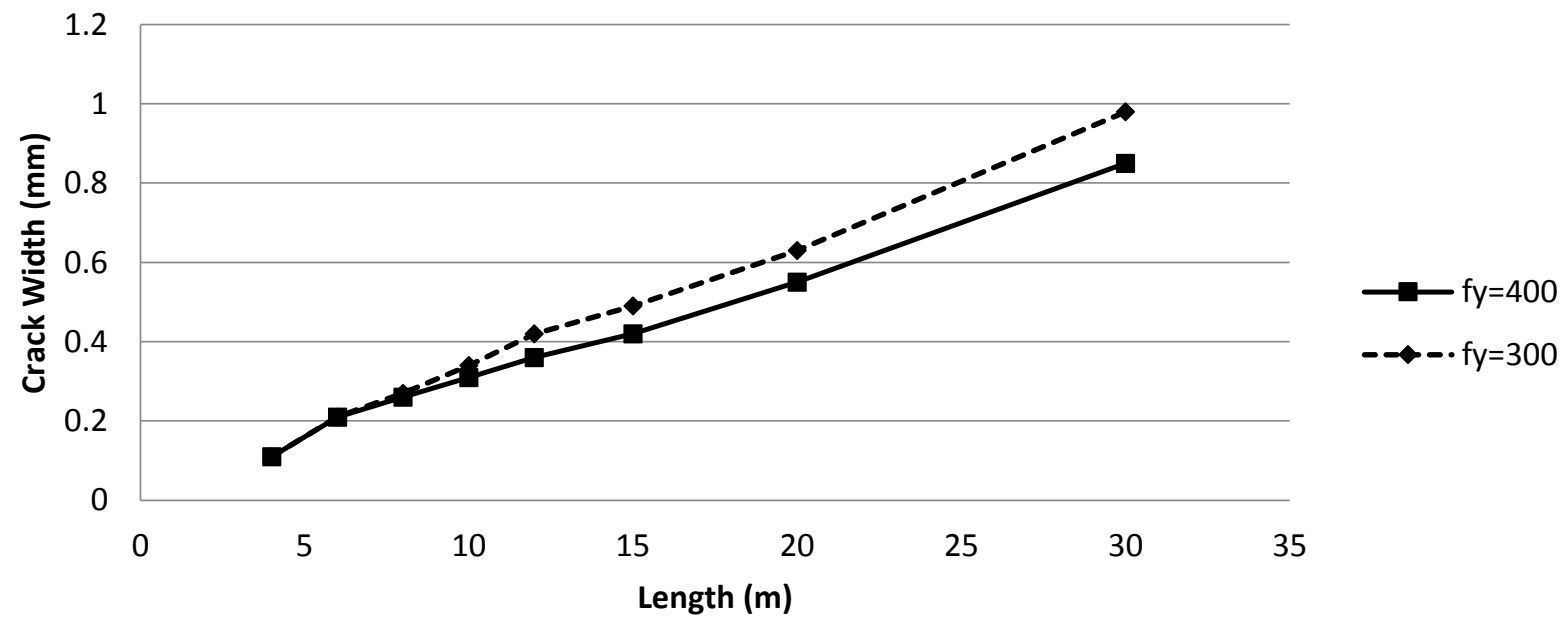

(a) $\mathrm{H}=6 \mathrm{~m}$ 

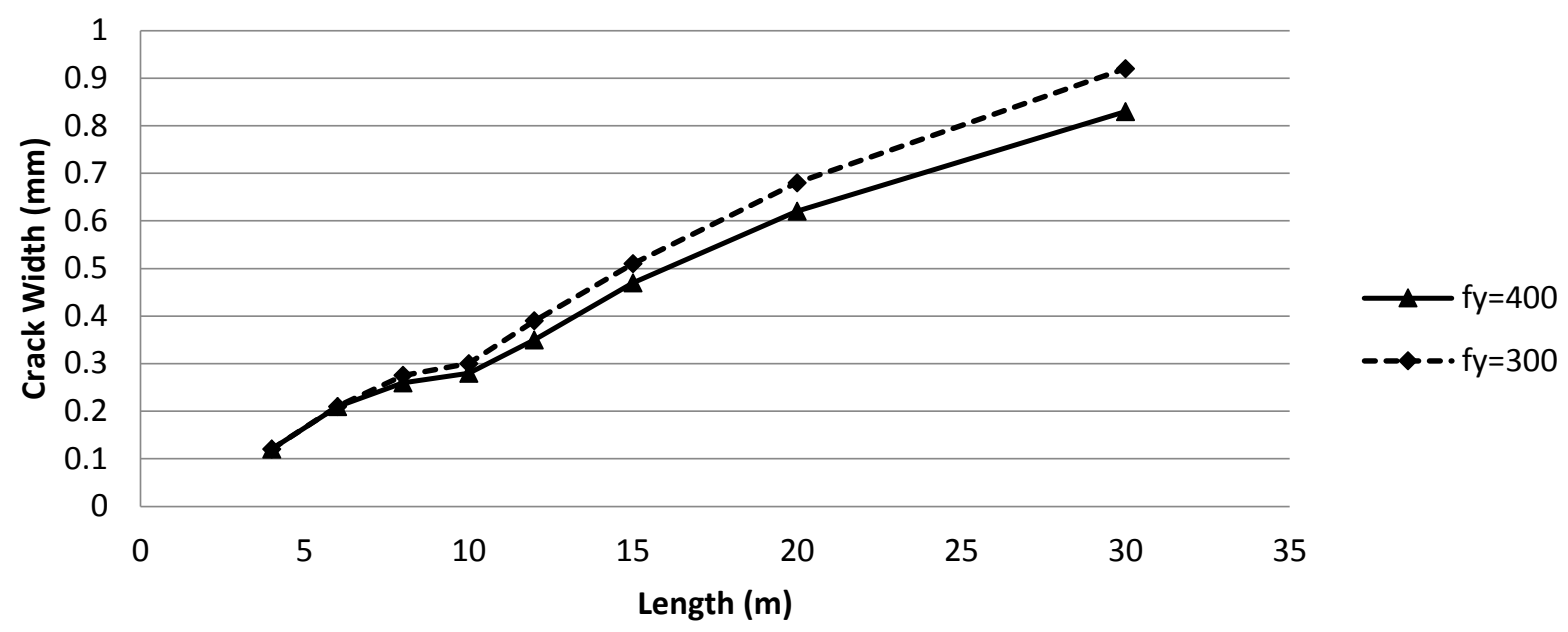

(b) $\mathrm{H}=8 \mathrm{~m}$

Figure B-12 Effect of steel yield strength on the crack width $(\rho=0.3 \%)$
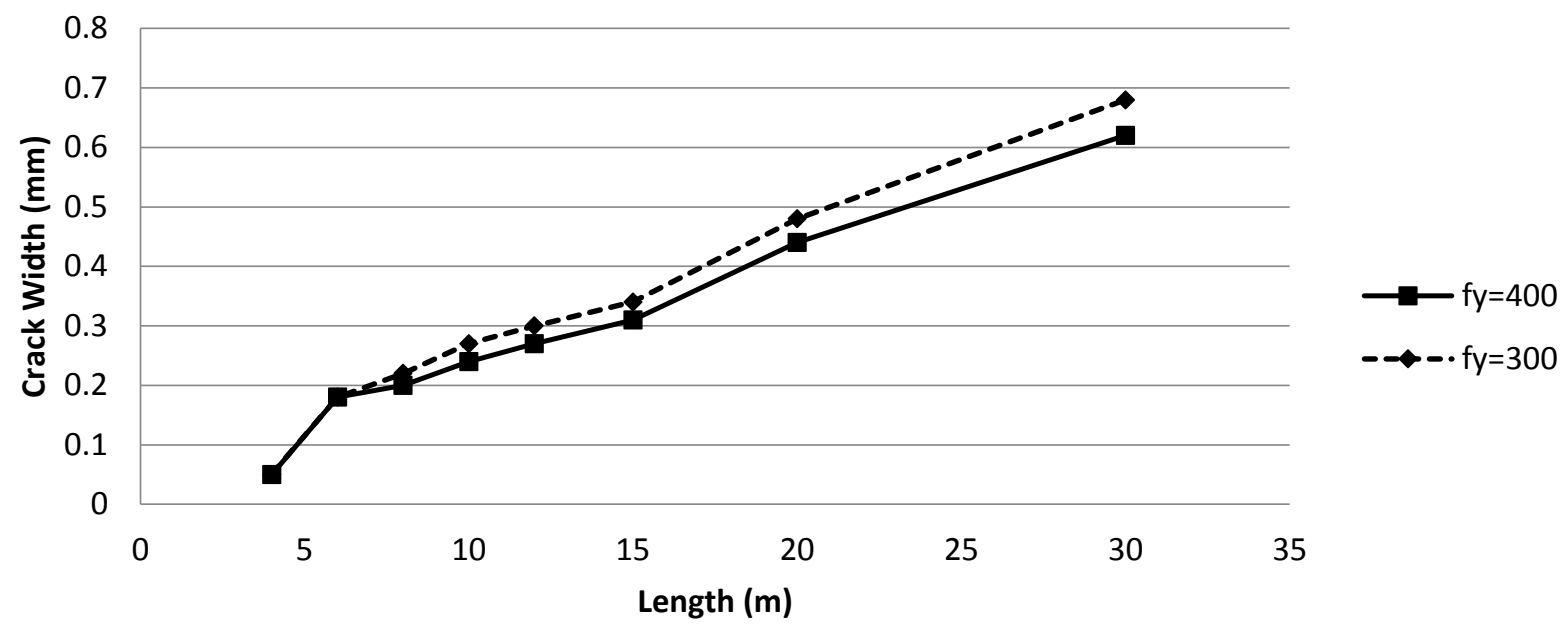

(a) $\rho=0.4 \%$
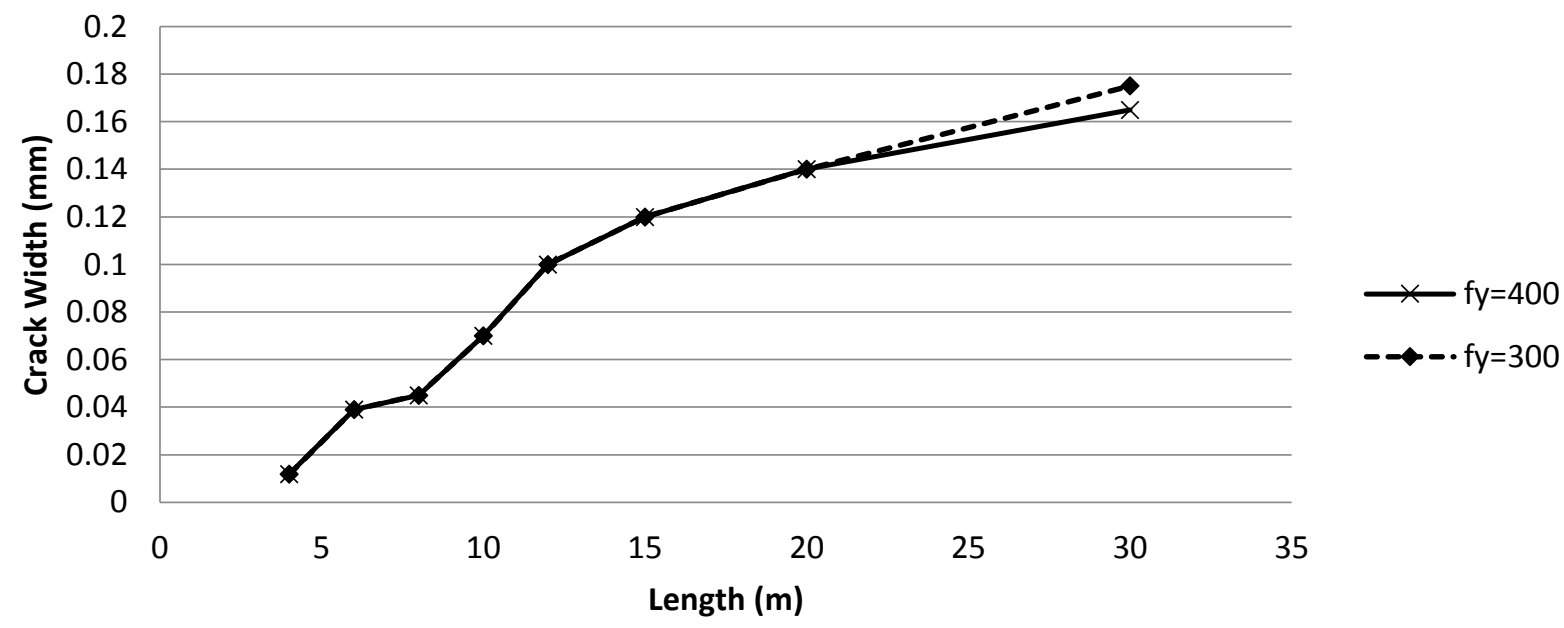

(b) $\rho=0.6 \%$ 


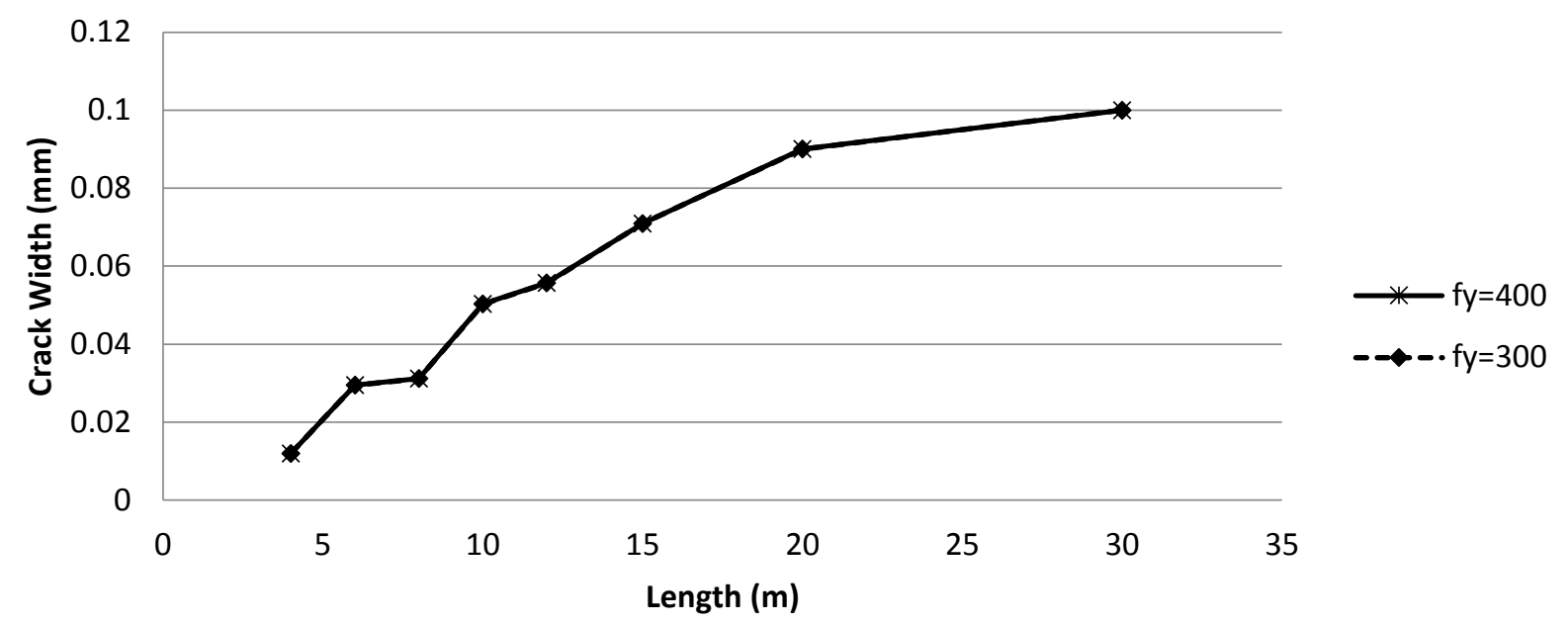

(c) $\rho=0.7 \%$

Figure B-13 Effect of steel yield strength on the crack width considering different steel ratios $(\mathrm{H}=4 \mathrm{~m})$

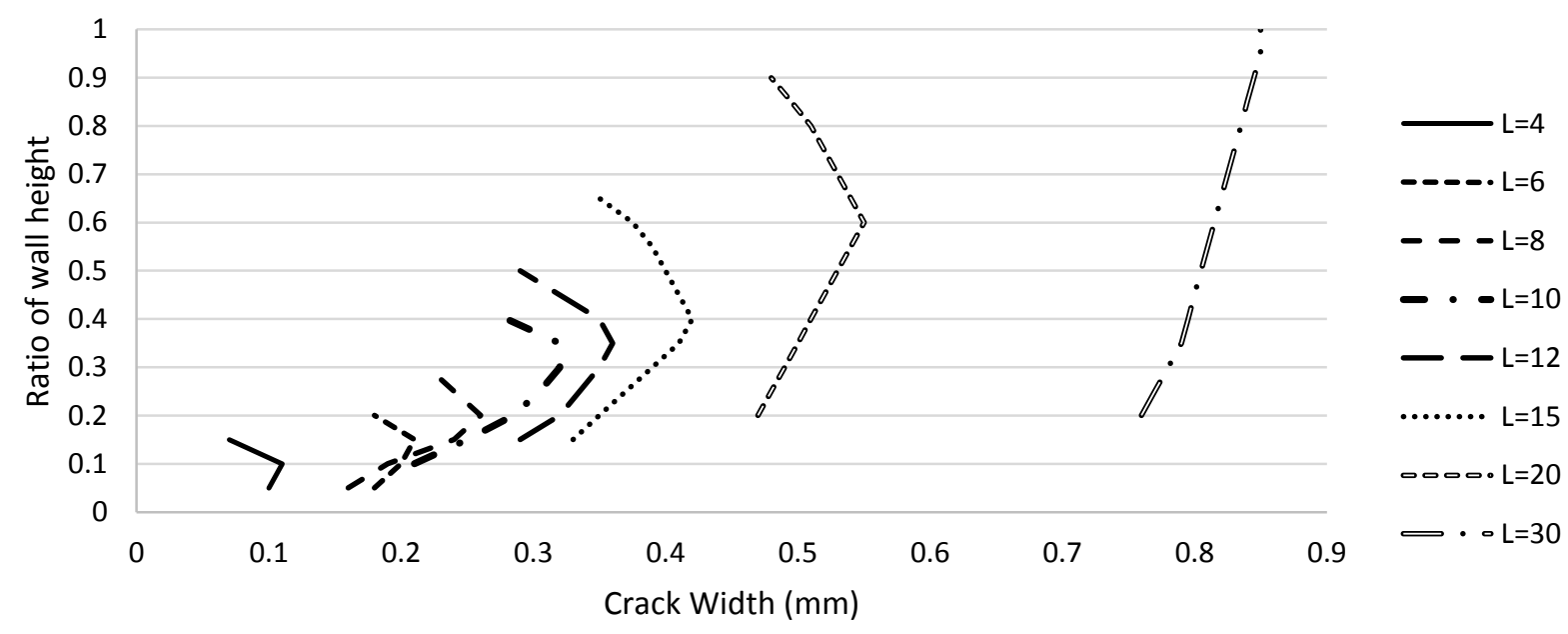

(a) $\mathrm{H}=6 \mathrm{~m}$

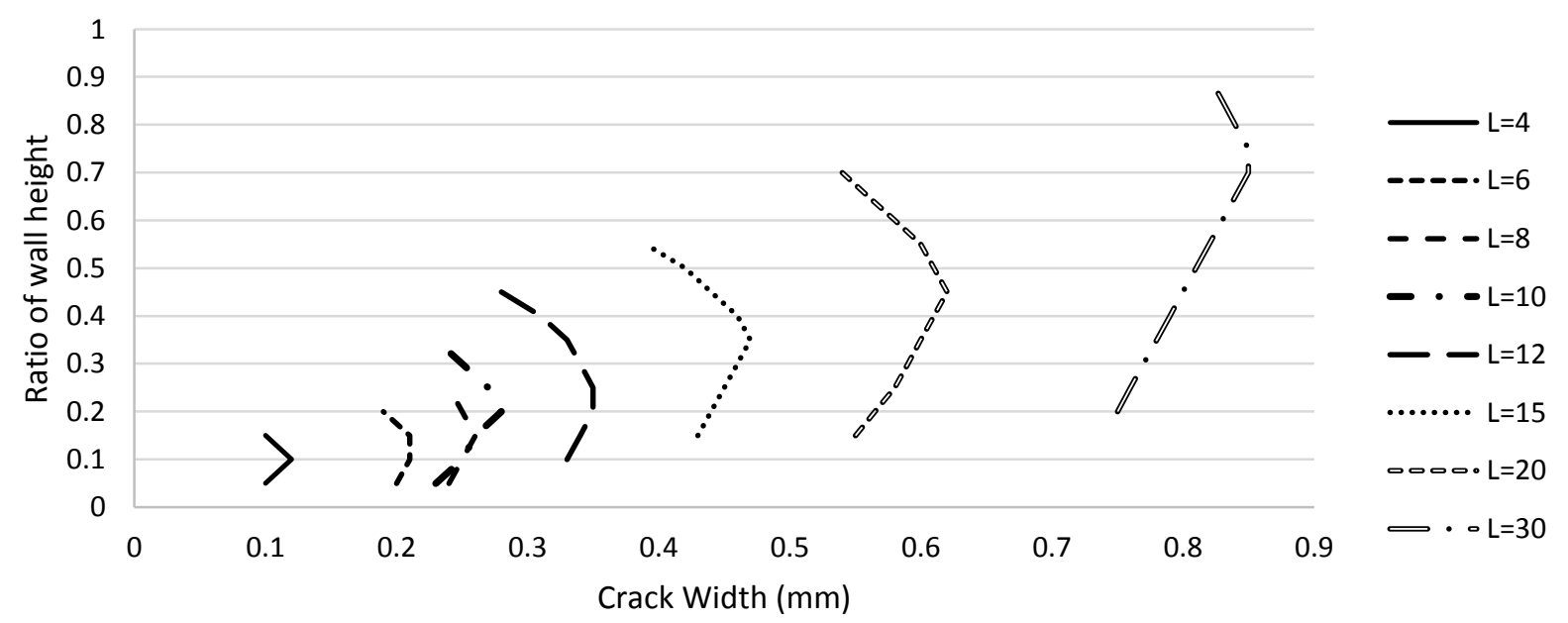

(b) $\mathrm{H}=8 \mathrm{~m}$

Figure B-14 Effect of wall length on the crack width over the wall height $(\rho=0.3 \%)$ 


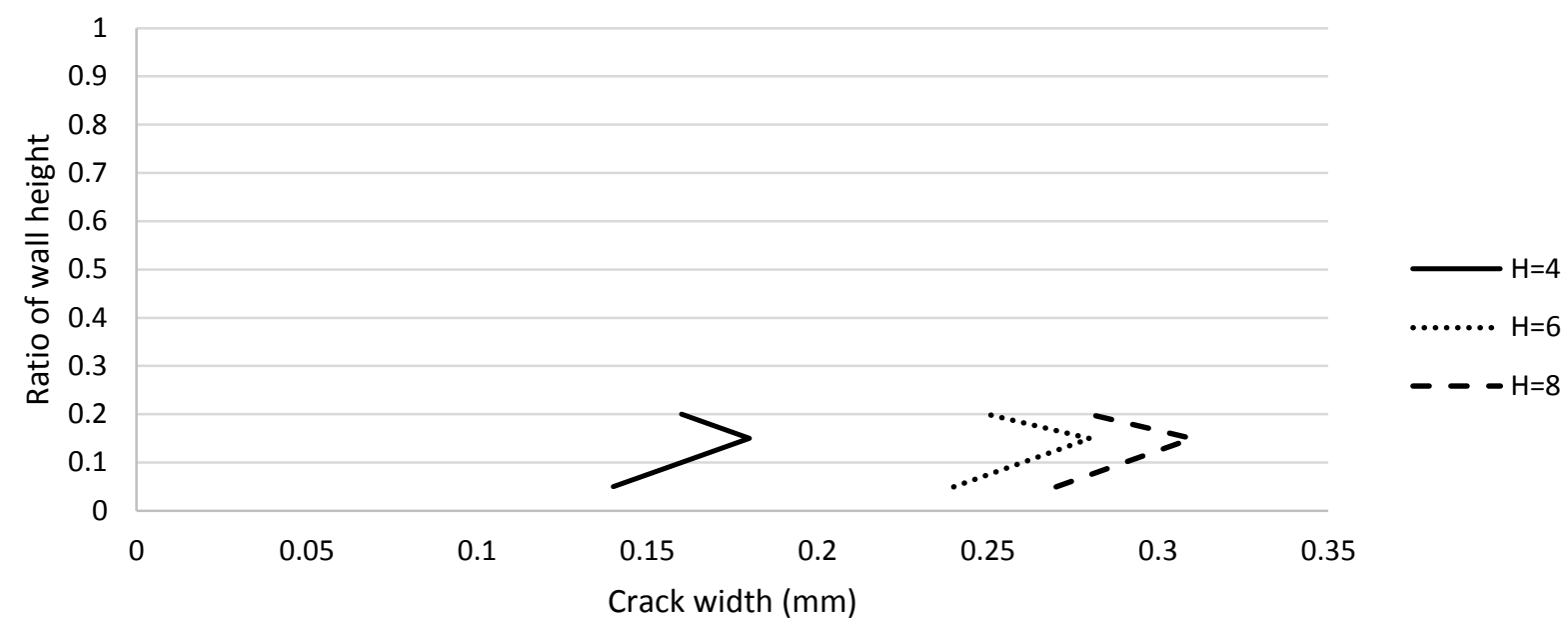

(a) $\mathrm{L} / \mathrm{H}=1.5$
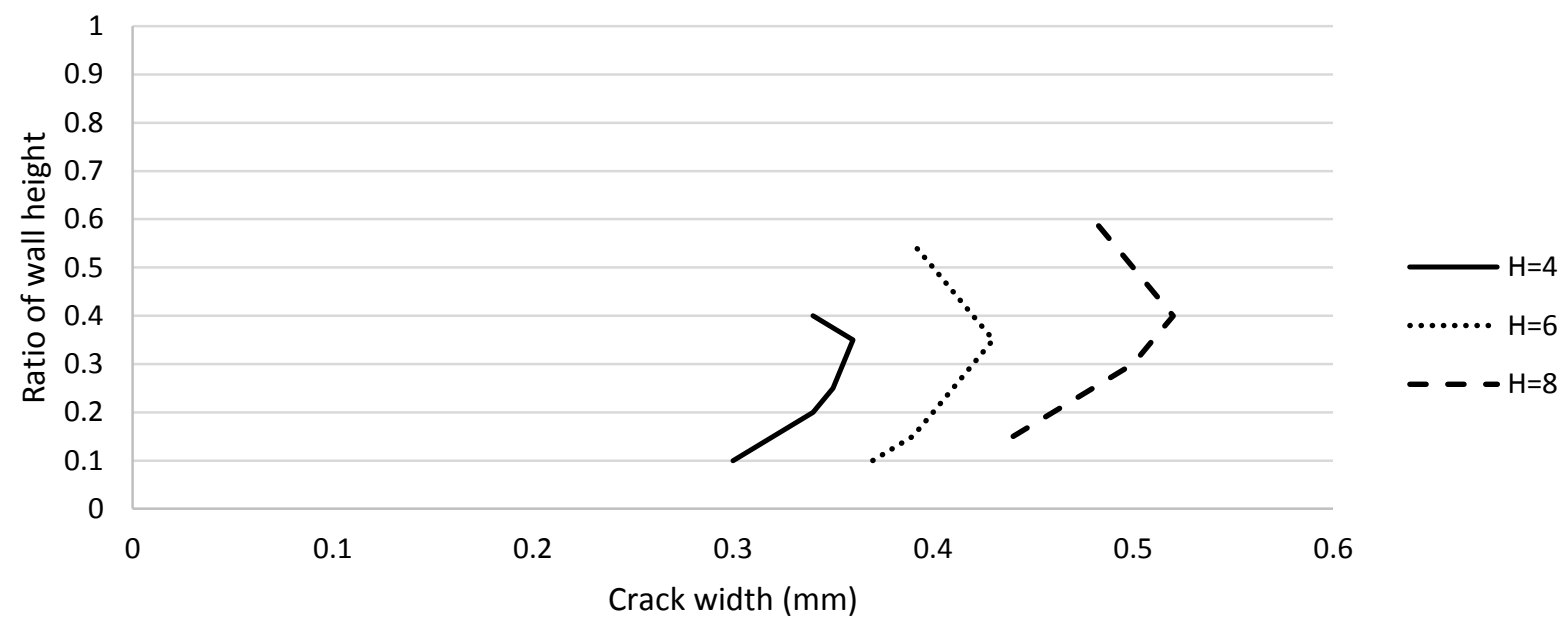

(b) $\mathrm{L} / \mathrm{H}=2.5$

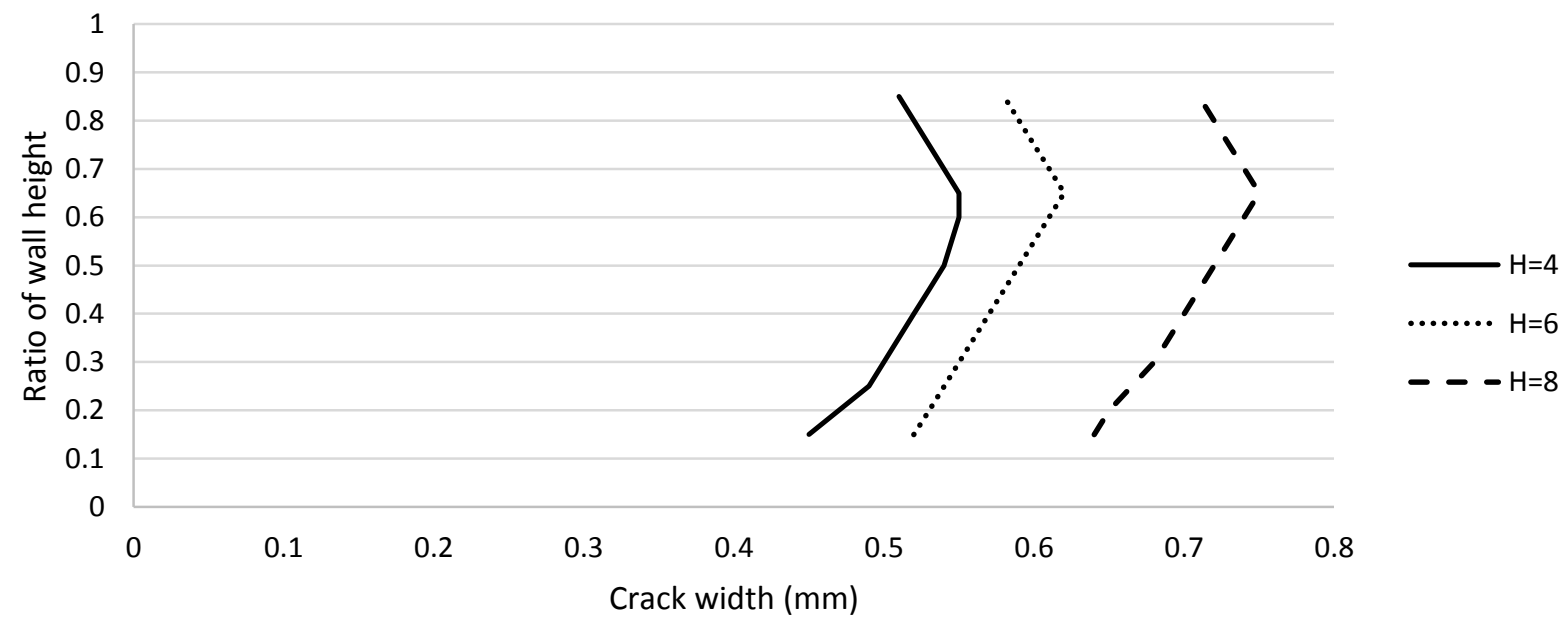

(c) $\mathrm{L} / \mathrm{H}=3.5$

Figure B-15 Effect of L/H ratio and height on the crack width over the wall height $(\rho=0.3 \%)$ 

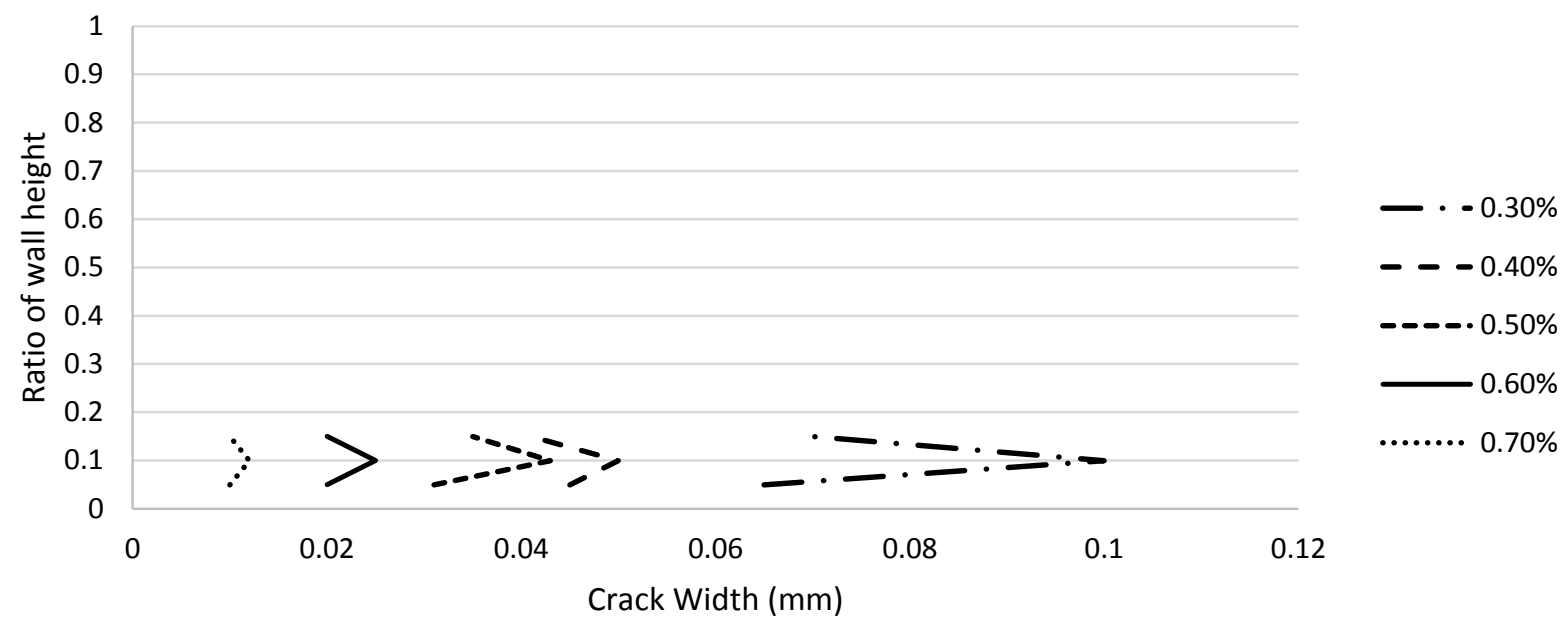

(a) $\mathrm{L}=4 \mathrm{~m}$
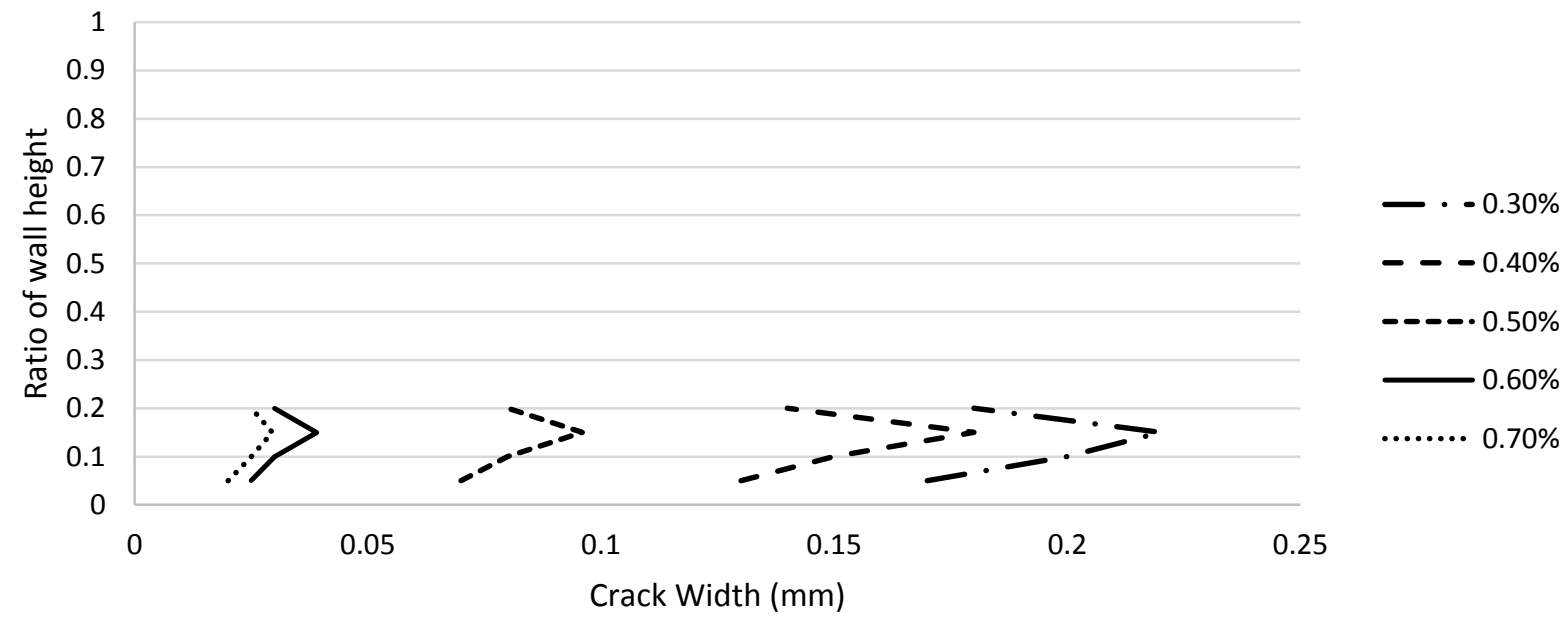

(b) $\mathrm{L}=6 \mathrm{~m}$
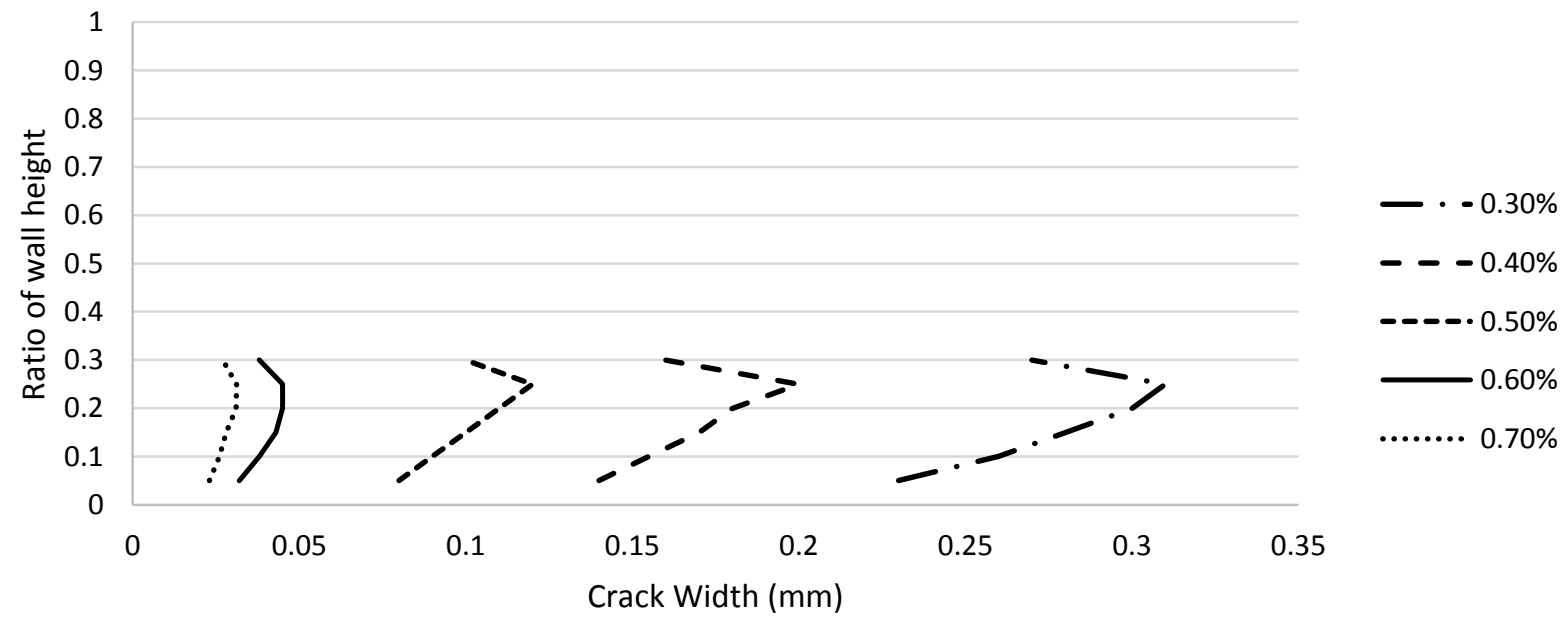

(c) $\mathrm{L}=8 \mathrm{~m}$ 

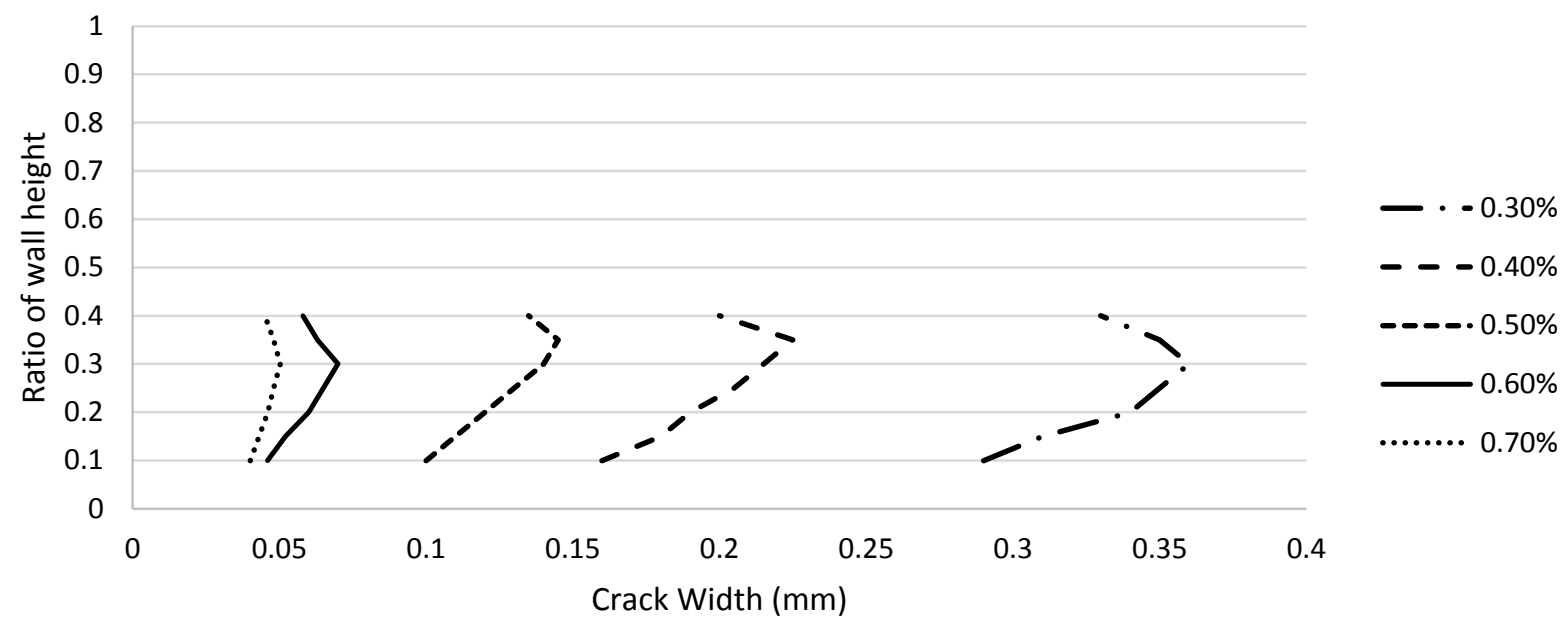

(d) $\mathrm{L}=10 \mathrm{~m}$
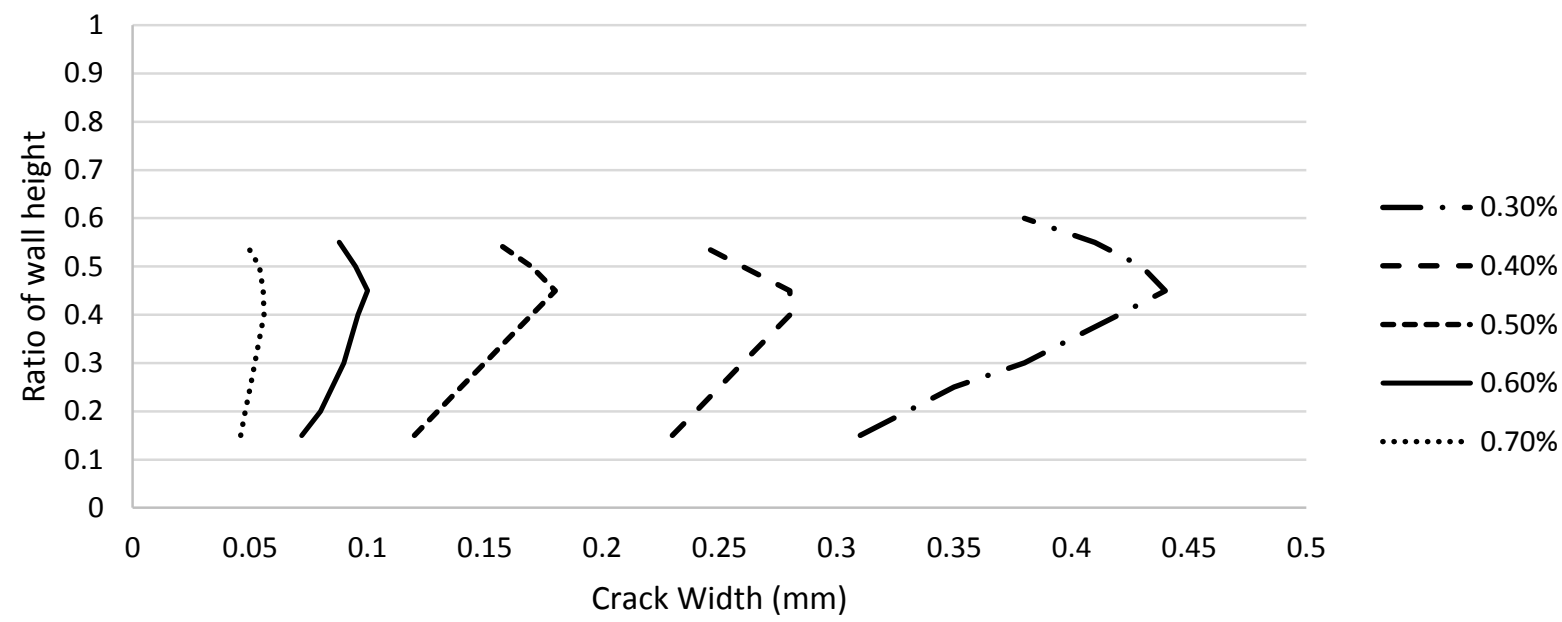

(e) $\mathrm{L}=12 \mathrm{~m}$
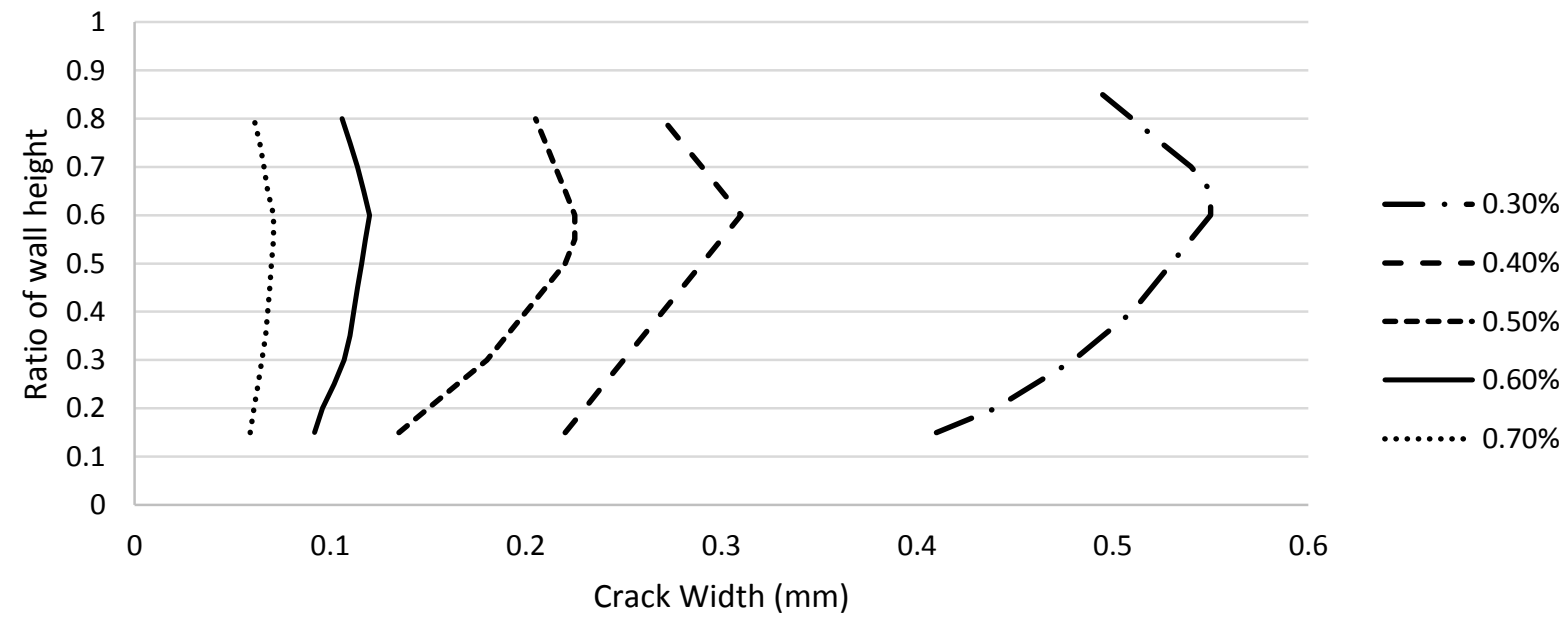

(f) $\mathrm{L}=15 \mathrm{~m}$ 


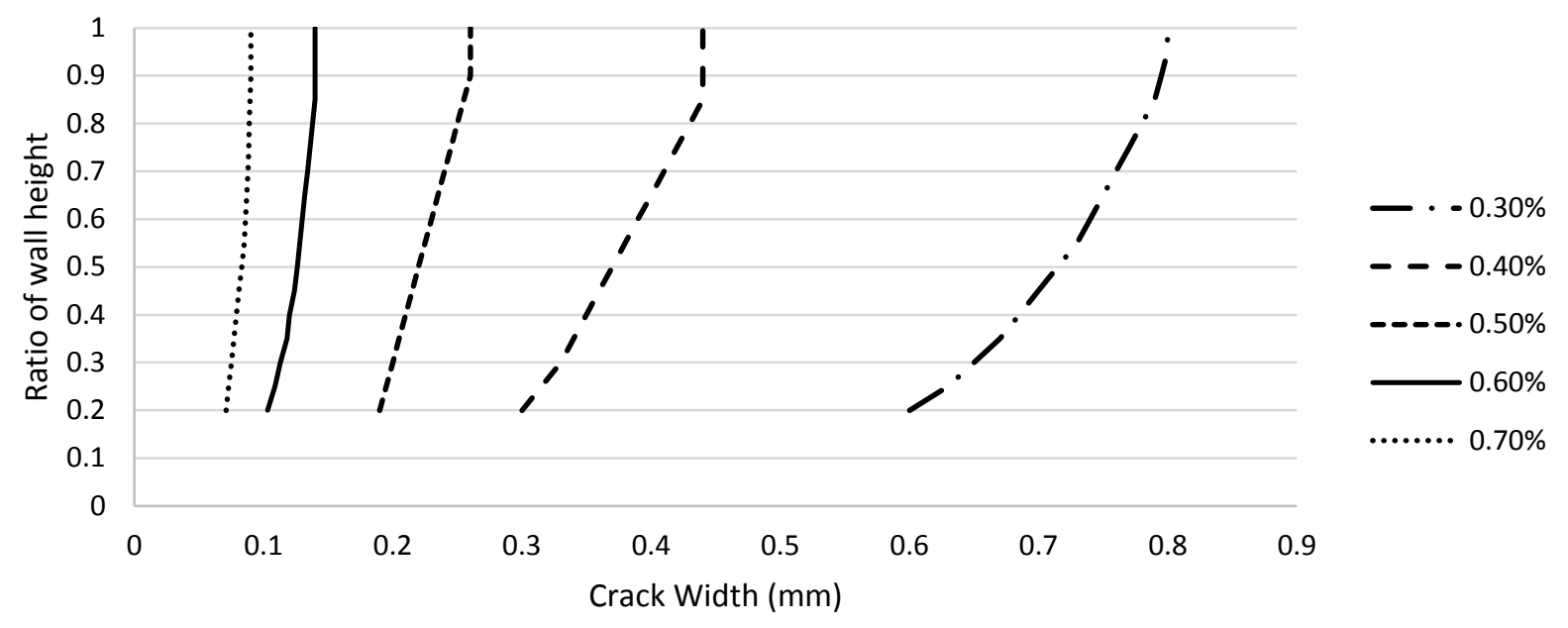

(g) $\mathrm{L}=20 \mathrm{~m}$

Figure B-16 Effect of reinforcement ratio on the crack width over the wall height $(\mathrm{H}=4 \mathrm{~m})$ 


\section{APPENDIX C - RESULTS OF BASE RESTRAINED WALLS CONSIDERING THE EFFECT OF CREEP}

\section{C.1 General}

This Appendix presents the remaining results of the parametric study on base restrained walls with no partial side restraint as in Chapter 6. The effect of creep is considered in the results that are presented in this Appendix. These graphs are demonstrated in order to further discuss the influence of each parameter on the crack width and its variation along the wall length.

\section{C.2 Results of the parametric study}

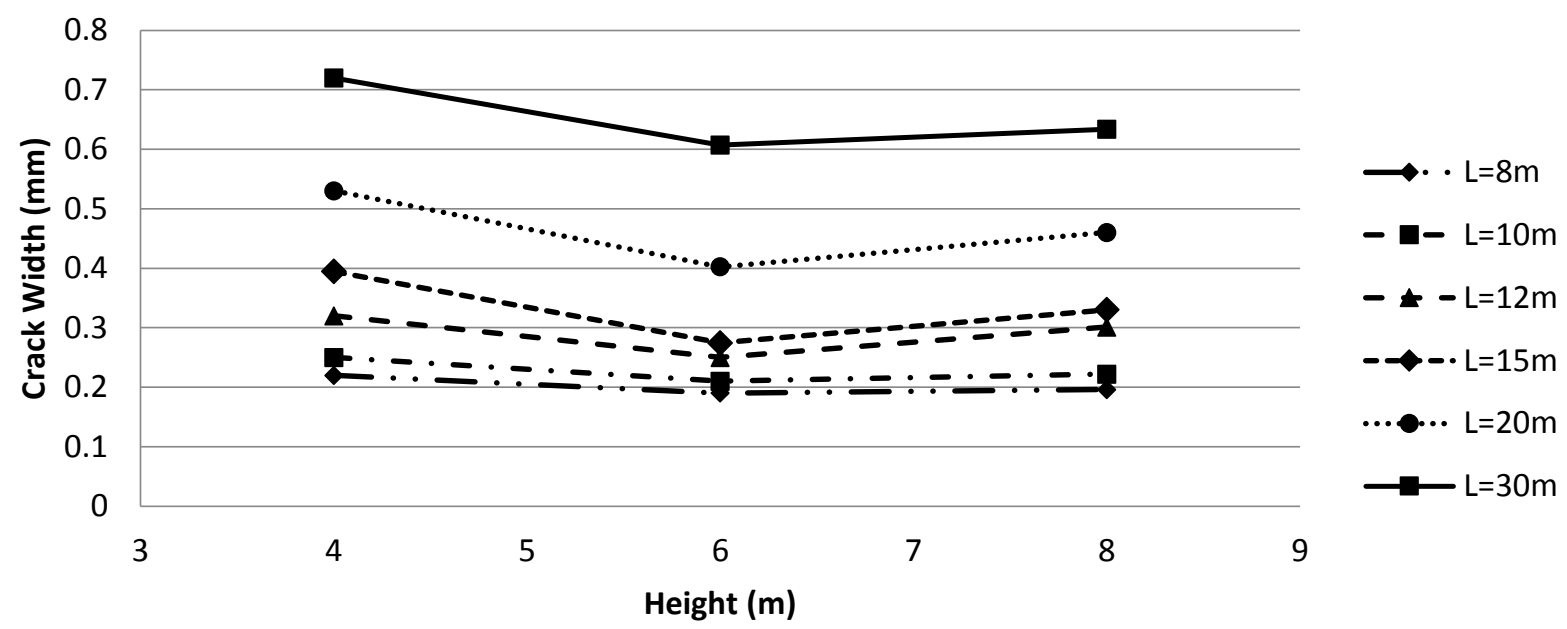

Figure C-1 Effect of wall height on the crack width considering constant wall lengths

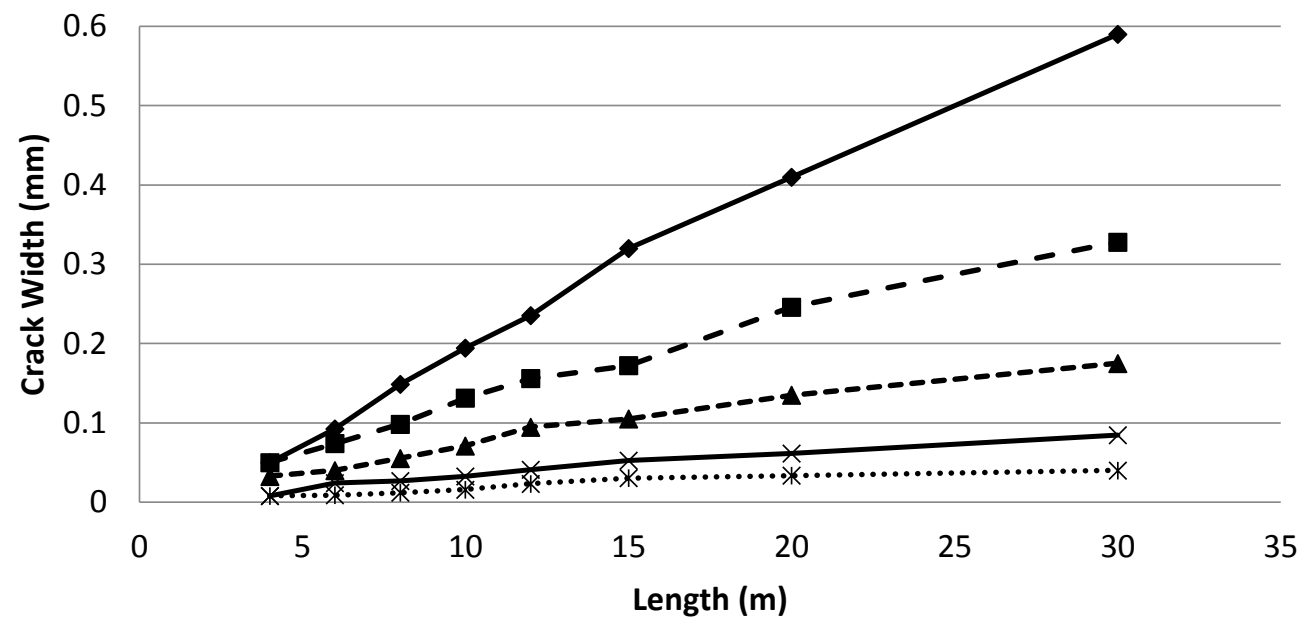

$\longrightarrow p=0.3 \%$

$-p=0.4 \%$

- - $-\mathbf{- P} p=0.5 \%$

$\multimap p=0.6 \%$

…*...p $p=0.7 \%$

(a) $\mathrm{e}=300 \mu \varepsilon$ 


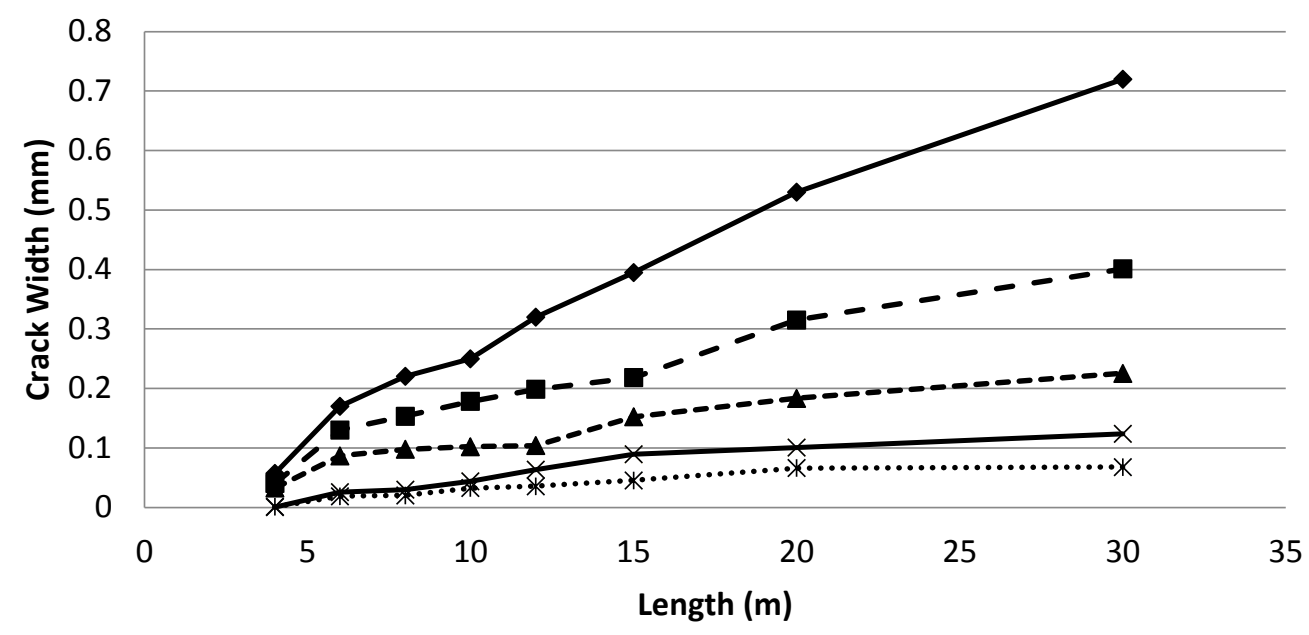

$\longrightarrow p=0.3 \%$

- $-p=0.4 \%$

- $-\mathbf{s}-p=0.5 \%$

$\longrightarrow p=0.6 \%$

...*...p $p=0.7 \%$

(b) $\mathrm{e}=600 \mu \varepsilon$

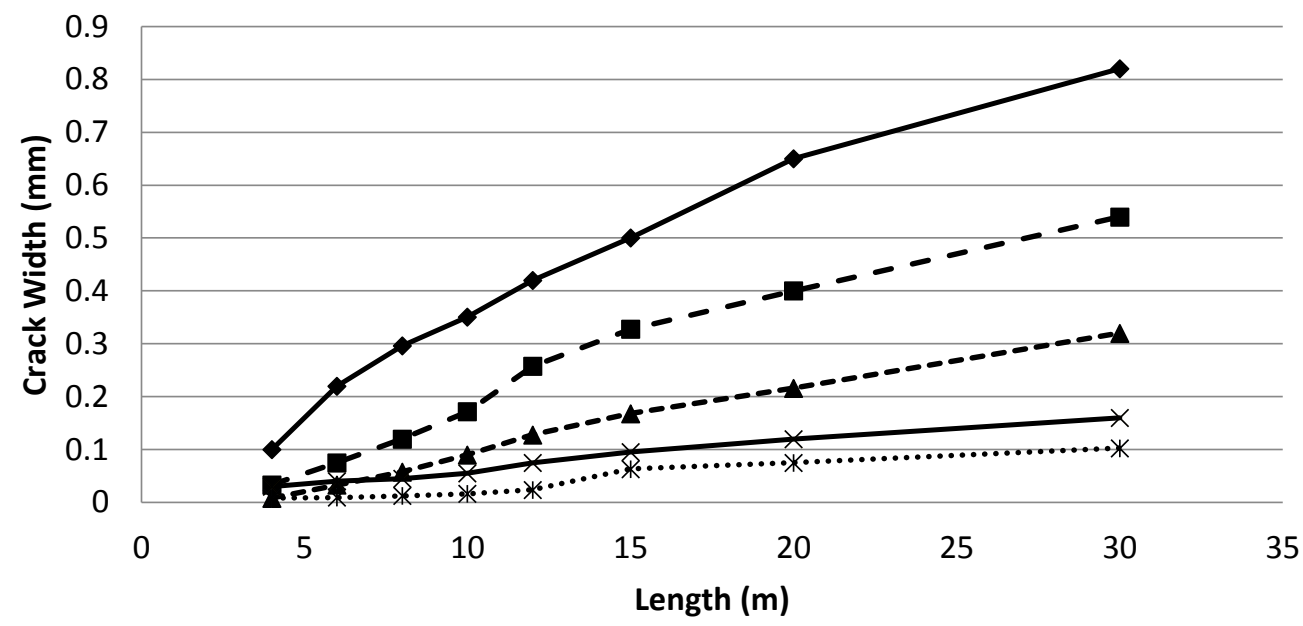

$\longrightarrow p=0.3 \%$

- - $p=0.4 \%$

- $\mathbf{p}-\cdot p=0.5 \%$

$\longrightarrow p=0.6 \%$

...*...p $p=0.7 \%$

(c) $\mathrm{e}=900 \mu \varepsilon$

Figure C-2 Effect of reinforcement ratio on the crack width considering different climates $(\mathrm{H}=4 \mathrm{~m})$

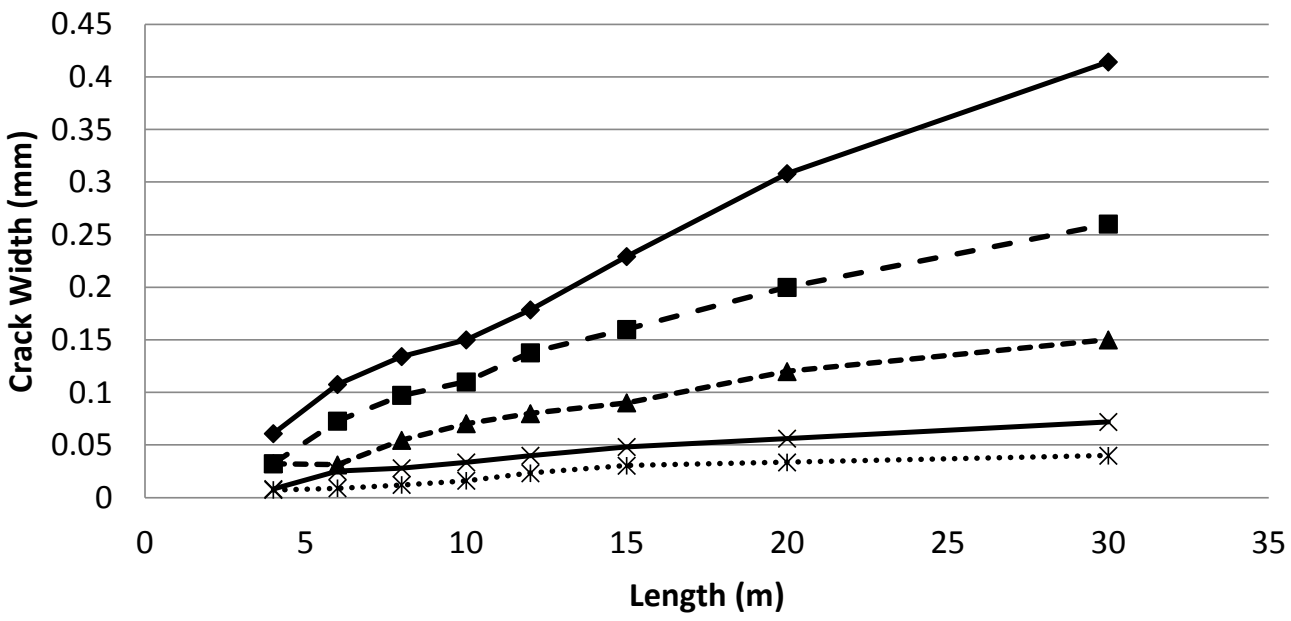

$\longrightarrow p=0.3 \%$

- $-p=0.4 \%$

- $\boldsymbol{-} \boldsymbol{- \boldsymbol { c }} \mathrm{p}=0.5 \%$

$\longrightarrow p=0.6 \%$

$\cdots * \cdots \cdot p=0.7 \%$

(a) $\mathrm{e}=300 \mu \varepsilon$ 

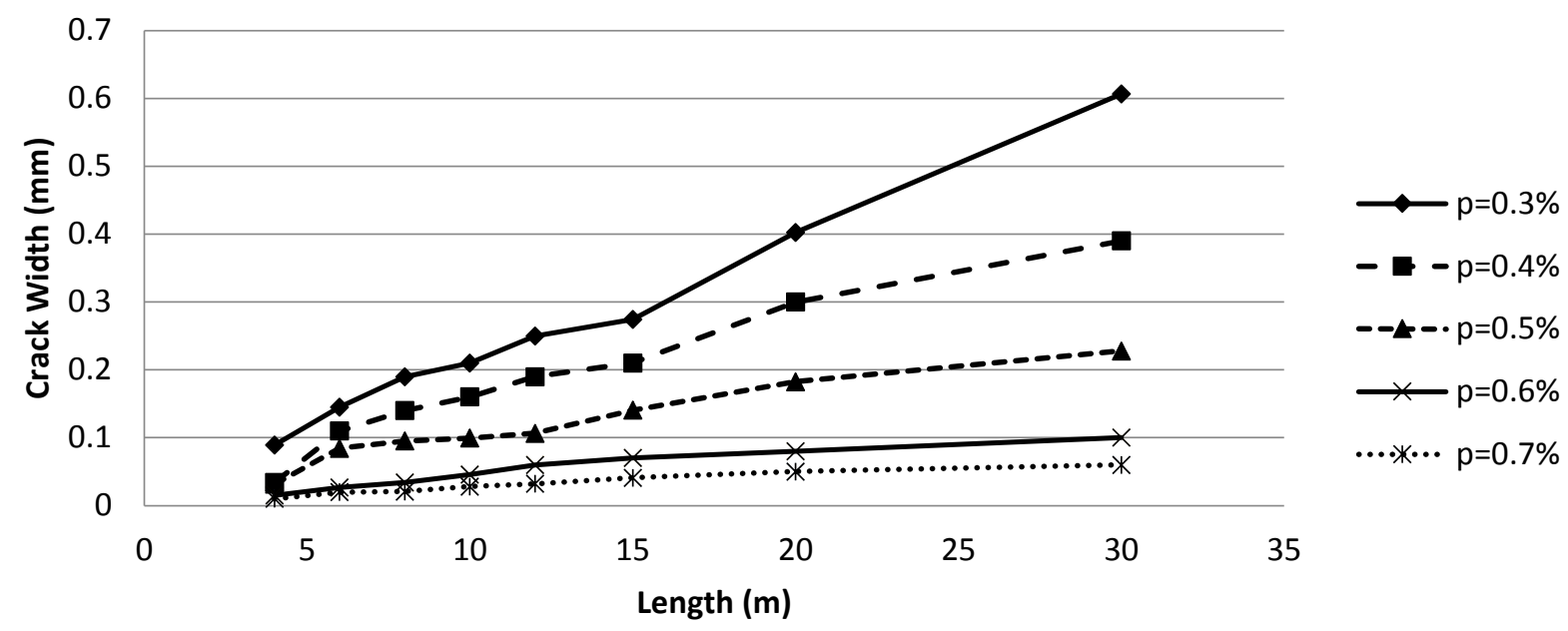

(b) $\mathrm{e}=600 \mu \varepsilon$

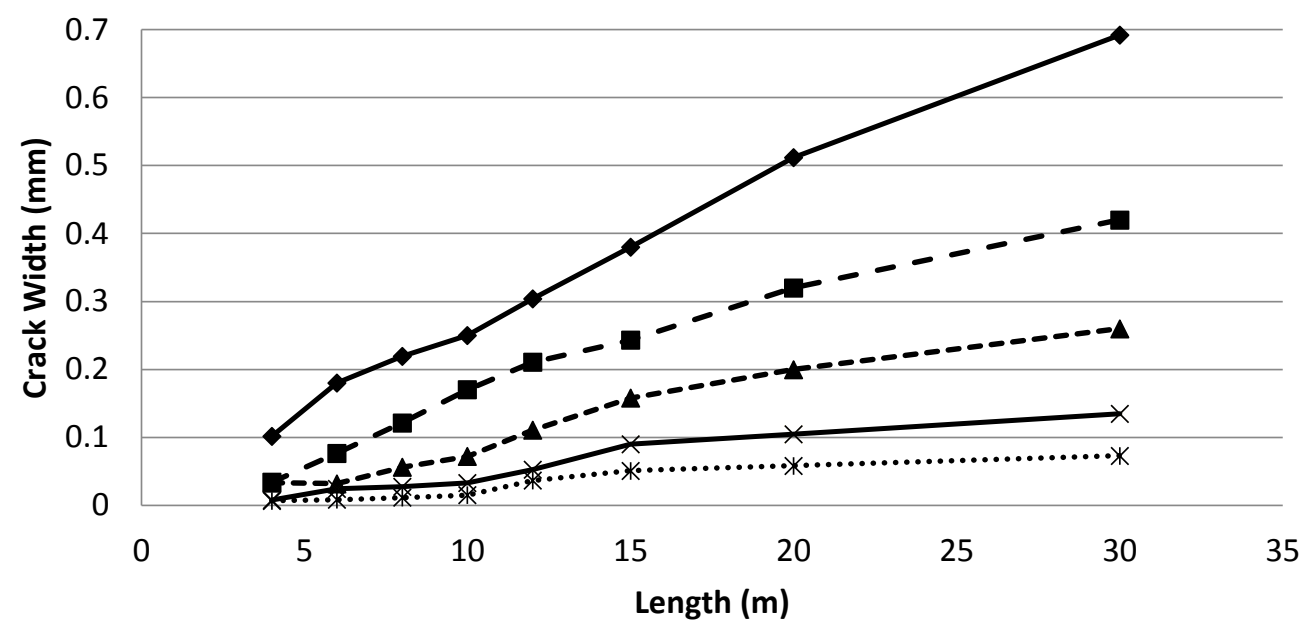

$\longrightarrow p=0.3 \%$

$-p=0.4 \%$

$--\leftarrow-\cdot p=0.5 \%$

$\longrightarrow p=0.6 \%$

$\cdots * \cdots p=0.7 \%$

(c) $\mathrm{e}=900 \mu \varepsilon$

Figure C-3 Effect of reinforcement ratio on the crack width considering different climates $(\mathrm{H}=6 \mathrm{~m})$

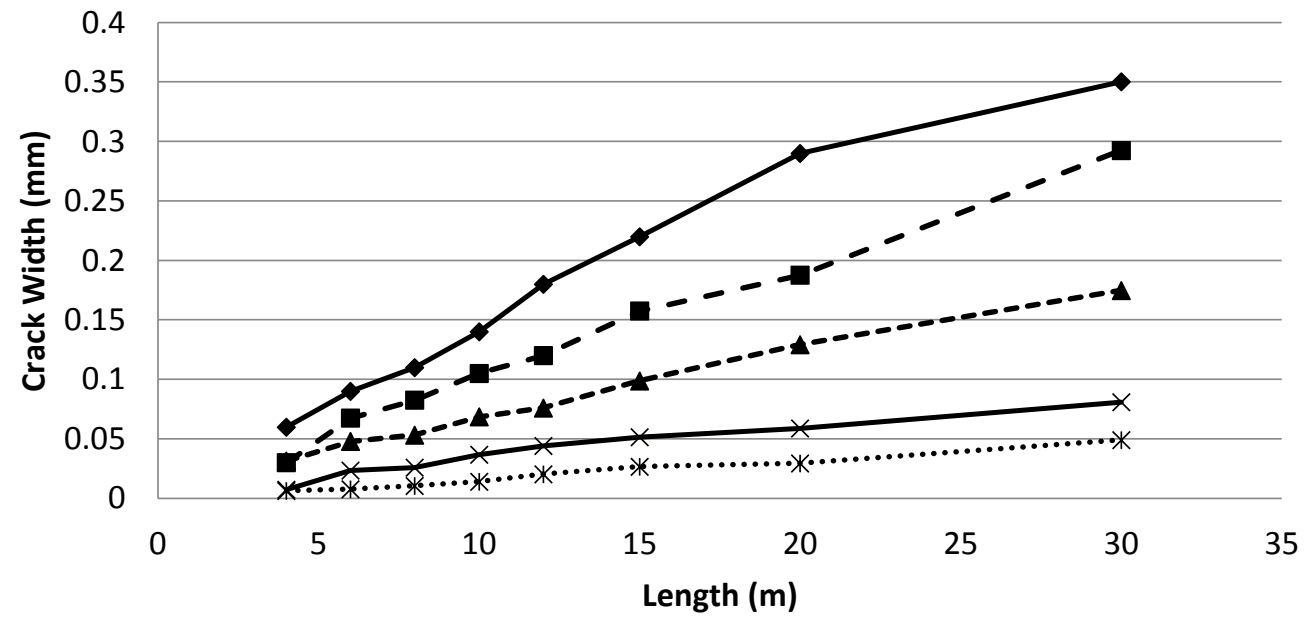

$\longrightarrow p=0.3 \%$

$-p=0.4 \%$

- -4-・p $p=0.5 \%$

$\longrightarrow p=0.6 \%$

....*...p $p=0.7 \%$

(a) $\mathrm{e}=300 \mu \varepsilon$ 

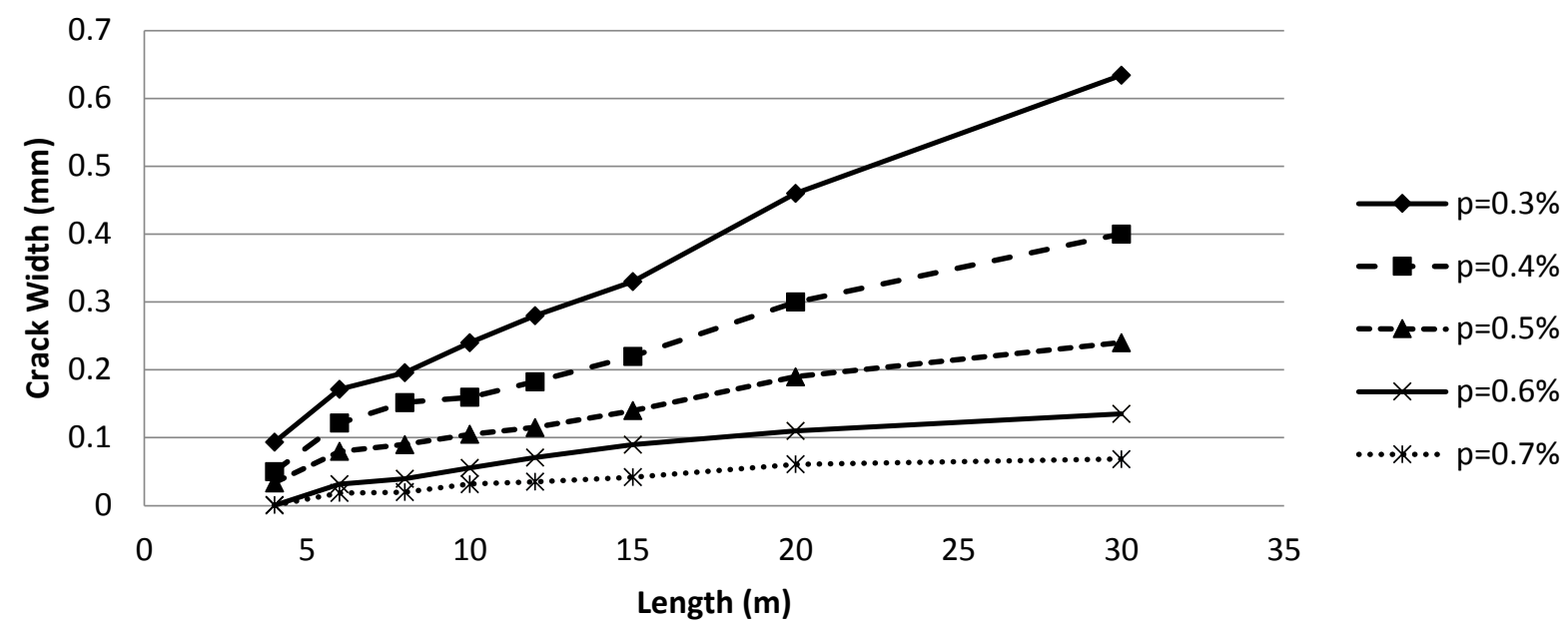

(b) $\mathrm{e}=600 \mu \varepsilon$

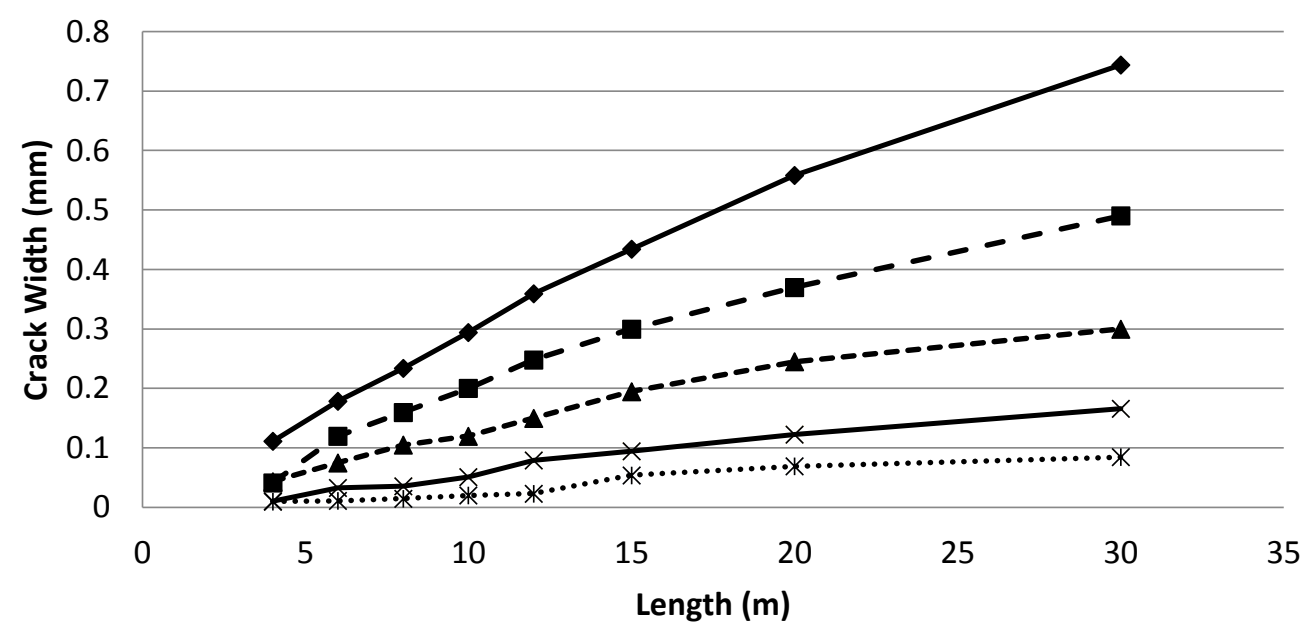

$\longrightarrow p=0.3 \%$

- $-p=0.4 \%$

$--4-\cdot p=0.5 \%$

$\longrightarrow p=0.6 \%$

$\cdots * \cdots p=0.7 \%$

(c) $\mathrm{e}=900 \mu \varepsilon$

Figure C-4 Effect of reinforcement ratio on the crack width considering different climates $(\mathrm{H}=8 \mathrm{~m})$

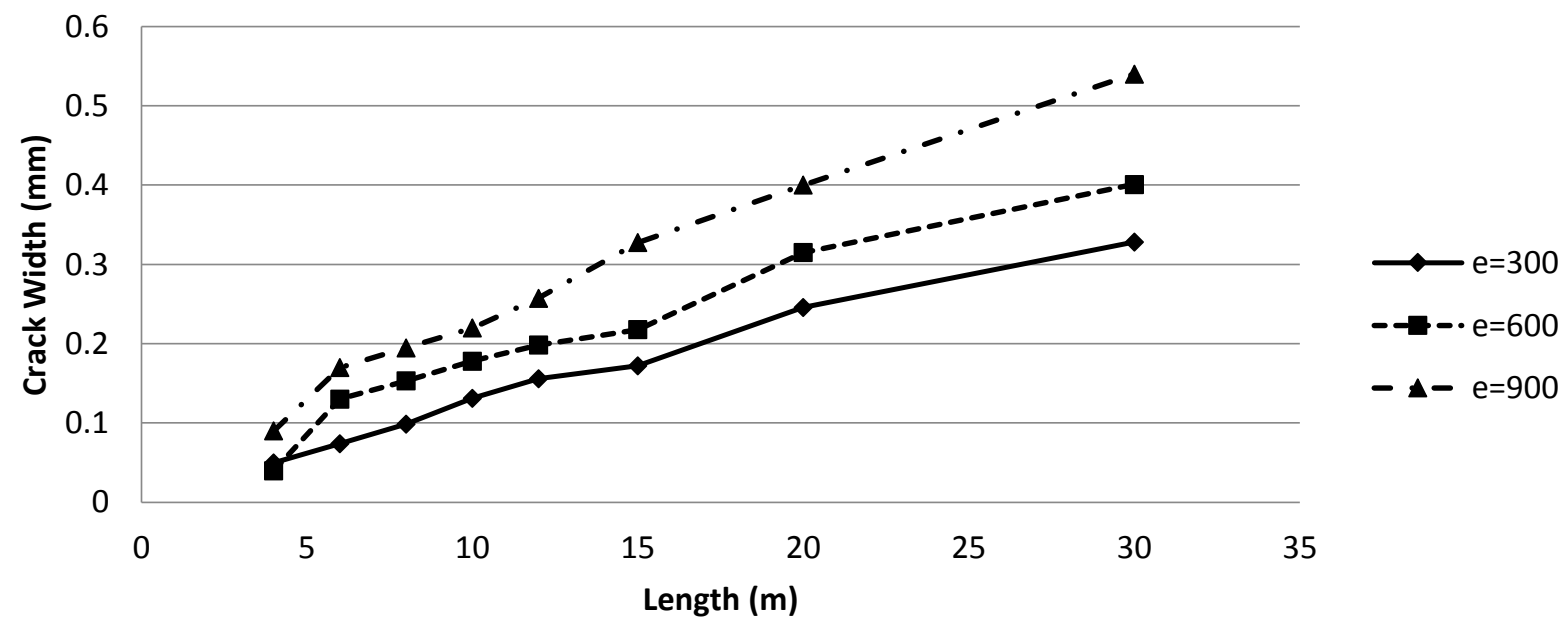

(a) $\rho=0.4 \%$ 

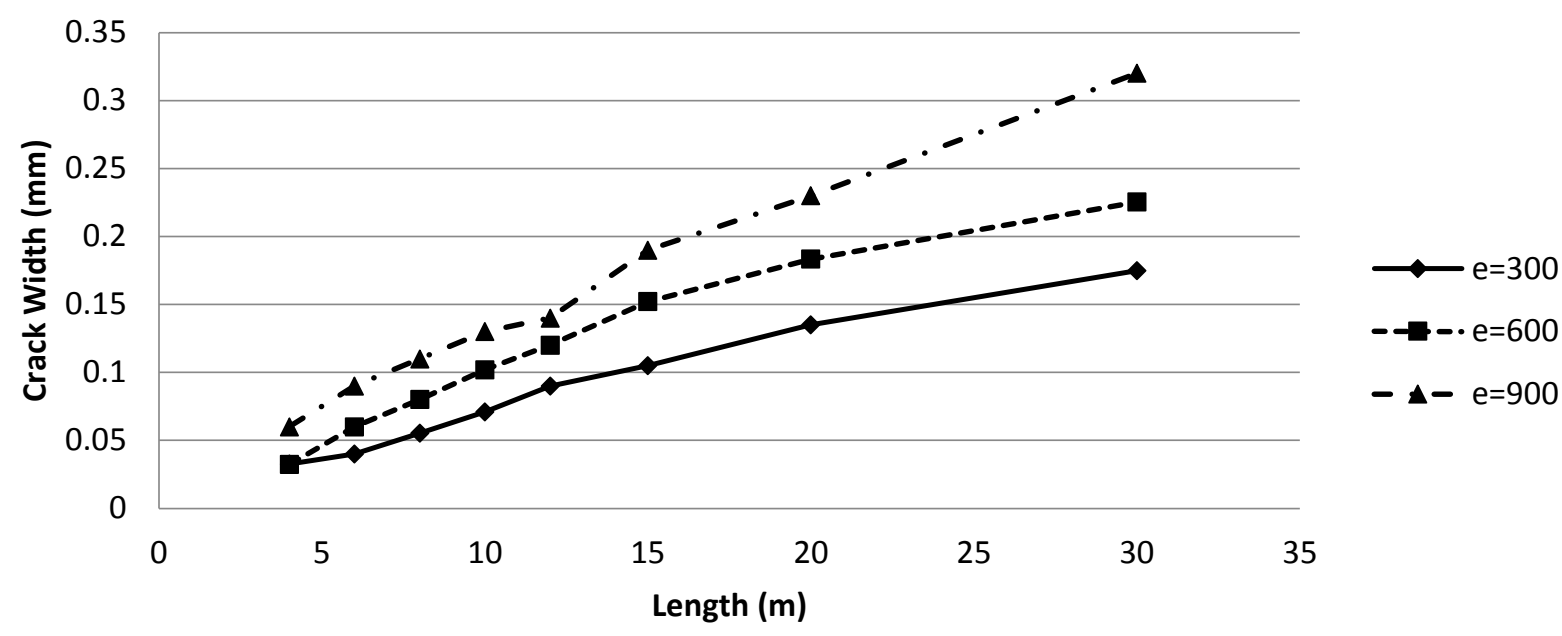

(b) $\rho=0.5 \%$
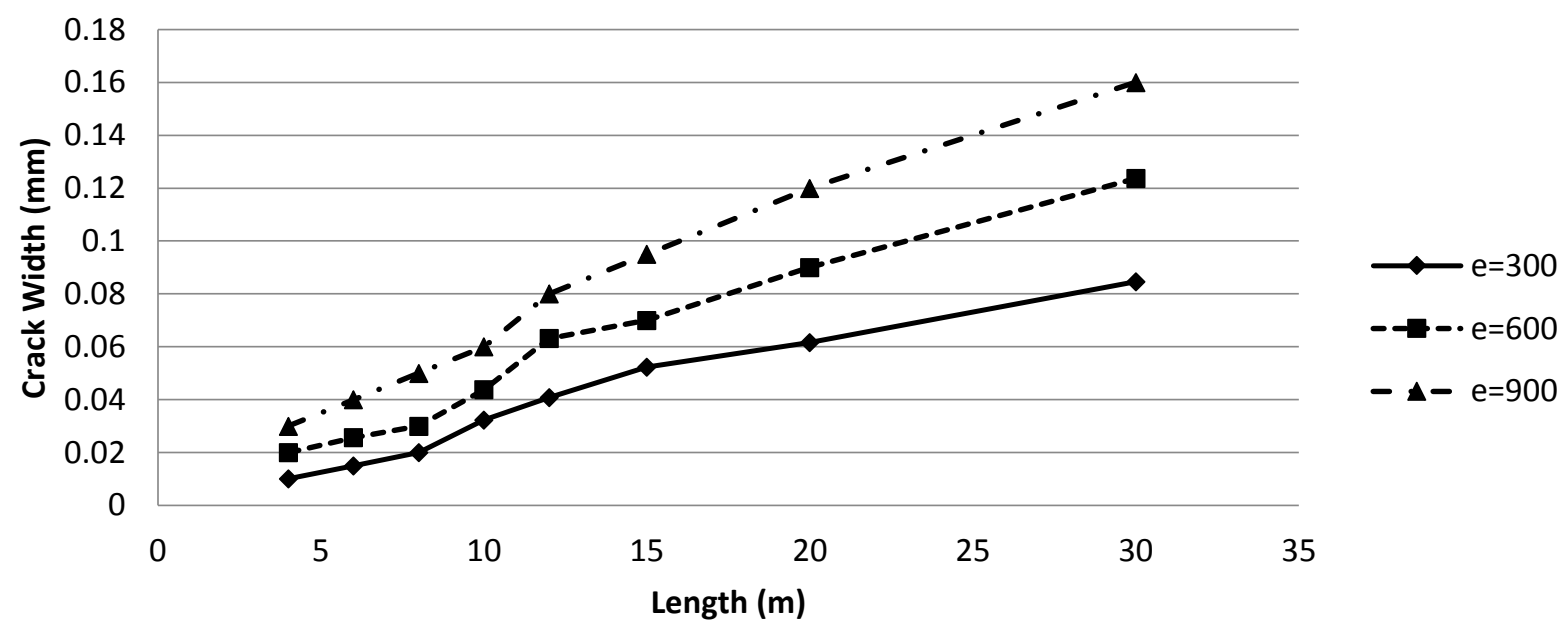

(c) $\rho=0.6 \%$

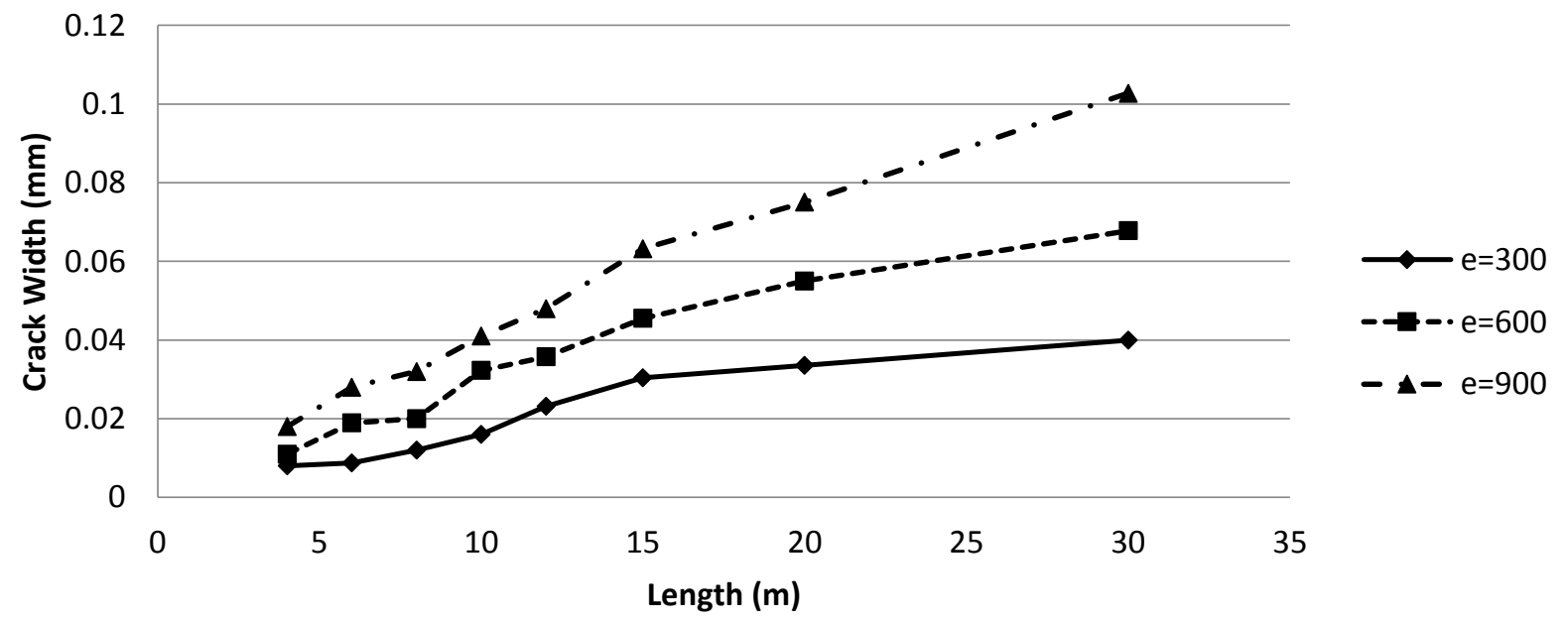

(d) $\rho=0.7 \%$

Figure C-5 Effect of volumetric strain on the crack width considering different steel ratios $(\mathrm{H}=4 \mathrm{~m})$ 

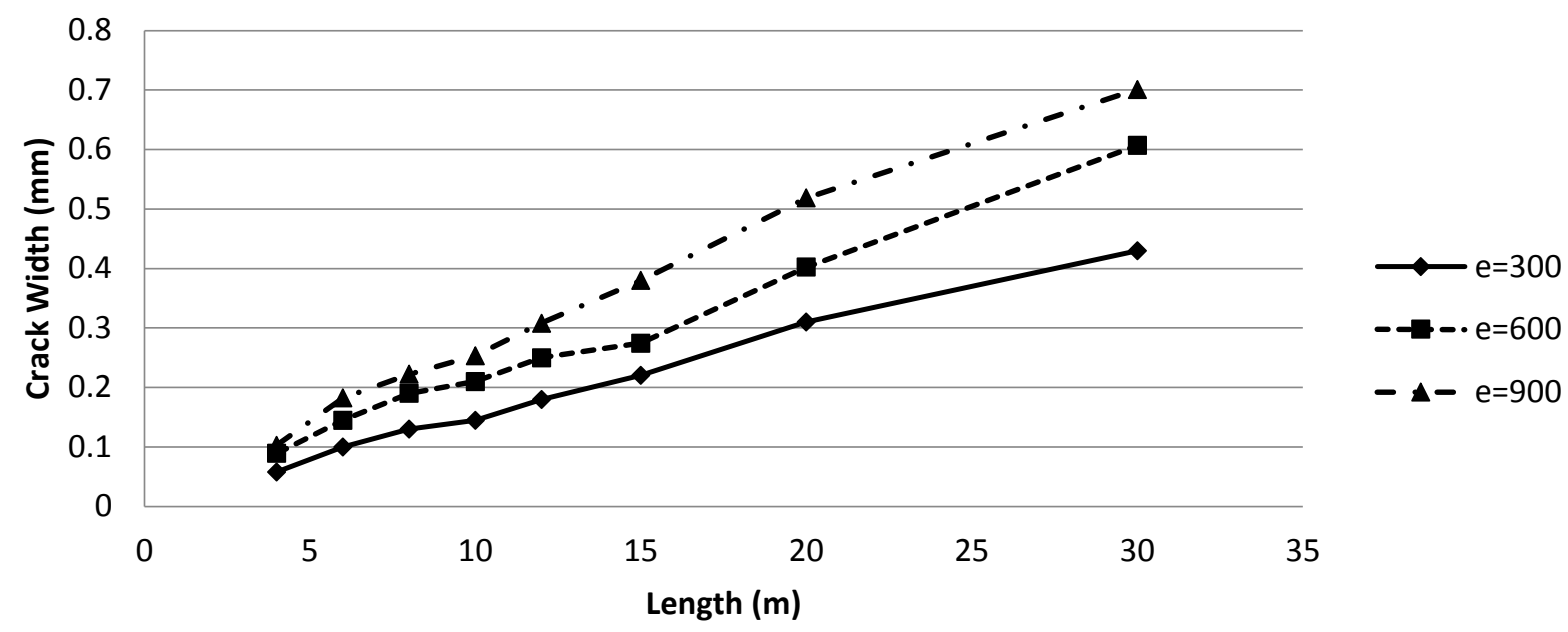

(a) $\rho=0.3 \%$
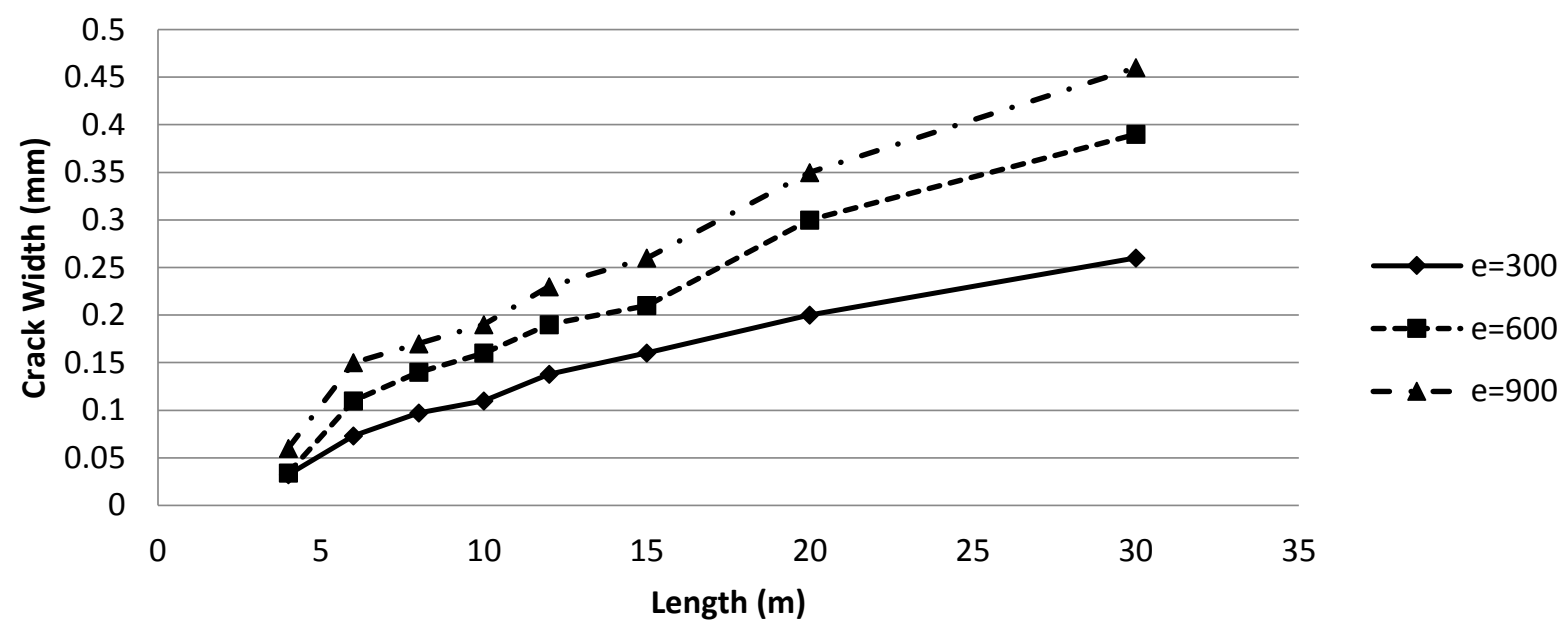

(b) $\rho=0.4 \%$
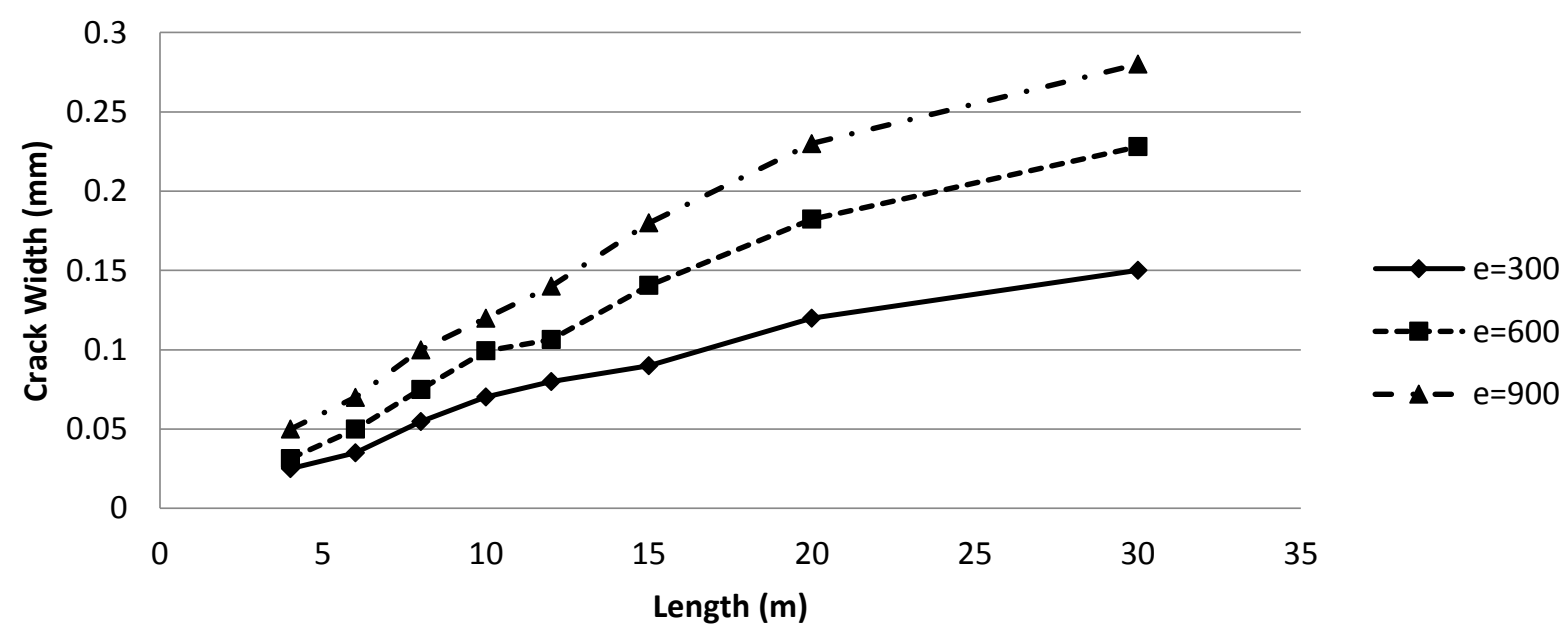

(c) $\rho=0.5 \%$ 

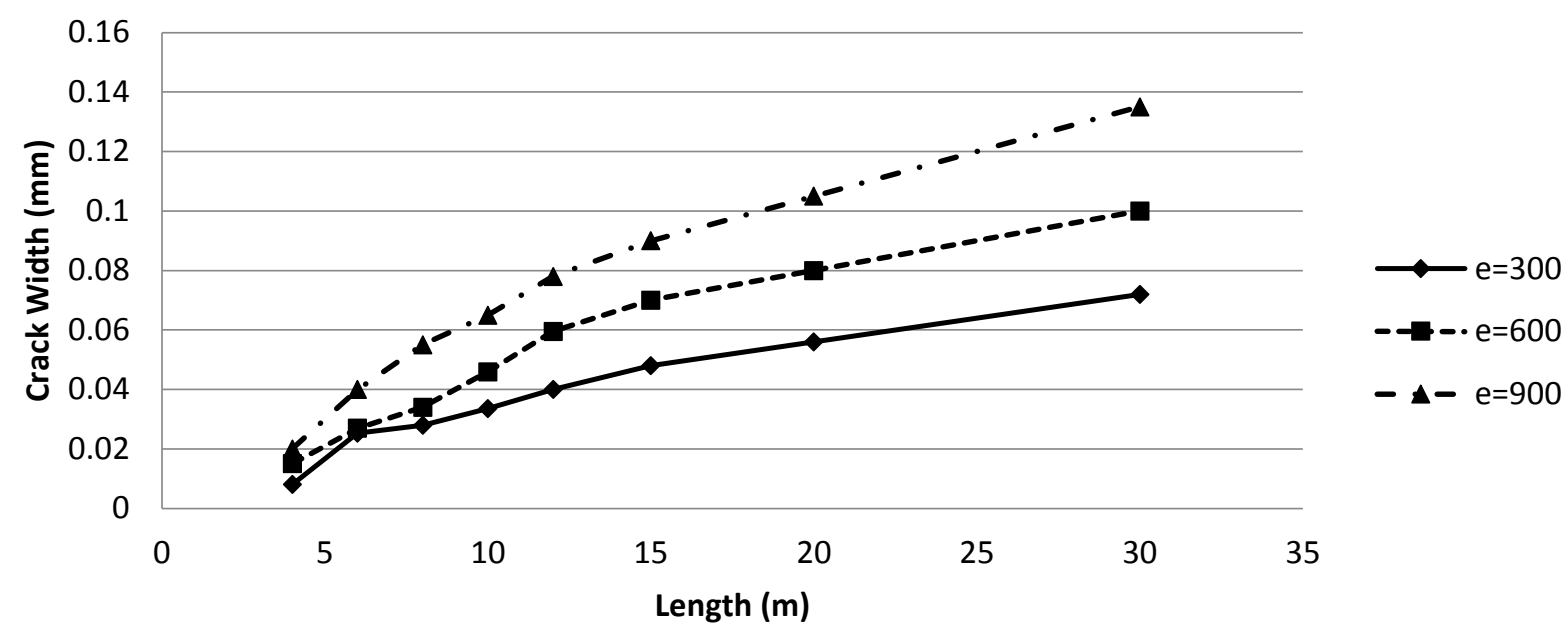

(d) $\rho=0.6 \%$

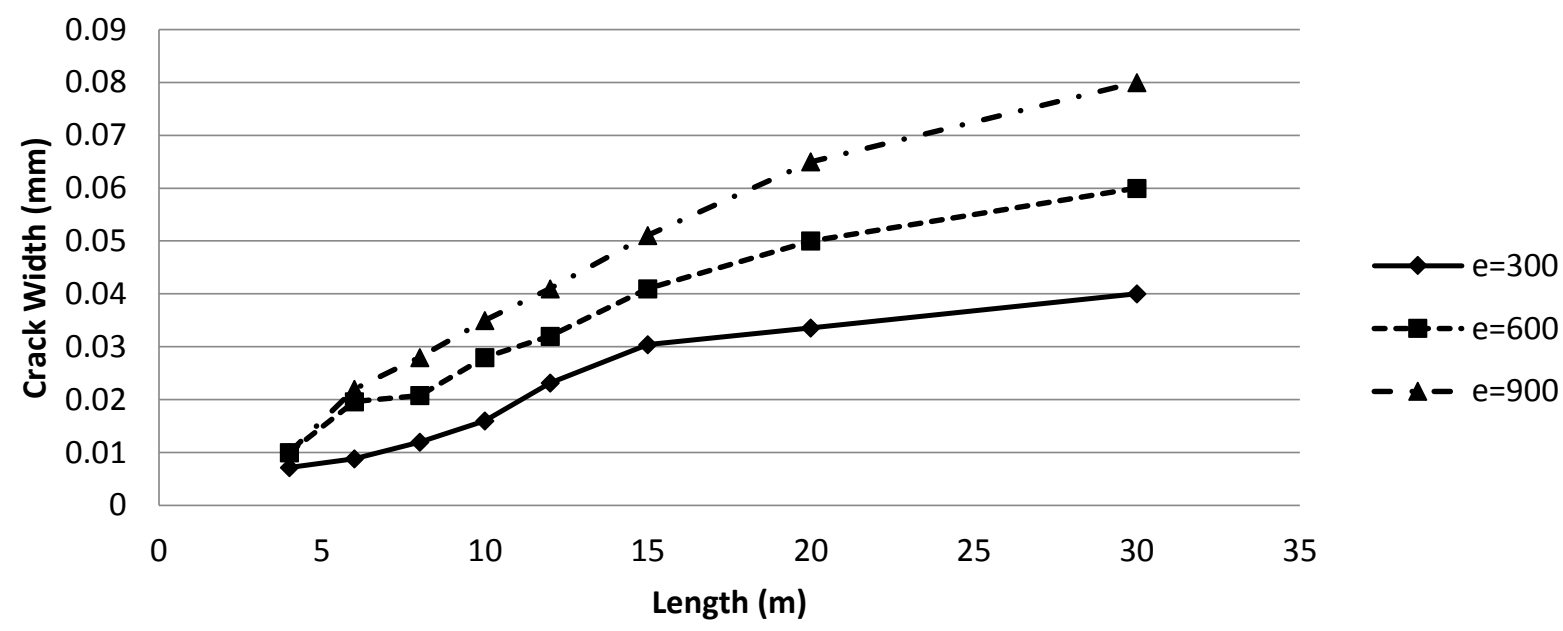

(e) $\rho=0.7 \%$

Figure C-6 Effect of volumetric strain on the crack width considering different steel ratios $(\mathrm{H}=6 \mathrm{~m})$

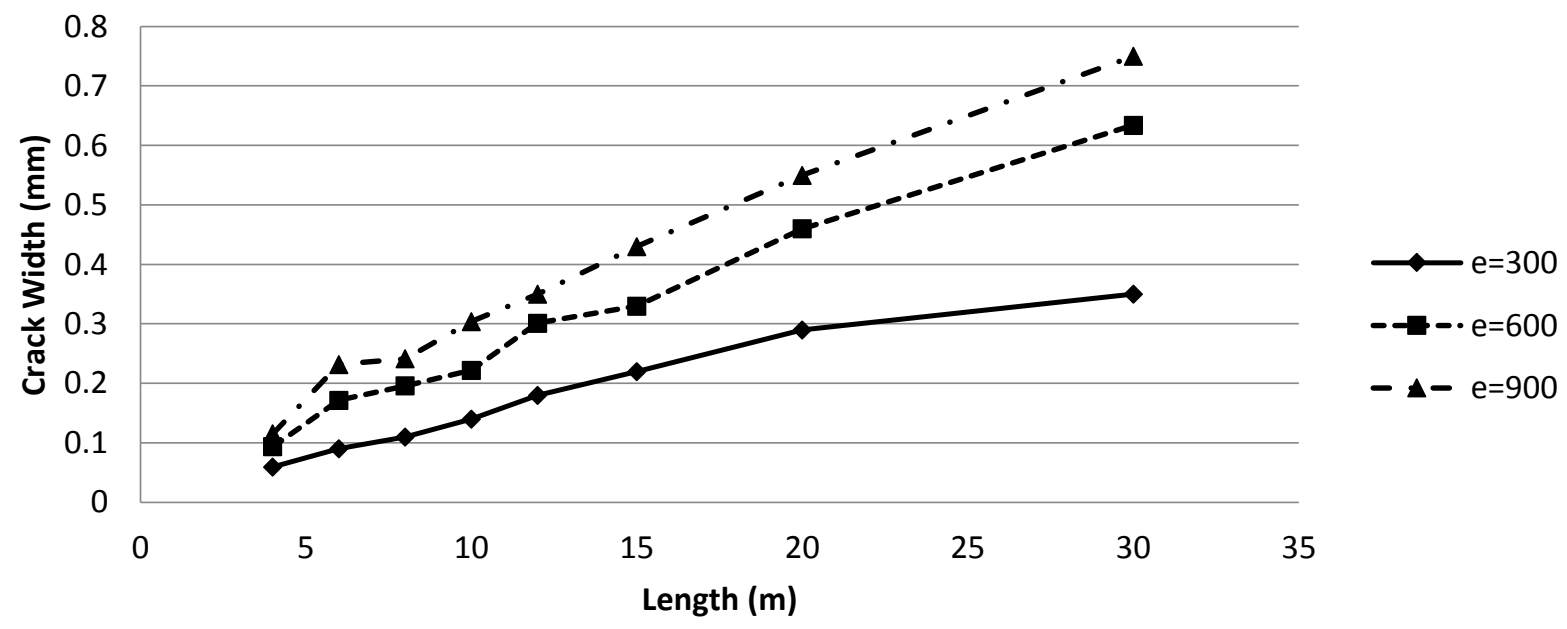

(a) $\rho=0.3 \%$ 

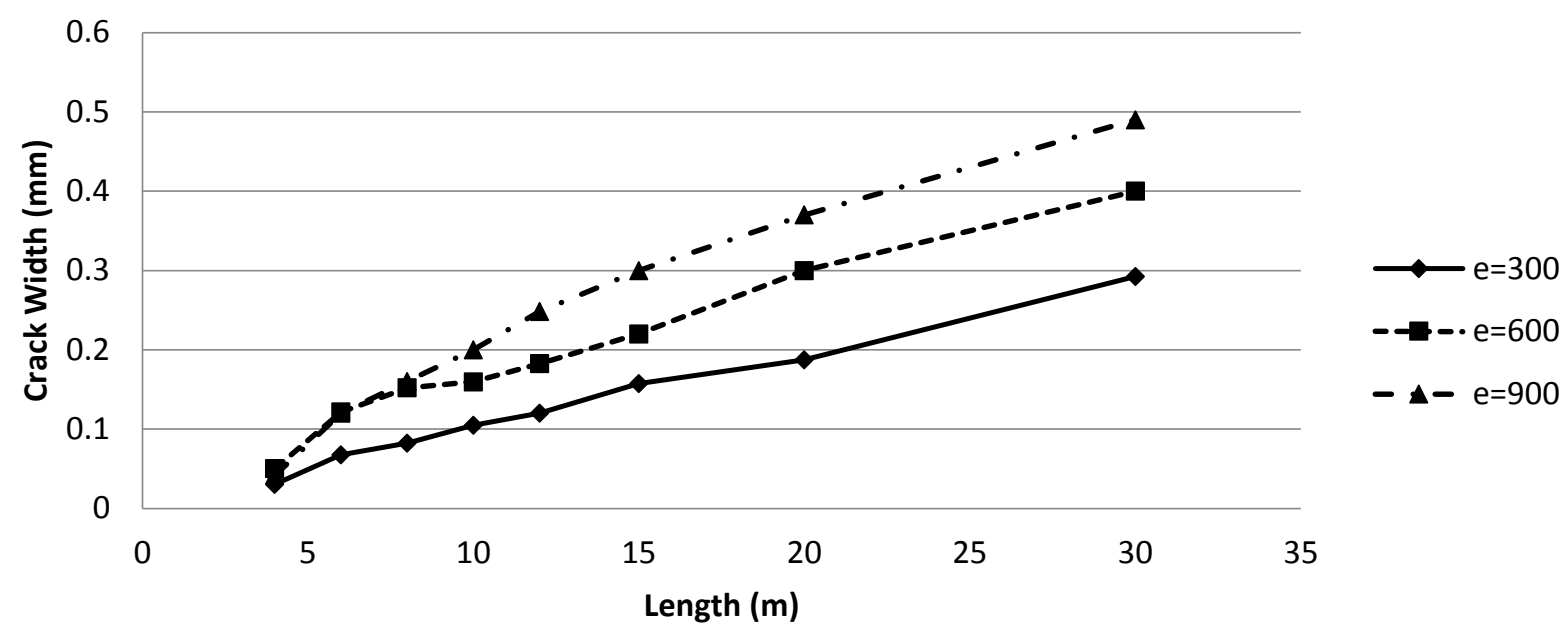

(b) $\rho=0.4 \%$
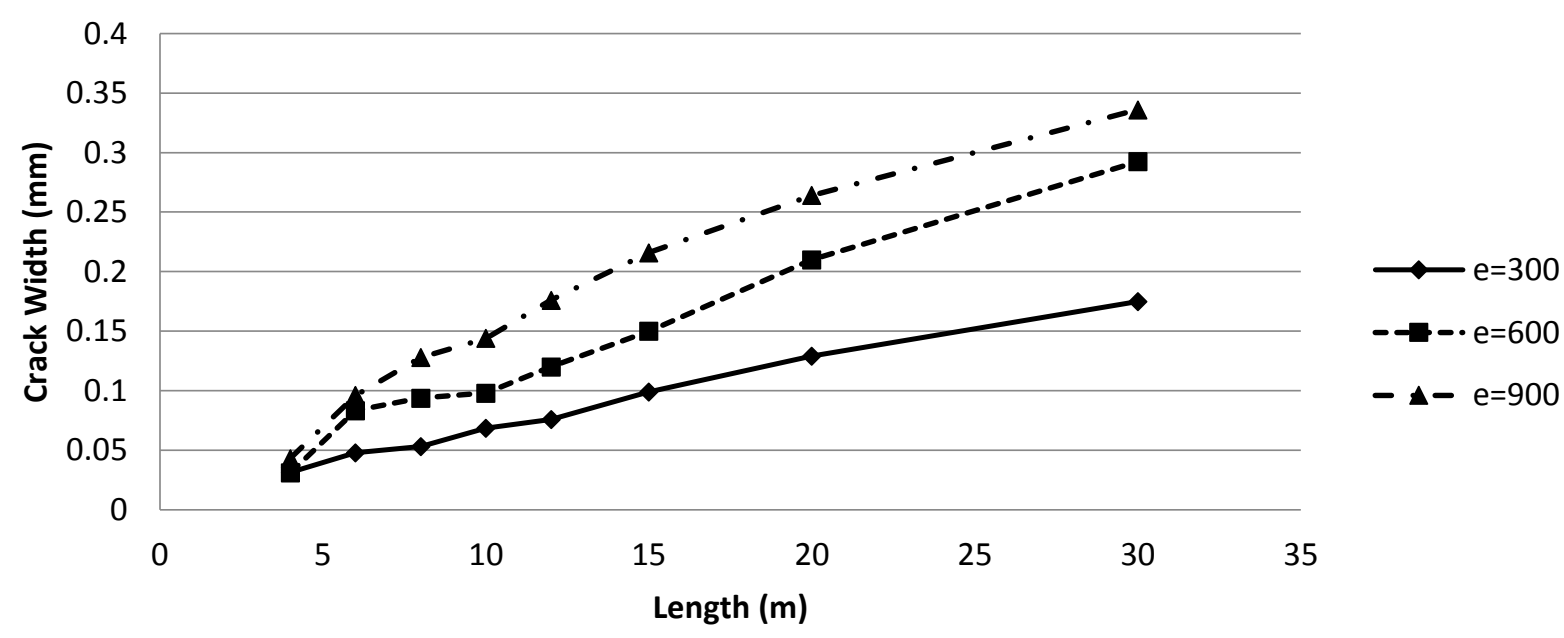

(c) $\rho=0.5 \%$
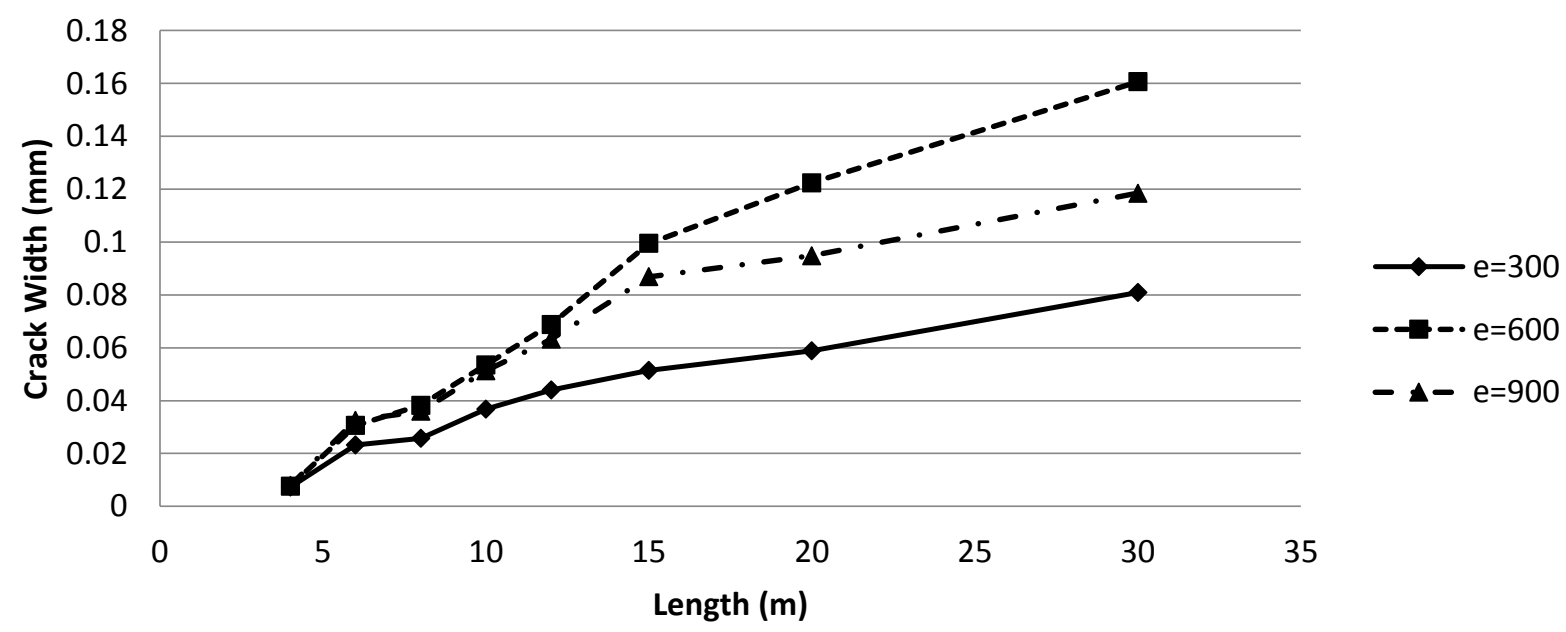

(d) $\rho=0.6 \%$ 


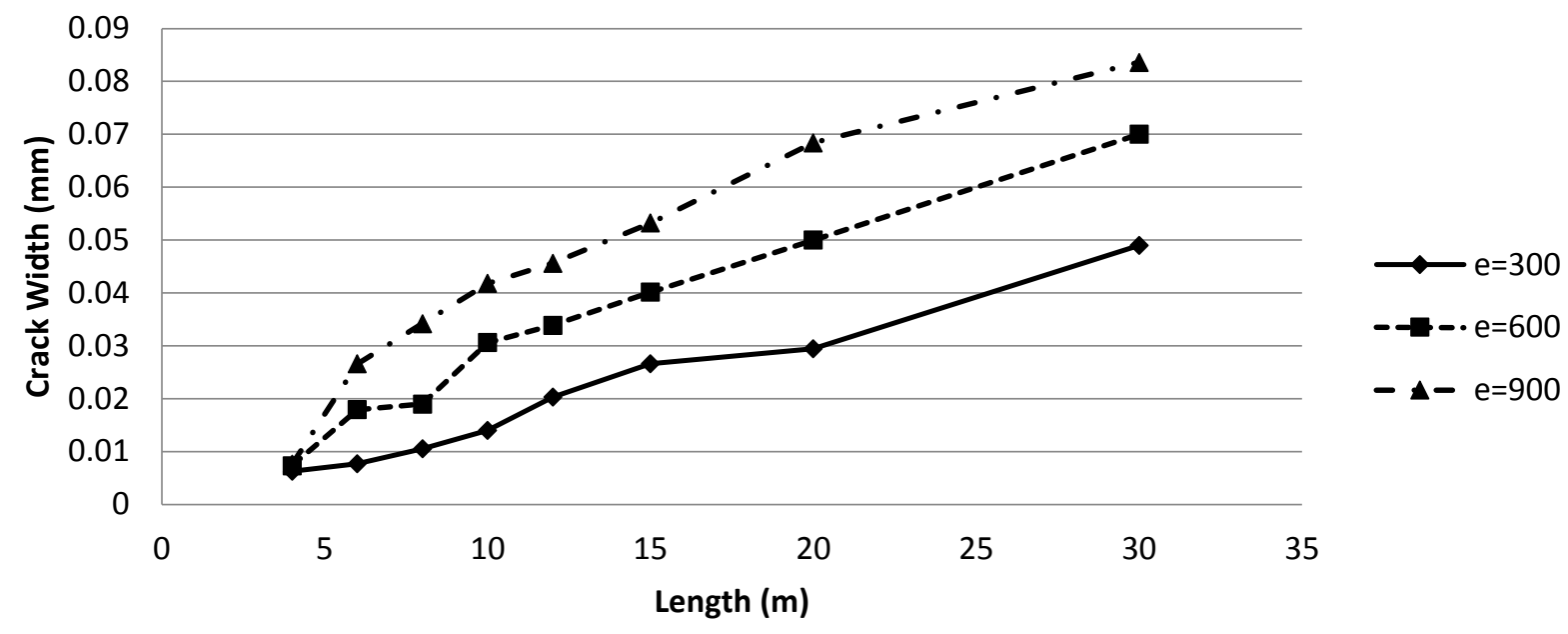

(e) $\rho=0.7 \%$

Figure C-7 Effect of volumetric strain on the crack width considering different steel ratios $(\mathrm{H}=8 \mathrm{~m})$
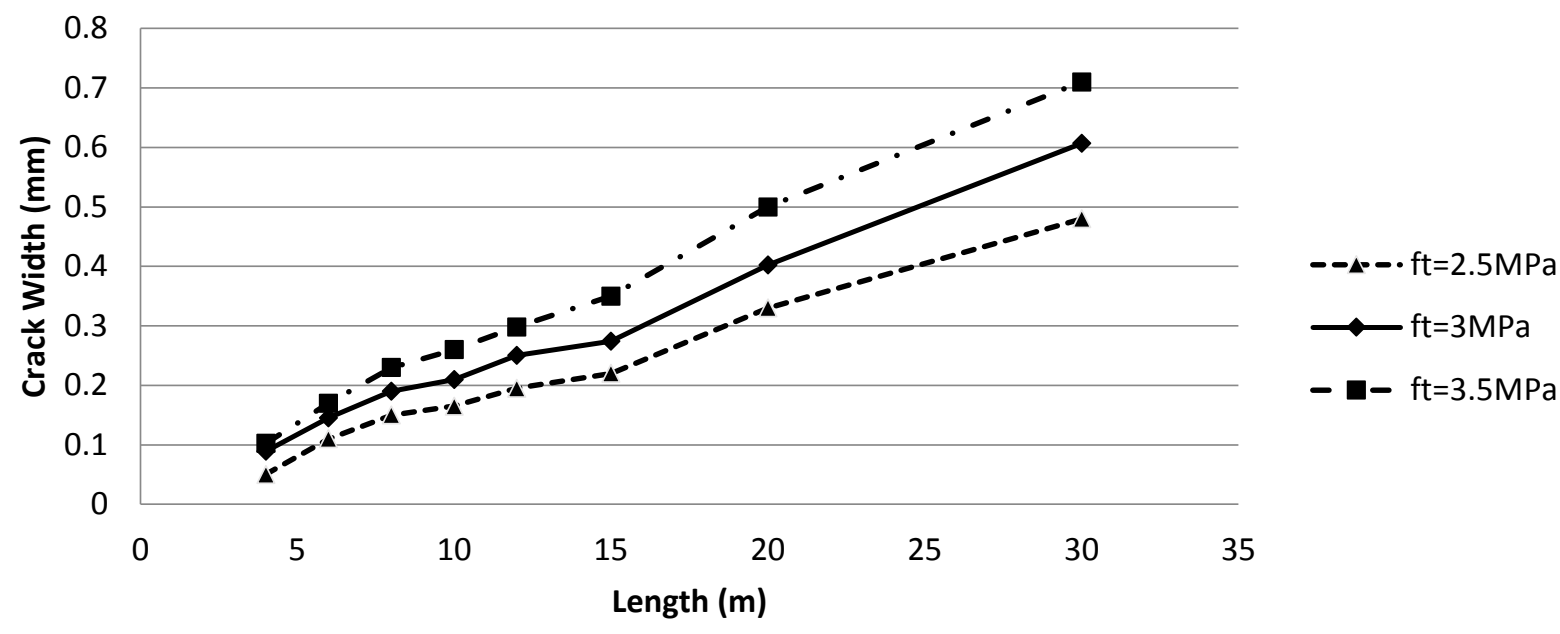

$\longrightarrow \mathrm{ft}=3 \mathrm{MPa}$

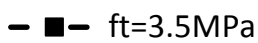

(a) $\mathrm{H}=6 \mathrm{~m}$

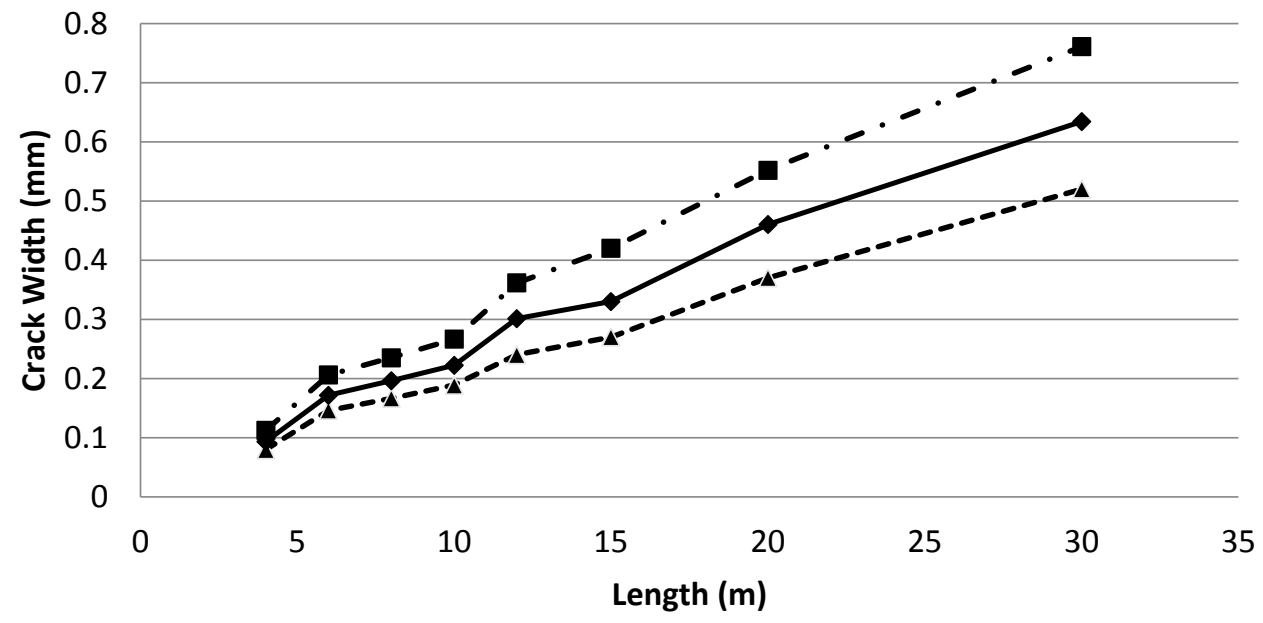

$--1-\cdot \cdot \mathrm{ft}=2.5 \mathrm{MPa}$

$\longrightarrow \mathrm{ft}=3 \mathrm{MPa}$

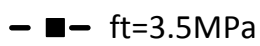

(b) $\mathrm{H}=8 \mathrm{~m}$

Figure C-8 Effect of concrete tensile strength on the crack width $(\rho=0.3 \%)$ 

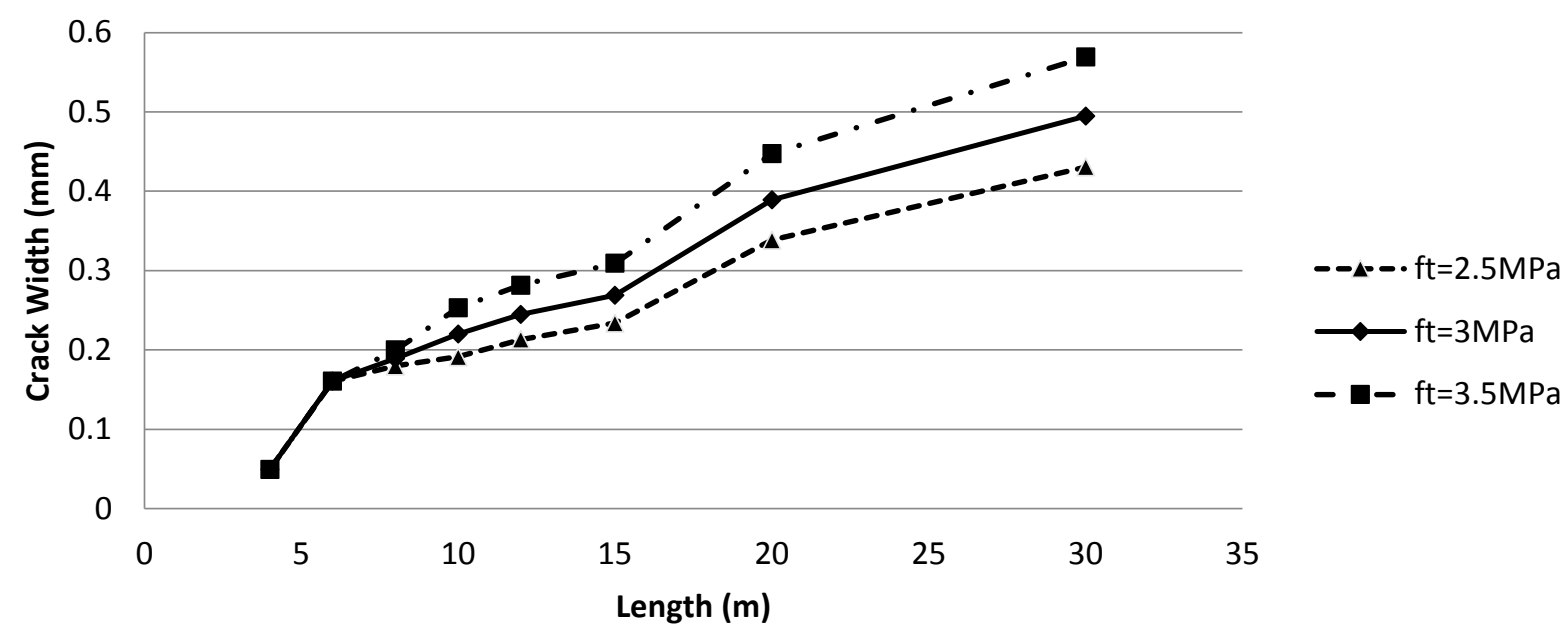

(a) $\rho=0.4 \%$

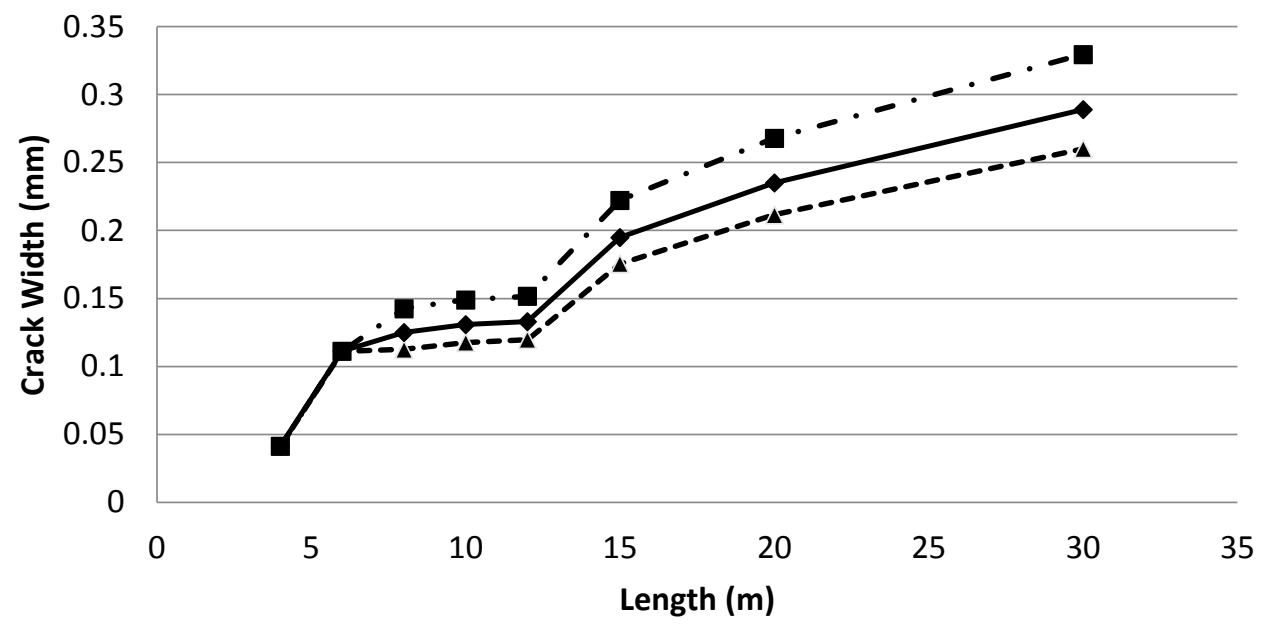

$--1-\cdot \cdot \mathrm{ft}=2.5 \mathrm{MPa}$

$\longrightarrow \mathrm{ft}=3 \mathrm{MPa}$

- $\mathrm{\square}-\mathrm{ft}=3.5 \mathrm{MPa}$

(b) $\rho=0.5 \%$

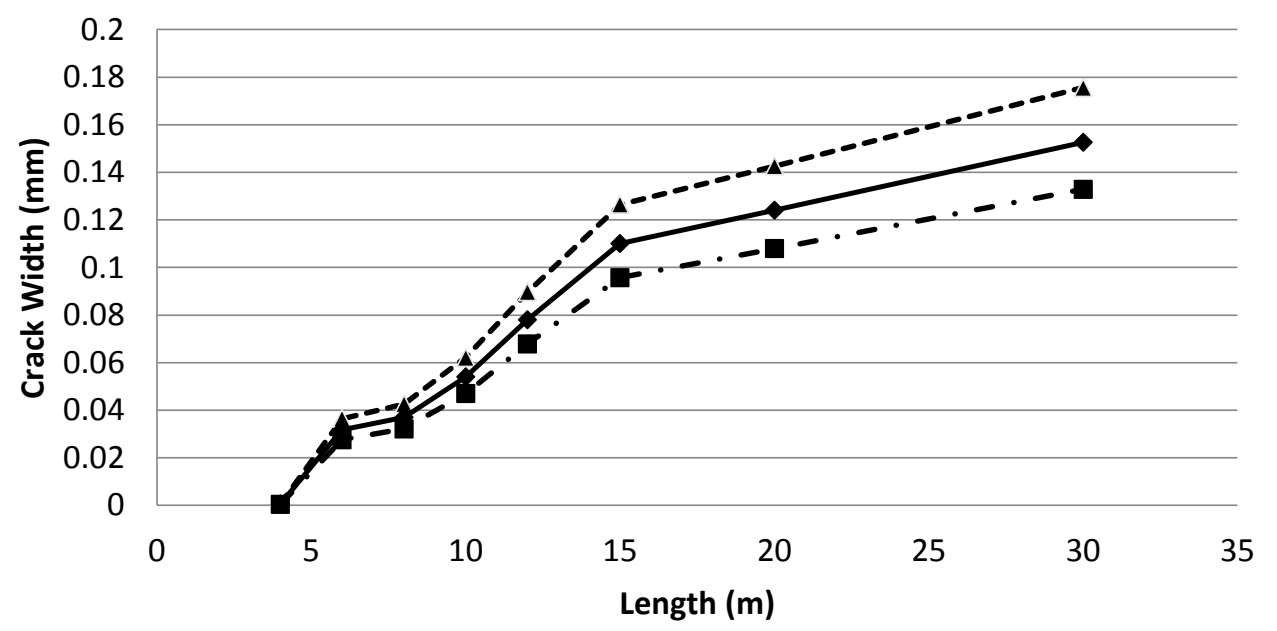

$--1 \cdot-\cdot f t=2.5 \mathrm{MPa}$

$\longrightarrow \mathrm{ft}=3 \mathrm{MPa}$

- $\mathbf{-} \mathrm{ft}=3.5 \mathrm{MPa}$

(c) $\rho=0.6 \%$ 


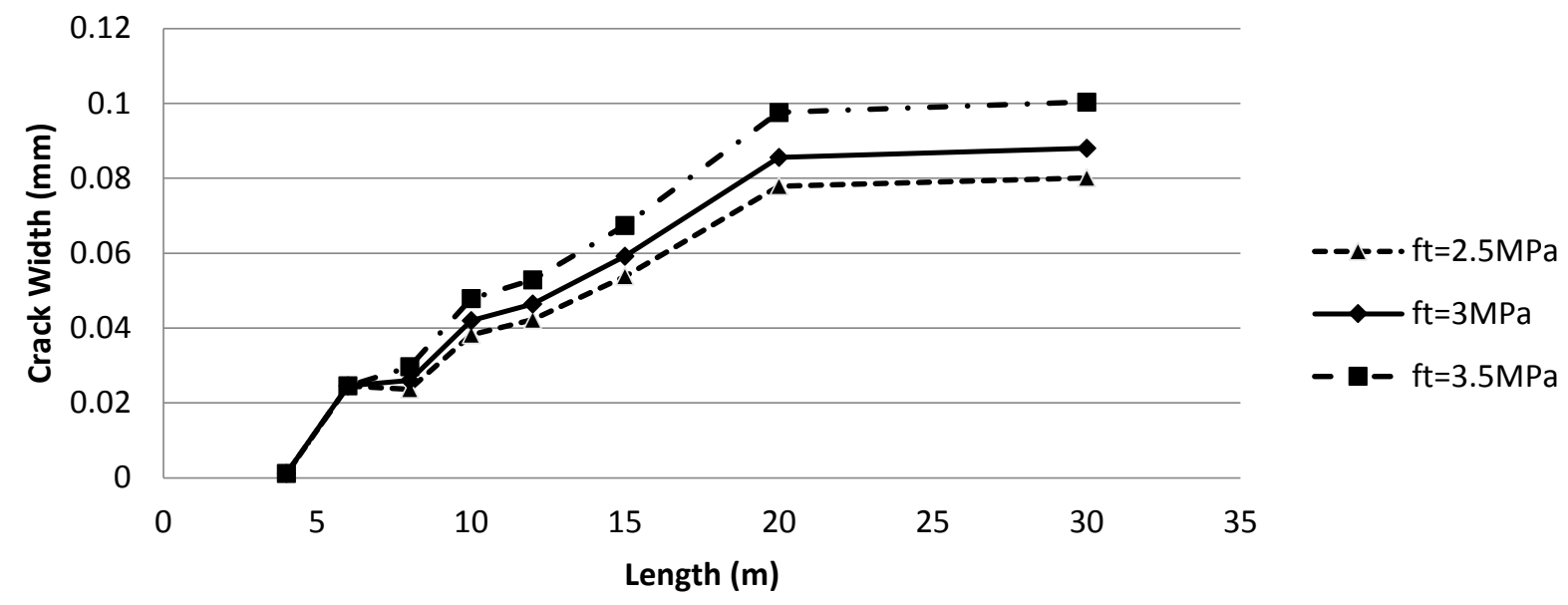

(d) $\rho=0.7 \%$

Figure C-9 Effect of concrete tensile strength on the crack width with different steel ratios $(\mathrm{H}=4 \mathrm{~m})$
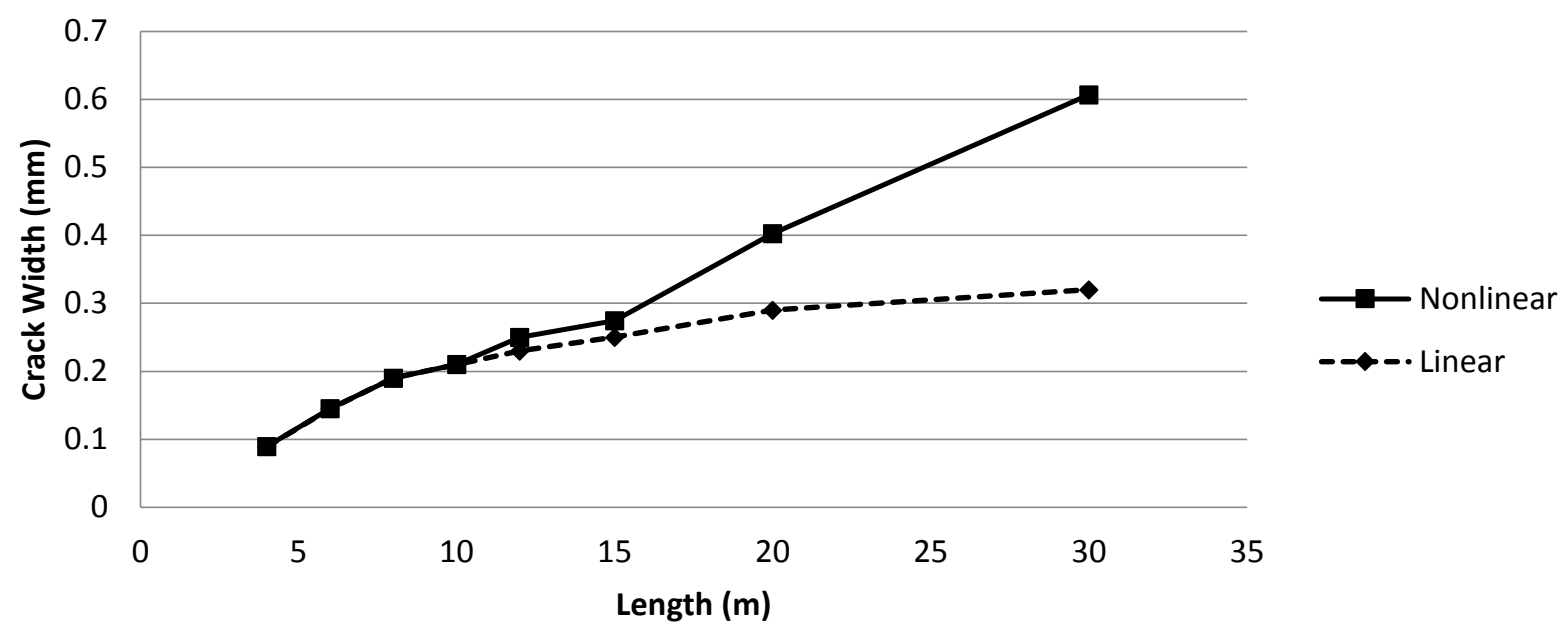

(a) $\mathrm{H}=6 \mathrm{~m}$

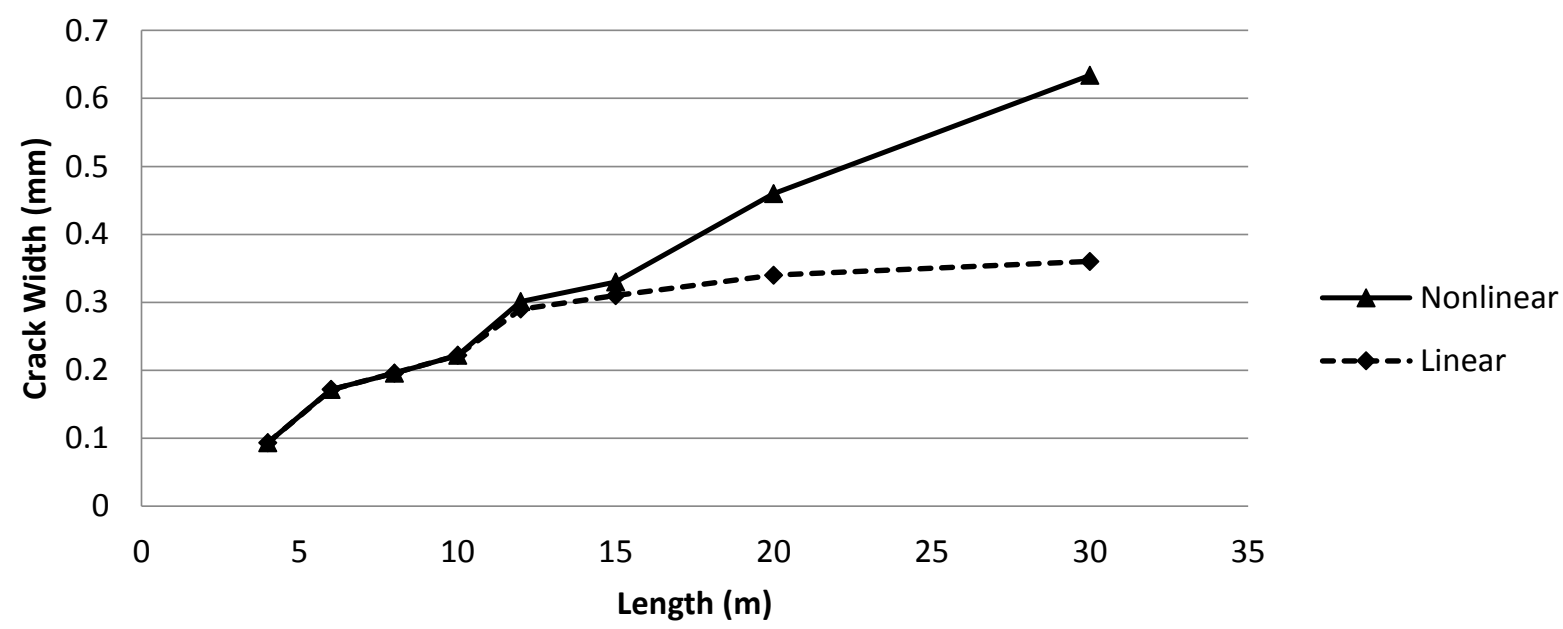

(b) $\mathrm{H}=8 \mathrm{~m}$

Figure C-10 Effect of steel behavior on the crack width $(\rho=0.3 \%)$ 

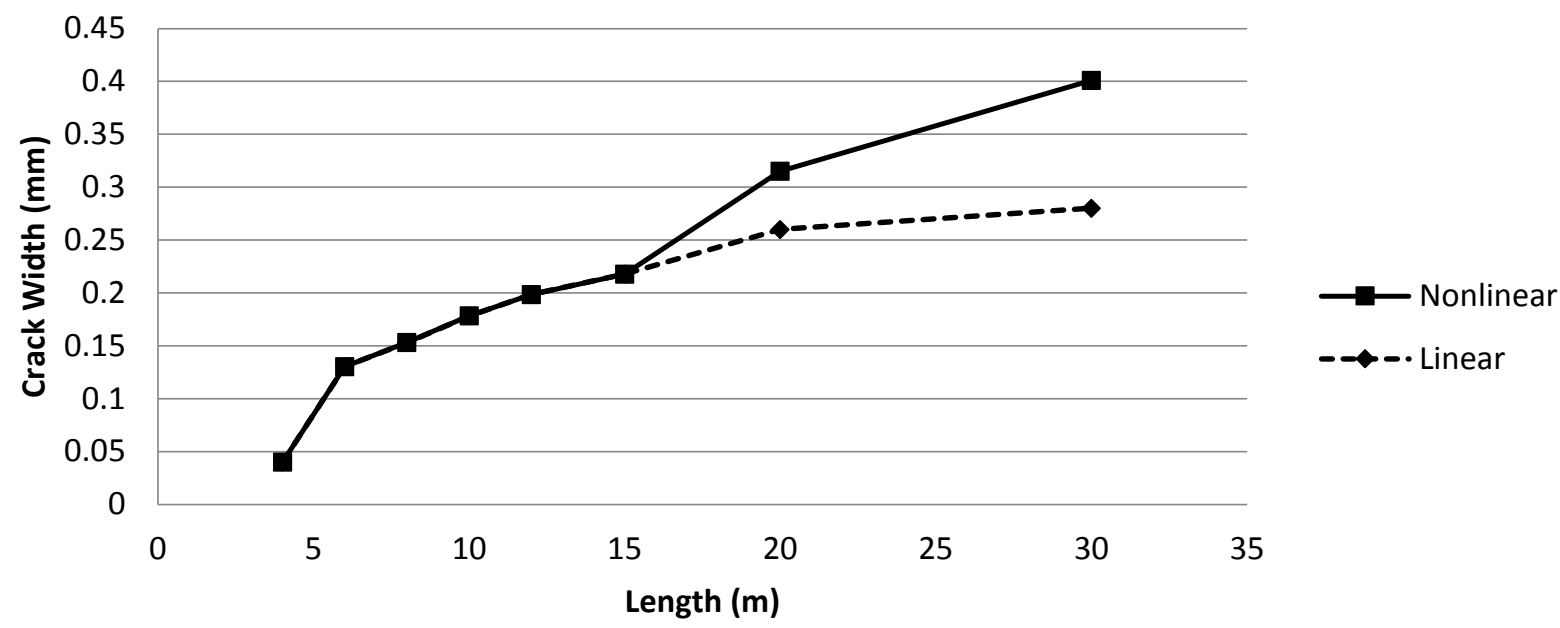

(a) $\rho=0.4 \%$
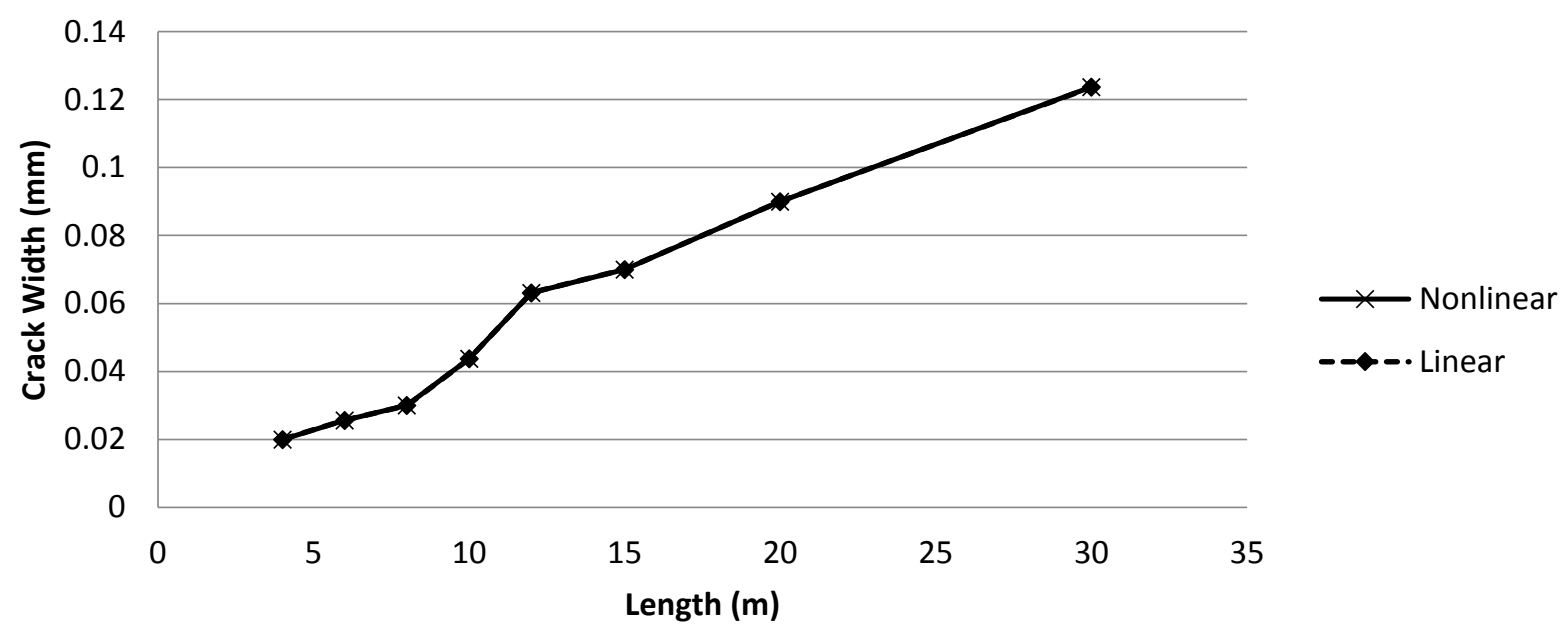

(b) $\rho=0.6 \%$

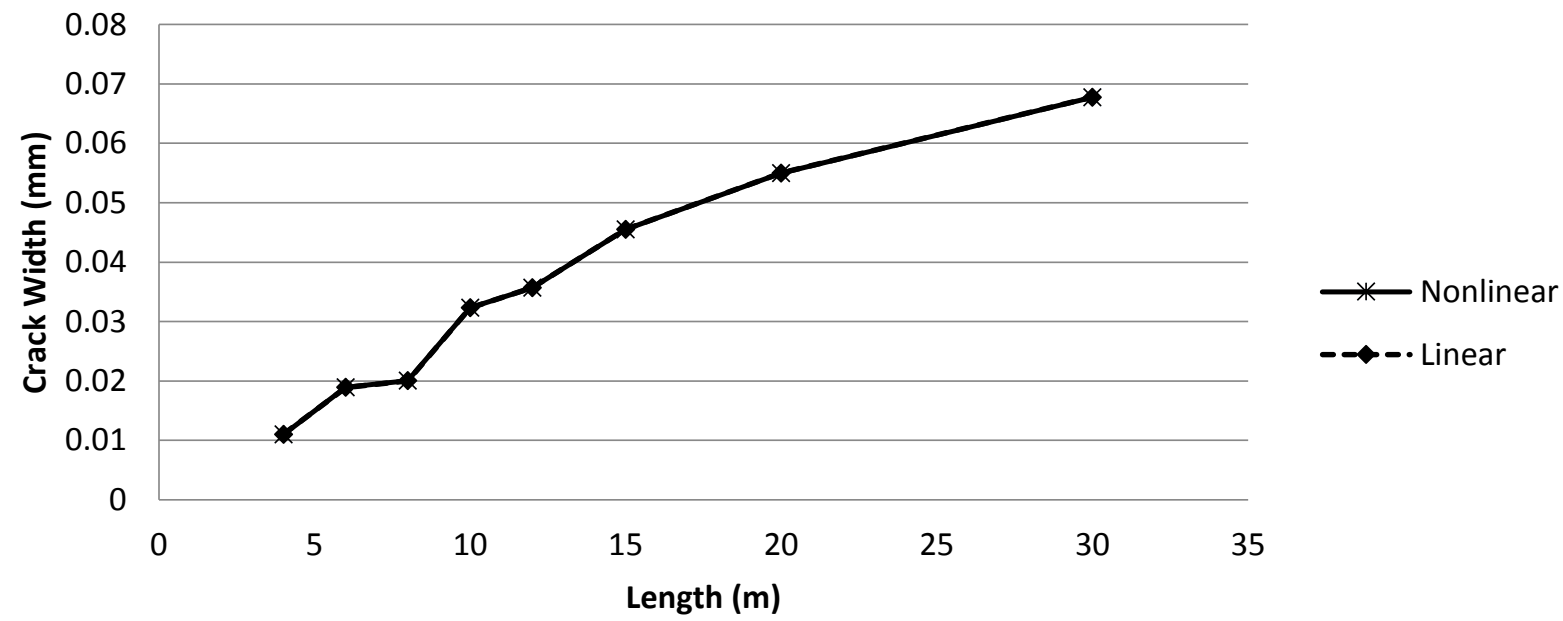

(c) $\rho=0.7 \%$

Figure C-11 Effect of steel behavior on the crack width with different steel ratios $(\mathrm{H}=4 \mathrm{~m})$ 


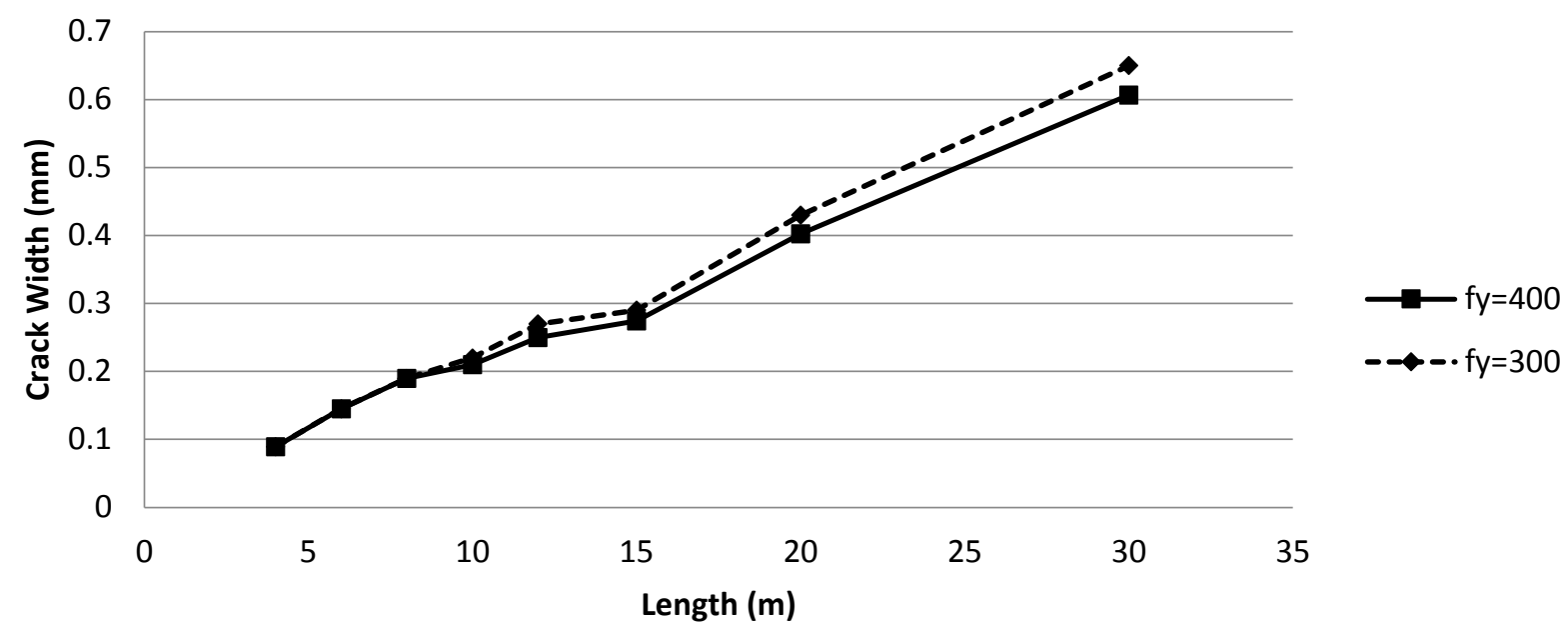

(a) $\mathrm{H}=6 \mathrm{~m}$

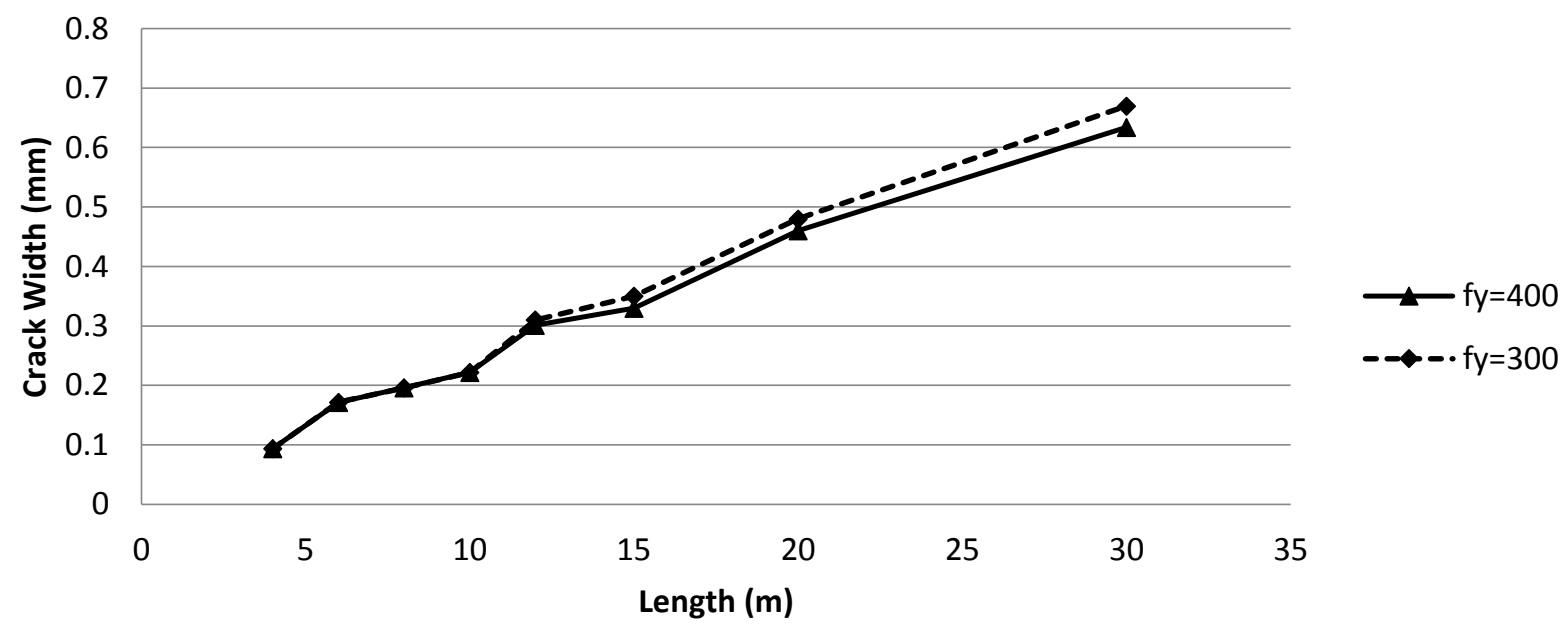

(b) $\mathrm{H}=8 \mathrm{~m}$

Figure C-12 Effect of steel yield strength on the crack width considering different heights $(\rho=0.3 \%)$

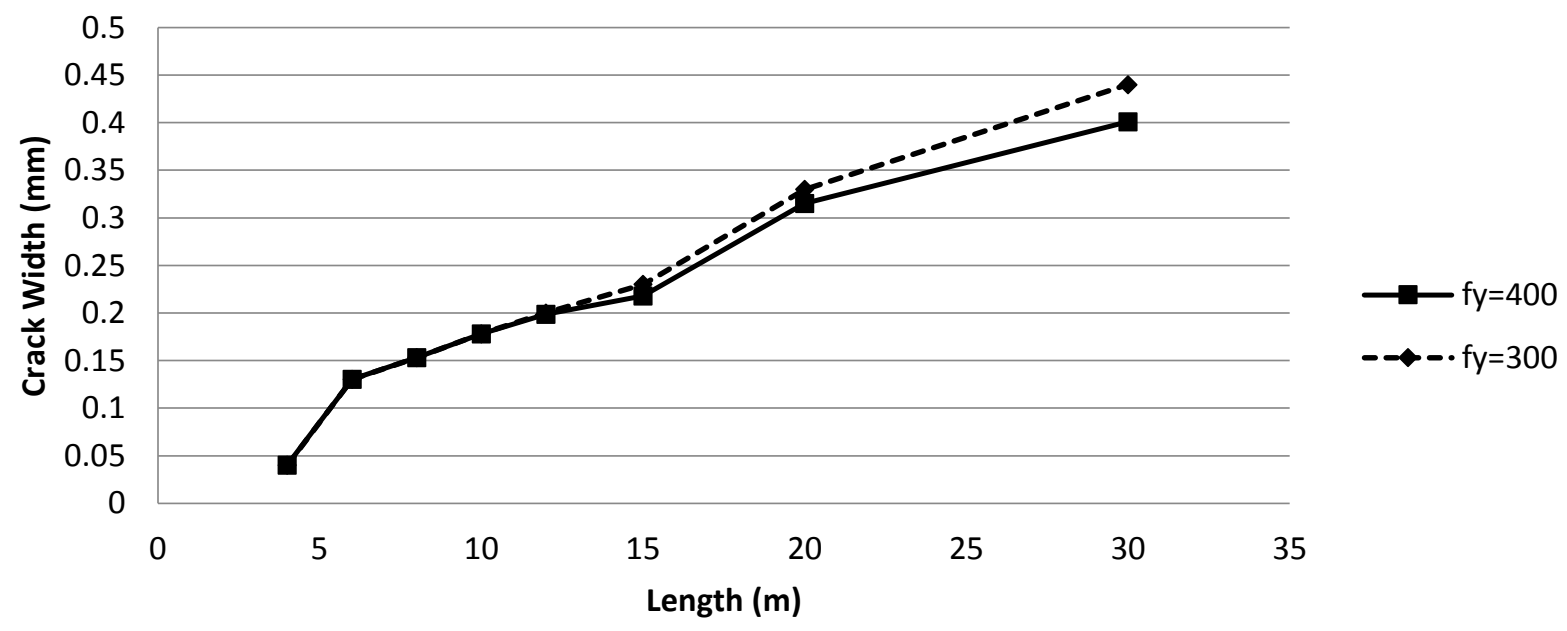

(a) $\rho=0.4 \%$ 


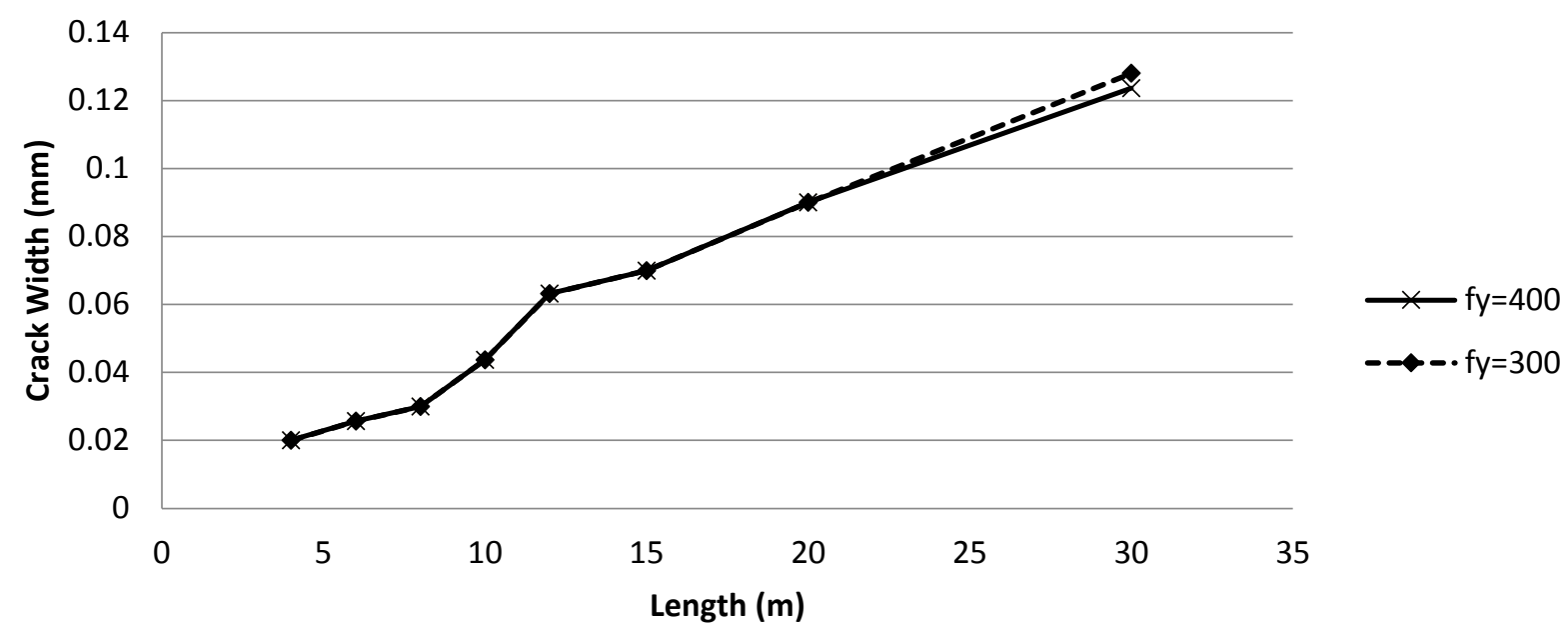

(b) $\rho=0.6 \%$

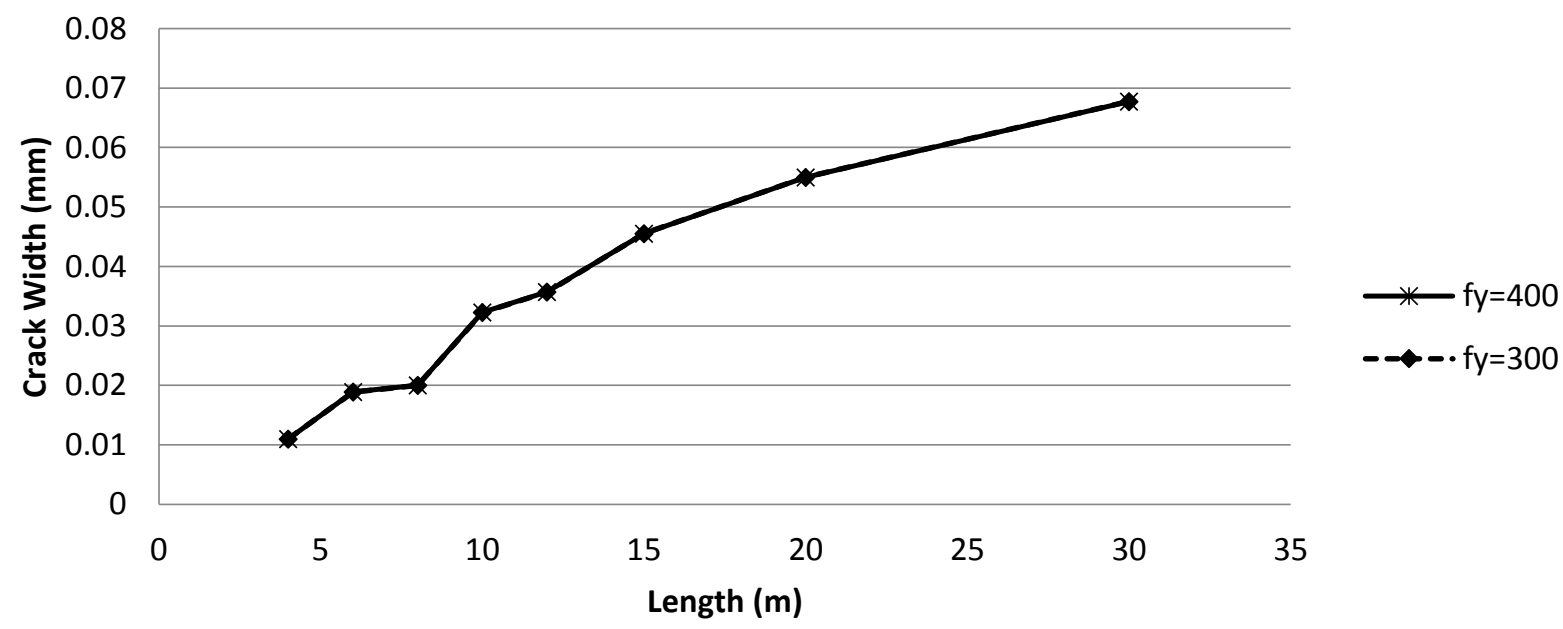

(c) $\rho=0.7 \%$

Figure C-13 Effect of steel yield strength on the crack width with different steel ratios $(\mathrm{H}=4 \mathrm{~m})$

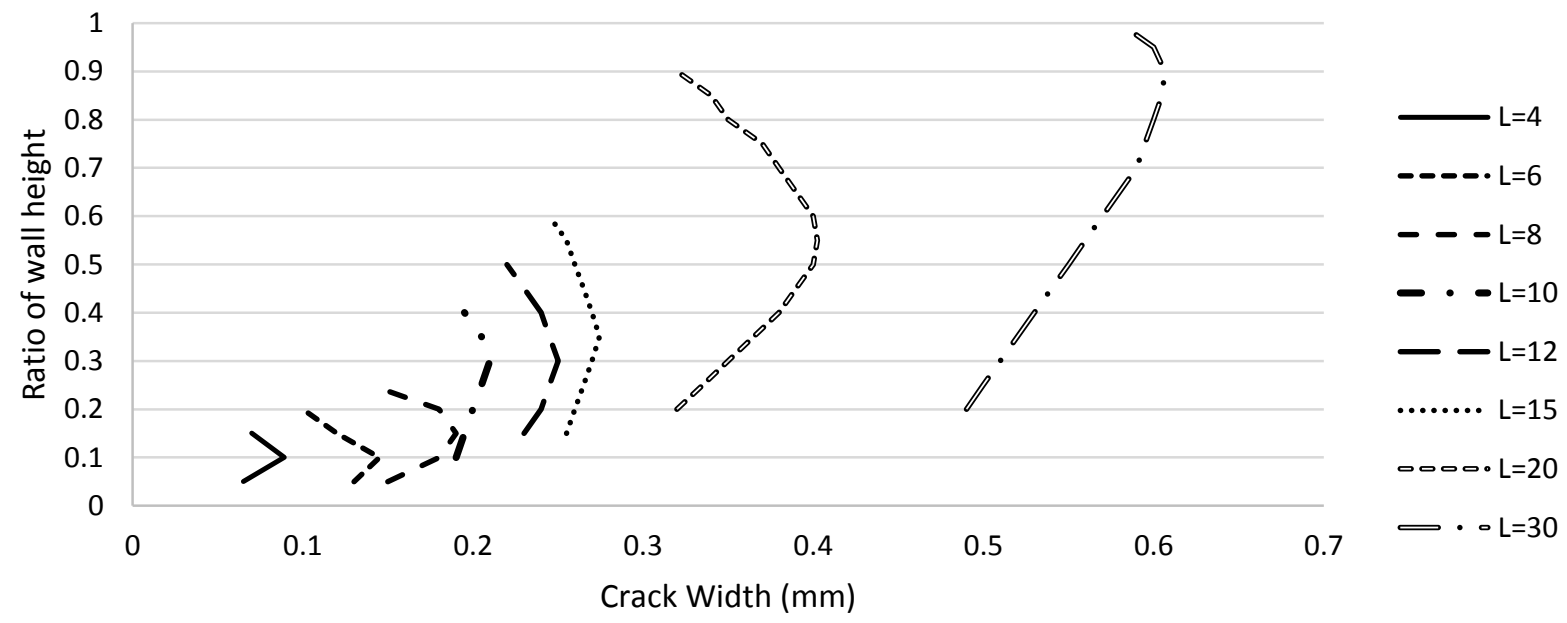

(a) $\mathrm{H}=6 \mathrm{~m}$ 


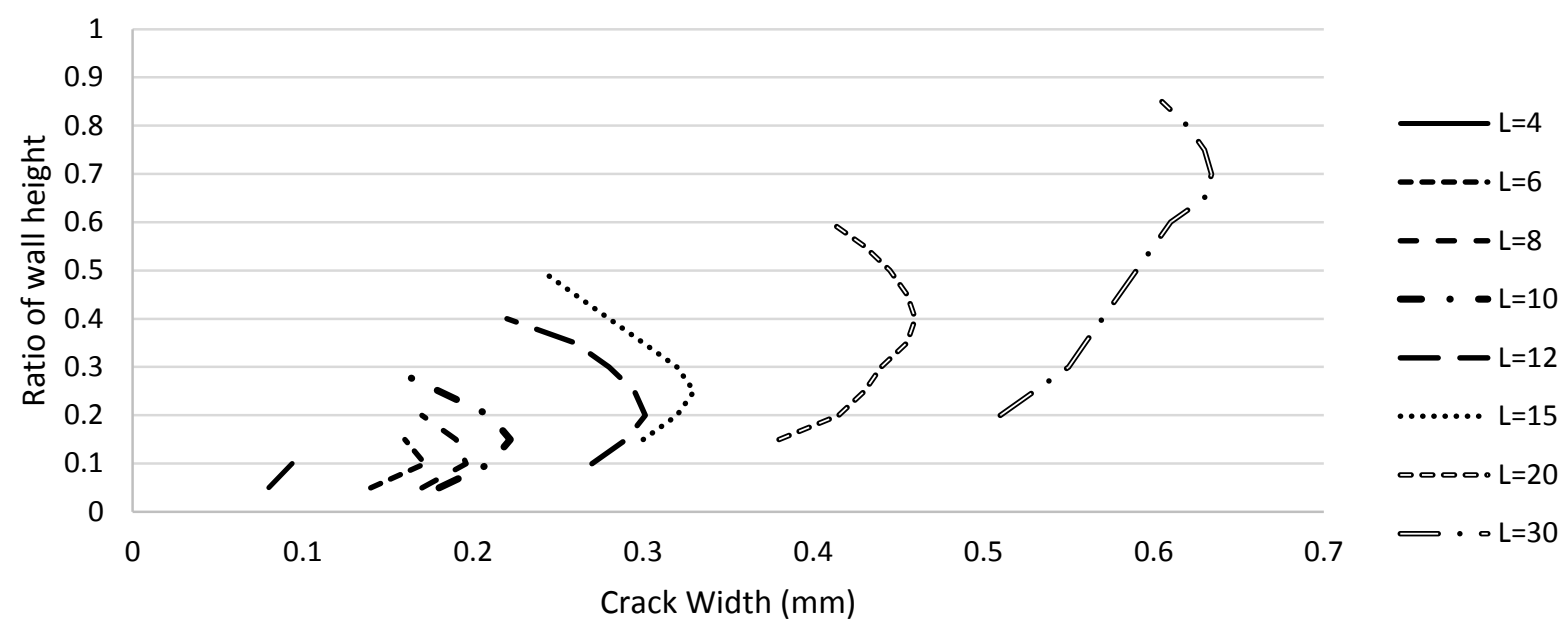

(b) $\mathrm{H}=8 \mathrm{~m}$

Figure C-14 Effect of wall length on the crack width over the wall height $(\rho=0.3 \%)$

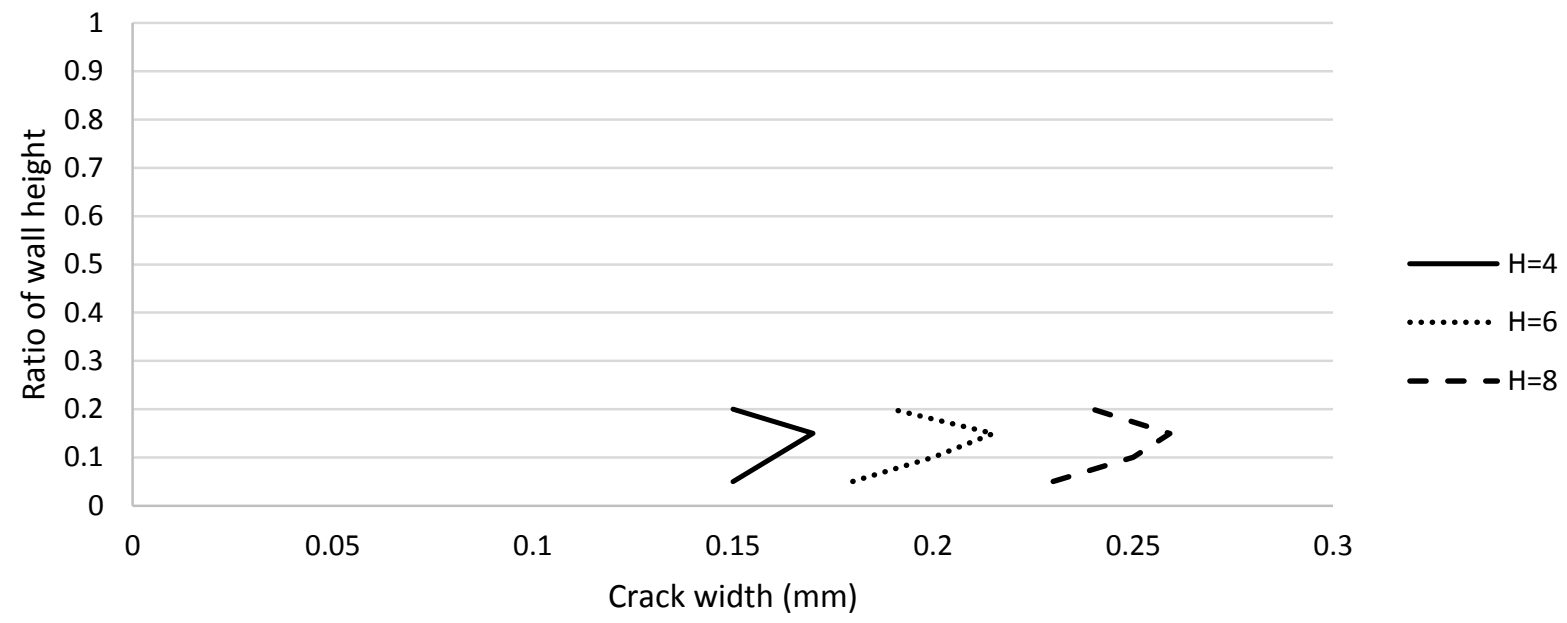

(a) $\mathrm{L} / \mathrm{H}=1.5$

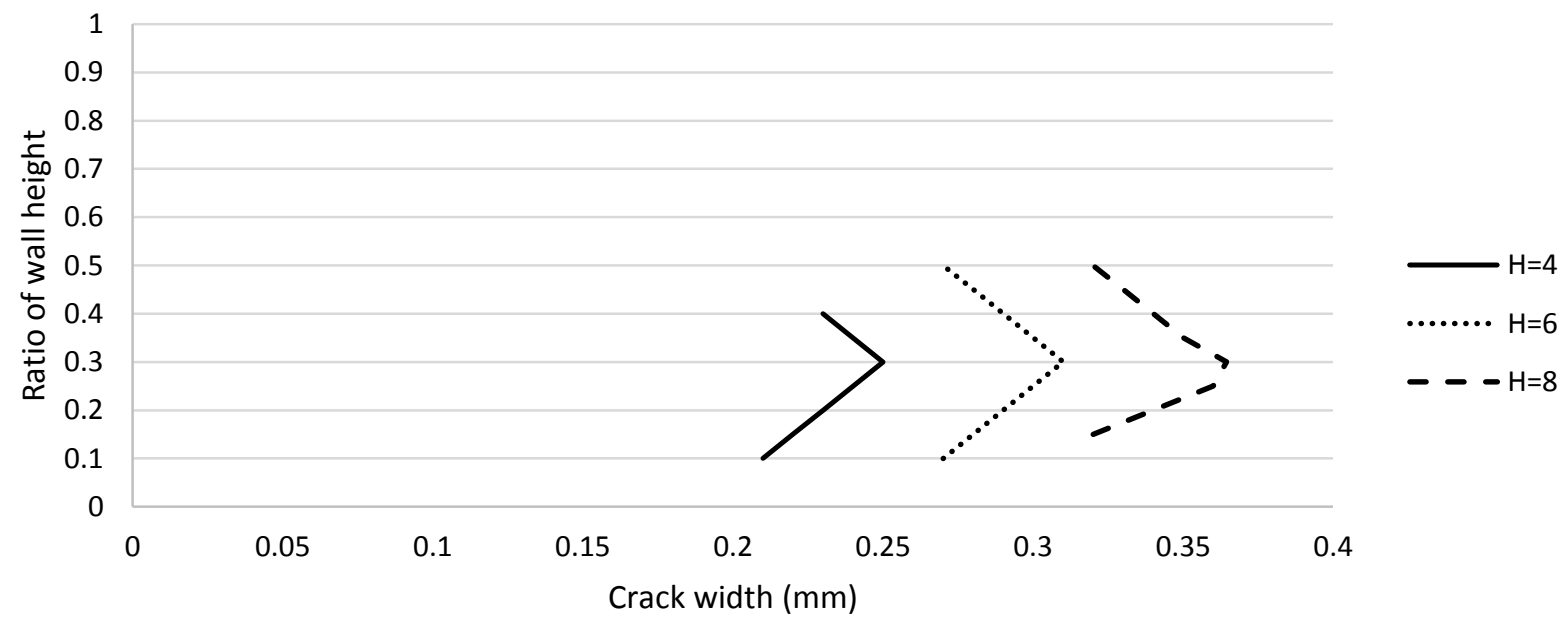

(b) $\mathrm{L} / \mathrm{H}=2.5$ 


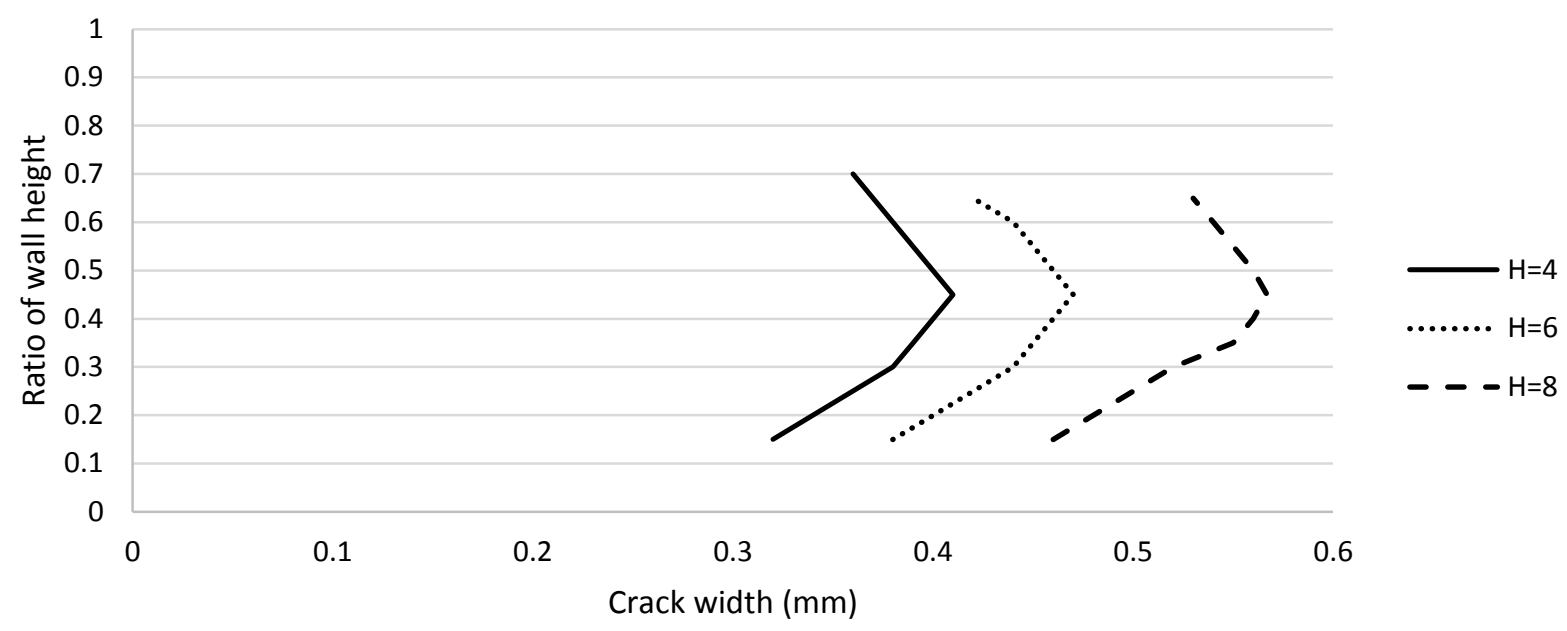

(c) $\mathrm{L} / \mathrm{H}=3.5$

Figure C-15 Effect of $\mathrm{L} / \mathrm{H}$ ratio on the crack width over the wall height $(\rho=0.3 \%)$
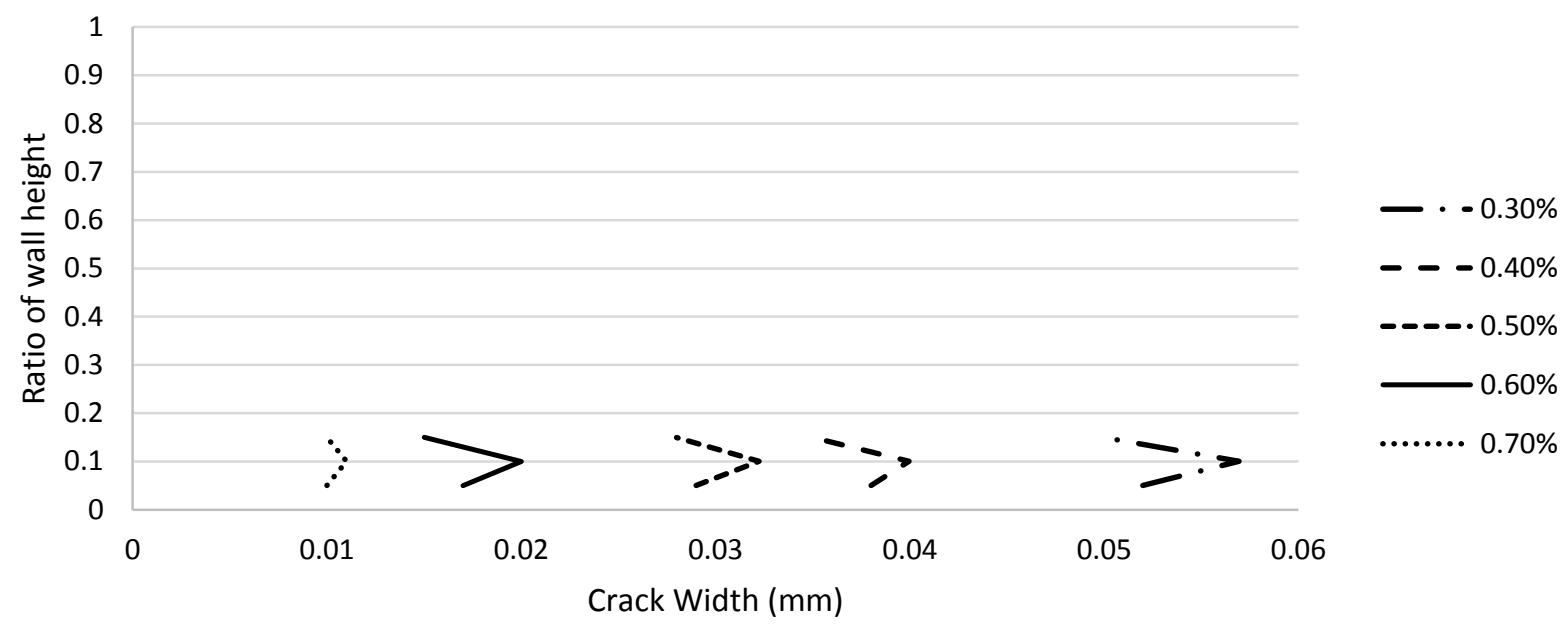

(a) $\mathrm{L}=4 \mathrm{~m}$

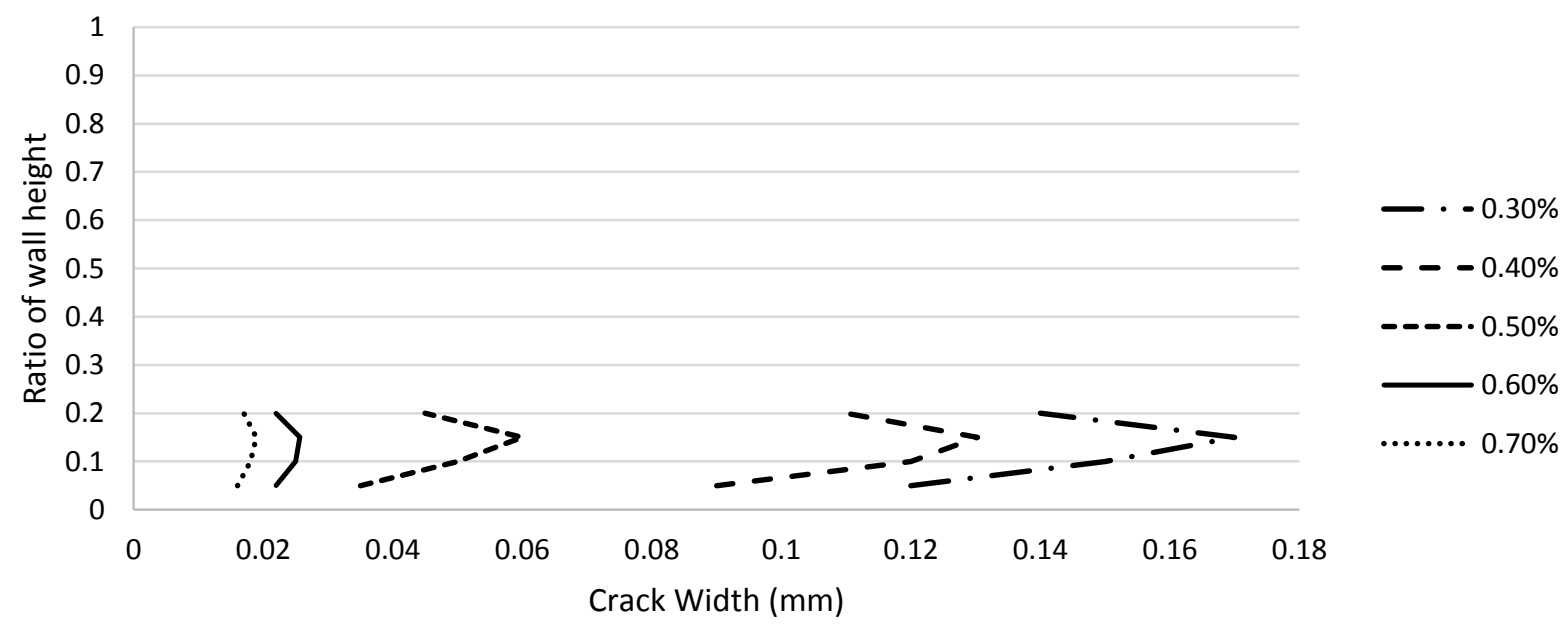

(b) $\mathrm{L}=6 \mathrm{~m}$ 

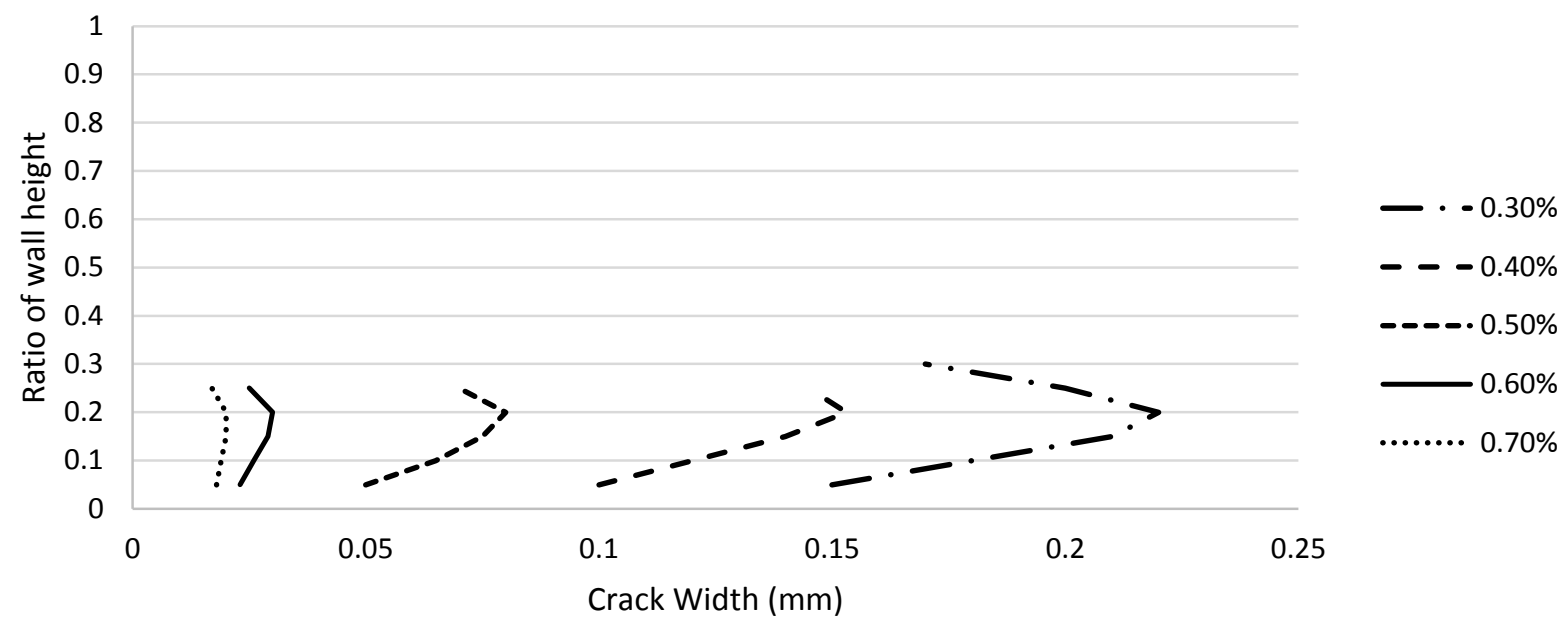

(c) $\mathrm{L}=8 \mathrm{~m}$
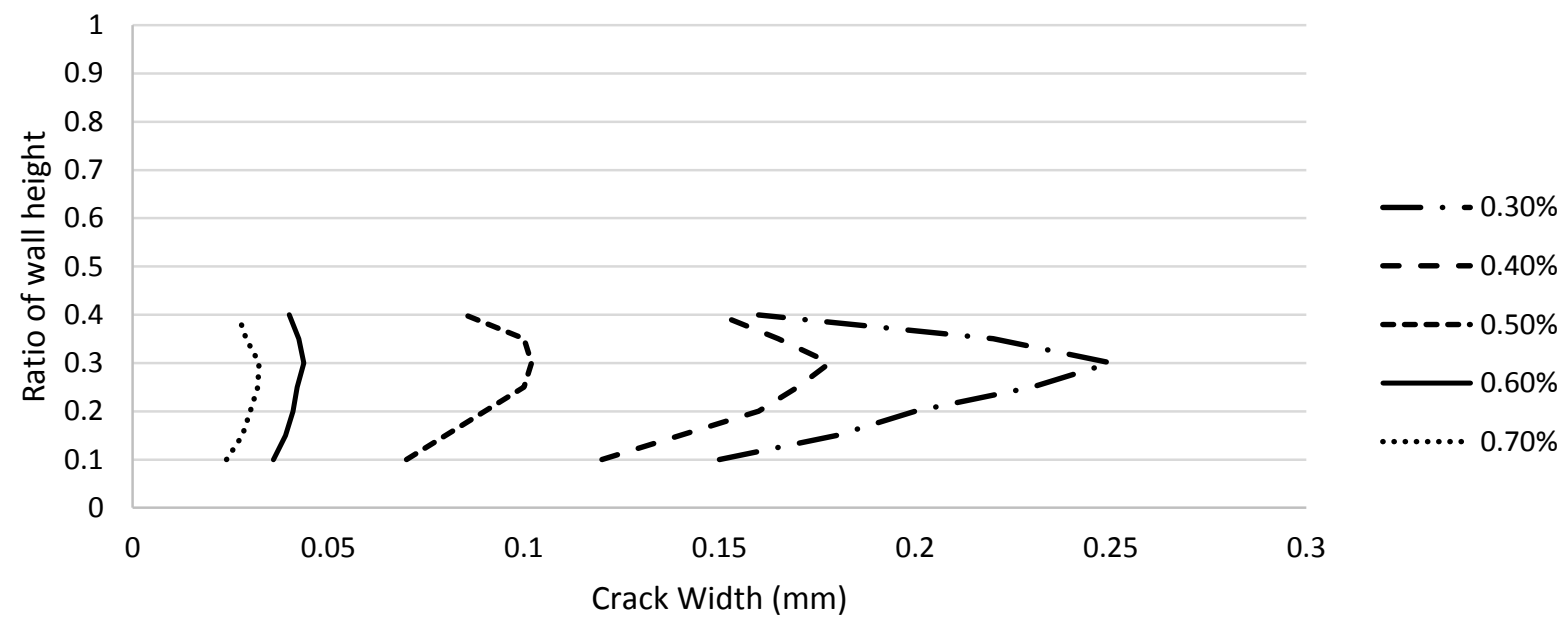

(d) $\mathrm{L}=10 \mathrm{~m}$
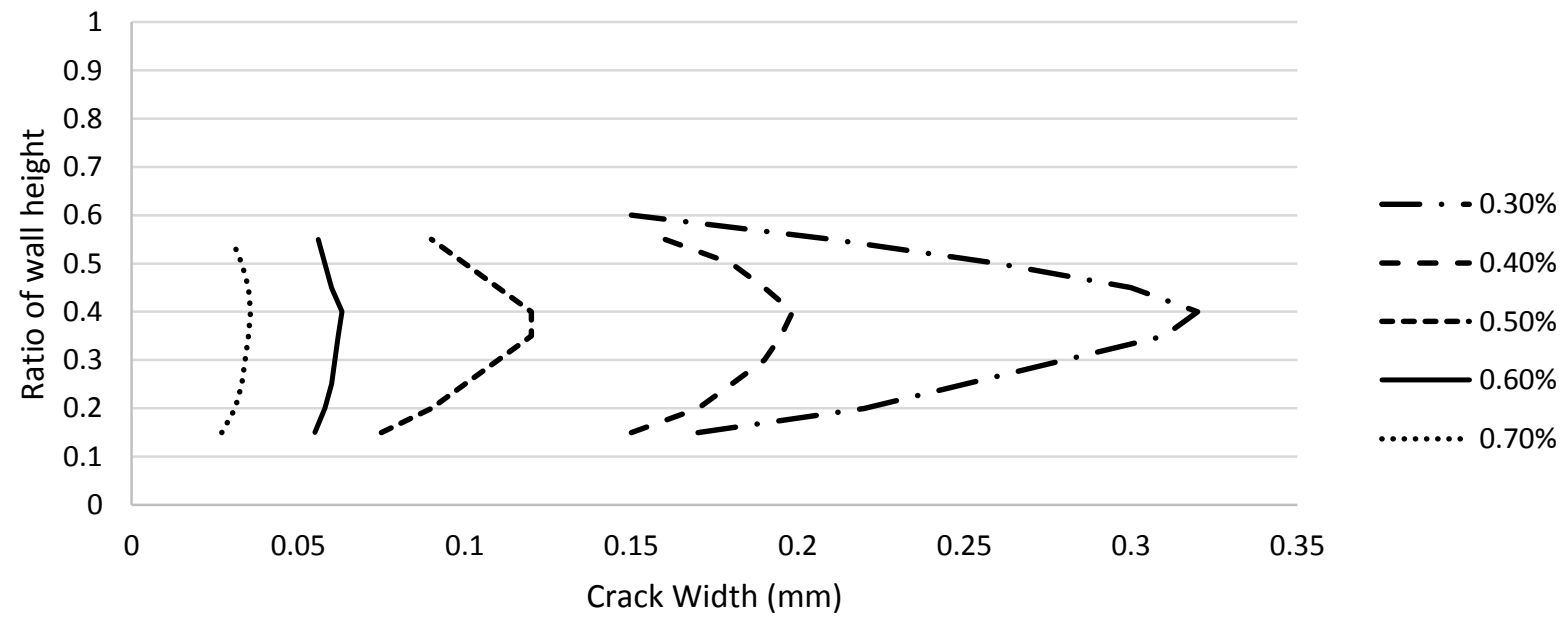

(e) $\mathrm{L}=12 \mathrm{~m}$ 


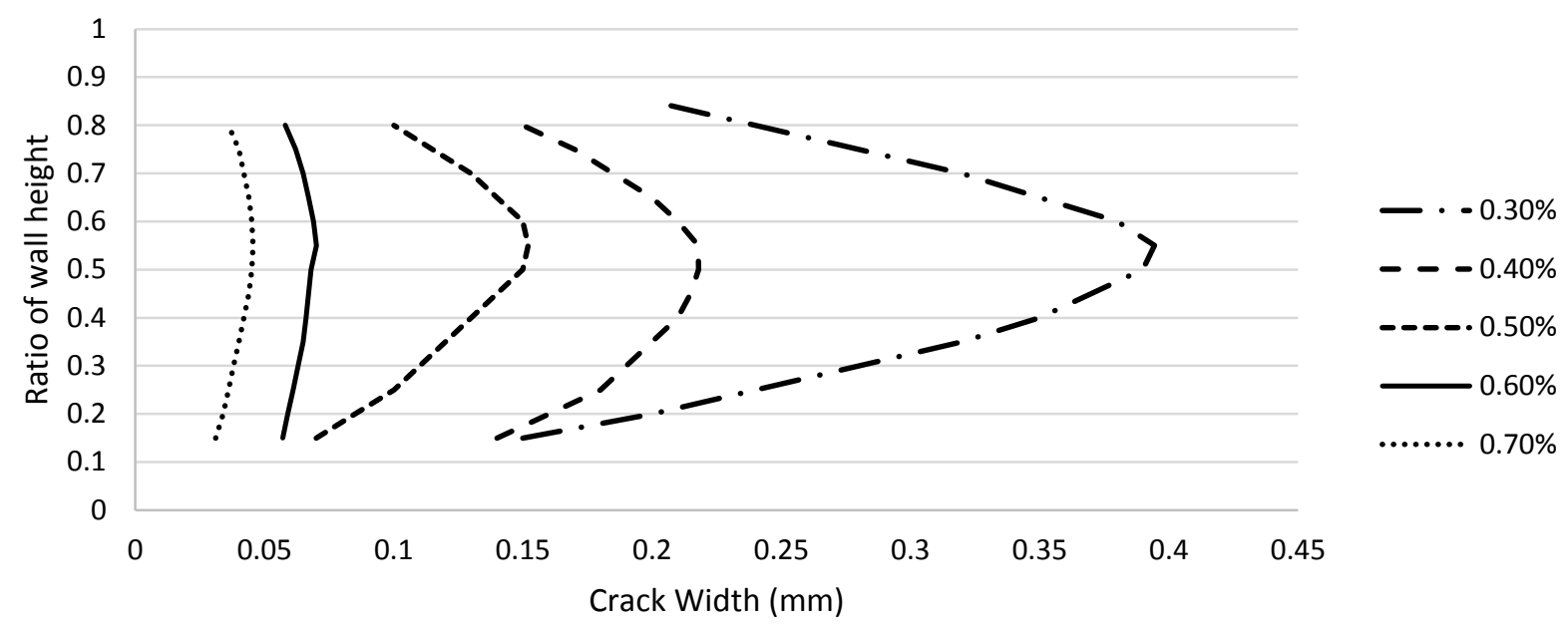

(f) $\mathrm{L}=15 \mathrm{~m}$

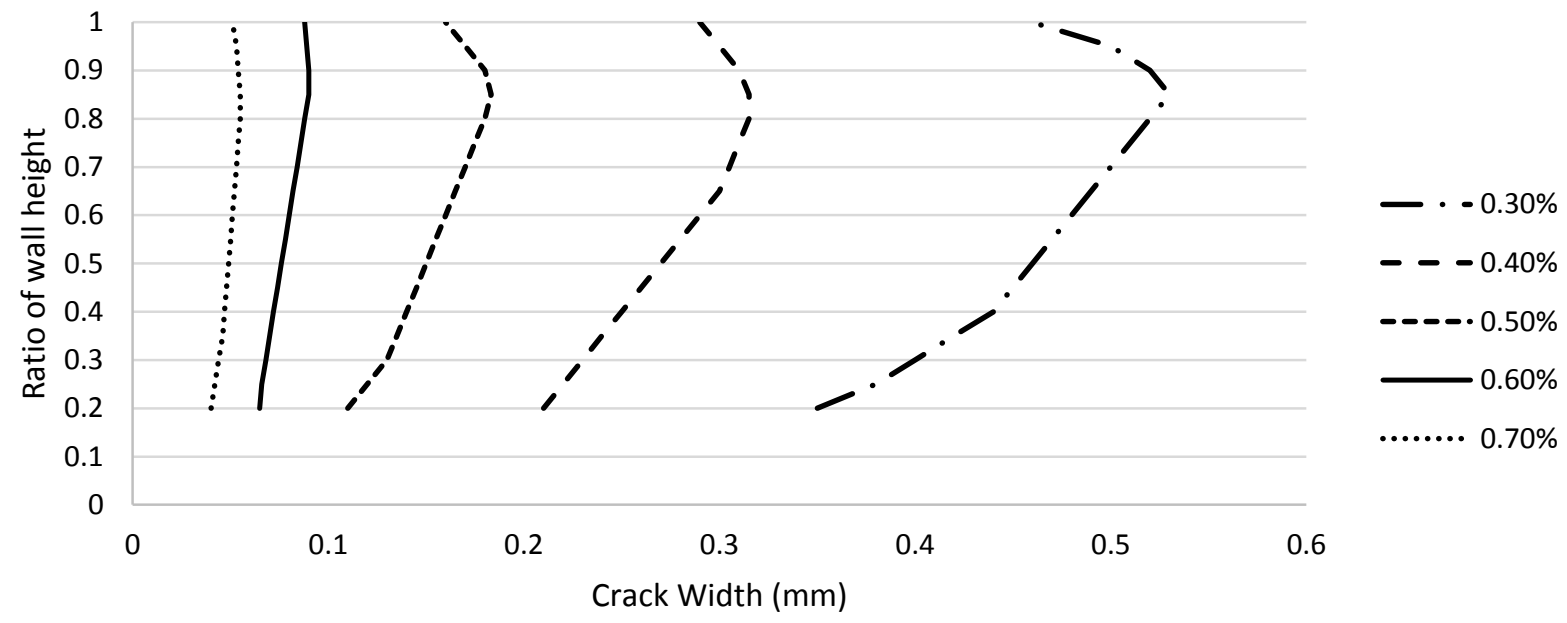

(g) $\mathrm{L}=20 \mathrm{~m}$

Figure C-16 Effect of steel ratio on the crack width over the walls height $(\mathrm{H}=4 \mathrm{~m})$ 


\section{APPENDIX D - RESULTS OF WALLS REINFORCED BASED ON MINIMUM STEEL RATIO RECOMMENDAITONS}

\section{D.1 General}

This Appendix presents the remaining results of the walls reinforced according to the minimum reinforcement ratios suggested by different codes as presented in Chapter 7. The modelled walls in this part are base restrained with no partial side restraint. The effect of creep is considered in the results that are presented in this Appendix.

\section{D.2 Results of the FE study}

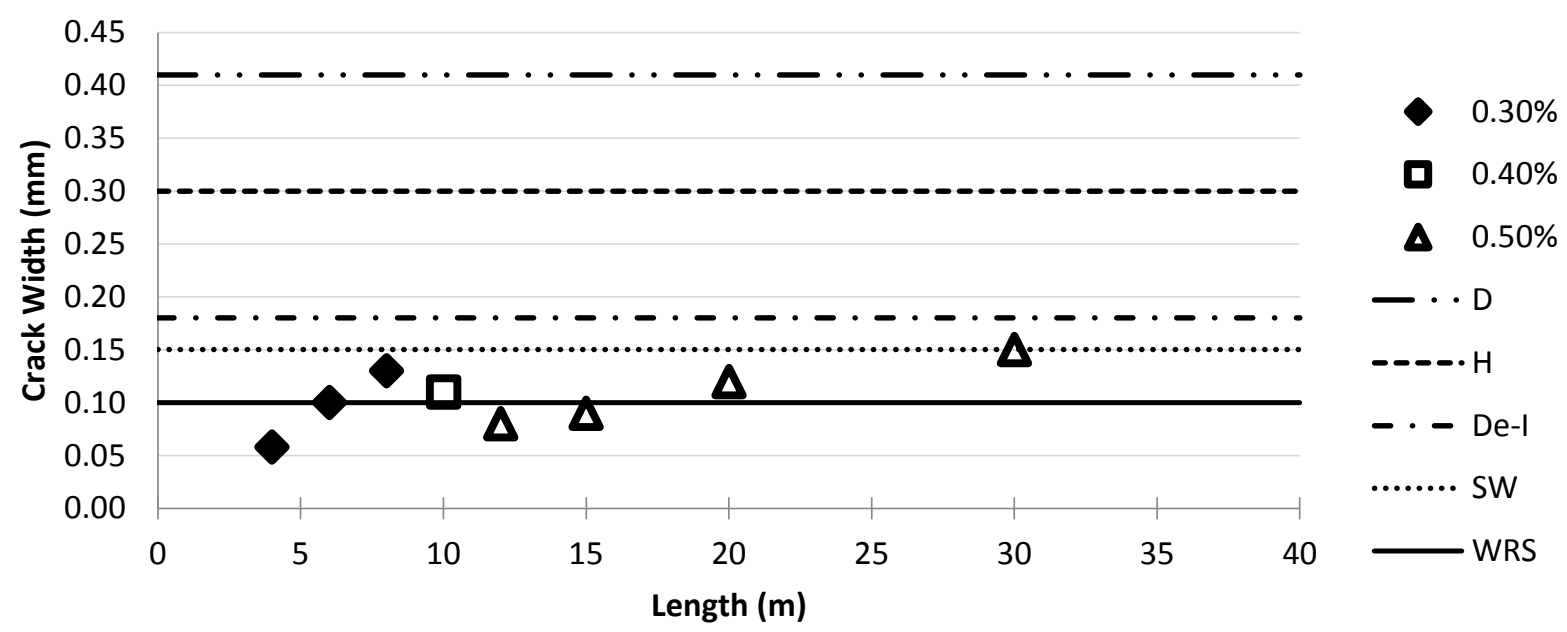

(a) Tropical climate

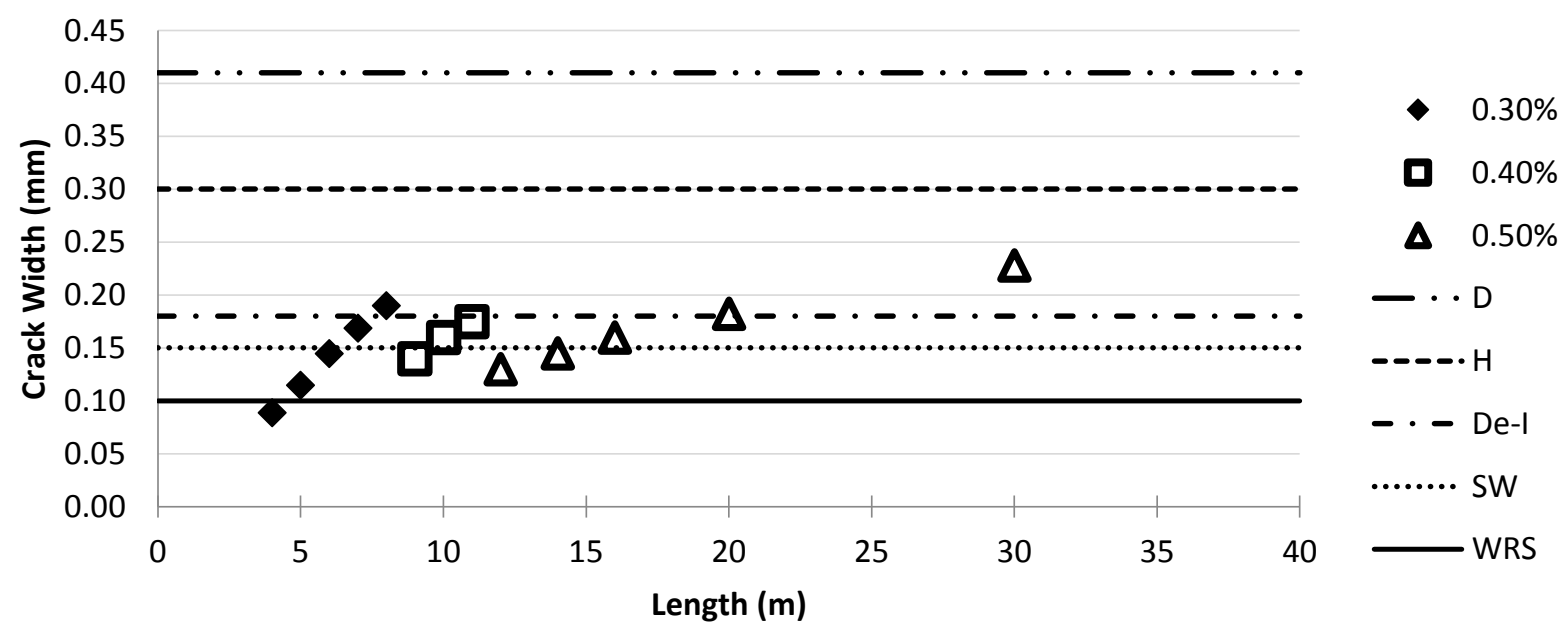

(b) Cold and humid climate 


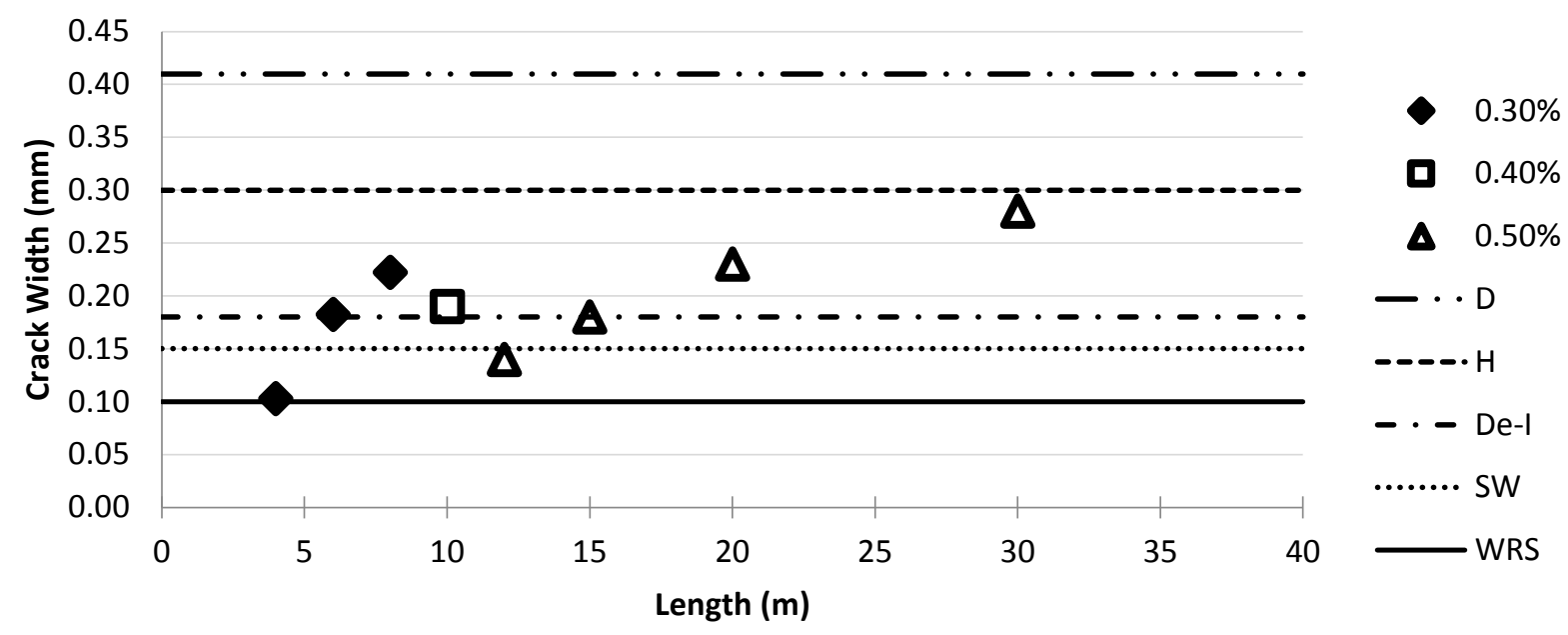

(c) Hot and dry climate

Figure D-1 Crack width of $6 \mathrm{~m}$ high RC walls reinforced based on ACI 350-06 recommendation

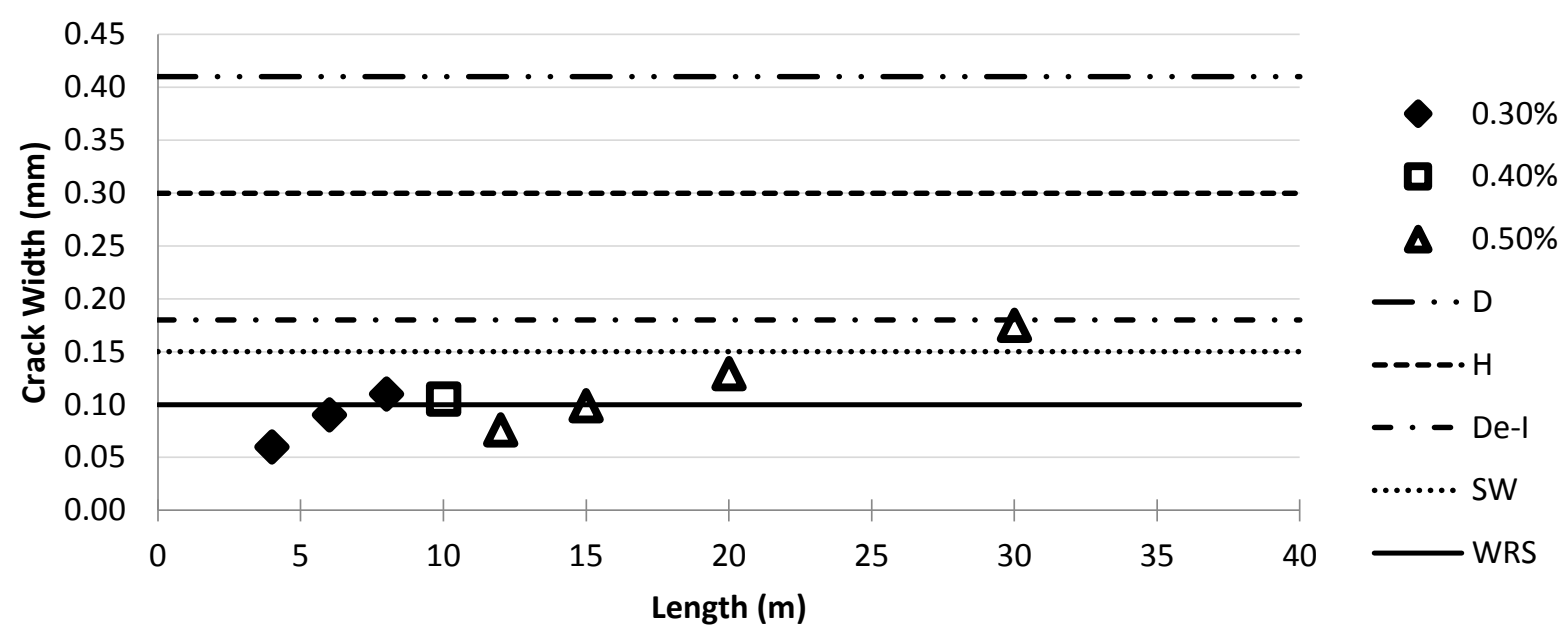

(a) Tropical climate

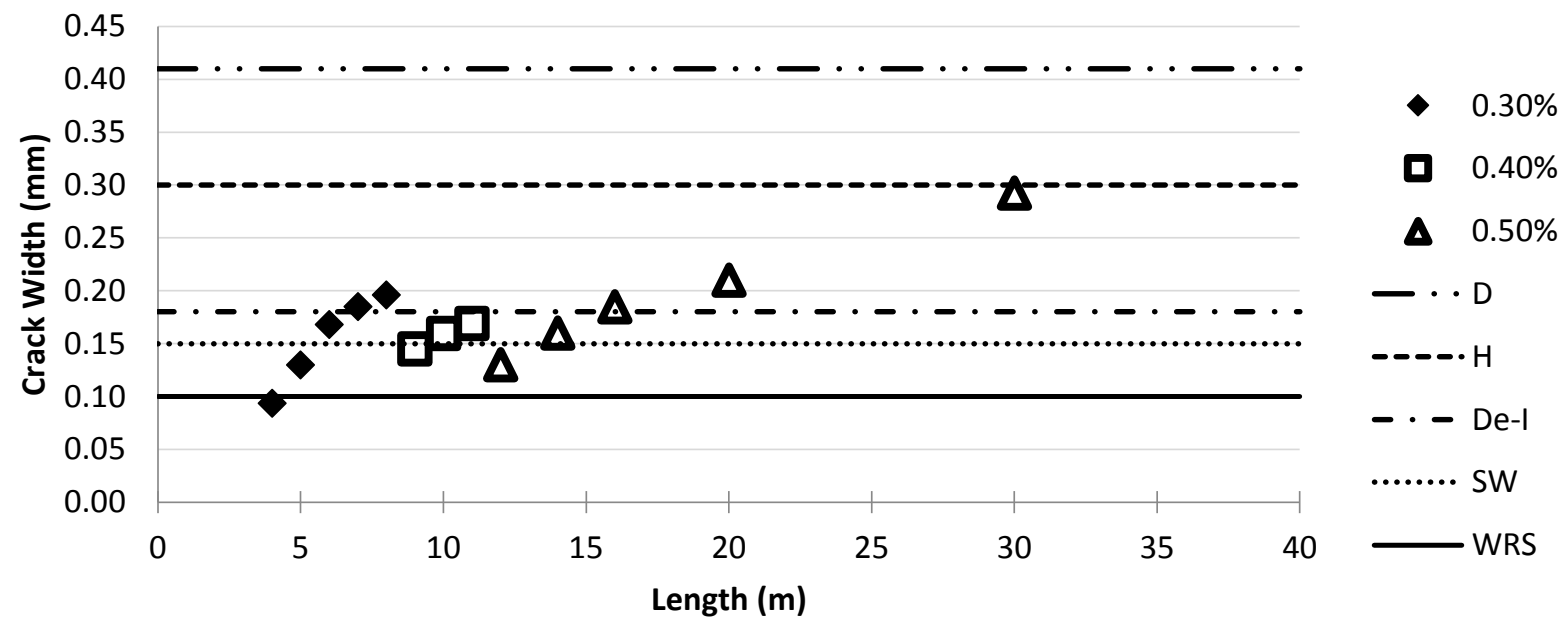

(b) Cold and humid climate 


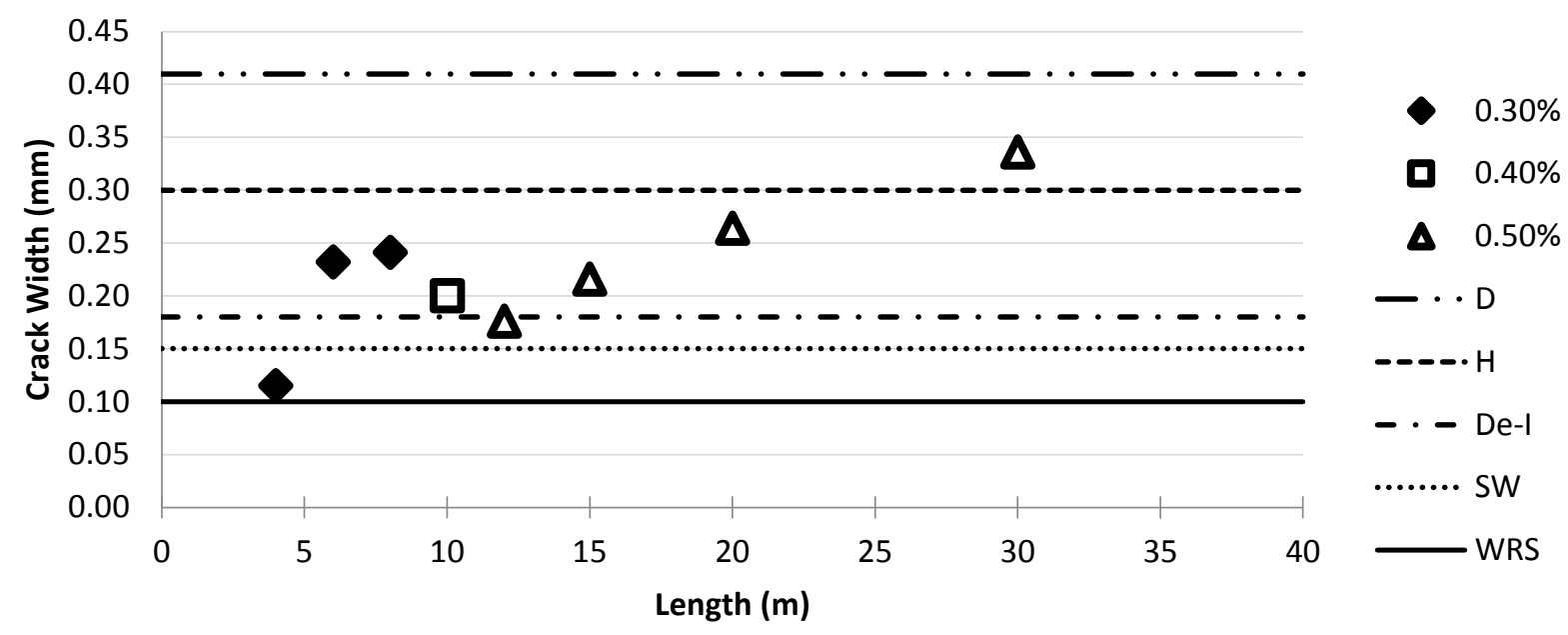

(c) Hot and dry climate

Figure D-2 Crack width of $8 \mathrm{~m}$ high RC walls reinforced based on ACI 350-06 recommendation

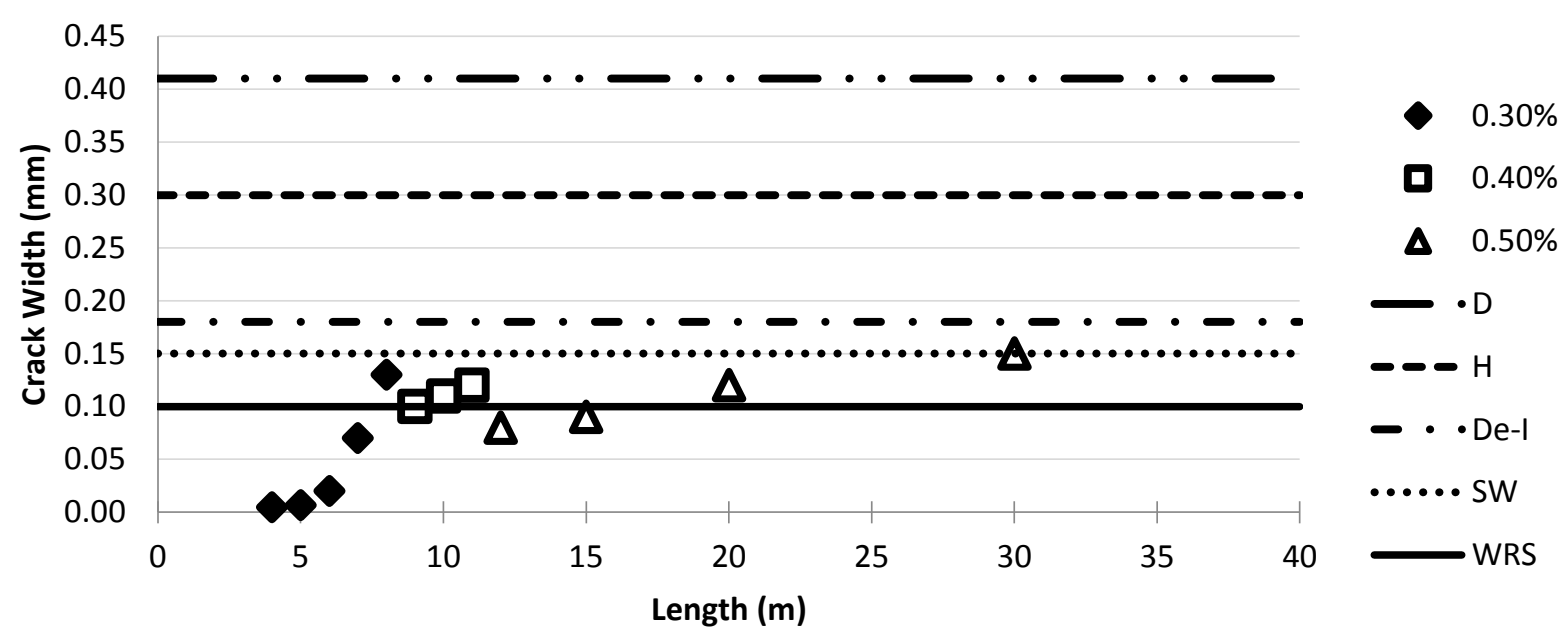

(a) Tropical climate

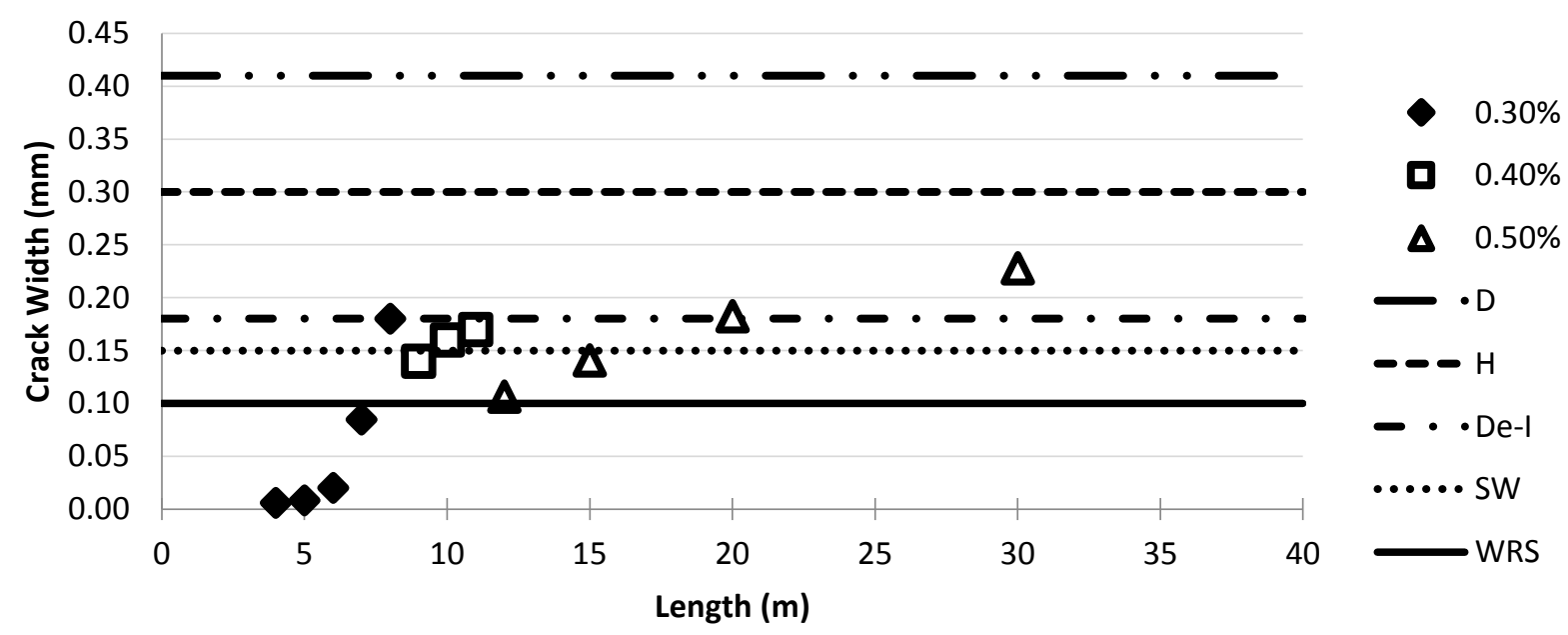

(b) Cold and humid climate 


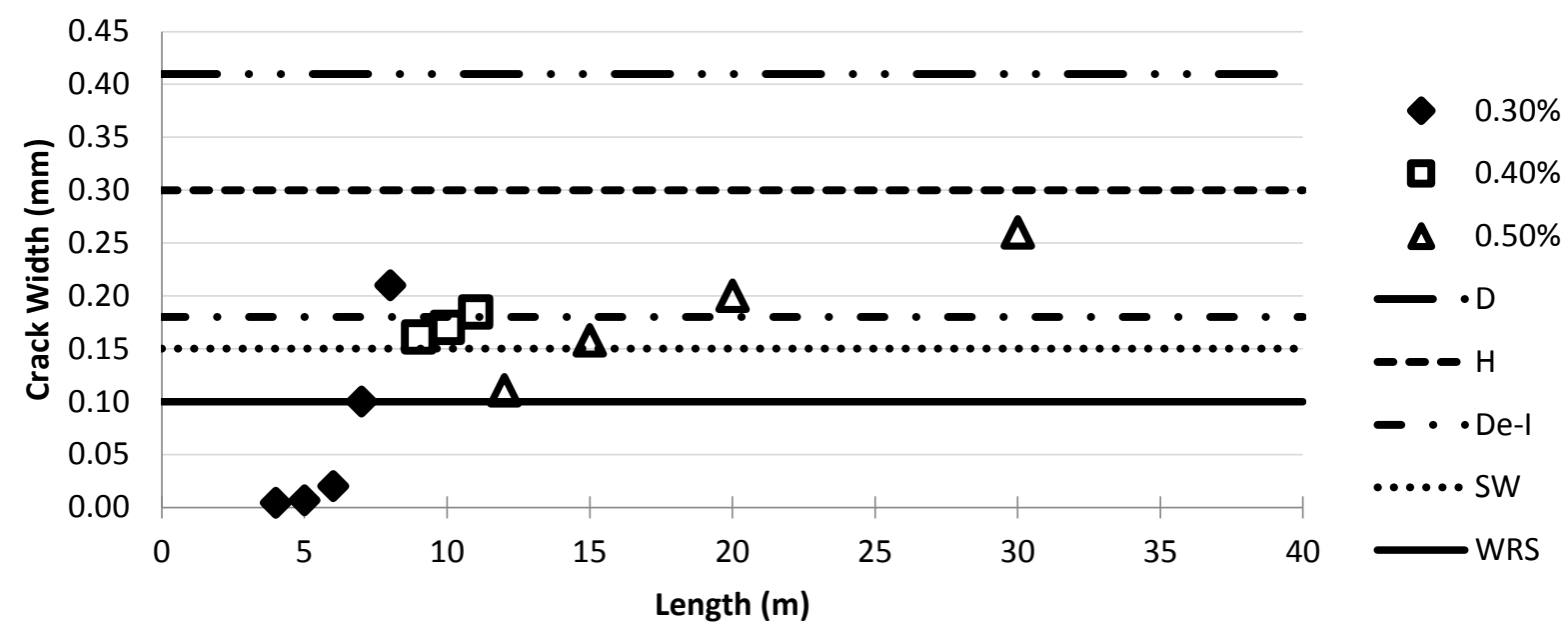

(c) Hot and dry climate

Figure D-3 Crack width of $6 \mathrm{~m}$ high RC walls reinforced based on ACI $350 \mathrm{Rec}$ II

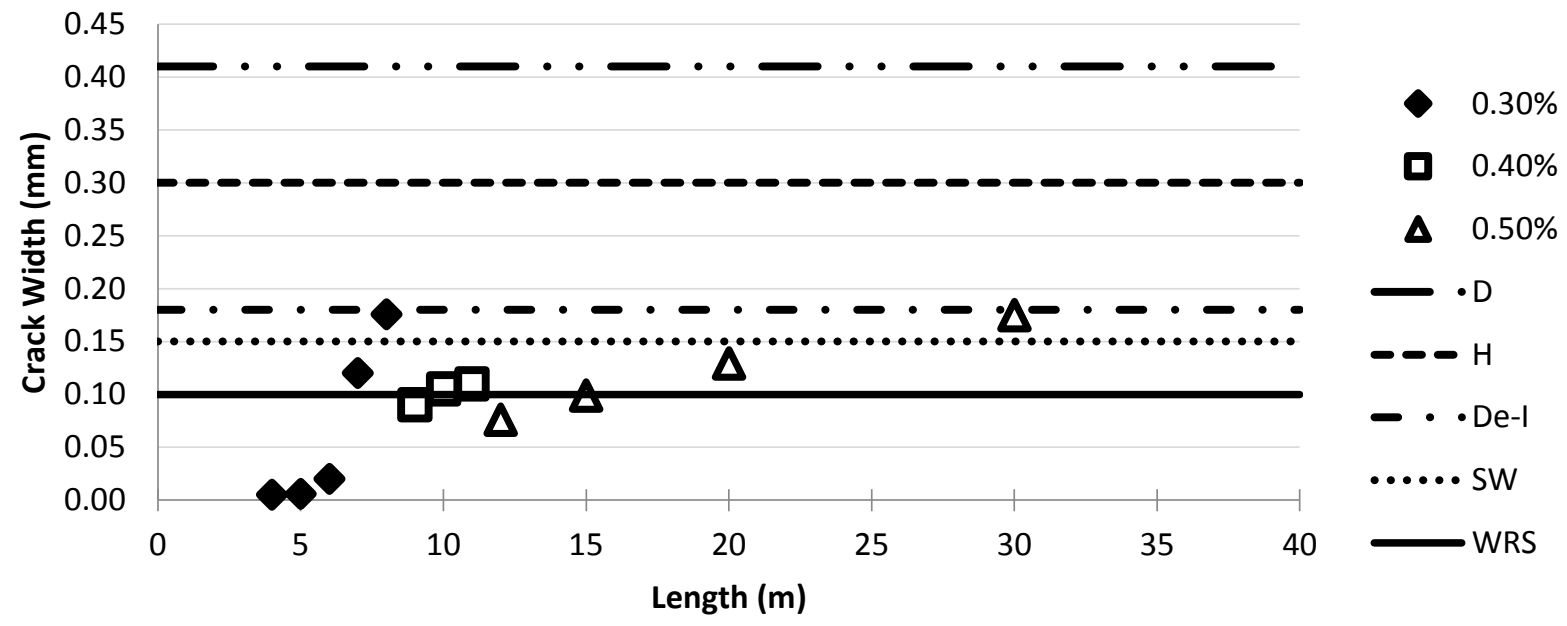

(a) Tropical climate

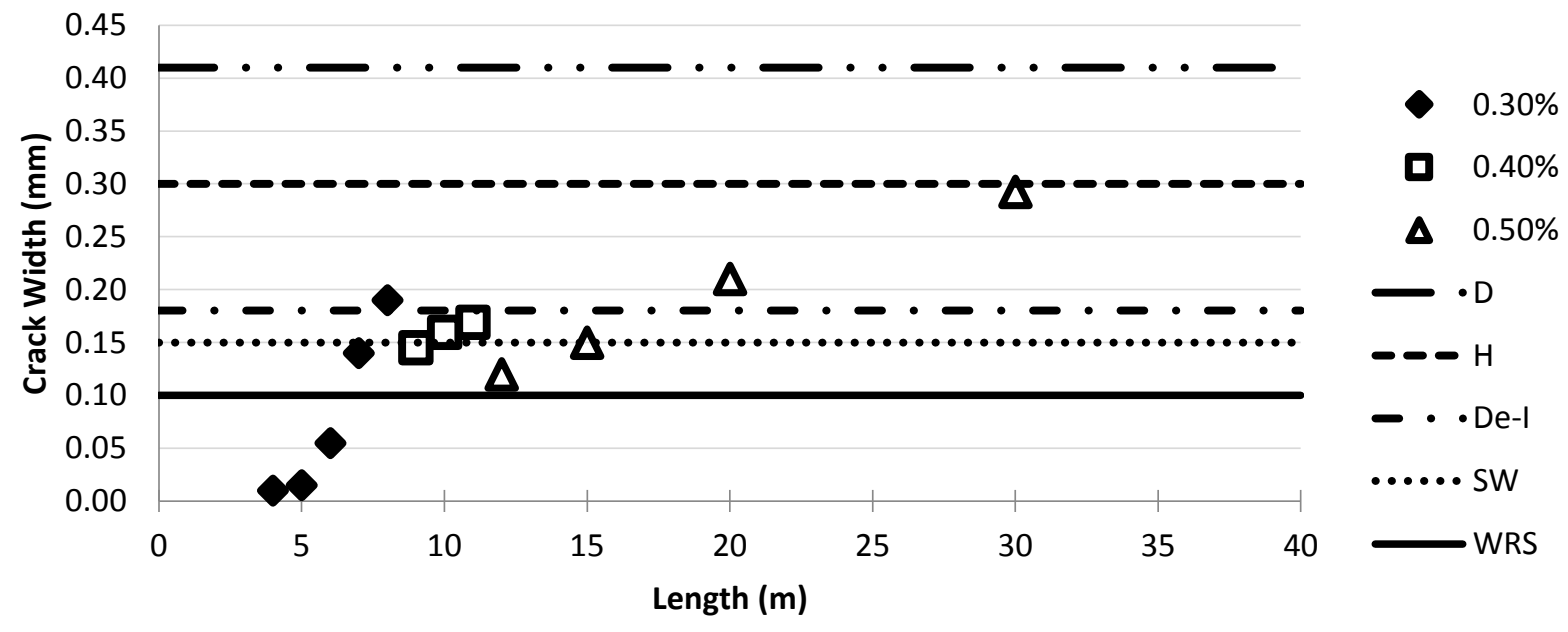

(b) Cold and humid climate 


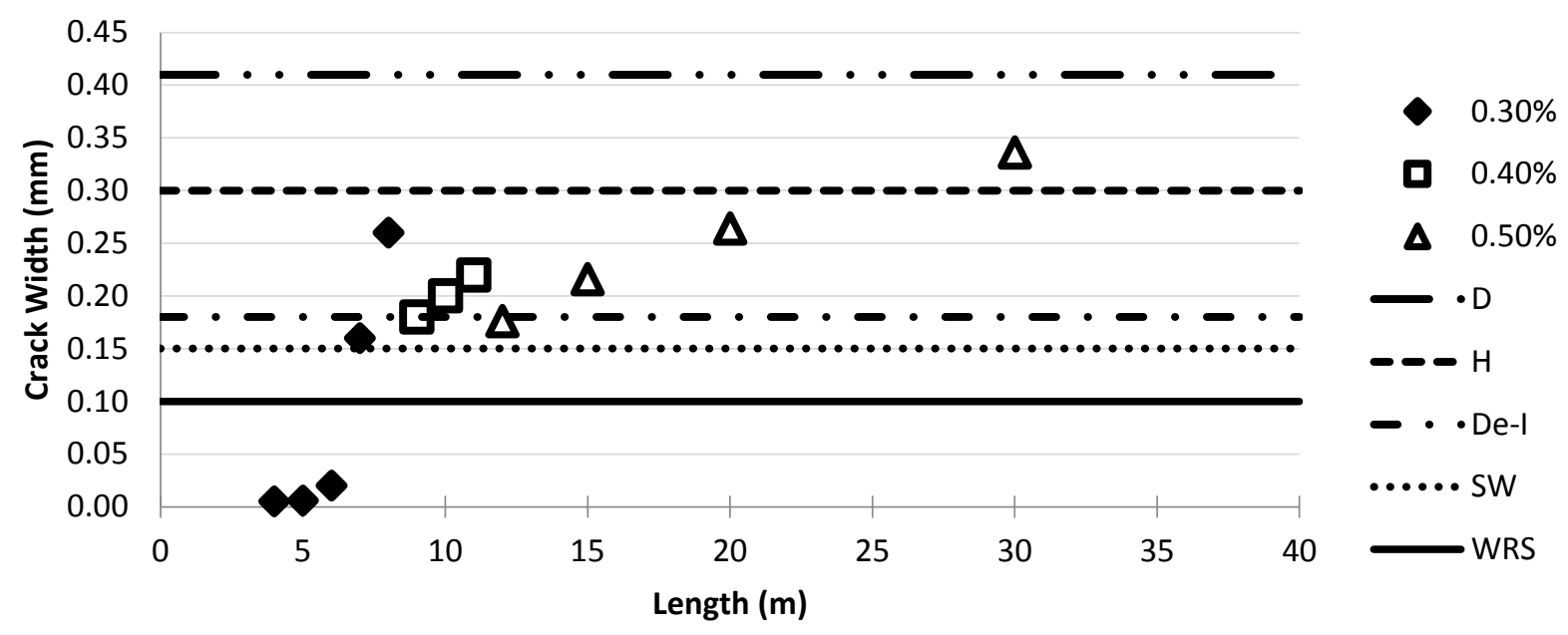

(c) Hot and dry climate

Figure D-4 Crack width of $6 \mathrm{~m}$ high RC walls reinforced based on ACI 350 Rec II 


\section{APPENDIX E - TYPICAL FE INPUT FILES}

\section{E.1 General}

This Appendix presents the typical FE input files of RC walls as modelled in Chapters 4, 5, and 6.

\section{E.2 Response of base restrained walls}

*Heading

** Job name: 2x4 Model name: Model-1

** Generated by: Abaqus/CAE 6.13-3

$*$ Preprint, echo $=\mathrm{NO}$, model $=\mathrm{NO}$, history $=\mathrm{NO}$, contact $=\mathrm{NO}$

$* *$

** PARTS

$* *$

*Part, name=Part-1

*End Part

$* *$

$* *$

** ASSEMBLY

**

*Assembly, name=Assembly

**

*Instance, name=Part-1-1, part=Part-1

*Node

1, $\quad 0 ., \quad 0 ., \quad 0$. 
2, 100., $\quad 0 ., \quad 0$.

861, 4000., 2000., $\quad 0$.

*Element, type $=\mathrm{S} 4 \mathrm{R}$

$1,1,2,43,42$

$800,819,820,861,860$

*Nset, nset=Set-1, generate

$1,861,1$

*Elset, elset=Set-1, generate

$1,800,1$

** Section: Reinforced concrete

*Shell Section, elset=Set-1, material=Concrete

150., 9

*Rebar Layer

H1, 20., 200., 50., Steel, 0., 1

H2, 20., 200., -50., Steel, 90., 1

V1, 20., 200., 50., Steel, 0., 1 
V2, 20., 200., -50., Steel, 90., 1

*End Instance

$* *$

$*$ Nset, nset $=$ Set-100, instance $=$ Part-1-1, generate

$1,861,1$

*Elset, elset=Set-100, instance=Part-1-1, generate

$1,800, \quad 1$

$*$ Nset, nset $=$ Set -102 , instance $=$ Part-1-1, generate

$1,41,1$

*Elset, elset=Set-102, instance=Part-1-1, generate

$1,40,1$

*End Assembly

$* *$

** MATERIALS

$* *$

*Material, name $=$ Concrete

*Brittle Cracking

2., 0.

$0 ., 0.006$

*Brittle Shear

1., 0.

$0 ., 0.002$

*Density 
2.4e- -09 ,

*Elastic

25000., 0.18

*Expansion

$1 \mathrm{e}-05$,

*Material, name=Steel

*Density

7.8e- 09 ,

*Elastic

200000.,0.

*Plastic

400., 0.

400., 0.02

**

** BOUNDARY CONDITIONS

$* *$

** Name: BC-13 Type: Symmetry/Antisymmetry/Encastre

*Boundary

Set-102, ENCASTRE

$* *$

** PREDEFINED FIELDS

**

** Name: Predefined Field-1 Type: Temperature 
*Initial Conditions, type=TEMPERATURE

Set-100, 1050.

**

$* *$

** STEP: Step-1

$* *$

*Step, name=Step -1, nlgeom $=$ YES

*Dynamic, Explicit

, 1 .

*Bulk Viscosity

$0.06,1.2$

$* *$

** PREDEFINED FIELDS

**

** Name: Predefined Field-1 Type: Temperature

*Temperature

Set-100, 0.

$* *$

** OUTPUT REQUESTS

$* *$

$*$ Restart, write, number interval $=1$, time marks $=\mathrm{NO}$

**

** FIELD OUTPUT: F-Output-1 
*Output, field

*Element Output, directions $=$ YES

LE, $S$

$* *$

** HISTORY OUTPUT: H-Output-1

$* *$

*Output, history, variable=PRESELECT

*End Step

\section{E.3 Response of base restrained walls with partial restraint at the sides}

*Heading

** Job name: 4x10 Model name: Model-1

** Generated by: Abaqus/CAE 6.13-3

*Preprint, echo $=\mathrm{NO}$, model $=\mathrm{NO}$, history $=\mathrm{NO}$, contact $=\mathrm{NO}$

$* *$

** PARTS

$* *$

*Part, name=Part-1

*End Part

$* *$

*Part, name=Part-1-Copy

*End Part 
** ASSEMBLY

**

*Assembly, name=Assembly

**

*Instance, name=Part-1-1, part=Part-1

11000., $\quad 0 ., \quad 10000$.

11000., $\quad$ 0., $\quad 10000 ., \quad 11000 ., \quad 1 ., \quad 10000 ., \quad 90$.

*Node

1, $\quad 0 ., \quad 0 ., \quad 0$.

2, 200., $\quad 0 ., \quad 0$.

3, 400., $\quad 0 ., \quad 0$.

546, 5000., 4000., 0 .

*Element, type $=\mathrm{S} 4 \mathrm{R}$

$1,1,2,28,27$

$2,2,3,29,28$

$3,3,4,30,29$ 
$500,519,520,546,545$

*Nset, nset=Set-1, generate

1, 546, 1

*Elset, elset=Set-1, generate

1, 500, 1

** Section: Reinforced concrete

*Shell Section, elset=Set-1, material=Concrete

300., 9

*Rebar Layer

H1, 90., 200., 50., Steel, 0., 1

H2, 90., 200., -50., Steel, 90., 1

V1, 90., 200., 50., Steel, 0., 1

V2, 90., 200., -50., Steel, 90., 1

*End Instance

$* *$

*Instance, name=Part-1-Copy-1, part=Part-1-Copy

11000., $\quad 0 ., \quad 5000$.

*Node

1, $\quad 0 ., \quad 0 ., \quad 0$.

2, 200., $\quad 0 ., \quad 0$.

3, 400., $\quad 0 ., \quad 0$. 
546, 5000., 4000., $\quad 0$.

*Element, type $=\mathrm{S} 4 \mathrm{R}$

$1,1,2,28,27$

$2,2,3,29,28$

$3,3,4,30,29$

$500,519,520,546,545$

*Nset, nset=Set-1, generate

1, 546, 1

*Elset, elset=Set-1, generate

$1,500,1$

** Section: Reinforced concrete

*Shell Section, elset=Set-1, material=Concrete

300., 9

*Rebar Layer

H1, 90., 200., 50., Steel, 0., 1

H2, 90., 200., -50., Steel, 90., 1

V1, 90., 200., 50., Steel, 0., 1 
V2, 90., 200., -50., Steel, 90., 1

*End Instance

$* *$

*Nset, nset=Set-32, instance=Part-1-1, generate

$1,546,1$

*Nset, nset=Set-32, instance=Part-1-Copy-1, generate

$1,546,1$

*Elset, elset=Set-32, instance $=$ Part-1-1, generate

$1,500,1$

*Elset, elset=Set-32, instance $=$ Part-1-Copy-1, generate

$1,500,1$

*Nset, nset=Set-33, instance=Part-1-1, generate

$1,26,1$

*Nset, nset=Set-33, instance=Part-1-Copy-1, generate

$1,26,1$

*Elset, elset=Set-33, instance $=$ Part-1-1, generate

$1,25,1$

*Elset, elset=Set-33, instance=Part-1-Copy-1, generate

$1,25,1$

*Nset, nset=Set-34, instance=Part-1-1, generate

$1,546,1$

*Nset, nset=Set-34, instance=Part-1-Copy-1, generate

$1,546,1$ 
*Elset, elset=Set-34, instance=Part-1-1, generate

1, 500, 1

*Elset, elset=Set-34, instance $=$ Part-1-Copy-1, generate

1, 500, 1

$*$ Nset, nset=Set-35, instance $=$ Part $-1-1$, generate

1, 26, 1

*Nset, nset=Set-35, instance=Part-1-Copy-1, generate

$1,26,1$

*Elset, elset=Set-35, instance=Part-1-1, generate

$1,25,1$

*Elset, elset=Set-35, instance $=$ Part-1-Copy-1, generate

$1,25,1$

*Nset, nset=Set-36, instance $=$ Part-1-1, generate

1, 26, 1

*Nset, nset=Set-36, instance=Part-1-Copy-1, generate

1, 26, 1

$*$ Elset, elset=Set-36, instance $=$ Part-1-1, generate

$1,25,1$

*Elset, elset=Set-36, instance=Part-1-Copy-1, generate

$1,25,1$

*Nset, nset=Set-37, instance $=$ Part-1-1, generate

$1,521,26$

*Elset, elset=Set-37, instance=Part-1-1, generate 
$1,476,25$

*Nset, nset=Set-38, instance=Part-1-Copy-1, generate

$26,546,26$

*Elset, elset=Set-38, instance=Part-1-Copy-1, generate

$25,500,25$

*Nset, nset=m_Set-28, instance=Part-1-Copy -1 , generate

26, 546, 26

*Elset, elset=m_Set-28, instance=Part-1-Copy-1, generate

$25,500,25$

*Nset, nset=m_Set-30, instance=Part-1-1, generate

26, 546, 26

*Elset, elset=m_Set-30, instance $=$ Part $-1-1$, generate

$25,500, \quad 25$

*Nset, nset=s_Set-24, instance=Part-1-1, generate

$1,521,26$

*Elset, elset=s_Set-24, instance=Part-1-1, generate

$1,476,25$

*Nset, nset=s_Set-30, instance=Part-1-Copy-1, generate

$1,521,26$

*Elset, elset=s_Set-30, instance=Part-1-Copy-1, generate

$1,476,25$

*Surface, type=NODE, name=m_Set-30_CNS_, internal m_Set-30, 1. 
*Surface, type=NODE, name=s_Set-30_CNS_, internal

s_Set-30, 1.

** Constraint: Constraint-4

*Tie, name $=$ Constraint -4 , adjust $=$ yes

s_Set-30_CNS_, m_Set-30_CNS_

*End Assembly

**

** MATERIALS

**

*Material, name $=$ Concrete

*Brittle Cracking

3., 0 .

$0 ., 0.002$

*Brittle Shear

1., 0.

$0 ., 0.002$

*Density

2.4e-09,

*Elastic

25000., 0.18

*Expansion

1e-05,

*Material, name=Steel 
*Density

$7.8 \mathrm{e}-06$

*Elastic

200000.,0.

*Plastic

400., 0.

400., 0.02

$* *$

** BOUNDARY CONDITIONS

$* *$

** Name: BC-8 Type: Symmetry/Antisymmetry/Encastre

*Boundary

Set-36, ENCASTRE

** Name: BC-9 Type: Symmetry/Antisymmetry/Encastre

*Boundary

Set-37, ZSYMM

** Name: BC-10 Type: Symmetry/Antisymmetry/Encastre

*Boundary

Set-38, XSYMM

$* *$

** PREDEFINED FIELDS

$* *$

** Name: Predefined Field-1 Type: Temperature 
*Initial Conditions, type=TEMPERATURE

Set-34, 60.

**

$* *$

** STEP: Step-1

$* *$

*Step, name=Step -1, nlgeom $=$ YES

*Dynamic, Explicit

, 1 .

*Bulk Viscosity

$0.06,1.2$

$* *$

** PREDEFINED FIELDS

**

** Name: Predefined Field-1 Type: Temperature

*Temperature

Set-34, 0 .

$* *$

** OUTPUT REQUESTS

$* *$

$*$ Restart, write, number interval $=1$, time marks $=\mathrm{NO}$

**

** FIELD OUTPUT: F-Output-1 
*Output, field

*Element Output, rebar, directions=YES

EVF, LE, PE, PEEQ, PEEQVAVG, PEVAVG, S, SVAVG

$* *$

** HISTORY OUTPUT: H-Output-1

$* *$

*Output, history, variable=PRESELECT

*End Step

\section{E.4 Response of base restrained walls considering the effect of creep}

*Heading

** Job name: BRW-Creep Model name: Model-1

** Generated by: Abaqus/CAE 6.14-2

$*$ Preprint, echo $=\mathrm{NO}$, model $=\mathrm{NO}$, history $=\mathrm{NO}$, contact $=\mathrm{NO}$

$* *$

** PARTS

$* *$

*Part, name=Part-1

*End Part

$* *$

$* *$

** ASSEMBLY

$* *$ 
*Assembly, name=Assembly

$* *$

*Instance, name=Part-1-1, part=Part-1
11000., $\quad 0 ., \quad-10000$.
11000., $\quad 0 ., \quad-10000 ., \quad 11000 ., \quad-1 ., \quad-10000 ., \quad 90$.

*Node

$1, \quad 0 ., \quad 0 ., \quad 0$.

$2, \quad 200 ., \quad 0 ., \quad 0$.

3, 400., $\quad 0 ., \quad 0$.

1071, 10000., $\quad 4000 ., \quad 0$.

*Element, type $=\mathrm{S} 4 \mathrm{R}$

$1, \quad 1,2,53,52$

$2, \quad 2, \quad 3,54,53$

$3,3, \quad 4,55,54$

$1000,1019,1020,1071,1070$

*Nset, nset=Set-1, generate

1, 1071, 1 
*Elset, elset=Set-1, generate

$1,1000, \quad 1$

** Section: Reinforced concrete

*Shell Section, elset=Set-1, material=Concrete

300., 9

*Rebar Layer

H1, 90., 200., 50., Steel, 0., 1

H2, 90., 200., -50., Steel, 90., 1

V1, 90., 200., 50., Steel, 0., 1

V2, 90., 200., -50., Steel, 90., 1

*End Instance

$* *$

$*$ Nset, nset $=$ Set-114, instance $=$ Part-1-1, generate

1, 1071, 1

*Elset, elset=Set-114, instance=Part-1-1, generate

1, 1000, 1

$*$ Nset, nset=Set-115, instance $=$ Part $-1-1$, generate

$1,51,1$

*Elset, elset=Set-115, instance=Part-1-1, generate

$1,50,1$

*Nset, nset=Set-117, instance $=$ Part-1 -1 , generate

$1,1071, \quad 1$

*Elset, elset=Set-117, instance=Part-1-1, generate 
$1,1000, \quad 1$

*Nset, nset=Set-118, instance $=$ Part-1-1, generate

$1,51,1$

*Elset, elset=Set-118, instance $=$ Part-1-1, generate

$1,50,1$

*Nset, nset=m_Set-110, instance=Part-1-1, generate

$1,1021, \quad 51$

*Elset, elset=m_Set-110, instance $=$ Part $-1-1$, generate

1, 951, 50

*Nset, nset=s_Set-112, instance $=$ Part-1-1, generate

$51,1071, \quad 51$

*Elset, elset=s_Set-112, instance=Part-1-1, generate

$50,1000, \quad 50$

*End Assembly

**

** MATERIALS

**

$*$ Material, name $=$ Concrete

*Brittle Cracking

3., $\quad 0 ., \quad 0$.

0., $0.028, \quad 0$.

3., $\quad 0 ., 5.85083$

$0 ., \quad 0.027,5.85083$ 
3., $\quad 0 ., 12.0465$

$0 ., \quad 0.026,12.0465$

3., $\quad 0 ., 18.8503$

$0 ., \quad 0.025,18.8503$

3., $\quad 0 ., 26.8838$

$0 ., \quad 0.024,26.8838$

3., $\quad 0 ., 31.8355$

$0 ., \quad 0.023,31.8355$

3., $\quad 0 ., 38.0554$

$0 ., \quad 0.023,38.0554$

3., $\quad 0 ., 43.4936$

$0 ., \quad 0.022,43.4936$

3., $\quad 0 ., 50.9169$

$0 ., \quad 0.021,50.9169$

$3.01, \quad 0 ., 53.7853$

$0 ., \quad 0.002,53.7853$

*Brittle Shear

1., 0.

$0 ., 0.002$

*Density

2.4e-09,

*Elastic

$8816.81, \quad 0.18, \quad 0$. 
$9044.72, \quad 0.18,5.85083$

$9356.25, \quad 0.18,12.0465$

$9818.12, \quad 0.18,18.8503$

$10607.2, \quad 0.18,26.8838$

$11288.3, \quad 0.18,31.8355$

$12474.2, \quad 0.18,38.0554$

$14039.5, \quad 0.18,43.4936$

$18710.2, \quad 0.18,50.9169$

$28599.6, \quad 0.18,53.7853$

*Expansion

1e-05,

*Material, name=Steel

*Density

7.8e-09,

*Elastic

200000.,0.

*Plastic

400., 0.

400., 0.02

$* *$

** BOUNDARY CONDITIONS

$* *$

** Name: BC-15 Type: Symmetry/Antisymmetry/Encastre 
*Boundary

Set-118, ENCASTRE

**

** PREDEFINED FIELDS

**

** Name: Predefined Field-1 Type: Temperature

*Initial Conditions, type=TEMPERATURE

Set-117, 53.78

**

$* *$

** STEP: Step-1

**

*Step, name=Step -1, nlgeom $=$ YES

*Dynamic, Explicit, fixed time incrementation

, 1 .

*Bulk Viscosity

$0.06,1.2$

$* *$

** PREDEFINED FIELDS

$* *$

** Name: Predefined Field-1 Type: Temperature

*Temperature

Set-117, 0 . 
$* *$

** OUTPUT REQUESTS

$* *$

$*$ Restart, write, number interval $=1$, time marks $=\mathrm{NO}$

$* *$

** FIELD OUTPUT: F-Output-1

$* *$

*Output, field

*Element Output, rebar, directions=YES

LE, S

$* *$

** HISTORY OUTPUT: H-Output-1

$* *$

*Output, history, variable=PRESELECT

*End Step 